LEANDRO GONÇALVES DE AGUIAR

SÍNTESE DE COPOLÍMEROS DE ESTIRENO-DIVINILBENZENO POR POLIMERIZAÇÃO RADICALAR CONVENCIONAL E MEDIADA POR NITRÓXIDO: EXPERIMENTOS E MODELAGEM MATEMÁTICA 
SÍNTESE DE COPOLÍMEROS DE ESTIRENO-DIVINILBENZENO POR POLIMERIZAÇÃO RADICALAR CONVENCIONAL E MEDIADA POR NITRÓXIDO: EXPERIMENTOS E MODELAGEM MATEMÁTICA

Tese apresentada à Escola

Politécnica da Universidade de São

Paulo para a obtenção do título de Doutor em Engenharia. 


\section{SÍNTESE DE COPOLÍMEROS DE ESTIRENO-DIVINILBENZENO POR POLIMERIZAÇÃO RADICALAR CONVENCIONAL E MEDIADA POR NITRÓXIDO: EXPERIMENTOS E MODELAGEM MATEMÁTICA}

Tese apresentada à Escola

Politécnica da Universidade de São Paulo para a obtenção do título de Doutor em Engenharia.

Área de concentração:

Engenharia Química

Orientador: Prof.Titular

Reinaldo Giudici

Co-Orientador: Prof. Doutor Mário

Rui P. F. N. Costa 
Autorizo a reprodução e divulgação total ou parcial deste trabalho, por qualquer meio convencional ou eletrônico, para fins de estudo e pesquisa, desde que citada a fonte.

Este exemplar foi revisado e alterado em relação à versão original, sob responsabilidade única do autor e com a anuência de seu orientador.

São Paulo, de fevereiro de 2013.

Assinatura do autor

Assinatura do orientador

FICHA CATALOGRÁFICA

Aguiar, Leandro Gonçalves de

Síntese de copolímeros de estireno-divinilbenzeno por polimerização radicalar convencional e mediada por nitróxido: experimentos e modelagem matemática / L.G. de Aguiar. -- ed.rev. -São Paulo, 2013.

$171 \mathrm{p}$.

Tese (Doutorado) - Escola Politécnica da Universidade de São Paulo. Departamento de Engenharia Química.

1. Polimerização 2. Reações químicas 3 . Modelos matemáticos I. Universidade de São Paulo. Escola Politécnica. Departamento de Engenharia Química II. t. 
AGUIAR, L. G. Síntese de copolímeros de estireno-divinilbenzeno por polimerização convencional e mediada por nitróxido: experimentos e modelagem matemática. Tese apresentada à escola politécnica da Universidade de São Paulo para obtenção do título de Doutor em Engenharia.

Aprovado em:

Banca Examinadora

Prof. Dr. Instituição:

Julgamento:

Assinatura:

Prof. Dr. Instituição:

Julgamento: Assinatura:

Prof. Dr. Instituição:

Julgamento: Assinatura:

Prof. Dr. Instituição:

Julgamento: Assinatura:

Prof. Dr. Instituição: 


\section{DEDICATÓRIA}

Aos meus pais Nanci e Paulo e à minha avó Rosária. 


\section{AGRADECIMENTOS}

Ao professor Dr. Reinaldo Giudici pela paciência, pela excelente orientação e pela enorme contribuição dada à minha formação.

Ao professor Dr. Mario Rui P. F. N. Costa por confiar no meu trabalho e transmitir sabedoria.

Ao professor Dr. Rolando C. S. Dias pela constante motivação e por criar um ambiente de trabalho descontraído.

Aos colegas Miguel e Virgínia por me receberem bem e me introduzirem harmoniosamente na equipe.

Aos colegas Dennis, Verónica, Celyna, Magda, Wilson, Paula e Carol pela companhia e auxílio prestado no decorrer do curso.

À CAPES e à CNPq pelo auxílio financeiro.

e a todos que colaboraram direta ou indiretamente na execução deste trabalho. 


\section{EPÍGRAFE}

"Toda a nossa ciência, comparada com a realidade, é primitiva e infantil e, no entanto, é a coisa mais preciosa que temos."

(Albert Einstein). 


\section{RESUMO}

AGUIAR, L. G. Síntese de copolímeros de estireno-divinilbenzeno por polimerização radicalar convencional e mediada por nitróxido: experimentos e modelagem matemática. 171 f. Tese (Doutorado) - Escola Politécnica (Departamento de Engenharia Química), Universidade de São Paulo, São Paulo, 2013.

Foram realizados experimentos de homopolimerização de estireno e copolimerização de estireno-divinilbenzeno em solução e suspensão aquosa pelos métodos convencional (FRP) e mediado por nitróxido (NMRP). Objetivou-se atingir um maior grau de entendimento sobre estes sistemas em relação ao que se tem na literatura. Para isto, três modelos matemáticos foram avaliados através de validação com os dados obtidos nos experimentos. Os experimentos foram conduzidos em reator de batelada isotérmico. As principais variáveis exploradas neste trabalho foram: temperatura de reação, concentração inicial de divinilbenzeno, diluição inicial da mistura de monômeros e técnicas de polimerização (FRP e NMRP). Os modelos matemáticos foram intitulados: Modelo A, Modelo B e Modelo C. O Modelo A consiste de um balanço de espécies não poliméricas e grupos poliméricos. A determinação das massas moleculares médias e da fração de gel foi feita através de balanços populacionais em termos de função geradora em conjunto com o método das características. Os modelos B e C consistiram de balanços de massa para espécies não poliméricas e método dos momentos para radicais ativos, radicais dormentes e polímero morto. A obtenção das massas moleculares médias e da fração de gel foi feita através do método do fracionamento numérico. Nestes dois modelos, foram consideradas as reações de ciclização através do método dos caminhos. Este método consiste num balanço de segmentos de cadeia que conectam grupos poliméricos. O número máximo de unidades monoméricas, considerado para estes segmentos foi 100 e o valor da constante cinética de ciclização do menor segmento ciclizável (3 unidades monoméricas) foi $450 \mathrm{~s}^{-1}$ para a temperatura de $90^{\circ} \mathrm{C}$. O Modelo $\mathrm{C}$ leva em conta a redução da reatividade das ligações cruzadas em função do tamanho médio das cadeias em cada geração. Os resultados mostraram que, quando comparado com a FRP, a polimerização NMRP permite somente um controle limitado sobre o processo de reticulação, produzindo distribuições largas de tamanhos de cadeia. Micro e nanoestruturas foram 
identificadas em produtos obtidos por FRP e NMRP lineares e não lineares. Estas estruturas parecem ser consequência do processo de síntese (ex.: operação em temperatura de reação acima da temperatura de transição vítrea) e do tratamento dos produtos. Massa molecular média mássica e fração de gel foram afetadas consideravelmente pelas reações de ciclização em copolimerizações FRP, porém apresentaram pouca sensibilidade a estas reações em copolimerizações NMRP. A inclusão do mecanismo de ciclização, por si só (no Modelo B), não foi suficiente para produzir bons ajustes modelo/experimentos em termos de massa molecular média mássica $(\mathrm{Mw})$ e fração de gel $(\mathrm{Wg})$. No entanto, o Modelo $\mathrm{C}$ é capaz de fornecer boas previsões de $\mathrm{Mw}$ e $\mathrm{Wg}$ simultaneamente para os experimentos realizados a $90^{\circ} \mathrm{C}$. O presente estudo mostrou uma análise na qual os modelos podem se complementar e fornecer subsídios para o desenvolvimento de um modelo unificado.

Palavras-chave: copolimerização, estireno, divinilbenzeno, modelagem matemática, ciclização. 


\title{
ABSTRACT
}

\begin{abstract}
AGUIAR, L. G. Synthesis of copolymers of styrene-divinylbenzene by conventional and nitroxide-mediated free radical polymerization: experiments and mathematical modeling. 171 p. Thesis (PhD) - Escola Politécnica (Departamento de Engenharia Química), Universidade de São Paulo, São Paulo, 2013.
\end{abstract}

Homopolymerizations of styrene and copolymerizations of styrene-divinylbenzene were carried out in solution and aqueous suspension through conventional (FRP) and nitroxide-mediated (NMRP) techniques. The aim of the work was to reach a higher level of understanding in comparison to what is found in literature. In order to reach this goal, three mathematical models were assessed through validation using experimental data. The experiments were conducted in isothermal batch reactor. The main variables explored in this work were: reaction temperature, divinylbenzene initial concentration, initial dilution of monomers and polymerization techniques (FRP and NMRP). The mathematical models were named: Model A, Model B and Model C. The Model A consists of a balance of non-polymeric species and polymer groups. The average molecular weights and gel fraction were calculated through population balances in terms of generation function together with the method of characteristics. The models $B$ and $C$ were built using mass balance for non-polymeric species and the method of moments for active radicals, dormant radicals and dead polymer. The average molecular weights and gel fraction were calculated through the numerical fractionation technique. In these two models, cyclization reactions were considered through the method of paths. This method consists of a balance of chain segments which connect polymer groups. The maximum number of monomeric units considered for these segments was 100 and the value of the kinetic constant of cyclization for the smaller cyclizable path ( 3 monomeric units) was $450 \mathrm{~s}^{-1}$ at $90^{\circ} \mathrm{C}$. The Model $\mathrm{C}$ takes into account the reduction of reactivity of the crosslink reactions in function of the average size of the chains in each generation. The results showed that, when compared with FRP, NMRP allows only a limited control over the crosslinking process, producing broad chain length distributions. Micro and nanostructures were identified in products obtained by linear and non-linear FRP and NMRP. These structures seem to be consequence of the synthesis process (e.g.: operation in reaction temperatures above the glass transition temperature) and of the 
products treatment. Weight average molecular weight and gel fraction were affected considerably by the cyclization reactions in FRP, however they presented few sensibility to these reactions in NMRP. The inclusion of the mechanism of cyclization, itself (in Model B), was not enough to obtain good model/experiments fittings in terms of weight average molecular weight $(\mathrm{Mw})$ and weight fraction of gel $(\mathrm{Wg})$. Although, the Model $\mathrm{C}$ is capable of providing good predictions of $\mathrm{Mw}$ and $\mathrm{Wg}$ simultaneously for the experiments carried out at $90^{\circ} \mathrm{C}$. The present study showed an analysis in which the models can complement each other, providing subsidies for the development of a unified model.

Keywords: copolymerization, styrene, divinylbenzene, mathematical modeling, cyclization. 


\section{LISTA DE ILUSTRAÇÕES}

Figura 1 - Mecanismo de desativação reversível de radicais no processo ATRP. . . . . . . . . . . . . . . . . . . . . . .

Figura 2 - Mecanismo de desativação reversível de radicais no processo RAFT.

Figura 3 - Mecanismo de desativação reversível em uma polimerização mediada por nitróxido.

Figura 4 - Diferenciação entre cadeias de polímero lineares e redes poliméricas.

Figura 5 - Reações de crosslink intermolecular e intramolecular. . . . . . . . . 12

Figura 6 - Esquerda: Córnea artificial Alphacor ${ }^{\mathrm{TM}}$. Direita: aplicação de estrutura intermediária (Hicks et al., 2003).

Figura 7 - Implante de canino artificial. Teste em aparato de laboratório (Reis et al., 2008).

Figura 8 - llustração de um polímero superabsorvente de base acrílica: (a) Comparação visual de uma partícula no estado seco (direita) e no estado intumescido (esquerda). A amostra é uma esfera preparada pela técnica de polimerização por suspensão inversa. (b) Representação esquemática do inchamento de um polímero superabsorvente (Mehr e Kabiri, 2008). . . . . . . .

Figura 9 - Estratégias física (a) e química (b) para armazenar o medicamento de forma a libera-lo lentamente (Hoare e Kohane, 2007). . . . . .

Figura 10 - Estrutura da partícula de polímero reticulado e sua função na análise cromatográfica por exclusão de tamanhos (Collins et al., 2006). . . . . . . Figura 11 - Mecanismo de desativação reversível numa copolimerização NMRP.

Figura 12 - Resultados experimentais de Tanaka et al. (2007). Testes realizados com partículas preparadas em microssuspensão aquosa. Pontos vazios: processo convencional. Pontos cheios: processo NMRP . . . . . . . . 18

Figura 13 - Representação esquemática do raio de giração. . . . . . . . . . . . . 19

Figura 14 - Classificação das reações de ciclização. . . . . . . . . . . . . . 20

Figura 15 - Reatividade das duplas ligações pendentes em função da conversão (Ward e Peppas, 2000). 
Figura 16 - Comparações de previsões do modelo com dados experimentais de (a) Conversão x tempo, (b) Mn, Mw x conversão, (c) Dispersão de massas moleculares $x$ conversão e (d) Fração de gel $x$ conversão para o processo NMRP de estireno/divinilbenzeno. $f_{20}$ refere-se à razão molar

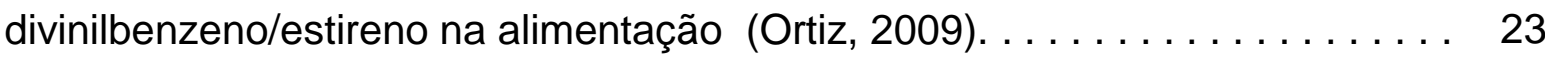

Figura 17 - (a) Predições e observações experimentais para conversão de monômero nos sistemas convencional e NMRP. (b) Predições e observações experimentais para Mn e Mw nos sistemas convencional e NMRP. (c) e (d) Valores medidos e simulados de $\mathrm{Mw}$ em função do tempo nos sistemas convencional e NMRP (runs 3-8: variação progressiva da quantidade de agente de crosslink (Gonçalves et al., 2010) . . . . . . . . . . . . . . .

Figura 18 - Representação esquemática de um sistema de cromatografia por exclusão de tamanhos (Teraoka, 2002). . . . . . . . . . . . . . . . . . . . . . .

Figura 19 - Transporte de moléculas de polímero em colunas de exclusão de tamanhos e cromatograma típico (Teraoka, 2002). . . . . . . . . . . . . . . .

Figura 20 - Intumescimento e encolhimento reversíveis da rede polimérica através do contato com solvente.

Figura 21 - Representação pictórica de espécies envolvidas nas reações. . . . 32

Figura 22 - Método do fracionamento numérico - transição entre gerações. . . 52

Figura 23 - Representação esquemática da reação de ciclização. . . . . . . . . 59

Figura 24 - Tipos de caminhos considerados no Modelo B............ 60

Figura 25 - Diferentes caminhos compartilhando o mesmo centro radicalar. ... 60

Figura 26 - Reações de ciclização em caminhos com 3 unidades. . . . . . . . 62

Figura 27 - Imobilização de PDBs em função do tamanho da molécula. .... . . 66

Figura 28 - Avaliação qualitativa da redução da reatividade das ligações cruzadas em função do tamanho da molécula de polímero. . . . . . . . . . .

Figura 29 - Volume de uma cadeia polimérica intumescida no meio reacional. 68

Figura 30 - Variação de $\mathrm{k}_{\mathrm{ppi}, \mathrm{sol}}$ em função da geração. . . . . . . . . . . . . 70

Figura 31 - Aparato experimental utilizado nos experimentos. . . . . . . . 74

Figura 32 - Caracterização dos copolímeros obtidos durante a reação. . . . . . 77

Figura 33 - Técnica da gravimetria utilizada na obtenção do grau de avanço da reação. . . . . . . . . . . . . . . . . . . . . . . . . . . . . 78

Figura 34 - Determinação da fração de gel. . . . . . . . . . . . . . . 79 
Figura 35 - Procedimento experimental para determinação de PDBs. . . . . . . 81

Figura 36 - Resultados de conversão de monômeros dos experimentos B1, B2 e B3.

Figura 37 - Resultados de conversão de monômeros dos experimentos B4, B5 e B6.

Figura 38 - Resultados de fração de gel dos experimentos B1, B2 e B3. . . . . 86

Figura 39 - Resultados de fração de gel dos experimentos B4, B5 e B6. . . . . 87

Figura 40 - Resultado de concentração de PDBs para os experimentos B3, B4 e B5.

Figura 41 - Evolução da conversão experimental com o tempo para NMRP de estireno em suspensão a $130^{\circ} \mathrm{C}$ (Experimento $\left.\mathrm{P} 12\right) \ldots \ldots \ldots \ldots \ldots \ldots$

Figura 42 - $[-\ln (1-X)]$ em função do tempo, para os mesmos dados de conversão da Figura 43, mostrando o comportamento linear de polimerizações controladas. . . . . . . . . . . . . . . . . . . . .

Figura 43 - Dependência das massas moleculares médias numérica $(\mathrm{Mn})$ e mássica $(\mathrm{Mw})$ com a conversão de monômero para o experimento P12. A dependência linear observada confirma o caráter "vivo" da polimerização. . . . .

Figura 44 - Evolução da dispersão de massas moleculares com o tempo para o experimento P12. A baixa dispersão de massa molecular confirma a eficiência do processo NMRP para sintetizar materiais mais homogêneos. . . . . Figura 45 - Sinal de espalhamento de luz observado para amostras do

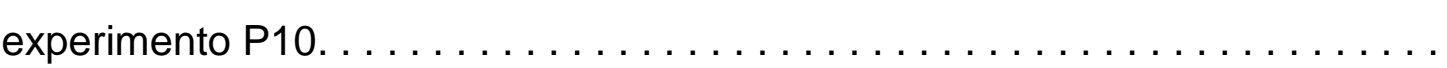

Figura 46 - Sinal de espalhamento de luz observado para amostras do experimento P12.

Figura 47 - Perfil de Mw em função da conversão de monômero para uma polimerização de divinilbenzeno (experimento $\mathrm{P} 3$ ). . . . . . . . . . . . .

Figura 48 - Efeito do conteúdo inicial de DVB sobre os sinais de MALLS obtidos para amostras coletadas em $\mathrm{t}=180$ minutos de reação. . . . . . . . . .

Figura 49 - Efeito da diluição inicial de monômeros sobre a evolução da conversão com o tempo de reação para polimerizações NMRP a $130^{\circ} \mathrm{C}$. . . . . . Figura 50 - Evolução da conversão de monômero $(X)$ com o tempo e fração de gel em massa (Wg) para FRP de estireno-divinilbenzeno em suspensão aquosa a $90^{\circ} \mathrm{C}$ (experimento $\left.\mathrm{P} 7\right) \ldots \ldots \ldots \ldots \ldots \ldots \ldots$ 
Figura 51 - Evolução da fração de gel com o tempo. Medições obtidas no

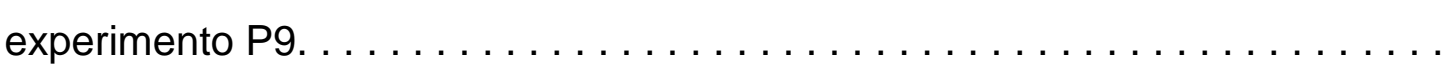

Figura 52 - Micrografias SEM de amostras de estireno-divinilbenzeno de copolimerizações com diferentes quantidades de DVB. Imagens com ampliação de 50000 vezes. Experimentos: (a) P1; (b) P2; (c): P3 e (d): P7. . . .

Figura 53 - Micrografias SEM de amostras de NMRPs conduzidas com 0 e 100\% de DVB. Imagens com ampliação de 50000 vezes. (a): Experimento P6 (0\% de DVB). (b): Experimento P4 (100\% de DVB). Ambas polimerizações a

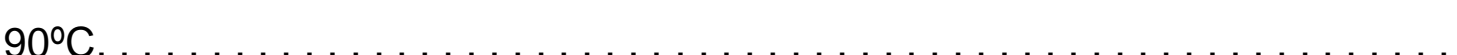

Figura 54 - Micrografias SEM de amostras de poliestireno (0\% de DVB) sintetizadas por FRP e NMRP. (a): P13 (FRP) com ampliação de 50000 vezes. (b): P14 (NMRP) com ampliação de 5000 vezes. Ambas as polimerizações foram realizadas a $90^{\circ} \mathrm{C} \ldots \ldots \ldots \ldots \ldots \ldots \ldots \ldots$

Figura 55 - Micrografias SEM de copolímeros de estireno-divinilbenzeno sintetizados por NMRP. (a): Experimento P8 com ampliação de 150 vezes. (b): Experimento P8 com ampliação de 1000 vezes. (c): Experimento P9 com ampliação de 150 vezes. (d): Experimento P9 com ampliação de 854 vezes. Ambos os experimentos foram realizados a $130^{\circ} \mathrm{C} . \ldots \ldots \ldots \ldots \ldots \ldots$. . . .

Figura 56 - Micrografias SEM de amostras de estireno-divinilbenzeno sintetizadas por NMRP. (a): Experimento P1 com ampliação de 10000 vezes. (b): Experimento P3 com ampliação de 1000 vezes. Ambos os experimentos

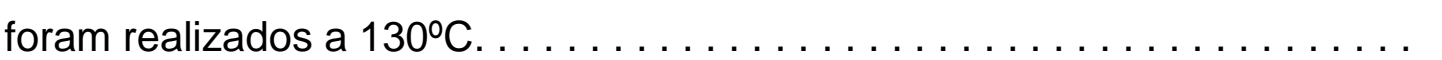

Figura 57 - Micrografias SEM de amostras de estireno-divinilbenzeno sintetizadas por FRP a $60^{\circ} \mathrm{C}$. (a): Experimento com $\phi_{M}=50 \%, Y_{D V B}=10 \%$, $Y_{\text {IDB }}=1,25 \%$ (neste experimento uma mistura 50/50 v/v de tolueno/n-heptano foi usada como solvente). (b): Experimento com $\phi_{M}=50 \%, Y_{D V B}=20 \%, Y_{I D B}=$ $1,25 \%$ (neste experimento uma mistura $25 / 75 \mathrm{v} / \mathrm{v}$ de tolueno/n-heptano foi usada como solvente).

Figura 58 - Simulações realizadas com os dados experimentais de Gonçalves

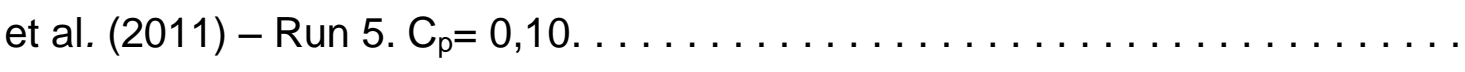
Figura 59 - Simulações realizadas com os dados experimentais de Gonçalves

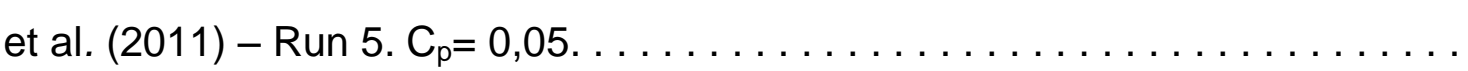

Figura 60 - Simulações realizadas com o experimento P2. $C_{p}=0,20 \ldots \ldots \ldots 106$ 
Figura 61 - Simulações realizadas com o experimento P2. $C_{p}=0,025 \ldots \ldots \ldots$

Figura 62 - Perfis de massa molecular média em função de $r_{\text {máx. Dados do }}$ experimento $\mathrm{P} 7 . \mathrm{kcic}=450 \mathrm{~s}^{-1} \ldots \ldots \ldots \ldots \ldots \ldots \ldots \ldots \ldots \ldots \ldots \ldots \ldots \ldots$

Figura 63 - Perfis de concentração de PDBs em função de $r_{\text {máx. Dados do }}$ experimento $\mathrm{P} 7 . \mathrm{kcic}=450 \mathrm{~s}^{-1}$. pol. = polímero.

Figura 64 - Perfis de massa molecular média em função de $r_{\text {máx. Dados do }}$ experimento $\mathrm{P} 3 . \mathrm{kcic}=450 \mathrm{~s}^{-1}$.

Figura 65 - Perfis de concentração de PDBs em função de $r_{\text {máx. Dados do }}$

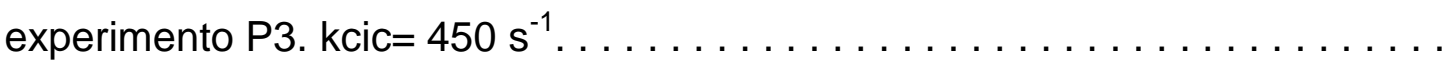

Figura 66 - Perfis de massa molecular média em função de $r_{\text {máx. Dados do }}$ experimento $\mathrm{P} 3$. kcic $=1700 \mathrm{~s}^{-1}$.

Figura 67 - Perfis de concentração de PDBs em função de $r_{\text {máx }}$. Dados do

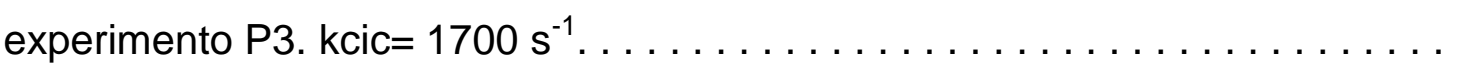

Figura 68 - Comparação entre previsões de conversão com os dados experimentais de Gonçalves et al. (2011) - Run 5. kcic em s ${ }^{-1}$. . . . . . . . . .

Figura 69 - Comparação entre previsões de massa molecular média com os dados experimentais de Gonçalves et al. (2011) - Run 5. kcic em s ${ }^{-1}$.

Figura 70 - Comparação entre previsões de fração de gel com os dados experimentais de Gonçalves et al. (2011) - Run 5. kcic em s ${ }^{-1} \ldots$. . . . . . . .

Figura 71 - Comparação entre previsões de conversão com os dados do experimento $\mathrm{P} 2$. kcic em $\mathrm{s}^{-1} \ldots \ldots \ldots \ldots \ldots \ldots \ldots \ldots \ldots \ldots \ldots$

Figura 72 - Comparação entre previsões de massa molecular média com os dados do experimento P2. kcic em $\mathrm{s}^{-1} \ldots \ldots \ldots \ldots \ldots \ldots \ldots \ldots \ldots$

Figura 73 - Comparação entre previsões de fração de gel com os dados do experimento P2. kcic em s${ }^{-1}$.

Figura 74 - Comparação entre previsões de concentração de PDBs. kcic= 0 $\mathrm{s}^{-1}$.

Figura 75 - Comparação entre previsões de concentração de PDBs. kcic= 450 $\mathrm{s}^{-1}$

Figura 76 - Comparação entre previsões de concentração de PDBs. kcic= $1700 \mathrm{~s}^{-1}$.

Figura 77 - Resultados de conversão. Comparação dos modelos A e B com os dados do experimento B4. kcic em s${ }^{-1}$. 
Figura 78 - Resultados de fração de gel. Comparação dos modelos A e B com os dados do experimento B4. kcic em s ${ }^{-1} \ldots \ldots \ldots \ldots \ldots \ldots \ldots \ldots$

Figura 79 - Resultados de concentração de PDBs. Comparação dos modelos A e $\mathrm{B}$ com os dados do experimento B4. kcic em s ${ }^{-1} \ldots \ldots \ldots \ldots \ldots \ldots \ldots$

Figura 80 - Previsão da concentração de PDBs através do Modelo A. . . . . . 125

Figura 81 - Previsão da concentração de PDBs através do Modelo B com

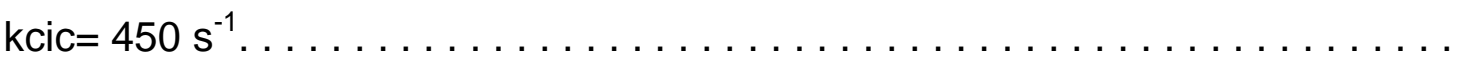

Figura 82 - Resultados de conversão. Comparação entre experimentos e o

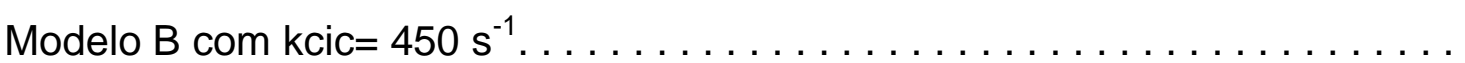

Figura 83 - Resultados de fração de gel. Comparação entre dados experimentais e o Modelo $\mathrm{B}$ com $\mathrm{kcic}=450 \mathrm{~s}^{-1} \ldots \ldots \ldots \ldots \ldots \ldots \ldots$

Figura 84 - Comparação de previsões dos modelos A e B com os resultados experimentais de Mw para o experimento P7. kcic em s $\mathrm{s}^{-1} \ldots \ldots \ldots \ldots \ldots$

Figura 85 - Comparação de previsões dos modelos A e B com os resultados experimentais de $\mathrm{Wg}$ para o experimento P7. kcic em $\mathrm{s}^{-1} \ldots \ldots \ldots \ldots \ldots \ldots$

Figura 86 - Comparação de previsões dos modelos A e C com os resultados experimentais de Mw para o experimento P7. kcic em s ${ }^{-1} \ldots \ldots \ldots \ldots \ldots \ldots$

Figura 87 - Comparação de previsões dos modelos A e C com os resultados experimentais de $\mathrm{Wg}$ para o experimento $\mathrm{P} 7$. kcic em $\mathrm{s}^{-1}$.

Figura 88 - Efeito da concentração de TEMPO sobre a conversão de monômero. Simulações realizadas com os dados do experimento P4 . . . . . . . Figura 89 - Simulação da concentração de PDBs com o Modelo A para diferentes experimentos. . . . . . . . . . . . . . . . . . . .

Figura 90 - Simulação da concentração de PDBs com o Modelo C para diferentes experimentos. $\mathrm{kcic}=450 \mathrm{~s}^{-1}$.

Figura 91 - Resultados de conversão. Comparação entre experimentos e simulações com os modelos A e C. Experimentos P6 e P14 (90). . . . . . . . . Figura 92 - Resultados de conversão. Comparação entre experimentos e simulações com os modelos A e C. Experimentos P1, P2 e P15 (90) . . . . . . Figura 93 - Resultados de conversão. Comparação entre experimentos e simulações com os modelos A e C. Experimentos P3, P4 e P5 (90C) . . . . . . Figura 94 - Resultados de conversão. Comparação entre experimentos e simulações com os modelos A e C. Experimentos P9, P10 e P11 (130C). . . . 
Figura 95 - Comparação entre os modelos A e C em previsões de Mw para

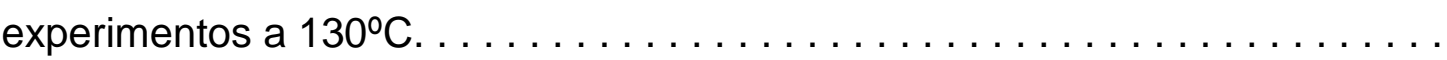

Figura 96 - Comparação entre os modelos $\mathrm{A}$ e $\mathrm{C}$ em previsões de $\mathrm{Wg}$ para experimentos a $130^{\circ} \mathrm{C}$. .

Figura 97 - Resultados de Mw para o experimento P8. Comparação entre os modelos A, B e C. . . . . . . . . . . . . . . . . . . . . . . . . . . . . .

Figura 98 - Resultados de Mw para o experimento P9. Comparação entre os

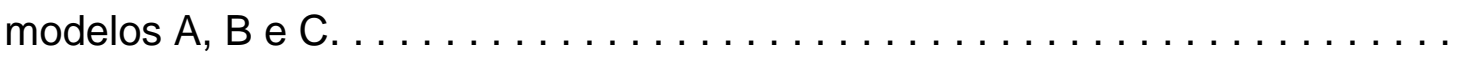

Figura 99 - Comparação entre dados experimentais e previsões de $\mathrm{Mw}$ e $\mathrm{Wg}$ com os modelos $\mathrm{A}$ e $\mathrm{C}$ para o experimento $\mathrm{P} 2 \ldots \ldots \ldots \ldots \ldots \ldots \ldots$

Figura 100 - Comparação entre dados experimentais e previsões de $\mathrm{Mw}$ e $\mathrm{Wg}$ com os modelos $A$ e $C$ para o experimento $P 3$. .

Figura 101 - Comparação entre dados experimentais e previsões de Mw e Wg com os modelos A e C para o experimento P15.

Figura 102 - Estrutura das moléculas de polímero formadas pelos diferentes processos de copolimerização, que explicaria as diferenças de aprisionamento de PDBs em função do tipo de processo. .

Figura 103 - Modelo $C$ : Variação do parâmetro $V_{G}$. Simulações com 0 experimento $\mathrm{P} 3$.

Figura 104 - Modelo C: Variação do parâmetro $\mathrm{f}_{\mathrm{rg}}$. Simulações com 0 experimento $\mathrm{P} 3$ 


\section{LISTA DE TABELAS}

Tabela 1 - Reações envolvidas no processo . . . . . . . . . . . . . . 29

Tabela 2 - Esquema reacional. . . . . . . . . . . . . . . . . . . . . 35

Tabela 3 - Reações químicas consideradas no Modelo B. . . . . . . . . 41

Tabela 4 - Reações envolvendo caminhos. .................... 64

Tabela 5 - Propriedades dos compostos utilizados nos experimentos. . . . . . 74

Tabela 6 - Condições dos experimentos realizados em solução (Brasil). . . . 82

Tabela 7 - Condições dos experimentos realizados em suspensão (Portugal). 82

Tabela 8 - Parâmetros cinéticos utilizados na análise preliminar (Modelo B). . 103

Tabela 9 - Parâmetros cinéticos utilizados na avaliação do efeito das

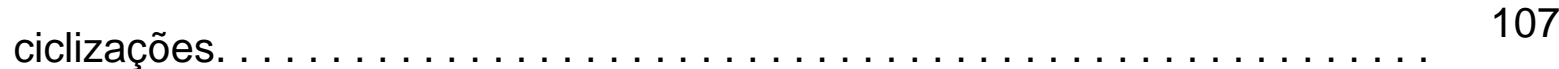

Tabela 10 - Parâmetros cinéticos utilizados nas simulações de copolimerizações FRP com o Modelo A. ...

Tabela 11 - Parâmetros cinéticos utilizados nas simulações de copolimerizações FRP com os modelos B e C. . . . . . . . . . . . . .

Tabela 12 - Parâmetros cinéticos utilizados nas simulações de processos

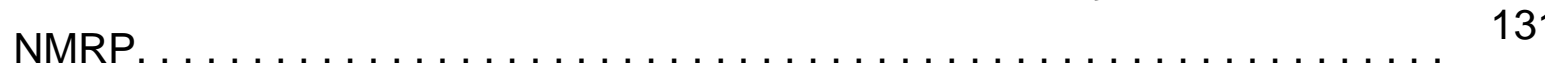

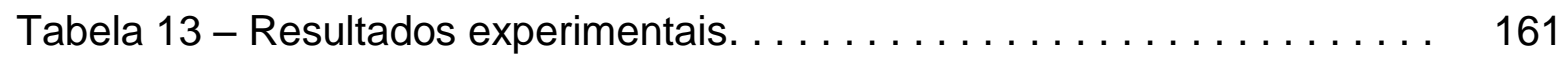

Tabela 14 - Perfil de temperaturas para as reações à $130^{\circ} \mathrm{C} \ldots \ldots \ldots \ldots .170$ 


\section{LISTA DE ABREVIATURAS E SIGLAS}
AIBN
Azobisisobutyronitrile (azo-bis isobutironitrila)
BPO
Benzoyl peroxide (peróxido de benzoíla)
Decomp Decompõe-se
DVB
Divinilbenzeno
Exp
Dados experimentais
ModA
Resultados de simulação com o Modelo $A$
ModB
Resultados de simulação com o Modelo $B$
ModC
Resultados de simulação com o Modelo $C$
PDB
Pendant double Bond (dupla ligação pendente)
Pol
Polímero
THF
Tetrahydrofuran (tetraidrofurano)
TEMPO 2,2,6,6-Tetramethyl piperidinyl-1-oxy (2,2,6,6-Tetrametil-piperidinil-1- oxy) 


\section{LISTA DE SÍMBOLOS}

Agm Reagente que participa de reação unimolecular

Agm- Reagente que participa de reação bimolecular

$\mathrm{A}_{\mathrm{gm}+}$

Reagente que participa de reação bimolecular

$\left[A_{j}\right]$

Concentração de entidades $A_{i}$

$A_{i}$

Entidade genérica (monômero, grupo polimérico ou outra espécie)

$A_{[m]}$

Reagente que participa de reação unimolecular

$A_{[m-]}$

Reagente que participa de reação bimolecular

$\mathrm{A}_{[\mathrm{m}+]}$

Reagente que participa de reação bimolecular

$\mathrm{C}_{D}$

Concentração de duplas ligações pendentes ( $\mathrm{mmol} / \mathrm{g}$ de polímero)

$\mathrm{C}_{\mathrm{j}}$

Concentração de entidades $A_{i}$ (mol/L)

$\mathrm{C}_{\mathrm{P}}$

Parâmetro de correlação entre reatividades

$\mathrm{C}_{\text {tit }}$

Concentração do titulante (mol/L)

D Dímero

$\mathrm{DL}_{r} \quad$ Caminho dormente contendo ' $r$ ' unidades monoméricas

$\mathrm{DR}_{0} \quad$ Radical primário dormente

$\mathrm{DR}_{\mathrm{r}} \quad$ Radical polimérico dormente contendo ' $r$ ' unidades monoméricas

$\mathrm{DR}_{\mathrm{r}, \mathrm{j}} \quad$ Radical polimérico dormente contendo dupla ligação pendente do tipo 'j' ( $\mathrm{j}=4$ : mPDB, $\mathrm{j}=5$ : pPDB) e 'r' unidades monoméricas

$\mathrm{F}$

$f_{i}$

$f_{M i}$

$f_{m P D B}$

$f_{\text {PPDB }}$

$f_{R i}$

$f_{\mathrm{rg}}$

$\mathrm{f}_{\mathrm{rr}}$

$\mathrm{G}(\mathrm{s})$

I

$k_{a}$

HON $\quad$ Composto inerte proveniente do consumo de radicais nitróxido

Segmento de cadeia

Fração molar do monômero ou PDB do tipo 'i' em relação à soma monômeros+PDBs

Fração molar do monômero 'i' dentre todos os monômeros

Fração molar de mPDB dentre todas as PDBs

Fração molar de pPDB dentre todas as PDBs

Fração molar do radical do tipo 'i' dentre todos os radicais

Fator de redução da reatividade referente à reação com o gel

Fator de redução da reatividade

Função geradora da distribuição de tamanhos de cadeia em termos de concentração molar com relação à contagem de grupos

Iniciador

Constante cinética da reação de ativação de radicais $\left(\mathrm{s}^{-1}\right)$ 
$\begin{array}{ll}k_{d} & \text { Constante cinética da reação de decomposição do iniciador }\left(\mathrm{s}^{-1}\right) \\ k_{d a} & \text { Constante cinética da reação de desativação de radicais }\left(\mathrm{L}_{\mathrm{mol}}{ }^{-1} \mathrm{~s}^{-1}\right) \\ \mathrm{k}_{\mathrm{ddij}} & \text { Constante cinética da reação de decomposição do dímero composto } \\ & \text { pelos monômeros } \mathrm{M}_{\mathrm{i}} \text { e } \mathrm{M}_{\mathrm{j}}\left(\mathrm{s}^{-1}\right) \\ \mathrm{k}_{\mathrm{dec}} & \text { Constante cinética da reação de decomposição de radicais dormentes }\end{array}$ $\left(\mathrm{s}^{-1}\right)$

$k_{\text {dimij }} \quad$ Constante cinética da reação de dimerização entre os monômeros $M_{i} e$ $\mathrm{M}_{\mathrm{j}}\left(\right.$ L. mol $\left.{ }^{-1} \mathrm{~s}^{-1}\right)$

$\mathrm{k}_{\mathrm{fmij}} \quad$ Constante cinética da reação de transferência de cadeia de um radical do tipo 'i' para o monômero $\mathrm{M}_{\mathrm{j}}\left(\mathrm{L} \cdot \mathrm{mol}^{-1} \mathrm{~s}^{-1}\right)$

$k_{h} \quad$ Constante cinética da reação de abstração de próton pelo radical nitróxido (L.mol $\left.{ }^{-1} \mathrm{~s}^{-1}\right)$

$\mathrm{k}_{\mathrm{l}} \quad$ Constante pseudo-cinética de iniciação de monômeros (L. $\left.\mathrm{mol}^{-1} \mathrm{~s}^{-1}\right)$

$\mathrm{k}_{\mathrm{lj}} \quad$ Constante cinética da reação de iniciação de monômero ou PDB do tipo 'j' $\left(\right.$ L.mol $\left.{ }^{-1} \mathrm{~s}^{-1}\right)$

$\mathrm{k}_{\mathrm{IP}} \quad$ Constante pseudo-cinética de iniciação de PDBs (L. $\left.\mathrm{mol}^{-1} \mathrm{~s}^{-1}\right)$

$\mathrm{k}_{\mathrm{p}} \quad$ Constante pseudo-cinética de propagação de monômeros ( $\mathrm{L}_{\mathrm{mol}}{ }^{-1} \mathrm{~s}^{-1}$ )

$k_{P i j, S}^{C} \quad$ Constante cinética da reação de ciclização de um segmento polimérico (caminho) contendo 's' unidades e, em seus extremos, um radical do tipo 'i' e uma dupla ligação pendente do tipo 'j' $\left(\mathrm{s}^{-1}\right)$

$\mathrm{k}_{\mathrm{Pij}} \quad$ Constante cinética da reação de propagação envolvendo radical do tipo 'i' e o monômero ou PDB do tipo 'j' (L.mol $\left.{ }^{-1} \mathrm{~s}^{-1}\right)$

$\mathrm{k}_{\mathrm{l}-\mathrm{Sty}} \quad$ Constante cinética de iniciação de estireno

$\mathrm{k}_{\mathrm{I}-\mathrm{DVB}} \quad$ Constante cinética de iniciação de divinilbenzeno

k।-PDB $\quad$ Constante cinética de iniciação de dupla ligação pendente

$\mathrm{k}_{\mathrm{PP}} \quad$ Constante pseudo-cinética de propagação de PDBs (L.mol $\left.{ }^{-1} \mathrm{~s}^{-1}\right)$

$k_{p p, i} \quad$ Constante cinética média de reação de ligação cruzada entre uma molécula da geração 'i' com qualquer molécula de polímero solúvel ou gel (L.mol $\left.{ }^{-1} \mathrm{~s}^{-1}\right)$

$k_{p p i, j} \quad$ Constante de velocidade da reação de ligação cruzada entre uma molécula da geração 'i’ e uma molécula da geração 'j' (L.mol $\left.{ }^{-1} \mathrm{~s}^{-1}\right)$

kppi,sol Constante cinética da reação entre uma molécula da geração 'i' com

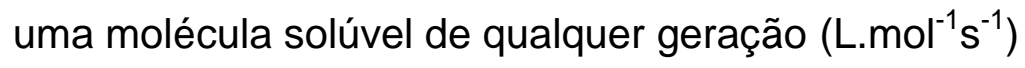

k $\mathrm{pR}_{\mathrm{P}-\mathrm{Sty}} \quad$ Constante cinética de propagação entre radical polimérico e estireno 
k Cons-DVB Contante cinética de propagação entre radical polimérico e divinilbenzeno

k $\mathrm{p}_{\mathrm{PR}-\mathrm{PDB}} \quad$ Constante cinética de propagação entre radical polimérico e dupla ligação pendente

$k_{t} \quad$ Constante cinética da reação de terminação de radicais poliméricos $M_{j}$ $\left(\right.$ L. $\left.\mathrm{mol}^{-1} \mathrm{~s}^{-1}\right)$

$k_{\text {tc }} \quad$ Constante cinética da reação de terminação por combinação de radicais poliméricos $\mathrm{M}_{\mathrm{j}}\left(\mathrm{L} \cdot \mathrm{mol}^{-1} \mathrm{~s}^{-1}\right)$

$k_{\text {thij }}$

Constante cinética da reação de iniciação térmica envolvendo dímero e o monômero $\mathrm{M}_{\mathrm{j}}\left(\mathrm{L} \cdot \mathrm{mol}^{-1} \mathrm{~s}^{-1}\right)$

$L_{r} \quad$ Caminho ativo contendo ' $r$ ' unidades monoméricas

M Concentração de monômeros (mol/L)

$\mathrm{m}_{\mathrm{i}} \quad$ Massa obtida na etapa 'i' da gravimetria

$\mathrm{M}_{\mathrm{i}, 0} \quad$ Concentração inicial do monômero do tipo ' $\mathrm{i}$ '

$\mathrm{M}_{\mathrm{j}} \quad$ Monômero do tipo $\mathrm{j}$ ( $\mathrm{j}=1$ : estireno, $\mathrm{j}=2$ : $\mathrm{mDVB}, \mathrm{j}=3$ : $p D V B$ )

$M_{n}$

$\mathrm{m}_{\mathrm{S}}$

$M_{w}$

$M_{\text {wi }}$

Massa molecular média numérica de cadeias de polímero $(\mathrm{g} / \mathrm{mol})$

Massa da amostra ( $\mathrm{g}$ )

Massa molecular média mássica de cadeias de polímero $(\mathrm{g} / \mathrm{mol})$

Massa molecular média mássica das cadeias de polímero pertencentes à geração i $(\mathrm{g} / \mathrm{mol})$

$M_{z} \quad$ Massa molecular média ' $z$ ' de cadeias de polímero $(\mathrm{g} / \mathrm{mol})$

n Número de gerações (fracionamento numérico)

$\mathrm{N}_{\mathrm{A}} \quad$ Número total de entidades

$N_{A G} \quad$ Número de tipos de grupos em moléculas de polímero que são grupos principais de alguma reação química

N $\quad$ Número de reações de combinação entre grupos pertencentes a diferentes moléculas de polímero

$\mathrm{N}_{\mathrm{CR}} \quad$ Número de reações de criação entre espécies

$\mathrm{N}_{\mathrm{ER}} \quad$ Número de reações de permuta entre um grupo polimérico e uma espécie não polimérica

$\mathrm{N}_{\mathrm{G}} \quad$ Número de grupos poliméricos

$\mathrm{N}_{\mathrm{M}} \quad$ Número de monômeros

$\mathrm{N}_{\mathrm{PR}} \quad$ Número de reações de propagação

$\mathrm{N}_{\mathrm{RB}} \quad$ Número de reações bimoleculares 
$\mathrm{N}_{\mathrm{RC}} \quad$ Número de categorias de reações entre espécies e/ou grupos poliméricos

$\mathrm{N}_{\mathrm{Ri}} \quad$ Número de reações compreendidas na categoria 'i'

NuR Número de reações unimoleculares de grupos poliméricos

$\mathrm{ON}_{\mathrm{x}} \quad$ Radical nitróxido (TEMPO)

$[\mathrm{P}(\mathrm{a})] \quad$ Concentração de moléculas de polímero contendo grupos poliméricos representados pelo vetor ' $a$ '

$P_{r, j} \quad$ Polímero morto contendo dupla ligação pendente do tipo 'j' ( $j=4$ : mPDB, j=5: pPDB) e ' $r$ ' unidades monoméricas

$Q_{i} \quad$ Momento global de ordem 'i’ para polímeros mortos

$\mathrm{Q}_{\mathrm{ji}} \quad$ Momento de ordem 'i’ para polímeros mortos pertencentes à geração ‘j'

$r \quad$ Número de unidades monoméricas

$\mathrm{R} \quad$ Concentração de radicais ( $\mathrm{mol} / \mathrm{L}$ )

$\mathrm{R}_{0} \quad$ Radical primário

$R_{i m, r} \quad$ Taxa de ciclização envolvendo caminhos ativos contendo radical do tipo 'i' e mPDB conectados por $r$ unidades monoméricas (mol. $\mathrm{L}^{-1} \mathrm{~s}^{-1}$ )

$\mathrm{RC}_{\mathrm{ip}, \mathrm{r}} \quad$ Taxa de ciclização envolvendo caminhos ativos contendo radical do tipo 'i' e pPDB conectados por $r$ unidades monoméricas (mol. $\mathrm{L}^{-1} \mathrm{~s}^{-1}$ )

$\mathrm{RC}_{\mathrm{m}} \quad$ Taxa de ciclização envolvendo caminhos ativos contendo mPDB $\left(\mathrm{mol} . \mathrm{L}^{-1} \mathrm{~S}^{-1}\right)$

$\mathrm{RC}_{\mathrm{p}} \quad$ Taxa de ciclização envolvendo caminhos ativos contendo pPDB $\left(\mathrm{mol} . \mathrm{L}^{-1} \mathrm{~s}^{-1}\right)$

$\mathrm{R}_{\mathrm{CR} 1} \quad$ Taxa de consumo de radicais do tipo 1 por terminação (mol.L ${ }^{-1} \mathrm{~s}^{-1}$ )

$<\mathrm{R}_{\mathrm{gi}}>\quad$ Raio de giração médio entre as moléculas de polímero intumescidas da geração 'i' (nm)

$\mathrm{R}_{\mathrm{GR} 1} \quad$ Taxa de geração de novos radicais do tipo 1 por iniciação

$\mathrm{R}_{\mathrm{m}} \quad$ Taxa da reação 'm'

$\mathrm{R}_{\mathrm{R}=1} \quad$ Radical polimérico contendo uma unidade monomérica

$\mathrm{R}_{r, \mathrm{i}} \quad$ Radical polimérico do tipo 'i' ( $\mathrm{i}=1$ : estireno, $\mathrm{i}=2$ : $m D V B, i=3$ : $p D V B, i=4$ : mPDB, i=5: pPDB) contendo 'r' unidades monoméricas

$\mathrm{R}_{\mathrm{r}, \mathrm{i}, \mathrm{j}, \mathrm{s}} \quad$ Radical polimérico contendo ' $r$ ' unidades monoméricas e contendo um segmento de cadeia (caminho) com ' $s$ ' unidades monoméricas, conectando um centro radicalar do tipo 'i’ ( $i=1$ : estireno, $i=2$ : mDVB, 
$\mathrm{i}=3$ : $p D V B, \mathrm{i}=4$ : mPDB, $\mathrm{i}=5$ : $p P D B$ ) à uma PDB do tipo 'j' ( $\mathrm{j}=4$ : mPDB, $j=5: p P D B)$

$S_{i} \quad$ Momento global de ordem 'i' para radicais dormentes

$S_{\mathrm{ji}} \quad$ Momento de ordem ' $\mathrm{i}$ ' para radicais dormentes pertencentes à geração 'j'

$\mathrm{U}_{\mathrm{i}} \quad$ Unidade monomérica do tipo 'i'

$V_{i} \quad$ Volume médio das moléculas constituintes da geração 'i' $\left(\mathrm{nm}^{3}\right)$

$\mathrm{V}_{\mathrm{sol}} \quad$ Volume médio das moléculas solúveis de polímero

$V_{\text {titB }} \quad$ Volume de titulante gasto na titulação do branco $(\mathrm{mL})$

$V_{\text {titA }} \quad$ Volume de titulante gasto na titulação da amostra $(\mathrm{mL})$

$\mathrm{W}_{\mathrm{g}} \quad$ Fração mássica de gel em relação a todo o conteúdo de polímero

$\mathrm{W}_{\mathrm{gEXP}} \quad$ Fração mássica de gel experimental

$X \quad$ Conversão de monômero

XXXP Conversão de monômero experimental

Y DVB $\quad$ Fração molar inicial de DVB na mistura de monômeros (\%)

$Y_{i} \quad$ Momento global de ordem ' $i$ ' para radicais poliméricos

Y IDB Relação molar inicial entre o iniciador e as duplas ligações carbonocarbono (\%)

$\mathrm{Y}_{\mathrm{ji}} \quad$ Momento de ordem 'i' para radicais poliméricos pertencentes à geração 'j'

ymo Fração mássica de monômero no meio reacional, no início da reação

YTEMPO Razão molar inicial entre TEMPO e iniciador

$\phi_{\mathrm{M}}$ Fração volumétrica de monômero na fase orgânica (\%)

$v_{m i} \quad$ Variação de mols da espécie $A_{i}$ causada pela reação ' $m$ '

$v_{m i-}, v_{m i+} \quad$ Variação de mols da espécie $A_{i}$ causada pela reação ' $m$ ', em cada molécula de polímero envolvida

$\psi_{m}, \psi_{m}^{+}, \psi_{m}^{-} \quad$ Funções estequiométricas (funções geradoras dos coeficientes estequiométricos) associadas à reação ' $m$ '

$\lambda_{\mathrm{Mi}} \quad$ Momento referente à massa molecular 


\section{SUMÁRIO}

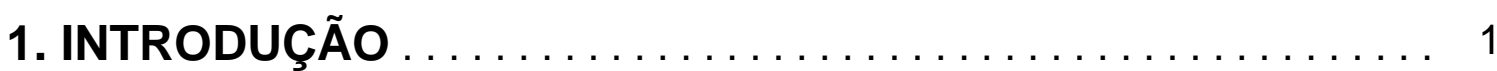

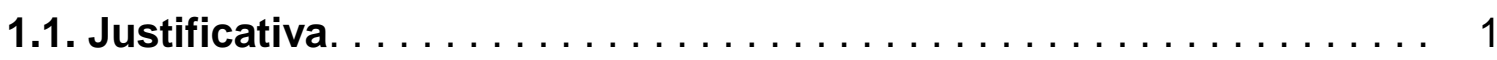

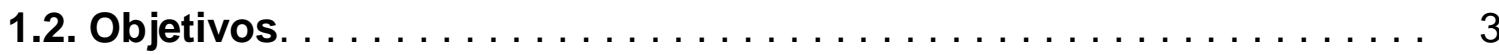

1.3. Estrutura do trabalho. ....................... 4

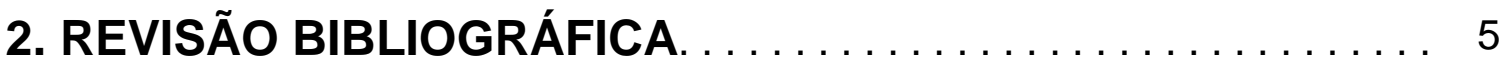

2.1. Polimerização radicalar convencional. ............... 5

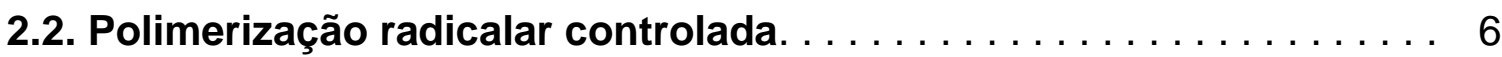

2.2.1. Técnica ATRP (Atom Transfer Radical Polymerization) . . . . . . . . 7

2.2.2. Técnica RAFT (Reversible Addition-Fragmentation Transfer Polymerization) $\ldots \ldots \ldots \ldots \ldots \ldots \ldots \ldots \ldots \ldots \ldots \ldots \ldots \ldots \ldots \ldots \ldots \ldots \ldots \ldots$

2.2.3. Técnica NMRP (Nitroxide-Mediated Radical Polymerization) ....... 9

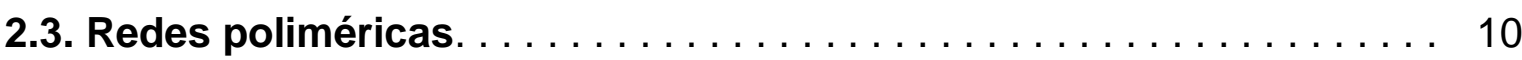

2.4. Comparação entre as copolimerizações convencional e mediada

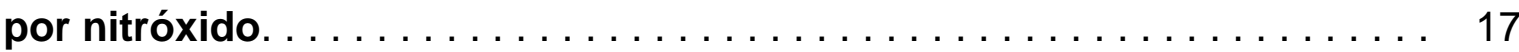

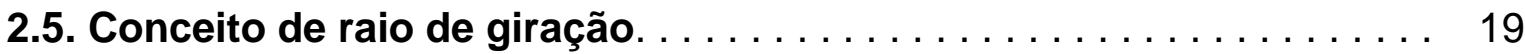

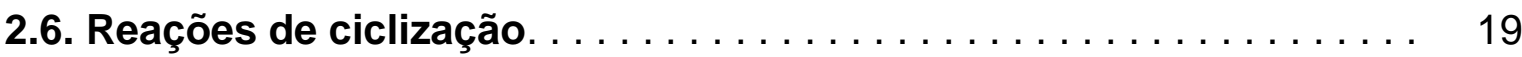

2.7. Modelagem matemática de processos de copolimerização radicalar

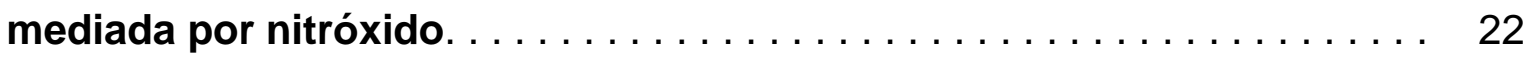

2.8. Caracterização dos copolímeros sintetizados............. 24

2.8.1. Cromatografia por exclusão de tamanhos. ................ 24

2.8.2. Caracterização do gel. . . . . . . . . . . . . . . . . . . . . . . 27

3. METODOLOGIA. . . . . . . . . . . . . . . . . . . . 29

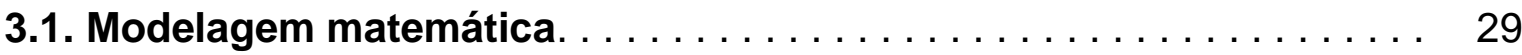

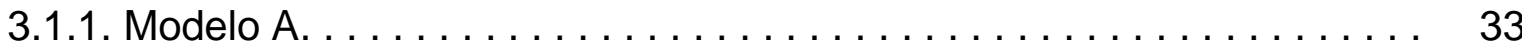

3.1.1.1. Sistema químico. ........................ 33

3.1.1.2. Taxa de formação de espécies poliméricas por reação química. . . . 36

3.1.2. Modelo B. . . . . . . . . . . . . . . . . . . 40

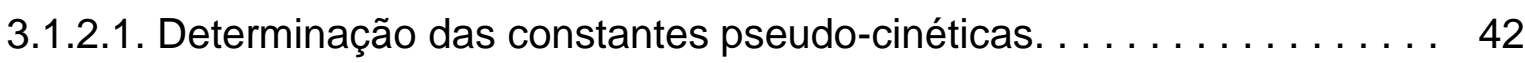

3.1.2.2. Balanço de massa para espécies não poliméricas. . . . . . . . . 46

3.1.2.3. Balanço de massa para espécies poliméricas............. 48 


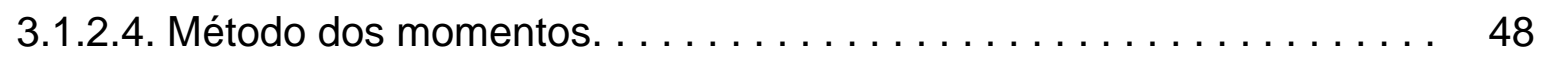

3.1.2.5. Fracionamento numérico $\ldots \ldots \ldots \ldots \ldots \ldots \ldots \ldots \ldots \ldots \ldots \ldots \ldots \ldots \ldots \ldots$

3.1.2.6. Método dos caminhos. ....................... 59

3.1.3. Modelo C.............................. 66

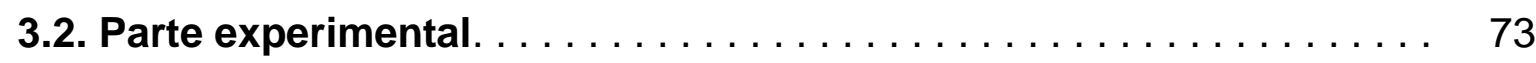

3.2.1. Procedimentos. . . . . . . . . . . 73

3.2.1.1. Reações em solução. . . . . . . . . . . . . . . . . 75

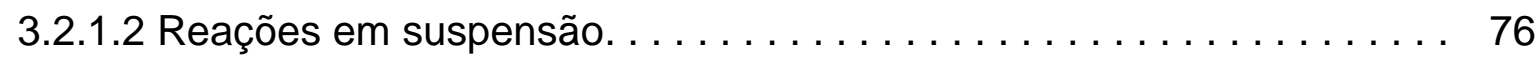

3.2.1.3. Análises. ............................ 76

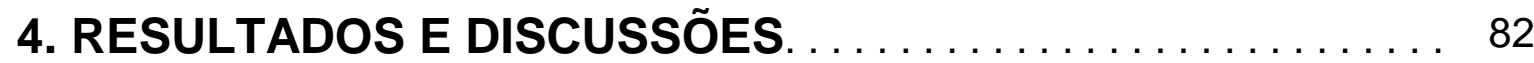

4.1. Resultados experimentais. . . . . . . . . . . . . . . . 82

4.1.1. Resultados experimentais das reações em solução. . . . . . . . . . . 83

4.1.2. Resultados experimentais das reações em suspensão . . . . . . . . . 89

4.2. Resultados das simulações. . . . . . . . . . . . . . . . . . . . 102

4.2.1. Análise preliminar referente à modelagem de copolimerizações de estireno-divinilbenzeno. . . . . . . . . . . . . . . . . . . . . . . . . . . . . 102

4.2.2. Avaliação do efeito das reações de ciclização. . . . . . . . . . . . . 107

4.2.3. Resultados de simulação de copolimerizações convencionais. ...... 119

4.2.4. Resultados de simulação de homo e copolimerizações mediadas por nitróxido. . . . . . . . . . . . . . . . . . . . . . . . . . . 131

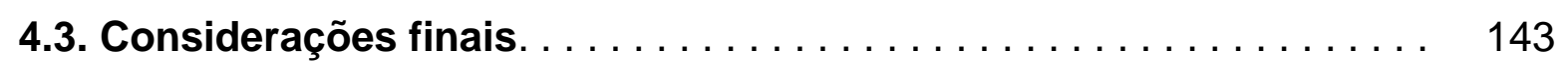

5. CONCLUSÕES . . . . . . . . . . . . . . . . . . . . . . . . 147

6. RECOMENDAÇÕES . . . . . . . . . . . . . . . . . . . . . . 149

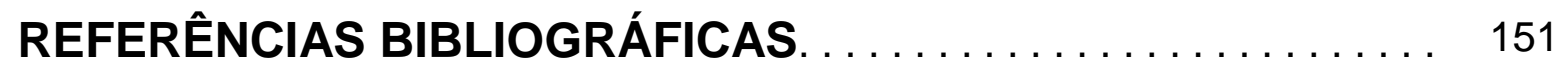

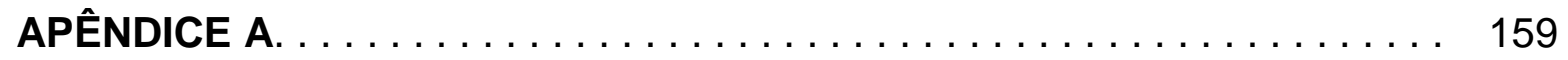

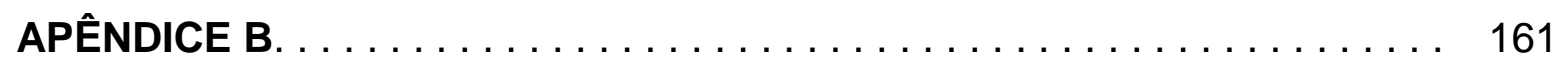

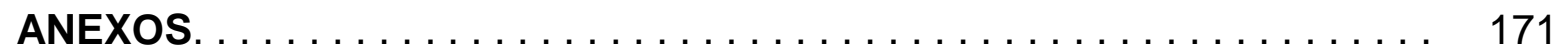




\section{INTRODUÇÃO}

\subsection{Justificativa}

A síntese e a caracterização de copolímeros ramificados e/ou reticulados têm recebido uma atenção especial em laboratórios de pesquisa nos últimos anos. Monômeros divinílicos como divinilbenzeno, diacrilatos e dimetacrilatos são responsáveis pela formação de redes poliméricas, as quais possuem propriedades que as destacam em relação aos polímeros lineares. Gamas de solubilidade e viscosidade apropriadas podem ser obtidas em polímeros hiper-ramificados produzidos por reações de copolimerização. As propriedades especiais deste tipo de polímero possibilitam a sua aplicação em diversos campos como nanotecnologia, biomateriais, medicina, agricultura, dentre outras, podendo-se destacar a produção de tintas e recobrimentos, lentes, borrachas, resinas trocadoras de íons, matrizes para a liberação controlada de medicamentos, cabos e dispositivos eletrônicos, embalagens de alimentos, sensores, órgãos artificiais, implantes e materiais superabsorventes (Gao e Yan, 2004). Em determinadas aplicações, é necessária a utilização de um polímero com cadeias altamente organizadas. Estas cadeias são denominadas dendrímeros e se aplicam, por exemplo, na fabricação de cápsulas para liberação de medicamento. Entretanto, os monômeros utilizados na síntese deste material são funcionalizados conforme a necessidade, exigindo-se mais de uma etapa para sua obtenção. Desta forma, a síntese de dendrímeros consome um tempo relativamente longo, tornando inviável sua produção em larga escala. Em determinados casos, pode-se usar polímeros hiper-ramificados, os quais, de uma forma menos refinada, são estruturalmente análogos aos dendrímeros (GrettonWatson et al., 2006). Esta alternativa consome menos tempo, pois requer somente uma etapa de síntese, sendo economicamente viável.

A síntese de polímeros hiper-ramificados através de reações de policondensação é um assunto relativamente bem estudado. Porém, determinados materiais são produzidos através da polimerização por radicais livres. Trabalhos mais recentes envolvem a síntese de polímeros hiper-ramificados através deste 
processo, utilizando-se monômeros vinílicos multifuncionais (Bannister et al., 2006). Uma característica deste método é a formação de gel (polímero insolúvel) em baixas conversões de monômero, o que pode prejudicar as propriedades do produto final, conforme a aplicação desejada. Deste modo, para manter o polímero solúvel em altas conversões, é necessário implementar estratégias de síntese como o uso de agentes de transferência de cadeia e operação em reator semi-fechado. É importante ressaltar que, em determinadas aplicações, necessita-se que o produto final seja uma rede de polímero insolúvel (partículas de gel). O gel formado prematuramente é denominado microgel. Ele possui um alto grau de reticulação em relação ao produto que se forma ao final do processo, o que resulta em um polímero heterogêneo. Quando se pretende produzir polímero solúvel, esta heterogeneidade causa impacto negativo sobre as propriedades físicas do material.

Nas últimas décadas, grande parte dos polímeros sintéticos tem sido produzida pelo processo de polimerização por radicais livres. Dentre as técnicas utilizadas na síntese, destacam-se a polimerização em massa, solução, suspensão e emulsão. Atualmente, novas tecnologias têm sido empregadas, como as polimerizações em miniemulsão, em dióxido de carbono supercrítico e a chamada polimerização viva ou controlada. Esta última foi descoberta na década de 50 e veio receber maior atenção à partir da década de 90, sendo capaz de produzir polímeros com menor dispersão de massas moleculares em relação à polimerização radicalar convencional. Dentre os diferentes tipos de polimerização viva destacam-se a ATRP (Atom Transfer Radical Polymerization), a RAFT (Reversible Addition-Fragmentation Transfer Polymerization) e a NMRP (Nitroxide-Mediated Radical Polymerization). As técnicas ATRP e RAFT são de uso versátil para diferentes sistemas químicos, mas envolvem complicações como à dificuldade em se obter os agentes de transferência (no caso RAFT) e o inconveniente de gerar produtos com quantidades inaceitáveis de metais (no caso ATRP). A técnica NMRP baseia-se na estabilidade de radicais nitróxido, os quais apresentam facilidade de manuseio e são comercialmente disponíveis, embora apresentem uma eficiência mais elevada com monômeros estirênicos. Tendo em vista o problema de formação prematura de gel durante a produção de polímeros hiper-ramificados e a capacidade da técnica NMRP de controlar o crescimento das cadeias poliméricas, torna-se interessante aliar estas duas técnicas para se obter materiais com menor dispersão de massas moleculares. Com essa junção, obtém-se o processo de copolimerização radicalar mediada por 
nitróxido, o qual tem apresentado bons resultados em termos de propriedades do material produzido conforme se encontra na literatura (Ide e Fukuda, 1997, 1999; Ward, 2000; Hernández-Ortiz, 2009).

No aspecto industrial, os avanços na produção de polímeros ocorrem de maneira acelerada. Um fator que auxilia nestes avanços é o fato de que este material possui versatilidade em termos de propriedades finais (ex.: temperatura de transição vítrea e módulo de elasticidade), as quais podem ser modificadas em função das variáveis de processo (ex.: concentração de reagentes, aditivos e temperatura). Isto gera uma grande flexibilidade para a realização de testes experimentais. Muitos polímeros são comercializados sem um claro entendimento sobre o polímero em si ou sobre as reações envolvidas em sua síntese. No âmbito do processo de copolimerização radicalar controlada, encontra-se a necessidade de esclarecer questões em aberto. Dentre elas observa-se a necessidade de definição do mecanismo envolvido no processo de copolimerização controlada, o qual tem constatado a presença de reações secundárias; os efeitos causados pela adição do agente controlador sobre o ponto de gel e sobre as propriedades do polímero produzido; a formação de ciclizações e seus efeitos sobre o produto final. $O$ presente trabalho se inclui nos esforços destinados à resolução das questões supracitadas e de suas possíveis vertentes. Os resultados experimentais e de modelagem deste estudo contribuem para a representação do processo a nível molecular, podendo posteriormente esclarecer resultados obtidos em escala industrial. Além disso, as melhorias obtidas neste trabalho, podem ser utilizadas na realização de modificações permanentes no processo de produção e na criação de ferramentas úteis no projeto de polímeros hiper-ramificados com propriedades por medida.

\subsection{Objetivos}

O presente trabalho tem por objetivo a realização de estudos cinéticos que permitam obter uma descrição mecanicista detalhada dos processos de copolimerização radicalar convencional e mediada por nitróxido. Dentre os mecanismos, propõe-se a inclusão de possíveis reações secundárias como, por 
exemplo, as ciclizações. Outro ponto a ser abordado é a possibilidade de controlar a velocidade de polimerização dos sistemas NMRP e a dispersão de massas moleculares das cadeias através da variação de temperatura. Propõe-se também, discutir questões relativas ao verdadeiro impacto da aplicação da técnica de copolimerização controlada, isto é, se é comprovada a obtenção de estruturas mais homogêneas ou se ocorre apenas atraso da gelificação. No entanto, entende-se que o aspecto mais importante a ser investigado neste campo está relacionado ao impacto das reações intramoleculares (ciclizações) sobre as propriedades dos produtos obtidos por NMRP em comparação com aqueles produzidos por polimerização radicalar convencional.

Dentro das investigações propostas, utilizam-se ferramentas matemáticas para modelar o processo de copolimerização mediada por nitróxido. Objetiva-se desenvolver e aperfeiçoar modelos matemáticos capazes de lidar com as complexidades associadas a estes sistemas: elevado número de espécies químicas com diferentes reatividades (ex.: diferentes tipos de ligações duplas e radicais poliméricos); possibilidade de formação de gel e a presença de reações de ciclização. Em laboratório, é proposto o estudo da influência das condições de operação, em especial, da diluição inicial e dosagem de DVB, sobre as propriedades dos materiais obtidos.

\subsection{Estrutura do trabalho}

Esta tese está estruturada conforme descrito a seguir.

No capítulo 2 é feita uma revisão bibliográfica sobre o assunto em questão, enfatizando alguns trabalhos recentes da área. São descritos também alguns conceitos que foram utilizados ao longo do trabalho.

No capítulo 3 está descrita a metodologia utilizada no trabalho: as técnicas de modelagem desenvolvidas no presente estudo, bem como métodos retirados da literatura e os procedimentos experimentais.

O capítulo 4 apresenta os resultados obtidos tanto no estudo experimental quanto no estudo de modelagem e as discussões pertinentes.

Os capítulos 5 e 6 descrevem as conclusões e recomendações do presente trabalho respectivamente. 


\section{REVISÃO BIBLIOGRÁFICA}

\subsection{Polimerização radicalar convencional}

No campo da engenharia de reações de polimerização, o processo realizado por radicais livres é um dos mais importantes do ponto de vista econômico. Plásticos encontrados no dia-a-dia, como polietilenos de baixa densidade, poliestireno, dentre outros, são fabricados através da polimerização por radicais livres. As principais razões para o uso extensivo dos processos radicalares, residem em sua efetividade em polimerizar a maioria dos monômeros vinílicos em condições de reação moderadas, podendo-se operar em um amplo intervalo de temperaturas e obter cadeias poliméricas de alto peso molecular em um tempo de reação consideravelmente baixo. Este processo de polimerização é tolerante à presença de água, o que permite executar a polimerização não só em massa como também em solução, suspensão e emulsão. Por outro lado, este processo pode ser empregado na elaboração de uma ampla variedade de copolímeros a partir da maioria dos monômeros vinílicos (Hernández-Ortiz, 2008).

A polimerização por radicais livres tem como principais reações a iniciação, a propagação e a formação de cadeias de polímero morto, que pode ocorrer através da terminação entre dois radicais ou através das reações de transferência. O mecanismo se desdobra através da decomposição do iniciador, a qual gera radicais primários. Estes iniciam a propagação (adição de moléculas de monômero), formando radicais de cadeia extensa, os quais sofrem terminação. A desvantagem do processo de polimerização radicalar convencional é o pobre controle que se tem sobre os elementos que compõem a estrutura do polímero (composição, massa molecular média, dispersão de massas moleculares, dentre outros). As propriedades do material são diretamente afetadas pela dispersão de massas moleculares, que é função da distribuição de tamanhos de cadeia que se desenvolve durante o processo.

Em determinados casos, necessitam-se massas moleculares pré-definidas, porém, o processo de polimerização radicalar convencional apresenta limitações em 
relação ao controle da distribuição de tamanhos de cadeia, dificultando sua aplicação para esses casos específicos.

\subsection{Polimerização radicalar controlada}

Antes do surgimento das técnicas de polimerização radicalar controlada, era possível administrar a velocidade da polimerização mediante à variação de temperatura, concentração de reagentes e ao emprego de retardantes ou inibidores (Bamford, 1989). Com o uso de agentes de transferência, tornou-se possível controlar o peso molecular. Por outro lado, mediavam-se os grupos do extremo das cadeias através de iniciadores ou agentes de transferência funcionais. No entanto, nunca havia sido possível controlar estes três parâmetros ao mesmo tempo. Um dos primeiros esforços em adaptar a polimerização por radicais livres a um processo controlado foi desenvolvido por Otsu (1982) e foi denominado INIFERTER (initiator transfer agent - terminator). Este consiste em utilizar ditiocarbamatos como agentes de iniciação, transferência e terminação, levando à geração reversível de radicais a partir de espécies dormentes, junto à propagação por radicais livres. No entanto, este método não se mostrou eficiente no controle da estrutura do polímero. Solomon et al. (1986) mencionam o uso de radicais nitróxido no processo de polimerização radicalar, o que leva a uma terminação reversível de cadeias poliméricas, podendose produzir um polímero de baixo peso molecular. Posteriormente, Georges et al. (1993) retomam o conceito de Solomon sobre nitróxidos e terminação reversível, reportando a polimerização controlada de estireno, a qual gerou polidispersidades muito baixas. Atualmente, o conceito de polimerização viva faz referência a um grupo de técnicas de polimerização por radicais livres que permitem sintetizar polímeros com estrutura controlada e com baixa dispersão de massas moleculares (Hernández-Ortiz, 2008).

A técnica NMRP se utiliza de radicais estáveis como 0 2,2,6,6Tetrametilpiperidinil-1-oxy (TEMPO), os quais desativam temporariamente os radicais poliméricos. Essa desativação interrompe o crescimento das cadeias poliméricas, impedindo que este ocorra de forma descontrolada no início da reação, permitindo que as moléculas de monômero sejam adicionadas às cadeias de forma 
menos desigual. Como a desativação é reversível, as cadeias de polímero dormente (desativadas pelo radical nitróxido) podem se reativar e propagar.

Muito trabalhos têm sido publicados acerca da técnica NMRP e sua aplicação, principalmente, em homopolimerizações de estireno (Belincanta-Ximenes et al, 2007; Roa-Luna et al, 2007, 2008; Murari et al, 2011; Montezuma, 2012). Esta técnica permite a obtenção de menor dispersão de massas moleculares em relação ao método convencional, ou seja, uma distribuição de tamanhos de cadeia mais estreita. Os mecanismos envolvidos no processo NMRP e nas demais técnicas de polimerização controlada estão descritos nos itens a seguir.

\subsubsection{Técnica ATRP (Atom Transfer Radical Polymerization)}

No processo ATRP, um complexo (em geral, de cobre) ligado a um halogênio, é utilizado para efetuar a terminação reversível dos radicais. A técnica tem sido aplicada em polimerizações em massa, utilizando-se dimetacrilatos. O ligante 1,1,4,7,10,10-hexametiltrietilenotetramina (HMTETA) é comumente utilizado como integrante do complexo. A Figura 1 mostra a ação deste aditivo dentro do processo ATRP.

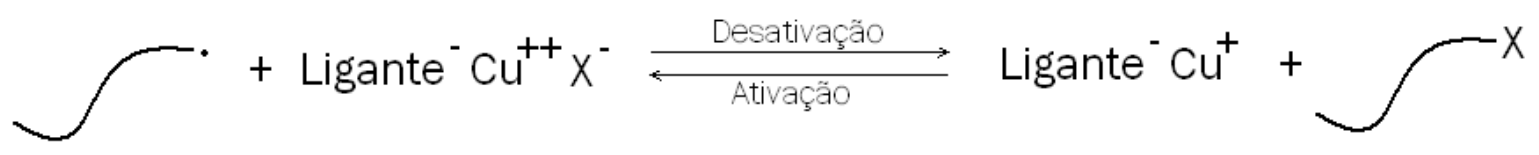

Figura 1 - Mecanismo de desativação reversível de radicais no processo ATRP.

Nesta técnica, o rápido equilíbrio entre radicais poliméricos e espécies dormentes resulta em uma baixa e constante concentração destes radicais, a qual faz com que a polimerização proceda de maneira viva. Estas características podem reduzir ou até mesmo eliminar o efeito da autoaceleração (efeito TrommsdorfNorrish) e assim produzir um polímero com menor dispersão de massas moleculares (Yu et al., 2001). Além do rápido equilíbrio das reações de ativação e desativação, o processo ATRP possui a vantagem de não originar reações paralelas que afetem significativamente a taxa de geração de calor, o que permite monitorar a conversão 
através da quantificação da energia liberada. Além disso, ele se aplica a quase todos os monômeros vinílicos, permite operação em amplo intervalo de temperaturas $\left(-30\right.$ à $\left.150^{\circ} \mathrm{C}\right)$ e suporta a presença de água e pequenas quantidade de oxigênio e inibidores com metais em estado de oxidação zero (Hernández-Ortiz, 2008). O processo tem como desvantagem a geração de quantidades consideráveis de metais de transição, sendo necessária a sua remoção e a precipitação do cobre.

\subsubsection{Técnica RAFT (Reversible Addition-Fragmentation Transfer Polymerization)}

O método RAFT caracteriza-se pela presença de ditiobenzoatos, que são usados como agentes de transferência nos processos de polimerização radicalar. $O$ mecanismo que caracteriza o método RAFT consiste em um equilíbrio químico entre as reações de adição e fragmentação. Um radical polimérico reage com espécies dormentes para formar um radical intermediário. Em seguida, este radical intermediário se fragmenta gerando um novo radical crescente. A rápida troca de um pequeno número de radicais em meio a um grande número de cadeias dormentes fornece a mesma probabilidade para todas as cadeias crescerem, gerando um bom controle sobre o desenvolvimento da microestrutura da cadeia, como peso molecular e composição (Yu et al., 2008). A Figura 2 apresenta o mecanismo reacional do processo RAFT.

Esta é uma técnica robusta e versátil devido à sua aplicabilidade a vários tipos de monômero. As condições de operação são similares ao processo convencional, com elevadas temperaturas para monômeros pouco reativos. Suporta a presença de água, mas é sensível a oxigênio (Hernández-Ortiz, 2008). Como desvantagem, destaca-se a dificuldade em se obter os agentes de transferência. Alternativamente, pode-se realizar a reação em solução e utilizar nitrobenzeno como agente de transferência. 

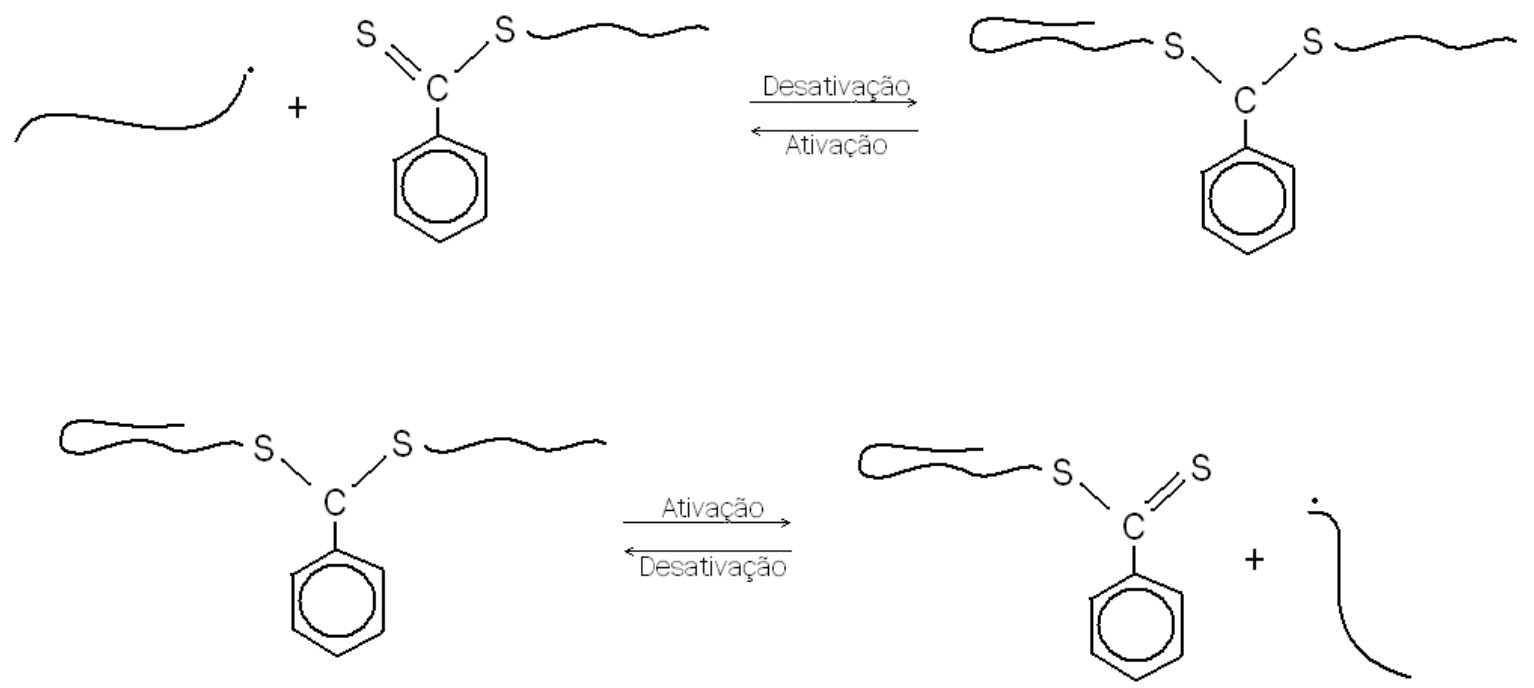

Figura 2 - Mecanismo de desativação reversível de radicais no processo RAFT.

2.2.3. Técnica NMRP (Nitroxide-Mediated Radical Polymerization)

O sistema NMRP tem sido estudado trabalhando-se com polimerizações em massa, solução, miniemulsão e microssuspensão. O processo é comumente aplicado a polimerizações e copolimerizações, nas quais o monômero principal é o estireno. A Figura 3 mostra o mecanismo de desativação reversível usando como exemplo o radical estável 2,2,6,6-Tetrametilpiperidinil-1-oxy (TEMPO).
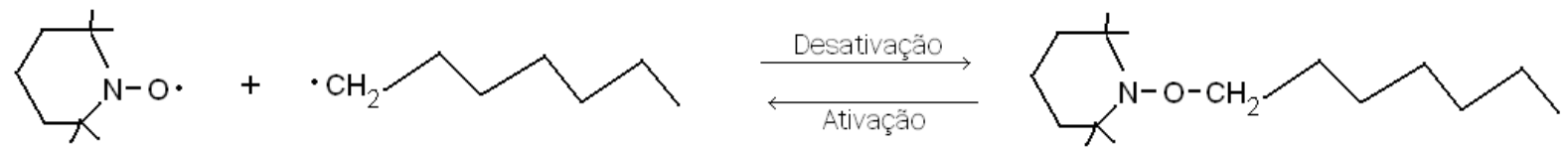

Figura 3 - Mecanismo de desativação reversível em uma polimerização mediada por nitróxido.

Na presença de monômeros, o radical polimérico propaga (cresce) até ser desativado pelo radical TEMPO, formando um polímero dormente. O número de ciclos ativação/desativação permite que todas as cadeias cresçam lentamente na mesma velocidade média, produzindo polímeros com uma dispersão de massas moleculares limitada. Detalhes cinéticos de polimerizações e copolimerizações mediadas por TEMPO mostraram que este processo pode ser considerado, em determinadas condições, um sistema controlado com um número de cadeias 
poliméricas aproximadamente constante ao longo da polimerização (Ide e Fukuda, 1997).

O método NMRP possui maior eficiência quando se trabalha com monômeros estirênicos em conjunto com o radical TEMPO, mas pode também ser aplicado a acrilatos e acrilamidas utilizando-se novos nitróxidos. Esta tecnologia permite a operação em altas temperaturas (maiores que $120^{\circ} \mathrm{C}$ para TEMPO), suporta a presença de água, porém é sensível ao oxigênio (Hernández-Ortiz, 2008).

\subsection{Redes poliméricas}

Os conceitos até aqui descritos têm como base o processo de homopolimerização, ou seja, a polimerização que envolve um único monômero. $\mathrm{O}$ poliestireno é um polímero linear produzido através da homopolimerização do estireno. Sua característica linear se deve à ausência de reações que geram ramificações ou ligações cruzadas (Ex.: transferência de cadeia à polímero). As redes poliméricas são estruturas resultantes de ligações entre as cadeias de polímero de forma tridimensional. Materiais com esta estrutura são sintetizados através de reações de homopolimerização, utilizando-se um monômero multifuncional ou através de copolimerização, utilizando-se mais de um monômero, sendo que, pelo menos um deles é multifuncional (agente de crosslink). A Figura 4 mostra a estrutura a nível molecular do poliestireno e do copolímero estireno/divinilbenzeno.

Durante a síntese de materiais poliméricos reticulados, é característico que em algum ponto da reação se obtenha uma fração polimérica insolúvel, também conhecida como gel. O gel é insolúvel em todos os solventes, mesmo em temperaturas elevadas. Ele corresponde à formação de uma rede polimérica grande, na qual as cadeias estão conectadas umas às outras, formando-se moléculas macroscópicas. Na verdade, o gel é considerado uma única molécula. A porção de polímero que permanece solúvel nos solventes é conhecida como fração sol. À medida que a polimerização procede além do ponto de gelificação, ocorre uma mudança física dramática na mistura reacional, formando-se um polímero de viscosidade infinita. A copolimerização por radicais livres de monômeros vinílicos 
com uma pequena quantidade de monômeros divinílicos, apresenta-se como uma das rotas mais simples para a síntese de redes poliméricas e géis.
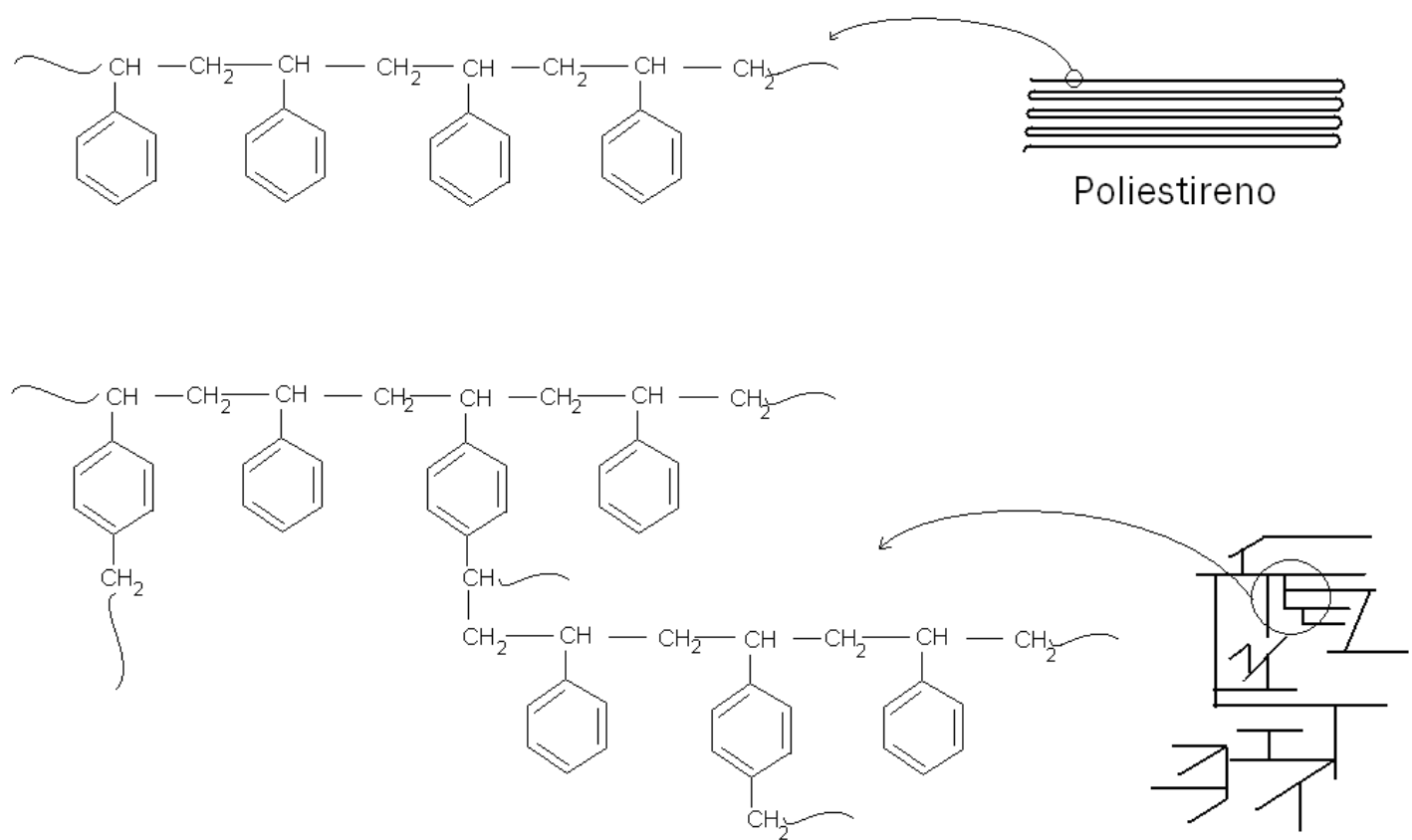

Copolímero estireno/divinilbenzeno

Figura 4 - Diferenciação entre cadeias de polímero lineares e redes poliméricas.

Nestes sistemas, as ligações cruzadas se formam quando se adiciona um radical polimérico a alguma dupla ligação não reagida, a qual está presente graças aos monômeros divinílicos que foram incorporados às cadeias. A reação de crosslink (ligação cruzada) pode ser intermolecular, caso o radical polimérico e a dupla ligação pendente pertençam à cadeias distintas; ou intramolecular, caso pertençam à mesma cadeia, levando à uma ciclização. Mrkvicková et al. (1981) estudaram a copolimerização do metacrilato de metila com dimetacrilatos e observaram que a maioria das duplas ligações pendentes é consumida por reações intramoleculares. Soper et al. (1972) mostraram que para conversões muito baixas, cerca de $10 \%$ das duplas ligações pendentes nas cadeias poliméricas reagiram formando ciclos. Portanto, as redes obtidas por polimerização radicalar convencional são de estrutura pouco homogênea, ou seja, a distribuição espacial dos pontos de crosslink ao longo do material é bastante irregular (Hernández-Ortiz, 2008).

A Figura 5 ilustra a ocorrência de ligações cruzadas intermoleculares e intramoleculares (ciclizações). 


\section{Crosslink intermolecular}
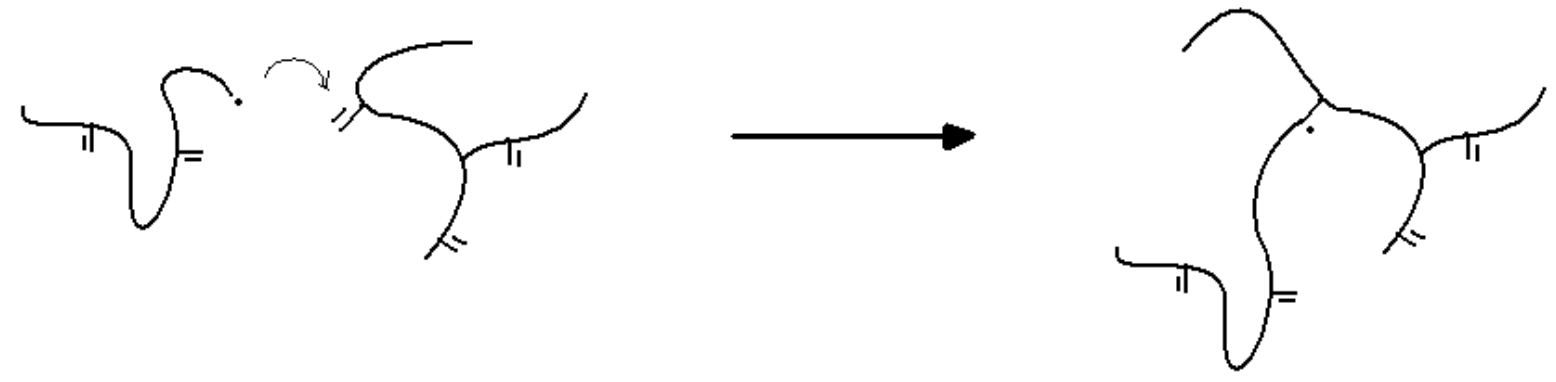

Crosslink intramolecular (ciclização)

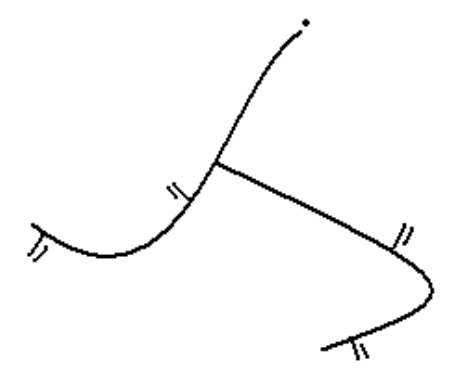

భ: Dupla ligação pendente

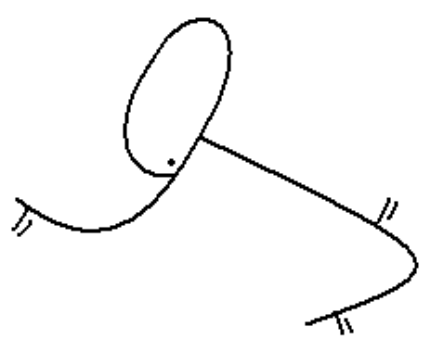

Figura 5 - Reações de crosslink intermolecular e intramolecular.

Hicks et al. (2003) destacaram a presença de redes poliméricas na composição de córneas artificiais. Trata-se de um polímero (polimetacrilato de 2hidroxietila) que apresenta diferentes tamanhos de poros em função da região ocular. A região periférica possui poros maiores em relação à região ótica (central). A união dessas duas estruturas de polímero é feita através de uma rede polimérica. A Figura 6 mostra a estrutura da córnea artificial.

Reis et al. (2008) apresentaram o uso de redes poliméricas em implantes dentários a partir de polimetacrilato de metila (PMMA). Nesta aplicação, necessita-se de um alto grau de ligações cruzadas a fim de melhorar a resistência do dente artificial. Esta área se utiliza de modificações de polímeros reticulados, como a criação de resinas com diferentes redes poliméricas interconectadas. Nesta publicação, Reis e colaboradores reportam simulações em laboratório, do uso de PMMA altamente reticulado no implante dentário (Figura 7). 
Géis hidrofílicos, comumente chamados de hidrogéis, são redes poliméricas que podem ser encontradas na forma coloidal onde se tem água como meio dispersante.
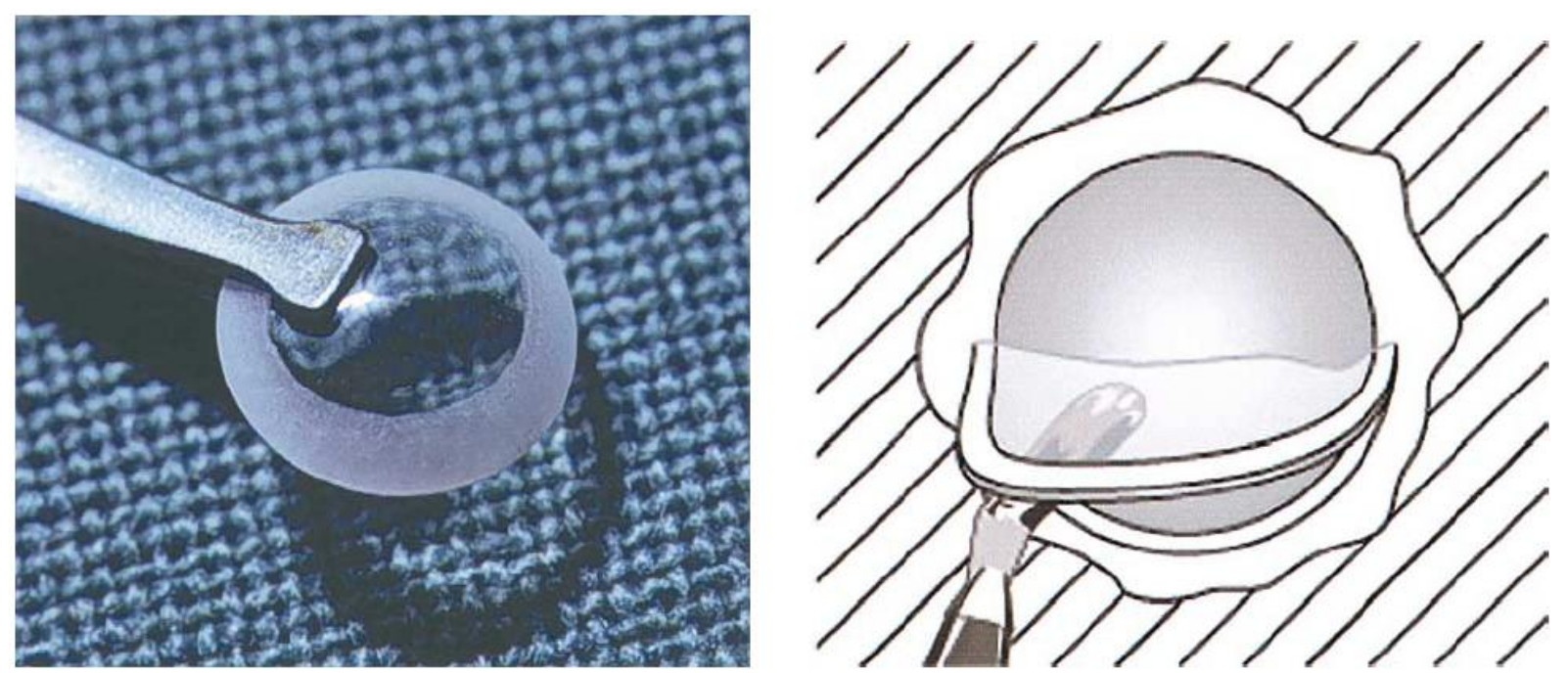

Figura 6 - Esquerda: Córnea artificial Alphacor ${ }^{\mathrm{TM}}$. Direita: aplicação de estrutura intermediária (Hicks et al., 2003).

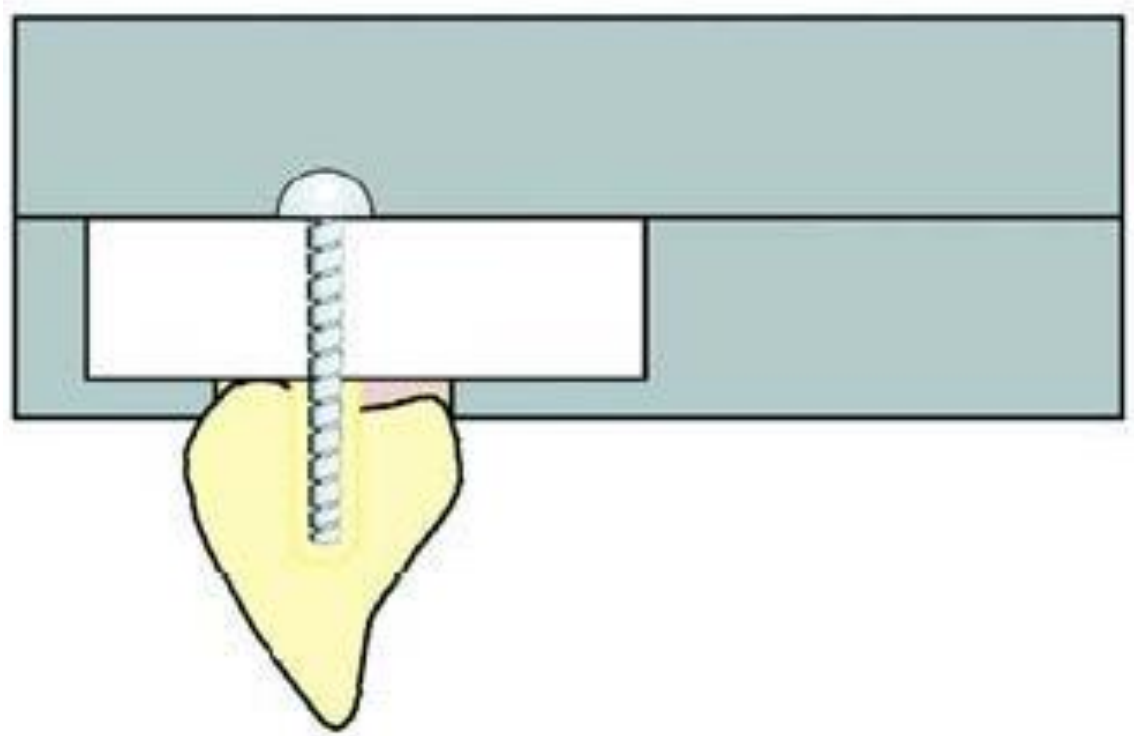

Figura 7 - Implante de canino artificial. Teste em aparato de laboratório (Reis et al., 2008).

Em outras palavras, eles são polímeros sintéticos ou naturais, podendo conter acima de $99 \%$ de água. Hidrogéis têm sido definidos como materiais poliméricos que possuem a facilidade de intumescer em água e reter uma fração significante desta em sua estrutura sem se dissociar. Hidrogéis especiais, como materiais superabsorventes, são amplamente aplicados na área de higiene, como por exemplo, fraudas e absorventes femininos. Uma variedade de monômeros, em sua 
maioria, acrílicos, são empregados na preparação de polímeros superabsorventes. Acido acrílico e seus sais de sódio e potássio e acrilamida são os monômeros mais usados na produção industrial (Mehr e Kabiri, 2008). A Figura 8 ilustra a ação de um material superabsorvente de base acrílica.

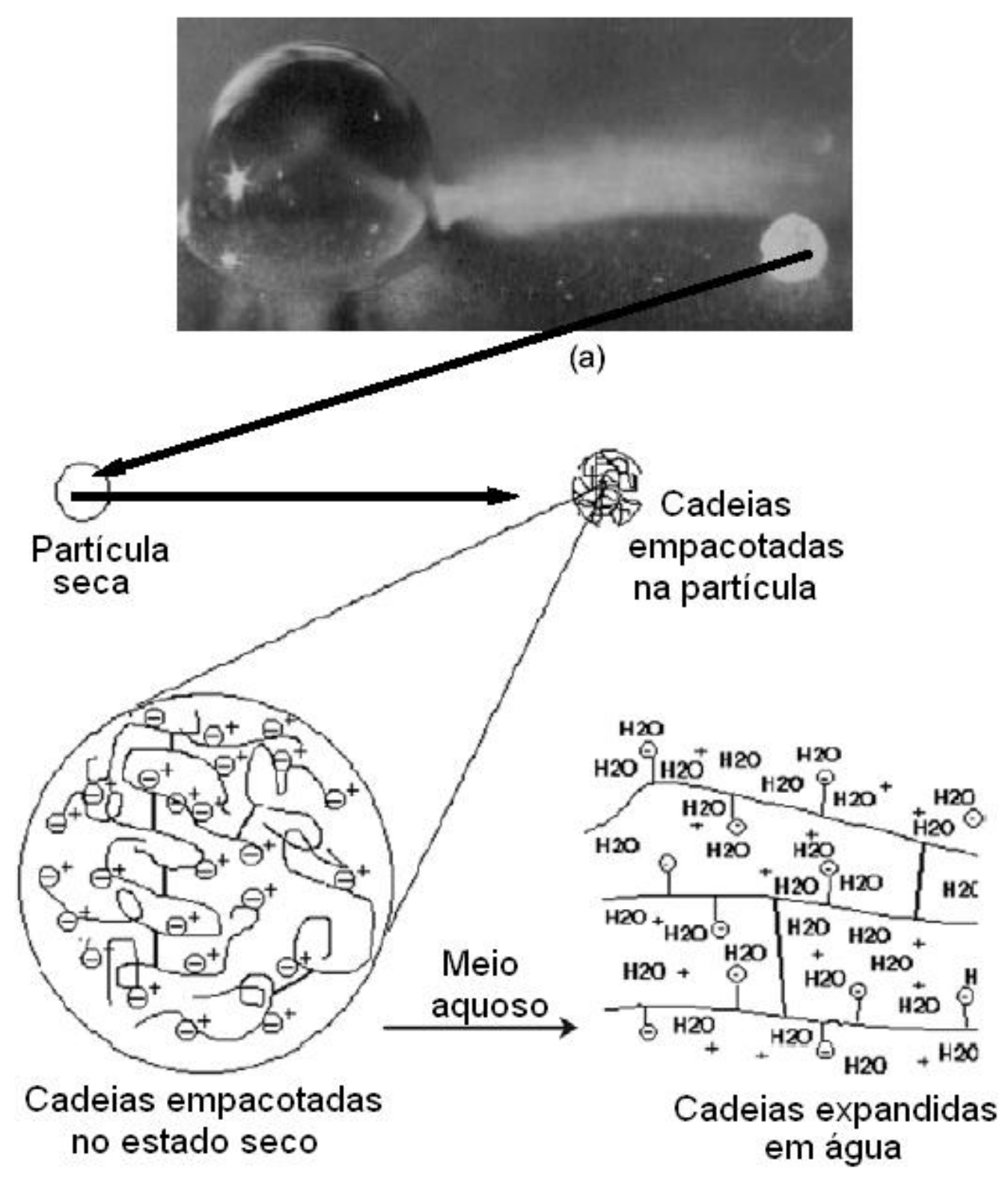

(b)

Figura 8 - llustração de um polímero superabsorvente de base acrílica: (a) Comparação visual de uma partícula no estado seco (direita) e no estado intumescido (esquerda). A amostra é uma esfera preparada pela técnica de polimerização por suspensão inversa. (b) Representação esquemática do inchamento de um polímero superabsorvente (Mehr e Kabiri, 2008).

Hidrogéis podem ser formulados em uma variedade de formas físicas: blocos, micropartículas, nanopartículas, recobrimentos e filmes. Desta forma, hidrogéis são 
frequentemente utilizados em práticas clinicas e medicina experimental em uma ampla faixa de aplicações. As propriedades únicas dos hidrogéis têm despertado interesse particular em aplicações de liberação controlada de medicamentos.

Sua estrutura altamente porosa pode ser ajustada através do controle da densidade de crosslinks na matriz do gel e da afinidade pelo meio aquoso no qual ele está intumescido. Sua porosidade permite o abastecimento de medicamento dentro da matriz e a subsequente liberação da droga numa taxa que depende do coeficiente de difusão das moléculas através do gel. A biocompatibilidade do hidrogel é promovida pela elevada quantidade de água e a similaridade físicoquímica em relação à matriz natural extracelular (Hoare e Kohane, 2007). A Figura 9 mostra um esquema da liberação controlada de medicamentos através de hidrogéis.

a

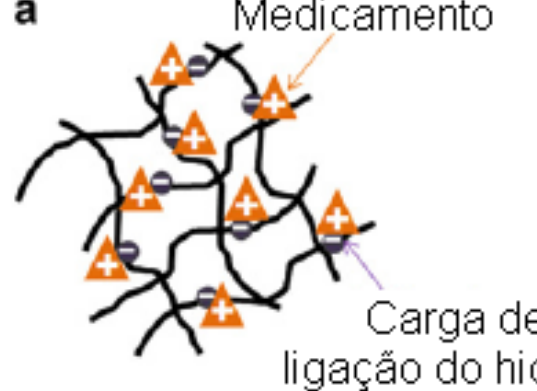

b

Medicamento ligado

à cadeia de polímero
Medicamento

liberado

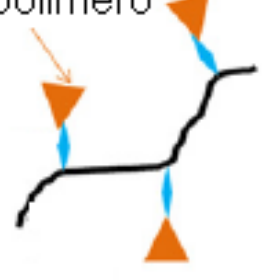

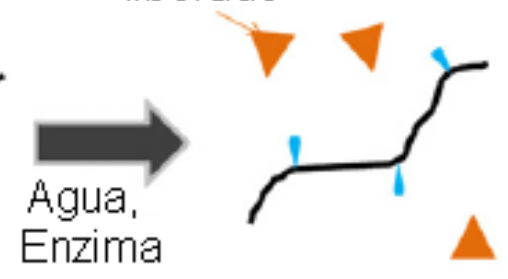

Figura 9 - Estratégias física (a) e química (b) para armazenar o medicamento de forma a libera-lo lentamente (Hoare e Kohane, 2007).

Em colunas de cromatografia, resinas constituídas de redes polímericas têm sido utilizadas. Copolímeros de estireno-divinilbenzeno com substituintes iônicos, são muito aplicados em bioquímica e seu uso teve início com as experiências de separação de aminoácidos originados de proteínas. Na técnica da cromatografia por exclusão de tamanhos também se utilizam polímeros reticulados no processo de análise. Neste caso, as moléculas da amostra a ser analisada, são separadas de forma seletiva de acordo com seu tamanho. A distribuição destas moléculas entre os líquidos dentro e fora do gel (copolímero reticulado) depende de efeitos estéreos; a partícula (estacionária), com suas ligações cruzadas, ocupa um espaço grande e intrincado ao qual só têm acesso moléculas pequenas, fazendo que haja uma distribuição homogênea entre os líquidos. Para moléculas maiores, esse acesso é muito mais difícil e a distribuição é favorecida em relação ao líquido fora do gel. Isso 
induz as moléculas grandes a emergir da coluna mais cedo do que as pequenas (Collins et al., 2006). A Figura 10 detalha a estrutura da partícula de polímero reticulado e o mecanismo envolvido em uma análise cromatográfica por exclusão de tamanhos. Ainda com relação a processos de separação, pode-se destacar o uso de poliestireno reticulado com divinilbenzeno como sendo uma alternativa econômica, prontamente disponível em diferentes tamanhos de partícula e com uma alta rigidez mecânica.
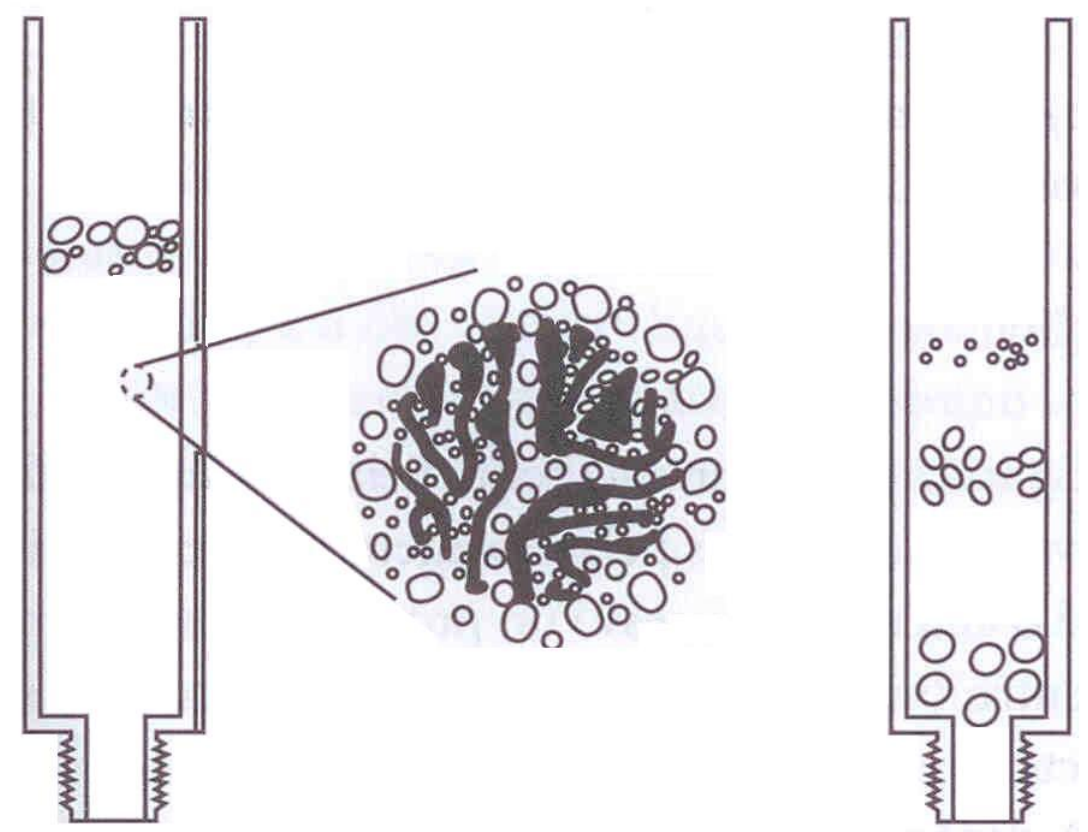

Figura 10 - Estrutura da partícula de polímero reticulado e sua função na análise cromatográfica por exclusão de tamanhos (Collins et al., 2006).

A grande vantagem dos materiais estirênicos em relação aos inorgânicos como a sílica, consiste em sua estabilidade dentro de uma larga faixa de pHs. Estirênicos também fornecem boa proteção contra umidade e são capazes de manter sua forma por longos períodos de tempo. Particulas porosas de poliestireno reticuladas através de divinilbenzeno e contendo grupos amina podem ser usadas como suporte para separar proteínas via interação por troca de íons. Vários tipos de absorventes estirênicos porosos e não-porosos têm sido sintetizados e empregados em cromatografia de proteínas por fase reversa, troca de ânion e afinidade (Bayramoglu, 2007). 


\subsection{Comparação entre as copolimerizações convencional e mediada por nitróxido}

Polimerizações radicalares controladas em geral fornecem uma rota para sintetizar polímeros com uma distribuição de massa molecular estreita, um peso molecular médio pré-determinado assim como inúmeras arquiteturas complexas. Tem-se observado que a técnica NMRP, para sistemas envolvendo estirênicos e o agente controlador TEMPO, procedeu com baixas reatividades para as duplas ligações pendentes em relação ao processo convencional. A reatividade aparentemente mais alta no sistema convencional é uma consequência da maior concentração localizada das duplas ligações pendentes ao redor dos radicais ativos. Isto se deve ao longo comprimento das cadeias primárias (os pesos moleculares no sistema NMRP são muito menores do que no convencional), o qual resulta em altos níveis de crosslink intramolecular em baixas conversões. A Figura 11 mostra o mecanismo de ativação/desativação num processo de copolimerização por NMRP.

Zetterlund (2005) constatou que em uma copolimerização NMRP de estireno e divinilbenzeno, a reatividade aparente das duplas ligações pendentes, a densidade de crosslinks e a taxa de polimerização foram significativamente mais baixas no sistema em miniemulsão aquosa do que no processo em massa. Este efeito pode ter uma aplicação na produção de polímeros com massa molecular controlada e com presença de duplas ligações pendentes. Estes polímeros podem ser posteriormente reagidos para formar ligações cruzadas, por exemplo, em aplicações de recobrimento.

No estudo de Tanaka et al. (2007), foi observado que no processo de copolimerização convencional, parâmetros como deformação de ruptura e energia de ruptura do material polimérico, se mostraram constantes ao longo do processo. Entretanto, estes parâmetros apresentaram um aumento, com tendência próxima da linear, com a conversão no caso NMRP. O principal fator que pode estar acarretando as diferenças é a formação de microgel logo no início da reação para o caso do sistema convencional. Ao fim da reação, os parâmetros citados apresentaram valores semelhantes, porém, os resultados indicam que a formação da rede é mais homogênea no sistema NMRP do que no convencional. A Figura 12 apresenta resultados do trabalho de Tanaka et al. (2007) 

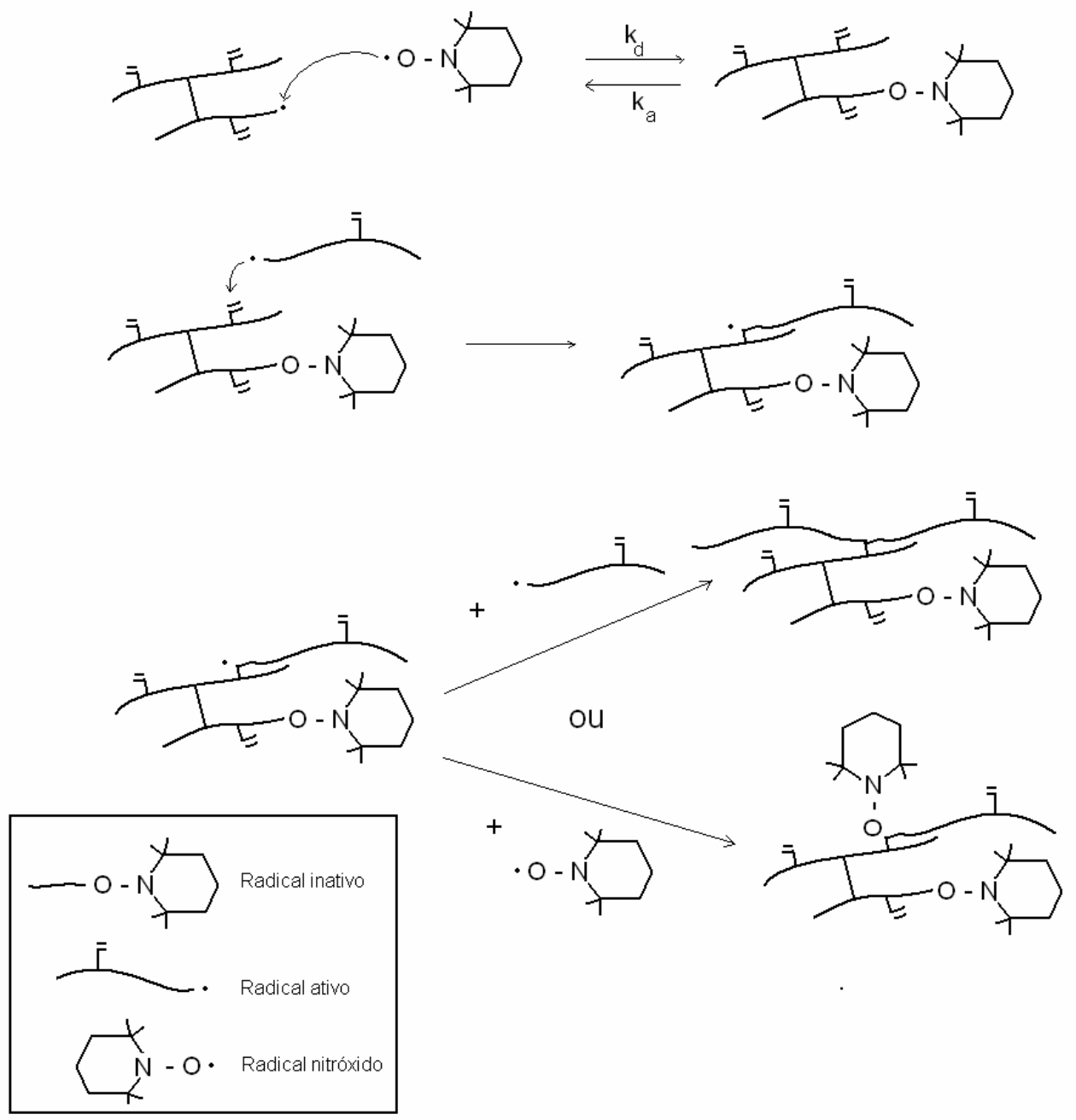

Figura 11 - Mecanismo de desativação reversível numa copolimerização NMRP.
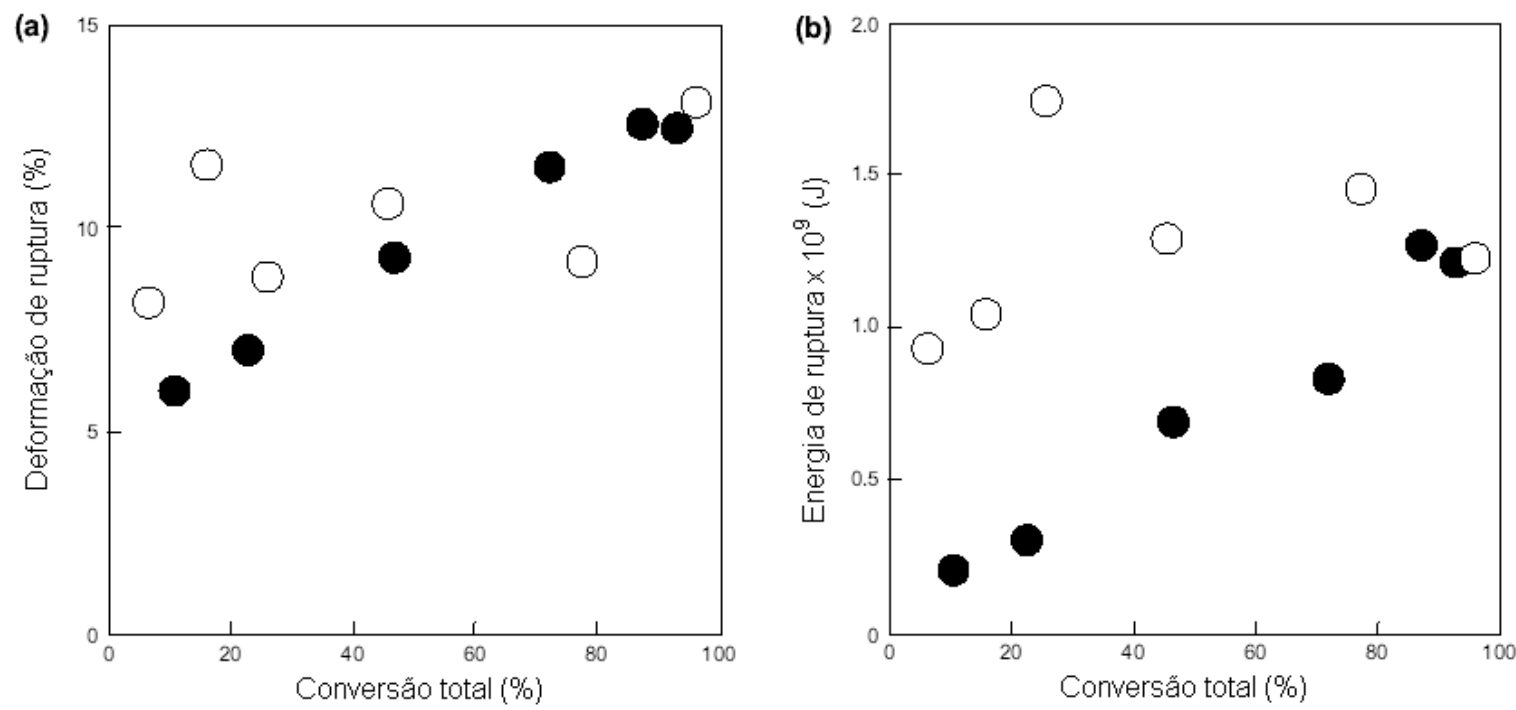

Figura 12 - Resultados experimentais de Tanaka et al. (2007). Testes realizados com partículas preparadas em microssuspensão aquosa. Pontos vazios: processo convencional. Pontos cheios: processo NMRP. 
Gonçalves (2008) estudou a copolimerização NMRP de estireno com divinilbenzeno em solução. Em seu trabalho, foi observado que a estrutura dos copolímeros sintetizados por NMRP se mostrou mais compacta do que aquela produzida pelo processo convencional. Neste estudo também foi constatada a presença da autoiniciação do estireno em temperaturas elevadas. Foi observado que, para a mesma massa molecular, copolímeros controlados apresentaram um tamanho molecular (raio de giração) inferior aos correspondentes convencionais.

\subsection{Conceito de raio de giração}

Raio de giração é um parâmetro que auxilia na quantificação do volume médio ocupado por uma cadeia de polímero. Ele é calculado fazendo-se uma média das distâncias entre o centro de massa e os segmentos da molécula de polímero (Figura 13a). Em geral, trabalha-se com a média do quadrado destas distâncias para assegurar que todos os valores sejam positivos (Figura 13b).

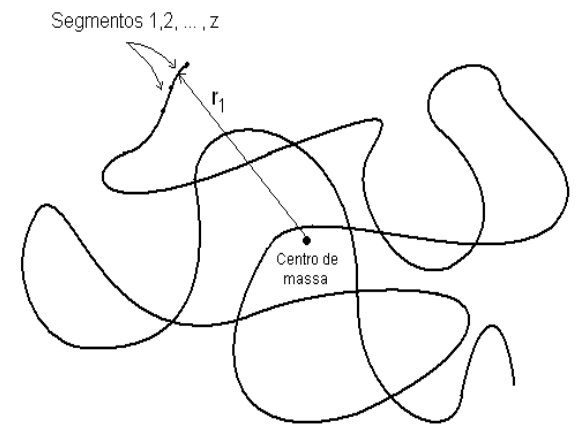

(a)

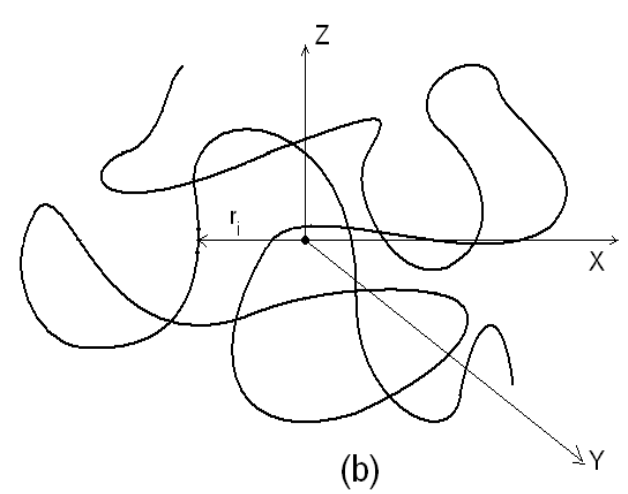

(b)

Figura 13 - Representação esquemática do raio de giração.

\subsection{Reações de Ciclização}

A reação de ciclização ocorre entre um centro radicalar e uma dupla ligação pendente, situados na mesma molécula de polímero. Podem-se classificar as 
reações de ciclização em dois tipos: ciclização primária, que ocorre em moléculas primárias de polímero (isentas de ramificação ou ligação cruzada) e ciclização secundária, que ocorre em moléculas compostas por duas ou mais cadeias primárias. A Figura 14 ilustra os tipos de reações de ciclização.

Desde os primeiros estudos sobre copolimerização envolvendo ligações cruzadas e formação de gel, já se discutia a respeito de reações de ciclização. Flory (1941, 1942) apresenta evidencias experimentais de que uma fração pequena, porém considerável das ligações em polímeros tridimensionais, são intramoleculares. Estima-se que essa fração se encontra na faixa de 2 a $6 \%$ das ligações entre unidades.
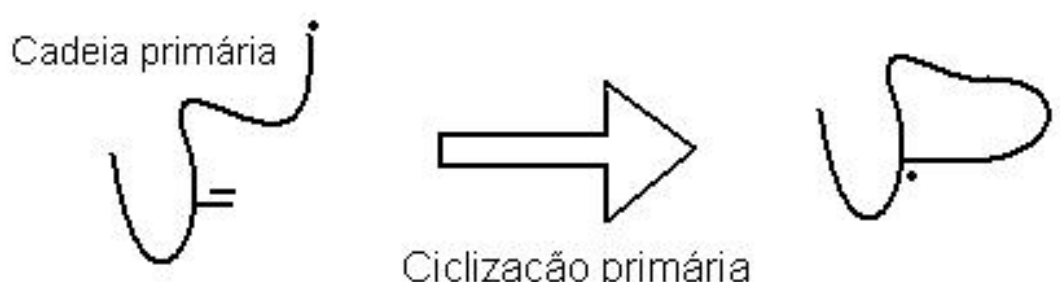

Ciclizaçẵo primária
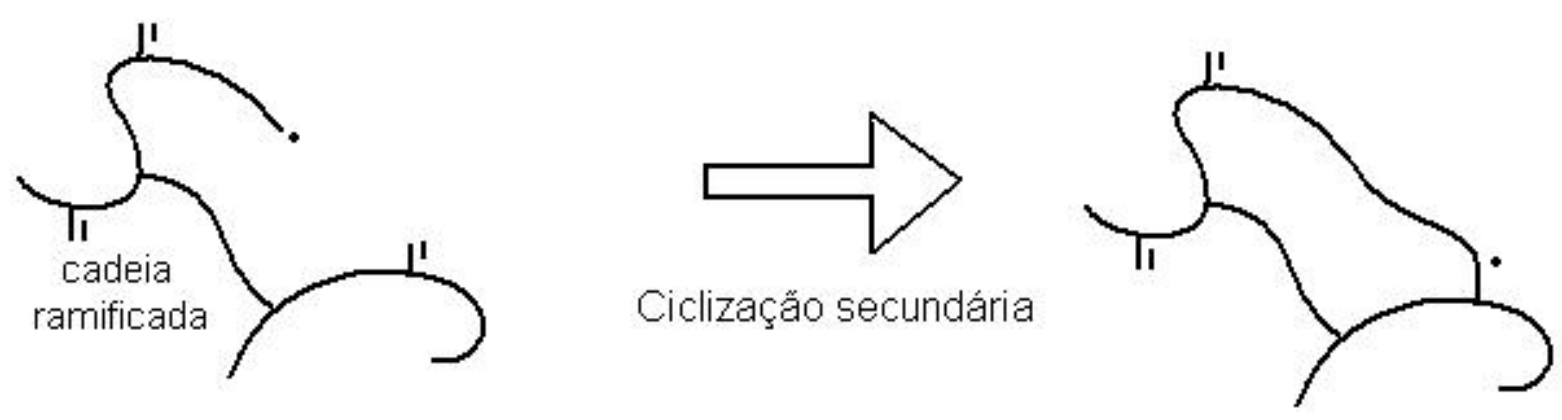

Figura 14 - Classificação das reações de ciclização.

De acordo com os resultados apresentados por Bradley (1938) e Kienle et al. (1939), esta estimativa se mostra razoável. Stockmayer $(1943,1944)$ inclui um parâmetro na descrição matemática do processo, que define a probabilidade relativa de ocorrência de reações inter e intramoleculares. Porém ele conclui que: descartar a ocorrência de ciclizações introduz somente um erro moderado na descrição do período pré-gel em sistemas não diluídos. Flory (1947) observa que quanto maior a quantidade de ligações cruzadas na região sol (moléculas solúveis), maior o número de ciclizações. Neste estudo ele conclui que o maior erro em desprezar as reações 
de ciclização é esperado que aconteça no ponto de gel e que este erro diminui à medida que a reação se distancia do ponto de gel para qualquer sentido (antes ou depois).

Soper et al. (1972) relatam que a competição entre as reações de ciclização e crosslink intermolecular pode ser controlada variando a diluição da base de polímeros. Dusek e Spevacek (1980) observaram que no começo da reação, as cadeias individuais (dissolvidas no monômero) são virtualmente isoladas umas das outras, gerando um alto grau de ciclização. Tobita e Hamielec (1989) relatam que uma das características importantes da ciclização é que ela é controlada não pela lei de taxa convencional usando concentrações médias de grupos funcionais, mas através de estatística conformacional de seqüências de ligações. Zhu e Hamielec (1989) afirmam que as ciclizações secundárias contribuem para a elasticidade da rede polimérica enquanto que as primárias unicamente consomem duplas ligações. A Figura 15 mostra como são consumidas as duplas ligações pendentes ao longo de uma copolimerização convencional com uma alimentação de $50 \%$ de monômero vinílico e 50\% de monômero divinílico.

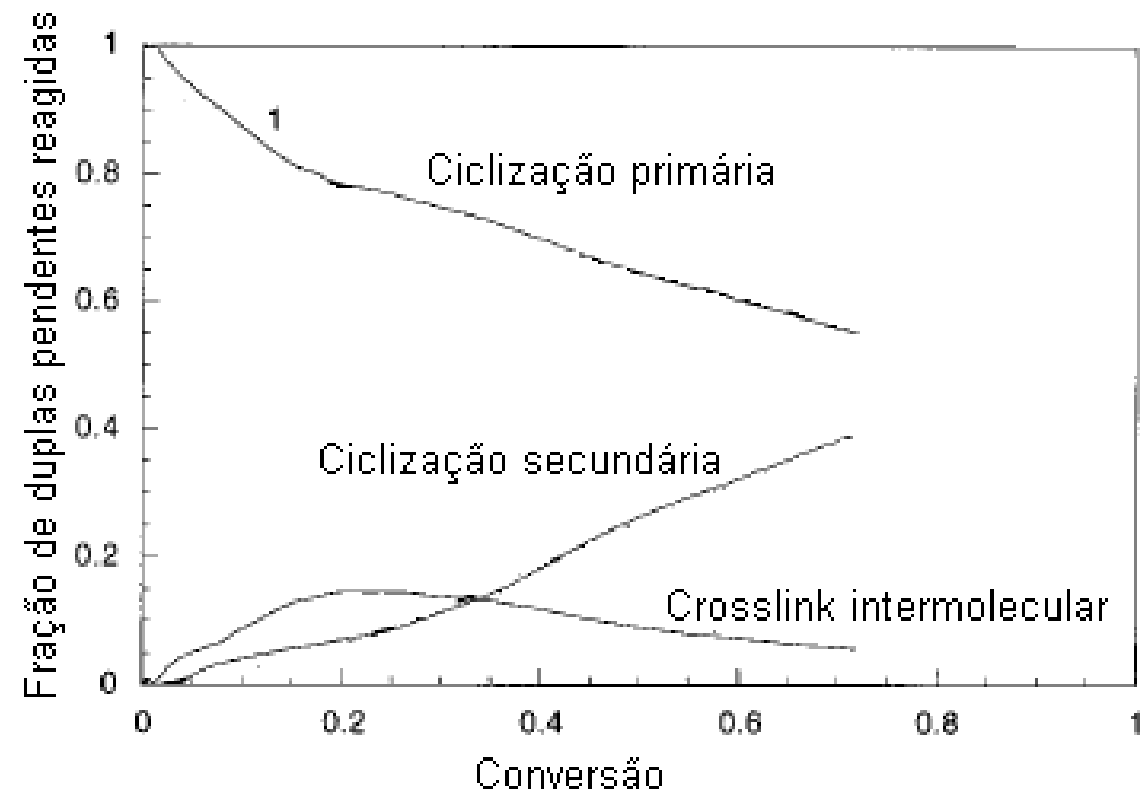

Figura 15 - Reatividade das duplas ligações pendentes em função da conversão (Ward e Peppas, 2000).

Tobita (1993) relata que mesmo sem considerar as reações de ciclização, pode-se investigar redes de polímero sob determinadas condições. Ele enfatiza que vários modelos para reações de ciclização têm sido propostos, porém, os resultados 
obtidos ainda eram muito prematuros para elucidar ciclizações reais. Vivaldo-Lima et al. (1998) definem uma constante de ciclização primária e estimam seu valor utilizando um modelo matemático. Foi concluído que esse valor aumenta proporcionalmente com a concentração de solvente em copolimerizações de estireno-divinilbenzeno. No trabalho de Ortega et al. (2005), foi assumido que a fração de duplas pendentes perdidas por ciclização é proporcional a fração de unidades divinílicas incorporadas as cadeias de polímero. Sua constante de proporcionalidade $\left(k_{\mathrm{cp}}\right)$ se mantém constante em copolimerizações em massa, mas pode variar quando se usa solvente. Devido à ciclização secundária envolver pelo menos duas ligações cruzadas para formar ciclos entre duas moléculas diferentes, a fração de unidades que participam de crosslink secundário é assumida ser proporcional à densidade média de crosslink.

Gonçalves et al. (2007) reporta que a causa mais importante do atraso na gelificação é a ocorrência de reações de ciclização. $O$ efeito combinado das reações de ciclização com o tipo de solvente usado no meio reacional foi levado em conta através de ajuste de valores aparentes de reatividade das duplas ligações pendentes, a qual é o principal parâmetro controlador da taxa de reação de crosslink.

\subsection{Modelagem matemática de processos de copolimerização radicalar mediada por nitróxido}

A modelagem matemática do processo de copolimerização de estireno/divinilbenzeno mediada por nitróxido é um estudo recente. Neste campo, pode-se destacar a modelagem das copolimerizações em massa (Hernández-Ortiz et al., 2009) e em solução (Gonçalves et al., 2010).

No trabalho de Hernández-Ortiz et al. (2009) foi estudado um sistema de copolimerização em massa de estireno/divinilbenzeno à $125^{\circ} \mathrm{C}$. Neste modelo foram considerados dois conjuntos de equações: o primeiro relativo ao período pré-gel onde se considera o balanço de massa e de momentos para as espécies envolvidas e o segundo relativo ao período pós-gel onde se utiliza expressões estatísticas para calcular o peso molecular médio e a fração de gel. Neste modelo foram 
consideradas as seguintes hipóteses: existe apenas um centro radicalar por cadeia (monorradical) e a reação é considerada uma pseudo-homopolimerização (método pseudo-cinético). A Figura 16 mostra alguns resultados do modelo de HernándezOrtiz et al. (2009).

a)

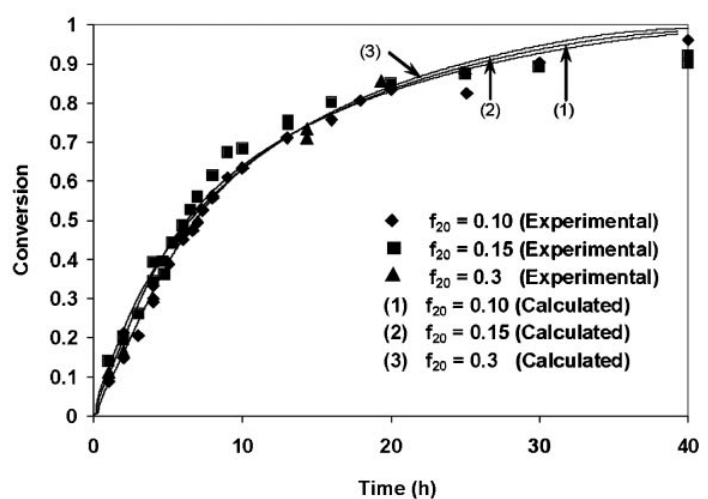

c)

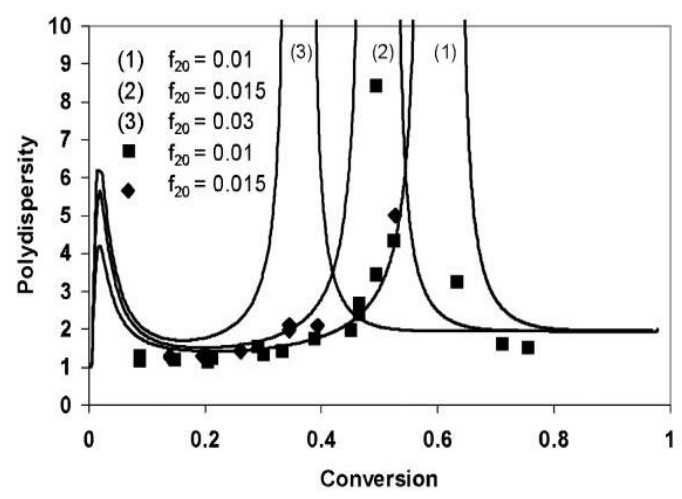

b)

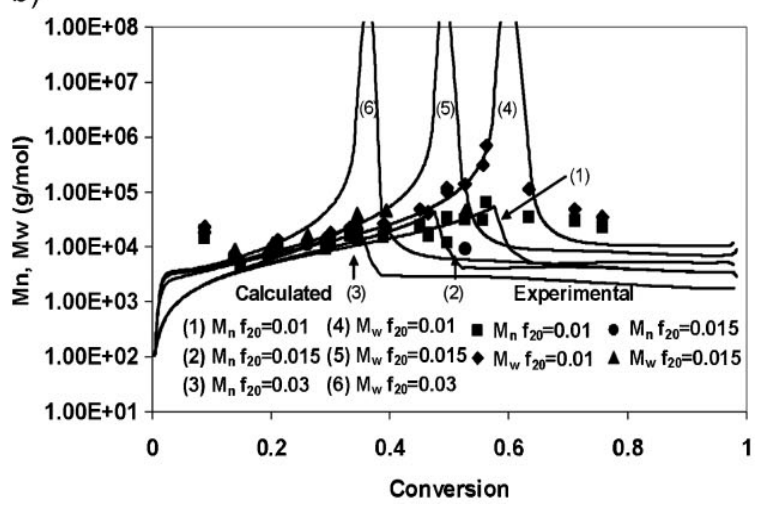

d)

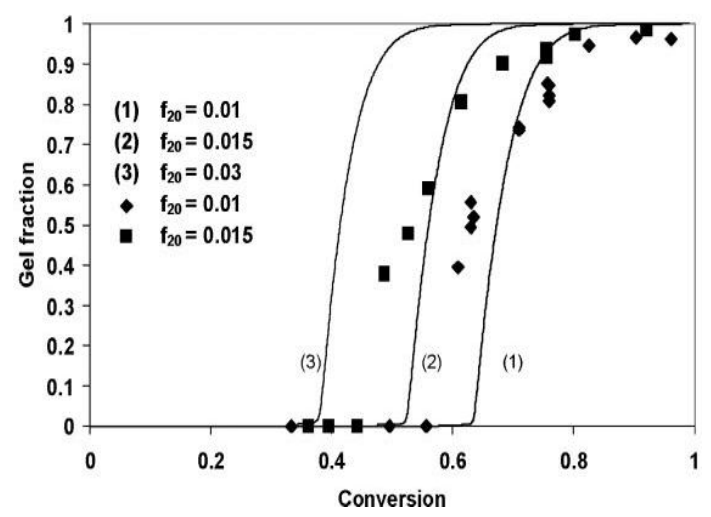

Figura 16 - Comparações de previsões do modelo com dados experimentais de (a) Conversão $x$ tempo, (b) Mn, Mw x conversão, (c) Dispersão de massas moleculares x conversão e (d) Fração de gel $x$ conversão para 0 processo NMRP de estireno/divinilbenzeno. $f_{20}$ refere-se à razão molar divinilbenzeno/estireno na alimentação (Hernández-Ortiz, 2009).

No trabalho de Gonçalves et al. (2010), o sistema NMRP de estireno/divinilbenzeno à $130^{\circ} \mathrm{C}$ foi modelado através de um conjunto de métodos os quais envolvem o método das características e balanços populacionais baseados em funções geradoras (Costa e Dias, 1994, 2003, 2005). Neste modelo, elimina-se a hipótese de regime pseudo-estacionário e também as hipóteses consideradas no modelo de Hernández-Ortiz (2009), ou seja, é um modelo mais rigoroso. A Figura 17 mostra alguns resultados do trabalho em questão. 
a)

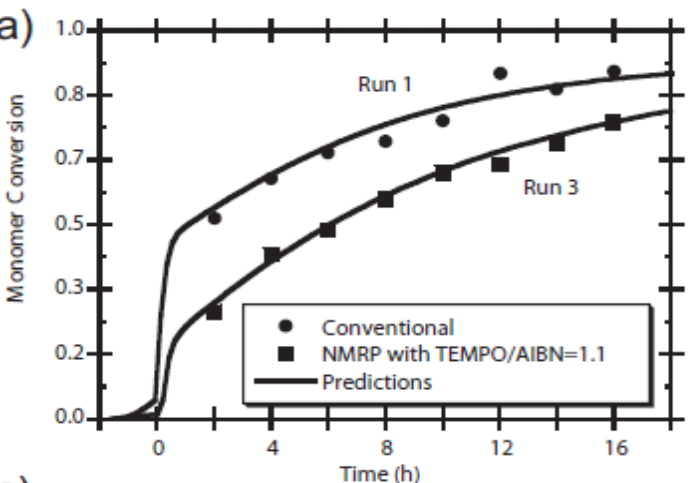

c)

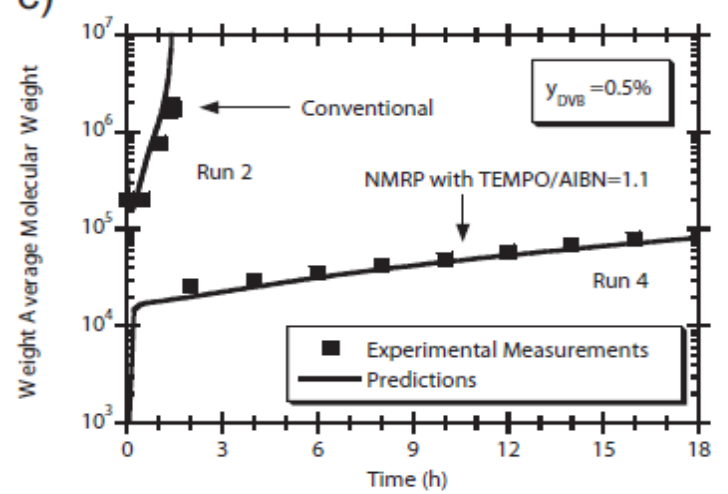

b)

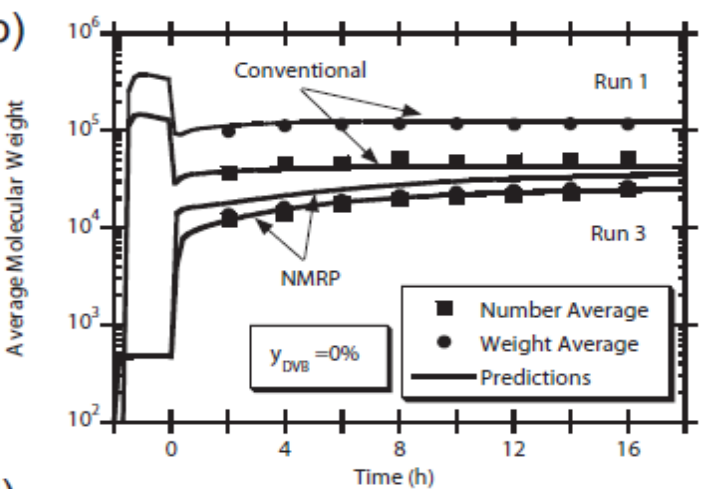

d)

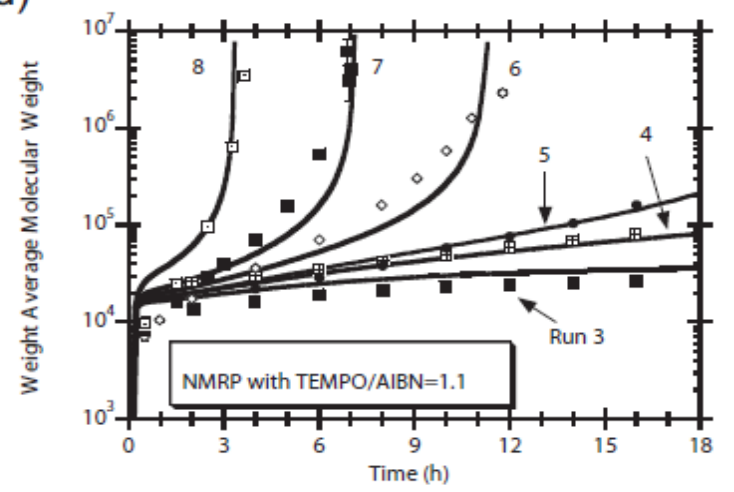

Figura 17 - (a) Predições e observações experimentais para conversão de monômero nos sistemas convencional e NMRP. (b) Predições e observações experimentais para Mn e Mw nos sistemas convencional e NMRP. (c) e (d) Valores medidos e simulados de Mw em função do tempo nos sistemas convencional e NMRP (runs 3-8: variação progressiva da quantidade de agente de crosslink (Gonçalves et al., 2010).

\subsection{Caracterização dos copolímeros sintetizados}

\subsubsection{Cromatografia por exclusão de tamanhos}

A cromatografia por exclusão de tamanhos tem sido amplamente utilizada desde seu surgimento na década de 1950. Ela oferece um método simples para caracterizar a distribuição de massas moleculares de um polímero. Utiliza-se um sistema em fluxo onde o princípio de separação e a análise são baseados nas propriedades das moléculas de polímero em solução. Uma bomba de alta pressão transporta um solvente de um reservatório até uma coluna ou uma série de colunas em fluxo constante. Uma pequena quantidade de uma solução diluída de polímero é 
injetada no sistema e é incorporada ao fluxo. As colunas são recheadas de material poroso, em geral, partículas de polímeros com diâmetros de poro variados. A Figura 18 ilustra o sistema de separação por exclusão de tamanhos.

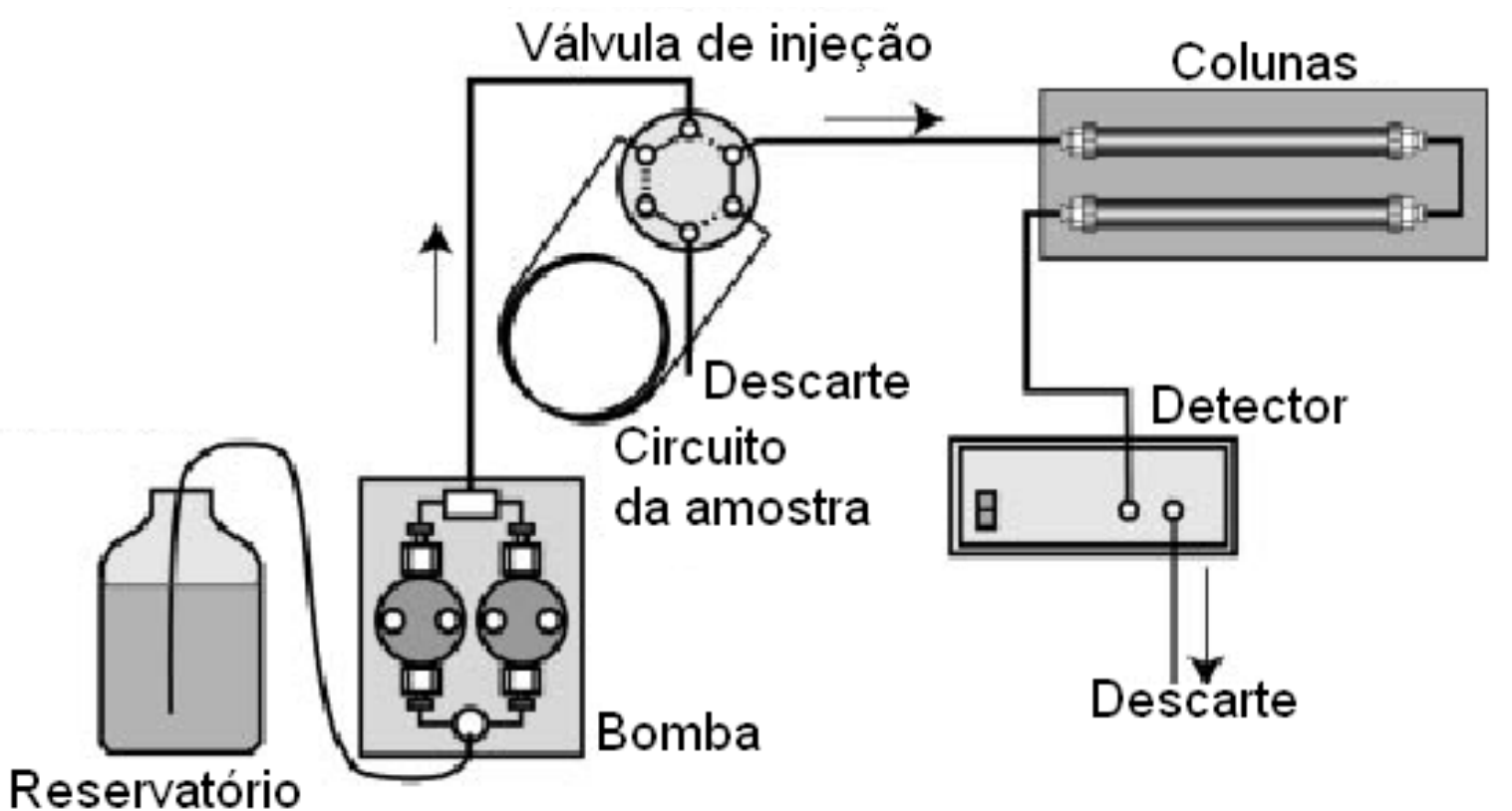

Figura 18 - Representação esquemática de um sistema de cromatografia por exclusão de tamanhos (Teraoka, 2002).

As moléculas de polímero são divididas entre os confinamentos dos poros (denominados de fase estacionária) e o espaço intersticial entre as partículas, que é chamado de fase móvel. Moléculas de polímero menores (baixa massa molecular) que o tamanho do poro, transferem-se para a fase estacionária enquanto que as maiores permanecem na fase móvel. Desta forma, leva-se um tempo relativamente longo para as moléculas de baixa massa molecular saírem da coluna. O líquido que sai da coluna é chamado eluente. Detectores localizam-se junto ao fluxo de saída do sistema. Um refratômetro diferencial é mais comumente utilizado para medir a diferença no índice de refração entre o eluente e o solvente puro. A diferença é proporcional à concentração. Se o polímero tem uma absorção na região ultravioleta e o solvente não tem, pode-se usar um detector ultravioleta (Teraoka, 2002).

A Figura 19 mostra o processo de separação dentro da coluna e um cromatograma típico. 


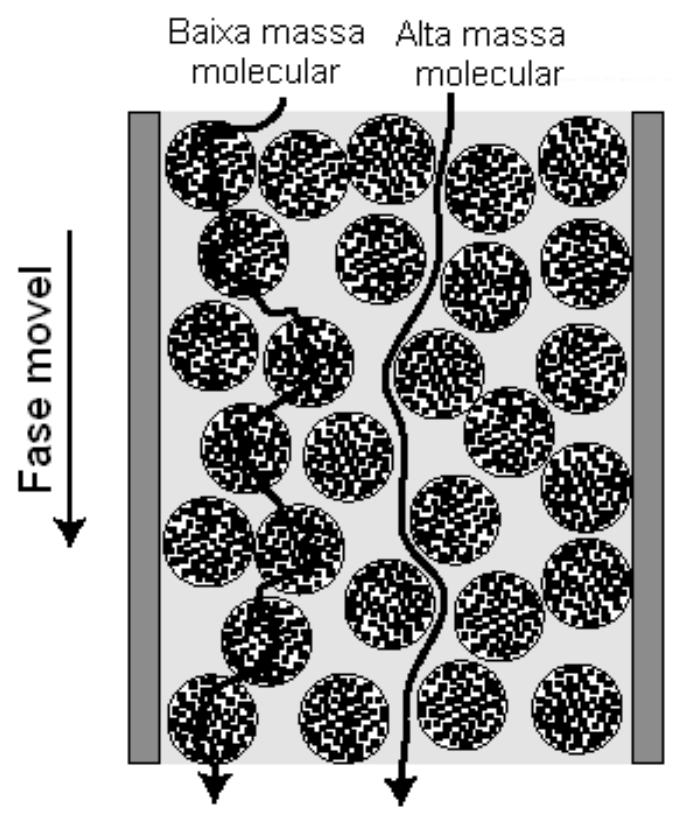

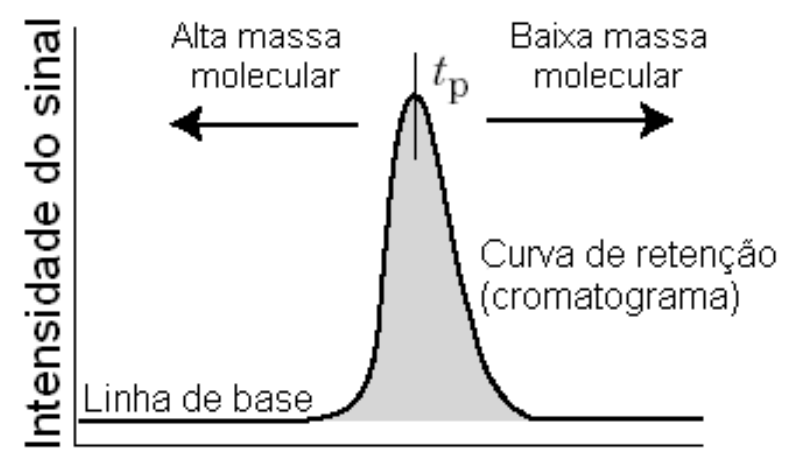

Tempo de retenção $t_{\mathrm{R}}$ Volume de retenção $V_{\mathrm{R}}$

Figura 19 - Transporte de moléculas de polímero em colunas de exclusão de tamanhos e cromatograma típico (Teraoka, 2002).

$O$ volume de retenção $\left(V_{R}\right)$, volume acumulado de fluido fora da coluna desde a injeção, também pode ser usado como abscissa. A curva é chamada curva de retenção ou cromatograma. A altura de um ponto sobre a curva acima da linha de base é proporcional à concentração num dado tempo de retenção. $O$ sinal é maximizado no pico do tempo de retenção $\left(t_{p}\right)$. A integral da curva é proporcional à quantidade total de polímero injetado.

Este método pode ser aplicado a casos onde a fase móvel é um solvente orgânico ou água. Quando se trata de um solvente orgânico o método pode também ser chamado de cromatografia de permeação em gel (Gel Permeation Chromatography - GPC). Quando se trata de uma solução aquosa, pode-se chamar de cromatografia de filtração em gel ou GPC aquoso.

Atualmente, sistemas mais completos de cromatografia por exclusão de tamanhos têm sido desenvolvidos. A inclusão de detectores adicionais permite a caracterização completa do polímero solúvel. Alguns equipamentos possuem um detector de concentração, um viscosímetro e um detector de espalhamento de luz trabalhando em conjunto e fornecendo informações que se autocomplementam. $O$ detector por espalhamento de luz fornece a medida direta da massa molecular absoluta e elimina a necessidade de calibração da coluna. O viscosímetro fornece a medida da viscosidade intrínseca e permite determinar o tamanho molecular, a 
conformação e a estrutura do polímero. A concentração, a qual é necessária para a determinação da massa molecular e da viscosidade intrínseca, pode ser medida através de índice de refração ou espectroscopia ultravioleta.

\subsubsection{Caracterização do gel}

Redes poliméricas são constituídas de segmentos de cadeia conectados de forma tridimensional. Alguns autores classificam gel como sendo um conjunto de pelo menos dois componentes: uma rede polimérica e um solvente (Almdal et al.., 1993; Kavanagh and Ross-Murphy, 1998; Yamauchi, 2001). Um polímero pode ser considerado gel se suas cadeias interagirem favoravelmente com um solvente, de forma que este ocupe os arredores dos segmentos poliméricos afastando-os entre si. Em outras palavras, a rede polimérica se torna inchada ou intumescida, porém, não é dissolvida no solvente. Este polímero intumescido recebe o nome de gel.

O produto de uma reação de copolimerização com formação de redes tridimensionais é constituído de uma fração de polímero solúvel e de uma fração de gel. A caracterização do gel se inicia na obtenção desta fração em função do tempo de reação. Para isto, é necessária uma extração da fração de polímero solúvel que, a princípio, se encontra no interior da rede polimérica. Detalhes sobre esta extração aplicada ao polímero do presente estudo serão apresentados no capítulo 3.

Quando um polímero linear é imerso em um solvente, as cadeias tendem a se dispersar e formar uma solução, dependendo da afinidade dos componentes. Em polímeros reticulados não há a formação de solução, mas esta tendência também existe. Devido à alta concentração de polímero na rede polimérica, uma pressão osmótica é gerada entre o solvente dentro e fora do gel. Esta pressão osmótica direciona as moléculas de solvente para dentro da rede, o que implica no aumento de seu volume. Isto resulta numa diluição da concentração de polímero no gel, acarretando na diminuição da pressão osmótica. Esta pressão é frequentemente chamada de pressão de mistura, devido à mistura das cadeias de polímero com as moléculas de solvente.

A maior diferença entre uma rede polimérica intumescida e uma solução de polímero linear é que a rede está restrita à sua habilidade de dispersão devido às 
conexões permanentes entre cadeias, conforme ilustrado na Figura 20. Todavia, a rede cresce o máximo possível através da absorção de quantidades apropriadas de solvente. Esta dilatação implica na deformação dos segmentos da rede polimérica, explorando sua elasticidade, a qual age contra o intumescimento. À medida que o inchamento procede, a concentração de polímero diminui e a propriedade elástica é explorada progressivamente devido ao estiramento das cadeias. Em presença de excesso de solvente, o gel continuará absorvendo solvente até as forças elásticas das cadeias estarem balanceadas em relação à pressão externa (Vervoort, 2006).
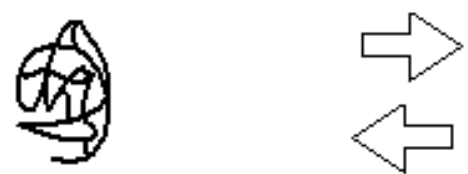

Rede encolhida

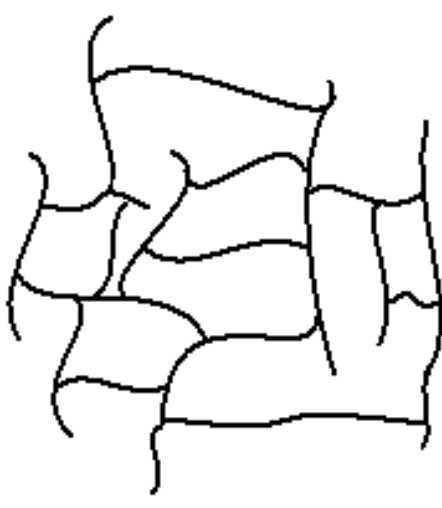

Rede intumescida

Figura 20 - Intumescimento e encolhimento reversíveis da rede polimérica através do contato com solvente.

$\mathrm{Na}$ caracterização do gel, pode-se quantificar o índice de intumescimento através de testes, nos quais se promove o contato da rede polimérica com um determinado solvente. O índice de intumescimento tem estreita relação com a densidade de ligações cruzadas, que é uma propriedade comumente usada na caracterização de polímeros reticulados. Em geral, pode-se dizer que, quanto maior o índice de intumescimento, menor a densidade de ligações cruzadas.

O presente trabalho visa fornecer uma melhor compreensão dos detalhes do processo NMRP e de sua modelagem matemática frente ao que se tem na literatura atualmente. 


\section{METODOLOGIA}

\subsection{Modelagem matemática}

Na modelagem do processo em questão, foram incluídas espécies químicas consideradas nos trabalhos citados no item 2.7. Desta forma, os mecanismos das reações envolvidas na síntese de copolímeros de estireno/divinilbenzeno através das polimerizações convencional e viva, podem ser descritos de acordo com a Tabela 1.

Tabela 1 - Reações envolvidas no processo (continua).

Nome da reação

Decomposição do iniciador

Iniciação

Ativação / Desativação de radicais primários

Ativação / Desativação de radicais poliméricos

Dimerização / Decomposição do dímero

Iniciação térmica

Propagação de monômero

Mecanismo

$$
\stackrel{k_{d}}{\rightarrow} 2 R_{0}
$$

$$
\begin{gathered}
R_{0}+M_{j} \stackrel{k_{l j}}{\rightarrow} R_{r, j} \\
(1 \leq j \leq 3)
\end{gathered}
$$

$$
R_{0}+O N_{x} \underset{k_{a}}{\stackrel{k_{d a}}{\rightleftarrows}} D R_{0}
$$

$$
R_{r}+O N_{x} \underset{k_{a}}{\stackrel{k_{d a}}{\longrightarrow}} D R_{r}
$$

$$
M_{i}+M_{j} \underset{k_{\text {ddij }}}{\stackrel{k_{\text {dimij }}}{\rightleftarrows}} D
$$

$(1 \leq i \leq 3) ; \quad(1 \leq j \leq 3)$

$$
\begin{gathered}
D+M_{j} \stackrel{k_{\text {thij }}}{\longrightarrow} 2 R_{0} \\
(1 \leq j \leq 3)
\end{gathered}
$$

$$
\begin{gathered}
R_{r, i}+M_{j} \stackrel{k_{P i j}}{\longrightarrow} R_{r+1, j} \\
(1 \leq i \leq 5) ; \quad(1 \leq j \leq 3)
\end{gathered}
$$


Tabela 1 - Reações envolvidas no processo (conclusão).

Iniciação de duplas ligações pendentes

de polímero morto

Iniciação de duplas ligações pendentes

de radical dormente

Propagação em dupla ligação pendente de polímero morto

Propagação em dupla ligação pendente de radical dormente

Ciclização *

Transferência de cadeia para monômero

$$
\begin{gathered}
R_{r, i}+M_{j} \stackrel{k_{f m i j}}{\longrightarrow} P_{r}+R_{0} \\
(1 \leq i \leq 5) ; \quad(1 \leq j \leq 3)
\end{gathered}
$$

Terminação por combinação

Decomposição de radical dormente

Abstração de próton pelo radical nitróxido

$$
\begin{gathered}
R_{0}+P_{r, j} \stackrel{k_{I j}}{\rightarrow} R_{r, j} \\
(4 \leq j \leq 5)
\end{gathered}
$$

$$
\begin{gathered}
R_{0}+D R_{r, j} \stackrel{k_{I j}}{\rightarrow} R_{r, j} \\
(4 \leq j \leq 5)
\end{gathered}
$$

$$
\begin{gathered}
R_{r, i}+P_{s, j} \stackrel{k_{P i j}}{\longrightarrow} R_{r+s, j} \\
(1 \leq i \leq 5) ; \quad(4 \leq j \leq 5)
\end{gathered}
$$

$$
\begin{gathered}
R_{r, i}+D R_{s, j} \stackrel{k_{P i j}}{\longrightarrow} R_{r+s, j} \\
(1 \leq i \leq 5) ; \quad(4 \leq j \leq 5) \\
R_{r, i, j, s} \stackrel{k_{P i j, s}^{C}}{\longrightarrow} R_{r, j} \\
(1 \leq i \leq 5) ; \quad(4 \leq j \leq 5)
\end{gathered}
$$

$$
\boldsymbol{R}_{r}+\boldsymbol{R}_{s} \stackrel{k_{t c}}{\rightarrow} \boldsymbol{P}_{r+s}
$$$$
D R_{r} \stackrel{k_{d e c}}{\longrightarrow} R_{r}+H_{O} N_{x}
$$

Reações retiradas de Gonçalves et al (2010) e Hernández-Ortiz (2008), exceto *: Presente trabalho.

Nomenclatura utilizada nos mecanismos da Tabela 1:

$I$ : Iniciador;

$\mathrm{R}_{0}$ : Radical primário;

$M_{j}$ : Monômero do tipo $\mathrm{j}(\mathrm{j}=1$ : estireno, $\mathrm{j}=2$ : $m$ DVB, $\mathrm{j}=3$ : $p D V B$ ); 
$\mathrm{R}_{\mathrm{r}, \mathrm{i}}$ : Radical polimérico do tipo 'i' ( $\mathrm{i}=1$ : estireno, $\mathrm{i}=2$ : $m$ DVB, $\mathrm{i}=3$ : $p D V B, \mathrm{i}=4$ : mPDB, i=5: pPDB) contendo ' $r$ ' unidades monoméricas;

$R_{r, i, j, s}:$ Radical polimérico contendo ' $r$ ' unidades monoméricas e contendo um segmento de cadeia (caminho) com 's' unidades monoméricas, conectando um centro radicalar do tipo ' $i$ ' $(i=1$ : estireno, $i=2$ : mDVB, $i=3$ : pDVB, $i=4: m P D B, i=5$ : PPDB) à uma PDB do tipo ' $\mathrm{j}$ ' ( $\mathrm{j}=4$ : $\mathrm{mPDB}, \mathrm{j}=5$ : $p P D B)$;

$\mathrm{ON}_{\mathrm{x}}$ : Radical nitróxido (TEMPO);

$\mathrm{DR}_{0}$ : Radical primário dormente;

$\mathrm{DR}_{r}$ : Radical polimérico dormente contendo 'r' unidades monoméricas;

$D$ : Dímero;

$P_{r, j}$ : Polímero morto contendo dupla ligação pendente do tipo 'j' $(j=4: m P D B, j=5$ : pPDB) e 'r' unidades monoméricas;

$D R_{r, j}$ : Radical polimérico dormente contendo dupla ligação pendente do tipo 'j' ( $\mathrm{j}=4$ : mPDB, $j=5$ : pPDB) e ' $r$ ' unidades monoméricas

$\mathrm{HON}_{\mathrm{x}}$ : Composto inerte proveniente do consumo de radicais nitróxido;

$\mathrm{k}_{d}$ : Constante cinética da reação de decomposição do iniciador $\left(\mathrm{s}^{-1}\right)$;

$\mathrm{k}_{\mathrm{lj}}$ : Constante cinética da reação de iniciação de monômero ou PDB do tipo 'i'

$\left(\right.$ L. $\left.\mathrm{mol}^{-1} \mathrm{~s}^{-1}\right)$;

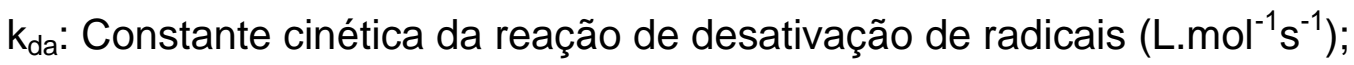

$\mathrm{k}_{\mathrm{a}}$ : Constante cinética da reação de ativação de radicais $\left(\mathrm{L} \cdot \mathrm{mol}^{-1} \mathrm{~s}^{-1}\right)$;

$k_{\text {dimij: }}$ : Constante cinética da reação de dimerização entre os monômeros $M_{i}$ e $M_{j}$ (L. $\mathrm{mol}^{-1} \mathrm{~s}^{-1}$ );

$\mathrm{k}_{\text {ddij: }}$ : Constante cinética da reação de decomposição do dímero composto pelos monômeros $\mathrm{M}_{\mathrm{i}}$ e $\mathrm{M}_{\mathrm{j}}\left(\mathrm{L} \cdot \mathrm{mol}^{-1} \mathrm{~s}^{-1}\right)$;

$\mathrm{k}_{\text {thij: }}$ : Constante cinética da reação de iniciação térmica envolvendo dímero e o monômero $\mathrm{M}_{\mathrm{j}}\left(\mathrm{L}_{\mathrm{mol}} \mathrm{m}^{-1} \mathrm{~s}^{-1}\right)$;

$k_{P i j, s}^{C}$ : Constante cinética da reação de ciclização de um segmento polimérico (caminho) contendo 's' unidades e, em seus extremos, um radical do tipo 'i' e uma dupla ligação pendente do tipo ' 'j' $\left(\mathrm{s}^{-1}\right)$;

$\mathrm{k}_{\mathrm{Pij}}$ : Constante cinética da reação de propagação envolvendo radical do tipo 'i' e o monômero ou PDB do tipo 'j' (L.mol $\left.{ }^{-1} \mathrm{~s}^{-1}\right)$;

$\mathrm{k}_{\mathrm{fmij}}$ : Constante cinética da reação de transferência de cadeia de um radical do tipo 'i' para o monômero $\mathrm{M}_{\mathrm{j}}\left(\mathrm{L} \cdot \mathrm{mol}^{-1} \mathrm{~s}^{-1}\right)$; 
$k_{\text {tc }}$ : Constante cinética da reação de terminação por combinação de radicais poliméricos $\mathrm{M}_{\mathrm{j}}\left(\mathrm{L} \cdot \mathrm{mol}^{-1} \mathrm{~s}^{-1}\right)$;

$\mathrm{k}_{\text {dec }}$ : Constante cinética da reação de decomposição de radicais dormentes $\left(\mathrm{s}^{-1}\right)$;

$\mathrm{k}_{\mathrm{h}}$ : Constante cinética da reação de abstração de próton pelo radical nitróxido

(L. $\left.\mathrm{mol}^{-1} \mathrm{~s}^{-1}\right)$;

Os diferentes tipos de radicais, monômeros e duplas ligações pendentes estão ilustrados na Figura 21.
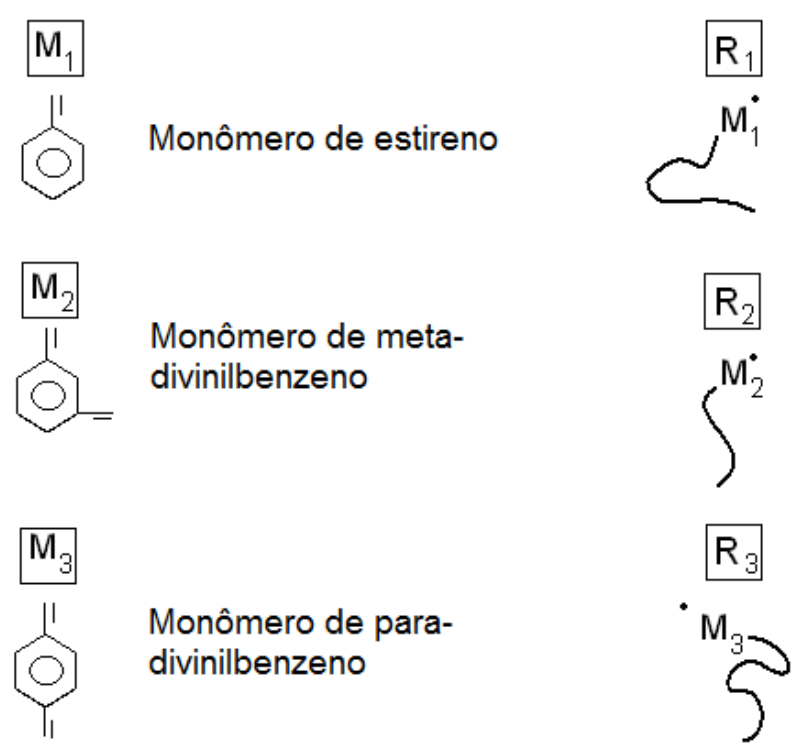

Radical de estireno

Monômero de meta-

divinilbenzeno

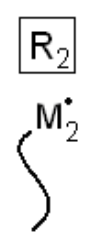

Radical de meta-divinilbenzeno

Monômero de para-

divinilbenzeno

\section{$\mathrm{R}_{3}$}

$\mathrm{M}_{3}$ Radical de para-divinilbenzeno

mPDB

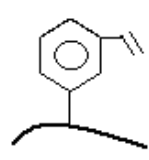

Dupla ligação pendente de meta-divinilbezeno

$\mathrm{R}_{4}$

pPDB

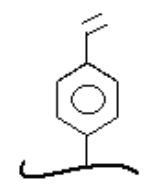

Dupla ligação pendente de para-divinilbezeno

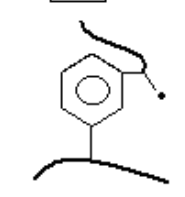

Radical proveniente da quebra da dupla ligação pendente de meta-divinilbenzeno

$\mathrm{R}_{5}$

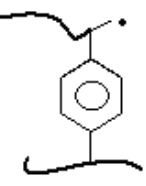

Radical proveniente da quebra da dupla ligação pendente de para-divinilbenzeno

Figura 21 - Representação pictórica de espécies envolvidas nas reações.

Foram estudadas três abordagens diferentes na modelagem matemática do processo de copolimerização de estireno-divinilbenzeno. Estas abordagens foram denominadas: Modelo A, Modelo B e Modelo C e estão descritas a seguir. 


\subsubsection{Modelo A}

Este modelo tem sido aperfeiçoado desde seu desenvolvimento, há cerca de duas décadas atrás por Costa e Dias (1994). A atual plataforma de simulação está escrita em linguagem C e se chama GENLP (Generic Non-Linear Polymerization simulator). Esta plataforma permite simular diferentes tipos de polimerização tais como aniônica, por radicais livres e policondensações. Este modelo é baseado em balanços populacionais em termos de funções geradoras, no método das características e emprega o algorítmo TWPBVP (Two Point Boundary Value Problem), o qual é usado na previsão de variáveis no período pós-gelificação. Este modelo utiliza uma nomenclatura independente e está representado à seguir com maiores detalhes, conforme descrito por Costa e Dias (2011).

\subsubsection{Sistema químico}

Um conjunto contendo um número arbitrário $\mathrm{N}_{\mathrm{M}}$ de monômeros é considerado juntamente com um número arbitrário $\mathrm{N}_{\mathrm{S}}$ de espécies químicas, incluindo iniciadores, agentes de transferência e solventes presentes em inúmeras alimentações. Reações envolvendo fragmentação de moléculas de polímero não podem ser incluídas neste modelo.

Por convenção, uma lista contendo $\mathrm{N}_{\mathrm{A}}$ entidades denominadas, genericamente, $A_{j}$ é definida. Estas entidades compreendem $N_{G}$ grupos poliméricos, $\mathrm{N}_{\mathrm{M}}$ monômeros e outras espécies. Os índices numéricos mais baixos são dados aos grupos poliméricos, seguidos de monômeros e outras espécies. Portanto, tomandose como exemplo o terceiro monômero $M_{3}(j=3)$, sua nomenclatura é dada como $A_{j+N G}$ e para a segunda espécie que não é monômero $(j=2)$, por exemplo, fica definido $A_{j+N G+N M}$.

Pelo menos um grupo polimérico deve ser definido como uma unidade monomérica. A contagem de todas unidades monoméricas determina o tamanho total da molécula de polímero. O conjunto de moléculas que possuem um determinado vetor representando os números dos grupos poliméricos, sem levar em 
conta as diferenças entre os isômeros, será descrito por $P(a)=P\left(a_{1}, \ldots, a_{N G}\right)$. Sua concentração molar está escrita como $[\mathrm{P}(\mathrm{a})]$. De forma semelhante, a concentração molar de um grupo ou espécie $A_{j}$ está representado por $\left[A_{j}\right]$ ou $C_{j}$. O modelo utiliza um vetor de função geradora $\mathrm{G}(\mathrm{s})$ da distribuição de tamanhos (em termos de contagem de grupos), conforme descrito na equação (1).

$$
G(s)=\sum_{a_{1}=0}^{\infty} \ldots \sum_{a_{N_{G}}=0}^{\infty} s_{1}^{a_{1}} \ldots s_{N_{G}}^{a_{N_{G}}}\left[P\left(a_{1}, \ldots, a_{N_{G}}\right)\right]
$$

As derivadas de $\mathrm{G}$ com relação à log $s_{i}$ estão nomeadas da seguinte forma:

$$
G_{n \ldots p}=\frac{\partial \ldots \partial G}{\partial \log s_{n} \ldots \partial \log s_{p}}
$$

Vetores e matrizes simétricas ou tensores de ordem maior ou igual a 3 são usados para agrupar estas derivadas:

$$
\begin{aligned}
G^{\prime} & =\left[\begin{array}{lll}
G_{1} & \ldots & G_{N_{G}}
\end{array}\right] \\
G^{\prime \prime} & =\left[\begin{array}{ccc}
G_{11} & \ldots & G_{1, N_{G}} \\
\ldots & & \ldots \\
G_{N_{G}, 1} & \ldots & G_{N_{G}, N_{G}}
\end{array}\right]
\end{aligned}
$$

Reações entre espécies e/ou grupos poliméricos são classificadas em $\mathrm{N}_{\mathrm{RC}}=4$ categorias, das quais, três compreendem processos bimoleculares com os reagentes principais $A_{g m}$ e $A_{g m+}$ e o quarto compreende a transformação unimolecular de $A_{g m}$. Alternativamente, pode-se utilizar a notação $A_{[m-]}, A_{[m+]}$ e $A_{[m]}$. $O$ critério utilizado para esta classificação é a mudança no número de moléculas de polímero formadas e o caráter unimolecular ou bimolecular da reação. Portanto:

- $\quad \mathrm{N}_{\text {Co }}$ reações de combinação entre grupos pertencentes a diferentes moléculas de polímero conduzem ao crescimento do polímero. Exemplo: terminação de radicais por combinação;

- $\quad \mathrm{N}_{\mathrm{CR}}$ reações de criação entre espécies geram novas moléculas de polímero. Exemplo: Iniciação de monômero através de radical primário; 
- NPR reações de propagação entre um grupo polimérico e um monômero criam novas ligações entre unidades monoméricas mas mantêm constante 0 número de moléculas de polímero. Exemplo: Propagação entre monômero e um centro radicalar ativo.

- $N_{E R}$ reações de permuta entre um grupo polimérico e uma espécie não polimérica alteram a contagem de grupos mas não alteram o número de moléculas de polímero. Exemplo: Iniciação de dupla ligação pendente através de radical primário;

- $\mathrm{N}_{\mathrm{UR}}$ reações unimoleculares mudam a contagem de grupos poliméricos, mas mantêm constante o número de moléculas de polímero. Decomposição térmica de iniciador é um membro deste grupo apesar de não envolver grupo polimérico.

A Tabela 2 apresenta as reações supracitadas.

O número de reações bimoleculares $N_{R B}$ e unimoleculares $N_{U R}$ está descrito através da equação (5) a seguir.

$$
N_{B R}=\sum_{i=1}^{4} N_{R i}=N_{R}-N_{U R}
$$

Tabela 2 - Esquema reacional.

\begin{tabular}{cc}
\hline Categoria da reação & Equação química \\
\hline 1- Combinação & $P\left(a^{-}\right)+P\left(a^{+}\right) \stackrel{k_{m}}{\rightarrow} P\left(a^{-}+a^{+}+v_{m}\right)+\sum_{j>N_{G}}^{N_{A}} v_{m j} A_{j}$ \\
2- Criação & $A_{[m-]}+A_{[m+]} \stackrel{k_{m}}{\rightarrow} P\left(v_{m}\right)+\sum_{j>N_{G}}^{N_{A}} v_{m j} A_{j}$ \\
3- Propagação & $P\left(a^{-}\right)+M_{[m+]} \stackrel{k_{m}}{\rightarrow} P\left(a^{-}+v_{m}\right)$ \\
4- Permuta & $P\left(a^{-}\right)+A_{[m+]} \stackrel{k_{m}}{\rightarrow} P\left(a^{-}+v_{m}^{-}\right)+\sum_{j>N_{G}}^{N_{A}} v_{m j}^{+} A_{j}$ \\
5- Unimolecular & $P\left(a^{-}\right) \stackrel{k_{m}}{\rightarrow} P\left(a^{-}+v_{m}\right)+\sum_{j>N_{G}}^{N_{A}} v_{m j} A_{j}$ \\
\hline
\end{tabular}


Na equação (5), 'i' representa a categoria da reação conforme apresentado na Tabela 2. Portanto, $\mathrm{N}_{\mathrm{Ri}}$ é o número de reações compreendidas na categoria 'i'. Por exemplo, as primeiras $\mathrm{N}_{\mathrm{R} 1}=\mathrm{N}_{\mathrm{Co}}$ reações serão as reações da categoria 1 (Tabela 2), as reações com $N_{R 1}<m \leq N_{R 2}=N_{R 1}+N_{1}$, serão as reações da categoria 2 e assim por diante. Dentre estas classificações, atribui-se $\mathrm{N}_{\mathrm{R} 0}=0$.

A taxa de reação é definida como sendo o produto da velocidade específica $\mathrm{k}_{\mathrm{m}}$ pelas concentrações dos grupos ou espécies principais:

$$
R_{m}= \begin{cases}k_{m} C_{[m-]} C_{[m+]} & m \leq N_{B R} \\ k_{m} C_{[m]} & m>N_{B R}\end{cases}
$$

A taxa de consumo de grupos e espécies $A_{i}$ nas reações bimoleculares e unimoleculares pode ser computada levando-se em conta a contribuição de todos os processos, de acordo com a equação (7), com a ajuda dos coeficientes estequiométricos $v_{m i}$.

$$
R_{A_{i}}=\sum_{m=1}^{N_{B R}} k_{m} v_{m i} C_{[m-]} C_{[m+]}+\sum_{m=1+N_{B R}}^{N_{R}} k_{m} v_{m i} C_{[m]}
$$

3.1.1.2. Taxa de formação de espécies poliméricas por reação química

A transformada discreta da taxa de formação de espécies poliméricas por reação química resultante do esquema cinético descrito na seção anterior toma a seguinte forma:

$$
\begin{aligned}
G_{R_{P}} & =R_{G}=\sum_{m=1}^{N_{R}} k_{m} F_{m}\left(s, G^{\prime}\right) \\
F_{m} & =\left\{\begin{array}{lr}
\psi_{m} G_{g m-} G_{g m+}-C_{g m-} G_{g m+}-C_{g m+} G_{g m-} & m \leq N_{R 1} \\
\psi_{m} C_{g m-} C_{g m+} & N_{R 1}<m \leq N_{R 2} \\
M_{g m+} G_{g m-}\left(\psi_{m}-1\right) & N_{R 2}<m \leq N_{R 3} \\
C_{g m+} G_{g m-}\left(\psi_{m}^{-}-1\right)+C_{g m-} G_{g m+}\left(\psi_{m}^{+}-1\right) & N_{R 3}<m \leq N_{R 4} \\
G_{g m}\left(\psi_{m}-1\right) & N_{R 4}<m \leq N_{R}
\end{array}\right.
\end{aligned}
$$


sendo que as funções auxiliares $\Psi_{\mathrm{m}}, \Psi_{\mathrm{m}}{ }^{-}$e $\Psi_{\mathrm{m}}{ }^{+}$são dadas pelas equações (11) e (12).

$\psi_{m}=\prod_{j=1}^{N_{G}}\left(s_{j}\right)^{v_{m}}$

$\psi_{m}^{U}=\prod_{j=1}^{N_{G}}\left(s_{j}\right)^{v_{m}^{U}} \quad U=+,-$

$\mathrm{G}_{\mathrm{j}}=0$ nas equações anteriores se $\mathrm{j}>\mathrm{N}_{\mathrm{G}}$, não correspondendo a um grupo polimérico.

Derivando-se a equação (9) para cada $F_{m}$ mostrado no conjunto de expressões (10) obtém-se:

$$
\begin{aligned}
& R_{G_{u}}=R_{G}=\sum_{m=1}^{N_{R}} k_{m} F_{m u}\left(s, G^{\prime}, G^{\prime \prime}\right) \\
& F_{m u}=F_{m u}^{k} \quad \text { se } N_{R, k-1}<m \leq N_{R, k} ; \quad k=1 \ldots 5 \\
& F_{m u}^{1}=\psi_{m}\left(v_{m u} G_{g m-} G_{g m+}+G_{u g m-} G_{g m+}+G_{u g m+} G_{g m-}\right)- \\
& C_{g m-} G_{u g m+}-C_{g m+} G_{u g m-} \\
& F_{m u}^{2}=v_{m u} \psi_{m} C_{g m-} C_{g m+} \\
& F_{m u}^{3}=C_{g m+}\left[G_{u g m-}\left(\psi_{m}-1\right)+v_{m u} C_{g m-} G_{g m+}\right] \\
& F_{m u}^{4}=C_{g m+}\left[G_{u g m-}\left(\psi_{m}^{-}-1\right)+v_{m u}^{-} C_{g m-} G_{g m+}\right]+ \\
& C_{g m-}\left[G_{u g m+}\left(\psi_{m}^{+}-1\right)+v_{m u}^{+} C_{g m+} G_{g m-}\right] \\
& F_{m u}^{5}=G_{u g m}\left(\psi_{m}-1\right)+G_{g m} v_{m u} \psi_{m} \\
& R_{G_{u v}}=\sum_{m=1}^{N_{R}} k_{m} F_{m u v}\left(s, G^{\prime}, G^{\prime \prime}, G^{\prime \prime \prime}\right) \\
& F_{\text {muv }}=F_{\text {muv }}^{k} \text { se } N_{R, k-1}<m \leq N_{R, k} ; \quad k=1 \ldots 5 \\
& F_{m u v}^{1}=\psi_{m}\left[\begin{array}{c}
v_{m u} v_{m v} G_{g m-} G_{g m+}+v_{m u}\left(G_{v g m-} G_{g m+}+G_{v g m+} G_{g m-}\right)+ \\
v_{m v}\left(G_{u g m-} G_{g m+}+G_{u g m+} G_{g m-}\right)+G_{u v g m+} G_{g m-}+ \\
G_{u g m+} G_{v g m-}+G_{u g m-} G_{v g m+}+G_{u v g m-} G_{g m+}
\end{array}\right]-C_{g m-} G_{u v g m+}- \\
& C_{g m+} G_{u v g m-} \\
& F_{m u v}^{2}=v_{m u} v_{m v} \psi_{m} C_{g m-} C_{g m+} \\
& F_{m u v}^{3}=C_{g m+}\left[G_{u v g m-}\left(\psi_{m}-1\right)+\psi_{m}\left(v_{m u} v_{m v} G_{g m-}+v_{m u} G_{v g m-}+v_{m v} G_{u g m-}\right)\right] \\
& F_{m u v}^{4}=C_{g m+}\left[G_{u v g m-}\left(\psi_{m}^{-}-1\right)+\psi_{m}^{-}\left(v_{m u}^{-} v_{m v}^{-} G_{g m-}+v_{m u}^{-} G_{v g m-}+v_{m v}^{-} G_{u g m-}\right)\right]+ \\
& C_{g m-}\left[G_{u v g m+}\left(\psi_{m}^{+}-1\right)+\psi_{m}^{+}\left(v_{m u}^{\mp} v_{m v}^{+} G_{g m+}+v_{m u}^{+} G_{v g m+}+v_{m v}^{+} G_{u g m+}\right)\right]
\end{aligned}
$$




$$
\begin{aligned}
& F_{m u v}^{5}=G_{u v g m}\left(\psi_{m}-1\right)+\psi_{m}\left(G_{u g m} v_{m v}+G_{v g m} v_{m u}+G_{g m} v_{m u} v_{m v}\right) \\
& R_{G_{u v w}}=\sum_{m=1}^{N_{R}} k_{m} F_{m u v w}\left(s, G^{\prime}, G^{\prime \prime}, G^{\prime \prime \prime}, G^{\prime \prime \prime}\right) \\
& F_{m u v w}=F_{m u v w}^{k} \text { se } N_{R, k-1}<m \leq N_{R, k} ; \quad k=1 \ldots 5 \\
& F_{m u v}^{1}=
\end{aligned}
$$$$
\psi_{m}\left[\begin{array}{c}
v_{m u} v_{m v} v_{m w} G_{g m-} G_{g m+}+v_{m u} v_{m v}\left(G_{w g m-} G_{g m+}+G_{w g m+} G_{g m-}\right)+ \\
v_{m u} v_{m w}\left(G_{v g m-} G_{g m+}+G_{v g m+} G_{g m-}\right)+v_{m v} v_{m w}\left(G_{u g m-} G_{g m+}+G_{u g m+} G_{g m-}\right)+ \\
v_{m u}\left(G_{v w g m+} G_{g m-}+G_{v g m+} G_{v g m-}+G_{v w g m-} G_{g m+}+G_{v g m-} G_{v g m+}\right)+ \\
v_{m v}\left(G_{u w g m+} G_{g m-}+G_{u g m+} G_{w g m-}+G_{u w g m-} G_{g m+}+G_{u g m-} G_{w g m+}\right)+ \\
v_{m w}\left(G_{u v g m+} G_{g m-}+G_{u g m+} G_{v g m-}+G_{u v g m-} G_{g m+}+G_{u g m-} G_{v g m+}\right)+ \\
G_{u v w g m+} G_{g m-}+G_{u v g m+} G_{w g m-}+G_{u w g m+} G_{v g m-}+G_{v w g m+} G_{u g m-}+ \\
G_{u g m+} G_{v w g m-}+G_{v g m+} G_{u w g m-}+G_{w g m+} G_{u v g m-}+G_{g m+} G_{u v g m-}
\end{array}\right]-
$$$$
C_{g m-} G_{u v w g m+}-C_{g m+} G_{u v w g m-}
$$$$
F_{\text {muvw }}^{2}=v_{m u} v_{m v} v_{m w} \psi_{m} C_{g m-} C_{g m+}
$$

$$
F_{m u v w}^{3}=C_{g m+}\left[G_{u v w g m-}\left(\psi_{m}-1\right)+\psi_{m}\left(\begin{array}{c}
v_{m w} G_{u v g m-}+v_{m v} G_{u w g m-}+ \\
v_{m u} G_{v w g m-}+v_{m v} v_{m w} G_{u g m-}+ \\
v_{m u} v_{m w} G_{v g m-}+v_{m u} v_{m v} G_{w g m-}+ \\
v_{m u} v_{m v} v_{m w} G_{g m-}
\end{array}\right)\right]
$$

$F_{m u v w}^{4}=C_{g m+}\left[G_{u v w g m-}\left(\psi_{m}^{-}-1\right)+\psi_{m}^{-}\left(\begin{array}{c}v_{m w}^{-} G_{u v g m-}+v_{m v}^{-} G_{u w g m-}+ \\ v_{m u}^{-} G_{v w g m-}+v_{m v}^{-} v_{m w}^{-} G_{u g m-}+ \\ v_{m u}^{-} v_{m w}^{-} G_{v g m-}+v_{m u}^{-} v_{m v}^{-} G_{w g m-}+ \\ v_{m u}^{-} v_{m v}^{-} v_{m w}^{-} G_{g m-}\end{array}\right)\right]+$

$C_{g m-}\left[G_{u v w g m+}\left(\psi_{m}^{+}-1\right)+\psi_{m}^{+}\left(\begin{array}{c}v_{m w}^{+} G_{u v g m+}+v_{m v}^{+} G_{u w g+}+ \\ v_{m u}^{+} G_{v w g m+}+v_{m v}^{+} v_{m w}^{+} G_{u g m+}+ \\ v_{m u}^{+} v_{m w}^{+} G_{v g m+}+v_{m u}^{+} v_{m v}^{+} G_{w g m+}+ \\ v_{m u}^{+} v_{m v}^{+} v_{m w}^{+} G_{g m+}\end{array}\right)\right]$

$F_{m u v w}^{5}=G_{u v w g m}\left(\psi_{m}-1\right)+\psi_{m}\left(\begin{array}{c}G_{u v g m} v_{m w}+G_{v w g m} v_{m v}+ \\ G_{v w g m} v_{m u}+G_{u g m} v_{m v} v_{m w}+ \\ G_{v g m} v_{m u} v_{m w}+G_{w g m} v_{m u} v_{m v}+ \\ G_{g m} v_{m u} v_{m v} v_{m w}\end{array}\right)$

Estas equações de taxa são necessárias para se calcular os momentos da distribuição de tamanhos até a ordem 3. Além disso, os momentos referentes à massa molecular, $\lambda_{\mathrm{Mi}}$, permitem obter as médias numérica, mássica e ' $z$ ' da massa molecular das cadeias de polímero, conforme equacionado a seguir. 


$$
\begin{aligned}
& \lambda_{0}=G(1) \\
& \lambda_{i}=G_{i}(1) \\
& \lambda_{i j}=G_{i j}(1) \\
& \lambda_{i j k}=G_{i j k}(1) \\
& \lambda_{M 0}=\lambda_{0} \\
& \lambda_{M 1}=\sum_{i=1}^{N_{G}} M_{A_{i}} \lambda_{i} \\
& \lambda_{M 2}=\sum_{i=1}^{N_{G}} \sum_{j=1}^{N_{G}} M_{A_{i}} M_{A j} \lambda_{i j} \\
& \lambda_{M 3}=\sum_{i=1}^{N_{G}} \sum_{j=1}^{N_{G}} \sum_{k=1}^{N_{G}} M_{A_{i}} M_{A j} M_{A k} \lambda_{i j k} \\
& M_{n}=\frac{\lambda_{M 1}}{\lambda_{M 0}} \\
& M_{w}=\frac{\lambda_{M 2}}{\lambda_{M 1}} \\
& M_{z}=\frac{\lambda_{M 3}}{\lambda_{M 2}}
\end{aligned}
$$

Desta forma, pode-se obter a concentração de espécies através de um balanço de massa levando em conta as taxas de reação (equação 7) e obtem-se também, propriedades como as massas moleculares médias das cadeias de polímero (equações 42-44). O sistema de equações diferenciais resultante deste estudo é solucionado através do integrador RADAU5. O Modelo A (GENLP) também leva em consideração variações de densidade e capacidade calorífica da mistura reacional, diferentes perfis de temperatura, efeitos difusivos e operações em regimes contínuo, semi-contínuo e em batelada. Maiores detalhes sobre este modelo e sua utilização podem ser encontrados nos trabalhos de Costa e Dias (1994, 2003, 2005, 2011). Na seção de ANEXOS da presente tese encontram-se alguns destes trabalhos.

As simulações com o Modelo A foram realizadas levando-se em conta todas as reações descritas na Tabela 1 , exceto as reações de ciclização. A vantagem deste modelo está na eliminação de hipóteses como o regime pseudo-estacionário, as constantes pseudo-cinéticas dentre outras, o que permite obter resultados que são, fisicamente, mais realistas. Por outro lado, à medida que se aumenta o número de grupos poliméricos, dificulta-se a solução do problema de valores de contorno em fronteira com dois pontos (TWPBVP) limitando-se a previsão até o período pré- 
gelificação para sistemas mais complexos (com maior número de grupos poliméricos).

Neste modelo, Costa e Dias (2011) utilizaram a seguinte notação:

$C_{\mathrm{j}}$ : Concentração molar da espécie 'j';

$\mathrm{G}(\mathrm{s})$ : Função geradora da distribuição de tamanhos de cadeia em termos de concentração molar com relação à contagem de grupos;

$g_{m-}, g_{m+}$ : Índices dos grupos ou espécies principais envolvidos na reação 'm';

$\mathrm{M}_{\mathrm{n}}$ : Massa molecular média numérica de cadeias de polímero;

$M_{\mathrm{w}}$ : Massa molecular média mássica de cadeias de polímero;

$M_{z}$ : Massa molecular média ' $z$ ' de cadeias de polímero;

$\mathrm{N}_{\mathrm{A}}$ : Número total de grupos, monômeros e espécies;

$\mathrm{N}_{\mathrm{AG}}$ : Número de tipos de grupos em moléculas de polímero que são grupos principais de alguma reação química;

$\mathrm{N}_{\mathrm{BR}}$ : Número de reações bimoleculares;

$\mathrm{N}_{\mathrm{G}}$ : Número total de tipos de grupos em moléculas de polímero;

$\mathrm{N}_{\mathrm{M}}$ : Número de monômeros;

$\mathrm{N}_{\mathrm{PR}}$ : Número de reações de propagação;

$\mathrm{N}_{\mathrm{S}}$ : Número de espécies químicas que não são monômeros, nem espécies poliméricas;

NUR: Número de reações unimoleculares;

$v_{m i}$ : Variação de mols da espécie ou grupo $A_{i}$ causada pela reação 'm';

$v_{m i-}, v_{m i+}$ : Variação de mols da espécie ou grupo $A_{i}$ causada pela reação 'm', em cada molécula de polímero envolvida;

$\psi_{m}, \psi_{m}^{+}, \psi_{m}^{-}$: Funções estequiométricas (funções geradoras dos coeficientes estequiométricos) associadas à reação ' $m$ '.

\subsubsection{Modelo B}

Neste modelo, são consideradas as seguintes hipóteses gerais: 
- Regime pseudo-estacionário para os radicais;

- Cada molécula solúvel de polímero pode possuir apenas um centro radicalar (monorradical);

- A variação de volume do meio reacional não afeta significativamente os resultados;

- Pseudo-homopolimerização;

- Reações bimoleculares envolvendo grupos poliméricos independem do tamanho de suas cadeias.

Hipóteses específicas estão descritas no estudo da inclusão de reações de ciclizações pelo método dos caminhos no item 3.2.1.6. O Modelo B consiste num sistema de equações diferenciais provenientes dos balanços de massa e de momentos para moléculas não-poliméricas e poliméricas respectivamente. Para as duplas ligações pendentes são feitos balanços individuais de grupos levando em conta a variação de concentração dos diferentes tipos de PDB. Para se calcular as propriedades das cadeias solúveis no período pós-gelificação, foi utilizado o método do fracionamento numérico. O sistema de equações diferenciais foi solucionado através do algoritmo ODE45 do MATLAB. Este modelo apresenta certas limitações referentes ao número de reações (reduzido em relação ao Modelo $A$ ) e referentes ao número de gerações utilizadas no método do fracionamento numérico, que será comentado mais adiante no item 4. Estas limitações estão associadas ao limite mínimo do passo de integração utilizado pelo MATLAB, cujo erro foi observado em todos os integradores disponíveis quando se utiliza o sistema em estudo.

Partindo-se da hipótese de pseudo-homopolimerização, pode-se escrever as reações químicas do Modelo B conforme mostrado na Tabela 3.

Tabela 3 - Reações químicas consideradas no Modelo B (continua)

\begin{tabular}{ccc}
\hline Nome da reação & Equação química & Constante cinética \\
\hline Decomposição do iniciador & $\mathrm{I} \rightarrow 2 \mathrm{R}_{0}$ & $\mathrm{k}_{d}$ \\
Desativação de radicais & $\mathrm{R}_{\mathrm{r}}+\mathrm{ON}_{\mathrm{x}} \rightarrow \mathrm{DR}$ & $\mathrm{k}_{\mathrm{da}}$ \\
Ativação de radicais & $\mathrm{DR}_{\mathrm{r}} \rightarrow \mathrm{R}_{\mathrm{r}}+\mathrm{ON}_{\mathrm{x}}$ & $\mathrm{k}_{\mathrm{a}}$ \\
Propagação de monômero & $\mathrm{R}_{\mathrm{r}}+\mathrm{M} \rightarrow \mathrm{R}_{\mathrm{r}+1}$ & $\mathrm{k}_{\mathrm{p}}$ (a)
\end{tabular}


Tabela 3 - Reações químicas consideradas no Modelo B (conclusão)

\begin{tabular}{ccc}
\hline Nome da reação & Equação química & Constante cinética \\
\hline Propagação de PDBs & $R_{r}+P_{s} \rightarrow R_{r+s}$ & $k_{p p}{ }^{(a)}$ \\
$R_{r}+D R_{s} \rightarrow R_{r+s}$ & \\
Iniciação de monômero & $R_{0}+M \rightarrow R_{1}$ & $k_{l}$ (a) \\
Iniciação de PDBs & $R_{0}+P_{r} \rightarrow R_{r}$ & $k_{i p}{ }^{(a)}$ \\
Terminação por combinação & $R_{0}+D R_{r} \rightarrow R_{r}$ & $k_{t}^{(b)}$ \\
Ciclização & $R_{r}+R_{s} \rightarrow P_{r+s}$ & $k_{p i j, s}^{c}$ \\
\hline
\end{tabular}

(a) Constantes pseudo-cinéticas. Índices ' $r$ ' e 's' se referem à número de unidades monoméricas; ${ }^{(b)}$ Não foram consideradas as reações de terminação por dimutação $\left(k_{t c}=k_{t}\right)$.

Para se considerar pseudo-homopolimerização, faz-se necessário determinar as constantes pseudo-cinéticas. Estas constantes foram determinadas para as reações de propagação e iniciação de monômeros e duplas ligações pendentes. Para as reações de ativação de radicais, desativação de radicais e terminação por combinação, foi definida uma única constante cinética por reação, independente do tipo de radical. A reação de ciclização foi estudada separadamente conforme mostrado no item 3.1.2.6. A seguir são equacionadas as constantes pseudocinéticas.

\subsubsection{Determinação das constantes pseudo-cinéticas}

Observa-se na Figura 21 que o sistema estudado leva em conta 3 espécies monoméricas, 5 tipos de radicais poliméricos e 2 tipos de duplas ligações pendentes. Através da utilização de constantes pseudo-cinéticas é possível simplificar o mecanismo reacional do processo, podendo este ser abordado como uma pseudo-homopolimerização. A equação (45) mostra a taxa total de propagação de monômero, a qual considera os diferentes tipos de radicais e monômeros presentes no meio reacional. Aplicando-se a hipótese de que reações bimoleculares 
envolvendo os radicais poliméricos não dependem do tamanho da cadeia, pode-se simbolizar os radicais na forma $R_{1}$ à $R_{5}$, conforme ilustrado na Figura 21 .

Constante pseudo-cinética da propagação de monômeros

$$
\begin{aligned}
& R_{p}=R_{1}\left(k_{p 11} M_{1}+k_{p 12} M_{2}+k_{p 13} M_{3}\right)+R_{2}\left(k_{p 21} M_{1}+k_{p 22} M_{2}+k_{p 23} M_{3}\right)+ \\
& R_{3}\left(k_{p 31} M_{1}+k_{p 32} M_{2}+k_{p 33} M_{3}\right)+R_{4}\left(k_{p 41} M_{1}+k_{p 42} M_{2}+k_{p 43} M_{3}\right)+ \\
& R_{5}\left(k_{p 51} M_{1}+k_{p 52} M_{2}+k_{p 53} M_{3}\right)
\end{aligned}
$$

Para uma homopolimerização, a taxa de propagação de monômero seria:

$$
R_{p}=k_{p} R M
$$

sendo que $R$ representa a concentração de radicais e $M$ representa a concentração de monômero. Substituindo (46) em (45) e dividindo por RM, obtém-se:

$$
\begin{aligned}
& k_{p}=f_{R 1}\left(k_{p 11} f_{M 1}+k_{p 12} f_{M 2}+k_{p 13} f_{M 3}\right)+f_{R 2}\left(k_{p 21} f_{M 1}+k_{p 22} f_{M 2}+k_{p 23} f_{M 3}\right)+ \\
& f_{R 3}\left(k_{p 31} f_{M 1}+k_{p 32} f_{M 2}+k_{p 33} f_{M 3}\right)+f_{R 4}\left(k_{p 41} f_{M 1}+k_{p 42} f_{M 2}+k_{p 43} f_{M 3}\right)+ \\
& f_{R 5}\left(k_{p 51} f_{M 1}+k_{p 52} f_{M 2}+k_{p 53} f_{M 3}\right)
\end{aligned}
$$

sendo que $f_{R i}$ e $f_{M j}$ são as frações molares do radical do tipo 'i' dentre todos os radicais e do monômero do tipo 'j' dentre todos os monômeros, respectivamente.

Observa-se que, apesar de simplificar o equacionamento, esta hipótese não traz prejuízo ao modelo, pois, trabalhar com a equação (47) é matematicamente equivalente a trabalhar com diferentes constantes cinéticas de propagação em função dos tipos de radicais e monômeros. Analogamente, obtém-se as equações (48), (49) e (50).

Constante pseudo-cinética da iniciação de monômeros

$$
k_{i}=k_{i 1} f_{M 1}+k_{i 2} f_{M 2}+k_{i 3} f_{M 3}
$$


Constante pseudo-cinética da propagação de duplas ligações pendentes

$$
\begin{aligned}
& k_{p p}=\left[f_{R 1}\left(k_{p 14} f_{m P D B}+k_{p 15} f_{p P D B}\right)+f_{R 2}\left(k_{p 24} f_{m P D B}+k_{p 25} f_{p P D B}\right)\right] \frac{P D B}{Q S_{1}}+ \\
& {\left[f_{R 3}\left(k_{p 34} f_{m P D B}+k_{p 35} f_{p P D B}\right)+f_{R 4}\left(k_{p 44} f_{m P D B}+k_{p 45} f_{p P D B}\right)\right] \frac{P D B}{Q S_{1}}+} \\
& f_{R 5}\left(k_{p 54} f_{m P D B}+k_{p 55} f_{p P D B}\right) \frac{P D B}{Q S_{1}}
\end{aligned}
$$

Constante pseudo-cinética da iniciação de duplas ligações pendentes

$$
k_{i p}=\left(k_{i 4} f_{m P D B}+k_{i 5} f_{p P D B}\right) \frac{P D B}{Q S_{1}}
$$

sendo que

$$
\begin{aligned}
& P D B=m P D B+p P D B \\
& f_{m P D B}=\frac{m P D B}{m P D B+p P D B} \\
& f_{p P D B}=\frac{p P D B}{m P D B+p P D B} \\
& f_{M i}=\frac{M_{i}}{M_{1}+M_{2}+M_{3}}
\end{aligned}
$$$$
(1 \leq i \leq 3)
$$

$\mathrm{QS}_{1}$ é o número total de unidades monoméricas presentes em cadeias de polímero morto e dormente. Esta variável será descrita com mais detalhes no item 3.1.2.4.

A fração de radicais do tipo 'i' $f_{R i}$ é determinada através da resolução de um sistema de equações lineares resultante do balanço de massa para cada radical. Hernández-Ortiz (2008) apresenta um estudo análogo utilizando dois tipos de radicais, que acarreta numa solução menos complexa para o sistema de equações. $O$ balanço de massa para o radical de estireno, $R_{1}$, está apresentado na equação (55). 


$$
\begin{aligned}
& \frac{\mathrm{dR}_{1}}{\mathrm{dt}}=\mathrm{R}_{\mathrm{GR} 1}-\mathrm{R}_{\mathrm{CR} 1}-\mathrm{R}_{1}\left(\mathrm{k}_{\mathrm{p} 12} \mathrm{M}_{2}+\mathrm{k}_{\mathrm{p} 13} \mathrm{M}_{3}+\mathrm{k}_{\mathrm{p} 14} \mathrm{mPDB}+\mathrm{k}_{\mathrm{p} 15} \mathrm{pPDB}\right)+ \\
& \mathrm{M}_{1}\left(\mathrm{k}_{\mathrm{p} 21} \mathrm{R}_{2}+\mathrm{k}_{\mathrm{p} 31} \mathrm{R}_{3}+\mathrm{k}_{\mathrm{p} 41} \mathrm{R}_{4}+\mathrm{k}_{\mathrm{p} 51} \mathrm{R}_{5}\right)
\end{aligned}
$$

De acordo com o regime pseudo-estacionário, a cada instante da reação, a taxa de geração de novos radicais do tipo $1\left(R_{G R 1}\right)$ através da reação de iniciação é igual à taxa de terminação de radicais do tipo $1\left(R_{C R 1}\right)$. Dividindo-se a eq.(55) por $R\left(M_{1}+M_{2}+M_{3}+m P D B+p P D B\right)$ e aplicando o regime pseudo-estacionário, obtémse a equação (56).

$0=-\mathrm{f}_{\mathrm{R} 1}\left(\mathrm{k}_{\mathrm{p} 12} \mathrm{f}_{2}^{\prime}+\mathrm{k}_{\mathrm{p} 13} \mathrm{f}_{3}^{\prime}+\mathrm{k}_{\mathrm{p} 14} \mathrm{f}_{4}^{\prime}+\mathrm{k}_{\mathrm{p} 15} \mathrm{f}_{5}^{\prime}\right)+$

$\mathrm{f}_{1}^{\prime}\left(\mathrm{k}_{\mathrm{p} 21} \mathrm{f}_{\mathrm{R} 2}+\mathrm{k}_{\mathrm{p} 31} \mathrm{f}_{\mathrm{R} 3}+\mathrm{k}_{\mathrm{p} 41} \mathrm{f}_{\mathrm{R} 4}+\mathrm{k}_{\mathrm{p} 51} \mathrm{f}_{\mathrm{R} 5}\right)$

Analogamente, para os demais radicais:

$$
\begin{aligned}
& 0=-\mathrm{f}_{\mathrm{R} 2}\left(\mathrm{k}_{\mathrm{p} 21} \mathrm{f}_{1}^{\prime}+\mathrm{k}_{\mathrm{p} 23} \mathrm{f}_{3}^{\prime}+\mathrm{k}_{\mathrm{p} 24} \mathrm{f}_{4}^{\prime}+\mathrm{k}_{\mathrm{p} 25} \mathrm{f}_{5}^{\prime}\right)+ \\
& \mathrm{f}_{2}^{\prime}\left(\mathrm{k}_{\mathrm{p} 12} \mathrm{f}_{\mathrm{R} 1}+\mathrm{k}_{\mathrm{p} 32} \mathrm{f}_{\mathrm{R} 3}+\mathrm{k}_{\mathrm{p} 42} \mathrm{f}_{\mathrm{R} 4}+\mathrm{k}_{\mathrm{p} 52} \mathrm{f}_{\mathrm{R} 5}\right) \\
& 0=-\mathrm{f}_{\mathrm{R} 3}\left(\mathrm{k}_{\mathrm{p} 31} \mathrm{f}_{1}^{\prime}+\mathrm{k}_{\mathrm{p} 32} \mathrm{f}_{2}^{\prime}+\mathrm{k}_{\mathrm{p} 34} \mathrm{f}_{4}^{\prime}+\mathrm{k}_{\mathrm{p} 35} \mathrm{f}_{5}^{\prime}\right)+ \\
& \mathrm{f}_{3}^{\prime}\left(\mathrm{k}_{\mathrm{p} 13} \mathrm{f}_{\mathrm{R} 1}+\mathrm{k}_{\mathrm{p} 23} \mathrm{f}_{\mathrm{R} 2}+\mathrm{k}_{\mathrm{p} 43} \mathrm{f}_{\mathrm{R} 4}+\mathrm{k}_{\mathrm{p} 53} \mathrm{f}_{\mathrm{R} 5}\right) \\
& 0=-\mathrm{f}_{\mathrm{R} 4}\left(\mathrm{k}_{\mathrm{p} 41} \mathrm{f}_{1}^{\prime}+\mathrm{k}_{\mathrm{p} 42} \mathrm{f}_{2}^{\prime}+\mathrm{k}_{\mathrm{p} 43} \mathrm{f}_{3}^{\prime}+\mathrm{k}_{\mathrm{p} 45} \mathrm{f}_{5}^{\prime}\right)+ \\
& \mathrm{f}_{4}^{\prime}\left(\mathrm{k}_{\mathrm{p} 14} \mathrm{f}_{\mathrm{R} 1}+\mathrm{k}_{\mathrm{p} 24} \mathrm{f}_{\mathrm{R} 2}+\mathrm{k}_{\mathrm{p} 34} \mathrm{f}_{\mathrm{R} 3}+\mathrm{k}_{\mathrm{p} 54} \mathrm{f}_{\mathrm{R} 5}\right) \\
& 0=-\mathrm{f}_{\mathrm{R} 5}\left(\mathrm{k}_{\mathrm{p} 51} \mathrm{f}_{1}^{\prime}+\mathrm{k}_{\mathrm{p} 52} \mathrm{f}_{2}^{\prime}+\mathrm{k}_{\mathrm{p} 53} \mathrm{f}_{3}^{\prime}+\mathrm{k}_{\mathrm{p} 54} \mathrm{f}_{4}^{\prime}\right)+ \\
& \mathrm{f}_{5}^{\prime}\left(\mathrm{k}_{\mathrm{p} 15} \mathrm{f}_{\mathrm{R} 1}+\mathrm{k}_{\mathrm{p} 25} \mathrm{f}_{\mathrm{R} 2}+\mathrm{k}_{\mathrm{p} 35} \mathrm{f}_{\mathrm{R} 3}+\mathrm{k}_{\mathrm{p} 45} \mathrm{f}_{\mathrm{R} 4}\right)
\end{aligned}
$$

em que:

$$
\mathrm{f}_{1}^{\prime}=\frac{\mathrm{M}_{1}}{\mathrm{M}+\mathrm{mPDB}+\mathrm{pPDB}}
$$


$\mathrm{f}_{2}^{\prime}=\frac{\mathrm{M}_{2}}{\mathrm{M}+\mathrm{mPDB}+\mathrm{pPDB}}$

$\mathrm{f}_{3}^{\prime}=\frac{\mathrm{M}_{3}}{\mathrm{M}+\mathrm{mPDB}+\mathrm{pPDB}}$

$\mathrm{f}_{4}^{\prime}=\frac{\mathrm{mPDB}}{\mathrm{M}+\mathrm{mPDB}+\mathrm{pPDB}}$

$\mathrm{f}_{5}^{\prime}=\frac{\mathrm{pPDB}}{\mathrm{M}+\mathrm{mPDB}+\mathrm{pPDB}}$

$M=M_{1}+M_{2}+M_{3}$

3.1.2.2. Balanço de massa para espécies não poliméricas

Aplicando o regime pseudo-estacionário para radicais primários, pode-se escrever o seguinte conjunto de equações:

Radical primário

$R_{0}=\frac{2 f k_{d} I+k_{a} D R_{0}}{k_{i} M+k_{i p} Q S_{1}+k_{d a} O N_{X}}$

Iniciador

$\frac{d I}{d t}=-k_{d} I$

Estireno

$\frac{d M_{1}}{d t}=-\left[k_{I 1} R_{0}+Y_{0}\left(k_{p 11} f_{R 1}+k_{p 21} f_{R 2}+k_{p 31} f_{R 3}+k_{p 41} f_{R 4}+k_{p 51} f_{R 5}\right)\right] M_{1}$ 
Meta-divinilbenzeno

$\frac{d M_{2}}{d t}=-\left[k_{I 2} R_{0}+Y_{0}\left(k_{p 12} f_{R 1}+k_{p 22} f_{R 2}+k_{p 32} f_{R 3}+k_{p 42} f_{R 4}+k_{p 52} f_{R 5}\right)\right] M_{2}$

Para-divinilbenzeno

$\frac{d M_{3}}{d t}=-\left[k_{I 3} R_{0}+Y_{0}\left(k_{p 13} f_{R 1}+k_{p 23} f_{R 2}+k_{p 33} f_{R 3}+k_{p 43} f_{R 4}+k_{p 53} f_{R 5}\right)\right] M_{3}$

Dupla ligação pendente de meta-divinilbenzeno (mPDB)

$\frac{d m P D B}{d t}=\left[k_{I 2} R_{0}+Y_{0}\left(k_{p 12} f_{R 1}+k_{p 22} f_{R 2}+k_{p 32} f_{R 3}+k_{p 42} f_{R 4}+k_{p 52} f_{R 5}\right)\right] M_{2}-$
$\left[k_{I 4} R_{0}+Y_{0}\left(k_{p 14} f_{R 1}+k_{p 24} f_{R 2}+k_{p 34} f_{R 3}+k_{p 44} f_{R 4}+k_{p 54} f_{R 5}\right)\right] m P D B-R C_{m}$

Dupla ligação pendente de para-divinilbenzeno (pPDB)

$\frac{d p P D B}{d t}=\left[k_{I 3} R_{0}+Y_{0}\left(k_{p 13} f_{R 1}+k_{p 23} f_{R 2}+k_{p 33} f_{R 3}+k_{p 43} f_{R 4}+k_{p 53} f_{R 5}\right)\right] M_{3}-$
$\left[k_{I 5} R_{0}+Y_{0}\left(k_{p 15} f_{R 1}+k_{p 25} f_{R 2}+k_{p 35} f_{R 3}+k_{p 45} f_{R 4}+k_{p 55} f_{R 5}\right)\right] p P D B-R C_{p}$

Radical primário desativado

$\frac{d D R_{0}}{d t}=k_{d a} O N_{X} R_{0}-k_{a} D R_{0}$

Radical nitróxido (TEMPO)

$\frac{d O N_{X}}{d t}=-k_{d a} O N_{X}\left(R_{0}+Y_{0}\right)+k_{a}\left(D R_{0}+S_{0}\right)$

Os termos $\mathrm{RC}_{\mathrm{m}}$ (eq. 72) e $\mathrm{RC}_{\mathrm{p}}$ (eq. 73) são definidos no item 3.1.2.6. 


\subsubsection{Balanço de massa para espécies poliméricas}

Neste balanço, faz-se uso das constantes pseudo-cinéticas, eliminando-se o uso de índices referentes ao tipo de monômero, radical e PDB. Nas equações a seguir, o índice ' $r$ ' está relacionado com o número de unidades monoméricas contidas na molécula.

Radical polimérico de tamanho 1

$\frac{d R_{r=1}}{d t}=k_{I} R_{0} M-k_{p} M R_{r=1}-k_{p p} R_{r=1} \sum_{s=1}^{\infty}\left(P_{s}+D R_{s}\right)-k_{d a} O N_{X} R_{r=1}+k_{a} D R_{r=1}-$

$k_{t} R_{r=1} \sum_{s=1}^{\infty} R_{S}$

Radical polimérico de tamanho $r(r>1)$

$\frac{d R_{r}}{d t}=k_{p} M R_{r-1}-k_{p} M R_{r}+k_{i p} R_{0}\left(r P_{r}+r D R_{r}\right)+k_{p p} \sum_{s=1}^{r-1} R_{r-s}\left(s P_{s}+s D R_{s}\right)-$
$k_{p p} R_{r} \sum_{s=1}^{\infty}\left(s P_{s}+s D R_{s}\right)-k_{d a} O N_{X} R_{r}+k_{a} D R_{r}-k_{t} R_{r} \sum_{s=1}^{\infty} R_{s}$

Polímero morto de tamanho $r$

$\frac{d P_{r}}{d t}=-k_{i p} R_{0} r P_{r}-k_{p p} Y_{0} r P_{r}+\frac{k_{t}}{2} \sum_{s=1}^{r-1} R_{s} R_{r-s}$

Radical dormente de tamanho $r$

$\frac{d D R_{r}}{d t}=-k_{i p} R_{0} r D R_{r}-k_{p p} Y_{0} r D R_{r}+k_{d a} O N_{X} R_{r}-k_{a} D R_{r}$

3.1.2.4. Método dos momentos

O método dos momentos contabiliza os diferentes tamanhos de cadeia, eliminando a necessidade de se fazer o balanço de massa para cada um. A seguir, 
são definidos os momentos globais de ordem 'i' para os radicais, as cadeias de polímero morto e dormente respectivamente.

$Y_{i}=\sum_{r=1}^{\infty} r^{i} R_{r}$

$Q_{i}=\sum_{r=1}^{\infty} r^{i} P_{r}$

$S_{i}=\sum_{r=1}^{\infty} r^{i} D R_{r}$

Uma vez determinadas as constantes pseudo-cinéticas, não há mais a necessidade de se distinguir o tipo de radical ou PDB nas reações de iniciação e propagação. Por isso, as equações (80), (81) e (82) apresentam somente índices relativos ao número de unidades monoméricas na cadeias $(r)$ e à ordem do momento (i). $O$ balanço dos momentos pode ser feito multiplicando-se $r^{i}$ pelas equações de balanço $(76+77,78$ e 79$)$ e em seguida, aplicando-se o somatório de zero até infinito em cada expressão. As equações resultantes da aplicação desta técnica estão descritas a seguir.

Momento de ordem zero

\section{$\underline{\text { Radical polimérico }}$}

$\mathrm{Na}$ aplicação do método dos momentos para os radicais poliméricos, deve-se somar as expressões (76) e (77), de forma a contabilizar todos os tamanhos de cadeia (números de unidades monoméricas), inclusive o tamanho 1. Aplicando-se o método dos momentos à expressão resultante desta soma, chega-se à equação (83).

$\frac{d Y_{0}}{d t}=k_{i} R_{0} M+k_{i p} R_{0} Q S_{1}-k_{d a} O N_{X} Y_{0}+k_{a} S_{0}-k_{t} Y_{0}^{2}$ 
A aplicação do regime pseudo-estacionário na equação (83) resulta na equação (84).

$k_{t} Y_{0}^{2}+k_{d a} O N_{X} Y_{0}-\left(k_{i} R_{0} M+k_{i p} R_{0} Q S_{1}+k_{a} S_{0}\right)=0$

Esta é uma equação de segundo grau que é solucionada através da fórmula de Bhaskara.

Polímero morto

$\frac{d Q_{0}}{d t}=-k_{i p} R_{0} Q_{1}-k_{p p} Y_{0} Q_{1}-k_{t} Y_{0}^{2}$

Radical dormente

$\frac{d S_{0}}{d t}=-k_{i p} R_{0} S_{1}-k_{p p} Y_{0} S_{1}+k_{d a} O N_{X} Y_{0}-k_{a} S_{0}$

Momento de ordem 1

As equações de balanço para o momento global de ordem 1 para radical polimérico, polímero morto e radical dormente são obtidas por analogia ao que foi feito para o momento de ordem zero (eqs. 83-86). A diferença está na mudança do fator $r^{0}$, que agora passa a ser $r^{1}$. Este fator é multiplicado membro à membro nas equações (76)-(79), aplicando-se em seguida, o somatório de 0 a infinito, conforme desenvolvido para o momento de ordem zero. Combinando-se as expressões resultantes deste procedimento análogo, chega-se à equação (87).

$\frac{d Q S_{1}}{d t}=k_{i} R_{0} M+k_{p} Y_{0} M$

sendo que $Q S_{1}=Q_{1}+S_{1}$, representando todas as unidades monoméricas presentes em cadeias de polímero morto e dormente. Neste desenvolvimento, as equações de balanço para $Q_{1}$ e $S_{1}$ eram funções de $Q_{2}$ e $S_{2}$ respectivamente. Como o processo envolve reações de crosslink (ligação cruzada), em um determinado instante da reação, as moléculas de polímero adquirem tamanhos infinitamente grandes 
(cadeias insolúveis - gel). Durante a simulação do processo, este efeito tem impacto direto no momento de ordem 2, o qual tende a infinito. Por esse motivo, os parâmetros $Q_{2}$ e $S_{2}$ devem ser eliminados do equacionamento. Como será visto mais a frente, na técnica do fracionamento numérico, não será necessário obter o valor de $Y_{1}$. Os parâmetros $Q_{2}$ e $S_{2}$ podem ser eliminados através da combinação das 3 equações de balanço de momentos globais de ordem $1\left(\mathrm{Y}_{1}, \mathrm{Q}_{1}\right.$ e $\left.\mathrm{S}_{1}\right)$, que resulta na equação (87). A determinação dos momentos individuais $Q_{1}$ e $S_{1}$ está descrita no item 3.1.2.5.

\subsubsection{Fracionamento numérico}

O método do fracionamento numérico, desenvolvido por Teymour e Campbell (1994), consiste em dividir as moléculas de polímero e radicais, em gerações, a fim de contornar o problema matemático gerado pela formação de gel no sistema. Conforme descrito anteriormente, a formação de gel (molécula de tamanho infinito) dificulta a simulação do processo, pois o momento global de ordem 2 tende a infinito. Porém, se considerarmos somente as moléculas de tamanho finito ${ }^{1}$, pode-se calcular o momento de ordem 2. Estas moléculas de tamanho finito (fração solúvel) serão divididas em gerações, conforme ilustrado na Figura 22.

Observa-se que as moléculas se tornam maiores ao longo das gerações. A geração zero compreende somente as cadeias lineares. A geração 1 abrange as cadeias que sofreram suas primeiras ligações cruzadas, ou seja, se um radical primário reagir com uma PDB de uma cadeia linear, esta cadeia passa da geração zero para a geração 1. Em geral, quando duas cadeias da mesma geração reagem por ligação cruzada ou terminação por combinação, forma-se uma molécula pertencente à geração seguinte. Isto não vale para a geração zero, visto que a terminação por combinação de duas cadeias lineares formará uma cadeia linear, que permanecerá na geração zero. Outra regra geral do fracionamento numérico determina que quando duas cadeias de gerações diferentes reagem formando uma única molécula, esta molécula pertence à maior geração dentre as duas.

\footnotetext{
${ }^{1}$ Fisicamente, todas moléculas do sistema são de tamanho finito. Neste caso, o termo "finito" é usado para diferenciar moléculas solúveis do gel, cujo tamanho médio, com base no método dos momentos, tende ao infinito
} 


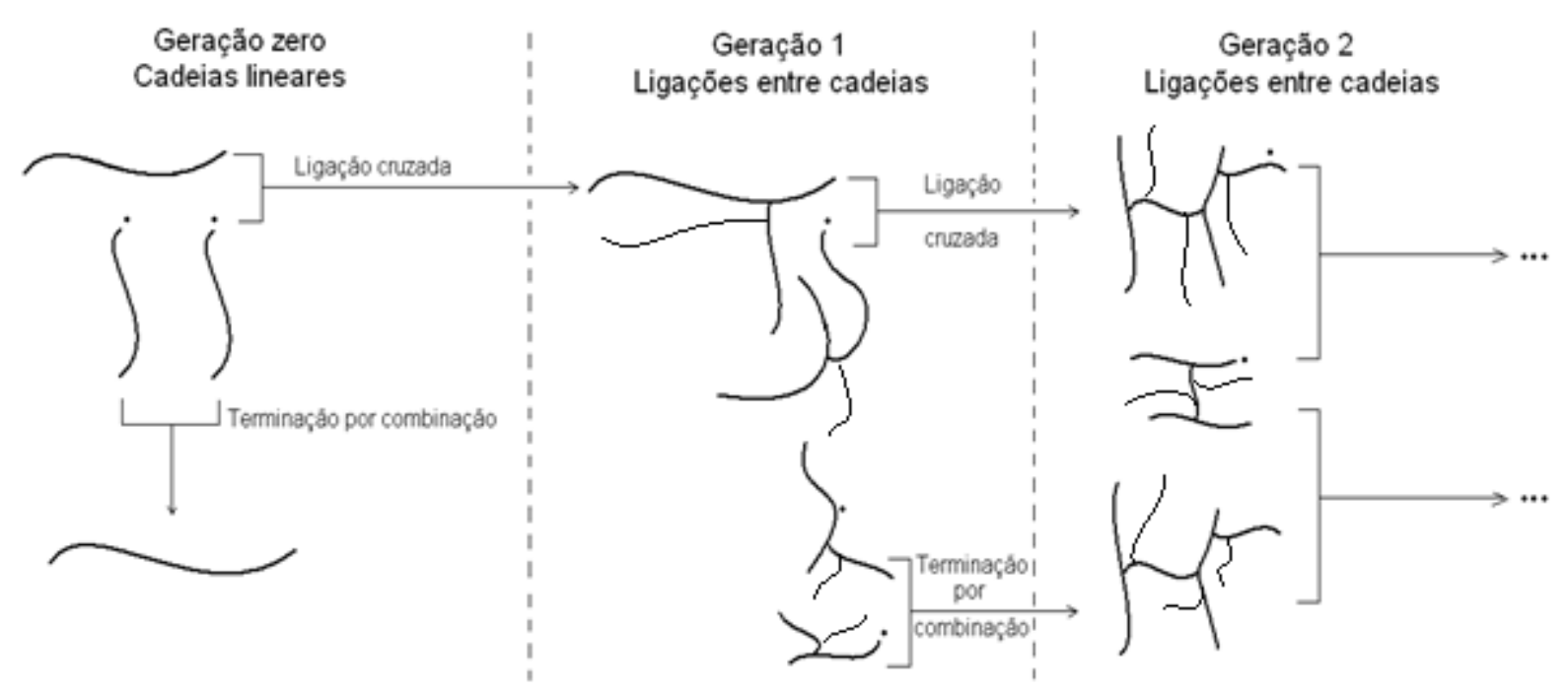

Figura 22 - Método do fracionamento numérico - transição entre gerações.

Estas considerações do fracionamento numérico geram restrições no balanço de massa, de forma que este não será o mesmo para todas as gerações. Porém, segue-se o mesmo método aplicado para o balanço global de radical polimérico, polímero morto e radical dormente (eqs. 76-86). A diferença neste caso é que se pode efetuar os balanços até o momento de ordem 2 para cada geração. Este método não apresenta o problema da divergência, pois não há acúmulo do momento de ordem 2 da forma que haveria se fosse considerado todo o polímero formado. Com o fracionamento numérico, o valor do momento de ordem 2 pode aumentar e reduzir conforme as cadeias mudam de geração. Os balanços de momentos para as cadeias de cada geração estão equacionados a seguir.

Balanço de momentos para radicais poliméricos

\section{Geração zero}

Momento de ordem zero

$$
Y_{00}=\frac{k_{i} R_{0} M+k_{a} S_{00}}{k_{p p} Q S_{1}+k_{t} Y_{0}+k_{d a} O N_{X}}
$$




\section{Momento de ordem 1}

$Y_{01}=\frac{k_{i} R_{0} M+k_{p} M Y_{00}+k_{a} S_{01}}{k_{p p} Q S_{1}+k_{t} Y_{0}+k_{d a} O N_{X}}$

Momento de ordem 2

$Y_{02}=\frac{k_{i} R_{0} M+k_{p} M\left(2 Y_{01}+Y_{00}\right)+k_{a} S_{02}}{k_{p p} Q S_{1}+k_{t} Y_{0}+k_{d a} O N_{X}}$

\section{Geração 1}

Momento de ordem zero

$Y_{10}=\frac{k_{i p} R_{0}\left(Q_{01}+Q_{11}+S_{01}+S_{11}\right)+k_{p p} Y_{00}\left(Q_{01}+S_{01}+S_{11}+Q_{11}\right)+k_{a} S_{01}}{k_{p p} Q S_{1}-k_{p p}\left(Q_{01}+S_{01}\right)+k_{t} Y_{0}+k_{d a} O N_{X}}$

Momento de ordem 1

$Y_{11}=\frac{k_{p p}\left[Y_{00}\left(Q_{02}+S_{02}+Q_{12}+S_{12}\right)+Y_{01}\left(Q_{01}+S_{01}+Q_{11}+S_{11}\right)+Y_{10}\left(Q_{02}+S_{02}\right)\right]+k_{a} S_{11} R_{1}\left(Q_{02}+Q_{12}+S_{02}+S_{12}\right)+}{k_{p p} Q S_{1}-k_{p p}\left(Q_{01}+S_{01}\right)+k_{t} Y_{0}+k_{d a} O N_{X}}$

Momento de ordem 2

$Y_{12}=\frac{k_{p p}\left[\begin{array}{c}Y_{00}\left(Q_{03} M\left(2 Y_{11}+Y_{10}\right)+Q_{i 1} R_{03}\left(Q_{13}\right)+2 Y_{01}\left(Q_{02}+Q_{13}+S_{03}+S_{13}\right)+\right. \\ Y_{02}\left(Q_{01}+S_{01}+Q_{11}+S_{11}\right)+Y_{10}\left(Q_{03}+S_{03}\right)+2 Y_{11}\left(Q_{02}+S_{02}\right)\end{array}\right]+k_{a} S_{12}}{k_{p p} Q S_{1}-k_{p p}\left(Q_{01}+S_{01}\right)+k_{t} Y_{0}+k_{d a} O N_{X}}$

Geração i (i $\geq 2$ )

Momento de ordem zero

$Y_{j 0}=\frac{k_{i p} R_{0}\left(Q_{j 1}+S_{j 1}\right)+k_{p p}\left[Y_{j-1,0}\left(Q_{j-1,1}+S_{j-1,1}\right)+\left(Q_{j 1}+S_{j 1}\right) \sum_{i=0}^{j-1} Y_{i 0}\right]+k_{a} S_{j 0}}{k_{p p} Q S_{1}-k_{p p} \sum_{i=0}^{j-1}\left(Q_{i 1}+S_{i 1}\right)+k_{t} Y_{0}+k_{d a} O N_{X}}$ 
Momento de ordem 1

$Y_{j 1}=\frac{k_{p p}\left[\begin{array}{c}k_{p} M Y_{j 0}+k_{i p} R_{0}\left(Q_{j 2}+S_{j 2}\right)+ \\ \left.Y_{j-1,0}\left(Q_{j-1,2}+S_{j-1,2}\right)+Y_{j-1,1}\left(Q_{j-1,1}+S_{j-1,1}\right)+Y_{j 0} \sum_{i=0}^{j-1}\left(Q_{i 2}+S_{i 2}\right)+\right]+k_{a} S_{j 1} \\ \left(Q_{j 2}+S_{j 2}\right) \sum_{i=0}^{j-1}\left(Y_{i 0}\right)+\left(Q_{j 1}+S_{j 1}\right) \sum_{i=0}^{j-1}\left(Y_{i 1}\right)\end{array}\right.}{k_{p p} Q S_{1}-k_{p p} \sum_{i=0}^{j-1}\left(Q_{i 1}+S_{i 1}\right)+k_{t} Y_{0}+k_{d a} O N_{X}}$

Momento de ordem 2

$Y_{j 2}=\frac{k_{p p}\left[\begin{array}{c}k_{p} M\left(2 Y_{j 1}+Y_{j 0}\right)+k_{i p} R_{0}\left(Q_{j 3}+S_{j 3}\right)+ \\ Y_{j-1,0}\left(Q_{j-1,3}+S_{j-1,3}\right)+2 Y_{j-1,1}\left(Q_{j-1,2}+S_{j-1,2}\right)+Y_{j-1,2}\left(Q_{j-1,1}+S_{j-1,1}\right)+ \\ Y_{j 0} \sum_{i=0}^{j-1}\left(Q_{i 3}+S_{i 3}\right)+2 Y_{j 1} \sum_{i=0}^{j-1}\left(Q_{i 2}+S_{i 2}\right)+\left(Q_{j 3}+S_{j 3}\right) \sum_{i=0}^{j-1}\left(Y_{i 0}\right)+ \\ 2\left(Q_{j 2}+S_{j 2}\right) \sum_{i=0}^{j-1}\left(Y_{i 1}\right)+\left(Q_{j 1}+S_{j 1}\right) \sum_{i=0}^{j-1}\left(Y_{i 2}\right)\end{array}\right]+k_{a} S_{j 2}}{k_{p p} Q S_{1}-k_{p p} \sum_{i=0}^{j-1}\left(Q_{i 1}+S_{i 1}\right)+k_{t} Y_{0}+k_{d a} O N_{X}}$

Balanço de momentos para polímeros mortos

\section{Geração zero}

Momento de ordem zero

$\frac{d Q_{00}}{d t}=-k_{i p} R_{0} Q_{01}-k_{p p} Y_{0} Q_{01}+\frac{1}{2} k_{t} Y_{00}{ }^{2}$

Momento de ordem 1

$\frac{d Q_{01}}{d t}=-k_{i p} R_{0} Q_{02}-k_{p p} Y_{0} Q_{02}+k_{t} Y_{00} Y_{01}$

Momento de ordem 2

$\frac{d Q_{02}}{d t}=-k_{i p} R_{0} Q_{03}-k_{p p} Y_{0} Q_{03}+k_{t}\left(Y_{00} Y_{02}+Y_{01}{ }^{2}\right)$ 


\section{Geração 1}

Momento de ordem zero

$\frac{d Q_{10}}{d t}=-k_{i p} R_{0} Q_{11}-k_{p p} Y_{0} Q_{11}+k_{t} Y_{00} Y_{10}$

Momento de ordem 1

$\frac{d Q_{11}}{d t}=-k_{i p} R_{0} Q_{12}-k_{p p} Y_{0} Q_{12}+k_{t}\left(Y_{00} Y_{11}+Y_{10} Y_{01}\right)$

Momento de ordem 2

$\frac{d Q_{12}}{d t}=-k_{i p} R_{0} Q_{13}-k_{p p} Y_{0} Q_{13}+k_{t}\left(Y_{02} Y_{10}+2 Y_{01} Y_{11}+Y_{00} Y_{12}\right)$

Geração i (i $\geq 2)$

Momento de ordem zero

$\frac{d Q_{j 0}}{d t}=-k_{i p} R_{0} Q_{j 1}-k_{p p} Y_{0} Q_{j 1}+k_{t}\left(\frac{1}{2} Y_{j-1,0}^{2}+Y_{j 0} \sum_{i=0}^{j-1} Y_{i 0}\right)$

Momento de ordem 1

$\frac{d Q_{j 1}}{d t}=-k_{i p} R_{0} Q_{j 2}-k_{p p} Y_{0} Q_{j 2}+k_{t}\left(Y_{j-1,1} Y_{j-1,0}+Y_{j 1} \sum_{i=0}^{j-1} Y_{i 0}+Y_{j 0} \sum_{i=0}^{j-1} Y_{i 1}\right)$

Momento de ordem 2

$\frac{d Q_{j 2}}{d t}=-k_{i p} R_{0} Q_{j 3}-k_{p p} Y_{0} Q_{j 3}+k_{t}\left(\begin{array}{c}Y_{j-1,2} Y_{j-1,0}+Y_{j-1,1}{ }^{2}+0,5 Y_{j 0} \sum_{i=0}^{j-1} Y_{i 2}+ \\ 2 Y_{j 1} \sum_{i=0}^{j-1} Y_{i 1}+0,5 Y_{j 2} \sum_{i=0}^{j-1} Y_{i 0}\end{array}\right)$ 
Balanço de momentos para polímeros dormentes

\section{Geração zero}

Momento de ordem zero

$\frac{d S_{00}}{d t}=-k_{i p} R_{0} S_{01}-k_{p p} Y_{0} S_{01}+k_{d a} O N_{X} Y_{00}-k_{a} S_{00}$

Momento de ordem 1

$\frac{d S_{01}}{d t}=-k_{i p} R_{0} S_{02}-k_{p p} Y_{0} S_{02}+k_{d a} O N_{X} Y_{01}-k_{a} S_{01}$

Momento de ordem 2

$\frac{d S_{02}}{d t}=-k_{i p} R_{0} S_{03}-k_{p p} Y_{0} S_{03}+k_{d a} O N_{X} Y_{02}-k_{a} S_{02}$

\section{Geração 1}

Momento de ordem zero

$\frac{d S_{10}}{d t}=-k_{i p} R_{0} S_{11}-k_{p p} Y_{0} S_{11}+k_{d a} O N_{X} Y_{10}-k_{a} S_{10}$

Momento de ordem 1

$\frac{d S_{11}}{d t}=-k_{i p} R_{0} S_{12}-k_{p p} Y_{0} S_{12}+k_{d a} O N_{X} Y_{11}-k_{a} S_{11}$

Momento de ordem 2

$\frac{d S_{12}}{d t}=-k_{i p} R_{0} S_{13}-k_{p p} Y_{0} S_{13}+k_{d a} O N_{X} Y_{12}-k_{a} S_{12}$ 


\section{Geração i (i $\geq 2)$}

Momento de ordem zero

$\frac{d s_{j 0}}{d t}=-k_{i p} R_{0} S_{j 1}-k_{p p} Y_{0} S_{j 1}+k_{d a} O N_{X} Y_{j 0}-k_{a} S_{j 0}$

Momento de ordem 1

$\frac{d s_{j 1}}{d t}=-k_{i p} R_{0} S_{j 2}-k_{p p} Y_{0} S_{j 2}+k_{d a} O N_{X} Y_{j 1}-k_{a} S_{j 1}$

Momento de ordem 2

$\frac{d S_{j 2}}{d t}=-k_{i p} R_{0} S_{j 3}-k_{p p} Y_{0} S_{j 3}+k_{d a} O N_{X} Y_{j 2}-k_{a} S_{j 2}$

Para as cadeias solúveis, os símbolos referentes aos momentos recebem um índice adicional que corresponde à geração:

$Y_{j i}:$ Momento de ordem 'i' para radicais poliméricos pertencentes à geração 'j';

$\mathrm{Q}_{\mathrm{ji}}$ : Momento de ordem 'i' para polímeros mortos pertencentes à geração 'j';

$S_{\mathrm{j} i}:$ Momento de ordem 'i' para radicais dormentes pertencentes à geração 'j'.

Os momentos globais $Q_{1}$ e $S_{1}$ podem ser obtidos individualmente através de sua soma, $\mathrm{QS}_{1}$, obtida na equação (87). Para isso deve-se definir uma proporção entre as unidades monoméricas presentes em cadeias de polímero morto e radical dormente. Dentre as cadeias solúveis, observa-se uma maior concentração de cadeias lineares (geração 1) em relação às demais durante as simulações. Desta forma, usou-se a proporção obtida com a geração 1, a qual pode variar ao longo da reação:

$$
\begin{aligned}
& Q_{1}=Q S_{1}\left(\frac{Q_{01}}{Q_{01}+S_{01}}\right) \\
& S_{1}=Q S_{1}\left(\frac{S_{01}}{Q_{01}+S_{01}}\right)
\end{aligned}
$$


Verifica-se que há um problema de fechamento no sistema de equações (88114), ou seja, o balanço para cada momento depende sempre do momento seguinte. Para tornar possível a solução deste sistema, é proposta uma relação de fechamento baseada em conceitos de probabilidade, conforme descrito por Saidel e Katz (1968). Aplicando-se esta relação para cada geração “i”, obtêm-se as equações a seguir.

$$
\begin{aligned}
Q_{i 3}=2 \frac{Q_{i 2}{ }^{2}}{Q_{i 1}}+\frac{Q_{i 2} Q_{i 1}}{Q_{i 0}} & (0 \leq \mathrm{i} \leq \mathrm{n}) \\
S_{i 3}=2 \frac{S_{i 2}{ }^{2}}{S_{i 1}}+\frac{S_{i 2} S_{i 1}}{S_{i 0}} & (0 \leq \mathrm{i} \leq \mathrm{n})
\end{aligned}
$$

O modelo consiste em um sistema de equações diferenciais e algébricas, no qual, conhecendo-se as concentrações iniciais de iniciador, monômeros e radical nitróxido, é possível simular o processo em estudo. Para esta tarefa, foram utilizadas 4 gerações $(n=4)$ ao se aplicar o método do fracionamento numérico.

Uma vez solucionado o sistema de equações, pode-se obter perfis das variáveis do processo de polimerização, como massas moleculares médias, fração de gel e conversão de monômero. As equações a seguir mostram como foram calculadas estas variáveis.

Massa molecular média mássica $\left(M_{w}\right)$

$$
M_{w}=\frac{\left(U_{1} 104.15+\left(U_{2}+U_{3}\right) 130.19\right)}{\left(U_{1}+U_{2}+U_{3}\right)} \frac{\sum_{i=0}^{n}\left(Q_{i 2}+S_{i 2}\right)}{\sum_{i=0}^{n}\left(Q_{i 1}+S_{i 1}\right)}
$$

Esta é a massa molecular média das cadeias solúveis. $U_{1}, U_{2}$ e $U_{3}$ são as concentrações molares de unidades monoméricas provenientes dos monômeros $M_{1}$, $M_{2}$ e $M_{3}$ respectivamente. Partindo-se da hipótese de que a variação de volume do meio reacional não afeta significativamente os resultados das simulações, pode-se escrever:

$$
\begin{aligned}
U_{1} & =M_{1,0}-M_{1} \\
U_{2} & =M_{2,0}-M_{2} \\
U_{3} & =M_{3,0}-M_{3}
\end{aligned}
$$


Fração de gel

$W_{g}=\frac{Q S_{1}-\sum_{i=0}^{n}\left(Q_{i 1}+S_{i 1}\right)}{Q S_{1}}$

Conversão de monômero

$X=\frac{U_{1}+U_{2}+U_{3}}{M_{1,0}+M_{2,0}+M_{3,0}}$

em que $M_{i, 0}$ representa a concentração do monômero $M_{i}$ no início da reação (alimentação).

3.1.2.6. Método dos caminhos

A reação de ciclização apresentada na Tabela 1 na forma de equação química $\left(R_{r, i j, s} \rightarrow R_{r, j}\right)$, pode ser exemplificada conforme mostrado na Figura 23.
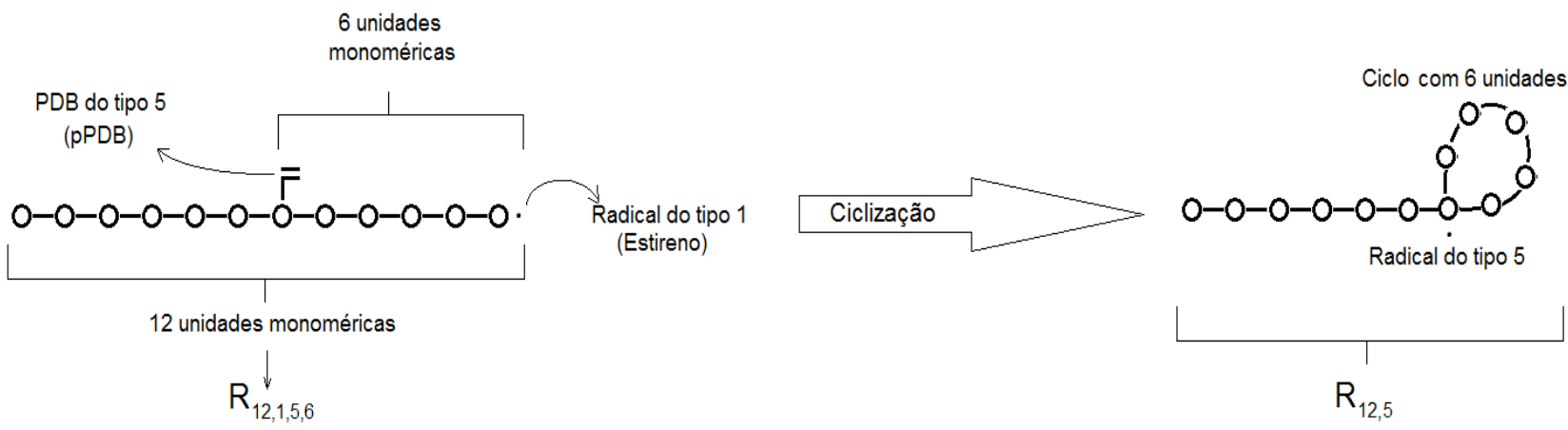

Figura 23 - Representação esquemática da reação de ciclização.

No presente trabalho foi introduzido o conceito de "caminho", que consiste em um segmento de cadeia polimérica que conecta dois grupos poliméricos. Para o sistema NMRP, foram considerados 3 tipos de grupos poliméricos: Centro radicalar ativo (1), dupla ligação pendente (2) e centro radicalar dormente (3). Para se 
adicionar as reações de ciclização ao sistema NMRP de estireno-divinilbenzeno, foram necessários dois tipos de caminhos, os quais estão ilustrados na Figura 24.
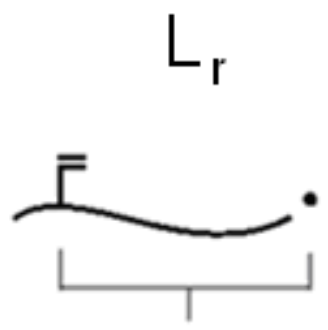

Caminho conectando centro radicalar ativo a $\mathrm{PDB}$
$D L_{r}$

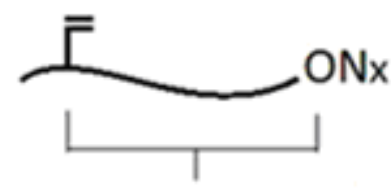

Caminho conectando centro radicalar dormente a $\mathrm{PDB}$

Figura 24 - Tipos de caminhos considerados no Modelo B.

Nesta abordagem, o índice ' $r$ ' representa o número de unidades monoméricas contidas no caminho (entre os dois grupos), portanto:

$L_{r}$ : Caminho ativo contendo ' $r$ ' unidades monoméricas (mol/L);

$D_{\mathrm{r}}$ : Caminho dormente contendo ' $r$ ' unidades monoméricas (mol/L).

Desta forma, uma molécula de polímero pode possuir caminhos sobrepostos, conforme mostrado na Figura 25.

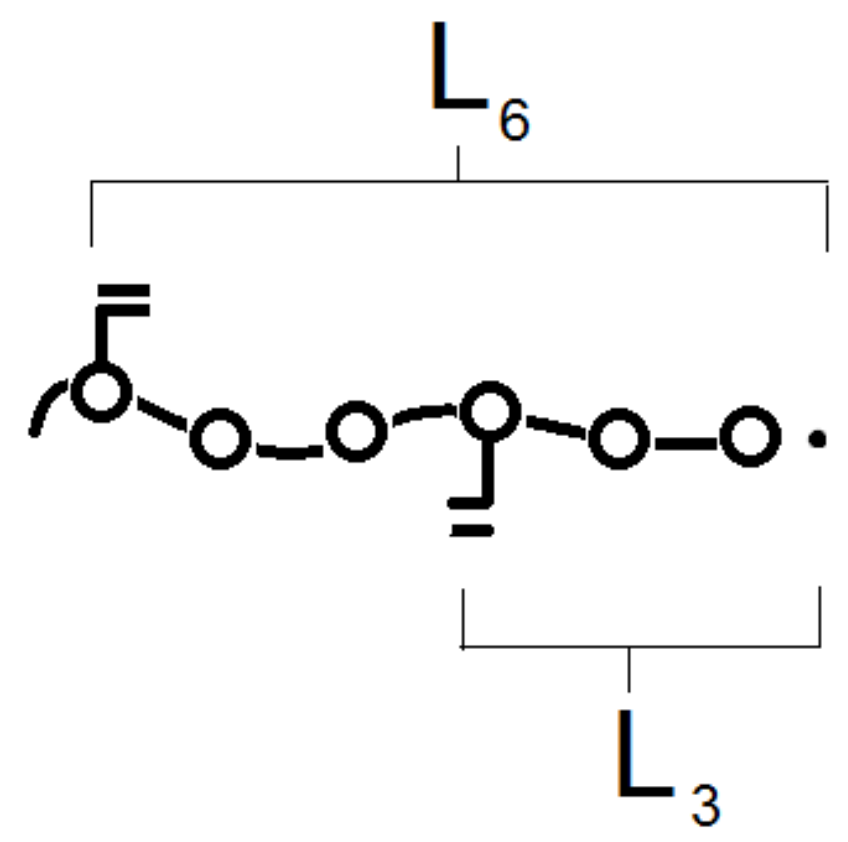

Figura 25 - Diferentes caminhos compartilhando o mesmo centro radicalar. 
O método dos caminhos leva em conta as seguintes hipóteses:

- O caminho precisa ter no mínimo 3 unidades monoméricas para que seja consumido por ciclização;

- Cada cadeia primária possui somente um centro radicalar;

- Somente cadeias primárias sofrem ciclização;

- A formação de novos caminhos devido à ciclização não é contabilizada.

A maioria das ciclizações primárias, supostamente ocorrem no início da copolimerização, uma vez que as cadeias estão afastadas umas das outras. A concentração de moléculas solúveis de polímero, contendo dois centros radicalares é muito baixa em comparação às cadeias com um único centro radicalar. As hipóteses utilizadas, indicam que o método se encontra mais próximo de representar as ciclizações no período pré-gelificação em comparação com o período pósgelificação.

$L_{r}$ e $D L_{r}$ representam uma simbologia simplificada, na qual, não há a identificação do tipo de centro radicalar e PDB que constituem o caminho. Porém, a distinção é necessária, pois, além de variar com o número de unidades monoméricas, a taxa de reação de ciclização varia também com os tipos de radical e de dupla ligação pendente. A Figura 26 apresenta os diferentes caminhos passíveis de ciclização e as respectivas constantes cinéticas para esta reação.

Neste método, foi ajustado o valor da constante cinética de ciclização de um caminho contendo 3 unidades monoméricas, as quais conectam um centro radicalar de estireno à uma mPDB $\left(\mathrm{k}_{\mathrm{P}} \mathrm{C}_{14,3}\right)$. As demais constantes de velocidade apresentadas na Figura 26 são obtidas seguindo-se a mesma proporção entre constantes cinéticas de propagação de PDBs, conforme mostrado nas equações (125) e (126).

$$
\begin{array}{ll}
k_{p i 5,3}^{C}=\frac{k_{p i 5}}{k_{p i 4}} k_{p i 4,3}^{C} & (1 \leq i \leq 5) \\
k_{p i 4,3}^{C}=\frac{k_{p i 4}}{k_{p 14}} k_{p 14,3}^{C} & (2 \leq i \leq 5)
\end{array}
$$



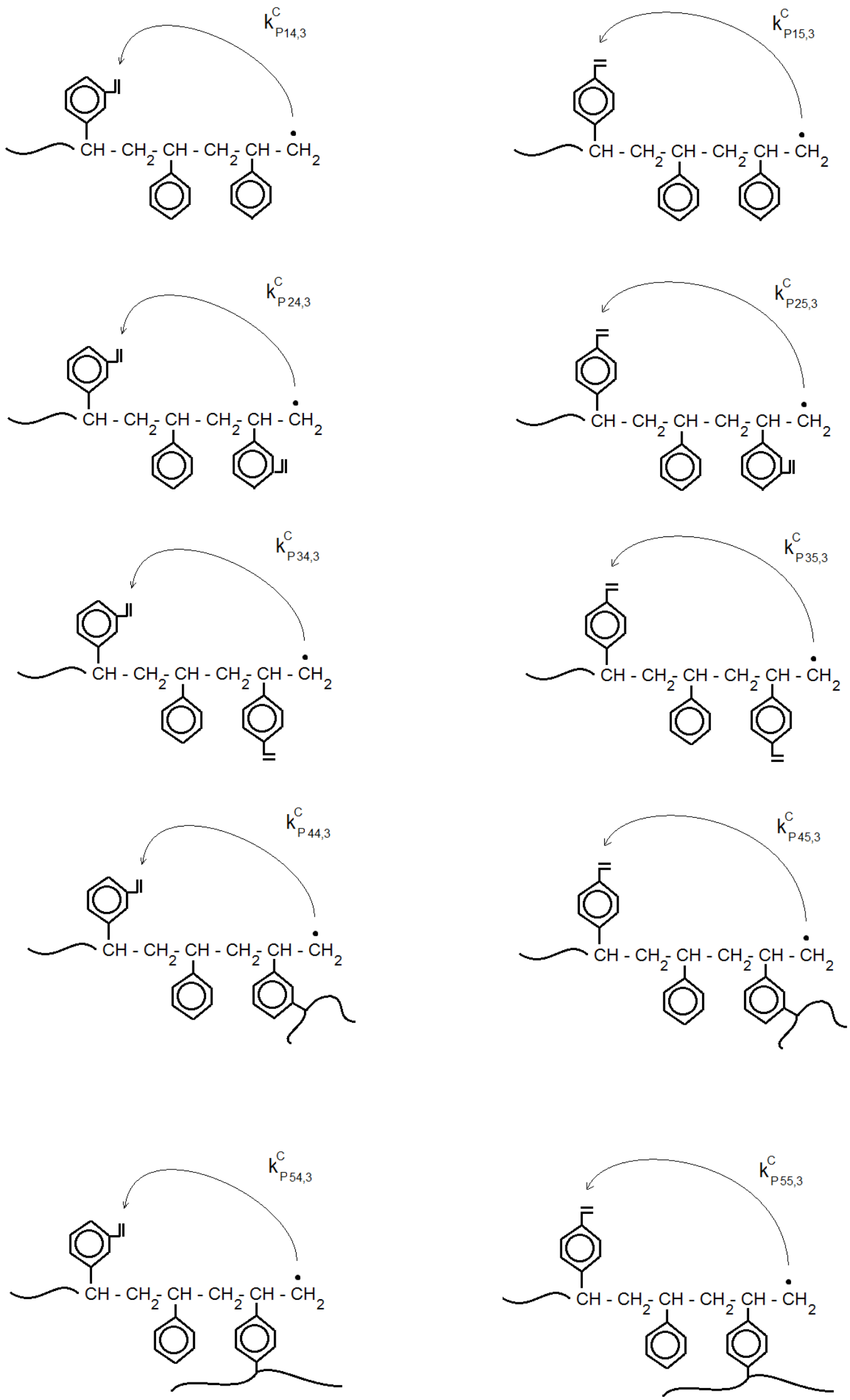

Figura 26 - Reações de ciclização em caminhos com 3 unidades. 
A variação da reatividade em função do tamanho do caminho foi determinada com base na equação de Rolfes e Stepto (1990). Esta equação foi desenvolvida para reações de policondensação e foi adaptada para o presente sistema conforme equacionado em (127).

$k_{p i j, r}^{C}=\left(\frac{2}{r-1}\right)^{1,5} k_{p i j, 3}^{C}$

A taxa de consumo do caminho ativo $L_{r}$, por ciclização, depende do tipo de radical e do tipo de PDB contidos no caminho. As taxas de ciclização para caminhos contendo radical do tipo 'i' conectado à mPDB $\left(R C_{i m, r}\right)$ e radical do tipo 'i' conectado à pPDB $\left(R C_{i p, r}\right)$ estão descritas nas equações (128) e (129), respectivamente.

$$
\begin{array}{ll}
\mathrm{RC}_{\mathrm{im}, \mathrm{r}}=\mathrm{k}_{\mathrm{pi}, \mathrm{r}}^{\mathrm{C}} \mathrm{f}_{\mathrm{mPDB}} \mathrm{f}_{\mathrm{Ri}} \mathrm{L}_{\mathrm{r}} & (1 \leq \mathrm{i} \leq 5) \\
\mathrm{RC}_{\mathrm{ip}, \mathrm{r}}=\mathrm{k}_{\mathrm{pi}, \mathrm{r}, \mathrm{r}}^{\mathrm{C}} \mathrm{f}_{\mathrm{pDBB}} \mathrm{f}_{\mathrm{Ri}} \mathrm{L}_{\mathrm{r}} & (1 \leq \mathrm{i} \leq 5)
\end{array}
$$

Desta forma, encontram-se as taxas totais de ciclização para caminhos contendo mPDB $\left(R C_{m}\right)$ e pPDB $\left(R C_{p}\right)$. Estas taxas correspondem à taxa de consumo de PDBs por ciclização:

$$
\begin{aligned}
& \mathrm{RC}_{\mathrm{m}}=\sum_{\mathrm{r}=1}^{\mathrm{r}_{\max }} \sum_{\mathrm{i}=1}^{5} \mathrm{RC}_{\mathrm{im}, \mathrm{r}} \\
& \mathrm{RC}_{\mathrm{p}}=\sum_{\mathrm{r}=1}^{\mathrm{r}_{\max }} \sum_{\mathrm{i}=1}^{5} \mathrm{RC}_{\mathrm{ip}, \mathrm{r}}
\end{aligned}
$$

sendo que, para qualquer radical 'i' conectado à qualquer PDB 'j': $\mathrm{k}_{\mathrm{pij}, 1}^{\mathrm{C}}=\mathrm{k}_{\mathrm{pij}, 2}^{\mathrm{C}}=0$ (Hipótese: ciclização ocorre somente em caminhos com 3 ou mais unidades monoméricas). ' $r_{\max }$ ' é o número máximo de unidades monoméricas, considerado para os caminhos ciclizáveis. Para o presente modelo, foi considerado $r_{\max }=100$. Detalhes sobre esta hipótese são apresentados no capítulo 4.

Nas equações (128) e (129), $L_{r}$ representa a concentração de todos os caminhos ativos presentes no sistema reacional. Estes caminhos, além de poderem ciclizar, também podem ser desativados, podem crescer (aumentar o número de unidades monoméricas), podem ser terminados ou iniciados por outro centro radicalar, etc. As reações envolvendo caminhos, na verdade, são as mesmas 
reações do processo de copolimerização, porém, vistas de uma forma diferente. Em vez de se utilizar, momentos para representar as cadeias poliméricas, usam-se os caminhos. Para contabilizar as reações de ciclização, é necessário estudar o surgimento e a evolução dos caminhos ao longo do processo. Este estudo resultou nas equações apresentadas na Tabela 4.

Tabela 4 - Reações envolvendo caminhos

\begin{tabular}{|c|c|c|}
\hline Nome da reação & Equação química & Constante cinética \\
\hline Iniciação de mDVB & $R_{0}+M_{2} \rightarrow L_{1}$ & $\mathrm{k}_{12}$ \\
\hline Iniciação de pDVB & $R_{0}+M_{3} \rightarrow L_{1}$ & $\mathrm{k}_{13}$ \\
\hline Geração do caminho $L_{1}$ por propagação em & $R_{r}+M_{2} \rightarrow L_{1}$ & $\mathrm{k}_{\mathrm{pj} 2}$ \\
\hline divinilbenzeno & $\mathrm{R}_{\mathrm{r}}+\mathrm{M}_{3} \rightarrow \mathrm{L}_{1}$ & $k_{p j 3}$ \\
\hline Crescimento do caminho & $L_{r}+M_{i} \rightarrow L_{r+1}$ & $\mathrm{k}_{\mathrm{pji}}$ \\
\hline Iniciação de PDB de caminho ativo & $L_{r}+R_{0} \rightarrow F$ & $\mathrm{k}_{14}$ e $\mathrm{k}_{15}$ \\
\hline Propagação de PDB de caminho ativo & $L_{r}+R_{r} \rightarrow F$ & $k_{p j 4}$ e $k_{p j 5}$ \\
\hline Iniciação de PDB de caminho dormente & $\mathrm{DL}_{r}+\mathrm{R}_{\mathrm{o}} \rightarrow \mathrm{F}$ & $\mathrm{k}_{14}$ e $\mathrm{k}_{15}$ \\
\hline Propagação de PDB de caminho dormente & $\mathrm{DL}_{\mathrm{r}}+\mathrm{R}_{\mathrm{r}} \rightarrow \mathrm{F}$ & $k_{p j 4}$ e $k_{p j 5}$ \\
\hline Desativação de caminhos & $L_{r}+O N_{X} \rightarrow D L_{r}$ & $\mathrm{k}_{\mathrm{da}}$ \\
\hline Ativação de caminhos & $\mathrm{DL}_{r} \rightarrow \mathrm{L}_{r}+\mathrm{ON} \mathrm{N}_{\mathrm{X}}$ & $\mathrm{k}_{\mathrm{a}}$ \\
\hline Terminação de caminhos ativos & $R_{j}+L_{r} \rightarrow F$ & $\mathrm{k}_{\mathrm{t}}$ \\
\hline Ciclização & $L_{r} \rightarrow C y_{r}$ & $\mathrm{k}_{\mathrm{pij}, \mathrm{r}}^{\mathrm{C}}$ \\
\hline
\end{tabular}

F: Segmento de cadeia; $\mathrm{Cy}_{\mathrm{r}}$ : Segmento cíclico de polímero contendo ' $r$ ' unidades monoméricas.

A seguir, estão descritos os balanços materiais para os caminhos dormentes e ativos (eqs 132-134), que levam em conta a hipótese do regime pseudoestacionário.

Balanço material para caminhos dormentes contendo ' $r$ ' unidades monoméricas

$$
\frac{d D L_{r}}{d t}=k_{d a} L_{r} O N_{X}-D L_{r}\left[\begin{array}{c}
k_{a}+f_{m P D B}\left(k_{i 4} R_{0}+Y_{0}\left(\begin{array}{c}
k_{p 14} f_{R 1}+k_{p 24} f_{R 2}+ \\
k_{p 34} f_{R 3}+k_{p 44} f_{R 4}+k_{p 54} f_{R 5}
\end{array}\right)\right)+ \\
f_{p P D B}\left(k_{i 5} R_{0}+Y_{0}\left(\begin{array}{c}
k_{p 15} f_{R 1}+k_{p 25} f_{R 2}+ \\
k_{p 35} f_{R 3}+k_{p 45} f_{R 4}+k_{p 55} f_{R 5}
\end{array}\right)\right)
\end{array}\right]
$$


Balanço material para caminhos ativos contendo 1 unidade monomérica

$$
L_{1}=\frac{\left[\begin{array}{c}
M_{2}\left(k_{i 2} R_{0}+Y_{0}\left(k_{p 12} f_{R 1}+k_{p 22} f_{R 2}+k_{p 32} f_{R 3}+k_{p 42} f_{R 4}+k_{p 52} f_{R 5}\right)\right)+ \\
M_{3}\left(k_{i 3} R_{0}+Y_{0}\left(k_{p 13} f_{R 1}+k_{p 23} f_{R 2}+k_{p 33} f_{R 3}+k_{p 43} f_{R 4}+k_{p 53} f_{R 5}\right)\right)+k_{a} D L_{1}
\end{array}\right]}{\left[\begin{array}{c}
M_{1}\left(k_{p 11} f_{R 1}+k_{p 21} f_{R 2}+k_{p 31} f_{R 3}+k_{p 41} f_{R 4}+k_{p 51} f_{R 5}\right)+ \\
M_{2}\left(k_{p 12} f_{R 1}+k_{p 22} f_{R 2}+k_{p 32} f_{R 3}+k_{p 42} f_{R 4}+k_{p 52} f_{R 5}\right)+ \\
M_{3}\left(k_{p 13} f_{R 1}+k_{p 23} f_{R 2}+k_{p 33} f_{R 3}+k_{p 43} f_{R 4}+k_{p 53} f_{R 5}\right)+ \\
m P D B\left(k_{p 14} f_{R 1}+k_{p 24} f_{R 2}+k_{p 34} f_{R 3}+k_{p 44} f_{R 4}+k_{p 54} f_{R 5}\right)+ \\
p P D B\left(k_{p 15} f_{R 1}+k_{p 25} f_{R 2}+k_{p 35} f_{R 3}+k_{p 45} f_{R 4}+k_{p 55} f_{R 5}\right)+ \\
f_{m P D B}\left(k_{i 4} R_{0}+Y_{0}\left(k_{p 14} f_{R 1}+k_{p 24} f_{R 2}+k_{p 34} f_{R 3}+k_{p 44} f_{R 4}+k_{p 54} f_{R 5}\right)\right)+ \\
f_{p P D B}\left(k_{i 5} R_{0}+Y_{0}\left(k_{p 15} f_{R 1}+k_{p 25} f_{R 2}+k_{p 35} f_{R 3}+k_{p 45} f_{R 4}+k_{p 55} f_{R 5}\right)\right)+ \\
k_{d a} O N_{X}+k_{t} Y_{0}
\end{array}\right]}
$$

Balanço material para caminhos ativos contendo ' $r$ ' unidades monoméricas

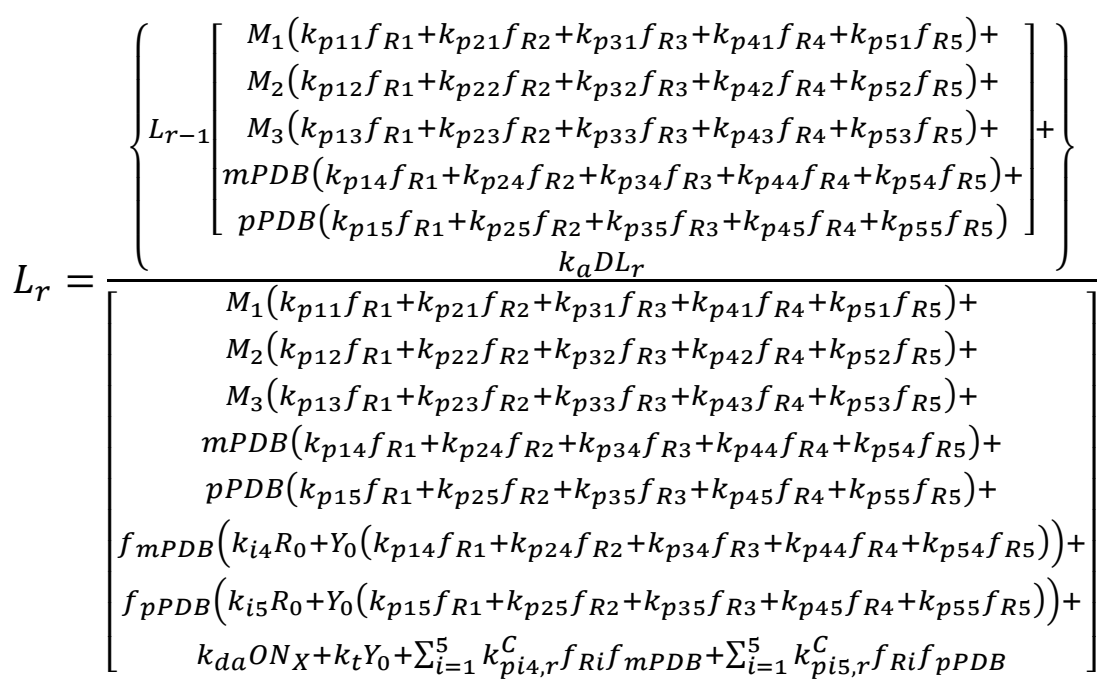

Desta forma, obtêm-se 100 equações diferenciais e 100 equações algébricas $\left(r_{\max }=100\right)$, as quais permitem considerar reações de ciclização ocorrendo em caminhos contendo de 3 à 100 unidades monoméricas. A determinação do valor de $r_{\text {máx }}$ é mostrada mais a frente no item 4.2.2. 


\subsubsection{Modelo C}

No Modelo C, utilizou-se a mesma metodologia do Modelo B, com exceção de uma hipótese adicional que foi introduzida no Modelo $\mathrm{C}$. Esta hipótese consiste em considerar uma variação do parâmetro cinético da reação de ligação cruzada em função do tamanho e/ou grau de reticulação das cadeias poliméricas que estão reagindo. Dusek e Spevacek (1980) relatam que as duplas ligações pendentes são imobilizadas (inacessíveis) nos núcleos das moléculas de polímero à medida que estas aumentam seu grau de reticulação ao longo de copolimerizações entre monômeros vinílicos e divinílicos. Com o Modelo $\mathrm{C}$, pretende-se quantificar o efeito gerado por este fenômeno, o qual consiste numa redução da taxa de ligações cruzadas devido à imobilização de duplas ligações pendentes. Esta redução foi quantificada através da variação da constante pseudo-cinética de ligações cruzadas, $\mathrm{k}_{\mathrm{PP}}$, em função do tamanho da molécula de polímero. Considerando-se que a estrutura de uma molécula de polímero intumescida se aproxima de uma esfera, pode-se ilustrar a imobilização de PDBs ao longo da reação conforme esquematizado na Figura 27.

\section{Crescimento da molécula}

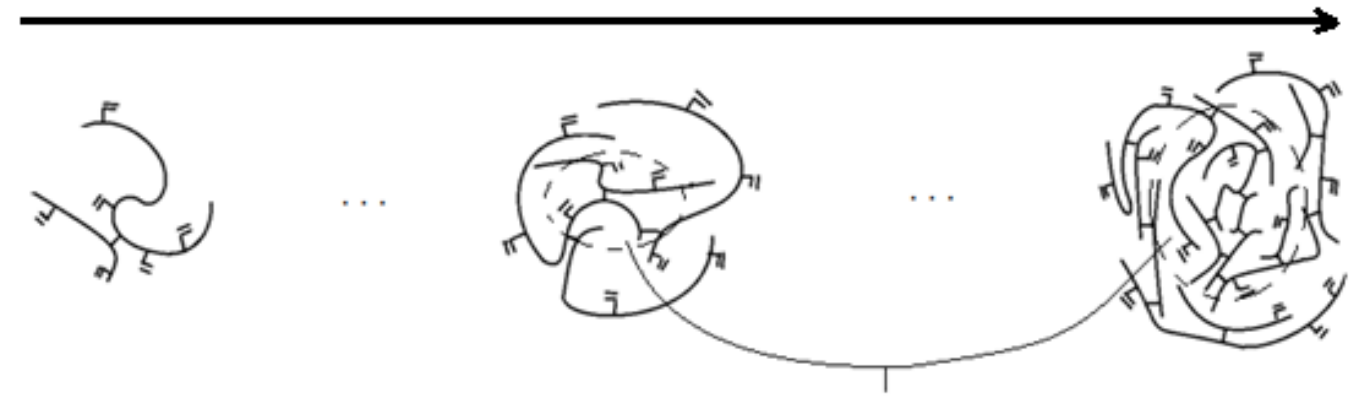

PDBs inacessíveis

Figura 27 - Imobilização de PDBs em função do tamanho da molécula.

Supõe-se que a redução da reatividade das ligações cruzadas não está diretamente associada ao aumento de tamanho da molécula, mas sim, indiretamente. $O$ aumento de tamanho em si pode não ser um fator que prejudica o acesso de radicais às PDBs, visto que a reação é processada em presença de solvente e as cadeias intumescem (gerando um certo espaço entre os segmentos de 
cadeia). Porém, quando a molécula cresce em função do ataque de um radical polimérico a uma dupla ligação pendente, inevitavelmente forma-se uma nova ligação cruzada que passa a fazer parte da rede polimérica. Entende-se que a disposição destas ligações cruzadas é o principal fator que causa o aprisionamento de PDBs. Portanto, de uma forma indireta, o aprisionamento de PDBs é proporcional ao crescimento da molécula de polímero, uma vez que este crescimento "caminha junto com o número de ligações cruzadas". Desta forma, pode-se propor uma redução de reatividade em função do tamanho da molécula conforme exposto na Figura 28.

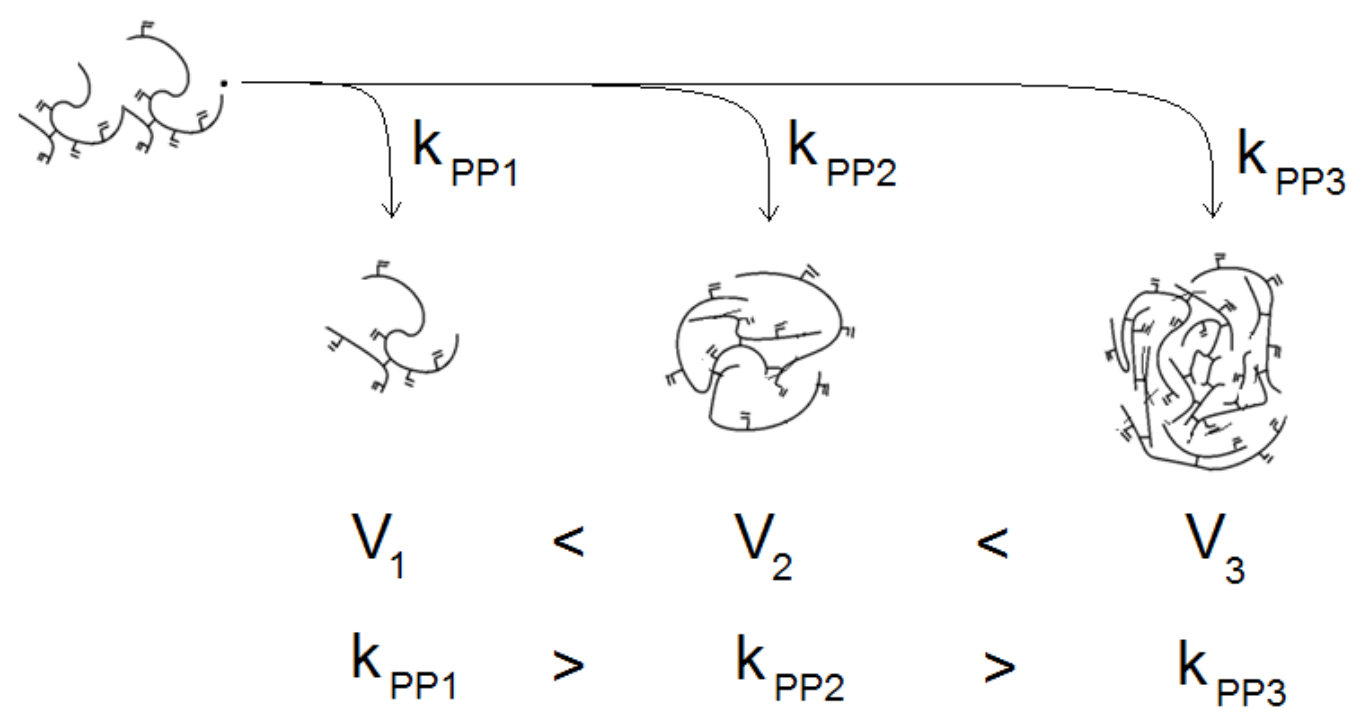

Figura 28 - Avaliação qualitativa da redução da reatividade das ligações cruzadas em função do tamanho da molécula de polímero.

A redução de $k_{P P}$ depende da interpenetração de cadeias de polímero. Moléculas pequenas, supostamente possuem maior facilidade de acesso aos núcleos das moléculas relativamente às moléculas grandes e com maior número de ligações cruzadas. Nesta análise, considerou-se que o radical primário é pequeno o bastante para acessar qualquer PDB, portanto, sua reatividade com PDBs, $\mathrm{k}_{\mathbb{P}}$, foi mantida inalterada no Modelo C. Já a interpenetração entre duas cadeias de polímero deve ser analisada levando-se em conta os volumes ocupados por estas cadeias. À princípio, fazendo-se uso da metodologia até aqui descrita, não é possível determinar o volume individual de cada molécula de polímero. Por outro lado, Pode-se determinar o volume médio das moléculas em cada geração (do fracionamento numérico) em função das massas moleculares médias. Desta forma, 
a geração zero possuirá um volume médio de cadeia $V_{0}$, a geração 1 possuirá um volume médio $\mathrm{V}_{1}$ e assim por diante. Estes volumes levam em conta as moléculas intumescidas na presença do solvente e das espécies envolvidas na reação, ou seja, é o volume contido no invólucro tracejado representado na Figura 29.

Conforme exposto anteriormente, foi considerado que a forma da molécula de polímero reticulado se aproxima de uma esfera. Com isto, o volume médio das moléculas constituintes da geração 'i' $\left(V_{i}\right)$ pode se escrito conforme a equação (135).

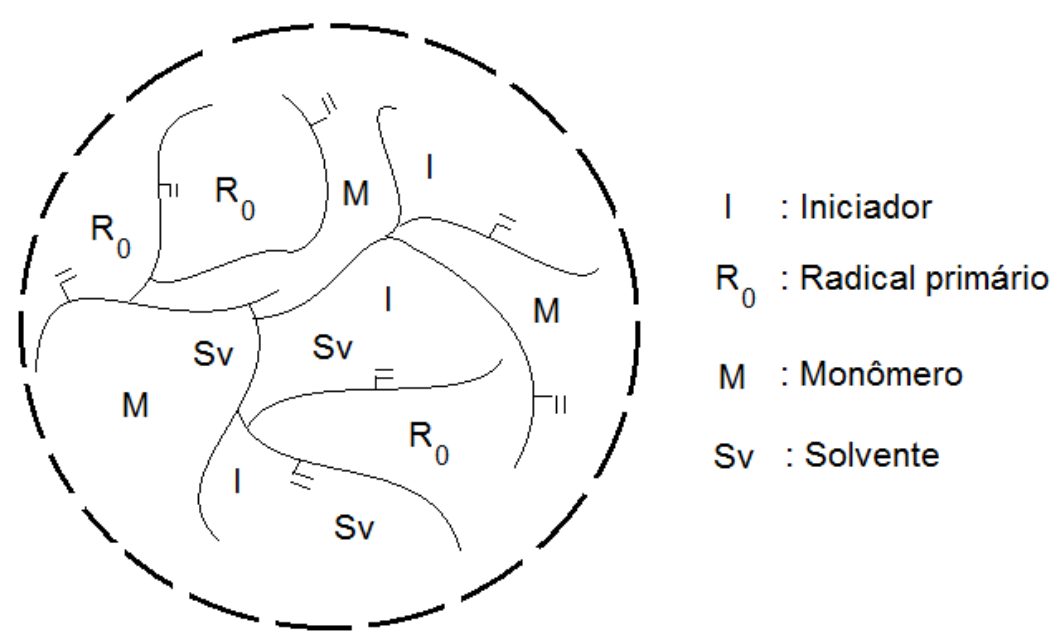

Figura 29 - Volume de uma cadeia polimérica intumescida no meio reacional.

$V_{i}=\frac{4}{3} \pi\left\langle R g_{i}\right\rangle^{3}$

sendo que $<R g_{i}>$ é o raio de giração médio entre as moléculas de polímero intumescidas da geração 'i'. Gonçalves et al. (2007, 2010) reporta uma expressão que permite calcular o raio de giração de moléculas de poliestireno. Como o presente sistema de polimerização é bem semelhante ao sistema estudado por Gonçalves et al $(2007,2010)$, utilizou-se a mesma expressão para o raio de giração, a qual está representada pela equação (136).

$\left\langle R g_{i}\right\rangle=0.0118 M_{w i}{ }^{0.6}$

sendo que

$$
M_{w i}=\frac{\left(U_{1} 104.15+\left(U_{2}+U_{3}\right) 130.19\right)}{\left(U_{1}+U_{2}+U_{3}\right)} \frac{\left(Q_{i 2}+S_{i 2}\right)}{\left(Q_{i 1}+S_{i 1}\right)}
$$


Considerando-se que a finalidade do presente estudo é relacionar diferentes volumes de moléculas, supõe-se que a relação entre volumes de moléculas lineares (poliestireno) não difere significativamente da relação entre volumes de moléculas reticuladas (estireno-divinilbenzeno). Desta forma, pode-se utilizar a equação (136) na presente abordagem, sem trazer grande prejuízo à formulação do Modelo $C$.

Com base nas condições até aqui expostas, propõe-se que a redução da constante cinética de ligações cruzadas é inversamente proporcional aos volumes das moléculas que participam desta reação. Em outras palavras, quanto maiores as moléculas de polímero, menor é a velocidade específica de reação de ligação cruzada entre elas. Sendo $k_{p p}$ a constante cinética de ligação cruzada entre moléculas pequenas, nas quais todas as PDBs estão acessíveis, pode-se propor um $\mathrm{k}_{\mathrm{PP}}$ reduzido através da seguinte proporção:

$k_{p p i, j} \propto \frac{1}{V_{i} V_{j}} k_{p p}$

sendo que $k_{\text {ppi,j }}$ é a constante de velocidade da reação de ligação cruzada entre uma molécula da geração 'i’ e uma molécula da geração ‘j'. A proporção (138) pode ser transformada em equação através da adição de uma constante de proporcionalidade. Esta constante foi denominada "fator de redução da reatividade" e está simbolizada por $f_{r r}$ na equação (139).

$k_{p p i, j}=f_{r r} \frac{k_{p p}}{V_{i} V_{j}}$

O volume médio dentre todas as cadeias solúveis pode ser obtido através da equação (137).

$V_{\text {sol }}=\frac{V_{0}\left(Q_{01}+S_{01}\right)+V_{1}\left(Q_{11}+S_{11}\right)+V_{2}\left(Q_{21}+S_{21}\right)+V_{3}\left(Q_{31}+S_{31}\right)+V_{4}\left(Q_{41}+S_{41}\right)}{\left(Q_{01}+Q_{11}+Q_{21}+Q_{31}+Q_{41}+S_{01}+S_{11}+S_{21}+S_{31}+S_{41}\right)}$

Assim, a equação (139) pode ser simplificada, considerando-se a reação entre uma molécula da geração 'i’ com uma molécula solúvel de qualquer geração. Esta simplificação resultou na equação (141). 


$$
k_{p p i, s o l}=f_{r r} \frac{k_{p p}}{V_{i} V_{s o l}} \quad(0 \leq \mathrm{i} \leq \mathrm{n})
$$

Com base no método do fracionamento numérico, verifica-se que o tamanho das cadeias de polímero aumenta à medida que se passa de uma geração para a seguinte. Quando as primeiras unidades de divinilbenzeno são incorporadas à cadeia polimérica, assume-se que todas as PDBs são acessíveis, uma vez que não há reticulação. Além disso, entende-se que cadeias muito pequenas podem penetrar em qualquer outra molécula de polímero tendo acesso a todas as PDBs. Do ponto de vista de gerações, torna-se subjetivo decidir qual seria a geração na qual o aprisionamento de PDBs passa a ser considerável. Para esta análise, foram feitas simulações preliminares de copolimerizações NMRP e, com base na concordância entre as previsões do modelo e os dados experimentais, verificou-se que a redução da reatividade das ligações cruzadas acentua-se a partir da geração 2. A Figura 30 ilustra a variação da constante cinética de ligações cruzadas com base nestes resultados preliminares.

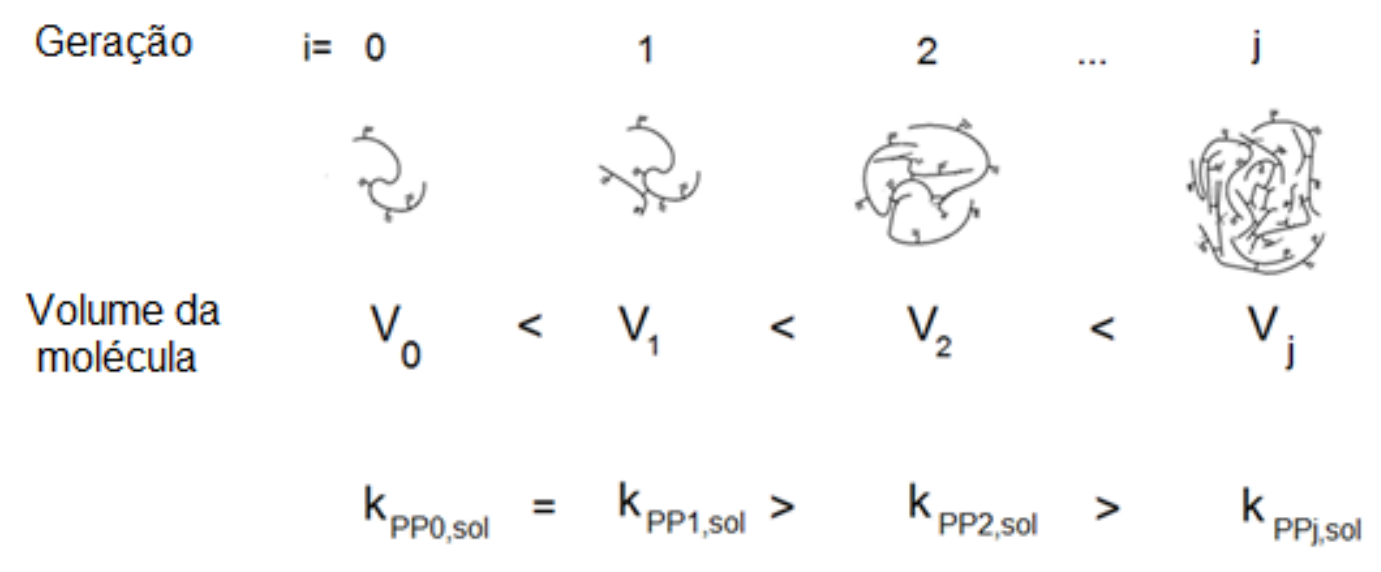

Figura 30 - Variação de $k_{\text {ppi,sol }}$ em função da geração.

Portanto, os estudos preliminares (ver APÊNDICE A) do presente trabalho indicaram que, reações de ligação cruzada envolvendo as gerações zero e 1 apresentam a mesma reatividade, ou seja, todas as duplas ligações pendentes são acessíveis. Assim sendo, pode-se dizer que a geração 1 é o limite máximo ( $\mathrm{i}=1)$ no qual $k_{\text {ppisol }}$ se mantém constante. Partindo-se deste limite, pode-se reescrever a equação (141): 
$k_{p p 1, s o l}=f_{r r} \frac{k_{p p}}{V_{1} V_{s o l}}=k_{p p}$

A equação (142) indica que $k_{p p 1, s o l}$ é igual ao $k_{p p}$ original definido no Modelo $B$, o qual considera que todas as PDBs são totalmente e igualmente acessíveis. Sendo assim, a igualdade $k_{p p 0, s o l}=k_{p p}$ também é válida com base no que foi estabelecido Figura 30. Da expressão (142), determina-se o fator de redução da reatividade $f_{r r}$ :

$f_{r r}=V_{1} V_{\text {sol }}$

Com isto, pode-se calcular as constantes cinéticas de ligações cruzadas envolvendo as gerações 2 e superiores ( $i$ > 1) utilizando-se a equação (141) juntamente com a equação (143):

$k_{p p i, s o l}=f_{r r} \frac{k_{p p}}{V_{i} V_{s o l}}=\frac{V_{1}}{V_{i}} k_{p p} \quad(2 \leq i \leq n)$

No caso da molécula de gel, não é possível determinar um volume médio. Porém, sabe-se que a molécula de gel possui maior número de ligações cruzadas quando comparada com as moléculas solúveis. Desta forma, foi definida uma redução da reatividade para reações envolvendo gel. Esta redução foi calculada com base na constante cinética determinada na equação (144). A equação (145) permite obter a constante cinética média de reação de ligação cruzada entre uma molécula da geração 'i' com qualquer molécula de polímero (solúvel ou gel).

$$
k_{p p, i}=\frac{V_{1}}{V_{i}} k_{p p}\left(1-W_{g}\right)+\frac{1}{10} \frac{V_{1}}{V_{i}} k_{p p} W_{g} \quad(2 \leq i \leq n)
$$

O fator $\frac{1}{10}$, presente na equação (145), também foi determinado através de simulações preliminares conforme mostrado no APÊNDICE A e contabiliza a redução de reatividade em função da presença de gel no sistema. Neste modelo, também foram consideradas 4 gerações $(n=4)$.

O Modelo $C$ possui o mesmo equacionamento do Modelo B, porém, são necessárias alterações nas constantes de ligação cruzada. Sendo assim, usou-se o mesmo equacionamento do Modelo $B$, substituindo-se as equações a seguir. 
Equação (94) substituída por:

$Y_{j 0}=\frac{k_{i p} R_{0}\left(Q_{j 1}+S_{j 1}\right)+k_{p p, j-1}\left[Y_{j-1,0}\left(Q_{j-1,1}+S_{j-1,1}\right)+\frac{k_{p p, j}}{k_{p p, j-1}}\left(Q_{j 1}+S_{j 1}\right) \sum_{i=0}^{j-1} Y_{i 0}\right]+k_{a} S_{j 0}}{k_{p p, j} Q S_{1}-k_{p p, j} \sum_{i=0}^{j-1}\left(Q_{i 1}+S_{i 1}\right)+k_{t} Y_{0}+k_{d a} O N_{X}}$

Equação (95) substituída por:

$Y_{j 1}=\frac{k_{p p, j-1}\left[\begin{array}{c}k_{p} M Y_{j 0}+k_{i p} R_{0}\left(Q_{j 2}+S_{j 2}\right)+ \\ Y_{j-1,0}\left(Q_{j-1,2}+S_{j-1,2}\right)+Y_{j-1,1}\left(Q_{j-1,1}+S_{j-1,1}\right)+\frac{k_{p p, j}}{k_{p p, j-1}} Y_{j 0} \sum_{i=0}^{j-1}\left(Q_{i 2}+S_{i 2}\right)+ \\ \frac{k_{p p, j}}{k_{p p, j-1}}\left(Q_{j 2}+S_{j 2}\right) \sum_{i=0}^{j-1}\left(Y_{i 0}\right)+\frac{k_{p p, j}}{k_{p p, j-1}}\left(Q_{j 1}+S_{j 1}\right) \sum_{i=0}^{j-1}\left(Y_{i 1}\right)\end{array}\right]+k_{a} S_{j 1}}{k_{p p, j} Q S_{1}-k_{p p, j} \sum_{i=0}^{j-1}\left(Q_{i 1}+S_{i 1}\right)+k_{t} Y_{0}+k_{d a} O N_{X}}$

Equação (96) substituída por:

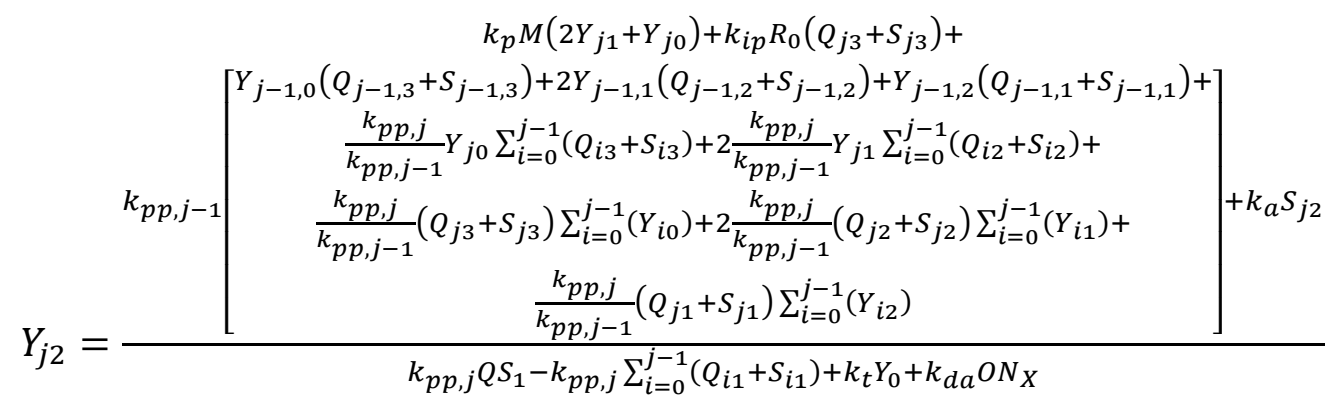

Equação (103) substituída por:

$\frac{d Q_{j 0}}{d t}=-k_{i p} R_{0} Q_{j 1}-k_{p p, j} Y_{0} Q_{j 1}+k_{t}\left(\frac{1}{2} Y_{j-1,0}{ }^{2}+Y_{j 0} \sum_{i=0}^{j-1} Y_{i 0}\right)$

Equação (104) substituída por:

$\frac{d Q_{j 1}}{d t}=-k_{i p} R_{0} Q_{j 2}-k_{p p, j} Y_{0} Q_{j 2}+k_{t}\left(Y_{j-1,1} Y_{j-1,0}+Y_{j 1} \sum_{i=0}^{j-1} Y_{i 0}+Y_{j 0} \sum_{i=0}^{j-1} Y_{i 1}\right)$

Equação (105) substituída por:

$\frac{d Q_{j 2}}{d t}=-k_{i p} R_{0} Q_{j 3}-k_{p p, j} Y_{0} Q_{j 3}+k_{t}\left(\begin{array}{c}Y_{j-1,2} Y_{j-1,0}+Y_{j-1,1}{ }^{2}+Y_{j 0} \sum_{i=0}^{j-1} Y_{i 2}+ \\ 2 Y_{j 1} \sum_{i=0}^{j-1} Y_{i 1}+Y_{j 2} \sum_{i=0}^{j-1} Y_{i 0}\end{array}\right)$ 
Equação (112) substituída por:

$\frac{d S_{j 0}}{d t}=-k_{i p} R_{0} S_{j 1}-k_{p p, j} Y_{0} S_{j 1}+k_{d a} O N_{X} Y_{j 0}-k_{a} S_{j 0}$

Equação (113) substituída por:

$\frac{d s_{j 1}}{d t}=-k_{i p} R_{0} S_{j 2}-k_{p p, j} Y_{0} S_{j 2}+k_{d a} O N_{X} Y_{j 1}-k_{a} S_{j 1}$

Equação (114) substituída por:

$\frac{d s_{j 2}}{d t}=-k_{i p} R_{0} S_{j 3}-k_{p p, j} Y_{0} S_{j 3}+k_{d a} O N_{X} Y_{j 2}-k_{a} S_{j 2}$

A correção dos termos envolvendo $k_{p p}$ para as equações (72), (73), (85), (86) e (132)-(134), não gerou diferença significativa nos resultados. Em outras palavras, para as equações supracitadas, diferentes valores de $k_{p p}$ dentro da faixa estudada ( mínimo $=k_{\mathrm{pp}, 4}$ e máximo $=k_{\mathrm{pp}}$ ), forneceram os mesmos resultados para as condições experimentais investigadas no presente trabalho.

\subsection{Parte experimental}

\subsubsection{Procedimentos}

Foram realizadas copolimerizações em solução e em suspensão. A Figura 31 apresenta um esquema genérico das instalações onde foram conduzidas as reações.

A Tabela 5 lista os compostos utilizados nas reações e na caracterização do polímero obtido. Esta tabela apresenta as propriedades do divinilbenzeno comercial, que consiste numa mistura contendo $56,2 \%$ de meta-divinilbenzeno, $24,2 \%$ de paradivinilbenzeno e $19,6 \%$ de etilvinilbenzeno. 


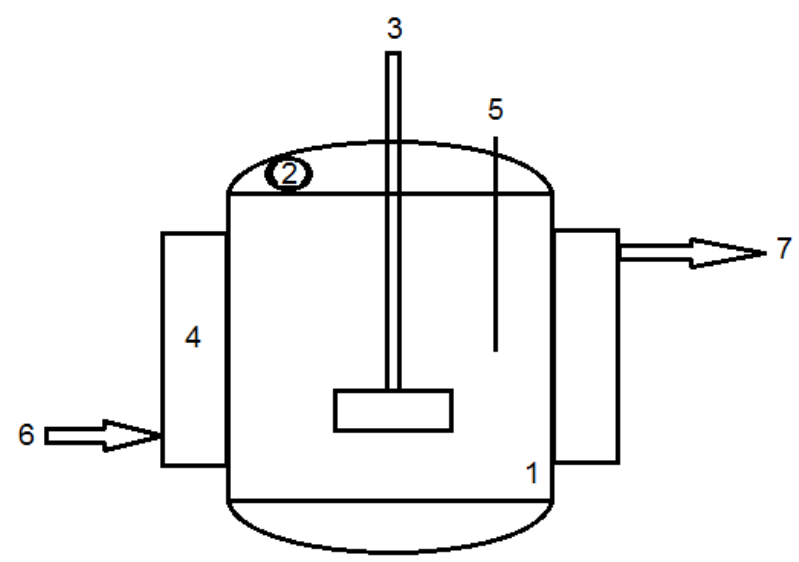
1- Reator
2- Orifício para coleta de amostra
3- Agitador mecânico
4- Camisa
5- Sensor de temperatura
6- Tubulação de entrada para o fluido da camisa
7- Tubulação de saída para o fluido da camisa

Figura 31 - Esquema do aparato experimental utilizado nos experimentos.

Tabela 5 - Propriedades dos compostos utilizados nos experimentos (continua)

\begin{tabular}{|c|c|c|c|c|c|}
\hline Composto & Descrição & $\begin{array}{l}\text { Massa } \\
\text { molar } \\
(\mathrm{g} / \mathrm{mol})\end{array}$ & $\begin{array}{c}\text { Densidade } \\
\text { relativa }\end{array}$ & $\begin{array}{c}\text { Ponto de } \\
\text { ebulição } \\
\left({ }^{\circ} \mathrm{C}\right)\end{array}$ & $\begin{array}{l}\text { Ponto de } \\
\text { fusão }\left({ }^{\circ} \mathrm{C}\right)\end{array}$ \\
\hline Estireno $^{(a)}$ & Monômero & 104,15 & 0,909 & 145,0 & $-30,6$ \\
\hline Divinilbenzeno ${ }^{(a)}$ & Monômero & 130,19 & 0,912 & 195,0 & $-66,9$ \\
\hline Tolueno ${ }^{(a)}$ & Solvente & 92,13 & 0,865 & 111,0 & $-95,0$ \\
\hline Xileno $^{(a)}$ & Solvente & 106,17 & 0,870 & 142,0 & $-30,0$ \\
\hline AIBN & Iniciador & $164,21^{(\mathrm{a})}$ & $1,100^{(a)}$ & $236.2^{(b)}$ & $103,0^{(b)}$ \\
\hline $\mathrm{BPO}$ & Iniciador & $242,20^{\text {(a) }}$ & $1,300^{(a)}$ & Decomp. & $105,0^{(\mathrm{c})}$ \\
\hline TEMPO & Mediador & $156,25^{\text {(a) }}$ & $1,000^{(e)}$ & $193,0^{(\mathrm{c})}$ & $39,0^{(c)}$ \\
\hline $\begin{array}{c}\text { Álcool } \\
\text { polivinílico } \\
{ }^{(d)}\end{array}$ & $\begin{array}{l}\text { Agente de } \\
\text { suspensão }\end{array}$ & $(44,05) n$ & $1,19-1,31$ & Decomp. & 200,0 \\
\hline Metanol (a) & $\begin{array}{c}\text { Agente de } \\
\text { precipitação }\end{array}$ & 32,00 & 0,690 & 65,0 & $-98,0$ \\
\hline THF (a) & Solvente & 72,10 & 0,890 & 66,0 & $-108,5$ \\
\hline $\begin{array}{c}\text { Tetracloreto de } \\
\text { carbono }^{(c)}\end{array}$ & Solvente & 153,82 & 1,590 & 77,0 & $-23,0$ \\
\hline $\begin{array}{l}\text { lodeto de } \\
\text { potássio }{ }^{(c)}\end{array}$ & Reagente & 166,00 & 3,120 & 1330 & 681,0 \\
\hline $\begin{array}{l}\text { Tiossulfato de } \\
\text { sódio }{ }^{(\mathrm{c})}\end{array}$ & Reagente & 158,11 & 1,690 & 100,0 & 48,0 \\
\hline
\end{tabular}


Tabela 5 - Propriedades dos compostos utilizados nos experimentos (conclusão)

\begin{tabular}{cccccc}
\hline Composto & Descrição & $\begin{array}{c}\text { Massa } \\
\text { molecular } \\
(\mathrm{g} / \mathrm{mol})\end{array}$ & $\begin{array}{c}\text { Densidade } \\
\text { relativa }\end{array}$ & $\begin{array}{c}\text { Ponto de } \\
\text { ebulição } \\
\left({ }^{\circ} \mathrm{C}\right)\end{array}$ & $\begin{array}{c}\text { Ponto de } \\
\text { fusão }\left({ }^{\circ} \mathrm{C}\right)\end{array}$ \\
\hline lodo-Cloro & Reagente & 162,36 & 3,182 & $96,0-98,0$ & $25,0-27,0$ \\
Amido $^{(t)}$ & Indicador & Variável & 1,500 & Decomp. & Decomp. \\
Água $^{(\mathrm{c})}$ & Fase contínua & 18,01 & 1,000 & 100,0 & 0,0 \\
\hline
\end{tabular}

Referência: ${ }^{(a)}$ Gonçalves (2008); Referências da internet: ${ }^{(b)}$ LookChem (2010), ${ }^{(c)}$ Chemspider (2012), (d) Emsdiasum (2012), (e) Chemicalbook (2012), (f) Wikipedia (2012). Decomp.: Decompõese. Todos reagentes foram comprados da Sigma-Aldrich exceto o tetracloreto de carbono (Lablmpex). A pureza de cada reagente pode ser encontrada em Gonçalves et al (2013).

O esquema apresentado na Figura 31 representa, de forma genérica, as características em comum de reatores distintos, sendo que, em um deles foram processadas as reações em solução e nos outros dois, as reações em suspensão. $O$ uso de 3 reatores se justifica pelo trabalho em colaboração com grupo de pesquisa português. A parte do projeto referente às reações em solução foi desenvolvida no Brasil (Escola Politécnica da Universidade de São Paulo) e as reações em suspensão foram conduzidas em Portugal (Instituto Politécnico de Bragança). Além disso, as reações em suspensão estão divididas em dois grupos: as que foram realizadas a $90^{\circ} \mathrm{C}$ com um reator à pressão atmosférica e as que foram realizadas à $130^{\circ} \mathrm{C}$ num reator pressurizado. A seguir, são mostrados maiores detalhes construtivos e operacionais referentes a estes reatores.

\subsubsection{Reações em solução}

As reações em solução foram realizadas em um reator de 1 litro, com agitação em $200 \mathrm{rpm}$, temperatura na faixa de 80 à $85^{\circ} \mathrm{C}$, pressão atmosférica, utilizando-se água em banho termostatizado como fluido da camisa para manter a reação isotérmica. Nestas reações, os reagentes foram previamente inertizados com gás nitrogênio e pré-aquecidos até a temperatura de reação. $O$ iniciador foi adicionado no instante em que se atingiu a temperatura programada para cada 
reação. Este conjunto de experimentos consistiu de copolimerizações convencionais, as quais utilizaram tolueno como solvente. Cada amostra coletada foi misturada com metanol frio na proporção 2 de metanol para 1 de amostra, a fim de precipitar o polímero e parar a reação.

\subsubsection{Reações em suspensão}

Nas reações em suspensão, utilizou-se água como fase contínua. A fase dispersa foi composta de monômeros, solvente (tolueno ou xileno), iniciador e TEMPO, no início de cada reação. Utilizou-se a razão 9:1 entre fase contínua e fase dispersa, sendo que a fase contínua recebeu $0,1 \%$ (massa/massa) de álcool polivinílico, o qual atuou como agente de suspensão. Nestas copolimerizações, foi utilizado um reator de $2,5 \mathrm{~L}$ para reações à $90^{\circ} \mathrm{C}$ e pressão atmosférica e um reator de $1 \mathrm{~L}$ para reações à $130^{\circ} \mathrm{C}$ e 4,6 bar. Neste último caso, o reator foi inicialmente pressurizado com argônio até 2 bar, atingindo a pressão final (4,6 bar) quando a temperatura atingiu $130^{\circ} \mathrm{C}$. As amostras coletadas (contendo fases orgânica e aquosa) foram imediatamente colocadas no refrigerador à $-14^{\circ} \mathrm{C}$ a fim de parar a reação. Para auxiliar na separação de fases, as amostras foram mantidas no refrigerador por, no mínimo, 24 horas. Desta forma, obteve-se a fase orgânica separada, a qual foi submetida às análises que estão descritas a seguir.

\subsubsection{Análises}

A caracterização do polímero obtido foi conduzida a partir das amostras coletadas conforme ilustra a Figura 32. Os itens a seguir descrevem as etapas de caracterização separadamente. 
Numa copolimerização, a conversão se refere à fração de monômeros que foram incorporados às cadeias poliméricas.

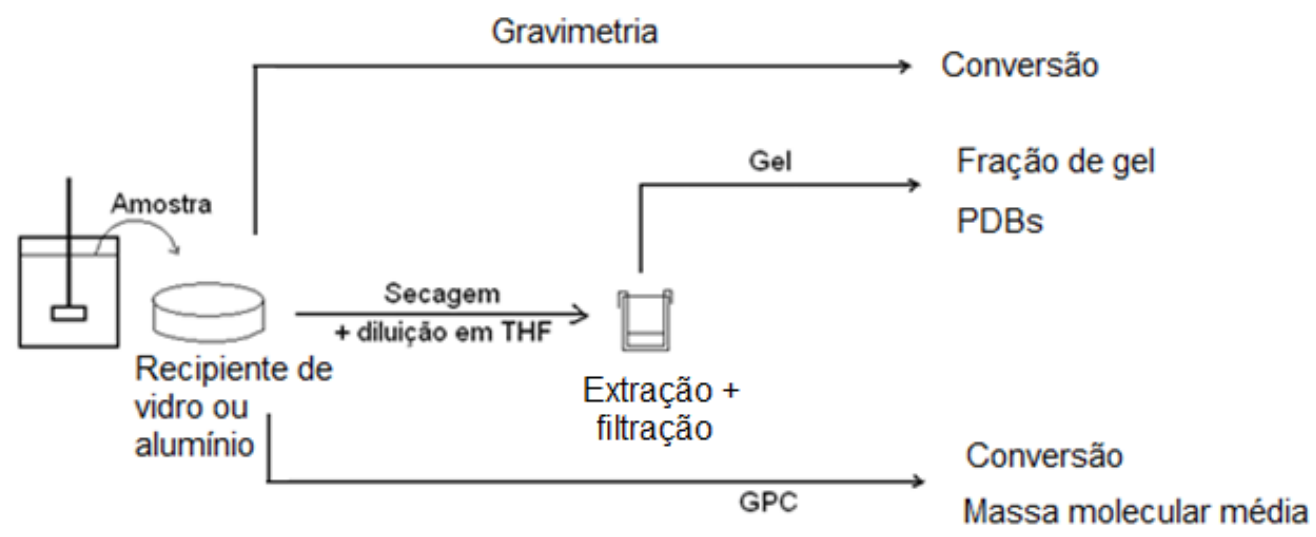

Figura 32 - Caracterização dos copolímeros obtidos durante a reação.

Para se obter a conversão das reações em solução, foi utilizada a técnica da gravimetria. Uma cápsula de alumínio previamente pesada recebe cerca de $3 \mathrm{~mL}$ de metanol, o qual é responsável pela precipitação do polímero. Pesa-se a cápsula contendo metanol e adiciona-se cerca de $1,5 \mathrm{~mL}$ de amostra. Após a adição da amostra, pesa-se novamente a cápsula, a qual, em seguida é submetida à secagem em estufa durante $24 \mathrm{~h}$ para remover o metanol, o tolueno e o monômero não reagidos. Por fim, após a secagem, pesa-se a cápsula com o polímero seco e calcula-se a conversão conforme mostrado na Figura 33.

A conversão experimental é obtida através da eq.(155).

$$
X_{E X P}=\frac{\left(m_{3}-m_{0}\right)}{\left(m_{2}-m_{1}\right) y_{m 0}}
$$

sendo que $\mathrm{y}_{\mathrm{m} 0}$ corresponde à fração mássica de monômero no meio reacional, no início da reação.

Para as reações em suspensão, a determinação da conversão por gravimetria foi realizada de forma semelhante ao procedimento supracitado. A diferença está no tratamento inicial das amostras coletadas (resfriamento por 24h). A fase orgânica separada foi misturada com metanol em excesso e as demais etapas do 
procedimento permaneceram as mesmas conforme descrito no presente item (Figura 33).

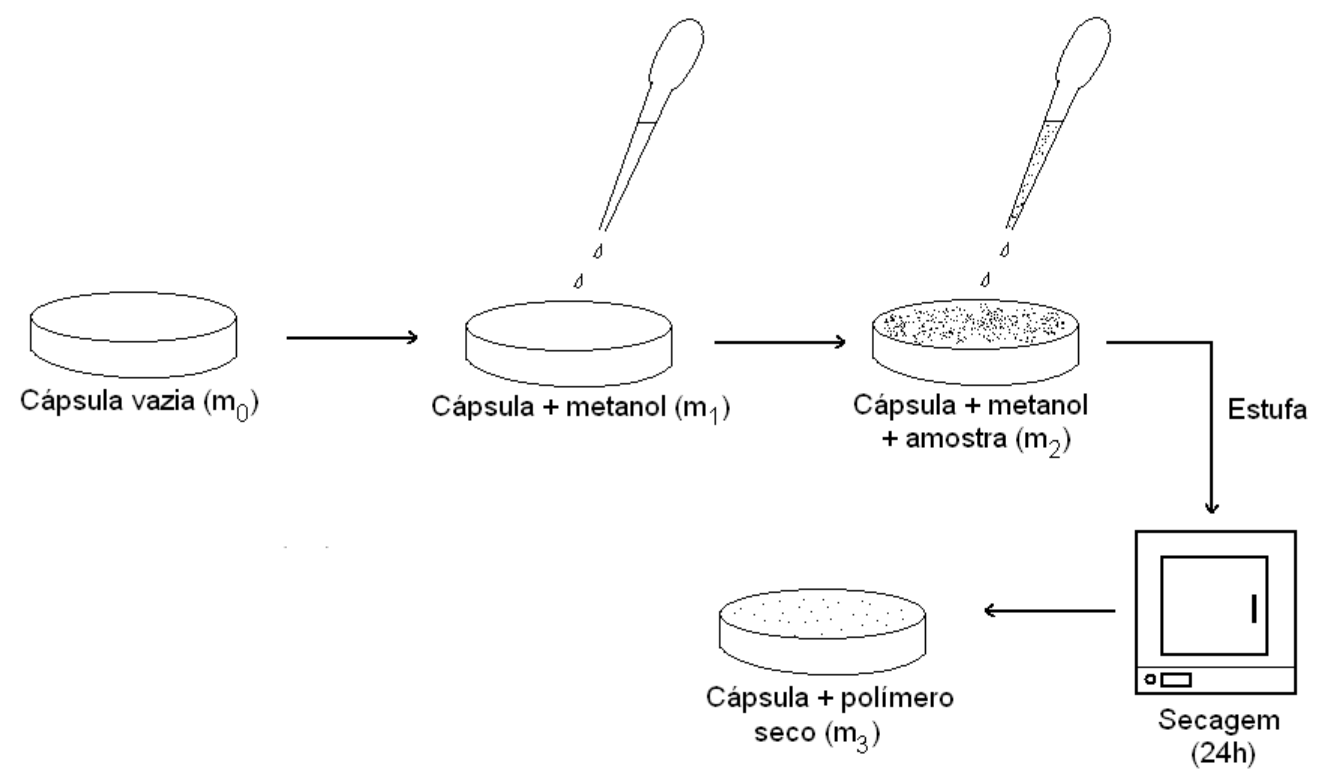

Figura 33 - Técnica da gravimetria utilizada na obtenção do grau de avanço da reação.

Além da gravimetria, utilizou-se a cromatografia por exclusão de tamanhos para se determinar a conversão nas reações em suspensão. Nesta técnica, a conversão é obtida relacionando-se as áreas dos picos referentes aos monômeros em cada cromatograma. Nesta análise, utilizou-se um aparato SEC/RI/MALLS (Size Exclusion Chromatography / Refraction Index / Multi-Angle Laser Light Scattering), o qual é composto por um sistema integrado de cromatografia de exclusão de tamanhos da Polymer Laboratories, PL-GPC-50, um refratômetro diferencial trabalhando a $950 \pm 30 \mathrm{~nm}$, anexado a um detector de espalhamento de luz multiângulo, DAWN8+ HELEOS $658 \mathrm{~nm}$ da Wyatt. Uma pequena quantidade da fase orgânica separada em cada amostra foi diluída em THF (concentração final em torno de $0,1 \% \mathrm{massa} / \mathrm{massa}$ ), filtrada e injetada no sistema SEC/RI/MALLS.

Fração de gel

A fração de gel foi obtida através de extração com THF em conjunto com a gravimetria. Inicialmente, corta-se um pedaço de papel de filtro (poro $=2 \mu \mathrm{m}$ ) de forma a revestir o fundo de um becker de $100 \mathrm{~mL}$. Este papel é submetido à secagem para remover a umidade recebida do ar. Após a secagem, mede-se a 
massa do filtro e em seguida a massa do filtro com o polímero seco (aproximadamente $1 \mathrm{~g}$ de polímero). Este conjunto é posicionado no fundo do bequer e então adiciona-se $20 \mathrm{~mL}$ de THF. O conteúdo é tampado e mantido em repouso por $24 \mathrm{~h}$, período no qual ocorre a transferência das cadeias solúveis para o solvente até que seja atingido o equilíbrio. Conforme mostrado na Figura 34, após o período de extração, o papel é reposicionado no bequer, de forma a se proceder uma filtração durante 30min.

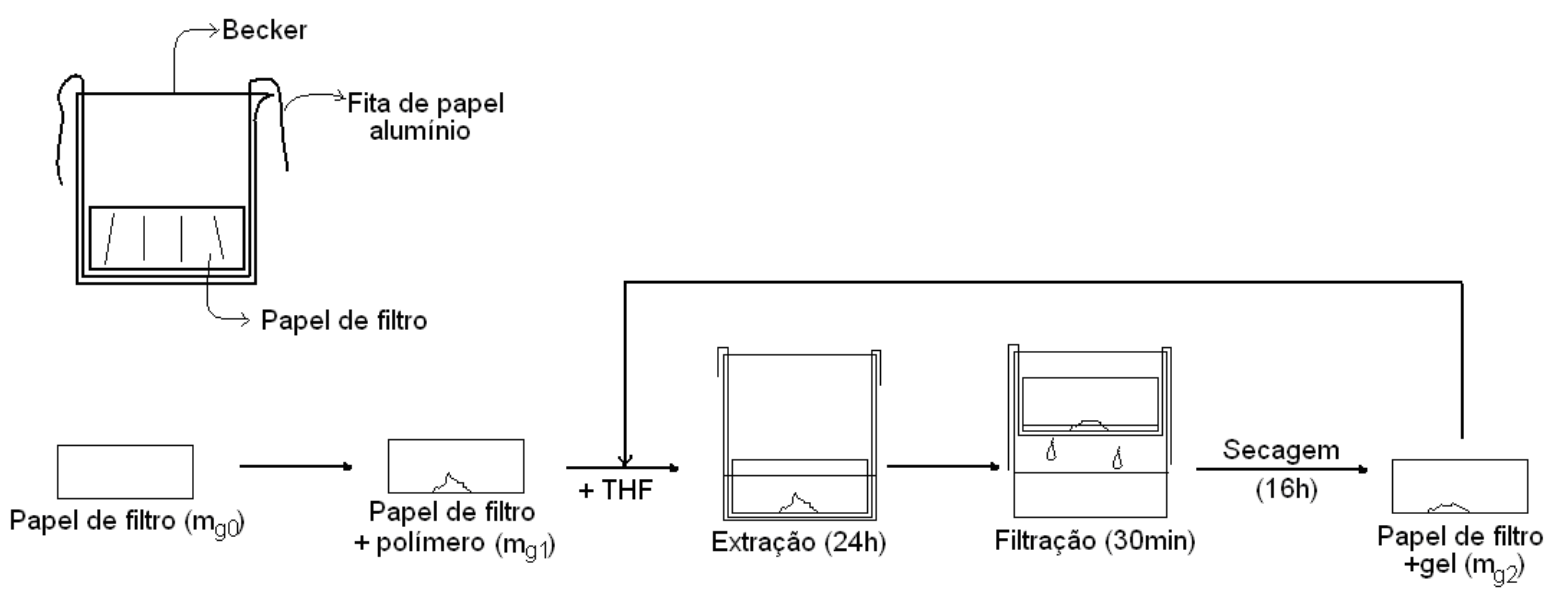

Figura 34 - Determinação da fração de gel.

Após a filtração, o conteúdo é submetido à secagem por 16h e em seguida, mede-se a massa final do papel de filtro com o gel. O processo é repetido até se obter massa de gel constante. As análises foram acompanhadas com um branco para se avaliar a variação de massa durante a manipulação do papel de filtro. A fração de gel experimental é obtida através da Eq.(156).

$W g_{E X P}=\frac{\left(m_{g 2}-m_{g 0}\right)}{\left(m_{g 1}-m_{g 0}\right)}$

Determinação da massa molecular média

As massas moleculares médias das amostras das reações em suspensão foram analisadas através de cromatografia de exclusão de tamanhos, utilizando-se o sistema descrito no item 3.2.1.3. As amostras contendo polímero foram fracionadas 
em função dos tamanhos das moléculas constituintes, usando-se um conjunto de 3 colunas de GPC (Gel Permeation Chromatography) em série. Utilizou-se colunas da PL gel $(300 \times 7,5 \mathrm{~mm})$ com um tamanho nominal de partícula de $10 \mu \mathrm{m}$, mantidas a temperatura constante de $30^{\circ} \mathrm{C}$, as quais operaram com um fluxo de THF de 1 $\mathrm{mL} / \mathrm{min}$.

Determinação da concentração de duplas ligações pendentes

A quantificação da concentração das duplas ligações pendentes (PDBs) nas cadeias de polímero foi realizada através de uma análise química, conforme reportada na literatura (Hecker, 2000; Cheyney e Kelley, 1942; Kemp e Peters 1943; Lee et al., 1948; Lee et al., 1950; Crompton e Reid, 1963 e Knothe, 2002). Cerca de $0,5 \mathrm{~g}$ de polímero seco foi colocado em contato com $20 \mathrm{~mL}$ de tetracloreto de carbono durante $15 \mathrm{~h}$ para amostras coletadas antes da gelificação e $90 \mathrm{~h}$ para amostras contendo gel (a fim de se promover intumescimento). Após este período, $25 \mathrm{~mL}$ de solução de Wijs (lodo-Cloro) foram adicionados à mistura e o conteúdo foi mantido em ambiente escuro durante $30 \mathrm{~h}$ (para amostras sem gel) e $75 \mathrm{~h}$ (para amostras contendo gel). Assim, promoveu-se a reação entre monocloreto de iodo (ICl) e as duplas ligações pendentes carbono-carbono, presentes na estrutura de polímero. Ao fim dessa etapa, $25 \mathrm{~mL}$ de iodeto de potássio e $150 \mathrm{~mL}$ de água deionizada foram adicionados à mistura. Nesta nova etapa, $\mathrm{KCl}$ e $\mathrm{I}_{2}$ são formados devido à reação de $\mathrm{ICl}$ livre e $\mathrm{KI}$ presente em excesso. A solução resultante foi titulada com uma solução $0,1 \mathrm{~N}$ de tiossulfato de sódio, inicialmente, até 0 desaparecimento parcial da cor amarelo escuro. Após isto, $2 \mathrm{~mL}$ de solução de amido a $1 \%$ foi adicionada à mistura e a titulação continuou até a nova mudança de cor: de azul para branco. A comparação entre os volumes de titulação observados para o branco (sem polímero) e para as amostras permite determinar a concentração de PDBs presentes no material. A Figura 35 mostra este procedimento de forma esquemática. 


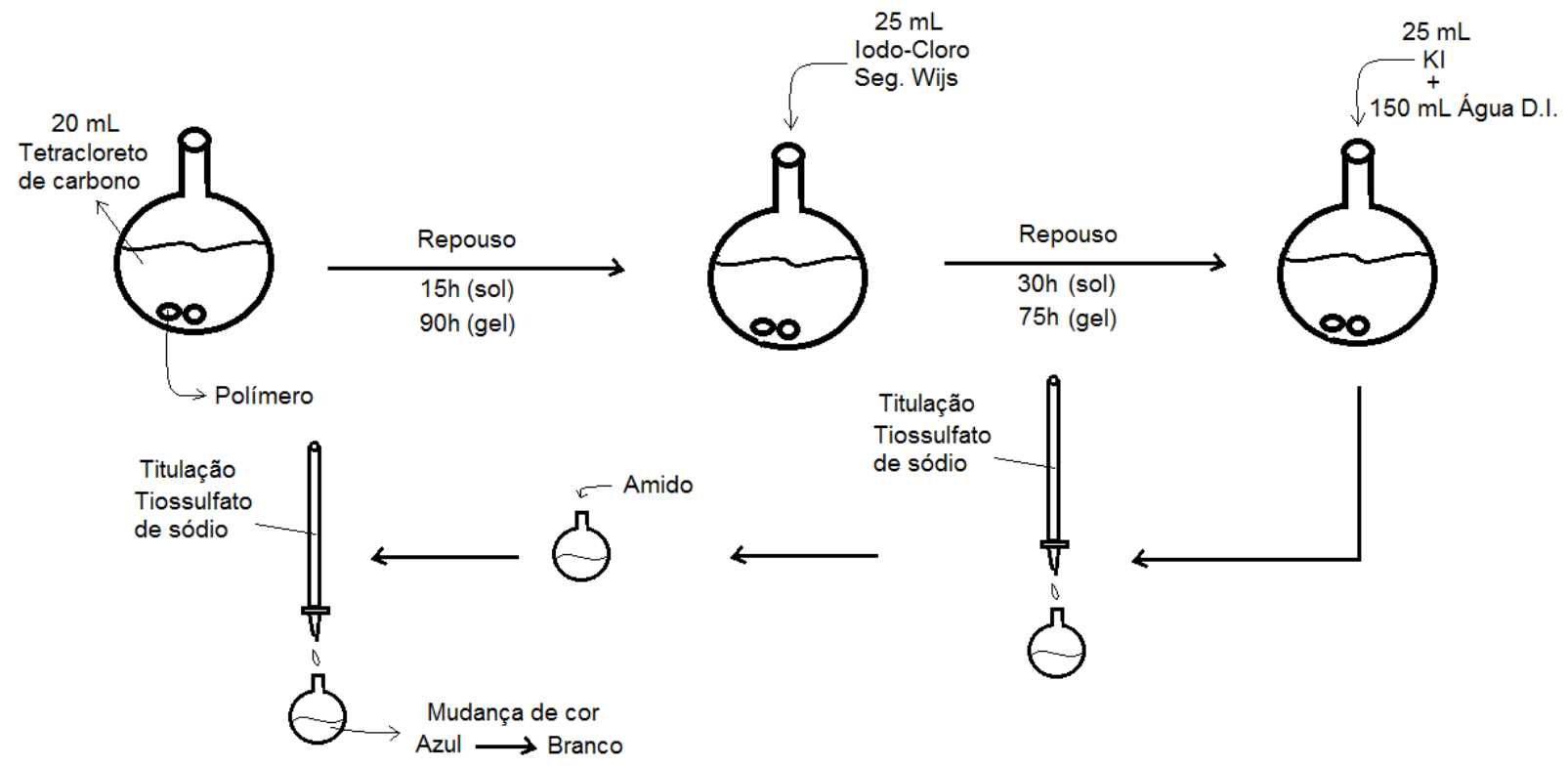

Figura 35 - Procedimento experimental para determinação de PDBs.

A concentração de PDBs foi calculada através da equação (157).

$C_{D}=\frac{\left(V_{t i t B}-V_{t i t A}\right) 0,5 C_{t i t}}{m_{S}}$

sendo que

$\mathrm{C}_{\mathrm{D}}$ : Concentração de duplas ligações pendentes ( $\mathrm{mmol} / \mathrm{g}$ de polímero);

$\mathrm{V}_{\text {titB: }}$ : Volume de titulante gasto na titulação do branco $(\mathrm{mL})$;

$\mathrm{V}_{\text {titA }}$ : Volume de titulante gasto na titulação da amostra $(\mathrm{mL})$;

$\mathrm{C}_{\text {tit }}$ : Concentração do titulante (mol/L);

$\mathrm{m}_{\mathrm{s}}$ : Massa da amostra (g). 


\section{RESULTADOS E DISCUSSÕES}

\subsection{Resultados experimentais}

As Tabelas 6 e 7 mostram as condições nas quais foram realizados os experimentos. Os experimentos foram programados com base nos resultados dos experimentos anteriores e nas previsões dos modelos. O objetivo principal das condições iniciais escolhidas foi obter resultados adequados para a validação dos modelos matemáticos.

Tabela 6 - Condições dos experimentos realizados em solução (Brasil).

\begin{tabular}{ccccc}
\hline Experimento & $\mathrm{T}\left({ }^{\circ} \mathrm{C}\right)$ & $\phi_{\mathrm{M}}(\%)$ & $\mathrm{Y}_{\mathrm{DVB}}(\%)$ & $\mathrm{Y}_{\mathrm{IDB}}(\%)$ \\
\hline B1 & 85 & 39 & 3 & 1,3 \\
B2 & 85 & 44 & 3 & 1,2 \\
B3 & 85 & 59 & 3 & 0,9 \\
B4 & 80 & 20 & 15 & 1,0 \\
B5 & 80 & 10 & 100 & 1,1 \\
B6 & 80 & 10 & 25 & 1,4 \\
\hline
\end{tabular}

Tabela 7 - Condições dos experimentos realizados em suspensão (Portugal).

\begin{tabular}{cccccc}
\hline Experimento & $\mathrm{T}\left({ }^{\circ} \mathrm{C}\right)$ & $\phi_{\mathrm{M}}(\%)$ & $\mathrm{Y}_{\mathrm{DVB}}(\%)$ & $\mathrm{Y}_{\text {IDB }}(\%)$ & $\mathrm{Y}_{\text {TEMPO }}$ \\
\hline P1 & 90 & 50 & 3 & 0,50 & 1,10 \\
P2 & 90 & 60 & 28 & 0,50 & 1,10 \\
P3 & 90 & 60 & 100 & 0,40 & 1,10 \\
P4 & 90 & 60 & 100 & 0,40 & 1,20 \\
P5 & 90 & 100 & 100 & 0,40 & 1,10 \\
P6 & 90 & 100 & 0 & 0,50 & 1,10 \\
P7 & 90 & 50 & 1 & 0,05 & 0,00 \\
P8 & 130 & 50 & 100 & 0,90 & 0,75 \\
P9 & 130 & 50 & 50 & 0,20 & 1,00 \\
P10 & 130 & 50 & 5 & 0,20 & 1,00 \\
P11 & 130 & 20 & 50 & 0,20 & 1,00 \\
P12 & 130 & 50 & 0 & 0,20 & 1,00 \\
P13 & 90 & 100 & 0 & 0,05 & 0,00 \\
P14 & 90 & 50 & 0 & 0,50 & 1,10 \\
P15 & 90 & 50 & 15 & 0,50 & 1,10 \\
\hline
\end{tabular}

Nestas tabelas, $\phi_{\mathrm{M}}$ é a fração volumétrica de monômero na fase orgânica (solventes: tolueno para reações com $\mathrm{T} \leq 90^{\circ} \mathrm{C}$ e xileno para reações a $130^{\circ} \mathrm{C}$ ); $\mathrm{Y}_{\mathrm{DVB}}$ 
é a fração molar inicial de DVB na mistura de monômeros; YIDB é a relação molar inicial entre iniciador (BPO utilizado no experimento P8 e AIBN nos demais) e as

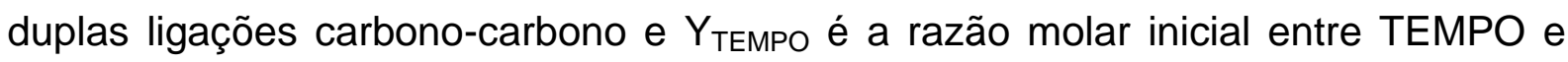
iniciador. Os dados coletados nos experimentos estão registrados no APENDICE B.

Nas figuras referentes aos resultados experimentais e de simulação foi utilizada a seguinte simbologia:

Mw: Massa molecular média mássica;

Mn: Massa molecular média numérica;

Wg: Fração de gel;

X: conversão de monômero;

PDB: Concentração de duplas ligações pendentes;

kcic: Constante cinética de ciclização envolvendo um caminho de 3 unidades monoméricas, o qual conecta um radical de estireno à uma $\operatorname{mPDB}\left(\mathrm{k}_{\mathrm{p} 14,3}^{\mathrm{C}}\right)$, para $90^{\circ} \mathrm{C}\left(\mathrm{s}^{-1}\right)$;

Exp: Dados experimentais;

ModA: Resultados de simulação com o Modelo A;

ModB: Resultados de simulação com o Modelo B;

ModC: Resultados de simulação com o Modelo C.

Os gráficos do presente trabalho foram construídos com o software SciDavis, que trabalha com o sistema inglês, no qual a vírgula é representada por ponto e vice-versa. Para os números que não fazem parte dos gráficos, foi utilizada a vírgula como separador decimal.

\subsubsection{Resultados experimentais das reações em solução}

A primeira série de experimentos consistiu de copolimerizações convencionais de estireno-divinilbezeno em solução. A vantagem em relação às polimerizações em suspensão está na eliminação da fase contínua, a qual dificulta a caracterização do polímero obtido. Por outro lado, nas copolimerizações em solução quando se forma considerável quantidade de gel, este intumesce, chegando a 
incorporar em seu interior, toda a solução do meio reacional. Nestas situações, o processo deve ser interrompido, pois não há mais a mesma homogeneização feita no início da reação. Os resultados a seguir correspondem às reações em solução, as quais apresentam um curto tempo de reação devido a esse comportamento no período pós-gelificação. As figuras 36 e 37 mostram os resultados de conversão de monômero para os experimentos listados na Tabela 6.

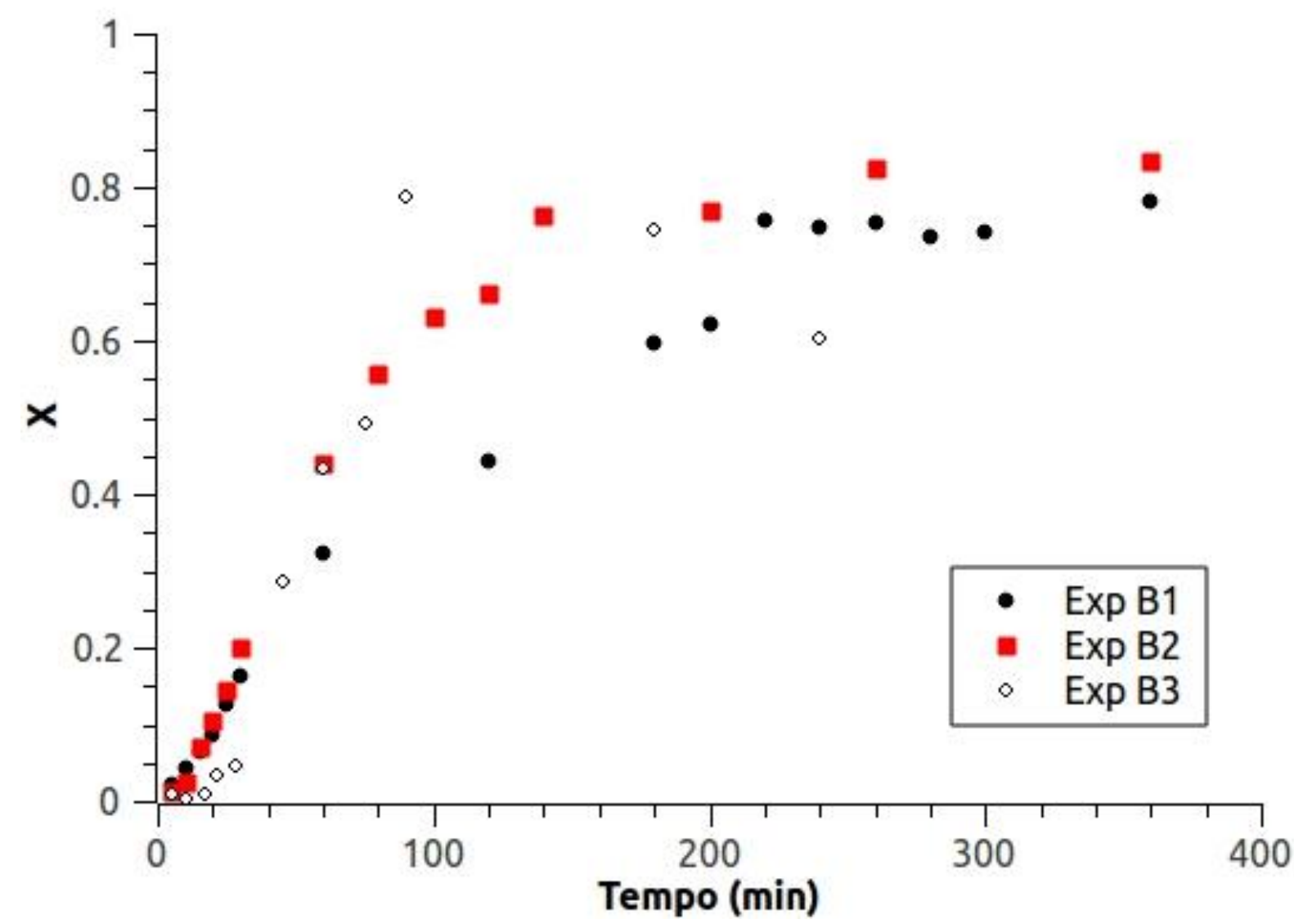

Figura 36 - Resultados de conversão de monômeros dos experimentos B1, B2 e B3.

Os perfis de conversão da Figura 36 apresentam tendências semelhantes para os três experimentos (B1, B2 e B3). Nestes experimentos, variou-se a diluição da mistura inicial de monômeros na faixa entre 39 e 59\% dos mesmos em relação à mistura (monômeros + solvente). Com base nos resultados, entende-se que esta variação na diluição não foi grande o suficiente para causar diferenças consideráveis nos dados de conversão. No perfil do experimento B3, nota-se clara redução no perfil de conversão, a qual pode estar associada a erros de amostragem que ocorrem em função da formação de gel no sistema. 
Na Figura 37 observa-se uma faixa ainda mais estreita para os resultados de conversão obtidos nos experimentos B4, B5 e B6. Os perfis estão quase sobrepostos apesar de se tratar de experimentos com diferentes diluições e concentrações iniciais de divinilbenzeno.

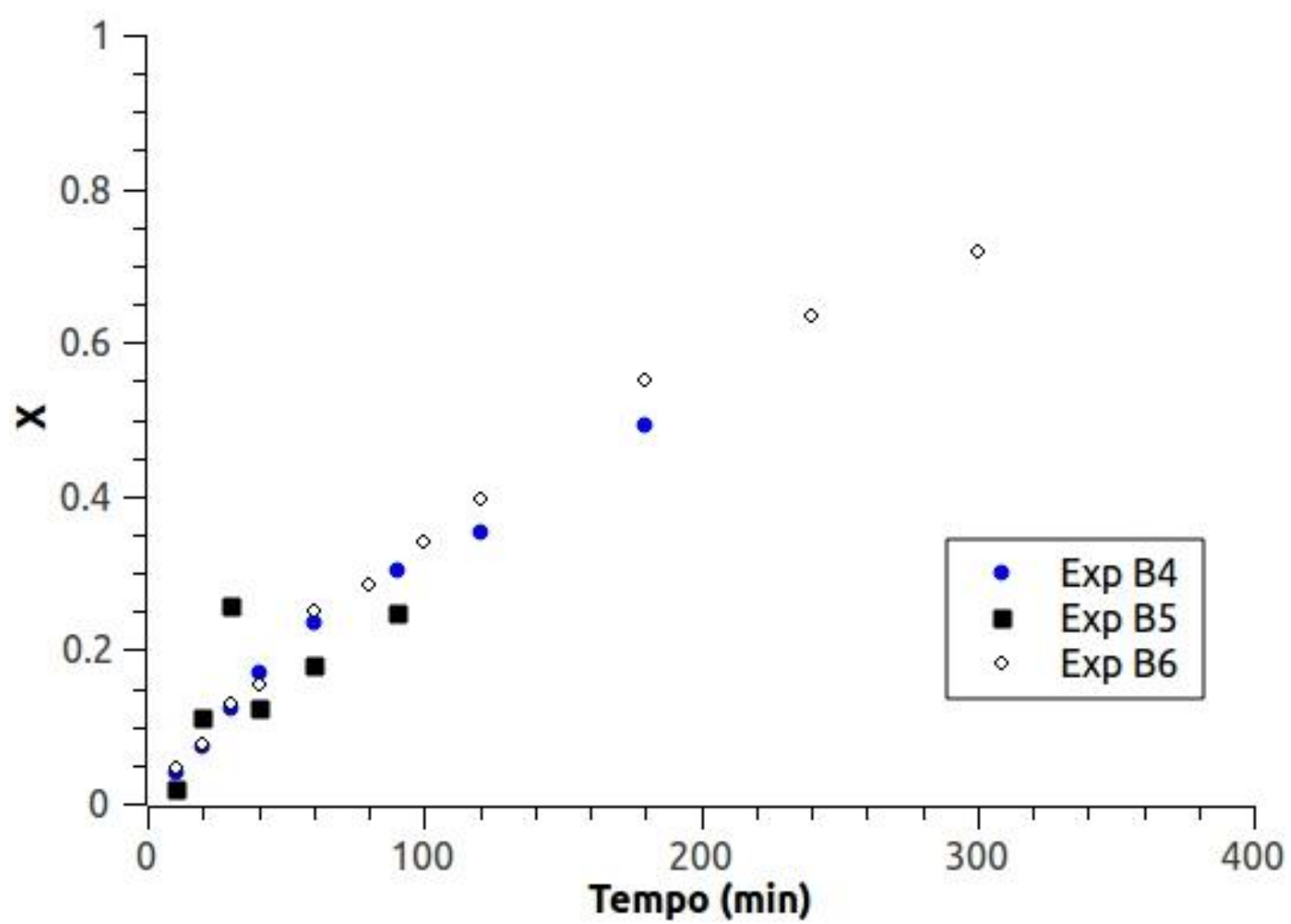

Figura 37 - Resultados de conversão de monômeros dos experimentos B4, B5 e B6.

O experimento B5 foi conduzido com $100 \%$ de DVB comercial e com ele visou-se avaliar o efeito das diferentes reatividades dos radicais de DVB em relação ao radical de estireno. O perfil de conversão obtido para o experimento B5 apresenta uma ligeira tendência a baixas conversões em relação aos experimentos B4 e B6. Porém, não é possível tirar conclusões sobre as diferentes reatividades devido à falta de dados de conversão para tempos maiores (reação interrompida devido à gelificação).

É provável que a diferença de inclinação nos minutos iniciais de reação entre os perfis das figuras 36 e 37 esteja associada à diferença de temperatura. Nos experimentos realizados a $85^{\circ} \mathrm{C}$ (B1, B2 e B3), aos 100 minutos de reação, já se obtém cerca de $60 \%$ de conversão enquanto que, nos experimentos realizados a $80^{\circ} \mathrm{C}$ (B4, B5 e B6), a conversão neste instante ainda se encontra em torno de $30 \%$. 
Apesar da interrupção da reação devido à incorporação da solução ao gel formado, é possível analisar a fração de gel em amostras anteriores a este ponto. $O$ aumento do tamanho das cadeias e a consequente formação progressiva de gel foram detectados observando-se o aumento da viscosidade do meio reacional. Amostras homogêneas (com o agitador ainda trabalhando), coletadas durante este período de aumento da viscosidade, apresentaram cadeias insolúveis (gel). No momento em que a viscosidade se tornou extremamente alta, a ponto de obstruir o impulsor, a reação foi interrompida. As figuras 38 e 39 mostram os resultados de fração de gel.

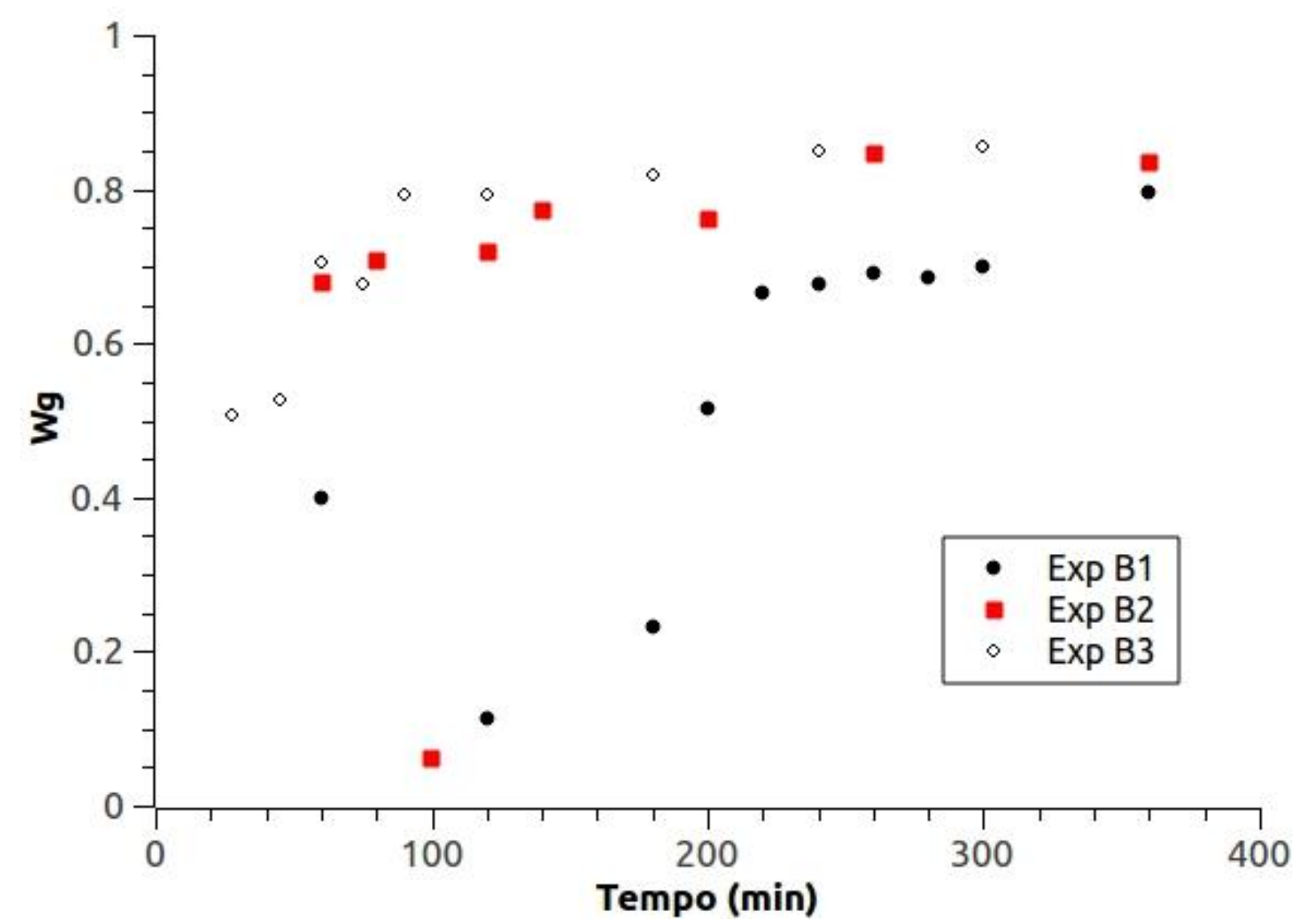

Figura 38 - Resultados de fração de gel dos experimentos B1, B2 e B3.

Nota-se uma tendência crescente dentre os perfis de fração de gel representados nas figuras 38 e 39. Na Figura 38, os perfis crescem no sentido do experimento B1 para o experimento B3. Isto condiz com as condições experimentais, que registram um aumento na concentração inicial de monômeros no sentido do experimento B1 para o B3. A análise da fração de gel torna-se menos 
precisa quanto menor for a quantidade de polímero analisado. As amostras coletadas no início das reações ainda possuem pouco polímero, o que diminui a precisão da análise, podendo gerar outliers neste período, conforme mostrado na Figura 38 (experimento B1). Na Figura 39, é nítido o efeito da concentração inicial de DVB sobre a fração de gel.

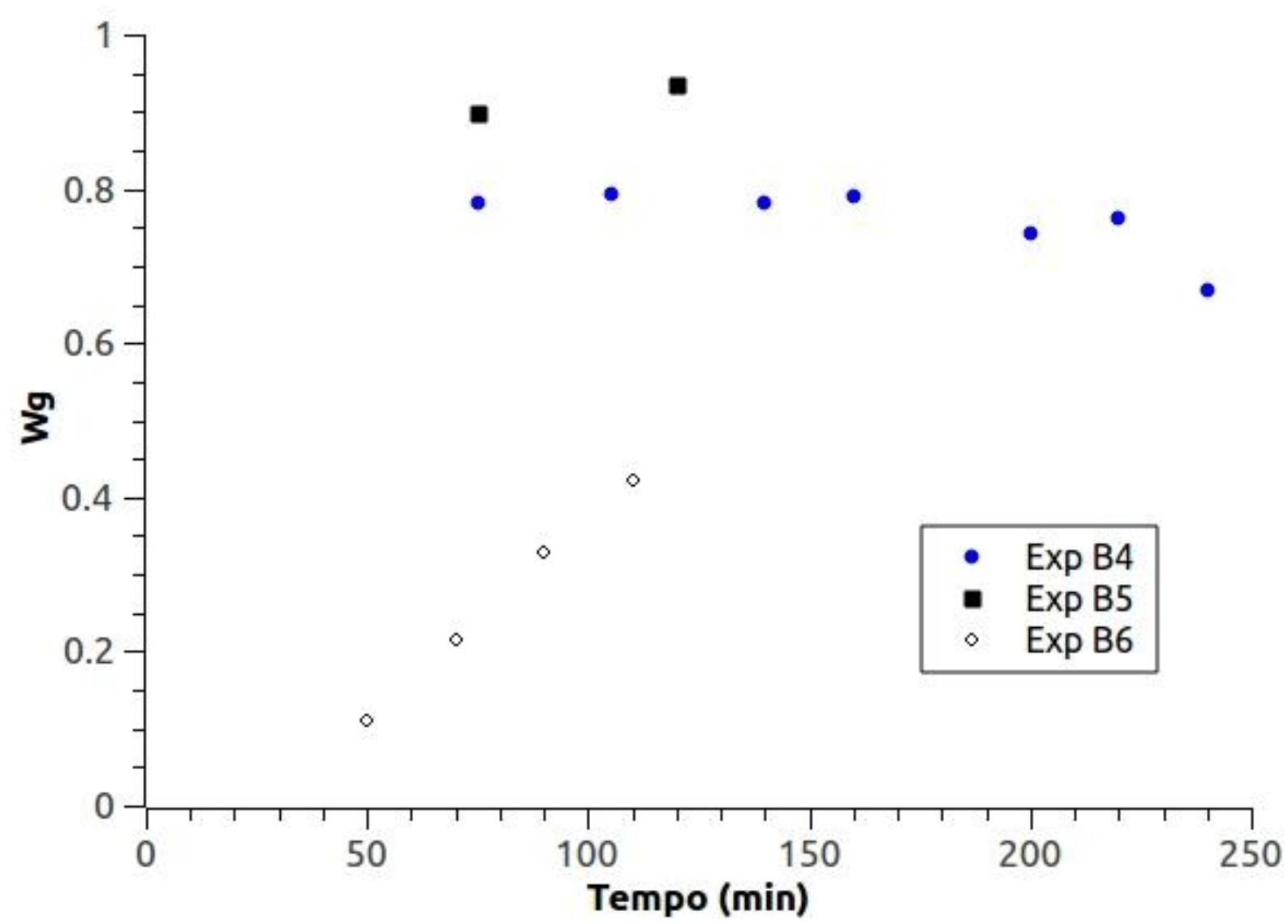

Figura 39 - Resultados de fração de gel dos experimentos B4, B5 e B6.

O experimento B5 (100\% DVB) apresentou os maiores valores de fração de gel, enquanto que os demais, que utilizaram uma menor faixa de concentrações iniciais de DVB (15\%-25\%), apresentaram perfis resultantes de uma combinação de efeitos (diluição e concentração inicial de DVB). O Experimento B4 foi realizado com $15 \%$ de DVB em relação à mistura monomérica e $20 \%$ de monômeros em relação à mistura total. No experimento B6 trabalhou-se com mais DVB (25\%), porém com menor concentração de monômeros (10\%). O aumento da concentração de DVB causa uma aceleração na gelificação e a redução da concentração de monômeros (aumento da diluição) tende a reduzir a taxa de ligações cruzadas. Analisando-se os dois casos (experimentos B4 e B6), verifica-se que o efeito da diluição foi maior do 
que o efeito da concentração inicial de DVB, visto que o experimento B4 apresentou maior fração de gel, apesar da menor concentração inicial de DVB.

Alguns dos experimentos conduzidos em solução apresentaram amostras com massa suficiente para se analisar a concentração de duplas ligações pendentes (PDBs) presentes nas cadeias de polímero. A Figura 40 mostra os resultados desta análise.

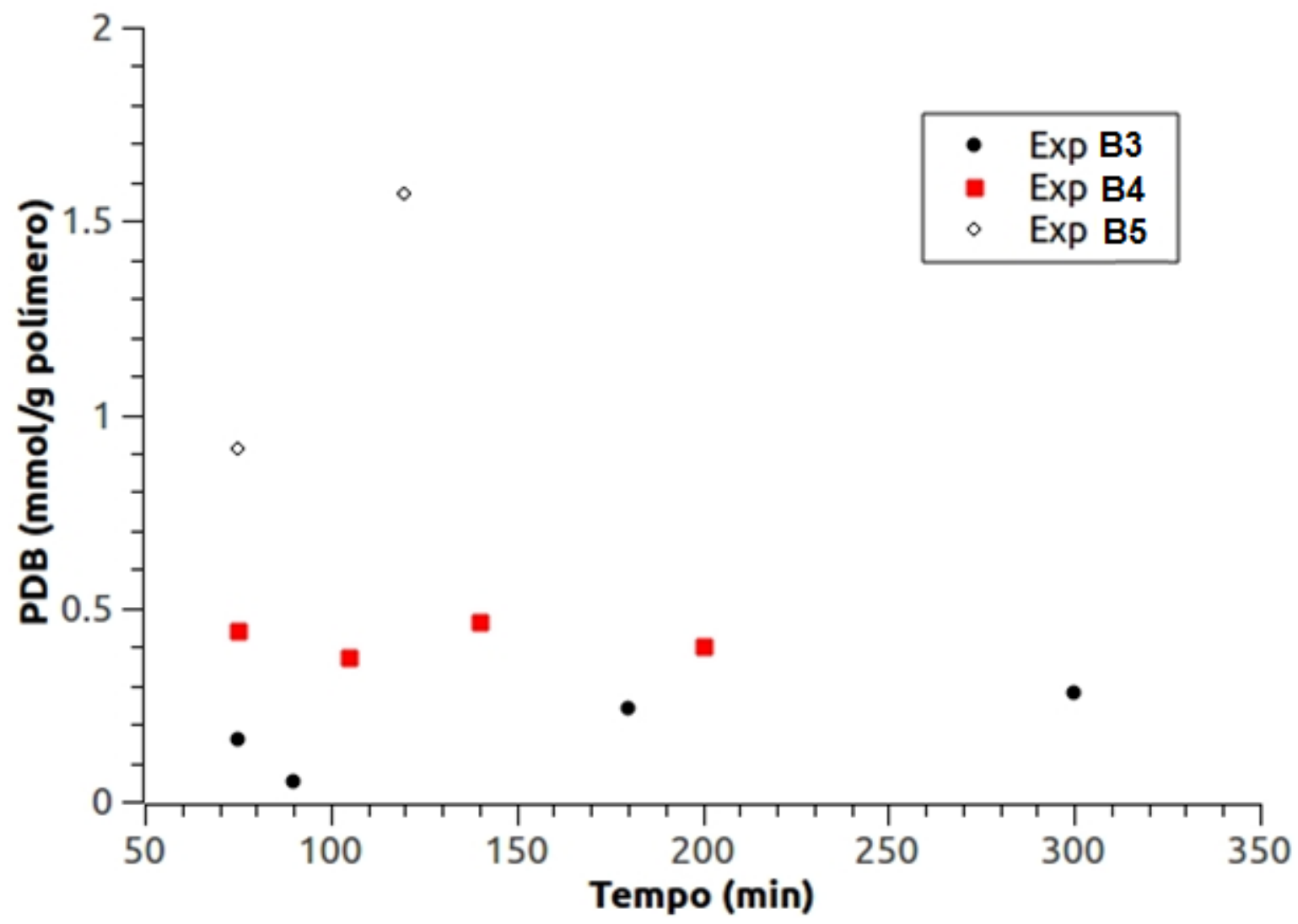

Figura 40 - Resultado de concentração de PDBs para os experimentos B3, B4 e B5.

Observa-se uma coerência nos perfis de concentração de PDBs com base na concentração inicial de DVB em cada experimento. As concentrações iniciais de DVB comercial utilizadas foram: $3 \%$ para o experimento $B 3,15 \%$ para o experimento B4 e 100\% para o experimento B5. Entende-se que, maiores quantidades de DVB resultam em maiores concentrações de PDBs, o que está de acordo com os resultados apresentados na Figura 40. No experimento B5, mais pontos seriam necessários para se eliminar possíveis outliers e para se traçar o perfil correto de concentrações de PDBs, o qual provavelmente apresentaria uma tendência constante ou decrescente ao longo do tempo de reação. 
4.1.2. Resultados experimentais das reações em suspensão

Uma avaliação da eficiência da polimerização controlada (NMRP) sob as condições experimentais particulares consideradas no presente trabalho foi realizada, tomando-se como referência, a homopolimerização de estireno. Resultados típicos obtidos estão apresentados nas figuras 41-43.

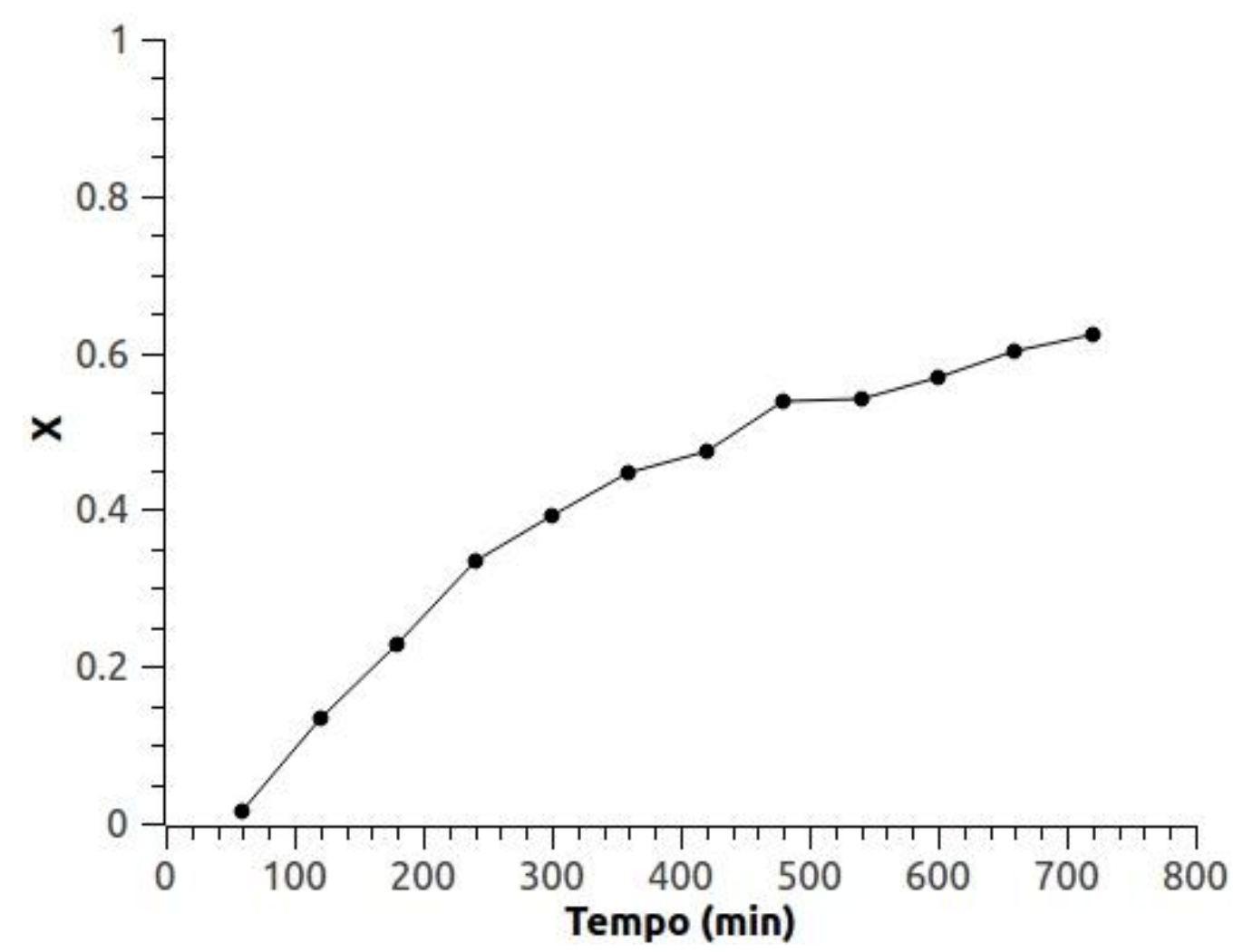

Figura 41 - Evolução da conversão experimental com o tempo para NMRP de estireno em suspensão a $130^{\circ} \mathrm{C}$ (Experimento P12).

A Figura 41 ilustra a evolução da conversão de monômero para NMRP de estireno à $130^{\circ} \mathrm{C}$ (Experimento P12). Quando estes valores de conversão são usados para gerar um perfil de $-\ln (1-X)$ em função do tempo (Figura 42), uma relação próxima da linear é obtida após o período de inibição, confirmando a característica controlada da polimerização. Outra característica típica de uma polimerização controlada está ilustrada nas figuras 43 (crescimento linear de massas moleculares com a conversão de monômero) e 44, onde baixa dispersão de massas moleculares é observada ao longo da polimerização. 


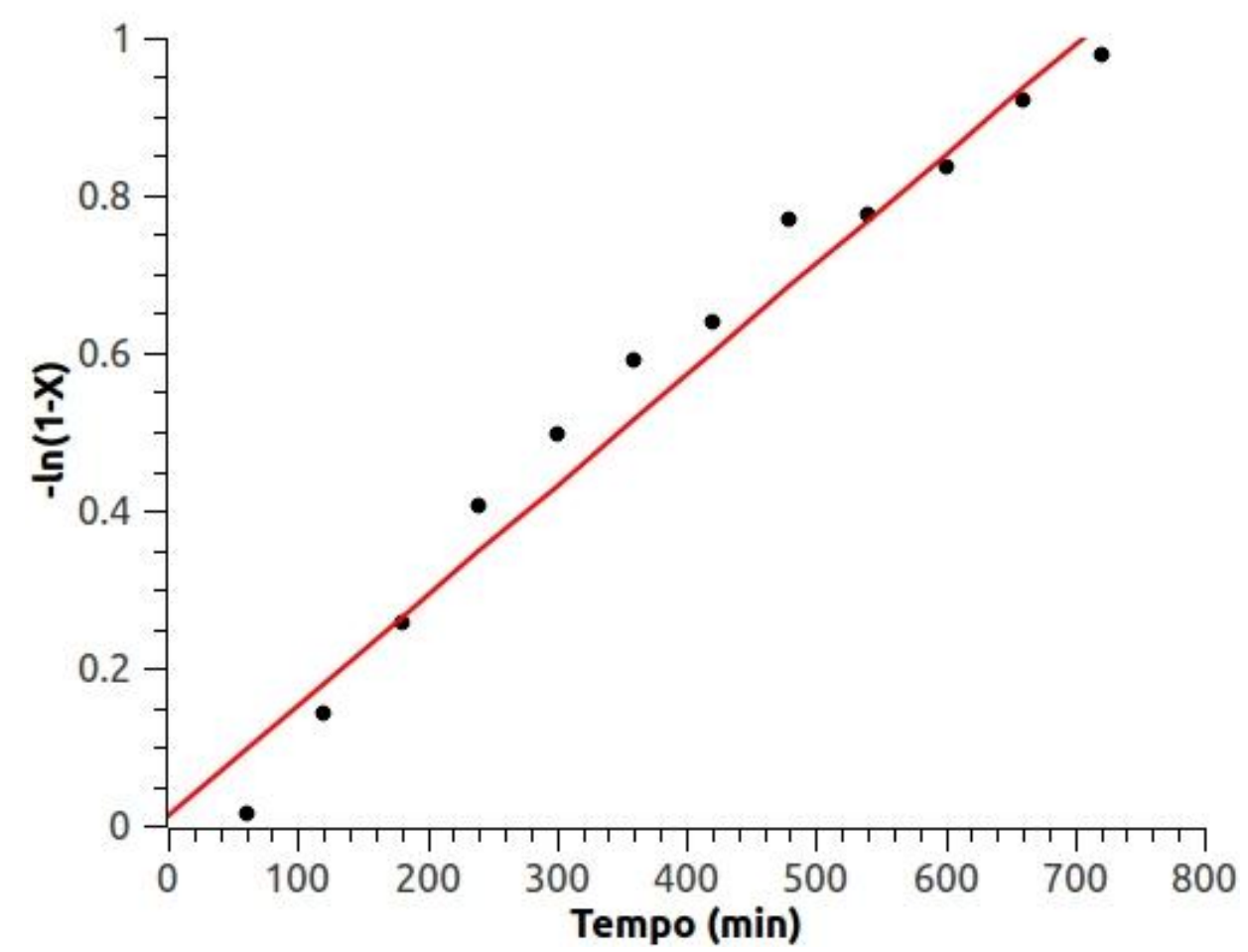

Figura 42 - $[-\ln (1-X)]$ em função do tempo, para os mesmos dados de conversão da Figura 43, mostrando o comportamento linear de polimerizações controladas.

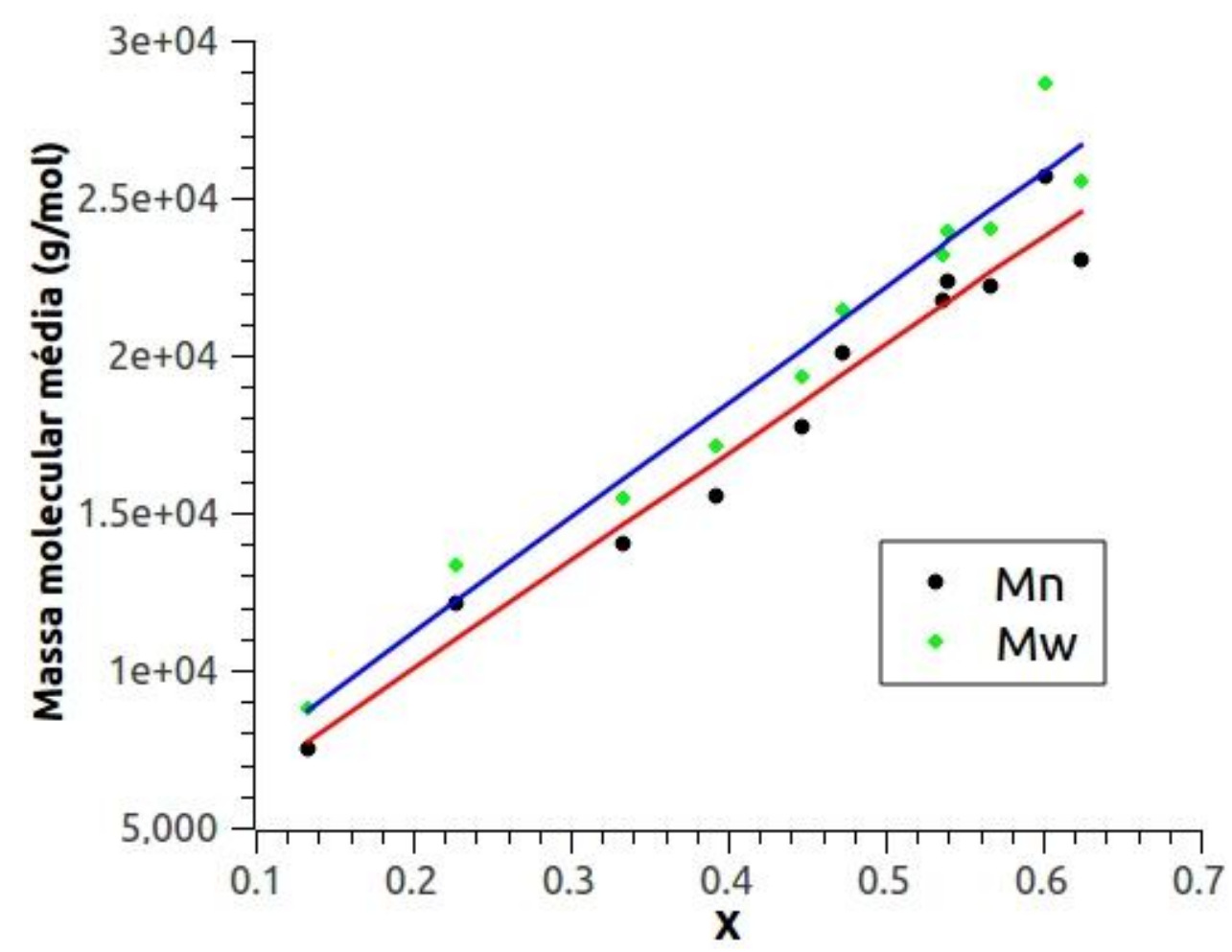

Figura 43 - Dependência das massas moleculares médias numérica $(\mathrm{Mn})$ e mássica $(\mathrm{Mw})$ com a conversão de monômero para o experimento P12. A dependência linear observada confirma o caráter "vivo" da polimerização. 


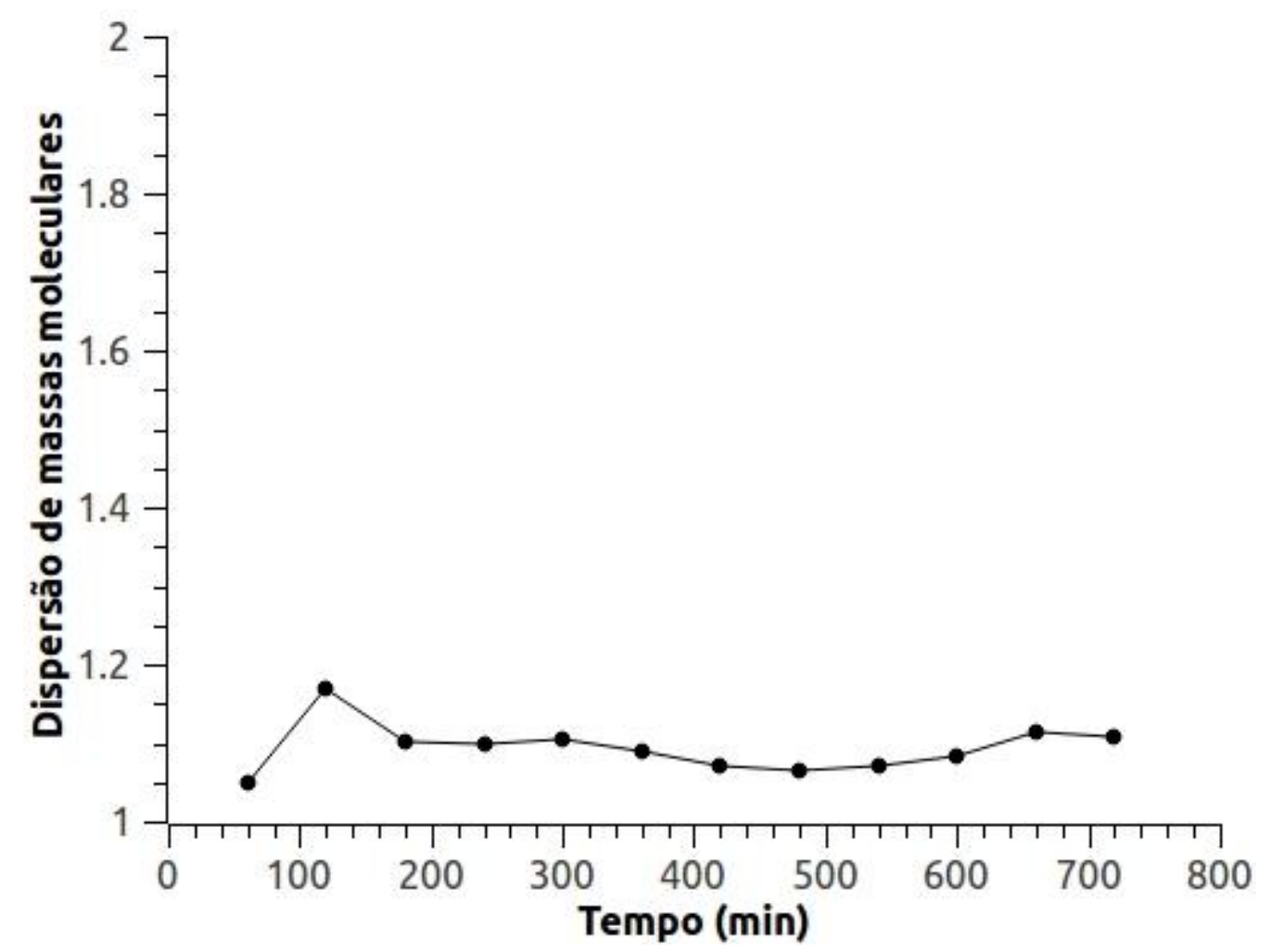

Figura 44 - Evolução da dispersão de massas moleculares com o tempo para o experimento P12. A eficiência do processo NMRP é confirmada através da baixa dispersão de massa molecular.

Uma grande mudança na arquitetura molecular de materiais produzidos através de NMRP é observada quando uma quantidade de DVB, mesmo que pequena, é adicionada à mistura reacional. Devido ao processo de reticulação, uma distribuição muito larga de espécies não lineares é formada, possibilitando a gelificação.

A Figura 45 mostra o sinal de espalhamento multiângulo de luz (Multi-angle laser light scattering - MALLS) para uma copolimerização de estireno-divinilbenzeno (experimento P10). Esta mesma análise é realizada para uma homopolimerização (experimento P12), conforme mostrado na Figura 46. Diferenças entre as polimerizações linear e não linear se tornam claras quando as figuras 45 e 46 são comparadas. A formação de polímero com larga distribuição de tamanhos e deslocamento da mesma para menores tempos de eluição são características típicas de processos de reticulação. A Figura 47 ilustra a não linearidade observada no perfil de massa molecular média mássica $(\mathrm{Mw})$ em função da conversão quando se utiliza monômero divinílico (DVB) na reação. 


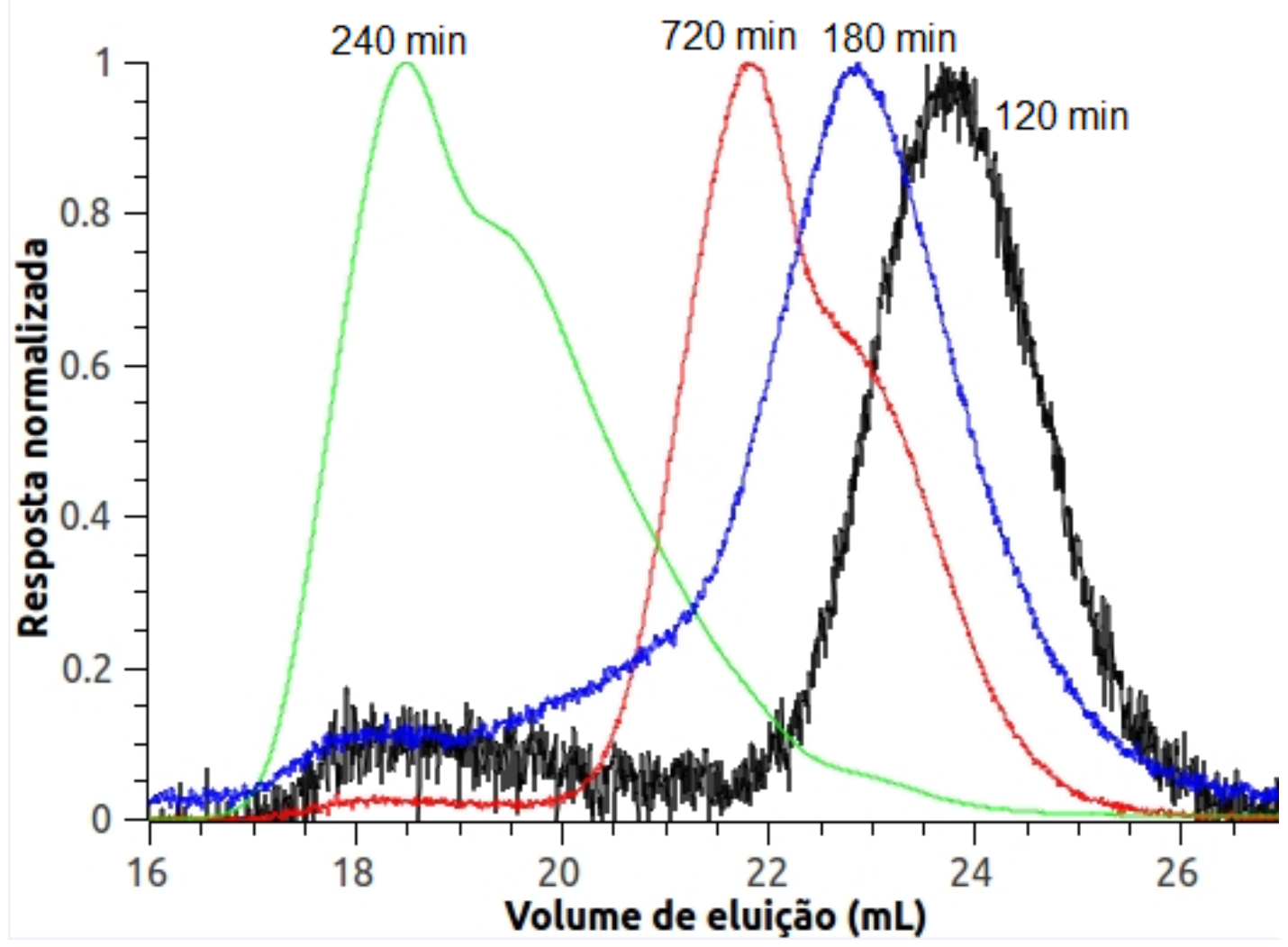

Figura 45 - Sinal de espalhamento de luz observado para amostras do experimento P10.

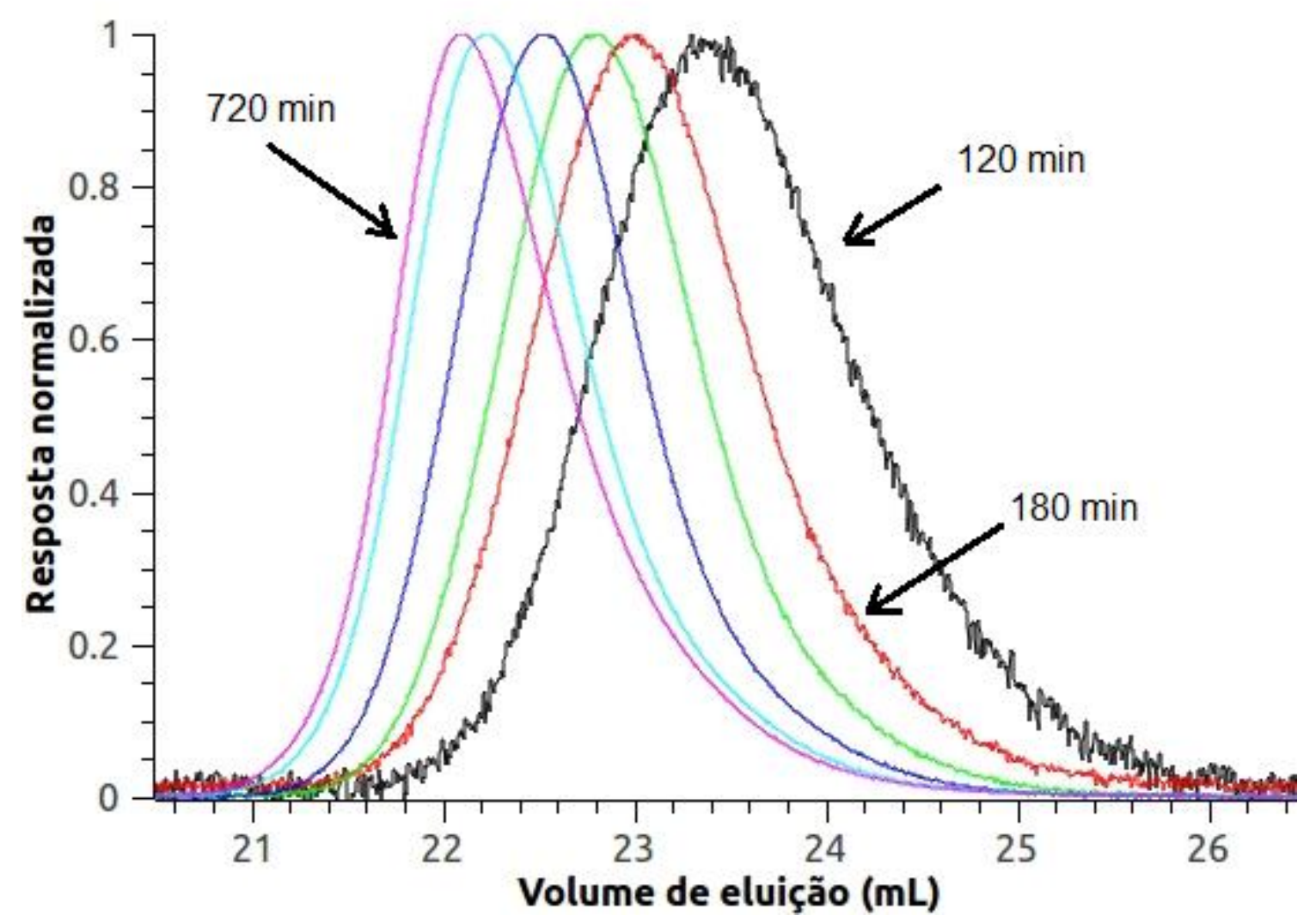

Figura 46 - Sinal de espalhamento de luz observado para amostras do experimento P12. 


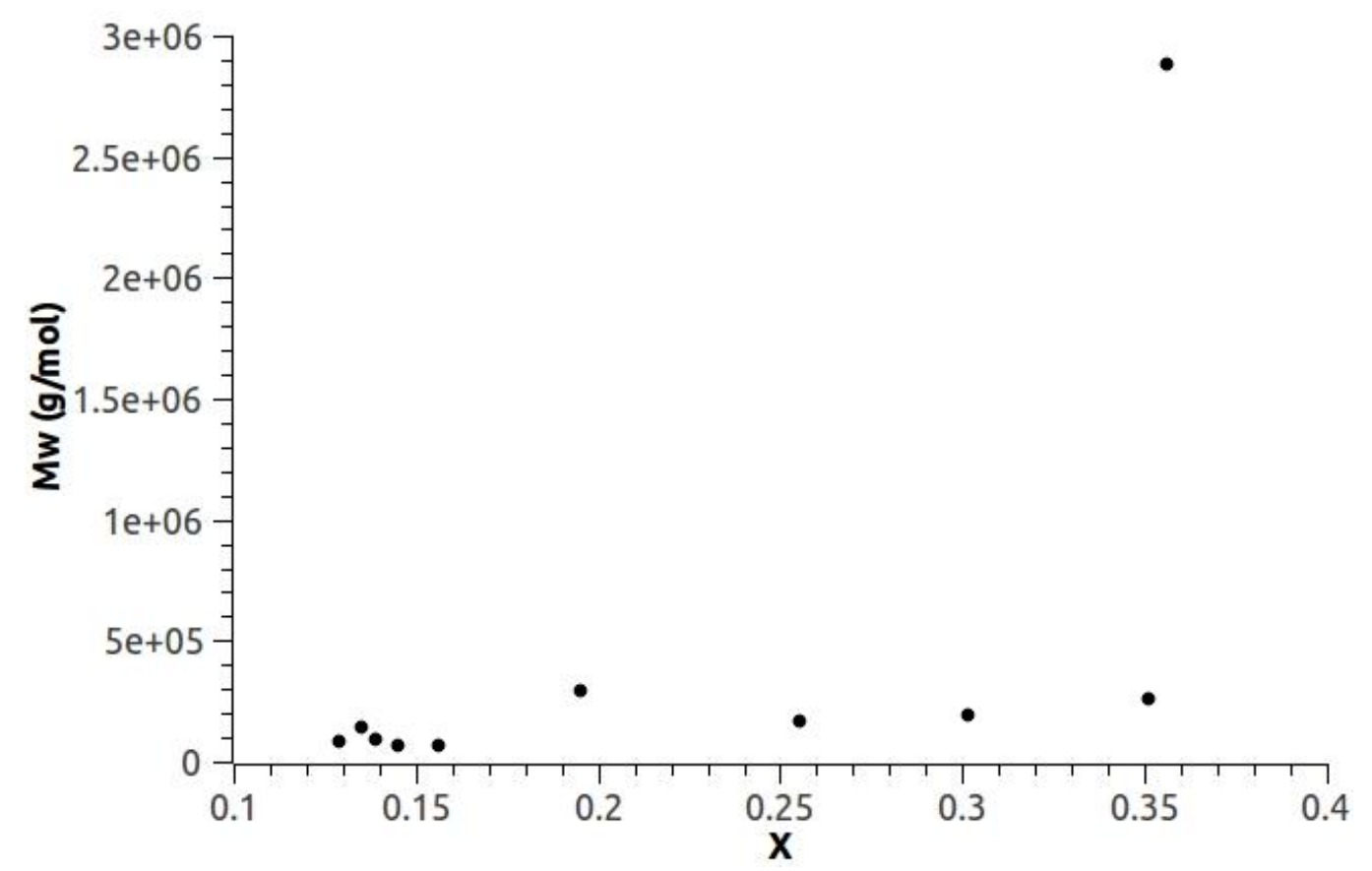

Figura 47 - Perfil de Mw em função da conversão de monômero para uma polimerização de divinilbenzeno (experimento P3).

A influência da quantidade inicial de DVB sobre a arquitetura molecular de copolímeros produzidos pela técnica NMRP está ilustrada na Figura 48.

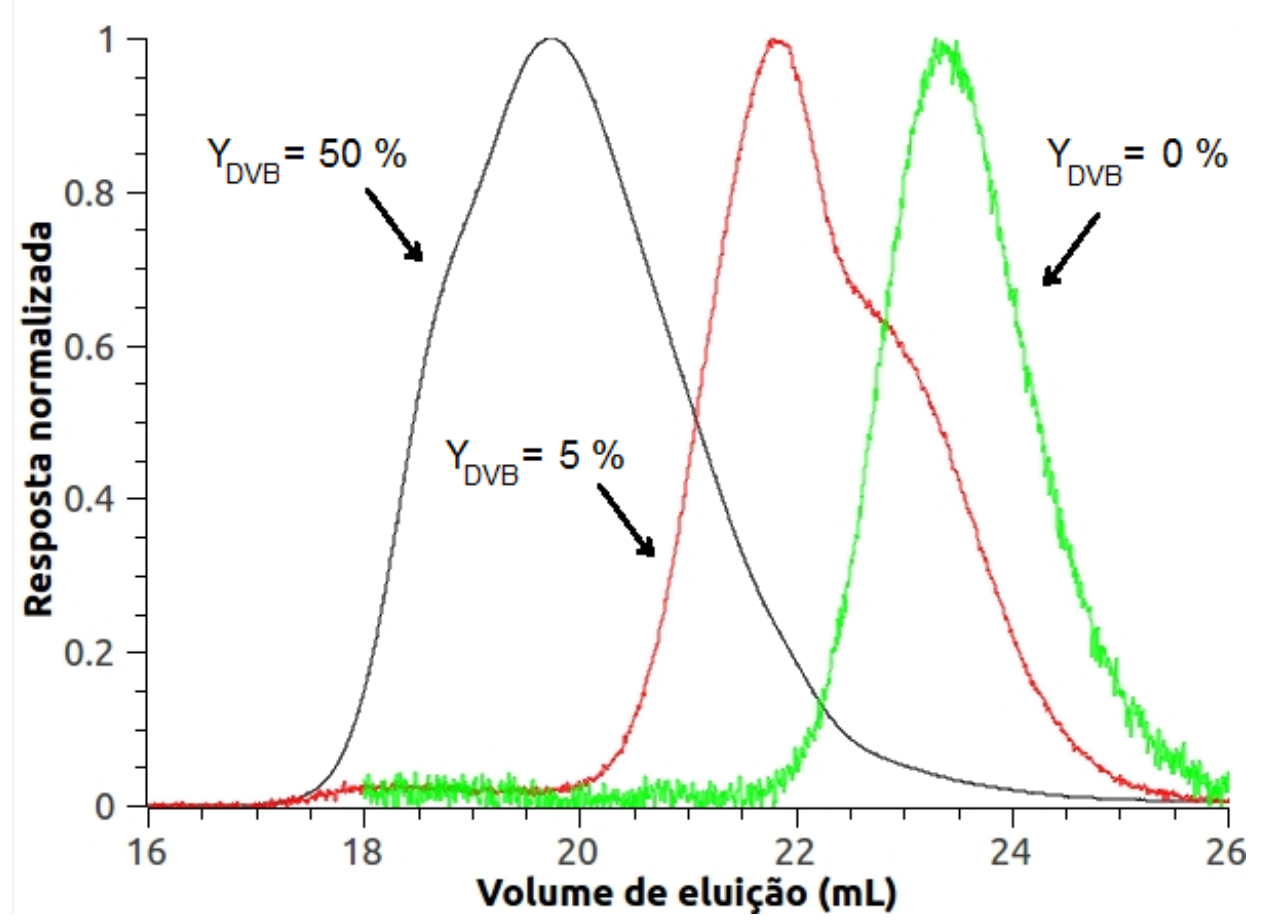

Figura 48 - Efeito do conteúdo inicial de DVB sobre os sinais de MALLS obtidos para amostras coletadas em $\mathrm{t}=180$ minutos de reação. 
Amostras com o mesmo tempo de reação, para três concentrações iniciais diferentes de DVB, são comparadas em termos de sinal de MALLS. A comparação com uma amostra de polímero linear $\left(Y_{D V B}=0\right)$ destaca o efeito da quantidade de DVB sobre a estrutura molecular do material. Verifica-se que a distribuição de tamanhos de cadeia se torna mais larga e com menores tempos de eluição à medida que se aumenta a quantidade inicial de DVB.

A concentração inicial de monômeros tem um efeito importante sobre a taxa das polimerizações NMRP, conforme mostrado na Figura 49. Nesta figura, são comparados processos NMRP em suspensão aquosa a $130^{\circ} \mathrm{C}$ com $50 \%$ (P12) e 20\% (P11) de monômero em relação à fase orgânica. Diferenças na concentração inicial de DVB, em geral, não afetam consideravelmente o perfil de conversão.

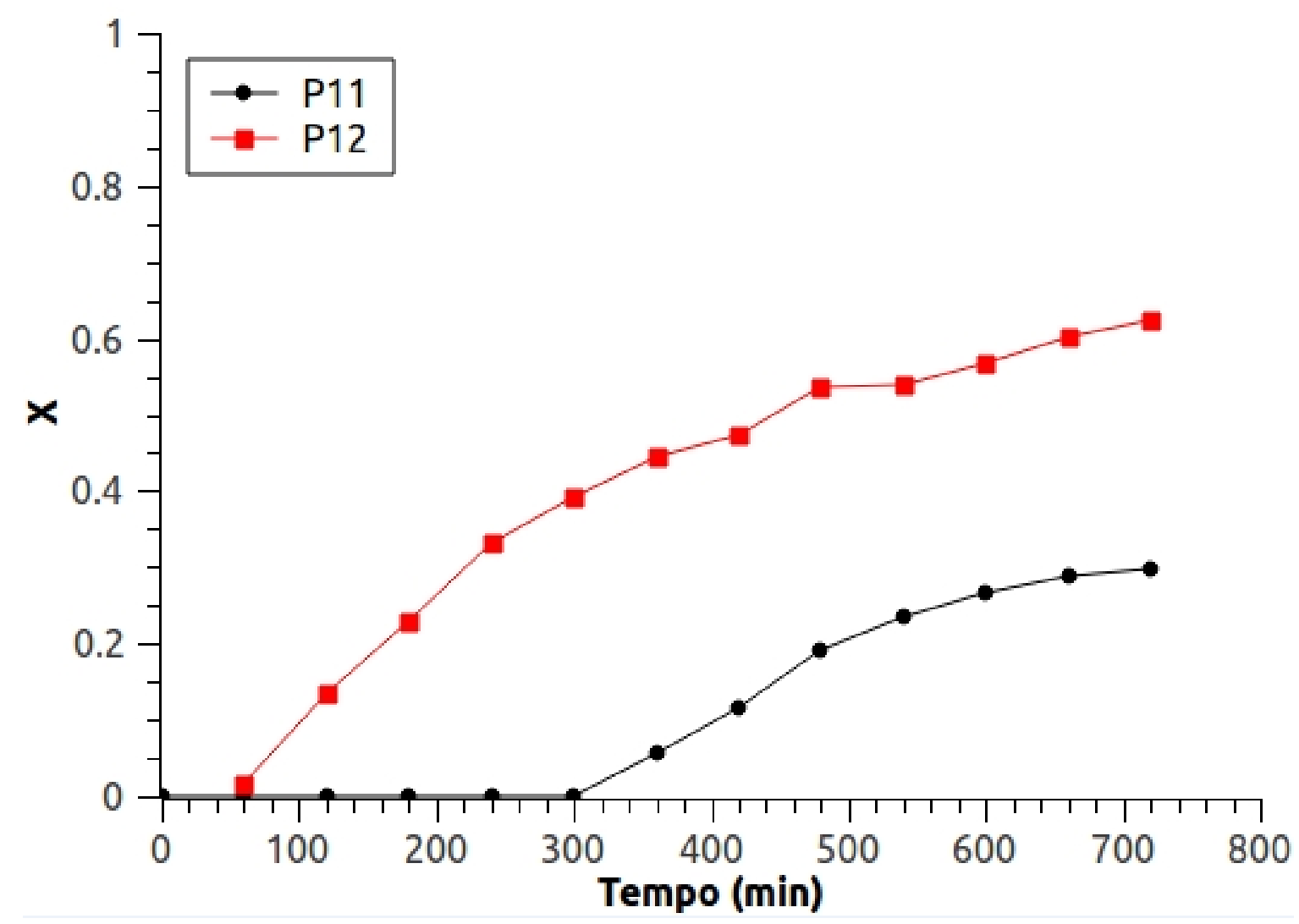

Figura 49 - Efeito da diluição inicial de monômeros sobre a evolução da conversão com o tempo de reação para polimerizações NMRP a $130^{\circ} \mathrm{C}$.

Um notável decréscimo na taxa de polimerização é observando quando a concentração inicial de monômero muda de 50\% para 20\%. Após 12 horas de reação, uma conversão de monômero próxima de $60 \%$ foi obtida para o caso com 
$50 \%$ de monômeros enquanto que a conversão correspondente para o caso com $20 \%$ de monômeros foi de $30 \%$.

A Figura 50 apresenta as dinâmicas da conversão de monômero e de fração de gel durante uma polimerização FRP de estireno-divinilbenzeno (experimento P7). Estes dados mostram a alta taxa de polimerização do sistema FRP quando comparado com o NMRP. Além disso, com o sistema FRP, obtém-se rápida gelificação (em torno de $45 \mathrm{~min}$, 20\% de monômero foram convertidos, conforme mostrado na Figura 50), utilizando-se apenas 1\% de DVB na mistura de monômeros. A Figura 51 apresenta a evolução da fração de gel para uma copolimerização NMRP.

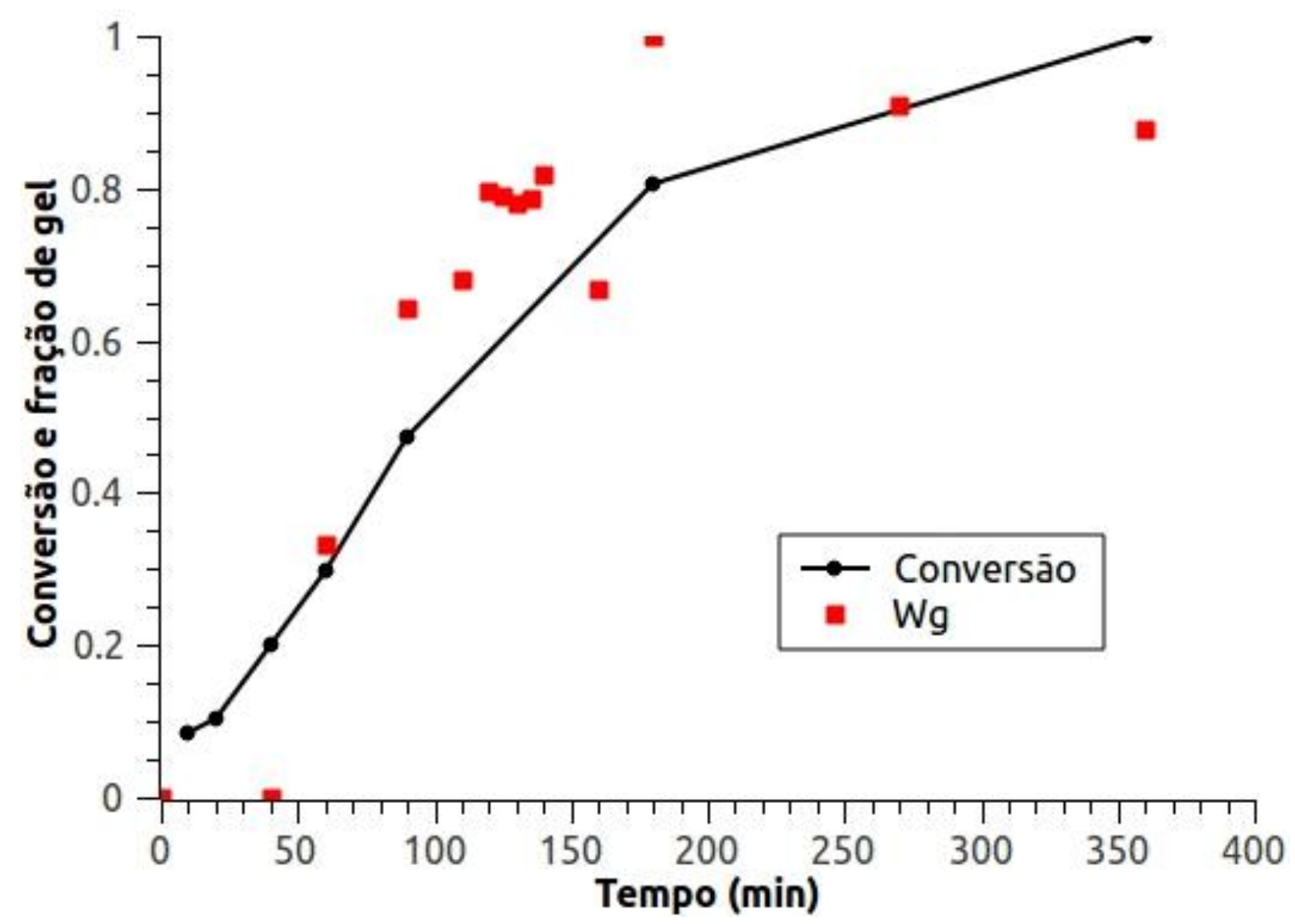

Figura 50 - Evolução da conversão de monômero $(X)$ com o tempo e da fração de gel em massa $(\mathrm{Wg})$ para FRP de estireno-divinilbenzeno em suspensão aquosa a 90ํㅡ (experimento $\mathrm{P} 7$ ). 


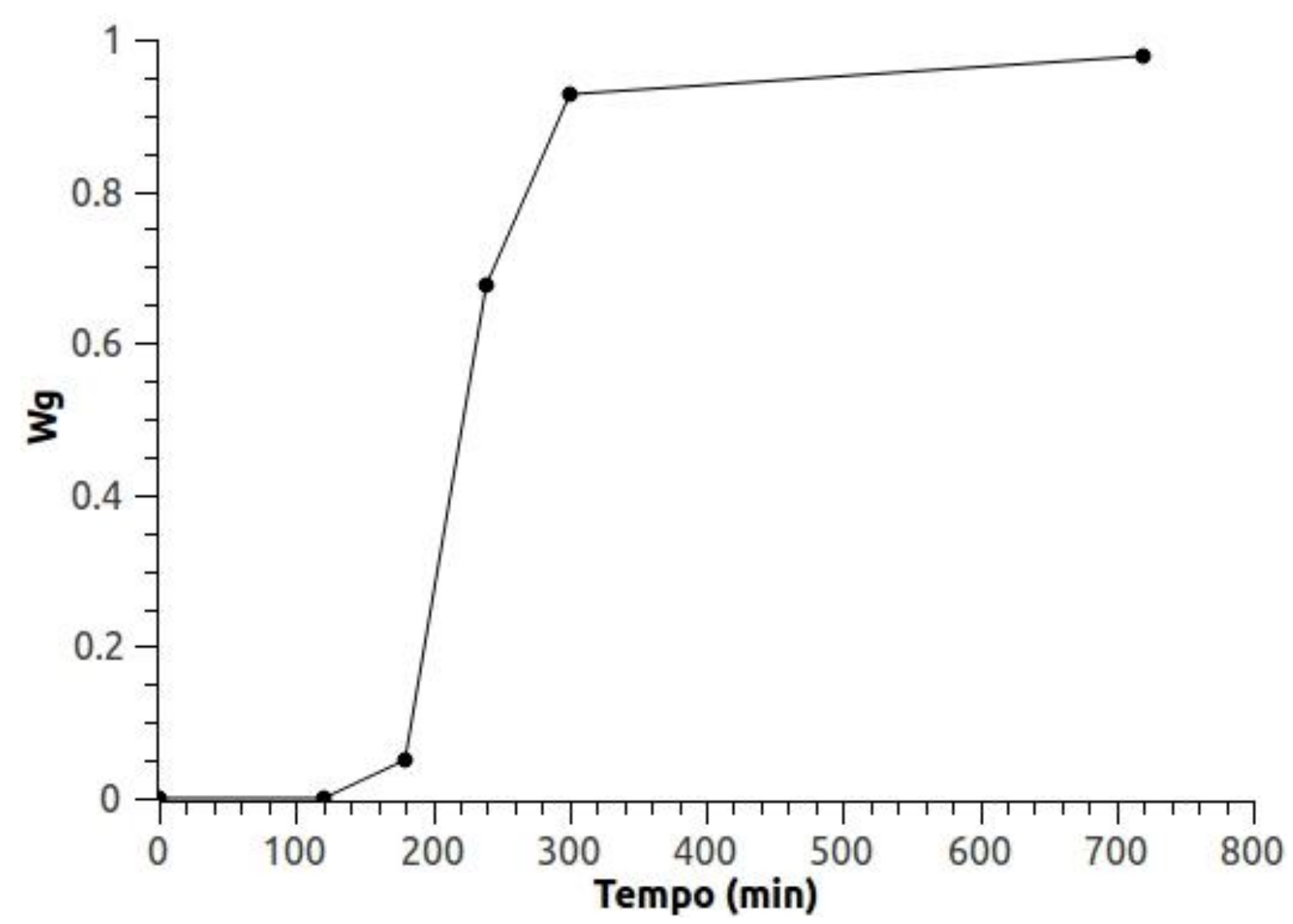

Figura 51 - Evolução da fração de gel com o tempo. Medições obtidas no experimento P9.

Pode-se notar que, mesmo com uma quantidade bem maior de DVB (50\%), o experimento P9 apresentou um tempo de gelificação consideravelmente maior do que o experimento P7. Isto reforça a característica viva dos experimentos mediados por nitróxido.

Os polímeros formados nas reações em suspensão foram submetidos à análise de microscopia eletrônica de varredura (Scanning Electron Microscopy SEM). O objetivo deste estudo foi estabelecer uma conexão entre as condições de síntese e a morfologia do produto. Em particular, foi analisada a formação de nano e microestruturas devido à ocorrência de gelificação não uniforme durante a síntese de estireno-divinilbenzeno. Resultados representativos são mostrados nas figuras 52-57. Micrografias de amostras de estireno-divinilbenzeno de experimentos a $90^{\circ} \mathrm{C}$ e diferentes quantidades de DVB são comparadas na Figura 52. 


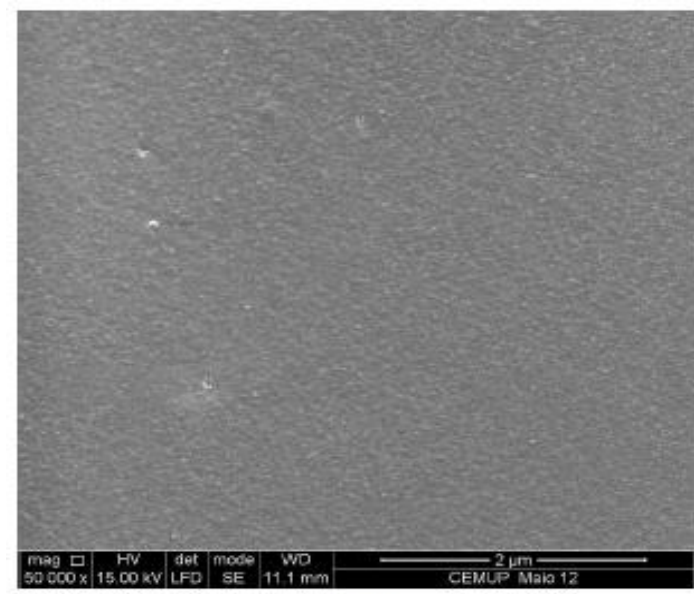

(a)

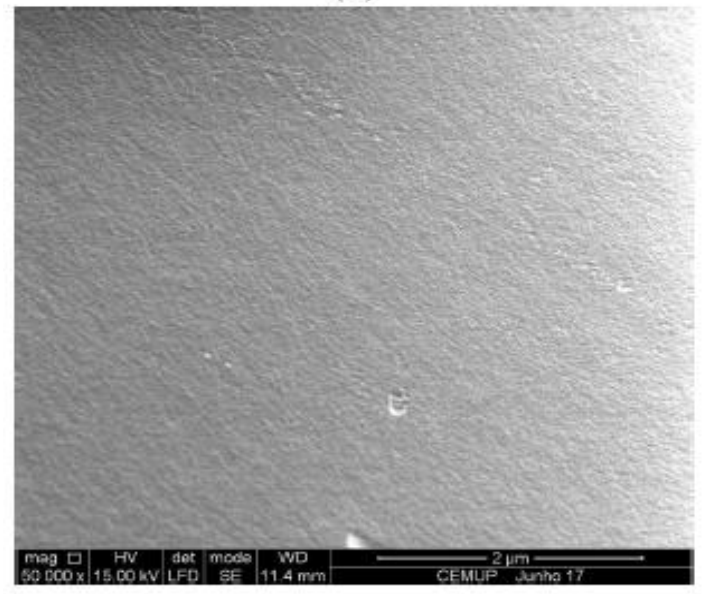

(c)

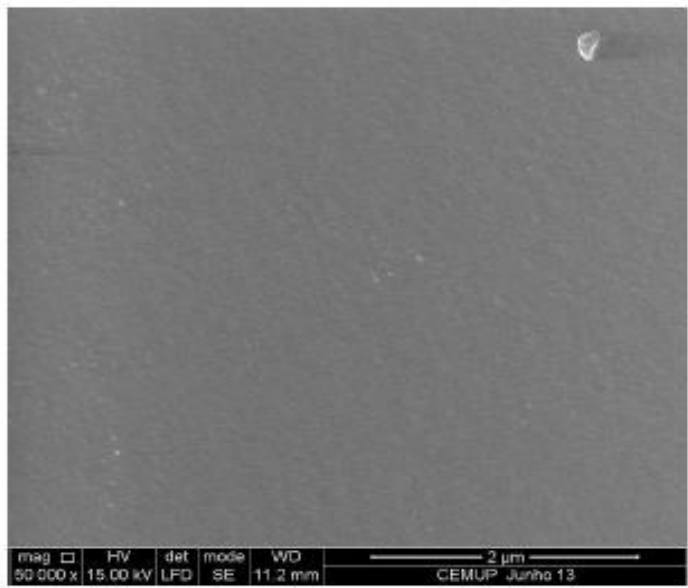

(b)

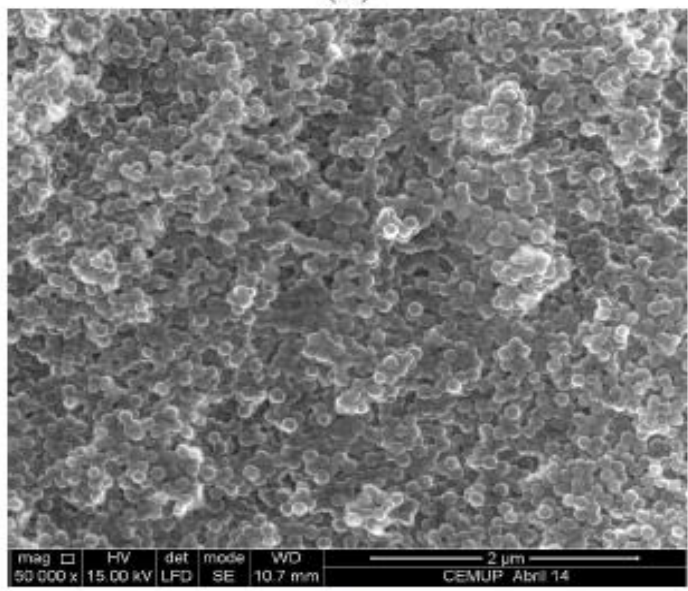

(d)

Figura 52 - Micrografias SEM de amostras de estireno-divinilbenzeno de copolimerizações com diferentes quantidades de DVB. Experimentos: (a) P1; (b) P2; (c): P3 e (d): P7.

Superfícies lisas e inexpressivas foram observadas em produtos obtidos das copolimerizações controladas P1, P2 e P3, as quais compõem uma faixa bem larga de concentração de DVB comercial (de 3 a 100\%). Entretanto, partículas esféricas nanométricas podem ser observadas em produtos do experimento P7 (FRP com apenas $1 \%$ de DVB). Mesmo com este único exemplo, confirmam-se ideias de trabalhos anteriores (como o de Dusek, 1996), mostrando que a FRP conduz à separação de fases devido à nano-gelificação (formação de partículas de polímero de escala nanométrica que possuem alto grau de reticulação). No presente trabalho, observa-se que este fenômeno é evitado para as polimerizações NMRP. Tais nanoestruturas também não são observadas em produtos das experiências P4 (NMRP com $100 \%$ de DVB) e P6 (NMRP de estireno), ambas a $90 \stackrel{\circ}{\circ}$ (ver Figura 53 ). 


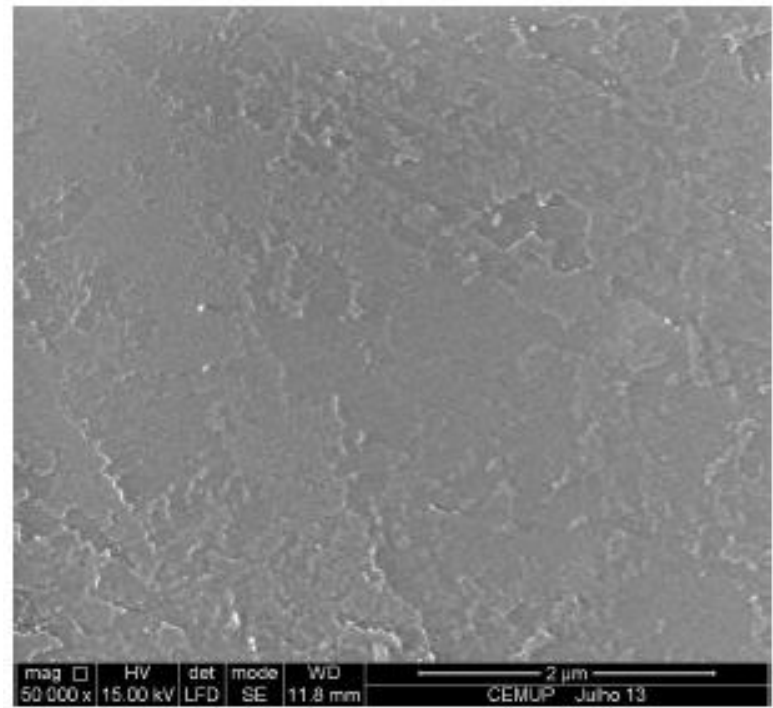

(a)

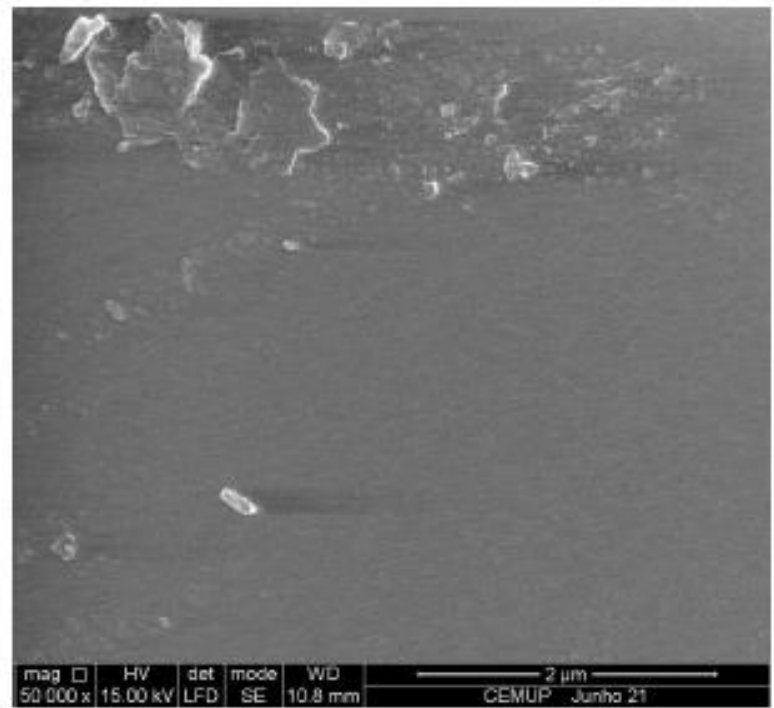

(b)

Figura 53 - Micrografias SEM de amostras de NMRPs conduzidas com 0 e 100\% de DVB. (a): Experimento P6 (0\% de DVB). (b): Experimento P4 (100\% de DVB). Ambas polimerizações a $90^{\circ} \mathrm{C}$.

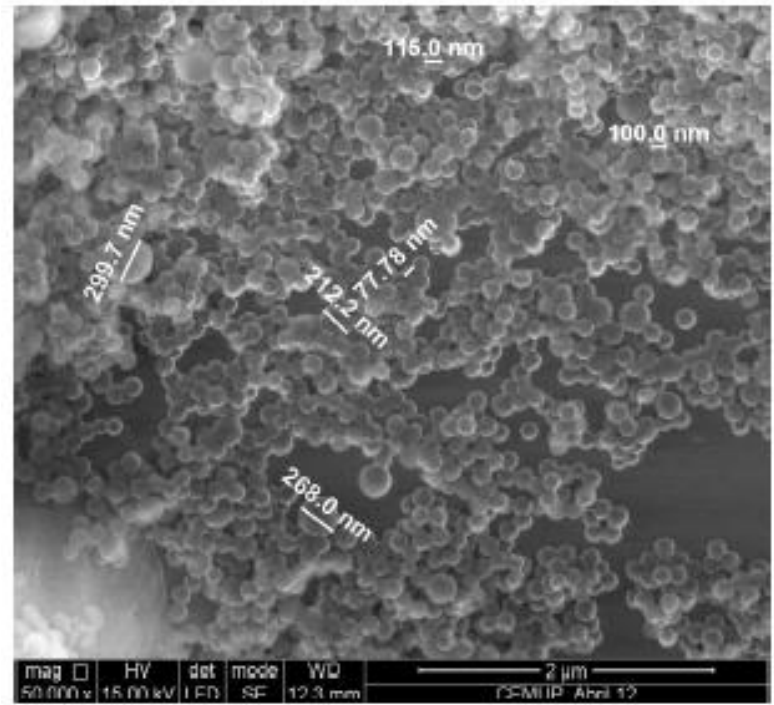

(a)

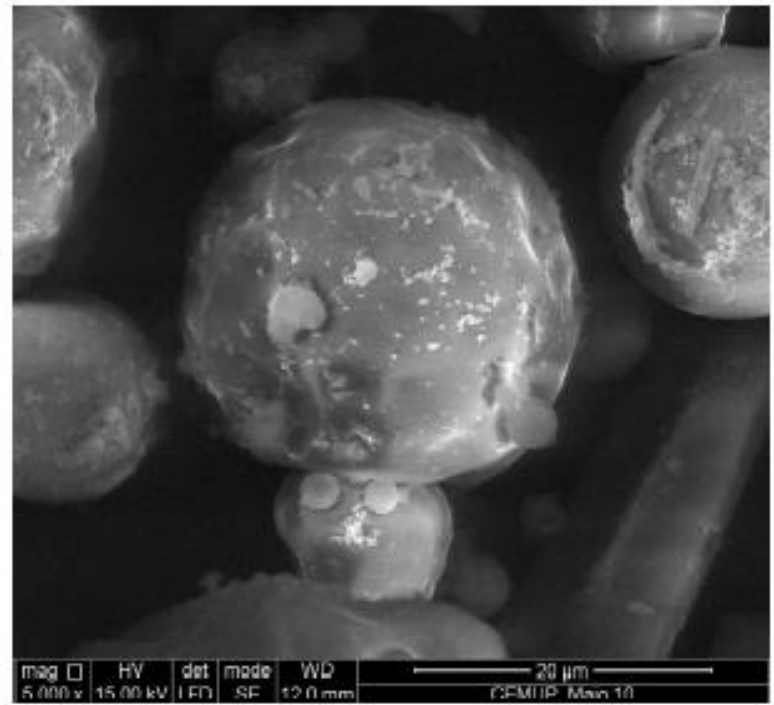

(b)

Figura 54 - Micrografias SEM de amostras de poliestireno (0\% de DVB) sintetizadas por FRP e NMRP. (a): P13 (FRP). (b): P14 (NMRP). Ambas as polimerizações foram realizadas a $90^{\circ} \mathrm{C}$.

Estes resultados também parecem negar a formação de fase segregada (devido à formação de nanogel), que poderia, eventualmente, ocorrer em experimentos NMRP. No entanto, tais nano-estruturas são observadas em produtos da experiência P13, que se trata de uma polimerização do tipo FRP de estireno, conforme apresentado na Figura 54(a). Portanto, segregação hipotética de fase pode não ser conseqüência da nanogelificação. Populações de partículas com 
diferentes tamanhos (por exemplo $20 \mu \mathrm{m}$ e cerca de 10 vezes menor) podem ser identificadas na Figura 54(b), as quais são resultado de uma NMRP de estireno (Experimento P14).

Micrografias SEM de produtos obtidos através de outras polimerizações NMRP de estireno-divinilbenzeno, são mostradas na Figura 55. Duas ampliações são consideradas para produtos dos experimentos P8 (100\% de DVB a $\left.130^{\circ} \mathrm{C}\right)$ e P9 (50\% de DVB a $\left.130^{\circ} \mathrm{C}\right)$. Em ambos os casos, com ampliação de 150 vezes, são discernidos aglomerados de partículas com tamanhos muito diferentes. Com maior ampliação (Figura 55 (b) e (d)), são observadas populações de partículas com larga faixa de tamanhos (de $100 \mu \mathrm{m}$ até menos que $1 \mu \mathrm{m}$ ).

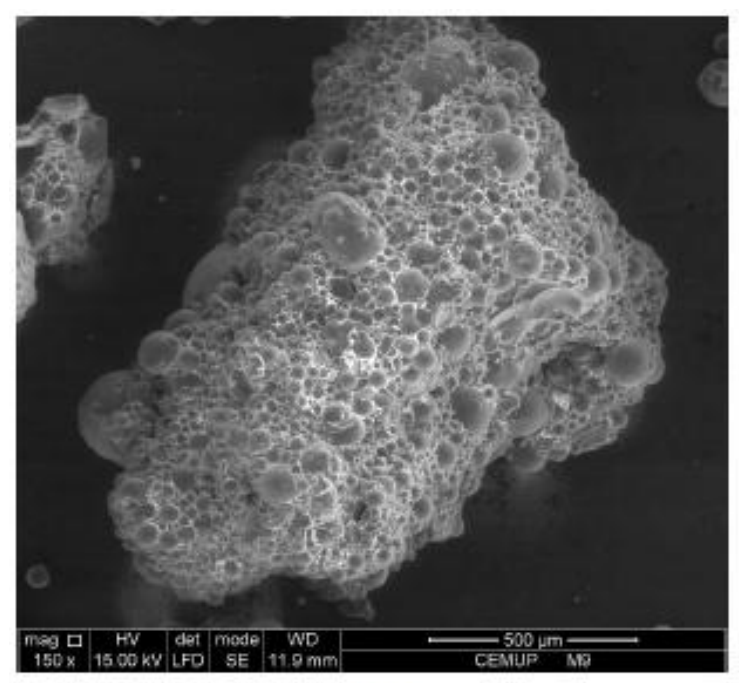

(a)

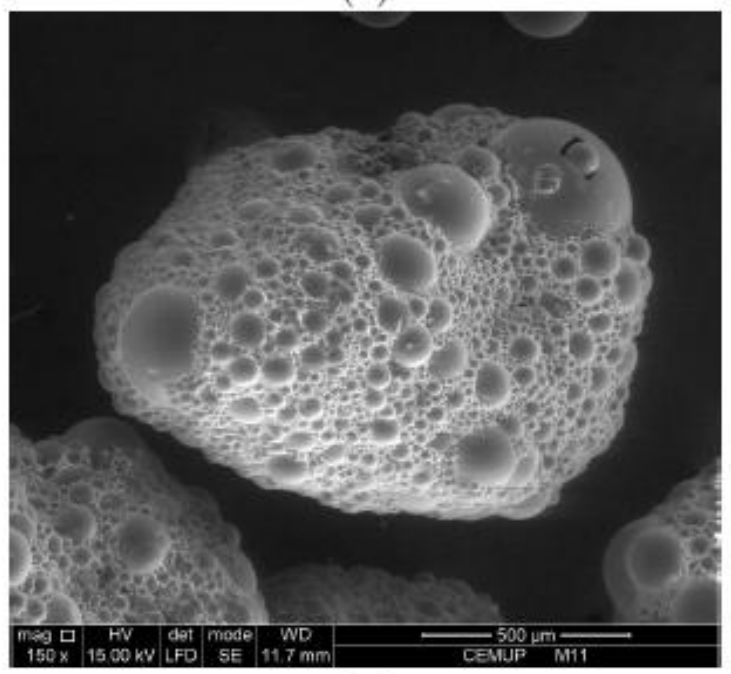

(c)

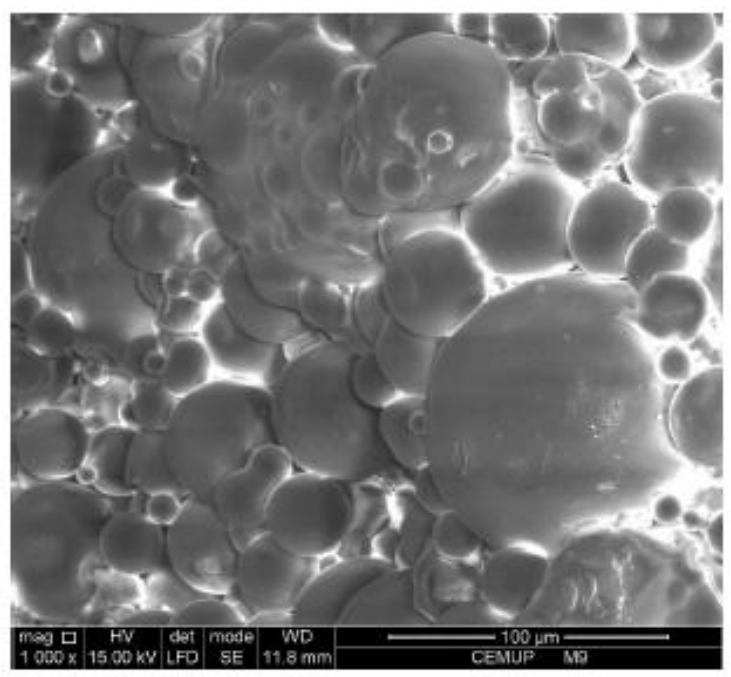

(b)

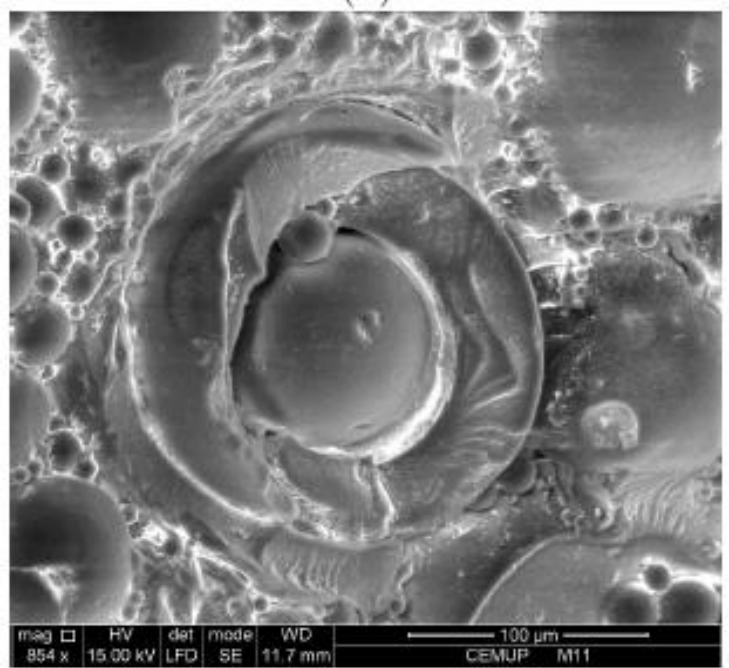

(d)

Figura 55 - Micrografias SEM de copolímeros de estireno-divinilbenzeno sintetizados por NMRP. (a): Experimento P8. (b): Experimento P8. (c): Experimento P9. (d): Experimento P9. Ambos os experimentos foram realizados a $130^{\circ} \mathrm{C}$. 
Em ambos os casos, são observadas regiões de material fundido. É possível que este material fundido apareça devido à temperatura relativamente alta. Estes experimentos foram conduzidos a $130^{\circ} \mathrm{C}$ (a fim de se ter altas taxas de polimerização para o sistema NMRP), que está bem acima da temperatura de transição vítrea do poliestireno (e possivelmente do polidivinilbenzeno). É admissível que, com estas condições de polimerização, o amolecimento das partículas em suspensão possa causar aglomeração do material polimérico. O pós-tratamento de produtos de polimerização (precipitação em metanol e secagem sob vácuo a $70^{\circ} \mathrm{C}$ ) poderia também contribuir para este processo de aglomeração.

A formação de material fundido também pode ser detectada na Figura 56, na qual, apesar do surgimento de superfícies lisas nas regiões fundidas, partículas micro e nanométricas também são observadas. Para fins de comparação, a Figura 56 mostra a análise de microscopia de produtos obtidos por FRP em suspensões aquosas de estireno-divinilbenzeno a $60^{\circ} \mathrm{C}$ (do trabalho de Gonçalves et al., 2011).

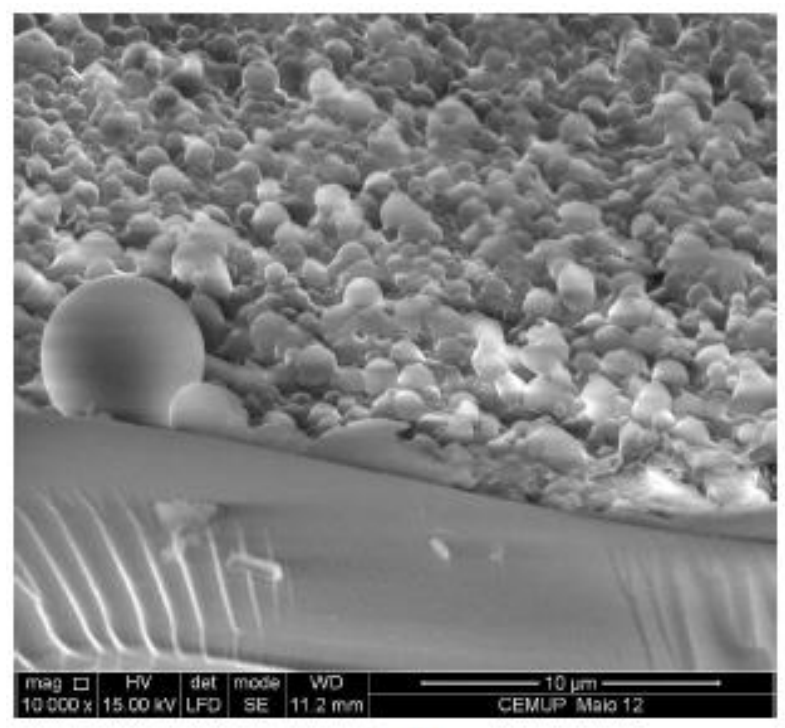

(a)

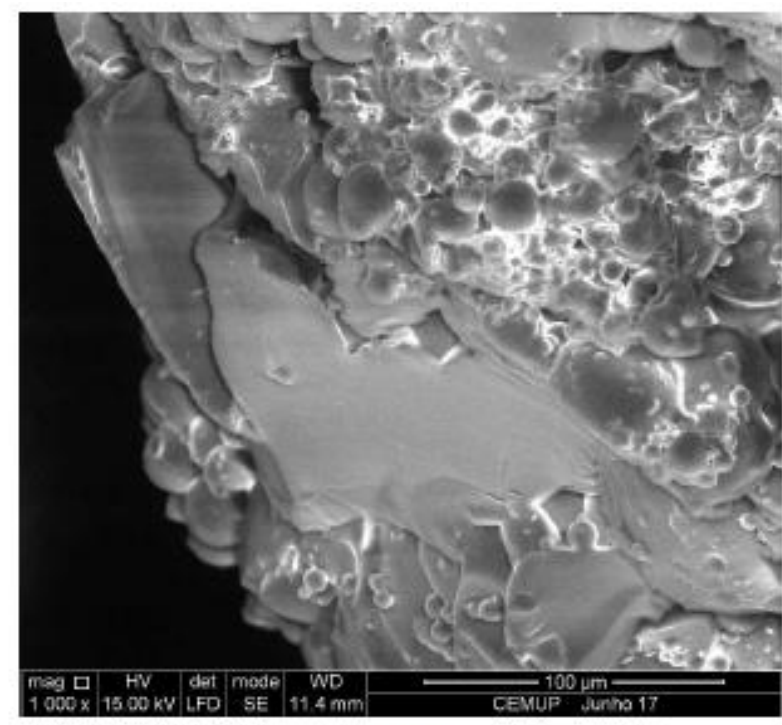

(b)

Figura 56 - Micrografias SEM de amostras de estireno-divinilbenzeno sintetizadas por NMRP. (a): Experimento P1. (b): Experimento P3. Ambos os experimentos foram realizados a $130^{\circ} \mathrm{C}$.

Partículas suspensas de gel com tamanhos até $0,5 \mathrm{~mm}$ podem ser observadas na Figura 57(a). Micro e nanopartículas também podem ser observadas em produtos sintetizados a $60^{\circ} \mathrm{C}$, conforme mostrado na Figura $57(\mathrm{~b})$. Pode-se notar que, para os materiais ilustrados na Figura 57, o processo de síntese envolveu 
uma mistura de solventes que possuem baixa e alta afinidade com o polímero ( $\mathrm{n}$ heptano e tolueno respectivamente) a fim de se promover a formação de macroporos nas partículas de gel.

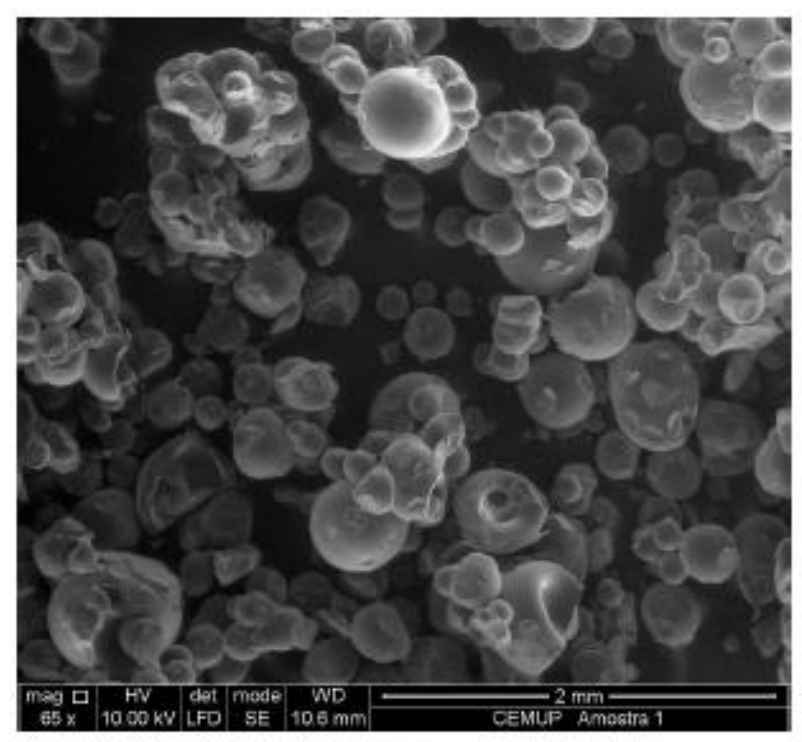

(a)

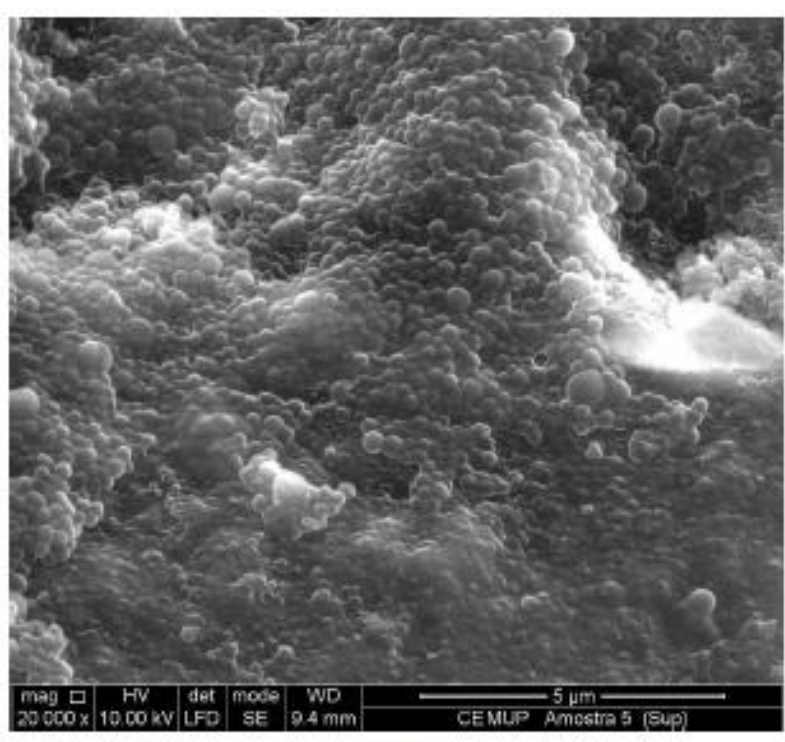

(b)

Figura 57 - Micrografias SEM de amostras de estireno-divinilbenzeno sintetizadas por FRP a $60^{\circ} \mathrm{C}$. (a): Experimento com $\phi_{M}=50 \%, Y_{D V B}=10 \%, Y_{I D B}=1,25 \%$ (neste experimento uma mistura $50 / 50 \mathrm{v} / \mathrm{v}$ de tolueno/n-heptano foi usada como solvente). (b): Experimento com $\phi_{M}=50 \%, Y_{D V B}=20 \%, Y_{I D B}=$ $1,25 \%$ (neste experimento uma mistura $25 / 75 \mathrm{v} / \mathrm{v}$ de tolueno/n-heptano foi usada como solvente).

Estruturas macroporosas com diâmetro em torno de $5 \mu \mathrm{m}$ foram identificadas, conforme mostrado no trabalho de Gonçalves et al. (2011). No presente trabalho, somente solventes com boa afinidade termodinâmica com polímero (tolueno e xileno) foram utilizados, pois se pretendeu estudar o efeito da técnica NMRP sobre a dispersão de massas moleculares dos produtos de estireno-divinilbenzeno.

Os resultados de SEM aqui descritos mostram que estruturas esféricas de escalas mili, micro e nanométricas são formadas em polimerizações em suspensão de estireno-divinilbenzeno usando-se diferentes condições (FRP, NMRP e diferentes temperaturas). Tais nanoestruturas também foram identificadas em homopolimerização de estireno. Portanto, é difícil concluir, através de microscopia eletrônica de varredura, se estas micro e nanoestruturas são resultados de segregação de fase devido a nano e micro-gelificações no caso das copolimerizações de estireno-divinilbenzeno. Estudos experimentais futuros em 
reatores de microcanais podem, eventualmente, elucidar esta questão e permitir a clara interpretação dos resultados de microscopia.

\subsection{Resultados das simulações}

4.2.1. Análise preliminar referente à modelagem de copolimerizações de estirenodivinilbenzeno

O principal desafio, em termos de modelagem matemática de polimerizações não lineares, reside na determinação da cinética responsável pela formação de ligações cruzadas. Esta cinética envolve diferentes tipos de radicais (de estireno, DVB e PDBs) e diferentes tipos de duplas ligações pendentes. As características das redes poliméricas são diretamente afetadas pela velocidade das reações de ligação cruzada. Na literatura, discordâncias têm sido observadas para os parâmetros cinéticos referentes a estas reações. Gonçalves et al. (2007, 2010) utilizaram parâmetros cinéticos publicados por Hecker (2000) em suas simulações e obtiveram uma previsão do ponto de gel adiantada em relação aos dados experimentais. Esta discrepância foi corrigida através da atribuição de valores aparentes de constante cinética de ligação cruzada. Estas constantes aparentes precisam ser reajustadas em função da concentração inicial de divinilbenzeno, conforme constatado por Gonçalves et al. (2011). Além disso, mesmo com o ajuste de constantes aparentes de ligação cruzada, não é possível prever com exatidão os perfis de massa molecular média mássica ( $\mathrm{Mw}$ ) e fração de gel (wg), simultaneamente. O parâmetro referente à cinética de ligação cruzada está representado por $\mathrm{C}_{\mathrm{p}}$, conforme mostrado na Tabela 8. Neste estudo preliminar, foi utilizado o Modelo $B$, pois trata-se de um modelo simplificado capaz de prever os períodos pré e pós-gelificação em copolimerizações convencional e mediada por nitróxido. Além disso, este modelo permite a inclusão de reações de ciclização, que será feita no item 4.2.2. 
Tabela 8 - Parâmetros cinéticos utilizados na análise preliminar.

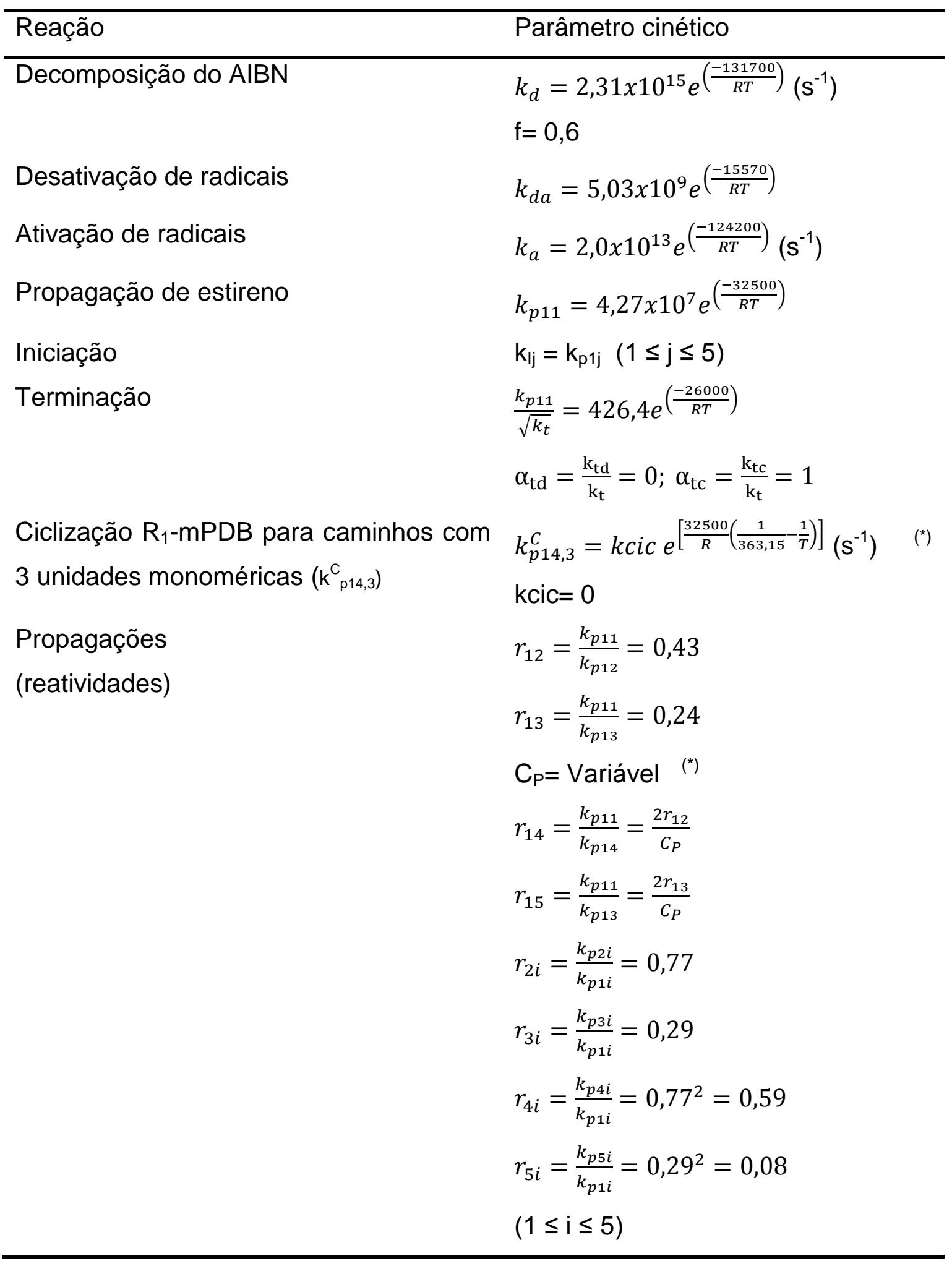

Constantes cinéticas em $\mathrm{L} /(\mathrm{mol} . \mathrm{s})$, exceto quando indicada outra unidade; $\mathrm{R}=8,314 \mathrm{~J} /(\mathrm{mol} . \mathrm{K})$; $\mathrm{k}_{\mathrm{td}}$ e $\mathrm{k}_{\mathrm{tc}}$ : Constantes cinéticas de terminação por dismutação e combinação, respectivamente; Referência: Gonçalves et al. (2010), exceto $\left(^{*}\right)$ : Presente trabalho. 
A Tabela 8 lista os parâmetros cinéticos utilizados nas simulações apresentadas neste item. Os parâmetro marcados com asterisco foram ajustados no presente trabalho, através de uma análise comparativa qualitativa entre os resultados experimentais e previstos pelo modelo. Este mesmo tipo de ajuste foi feito nos estudos posteriores (tabelas 9, 10, 11 e 12). $r_{\mathrm{ji}}$ representa a razão de reatividade e os índices das constantes cinéticas possuem o mesmo significado atribuído no capítulo 3. Os valores do parâmetro $C_{p}$ estão mostrados nas legendas das figuras a seguir 58 e 59.

É importante ressaltar que essa análise inicial não leva em conta as reações de ciclização $(k c i c=0)$. Neste caso, verifica-se que, tanto os resultados da literatura quanto os resultados do presente item, apresentam o mesmo problema de ajuste simultâneo entre $\mathrm{Mw}$ e $\mathrm{Wg}$. Vale ressaltar que nos modelos, a molécula de gel é definida de diferentes formas. Por exemplo, nos modelos B e C, a molécula de gel é formada quando duas moléculas poliméricas da geração 4 reagem entre si. Experimentalmente, o gel é definido como a quantidade de polímero que fica retida no papel de filtro. Isto pode tornar subjetiva a determinação da fração de gel absoluta. Portanto, no presente trabalho, a avaliação dos perfis de fração de gel foi feita comparando-se dois ou mais perfis, referentes a diferentes condições iniciais de reação.

As Figuras 58 e 59 ilustram este problema inicial através da simulação de uma copolimerização convencional (FRP), utilizando-se dados da literatura. Observa-se que são necessários valores distintos de $C_{p}$ para ajustar cada variável (Mw e Wg) numa mesma reação. Este mesmo problema é verificado quando se realiza simulações com dados experimentais de reações NMRP do presente trabalho. As Figuras 60 e 61 apresentam os resultados.

Gonçalves et al. $(2007,2010,2011)$ sugerem a inclusão de reações de ciclização, a fim de corrigir as discrepâncias referentes à localização do ponto de gel e aos perfis de Mw e Wg. No item a seguir, são discutidos os efeitos da inclusão das reações de ciclização no Modelo $B$. 


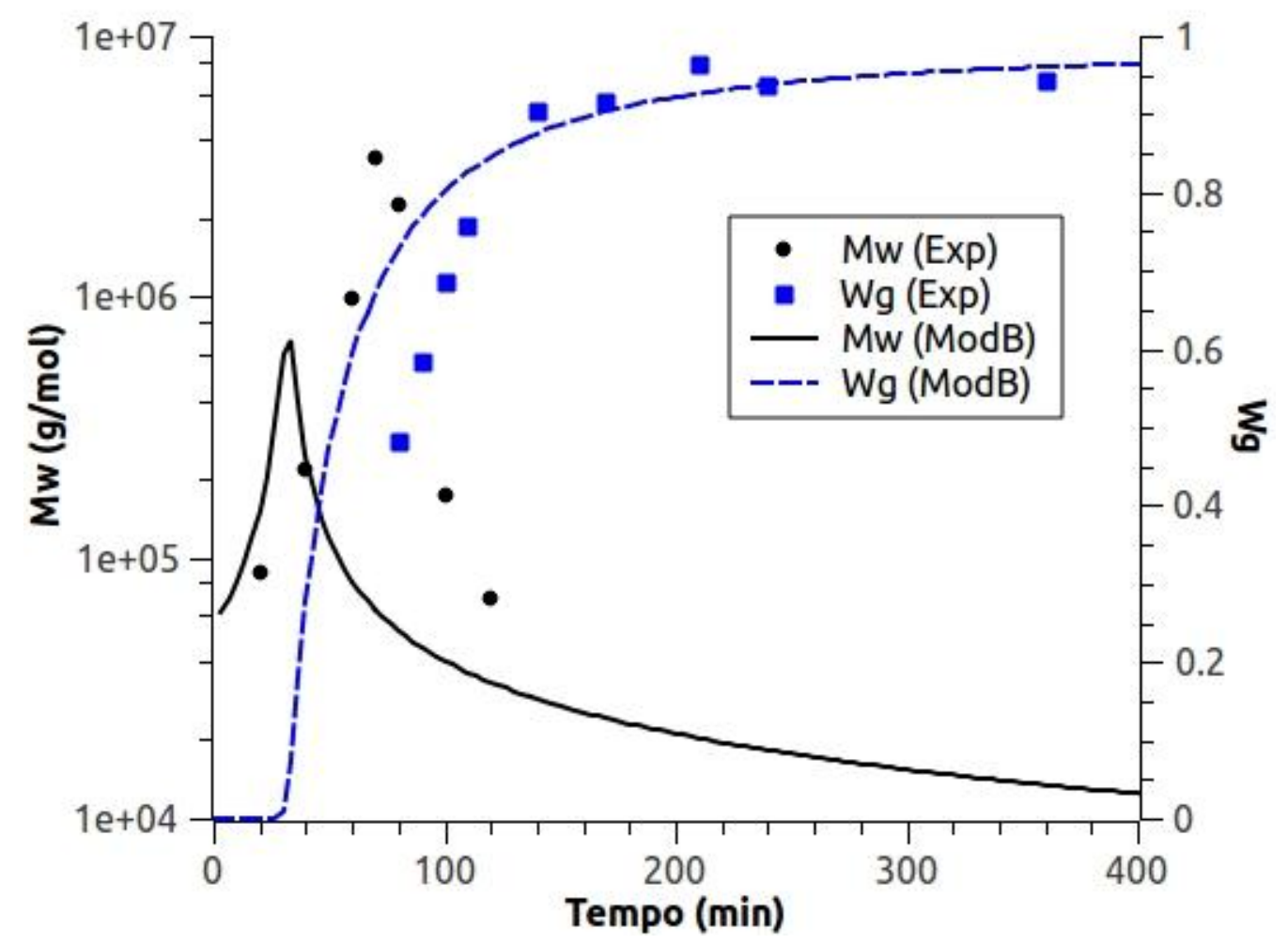

Figura 58 - Simulações realizadas com os dados experimentais de Gonçalves et al. (2011) - Run 5 . $\mathrm{C}_{\mathrm{p}}=0,10$.

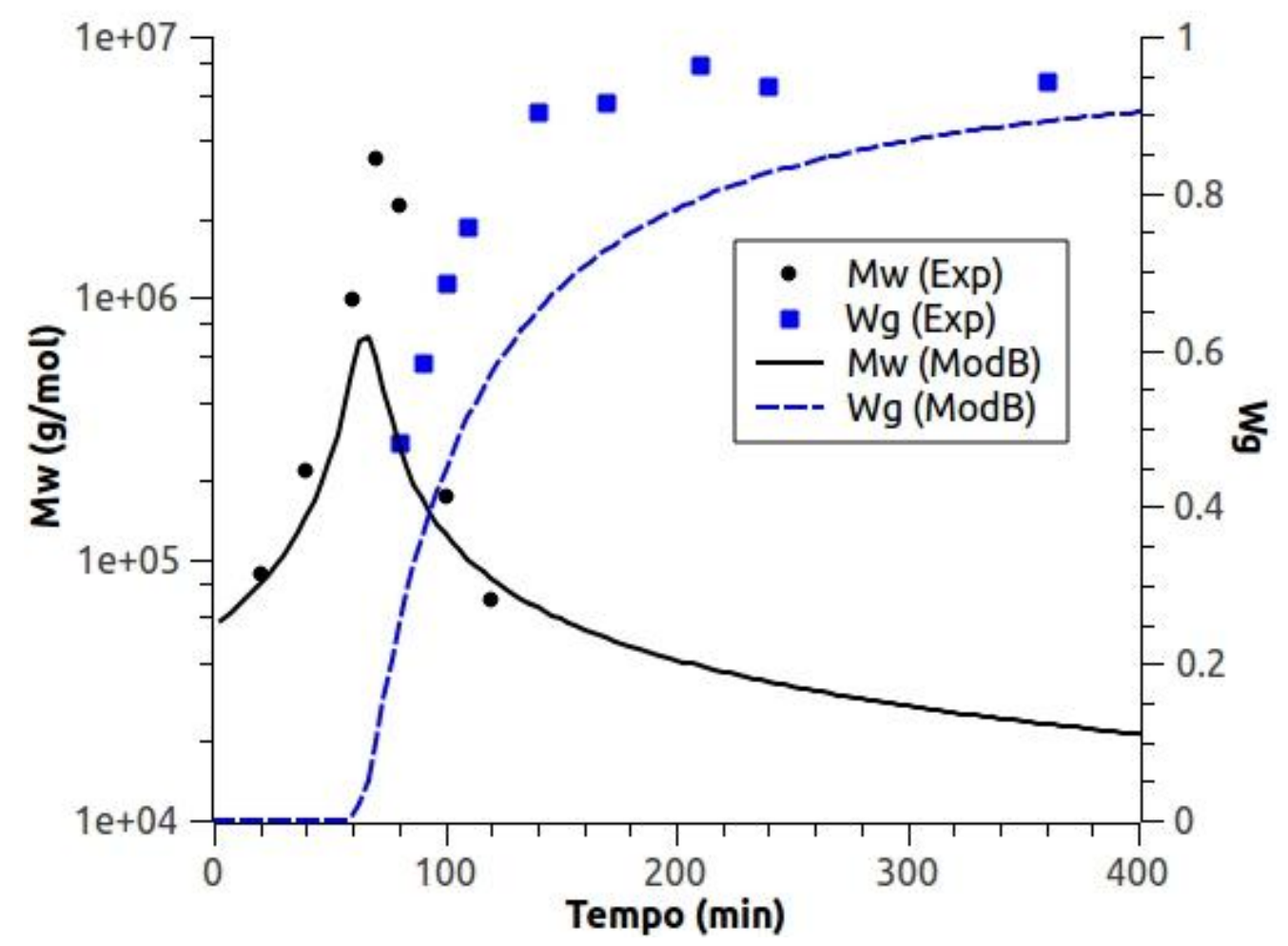

Figura 59 - Simulações realizadas com os dados experimentais de Gonçalves et al. (2011) - Run 5. $C_{p}=0,05$. 


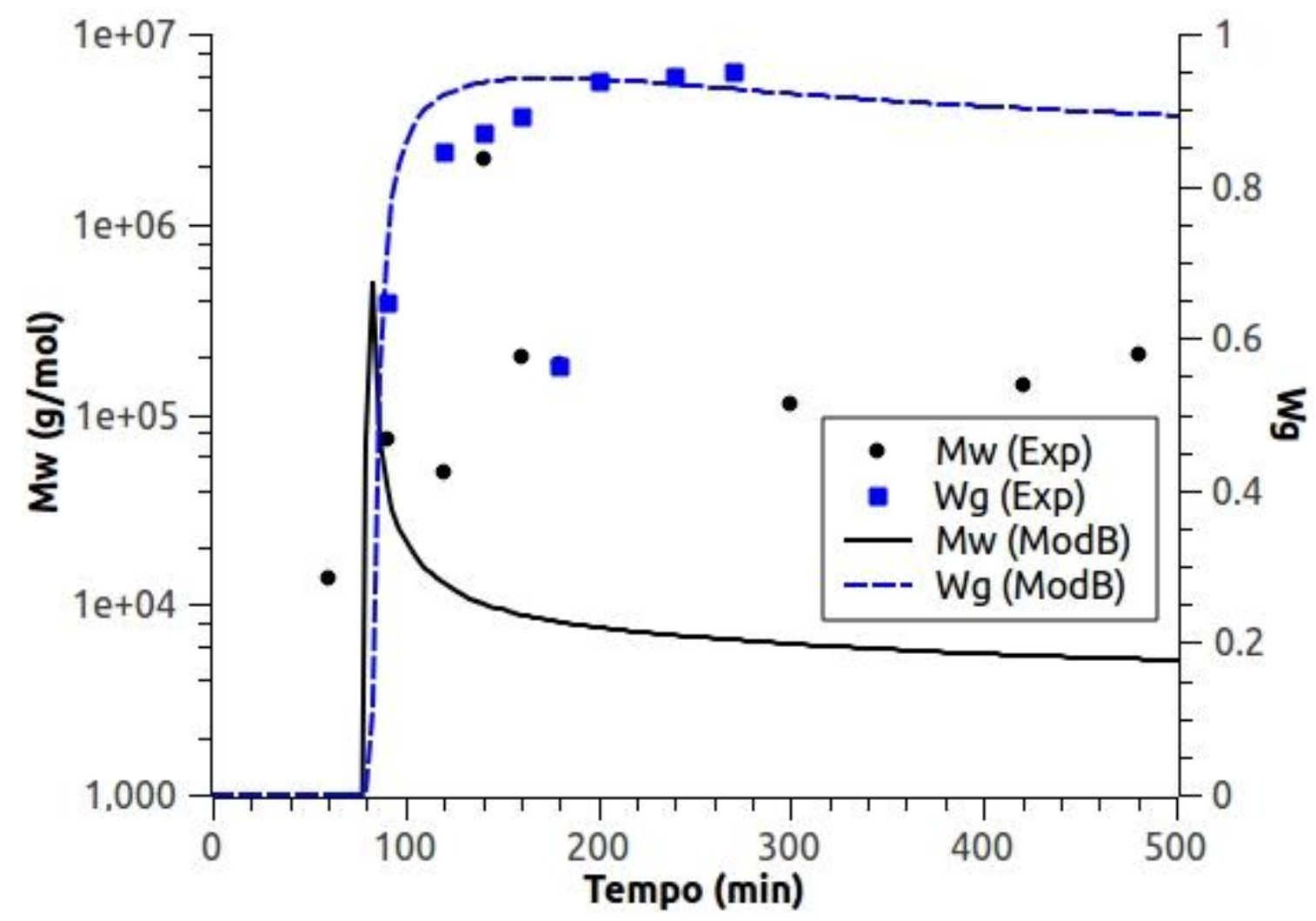

Figura 60 - Simulações realizadas com o experimento $P 2 . C_{p}=0,20$.

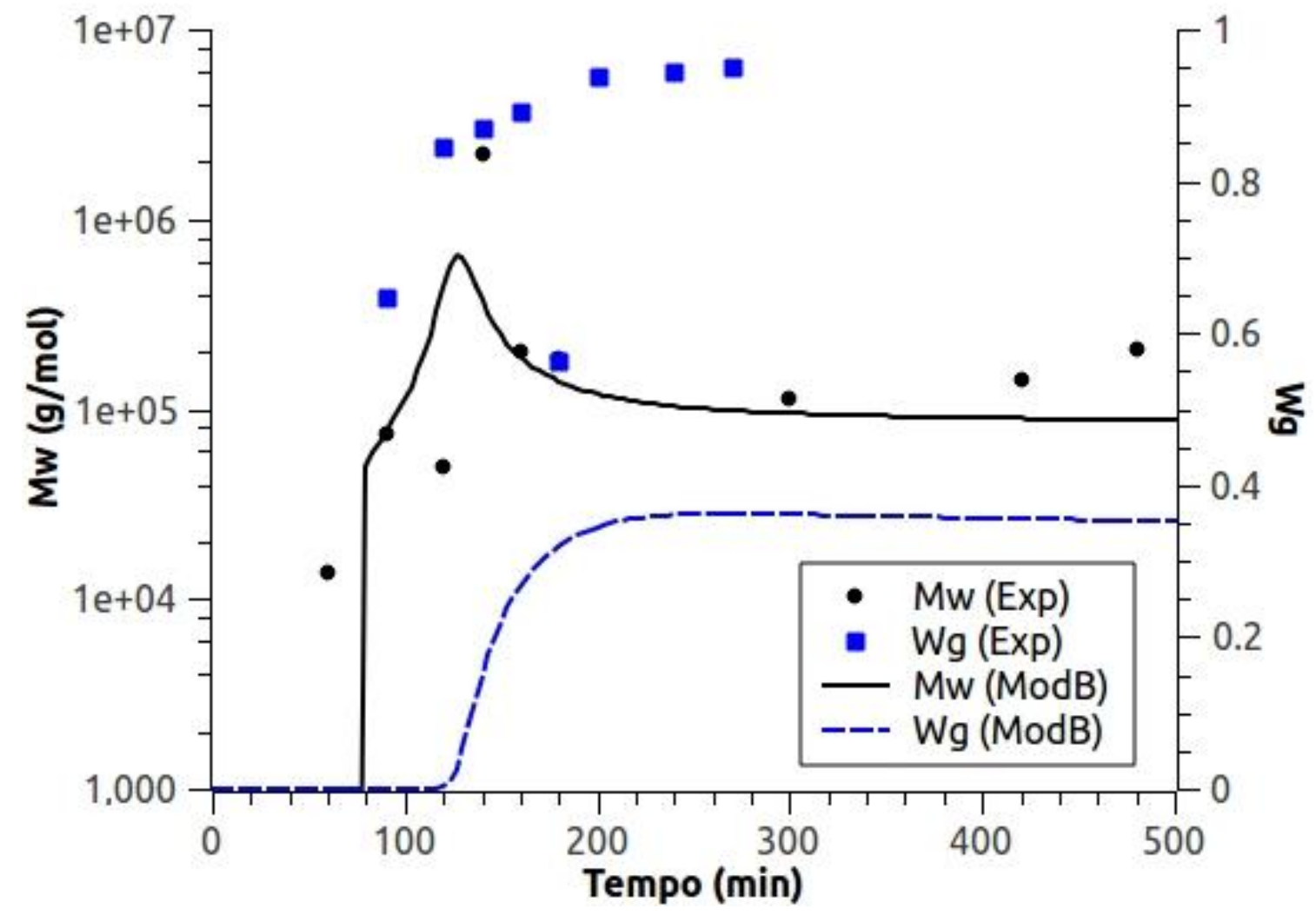

Figura 61 - Simulações realizadas com o experimento P2. $C_{p}=0,025$. 


\subsubsection{Avaliação do efeito das reações de ciclização}

A avaliação do efeito das ciclizações sobre os resultados obtidos com 0 Modelo $\mathrm{B}$, foi feita mantendo-se todos os parâmetros cinéticos constantes, inclusive o $C_{P}$ e variando-se a constante de ciclização kcic, de acordo com a Tabela 9.

A expressão de Arrhenius para a reação de ciclização apresentada nas Tabelas 8 e 9, foi escrita com base na reação de propagação. Assim como nas propagações, a reação de ciclização consiste no ataque de um carbono com um elétron desemparelhado a uma dupla ligação carbono-carbono. Devido a isto, supõe-se que as energias de ativação das reações de propagação e ciclização não apresentem valores muito discrepantes. Desta forma, manteve-se o valor 32500 $\mathrm{J} / \mathrm{mol}$ para a energia de ativação das reações de ciclização.

Tabela 9 - Parâmetros cinéticos utilizados na avaliação do efeito das ciclizações (continua).

\begin{tabular}{|c|c|}
\hline Reação & Parâmetro cinético \\
\hline Decomposição do AIBN & $\begin{array}{l}k_{d}=2,31 \times 10^{15} e^{\left(\frac{-131700}{R T}\right)}\left(\mathrm{s}^{-1}\right) \\
\mathrm{f}=0,6\end{array}$ \\
\hline Desativação de radicais & $k_{d a}=5,03 \times 10^{9} e^{\left(\frac{-15570}{R T}\right)}$ \\
\hline Ativação de radicais & $k_{a}=2,0 \times 10^{13} e^{\left(\frac{-124200}{R T}\right)}\left(\mathrm{s}^{-1}\right)$ \\
\hline Propagação de estireno & $k_{p 11}=4,27 \times 10^{7} e^{\left(\frac{-32500}{R T}\right)}$ \\
\hline Iniciação & $\begin{array}{l}\mathrm{k}_{\mathrm{lj}}=\mathrm{k}_{\mathrm{p} 1 \mathrm{j}} \\
(1 \leq \mathrm{j} \leq 5)\end{array}$ \\
\hline Terminação & $\begin{array}{l}\frac{k_{p 11}}{\sqrt{k_{t}}}=426,4 e^{\left(\frac{-26000}{R T}\right)} \\
\alpha_{\mathrm{td}}=\frac{\mathrm{k}_{\mathrm{td}}}{\mathrm{k}_{\mathrm{t}}}=0 ; \alpha_{\mathrm{tc}}=\frac{\mathrm{k}_{\mathrm{tc}}}{\mathrm{k}_{\mathrm{t}}}=1\end{array}$ \\
\hline $\begin{array}{l}\text { Ciclização } R_{1}-\text { mPDB para caminhos com } 3 \\
\text { unidades monoméricas }\left(k_{p 14,3}^{C} \text { (a) }\right.\end{array}$ & $\begin{array}{l}k_{p 14,3}^{C}=k c i c e^{\left[\frac{32500}{R}\left(\frac{1}{363,15}-\frac{1}{T}\right)\right]}\left(\mathrm{s}^{-1}\right) \\
\text { kcic= Variável }\end{array}$ \\
\hline
\end{tabular}


Tabela 9 - Parâmetros cinéticos utilizados na avaliação do efeito das ciclizações (conclusão).

\begin{tabular}{ll}
\hline Reação & Parâmetro cinético \\
\hline Propagações & $r_{12}=\frac{k_{p 11}}{k_{p 12}}=0,43$ \\
(reatividades) & $r_{13}=\frac{k_{p 11}}{k_{p 13}}=0,24$ \\
$\mathrm{C}_{\mathrm{P}}=0,32$ & $(\mathrm{~b})$ \\
$r_{14}$ & $=\frac{k_{p 11}}{k_{p 14}}=\frac{2 r_{12}}{C_{P}}$ \\
& $r_{15}=\frac{k_{p 11}}{k_{p 13}}=\frac{2 r_{13}}{C_{P}}$ \\
$r_{2 i}$ & $=\frac{k_{p 2 i}}{k_{p 1 i}}=0,77$ \\
$r_{3 i}$ & $=\frac{k_{p 3 i}}{k_{p 1 i}}=0,29$ \\
$r_{4 i}$ & $=\frac{k_{p 4 i}}{k_{p 1 i}}=0,77^{2}=0,59$ \\
$r_{5 i}$ & $=\frac{k_{p 5 i}}{k_{p 1 i}}=0,29^{2}=0,08$ \\
$(1 \leq \mathrm{i} \leq 5)$
\end{tabular}

Constantes cinéticas em L/(mol.s), exceto quando indicada outra unidade; Referência:

Gonçalves et al. (2010), exceto ${ }^{\text {(a) }}$ : Presente trabalho e ${ }^{(b)}$ : Gonçalves et al. (2007).

Conforme descrito no capítulo 3, a implementação do método dos caminhos requer que seja estabelecido um número máximo de unidades monoméricas que um caminho pode possuir $\left(r_{\text {máx }}\right)$. A determinação deste valor máximo foi feita através de simulações preliminares com diferentes casos, nas quais variou-se $r_{\text {máx }}$ e comparouse os resultados. Esta determinação foi feita avaliando-se diferentes variáveis do sistema, conforme mostrado nas Figuras 62 e 63. 


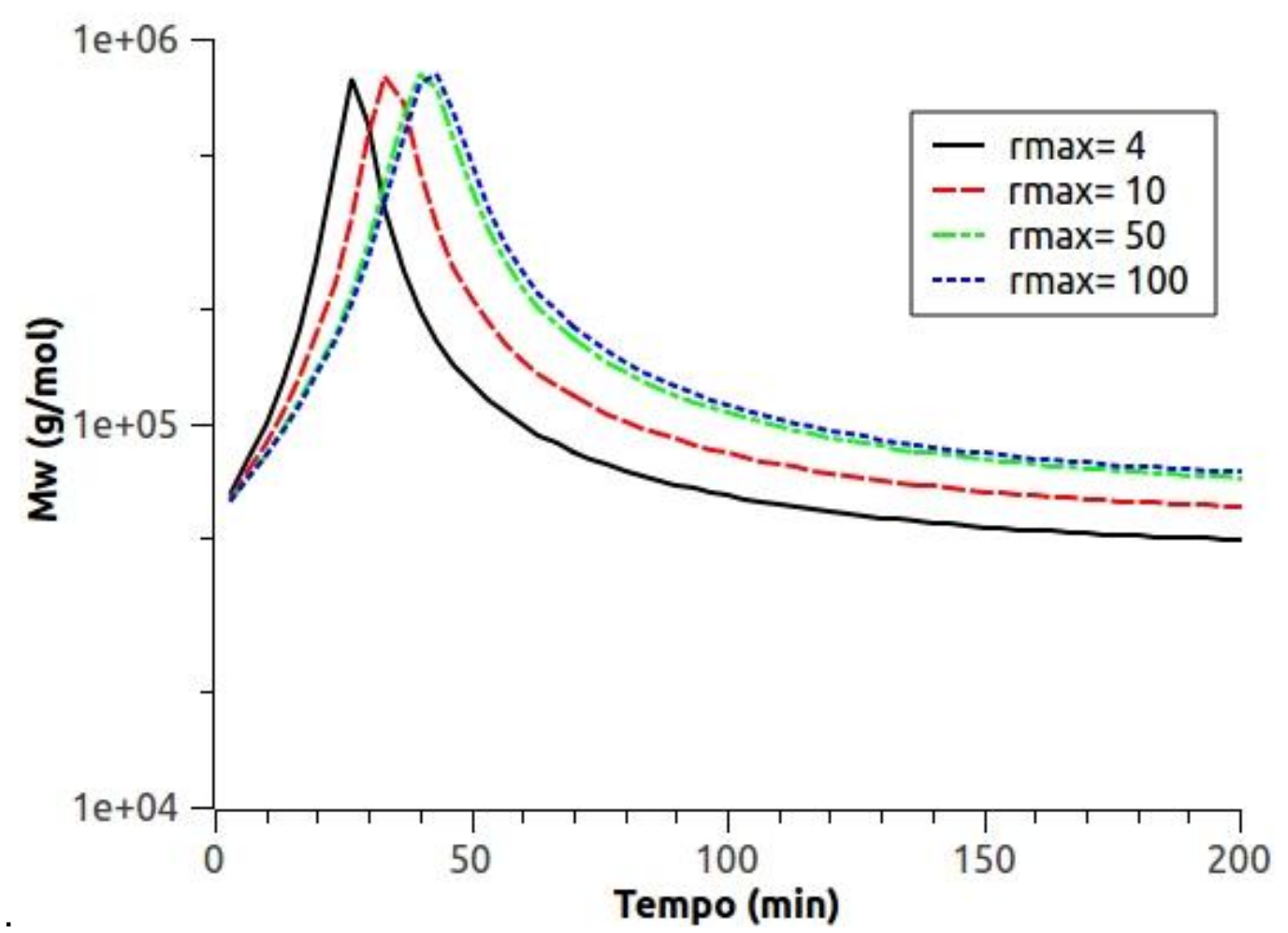

Figura 62 - Perfis de massa molecular média em função de $r_{\text {máx }}$. Dados do experimento P7. $\mathrm{kcic}=450 \mathrm{~s}^{-1}$.

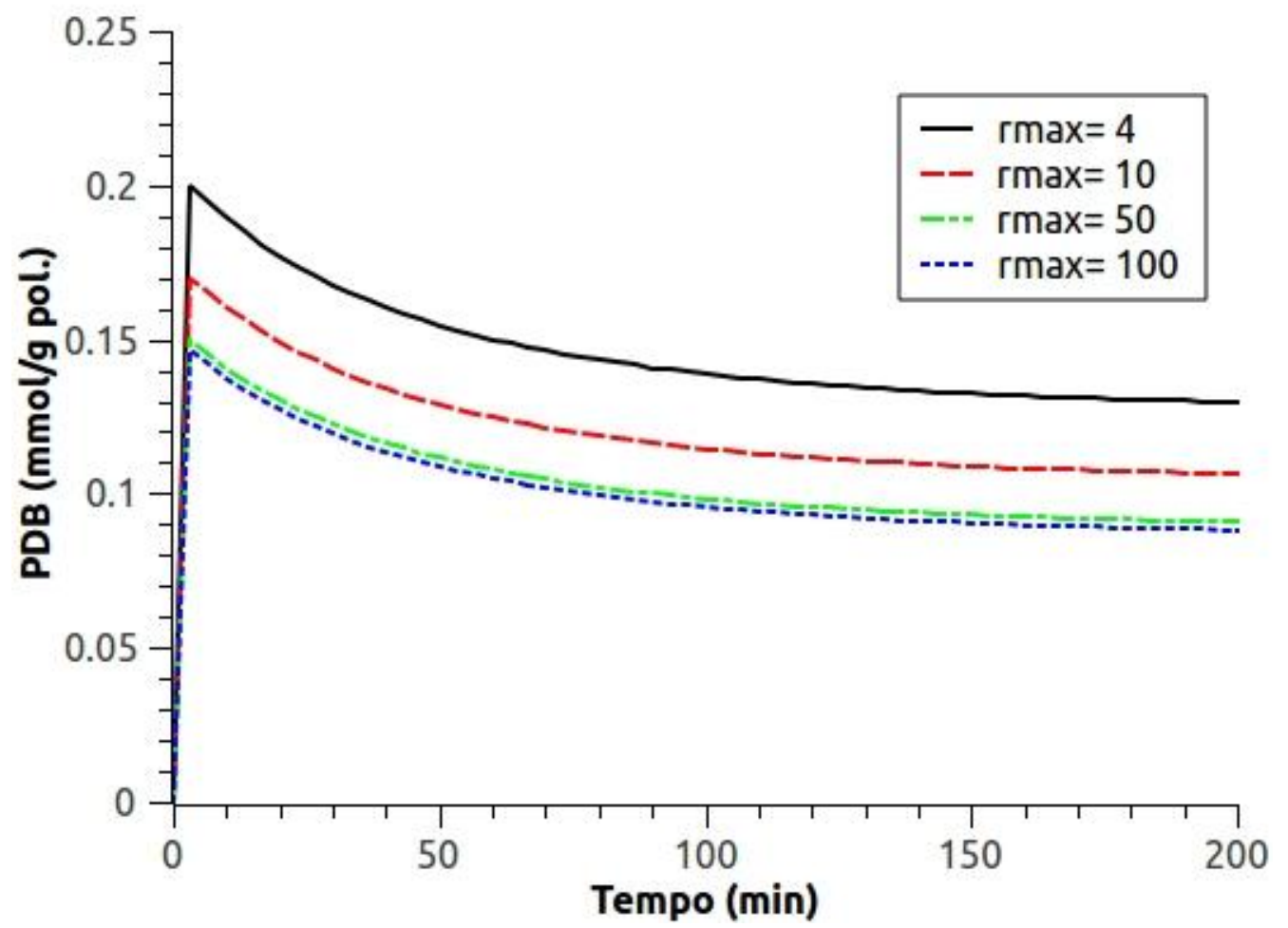

Figura 63 - Perfis de concentração de PDBs em função de $r_{\text {máx }}$. Dados do experimento P7. $\mathrm{kcic}=450 \mathrm{~s}^{-1}$. pol. $=$ polímero . 
Observa-se que as diferenças entre os perfis reduzem-se consideravelmente à medida que se aumenta o valor de $r_{\text {máx }}$. Estes resultados indicam que, para $r_{\text {máx }} \geq$ 50, as diferenças nos resultados passam a ser desprezíveis. Analisando a nível molecular, pode-se dizer que estes resultados fazem sentido, pois, dentro dos limites possíveis, quanto maior for o segmento de cadeia, mais improvável é o encontro entre seus extremos (a reação de ciclização). As Figuras 64 e 65 mostram a mesma análise, porém, feita com o experimento P3 do presente trabalho.

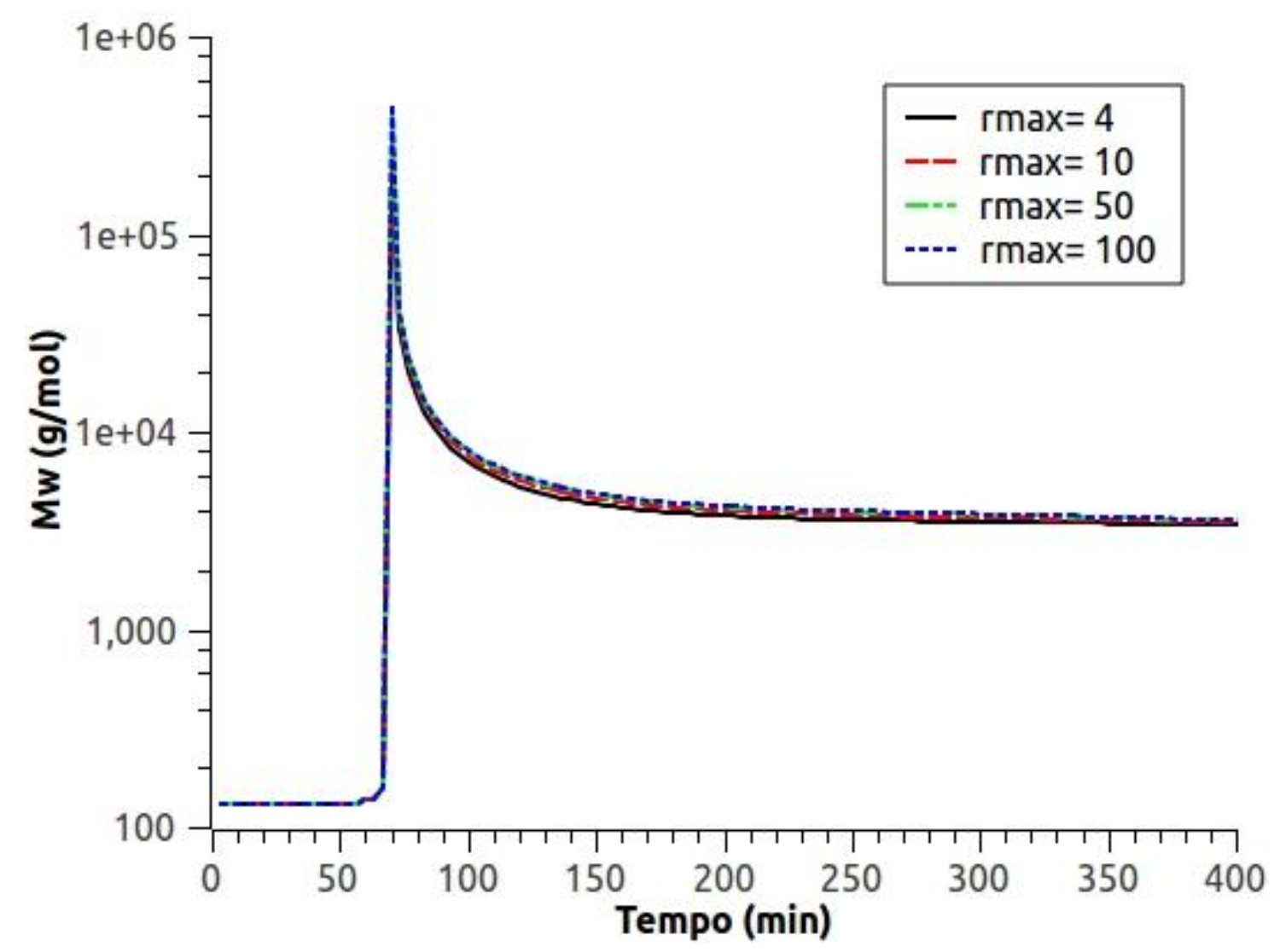

Figura 64 - Perfis de massa molecular média em função de $r_{\text {máx. }}$. Dados do experimento P3. $\mathrm{kcic}=450 \mathrm{~s}^{-1}$.

A Figura 64 mostra que, para o caso do experimento P3, não há variação considerável no perfil de massas moleculares médias em função de $r_{\text {máx. Este }}$ comportamento pode estar relacionado com a competição entre as reações de ligação cruzada e ciclização. Nas condições do experimento P3, é possível que, para kcic= $450 \mathrm{~s}^{-1}$, a taxa de ciclização seja baixa quando comparada à taxa de ligações cruzadas. Entende-se que este comportamento acarreta num perfil de $\mathrm{Mw}$ que praticamente independe da concentração de caminhos ciclizáveis. 


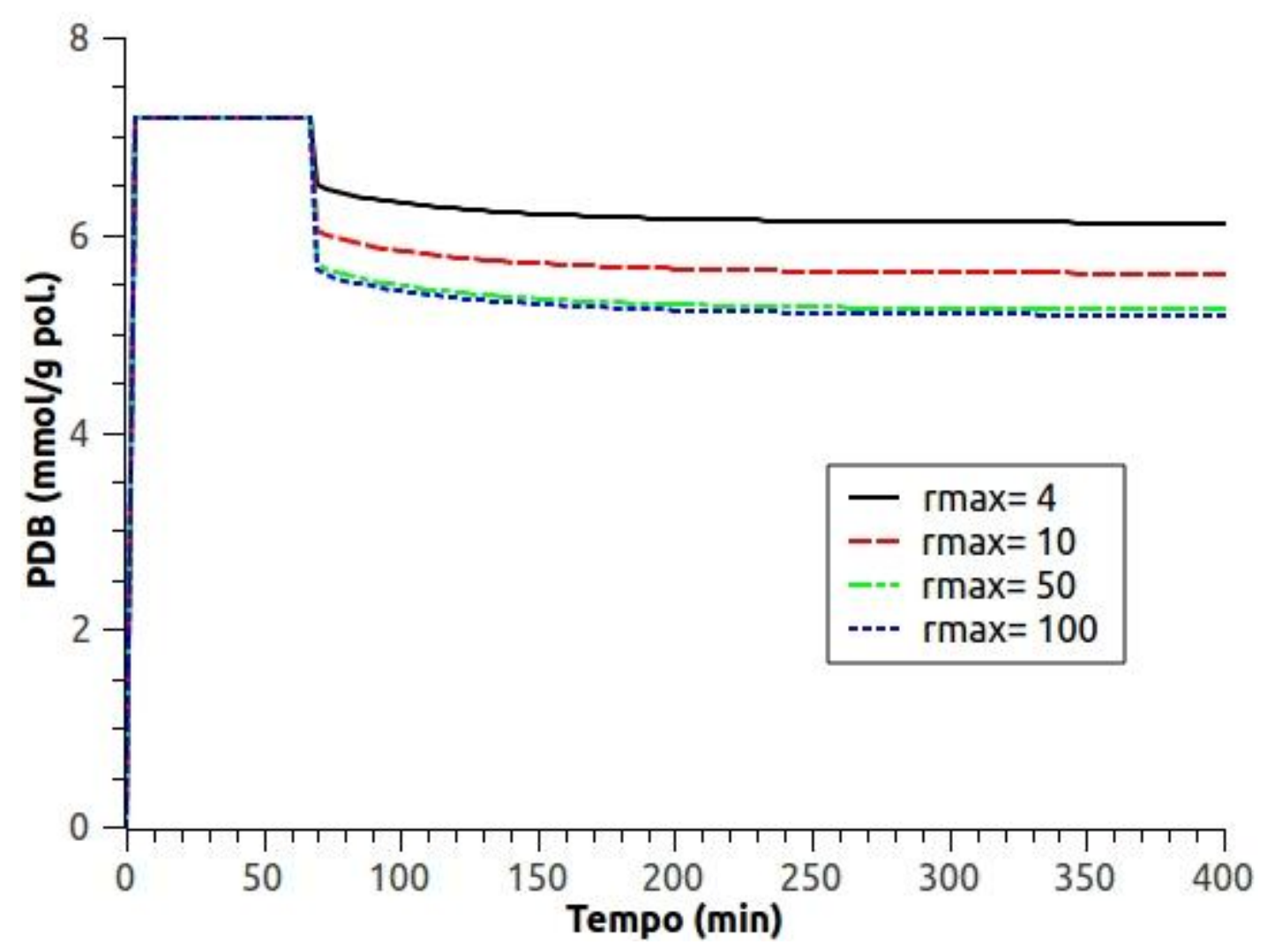

Figura 65 - Perfis de concentração de PDBs em função de $r_{\text {máx }}$. Dados do experimento P3. $\mathrm{kcic}=450 \mathrm{~s}^{-1}$.

Comparada com Mw, a concentração de PDBs apresentou maior sensibilidade ao parâmetro $r_{\text {máx }}$ nas simulações com o experimento P3. Novamente, observa-se uma diferença desprezível entre os perfis obtidos para $r_{\text {máx }}=50$ e $r_{\text {máx }}=$ 100. A simulação com as condições do experimento $P 3$ foi repetida, porém utilizando-se kcic $=1700 \mathrm{~s}^{-1}$. Os resultados são apresentados nas Figuras 66 e 67.

Neste caso, os perfis de $\mathrm{Mw}$ apresentaram uma variação nitidamente

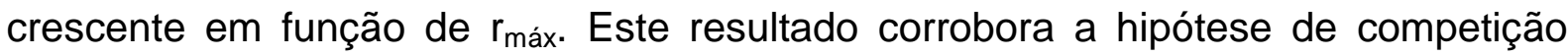
entre as reações de ligação cruzada e ciclização. Com $k c i c=1700 \mathrm{~s}^{-1}$, a velocidade das ciclizações aumenta e a massa molecular média passa a ser afetada significativamente pela variação de $r_{\text {máx }}$.

As reações de ciclização afetam diretamente a concentração de PDBs enquanto que a massa molecular média é afetada indiretamente por tais reações. A validade desta afirmação pode ser verificada analisando-se as Figuras 64-67, as quais apresentam uma discrepância de perfis muito maior para a concentração de PDBs do que para Mw em ambos os casos. 


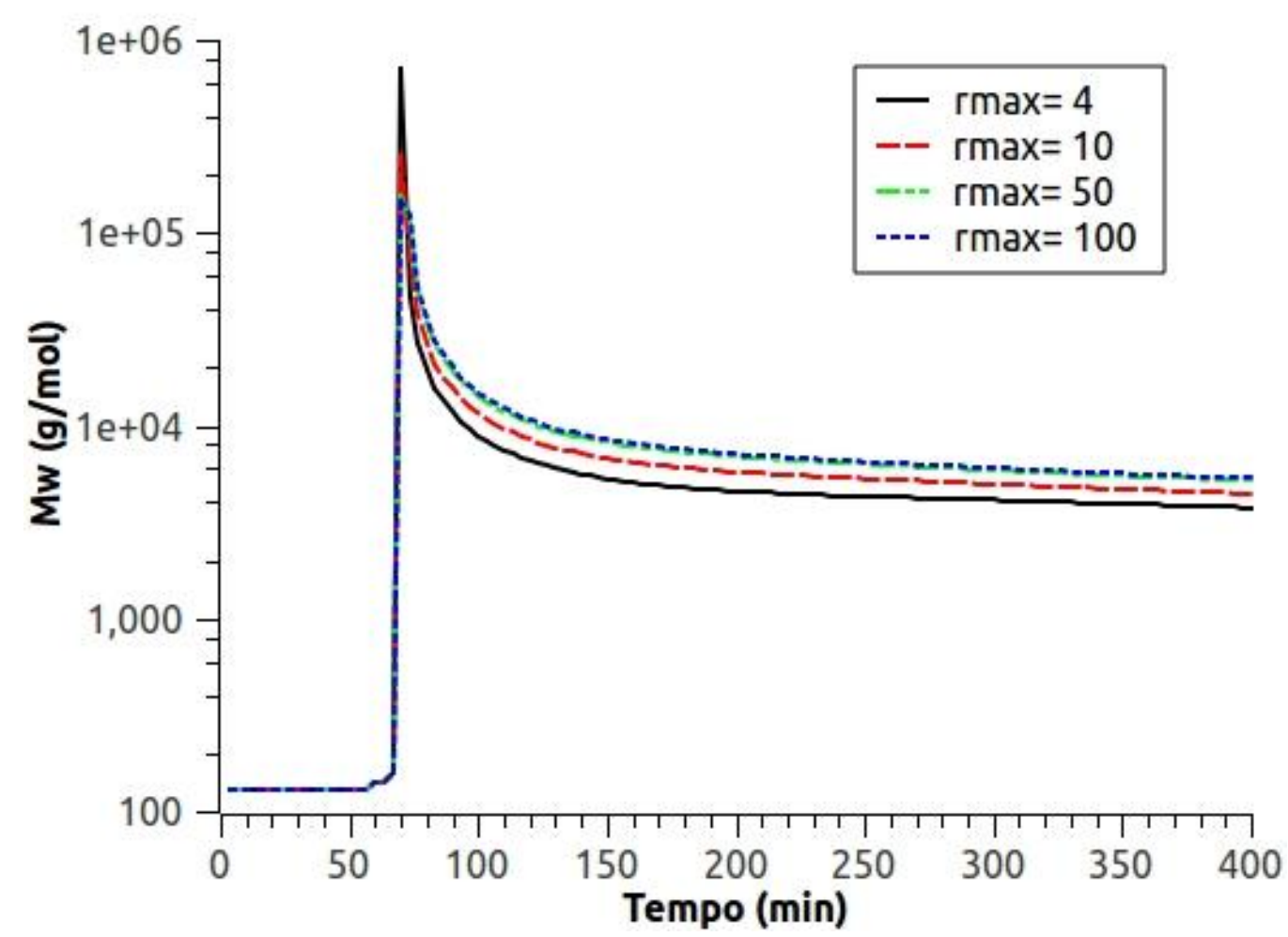

Figura 66 - Perfis de massa molecular média em função de $r_{\text {máx. }}$ Dados do experimento P3. $\mathrm{kcic}=1700 \mathrm{~s}^{-1}$.

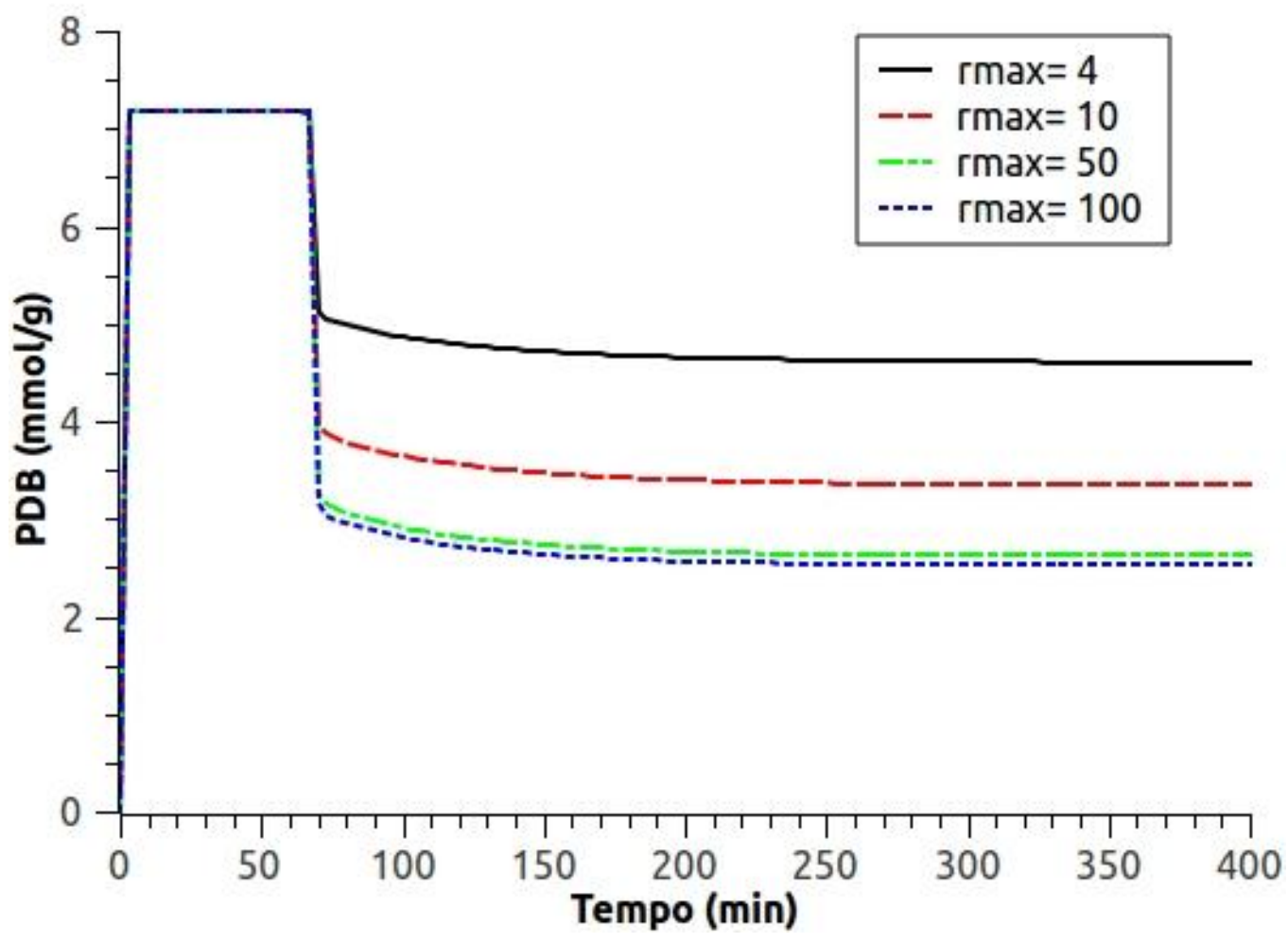

Figura 67 - Perfis de concentração de PDBs em função de $r_{\text {máx }}$. Dados do experimento P3. $k c i c=1700 \mathrm{~s}^{-1}$. 
Levando-se em conta a proximidade das curvas obtidas para $r_{\text {máx }}=50$ e para $r_{\text {máx }}=100$, determinou-se um limite máximo de 100 unidades monoméricas para os caminhos. Portanto, os próximos resultados de simulação com modelos envolvendo o método dos caminhos, foram obtidos com $r_{\text {máx }}=100$.

Com base no que foi exposto no item 4.2.1, tomou-se como ponto de partida dos estudos de simulação do presente trabalho, a questão do ajuste modelo/experimentos para as variáveis $\mathrm{Mw}$ e $\mathrm{Wg}$, considerando um único valor de $\mathrm{C}_{\mathrm{P}}$. Isto tornaria o modelo mais realista, visto que a reatividade intrínseca das ligações cruzadas é constante. O estudo da inclusão das reações de ciclização foi feito variando-se o parâmetro kcic e mantendo-se constante o valor de $C_{P}$. As Figuras 68-70 mostram os resultados deste estudo.

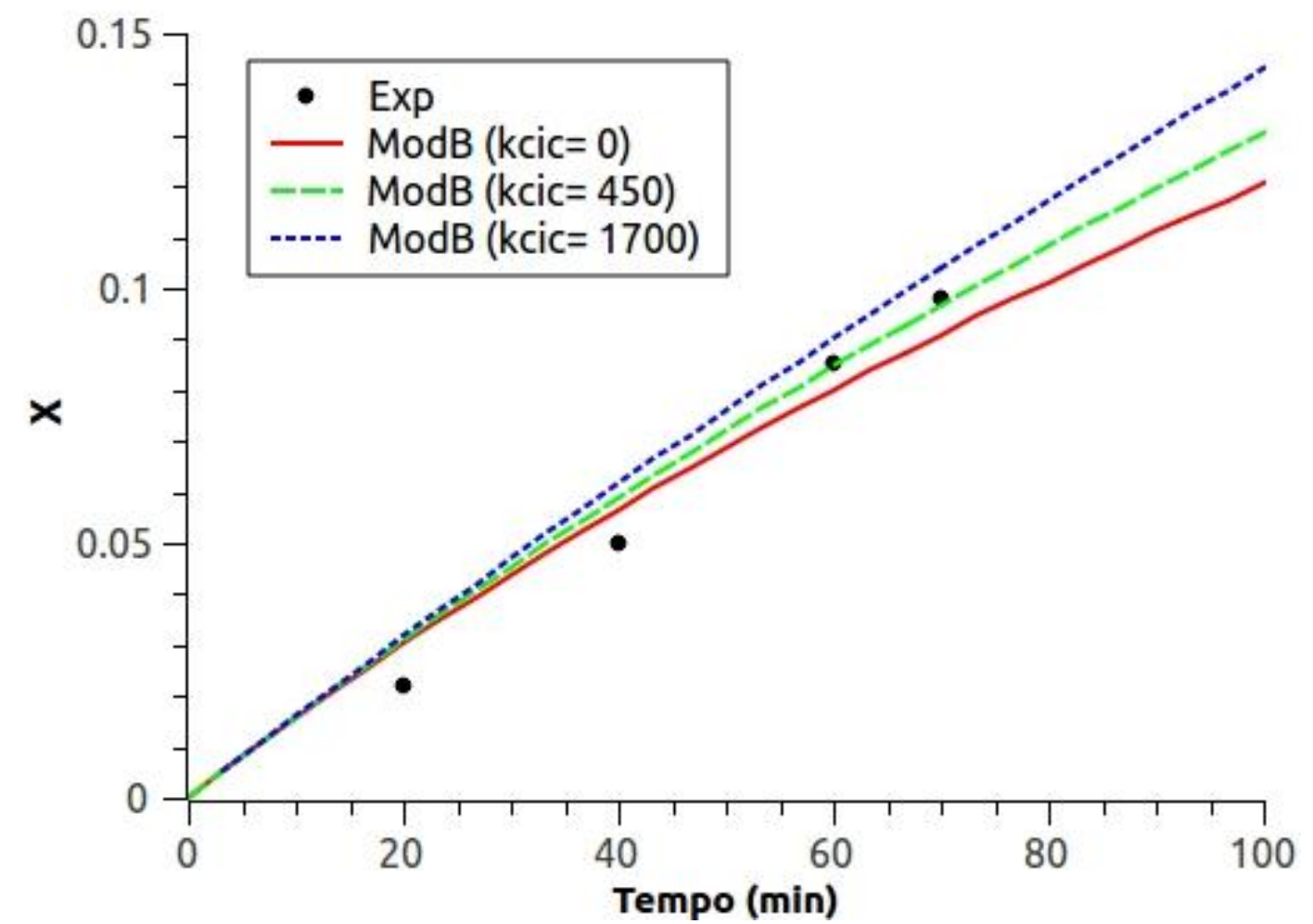

Figura 68 - Comparação entre previsões de conversão com os dados experimentais de Gonçalves et al. (2011) - Run 5. kcic em s ${ }^{-1}$.

Na Figura 68, as previsões de conversão não apresentam grandes diferenças de ajuste, pois se têm apenas os resultados experimentais do trecho inicial da reação. Porém, para os resultados de $\mathrm{Mw}$ e $\mathrm{Wg}$, verifica-se um melhor ajuste quando se utiliza kcic $=1700 \mathrm{~s}^{-1}$. As Figuras 69 e 70 indicam que, quando as reações 
de ciclização são desconsideradas ( $\mathrm{kcic}=0$ ), a previsão do ponto de gel é adiantada em relação aos valores experimentais. $O$ experimento referente a estas figuras se trata de uma copolimerização convencional. Com base nestes resultados, chega-se a um valor de kcic relativamente alto. É importante ressaltar que o experimento correspondente às figuras 69 e 70 foi realizado em presença de heptano. Heptano possui baixa afinidade com polímeros estirênicos, o que pode acarretar em um processo de polimerização diferente em relação às reações conduzidas com tolueno, que possui maior afinidade.

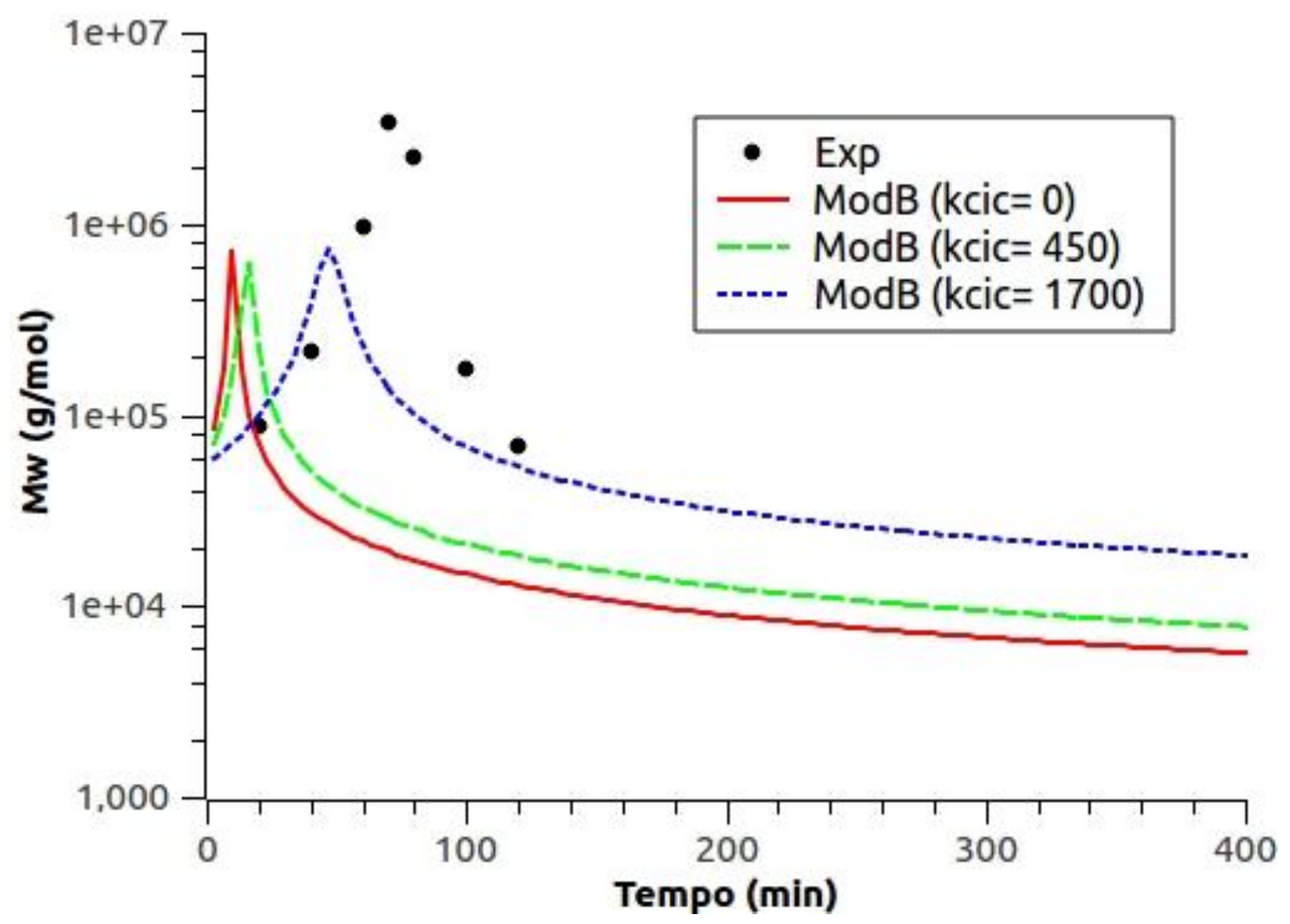

Figura 69 - Comparação entre previsões de massa molecular média com os dados experimentais de Gonçalves et al. (2011) - Run 5. kcic em s' ${ }^{-1}$.

Para o caso NMRP (figuras 71-73), não é possível chegar a uma conclusão em termos de conversão, visto que os dados experimentais da Figura 71 apresentam coerência somente até o tempo de $200 \mathrm{~min}$. Neste trecho inicial, os três valores de kcic resultam em perfis semelhantes de conversão, sem uma clara melhoria de um caso para o outro. 


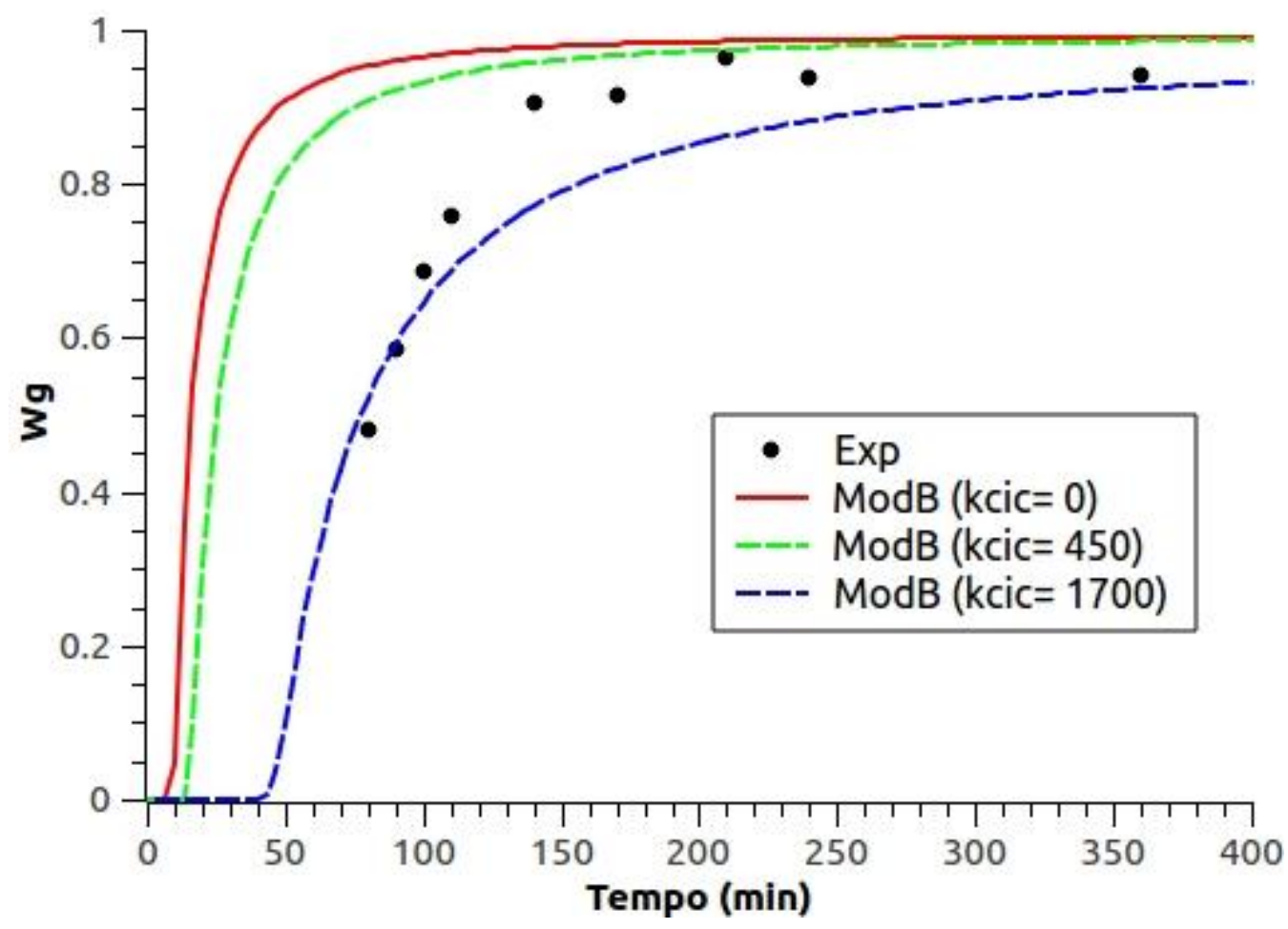

Figura 70 - Comparação entre previsões de fração de gel com os dados experimentais de Gonçalves et al. (2011) - Run 5. kcic em s${ }^{-1}$.

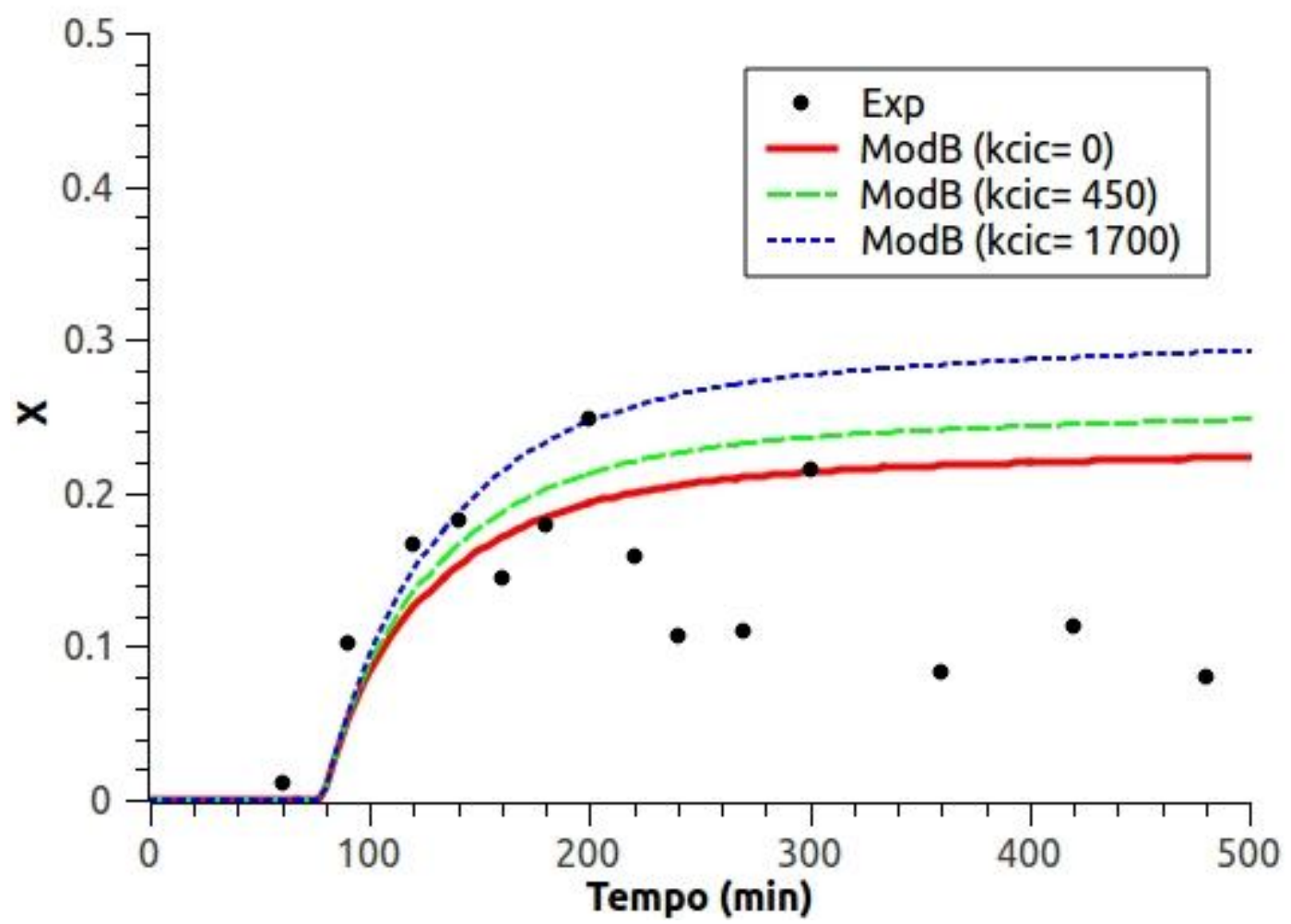

Figura 71 - Comparação entre previsões de conversão com os dados do experimento P2. kcic em s ${ }^{-1}$. 


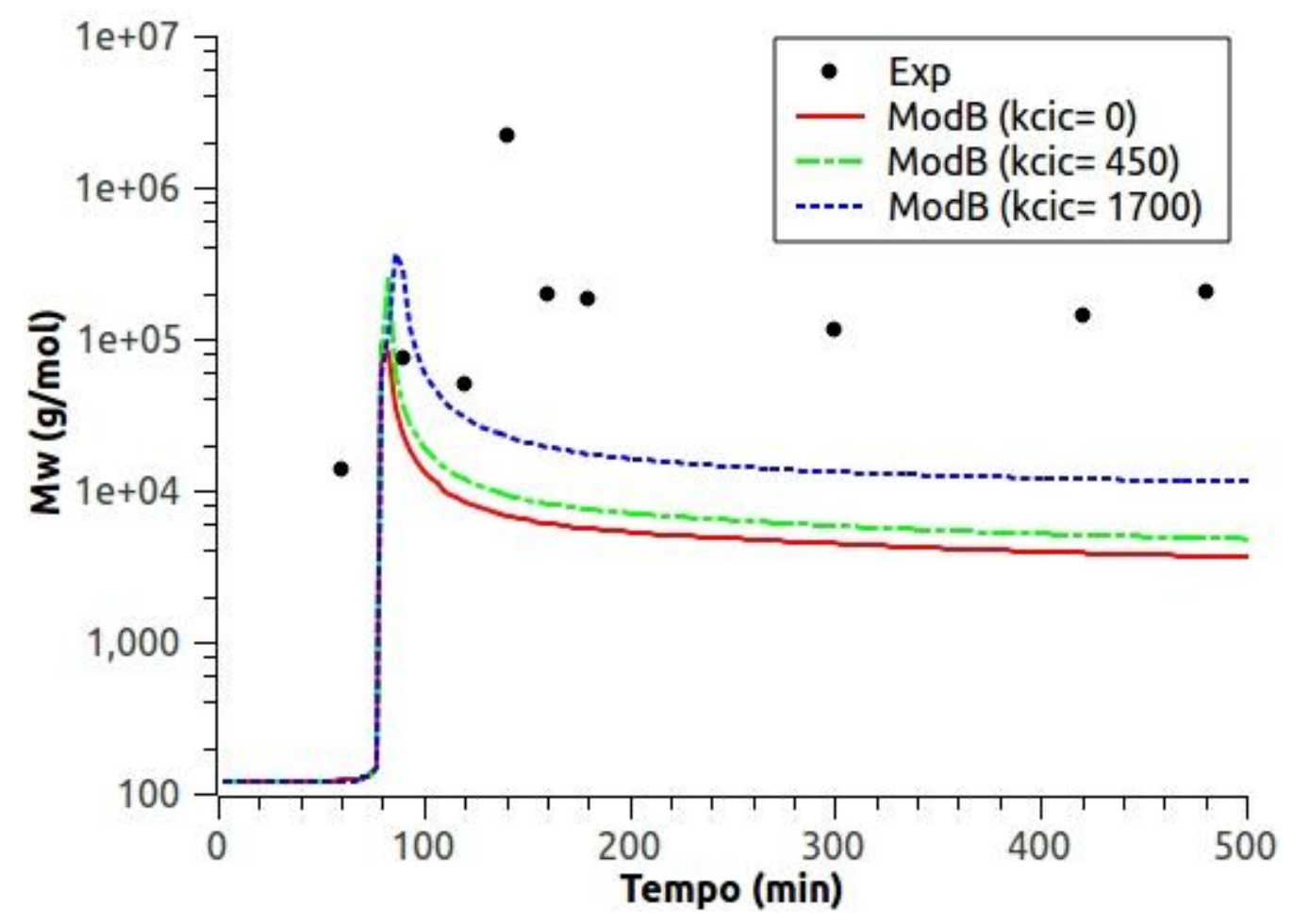

Figura 72 - Comparação entre previsões de massa molecular média com os dados do experimento P2. kcic em s${ }^{-1}$.

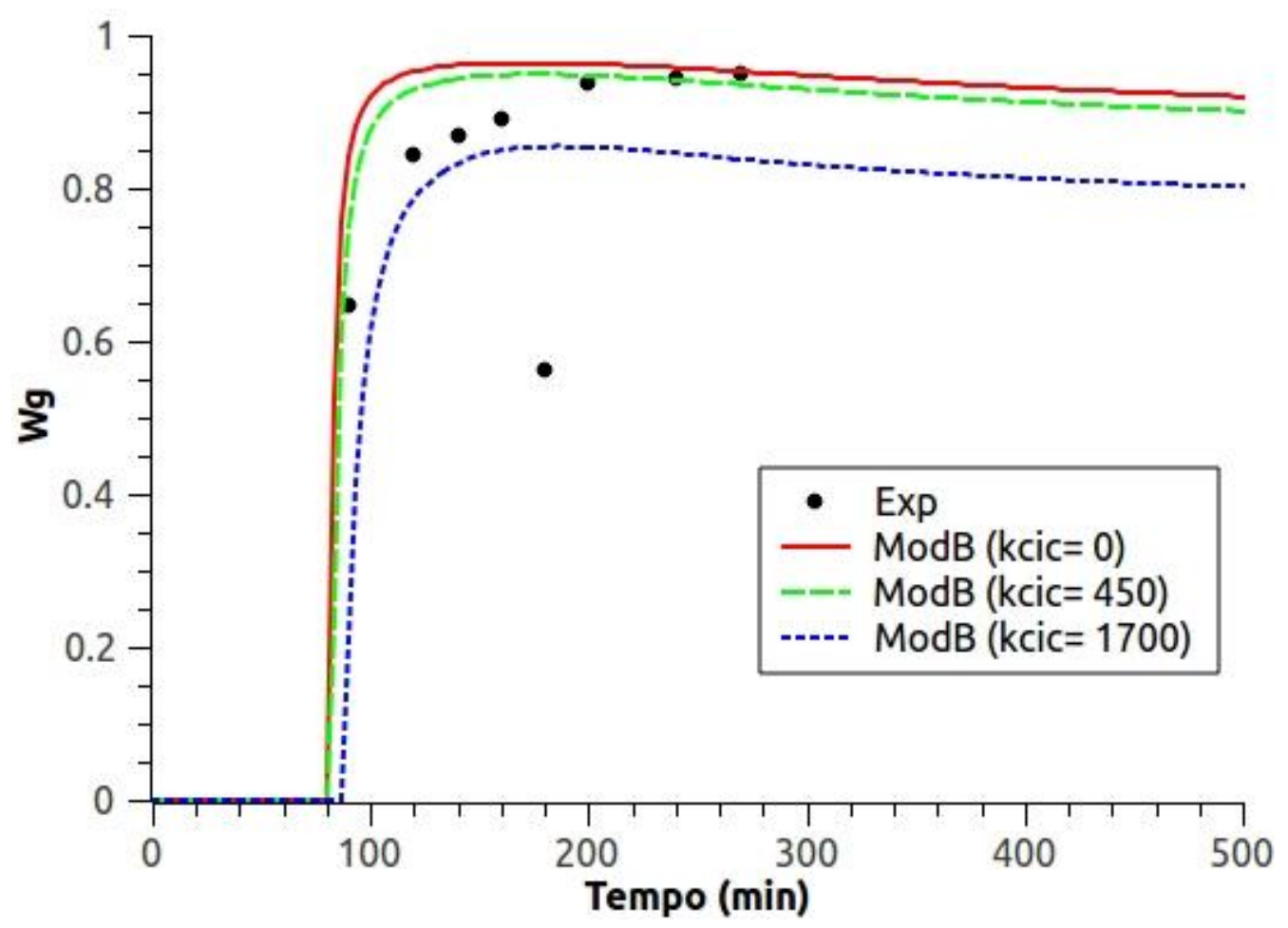

Figura 73 - Comparação entre previsões de fração de gel com os dados do experimento P2. kcic em s ${ }^{-1}$. 
$\mathrm{Na}$ Figura 72, verifica-se que nenhum dos valores de kcic gerou bom ajuste, principalmente no período pós-gelificação. Observa-se que os pontos experimentais de $\mathrm{Mw}$ localizam-se acima das curvas do Modelo $\mathrm{B}$, indicando que ainda restam moléculas solúveis relativamente grandes após gelificação. Este comportamento pode estar relacionado à distribuição mais homogênea de pontos de crosslink nas cadeias, obtida pelo processo NMRP e também ao problema das PDBs inacessíveis. Este ponto será discutido com base nos resultados de simulação com o Modelo $\mathrm{C}$, os quais serão apresentados no item 4.2.4. $O$ perfil de $\mathrm{Wg}$ obtido para $\mathrm{kcic}=450 \mathrm{~s}^{-1}$ apresentou um ajuste ligeiramente melhor com os pontos experimentais em relação às demais curvas (Figura 73). Isto indica que a taxa de ciclização para o sistema NMRP parece ser mais moderada em relação ao sistema FRP, uma vez que, para FRP, o melhor ajuste ocorreu com kcic $=1700 \mathrm{~s}^{-1}$ (Figuras 69 e 70). Porém, esta diferença de velocidades entre as reações de ciclização nos dois sistemas pode estar relacionada ao tipo de solvente utilizado, conforme descrito anteriormente. Esta diferença pode também estar relacionada à formação de microgéis na copolimerização convencional e à formação de redes poliméricas homogêneas no sistema NMRP. Os microgéis são resultado de uma taxa alta de consumo de PDBs no início da reação, o que gera estruturas heterogêneas, de forma que, o crescimento das cadeias não se dá de forma regular como no processo NMRP. Como, no início da reação, as cadeias ainda são pequenas e estão relativamente afastadas umas das outras, a taxa de ciclização é alta para o sistema FRP, no qual todos os radicais são ativos. Por outro lado, no sistema NMRP, a quantidade de radical nitróxido no início da reação, é alta, resultando em elevada taxa de desativação de radicais. Isto permite que as cadeias cresçam regularmente, "aprisionando" as PDBs de forma sistemática ao longo do processo, o que resulta em baixa reatividade de ligações cruzadas e menor incorporação de moléculas grandes ao gel (ver Figura 72).

Conforme descrito no capítulo 3 do presente trabalho, os modelos B e C apresentam limitações relacionadas aos integradores do MATLAB. Com o método do fracionamento numérico, a partir de 5 gerações, observa-se um erro relativo ao passo de integração. Por este motivo, foi fixado o valor de 4 gerações $(n=4)$ para todas as simulações com os modelos B e C. Um prejuízo causado por esta limitação é a obtenção de um valor relativamente baixo de Mw no ponto de gel. Nas Figuras 69 e 72, verifica-se que os pontos de gel estão bem definidos, porém, o pico do perfil 
de $\mathrm{Mw}$ não atinge valores adequados para comparação com os pontos experimentais. Contudo, isto não prejudica de forma acentuada a comparação modelo/experimentos. As figuras 74-76 mostram o efeito da ciclização sobre a concentração de duplas ligações pendentes.

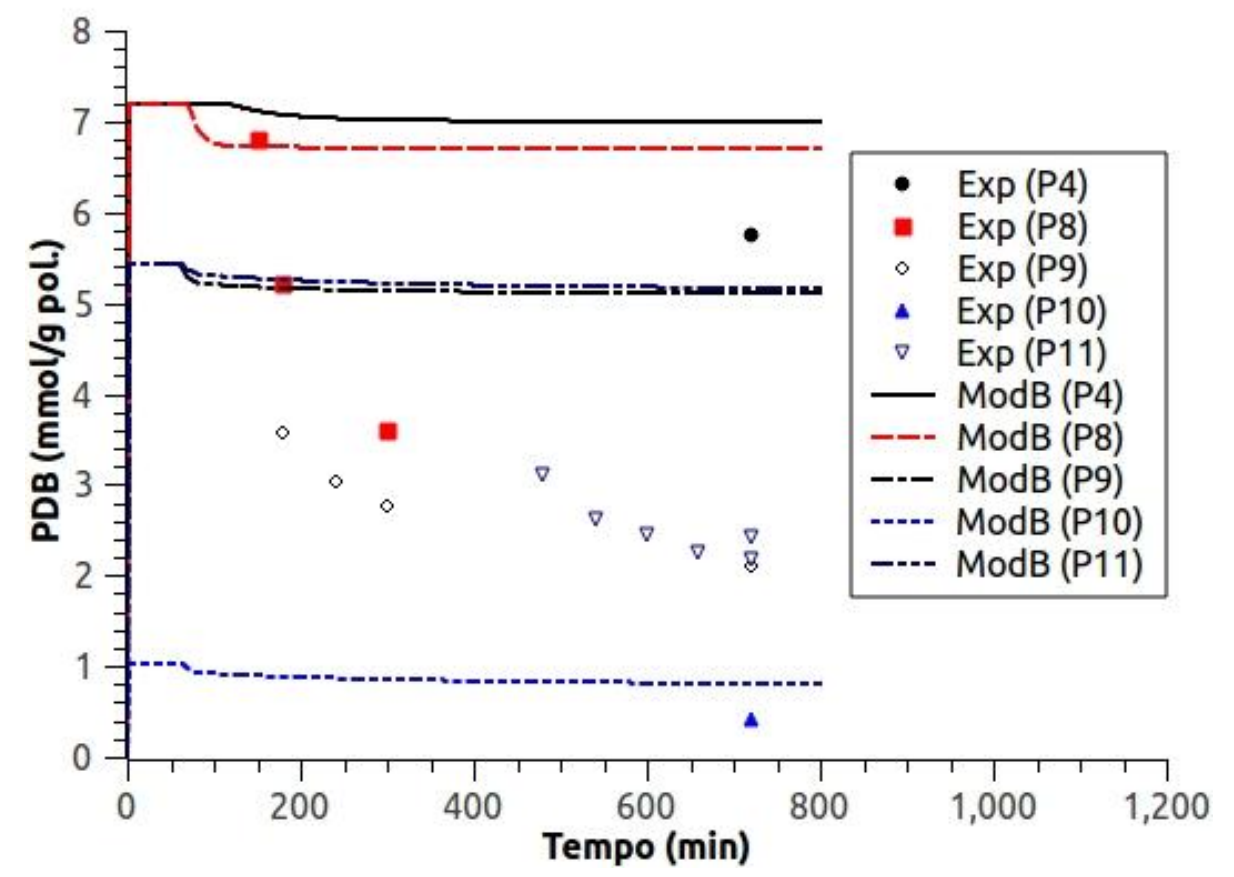

Figura 74 - Comparação entre previsões de concentração de PDBs. $k c i c=0 \mathrm{~s}^{-1}$.

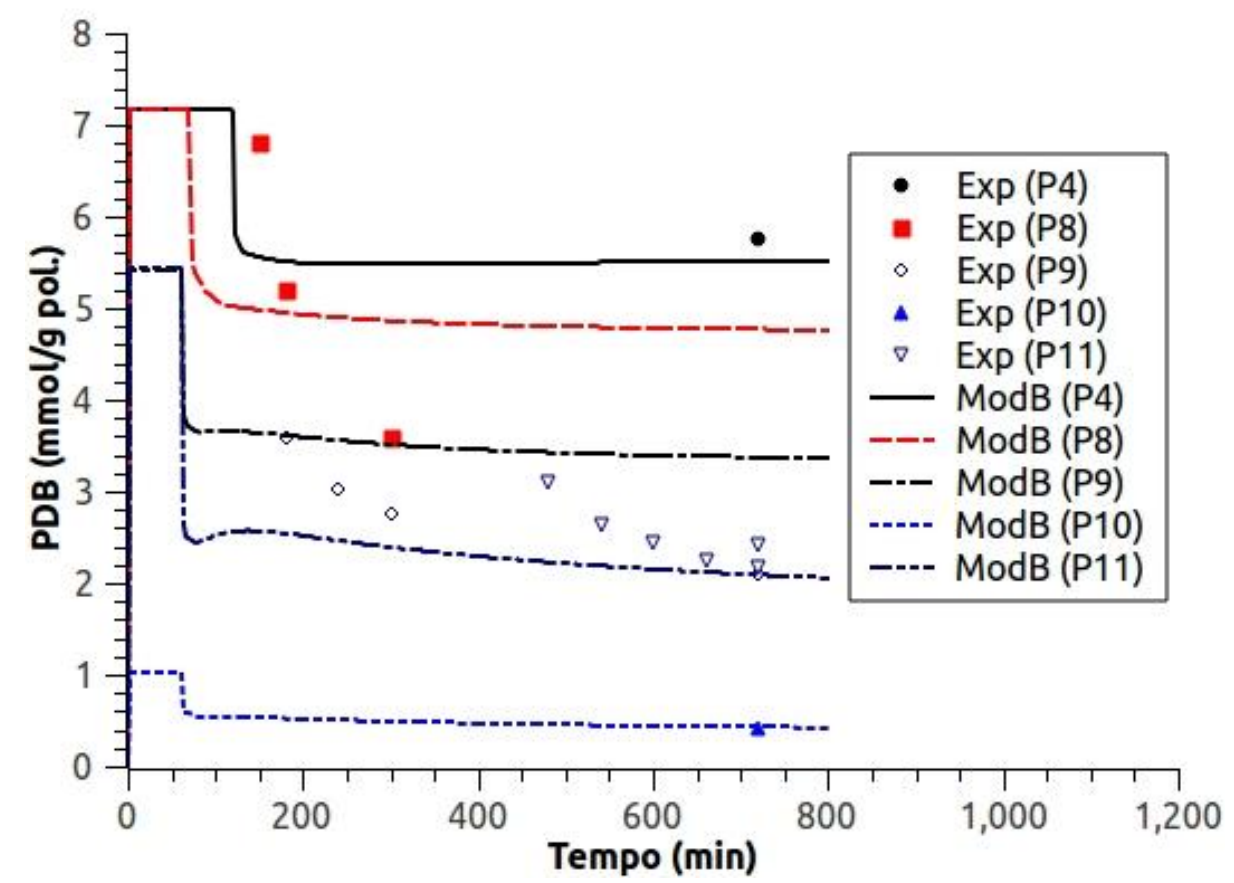

Figura 75 - Comparação entre previsões de concentração de PDBs. $k c i c=450 \mathrm{~s}^{-1}$. 


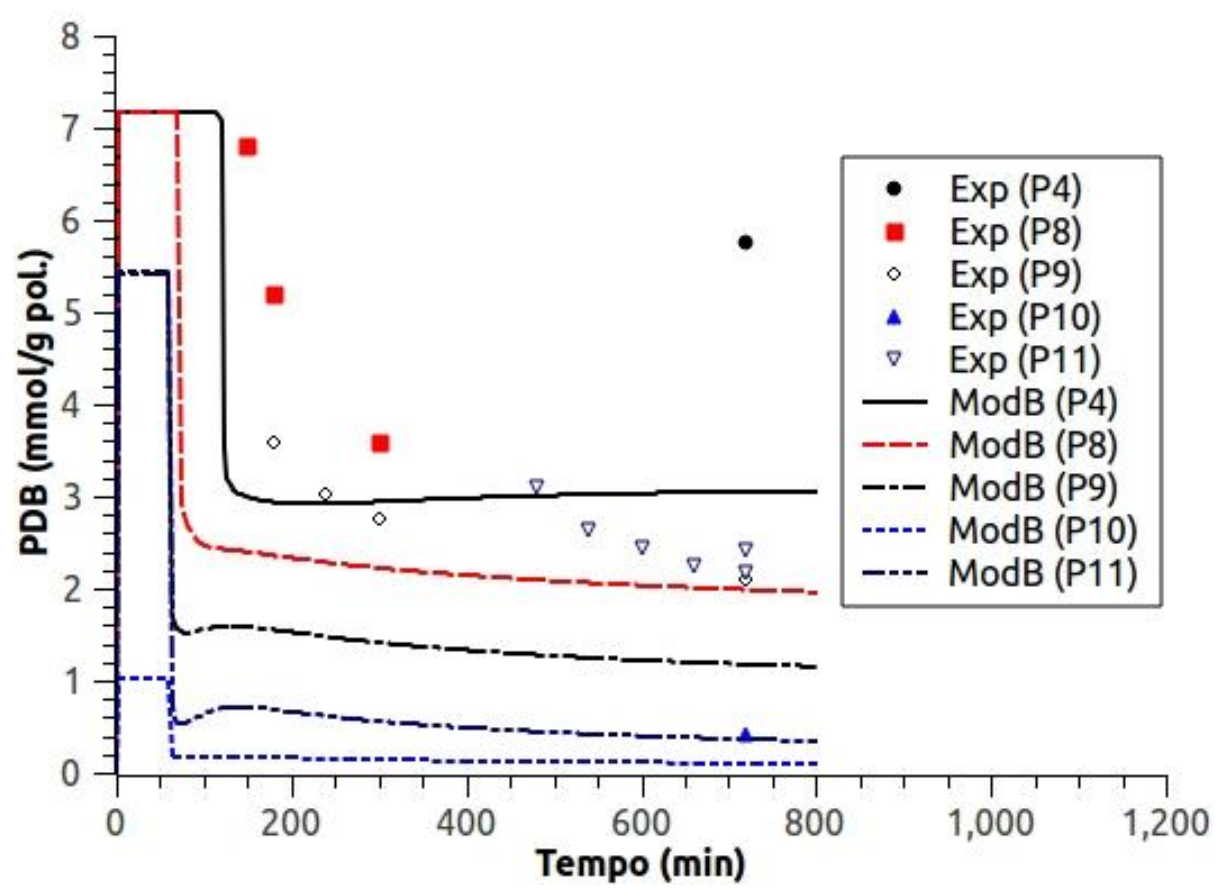

Figura 76 - Comparação entre previsões de concentração de PDBs. $k c i c=1700 \mathrm{~s}^{-1}$.

Analisando-se as figuras 74-76, observa-se um melhor ajuste quando kcic= $450 \mathrm{~s}^{-1}$, obtendo-se mais um indício de que o parâmetro cinético de ciclização situase em torno deste valor. Os perfis de concentração de PDBs gerados pelo Modelo B, apresentam uma redução brusca após o patamar inicial referente ao período de inibição da reação. Por outro lado, os perfis experimentais apresentam uma redução mais suave da concentração de PDBs ao longo de tempo de reação. Esta discrepância pode estar associada à reatividade da ciclização de caminhos pequenos, que pode ser menor do que a reatividade de ciclização de caminhos maiores. A seguir, são discutidos os resultados obtidos com os 3 modelos descritos no presente trabalho.

4.2.3. Resultados de simulação das copolimerizações convencionais

Os resultados de simulação envolvendo as copolimerizações convencionais foram obtidos utilizando-se os parâmetros cinéticos das Tabelas 10 e 11.

Nestas simulações, utilizou-se a nomenclatura a seguir. 
k $\mathrm{k}_{\text {-Sty }}$ e $\mathrm{k}_{\mathrm{pR} \text {-Sty: }}$ Constantes cinéticas de iniciação e propagação de estireno respectivamente;

$\mathrm{k}_{\mathrm{I}-\mathrm{DVB}}$ e $\mathrm{k}_{\mathrm{pR} \text {-DVB: }}$ Constantes cinéticas de iniciação e propagação de DVB respectivamente;

$\mathrm{k}_{\mathrm{I}-\mathrm{PDB}}$ e $\mathrm{k}_{\mathrm{pR} \text {-PDB: }}$ Constantes cinéticas de iniciação e propagação de PDB respectivamente.

Tabela 10 - Parâmetros cinéticos utilizados nas simulações de FRPs com o Modelo A.

\begin{tabular}{|c|c|}
\hline Reação & Parâmetro cinético \\
\hline Decomposição do AIBN & $\begin{array}{l}k_{d}=2,31 \times 10^{15} e^{\left(\frac{-131700}{R T}\right)}\left(\mathrm{s}^{-1}\right) \\
\mathrm{f}=0,6\end{array}$ \\
\hline Desativação de radicais & $k_{d a}=5,03 \times 10^{9} e^{\left(\frac{-15570}{R T}\right)}$ \\
\hline Ativação de radicais & $k_{a}=2,0 \times 10^{13} e^{\left(\frac{-124200}{R T}\right)}\left(\mathrm{s}^{-1}\right)$ \\
\hline Propagação de estireno & $k_{p R-S t y}=4,27 x 10^{7} e^{\left(\frac{-32500}{R T}\right)}$ \\
\hline Propagação de DVB & $k_{p R-D V B}=9,93 \times 10^{7} e^{\left(\frac{-32500}{R T}\right)}$ \\
\hline Propagação de PDBs * & $k_{p R-P D B}=1,87 \times 10^{7} e^{\left(\frac{-32500}{R T}\right)}$ \\
\hline \multirow[t]{3}{*}{ Iniciações } & $\mathrm{k}_{\mathrm{I}-\mathrm{Sty}}=\mathrm{k}_{\mathrm{pR}-\mathrm{Sty}}$ \\
\hline & $\mathrm{k}_{\mathrm{I}-\mathrm{DVB}}=\mathrm{k}_{\mathrm{pR}-\mathrm{DVB}}$ \\
\hline & $\mathrm{k}_{\mathrm{I}-\mathrm{PDB}}=\mathrm{k}_{\mathrm{pR}-\mathrm{PDB}}$ \\
\hline Transferência de cadeia para monômero & $C_{M}=\frac{k_{f m 11}}{k_{p 11}}=0,2198 e^{\left(\frac{-23500}{R T}\right)}$ \\
\hline Dimerizações & $k_{d i m i j}=188,97 e^{\left(\frac{-67700}{R T}\right)}$ \\
\hline Decomposição de dímero & $k_{d d}=5,49 \times 10^{9} e^{\left(\frac{-106100}{R T}\right)}$ \\
\hline Iniciação térmica de estireno & $k_{t h i}=6,359 \times 10^{12} e^{\left(\frac{-153100}{R T}\right)}$ \\
\hline Decomposição de radicais dormentes & $k_{d e c}=5,7 \times 10^{14} e^{\left(\frac{-153300}{R T}\right)} \quad\left(\mathrm{s}^{-1}\right)$ \\
\hline Abstração de próton pelo radical nitróxido & $k_{h}=10^{-3}$ \\
\hline Terminação & $\frac{\mathrm{k}_{\mathrm{p} 11}}{\sqrt{\mathrm{k}_{\mathrm{t}}}}=426,4 \mathrm{e}^{\left(\frac{-26000}{\mathrm{RT}}\right)}$ \\
\hline & $\alpha_{\mathrm{td}}=\frac{\mathrm{k}_{\mathrm{td}}}{\mathrm{k}_{\mathrm{t}}}=0 ; \alpha_{\mathrm{tc}}=\frac{\mathrm{k}_{\mathrm{tc}}}{\mathrm{k}_{\mathrm{t}}}=1$ \\
\hline
\end{tabular}

Constantes cinéticas em L/(mol.s), exceto quando indicada outra unidade; Referência: Gonçalves et al. (2010), exceto *: Presente trabalho. 
Tabela 11 - Parâmetros cinéticos utilizados nas simulações de FRPs com os modelos B e C.

\begin{tabular}{|c|c|}
\hline Reação & Parâmetro cinético \\
\hline Decomposição do AIBN & $\begin{array}{l}k_{d}=2,31 \times 10^{15} e^{\left(\frac{-131700}{R T}\right)}\left(\mathrm{s}^{-1}\right) \\
\mathrm{f}=0,6\end{array}$ \\
\hline Desativação de radicais & $k_{d a}=5,03 \times 10^{9} e^{\left(\frac{-15570}{R T}\right)}$ \\
\hline Ativação de radicais & $k_{a}=2,0 \times 10^{13} e^{\left(\frac{-124200}{R T}\right)}\left(\mathrm{s}^{-1}\right)$ \\
\hline Propagação de estireno & $k_{p 11}=4,27 \times 10^{7} e^{\left(\frac{-32500}{R T}\right)}$ \\
\hline Iniciação & $k_{l j}=k_{p 1 j}(1 \leq j \leq 5)$ \\
\hline \multirow{10}{*}{$\begin{array}{l}\text { Propagações } \\
\text { (reatividades) }\end{array}$} & $r_{12}=\frac{k_{p 11}}{k_{n 12}}=0,43$ \\
\hline & $r_{13}=\frac{k_{p 11}}{k_{p 13}}=0,24$ \\
\hline & $C_{P}=0,20$ \\
\hline & $r_{14}=\frac{k_{p 11}}{k_{p 14}}=\frac{2 r_{12}}{C_{P}}$ \\
\hline & $r_{15}=\frac{k_{p 11}}{k_{p 13}}=\frac{2 r_{13}}{C_{P}}$ \\
\hline & $r_{2 i}=\frac{k_{p 2 i}}{k_{p 1 i}}=0,77$ \\
\hline & $r_{3 i}=\frac{k_{p 3 i}}{k_{p 1 i}}=0,29$ \\
\hline & $r_{4 i}=\frac{k_{p 4 i}}{k_{p 1 i}}=0,77^{2}=0,59$ \\
\hline & $r_{5 i}=\frac{k_{p 5 i}}{k_{p 1 i}}=0,29^{2}=0,08$ \\
\hline & $(1 \leq \mathrm{i} \leq 5)$ \\
\hline \multirow[t]{2}{*}{ Terminação } & $\frac{k_{p 11}}{\sqrt{k_{t}}}=426,4 e^{\left(\frac{-26000}{R T}\right)}$ \\
\hline & $\alpha_{\mathrm{td}}=\frac{\mathrm{k}_{\mathrm{td}}}{\mathrm{k}_{\mathrm{t}}}=0 ; \alpha_{\mathrm{tc}}=\frac{\mathrm{k}_{\mathrm{tc}}}{\mathrm{k}_{\mathrm{t}}}=1$ \\
\hline $\begin{array}{l}\text { Ciclização } R_{1} \text {-mPDB para caminhos com } 3 \\
\text { unidades monoméricas }\left(k_{p 14,3}^{\mathrm{C}}{ }^{*}\right.\end{array}$ & $k_{p 14,3}^{C}=k \operatorname{cic} e^{\left[\frac{32500}{R}\left(\frac{1}{363,15}-\frac{1}{T}\right)\right]}\left(\mathrm{s}^{-1}\right)$ \\
\hline
\end{tabular}

Constantes cinéticas em L/(mol.s), exceto quando indicada outra unidade; Referência: Gonçalves et al. (2010), exceto *: Presente trabalho. $\mathrm{kcic}=450 \mathrm{~s}^{-1}$, exceto quando indicado outro valor. 
O Modelo A é capaz de prever o período pós-gelificação para sistemas mais simples como o FRP. Neste caso, utilizou-se um único grupo polimérico para representar todos os radicais do meio (radicais de estireno, DVB e PDB). Portanto, neste estudo, trabalhou-se somente com 2 grupos poliméricos: um para as duplas ligações pendentes (mPDB + pPDB) e outro para os radicais. Isto permitiu a obtenção de resultados de simulação para grande parte do período pós-gelificação nos processos FRP.

As simulações com dados das copolimerizações FRP mostraram-se sensíveis ao parâmetro de ciclização kcic. Diferentemente das reações do tipo NMRP, as cadeias obtidas no processo FRP, se arranjam de forma menos homogênea. A constante cinética de ciclização depende dos caminhos presentes no meio, porém, o método dos caminhos não leva em conta a forma como estes caminhos estão dispostos nas cadeias. Isto pode gerar uma diferença nos valores das constantes cinéticas quando se comparam os processos FRP e NMRP. Desta forma, compararam-se os resultados de simulações realizadas com diferentes valores de kcic, conforme mostrado nas figuras 77-79.

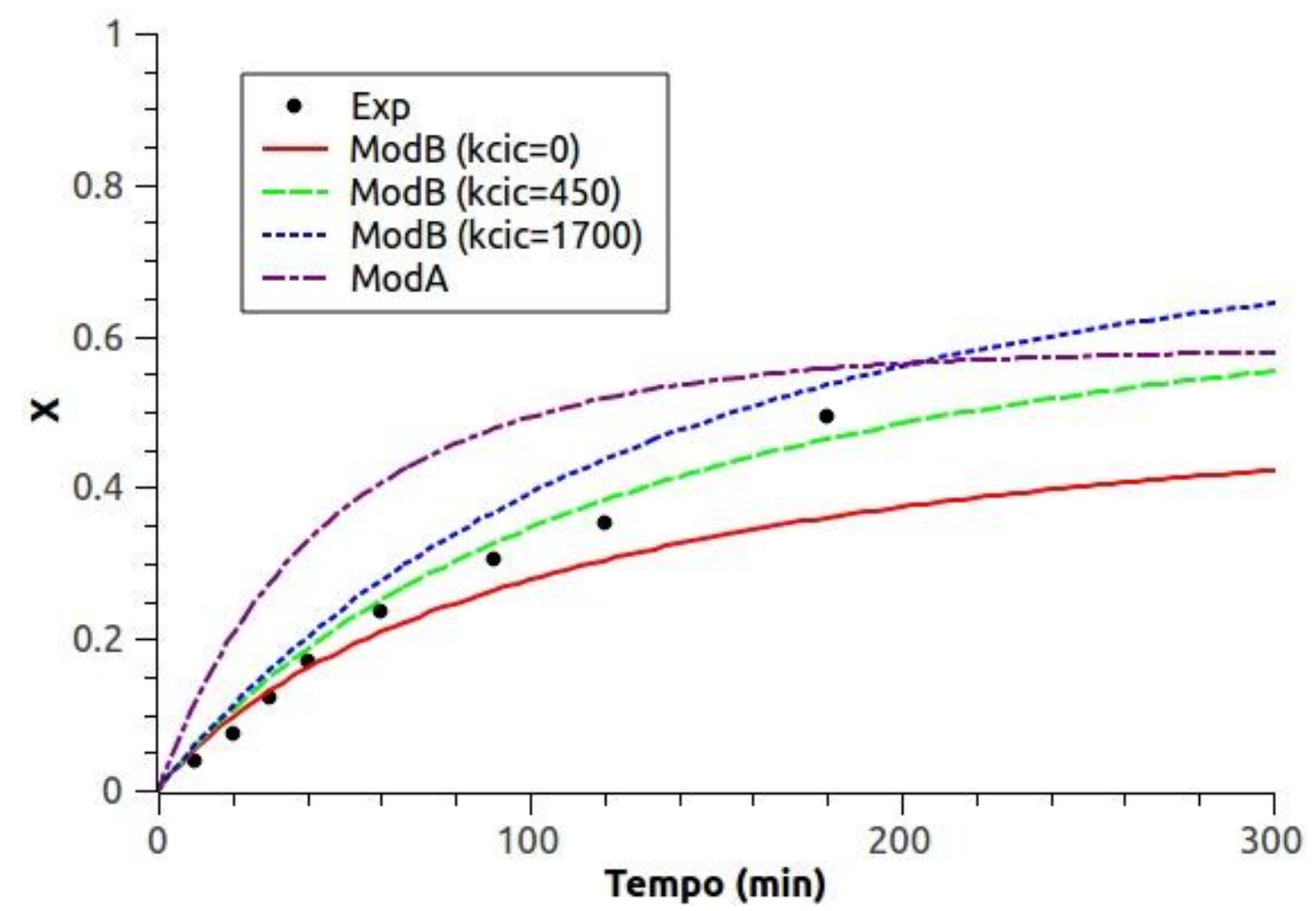

Figura 77 - Resultados de conversão. Comparação dos modelos A e B com os dados do experimento B4. $\mathrm{kcic} \mathrm{em} \mathrm{s}^{-1}$. 


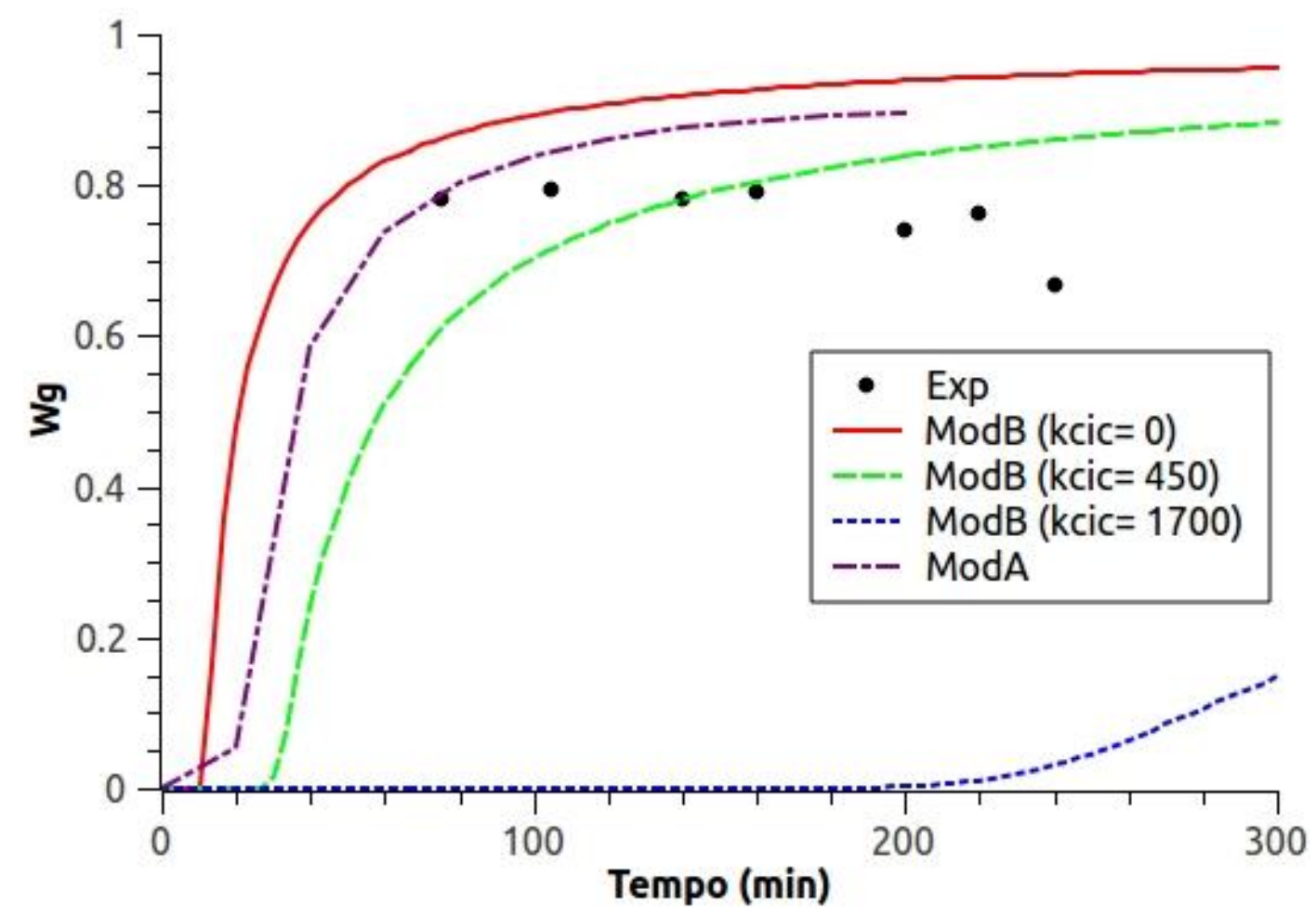

Figura 78 - Resultados de fração de gel. Comparação dos modelos A e B com os dados do experimento B4. kcic em s${ }^{-1}$.

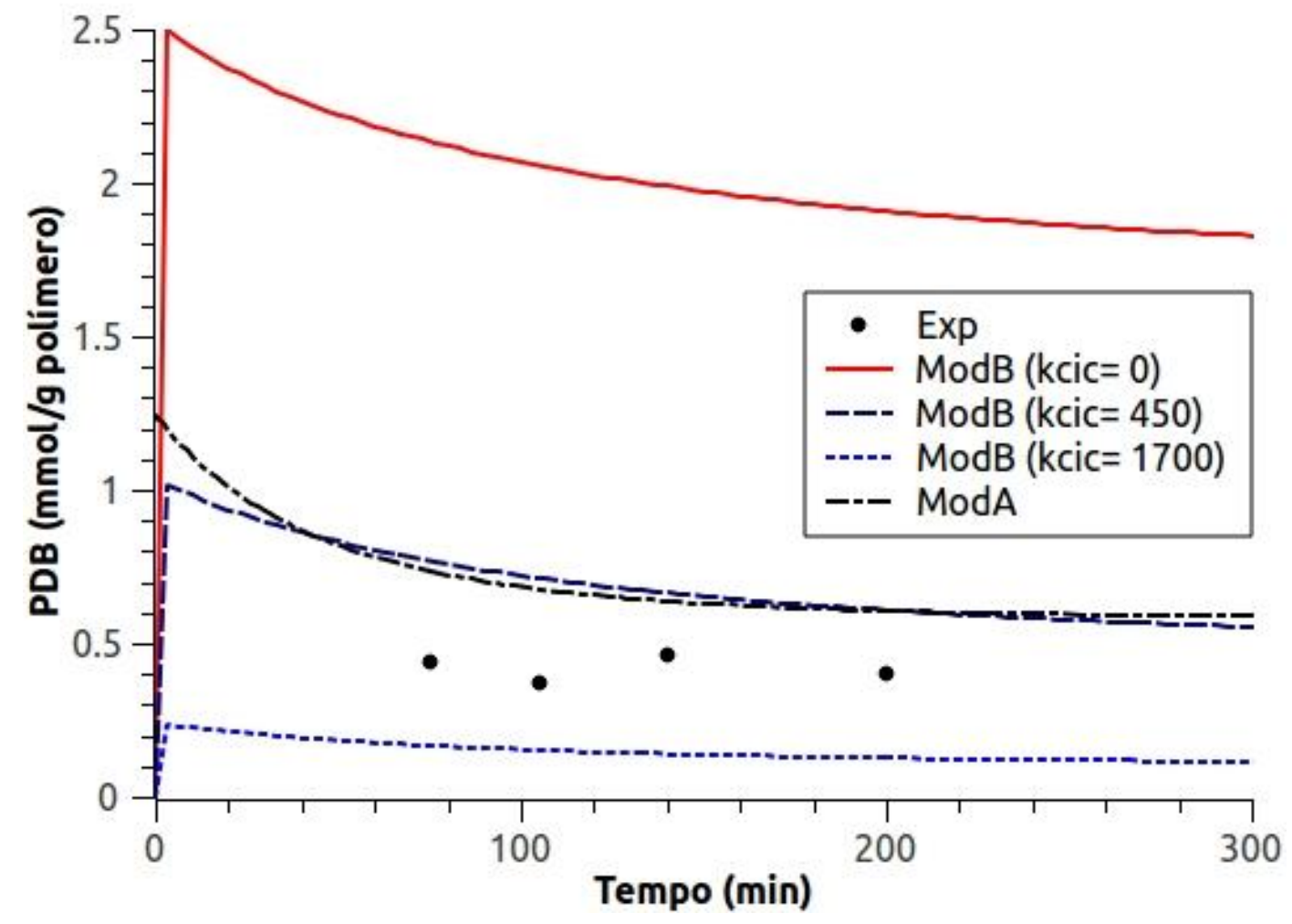

Figura 79 - Resultados de concentração de PDBs. Comparação dos modelos A e B com os dados do experimento B4. $\mathrm{kcic} \mathrm{em} \mathrm{s}^{-1}$. 
Nota-se nas figuras 77-79, que as previsões obtidas com o Modelo B, utilizando-se $\mathrm{kcic}=450 \mathrm{~s}^{-1}$, apresentaram maior proximidade dos dados experimentais em relação às previsões obtidas com $\mathrm{kcic}=0$ e $\mathrm{kcic}=1700 \mathrm{~s}^{-1}$. Observa-se na Figura 76, que o perfil de conversão se desloca de forma crescente à medida que se aumenta a constante de ciclização kcic. Este comportamento se deve à competição entre as reações de ligação cruzada e de ciclização em relação ao consumo de PDBs. No Modelo $B$ foi considerado que a proporção de radicais não se altera devido à reação de ciclização (não há distinção de centro radicalar presente em cadeia cíclica). Desta forma, o aumento no consumo de PDBs por ciclização causa a diminuição do consumo das mesmas por ligação cruzada, reduzindo a formação de radicais de PDBs, que são menos reativos. A conversão obtida com o Modelo $A$ está superestimada em relação aos dados experimentais. Isto se deve à taxa de propagação de monômero prevista por este modelo, que leva em conta somente um tipo de radical. Neste modelo, considerou-se que todos os radicais possuem a reatividade do radical de estireno, que é a maior em relação aos outros radicais produzidos no processo. Portanto, para casos com altas concentrações iniciais de DVB (> 5\%), os erros se acentuam, acarretando em conversões demasiadamente altas.

As variáveis $\mathrm{Wg}$ e concentração de PDBs apresentaram resultados de simulação coerentes com respeito às diferentes constantes de ciclização. O perfil de fração de gel diminui com o aumento de kcic devido à competição entre as reações de ciclização e as reações de ligação cruzada. O consumo de PDBs aumenta com o aumento de kcic. Observa-se que os perfis de $\mathrm{Wg}$ e de concentração de PDBs obtidos com o Modelo A, apresentam certa proximidade dos dados experimentais. Estes bons resultados estão associados à constante média de ligação cruzada ajustada para este caso específico (modelo com um único tipo de centro radicalar).

As figuras 80 e 81 mostram os resultados de simulação com os modelos $A$ e $B$ para a variável concentração de PDBs. No modelo $A$, a previsão da concentração de PDBs não foi satisfatória para o experimento B5. Este modelo não inclui reações de ciclização, portanto, o consumo de PDBs se dá somente por ligações cruzadas e reação com radicais primários. Desta forma, o ajuste de uma constante cinética de ligações cruzadas produziu bons resultados para os experimentos com menores concentrações de DVB (B3 e B4), mas não gerou bom resultado para o caso mais extremo (100\% DVB) representado pelo experimento B5. 


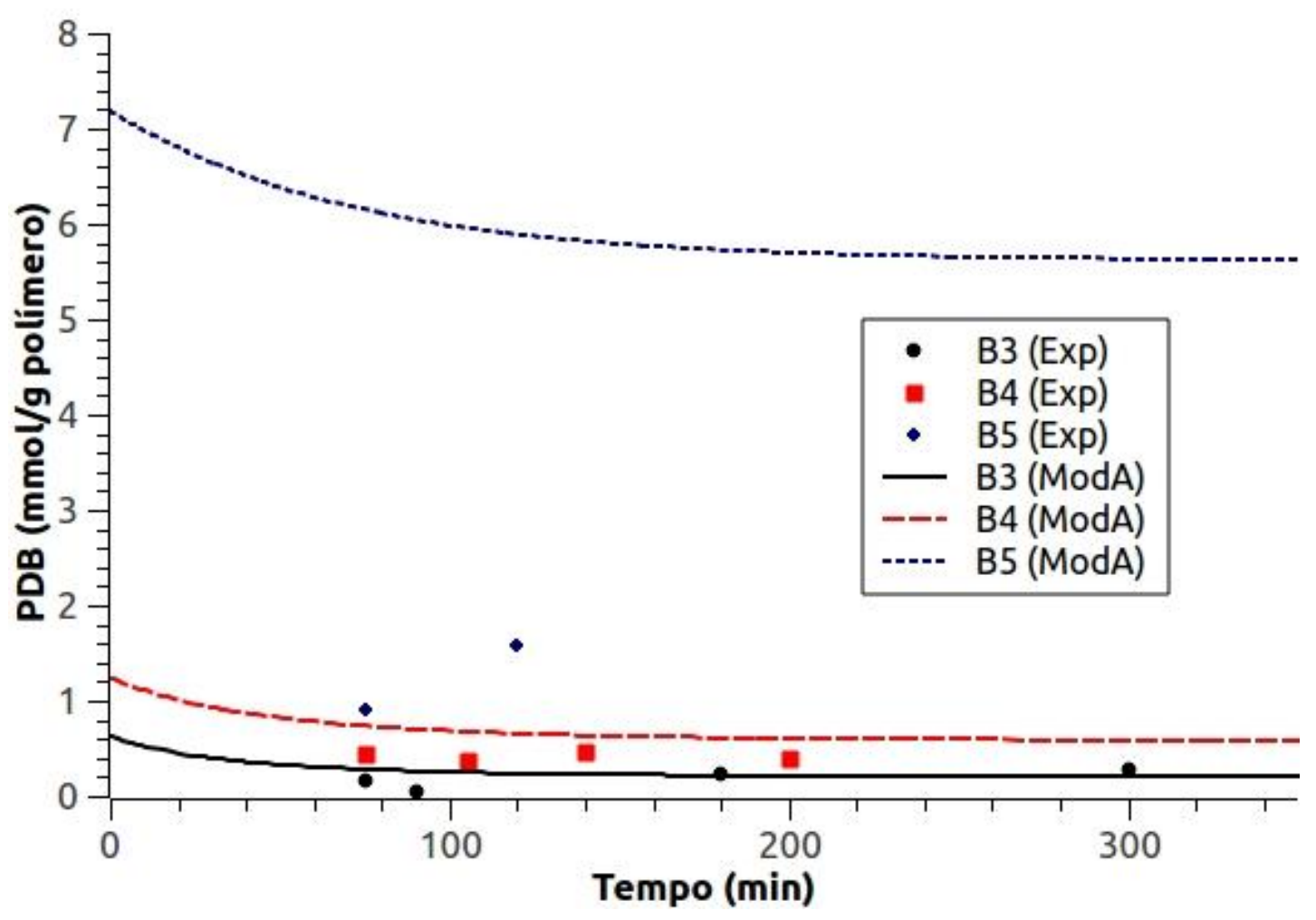

Figura 80 - Previsão da concentração de PDBs através do Modelo A.

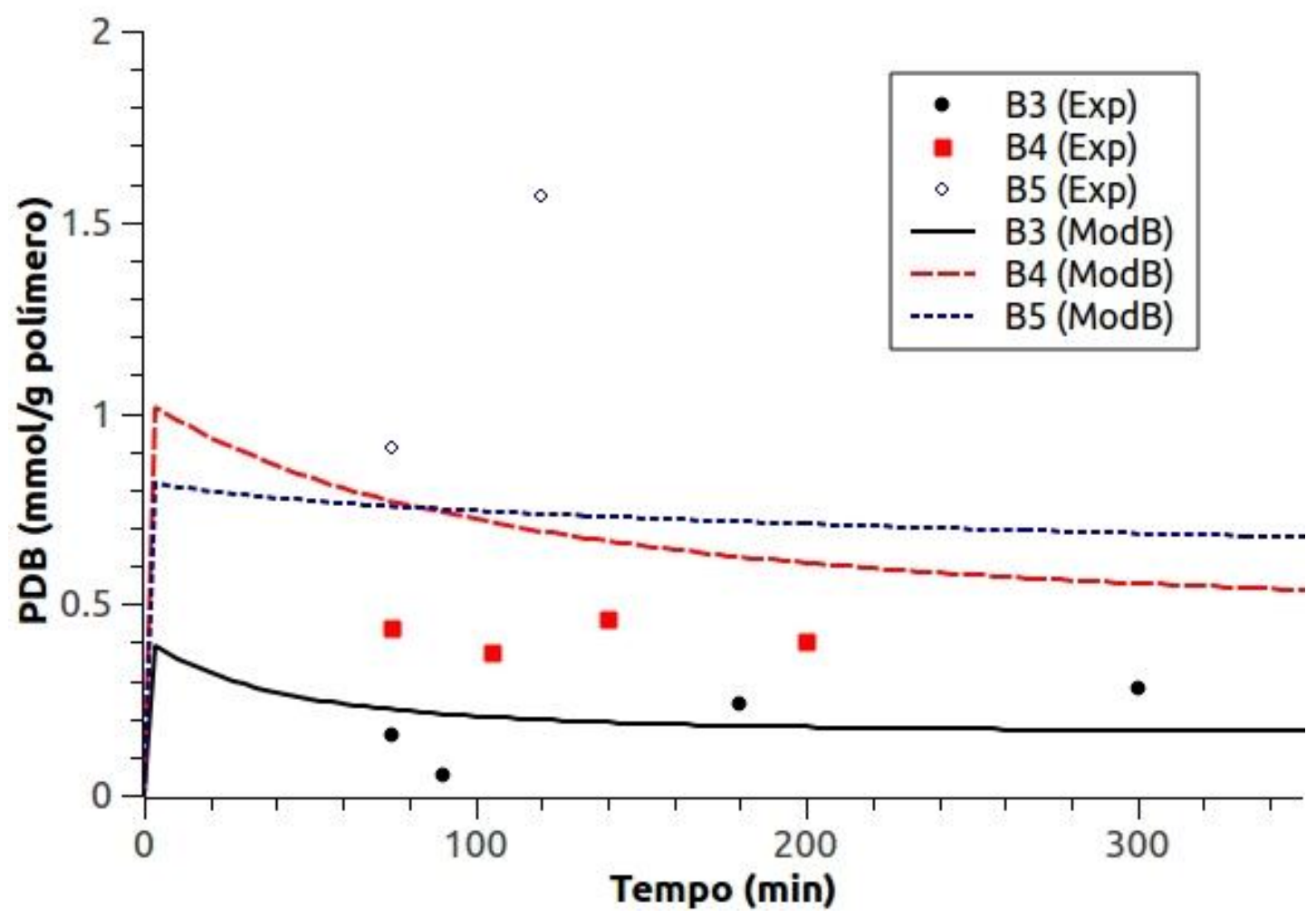

Figura 81 - Previsão da concentração de PDBs através do Modelo B com $\mathrm{kcic}=450 \mathrm{~s}^{-1}$. 
O Modelo B apresenta previsões de concentração de PDBs razoavelmente próximas aos dados experimentais para kcic $=450 \mathrm{~s}^{-1}$. O perfil crescente dos dados do experimento B5 sugere um erro experimental na análise de pelo menos um dos pontos. Com base na previsão do Modelo $B$, o ponto mais alto (cerca de 1,5 mmol/g polímero) aparenta conter um erro experimental. Estes resultados de simulação estão de acordo com os estudos preliminares sobre ciclização, feitos no item 4.2.2, indicando um valor de kcic em torno de $450 \mathrm{~s}^{-1}$.

Com base nos resultados obtidos com o Modelo B para kcic $=450 \mathrm{~s}^{-1}$, testouse este modelo, comparando-o com dados experimentais obtidos no presente trabalho, conforme mostrado nas figuras 82 e 83 .

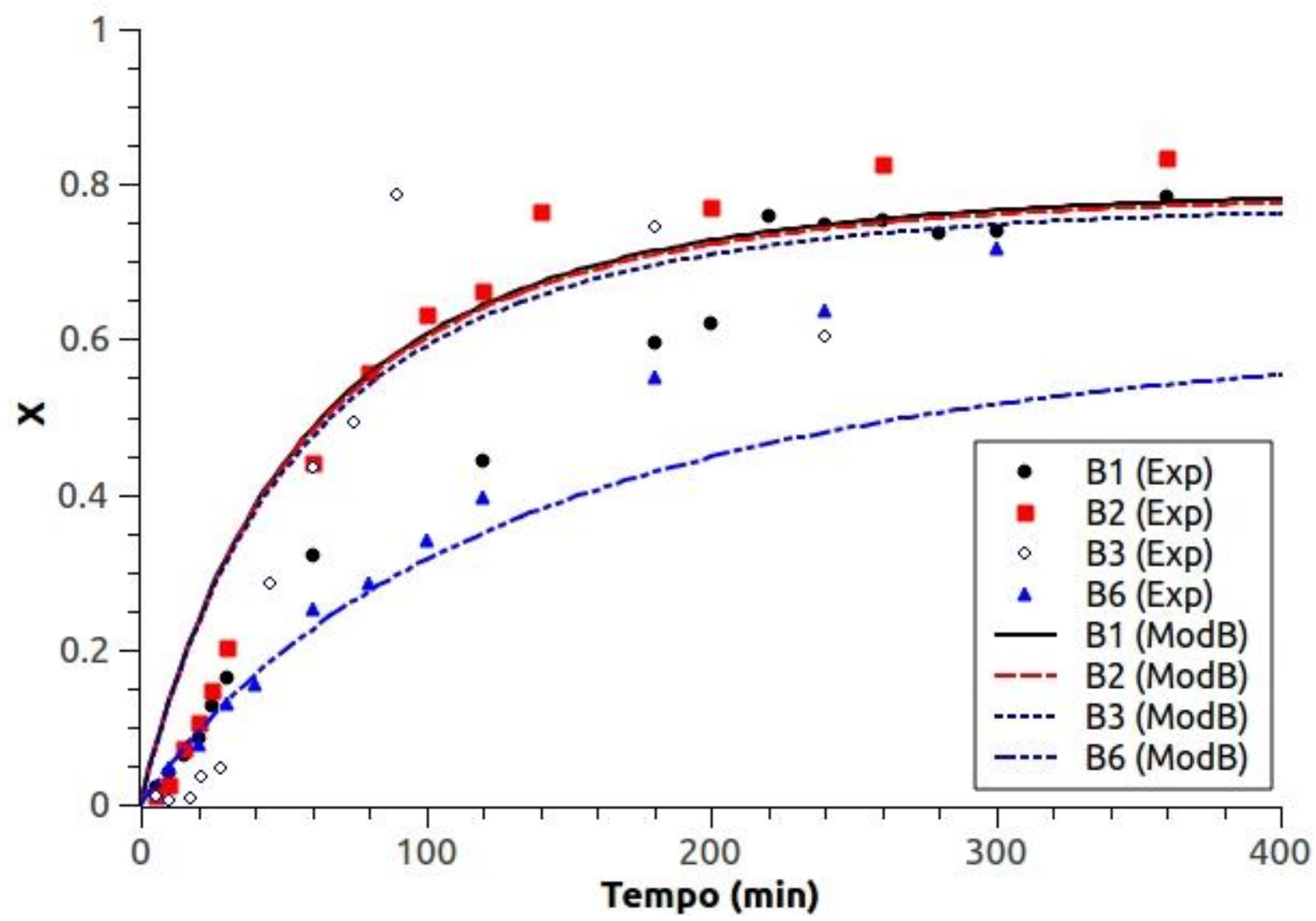

Figura 82 - Resultados de conversão. Comparação entre experimentos e o Modelo B com $\mathrm{kcic}=450 \mathrm{~s}^{-1}$.

As figuras 82 e 83 apresentam resultados aceitáveis para as simulações feitas com os dados dos experimentos B1, B2 e B3. Com os dados do experimento B6, o Modelo $\mathrm{B}$ fornece boas previsões para a região de baixas conversões. Os resultados 
foram semelhantes para o experimento $\mathrm{B} 5$, porém ele não foi apresentado devido à escassez de dados experimentais.

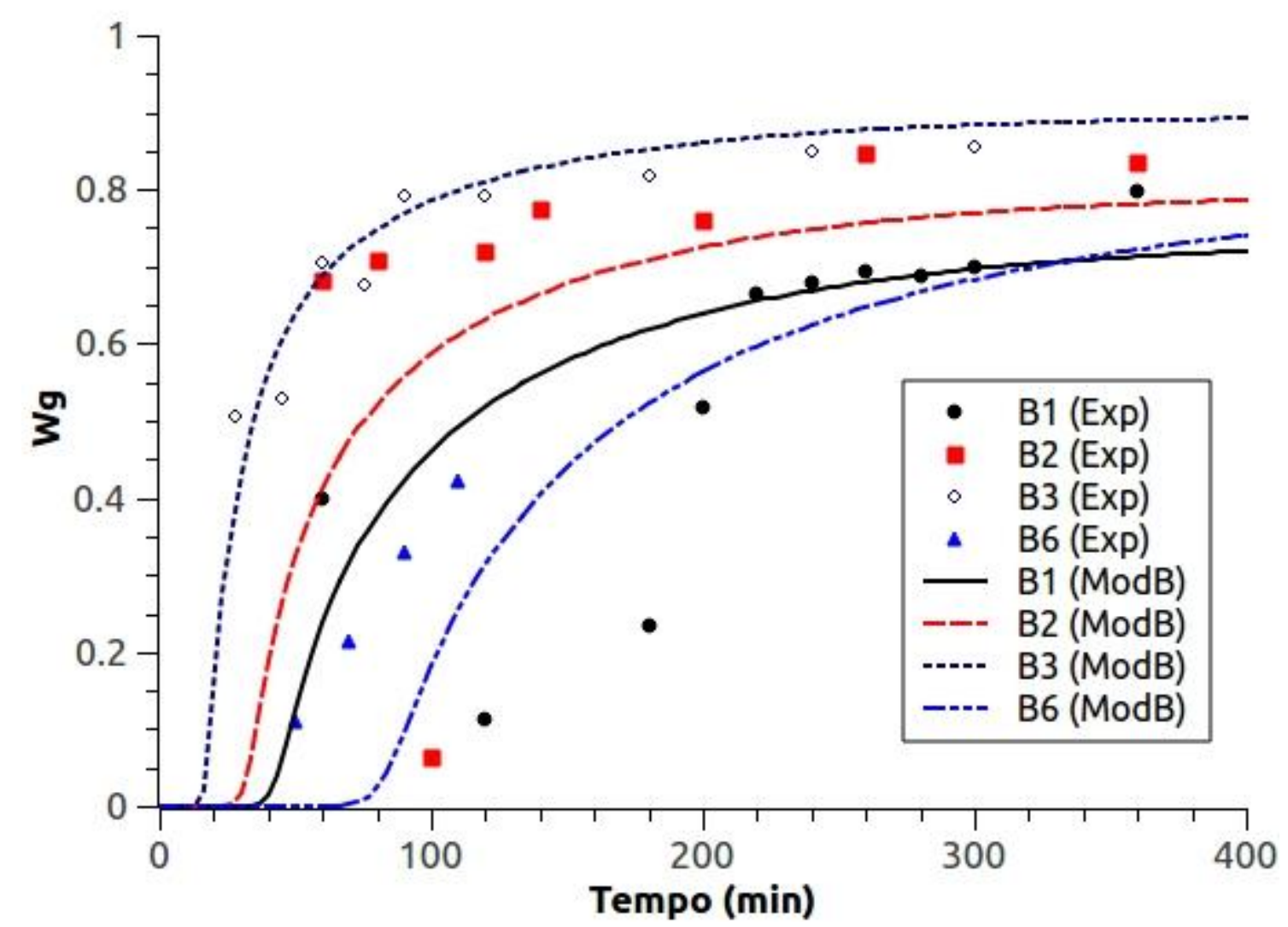

Figura 83 - Resultados de fração de gel. Comparação entre dados experimentais e o Modelo B com $\mathrm{kcic}=450 \mathrm{~s}^{-1}$.

A previsão do modelo referente ao experimento B6 apresentou um perfil de conversão abaixo do perfil experimental para tempos acima de $150 \mathrm{~min}$ e um perfil de fração de gel um pouco atrasado em relação aos dados experimentais. Este comportamento pode estar associado à diluição estabelecida para este experimento. A Tabela 11 indica uma reatividade relativamente baixa para propagações envolvendo radicais de DVB. Num meio bastante diluído (que é o caso do experimento B6), os radicais poliméricos podem se tornar mais acessíveis (com menor número de cadeias de polímero ao seu redor), possuindo maior reatividade com PDBs. Apesar de as taxas das reações, em geral, diminuírem com o aumento da diluição, este aumento da taxa de crosslink devido à maior mobilidade de cadeias promoveria um adiantamento do ponto de gel, gerando uma competição de efeitos. É possível que a inclusão de equações referentes a efeitos difusivos no modelo, 
poderia corrigir a discrepância do perfil de $\mathrm{Wg}$ em relação aos dados do experimento B6.

Neste item também foi estudada a copolimerização convencional realizada em suspensão (experimento P7). Teoricamente, as reações que ocorrem dentro de um processo em solução são as mesmas que ocorrem dentro das gotas de fase orgânica num processo em suspensão. As figuras 84 e 85 apresentam uma comparação das previsões dos modelos A e B com os resultados experimentais de conversão de monômero e fração de gel para o experimento P7.

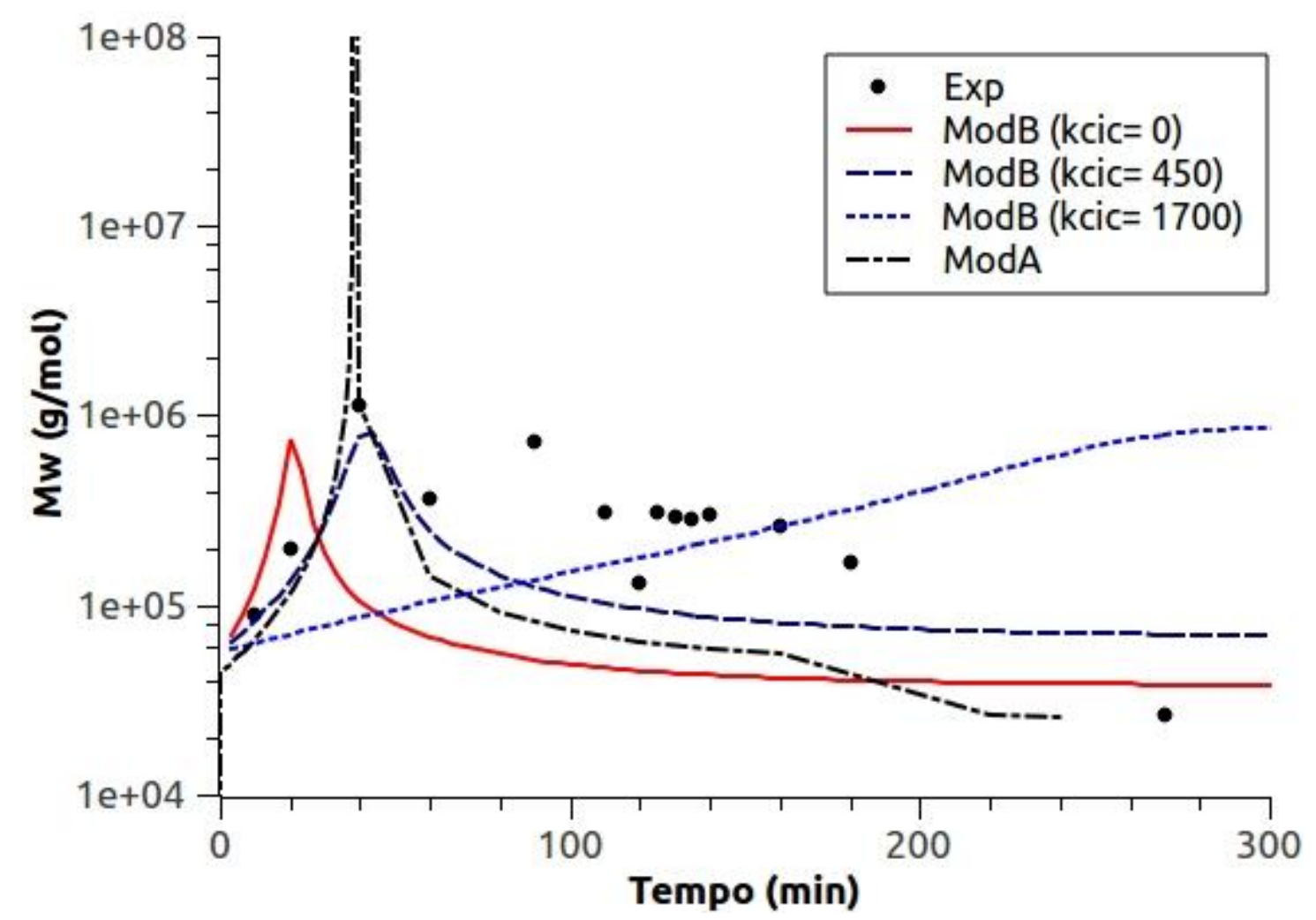

Figura 84 - Comparação de previsões dos modelos A e B com os resultados experimentais de Mw para o experimento P7. kcic em s${ }^{-1}$.

Conforme mostrado nas figuras 84 e 85 , o Modelo $A$ representou bem os perfis de Mw e Wg para o experimento P7. A utilização da reatividade do radical de estireno nas propagações de monômeros (ver Tabela 10) desempenha um papel importante na obtenção destes resultados, uma vez que o experimento P7 foi realizado com baixa concentração de DVB (1\%). Por outro lado, a constante cinética de ligações cruzadas ajustada para o Modelo A, é aparente, pois o modelo produziu boa previsão para a fração de gel sem considerar as reações de ciclização. $\mathrm{Na}$ Figura 85, fica claro o papel desempenhado pelas reações de ciclização sobre o 
tempo de gelificação. Os resultados com o Modelo B para o experimento P7 corroboram a validade do valor de kcic estimado anteriormente $\left(450 \mathrm{~s}^{-1}\right)$.

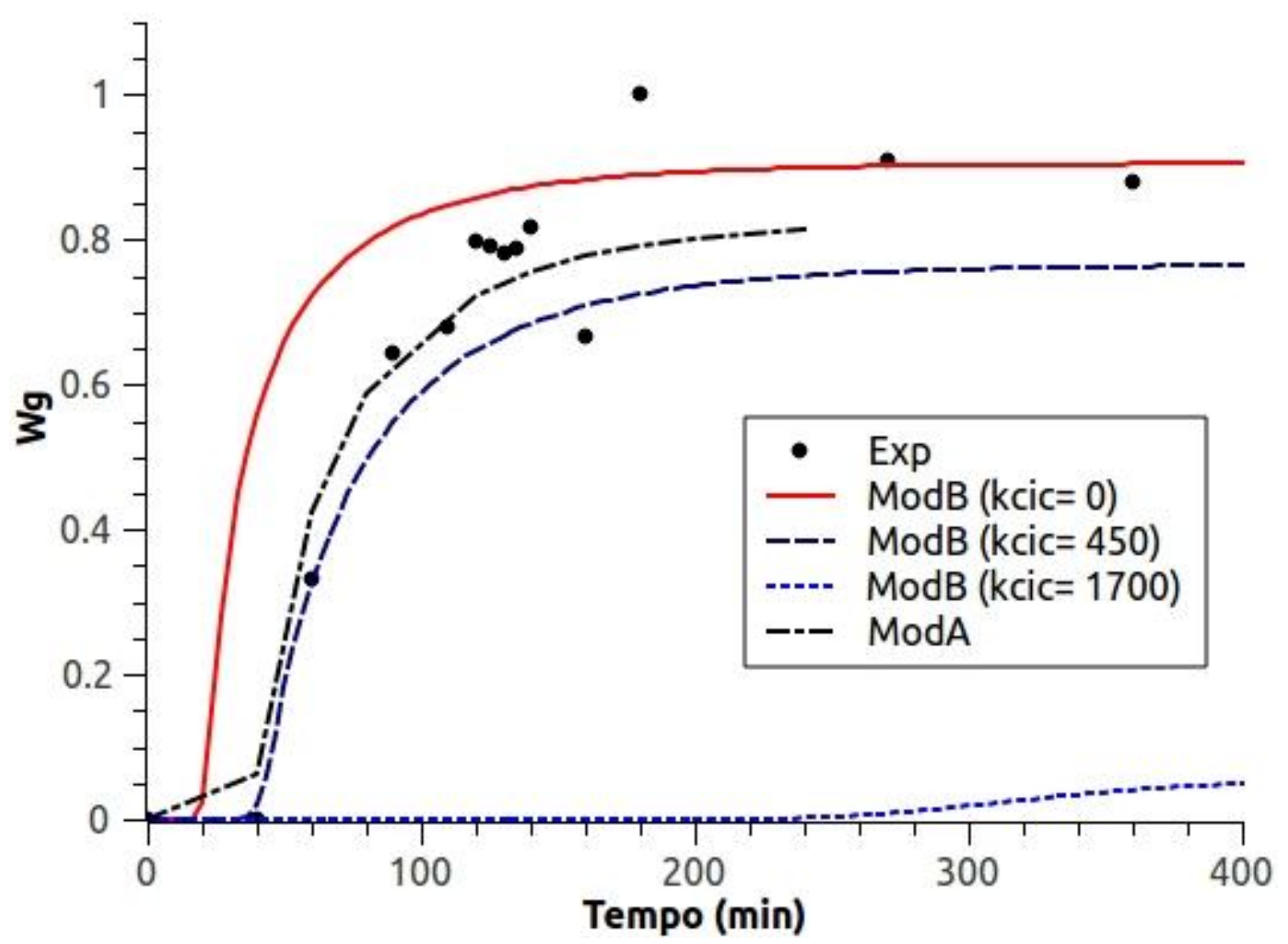

Figura 85 - Comparação de previsões dos modelos A e B com os resultados experimentais de Wg para o experimento P7. kcic em s ${ }^{-1}$.

As figuras 86 e 87 apresentam a comparação dos resultados obtidos com os modelos A e C. A Figura 86 apresenta perfis de Mw para o Modelo $C$ situados num patamar acima do perfil obtido com o Modelo A no trecho pós-gelificação. Nas previsões de $\mathrm{Mw}$ com o Modelo $\mathrm{C}$ não é possível visualizar com clareza os pontos de gelificação. Porém, eles existem e podem ser bem identificados através dos perfis de fração de gel apresentados na Figura 86 A previsão de fração de gel com o Modelo $C\left(\mathrm{kcic}=450 \mathrm{~s}^{-1}\right)$ não se mostrou aceitável. $O$ Modelo $C$ considera uma redução compassada da reatividade das ligações cruzadas. Este comportamento parece se manifestar com maior intensidade nas copolimerizações NMRP, nas quais as moléculas de polímero apresentam maior homogeneidade em termos de distribuição das ligações cruzadas. A abordagem utilizada no Modelo $\mathrm{C}$ e a comparação do mesmo com o Modelo B serão melhor exploradas no item a seguir (4.2.4). 


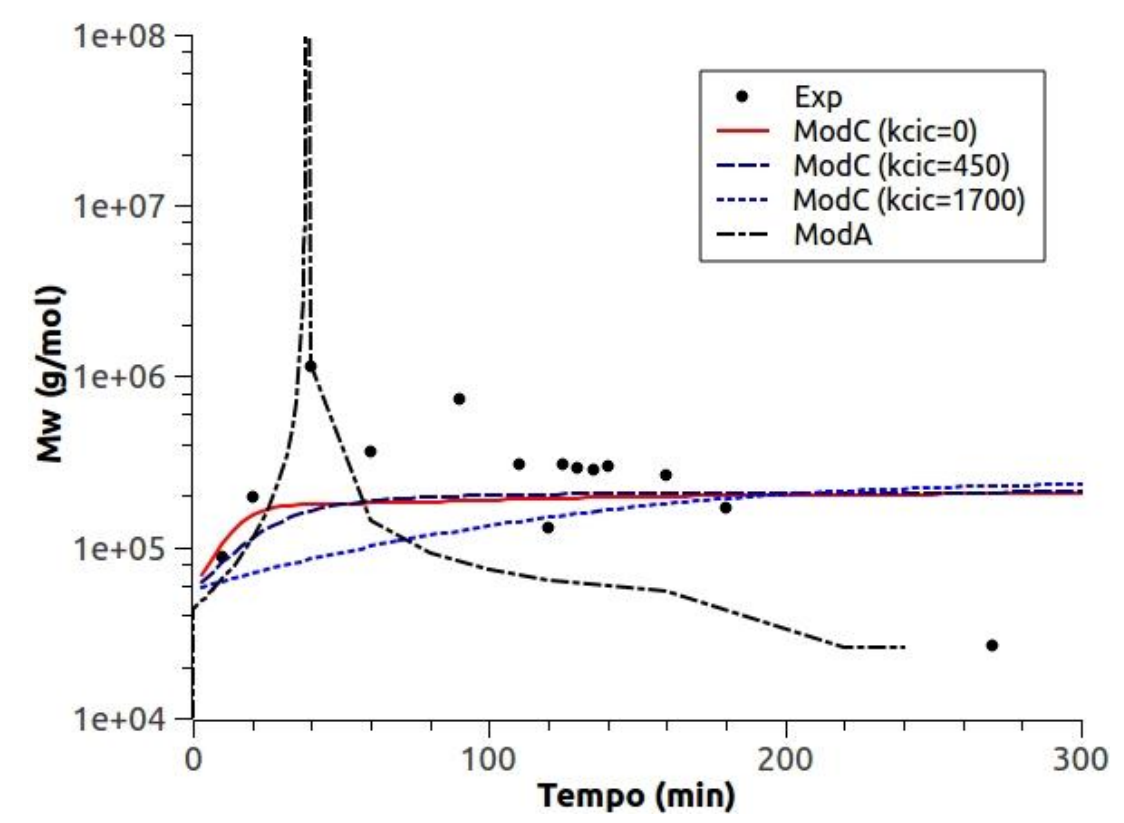

Figura 86 - Comparação de previsões dos modelos $A$ e C com os resultados experimentais de $\mathrm{Mw}$ para o experimento P7. kcic em s${ }^{-1}$.

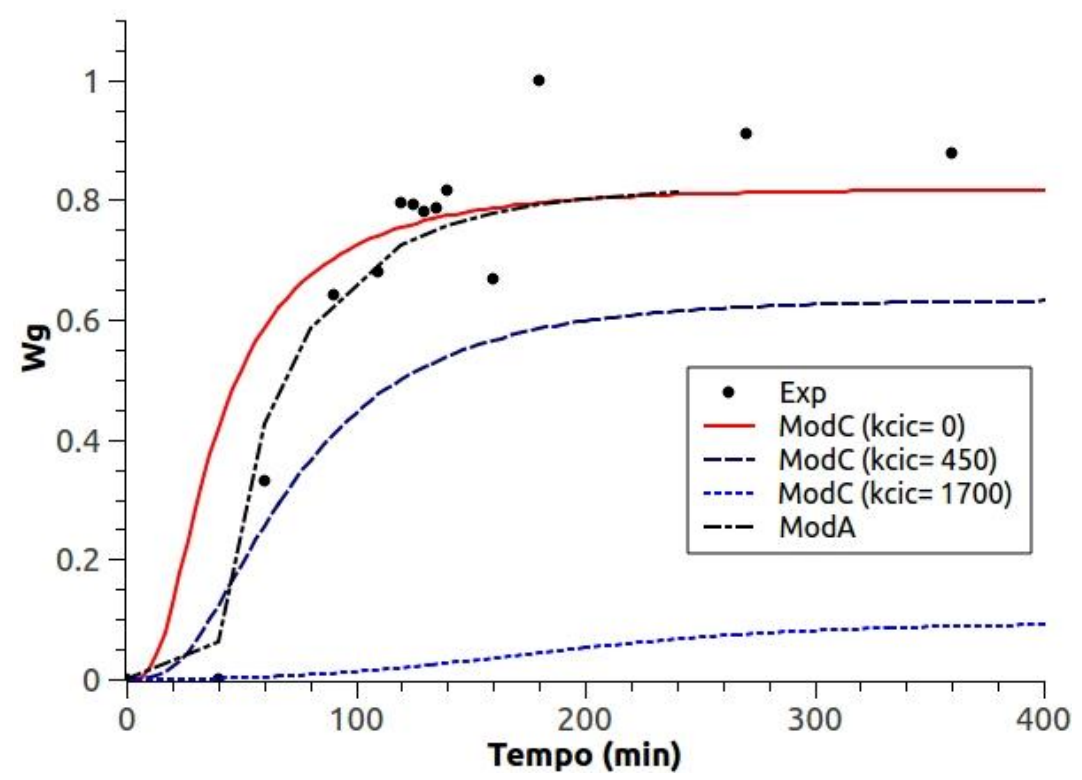

Figura 87 - Comparação de previsões dos modelos A e C com os resultados experimentais de $\mathrm{Wg}$ para o experimento P7. kcic em s${ }^{-1}$.

Vale ressaltar que a obtenção de um bom ajuste quantitativo entre modelos e experimentos foi um problema secundário no presente trabalho. Frente a complexidade do sistema em questão, objetivou-se inicialmente, fazer uma avaliação qualitativa dos resultados experimentais e suas respectivas previsões por parte dos modelos. 
4.2.4. Resultados de simulação de homo e copolimerizações mediadas por nitróxido

Neste item são descritos os resultados de simulação com os dados das polimerizações NMRP, as quais foram conduzidas em suspensão aquosa. As simulações foram realizadas utilizando-se os modelos $A$, B e C. Os dados cinéticos utilizados neste estudo estão descritos na Tabela 12.

Tabela 12 - Parâmetros cinéticos utilizados nas simulações de processos NMRP (continua)

Reação Parâmetro cinético

Reação considerada nos modelos:

\begin{tabular}{lll}
\hline Decomposição do AIBN & $k_{d}=2,31 \times 10^{15} e^{\left(\frac{-131700}{R T}\right)}\left(\mathrm{s}^{-1}\right)$ & A, B e C \\
& $\mathrm{f}=0,6$ & \\
Decomposição do BPO & $k_{d}=6,94 \times 10^{13} e^{\left(\frac{-29229}{R T}\right)}\left(\mathrm{s}^{-1}\right)$ & A, B e C \\
& $\mathrm{f}=0,55$ & A, B e C \\
Desativação de radicais & $k_{d a}=5,03 \times 10^{9} e^{\left(\frac{-15570}{R T}\right)}$ & A, B e C \\
Ativação de radicais & $k_{a}=2,0 \times 10^{13} e^{\left(\frac{-124200}{R T}\right)}\left(\mathrm{s}^{-1}\right)$ & A, B e C \\
Propagação de estireno & $k_{p 11}=4,27 \times 10^{7} e^{\left(\frac{-325500}{R T}\right)}$ & A, B e C \\
Propagações & $r_{12}=\frac{k_{p 11}}{k_{p 12}}=0,43$ & \\
(reatividades) & $r_{13}=\frac{k_{p 11}}{k_{p 13}}=0,24$ & \\
& $\mathrm{C} p=0,20$ \\
& $r_{14}=\frac{k_{p 11}}{k_{p 14}}=\frac{2 r_{12}}{C_{P}}$ & \\
& $r_{15}=\frac{k_{p 11}}{k_{p 13}}=\frac{2 r_{13}}{C_{P}}$ & \\
& $r_{2 i}=\frac{k_{p 2 i}}{k_{p 1 i}}=0,77$ \\
& $r_{3 i}=\frac{k_{p 3 i}}{k_{p 1 i}}=0,29$ \\
& $r_{4 i}=\frac{k_{p 4 i}}{k_{p 1 i}}=0,77^{2}=0,59$ \\
& $r_{5 i}=\frac{k_{p 5 i}}{k_{p 1 i}}=0,29^{2}=0,08$ \\
$(1 \leq \mathrm{i} \leq 5)$ &
\end{tabular}


Tabela 12 - Parâmetros cinéticos utilizados nas simulações de processos NMRP (conclusão)

\begin{tabular}{|c|c|c|}
\hline Reação & Parâmetro cinético & $\begin{array}{l}\text { Reação considerada } \\
\text { nos modelos: }\end{array}$ \\
\hline Iniciação & $\mathrm{k}_{\mathrm{lj}}=\mathrm{k}_{\mathrm{p} 1 \mathrm{j}}(1 \leq \mathrm{j} \leq 5)$ & $A, B$ e C \\
\hline $\begin{array}{l}\text { Transferência de cadeia } \\
\text { para monômero }\end{array}$ & $C_{M}=\frac{k_{f m 11}}{k_{p 11}}=0,2198 e^{\left(\frac{-23500}{R T}\right)}$ & $A$ \\
\hline Dimerizações & $k_{d i m i j}=188,97 e^{\left(\frac{-67700}{R T}\right)}$ & $A$ \\
\hline Decomposição de dímero & $k_{d d}=5,49 \times 10^{9} e^{\left(\frac{-106100}{R T}\right)}$ & $A$ \\
\hline $\begin{array}{l}\text { Iniciação térmica de } \\
\text { estireno }\end{array}$ & $k_{t h i}=6,359 \times 10^{12} e^{\left(\frac{-153100}{R T}\right)}$ & $A$ \\
\hline $\begin{array}{l}\text { Decomposição de radicais } \\
\text { dormentes }\end{array}$ & $k_{d e c}=5,7 \times 10^{14} e^{\left(\frac{-153300}{R T}\right)} \quad\left(\mathrm{s}^{-1}\right)$ & $A$ \\
\hline $\begin{array}{l}\text { Abstração de próton pelo } \\
\text { radical nitróxido }\end{array}$ & $k_{h}=10^{-3}$ & $A$ \\
\hline Terminação & $\begin{array}{l}\frac{k_{p 11}}{\sqrt{k_{t}}}=426,4 e^{\left(\frac{-26000}{R T}\right)} \\
\alpha_{\mathrm{td}}=\frac{\mathrm{k}_{\mathrm{td}}}{\mathrm{k}_{\mathrm{t}}}=0 ; \alpha_{\mathrm{tc}}=\frac{\mathrm{k}_{\mathrm{tc}}}{\mathrm{k}_{\mathrm{t}}}=1\end{array}$ & $A, B$ e $C$ \\
\hline $\begin{array}{l}\text { Ciclização } \mathrm{R}_{1} \text {-mPDB para } \\
\text { caminhos com } 3 \text { unidades } \\
\text { monoméricas }\left(\mathrm{k}_{\mathrm{p} 14,3}^{\mathrm{C}}\right)^{*}\end{array}$ & $\begin{array}{l}k_{p 14,3}^{C}=k c i c e^{\left[\frac{32500}{R}\left(\frac{1}{363,15}-\frac{1}{T}\right)\right]}\left(\mathrm{s}^{-1}\right) \\
\mathrm{kcic}=450 \mathrm{~s}^{-1}\end{array}$ & $B$ e $C$ \\
\hline
\end{tabular}

Constantes cinéticas em L/(mol.s), exceto quando indicada outra unidade; Referência: Gonçalves et al. (2010), exceto *: Presente trabalho.

Foram considerados 5 tipos de radical (estireno, mDVB, pDVB, mPDB e pPDB), 3 tipos de monômero (estireno, mDVB e pDVB) e 2 tipos de duplas ligações pendentes (mPDB e pPDB) nas simulações. Conforme descrito no capítulo 3, o Modelo A apresenta limitações relacionadas ao número de grupos poliméricos, as quais restringem a aplicação deste modelo, permitindo a simulação de Mw somente até o ponto de gel para os casos NMRP. Portanto, no presente item, as previsões de concentração de PDBs e de conversão de monômero, com o Modelo A, foram obtidas para todo o período de reação enquanto que as previsões de $\mathrm{Mw}$ foram feitas somente até o ponto de gel. 
Nas polimerizações NMRP, um parâmetro importante que afeta consideravelmente os resultados é a razão molar TEMPO/Iniciador ( $\mathrm{Y}_{\text {TEMPO }}$ ). No presente trabalho, foi utilizada a faixa de 0,75 até 1,2 para este parâmetro. Durante os estudos de simulação, verificou-se que, pequenas variações neste parâmetro geram consideráveis desvios nos resultados. A Figura 88 mostra o efeito da concentração inicial de TEMPO sobre os resultados de simulação.

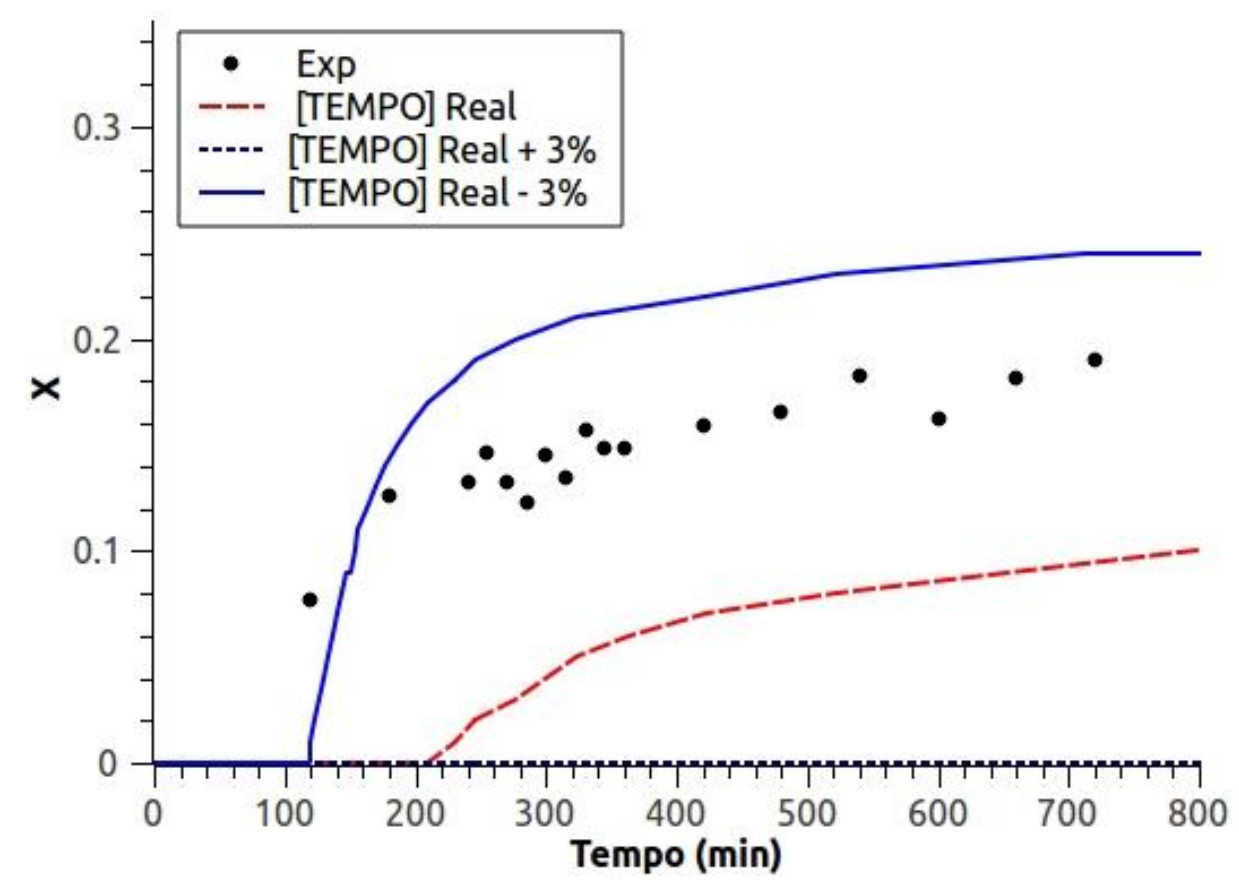

Figura 88 - Efeito da concentração de TEMPO sobre a conversão de monômero. [TEMPO] Real= Concentração inicial real de radical nitróxido. Simulações realizadas com os dados do exp. P4.

Como as quantidades de iniciador e TEMPO, adicionadas aos experimentos foram relativamente pequenas, quaisquer erros associados a estas massas podem afetar consideravelmente os resultados. Desta forma, as simulações foram realizadas, levando-se em conta um erro de $\pm 3 \%$, tanto para a concentração inicial de iniciador quanto para a concentração inicial de TEMPO. Esta faixa foi definida com base nos ajustes modelo/experimentos e pode estar relacionada a erros referentes à pureza dos reagentes, pesagem, dissolução incompleta (os iniciadores e o TEMPO são sólidos à temperatura ambiente), dentre outros.

O valor de kcic mostrado na Tabela 12 foi definido com base nos ajustes obtidos entre os experimentos e os modelos (ver itens 4.2 .2 e 4.2.3). Conforme descrito anteriormente, a concentração de PDBs é a variável afetada diretamente 
pelas reações de ciclização. Em simulações de NMRPs com o Modelo C, obtiveramse os melhores ajustes quando $\mathrm{kcic}=450 \mathrm{~s}^{-1}$, confirmando-se os indícios verificados no item 4.2.2. As figuras 89 e 90 mostram os resultados de simulação com os Modelos A e C para a concentração de PDBs.

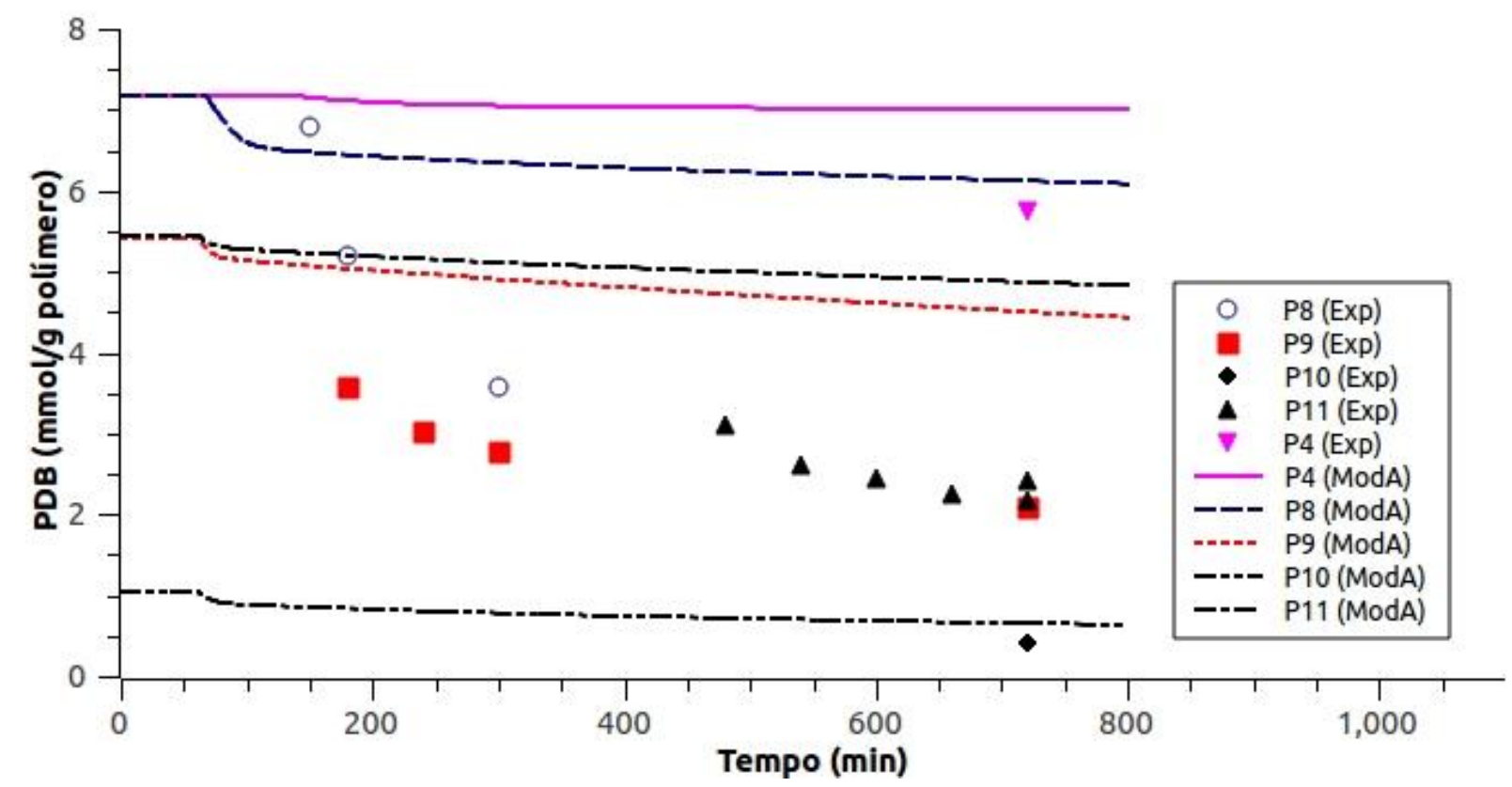

Figura 89 - Simulação da concentração de PDBs com o Modelo A para diferentes experimentos.

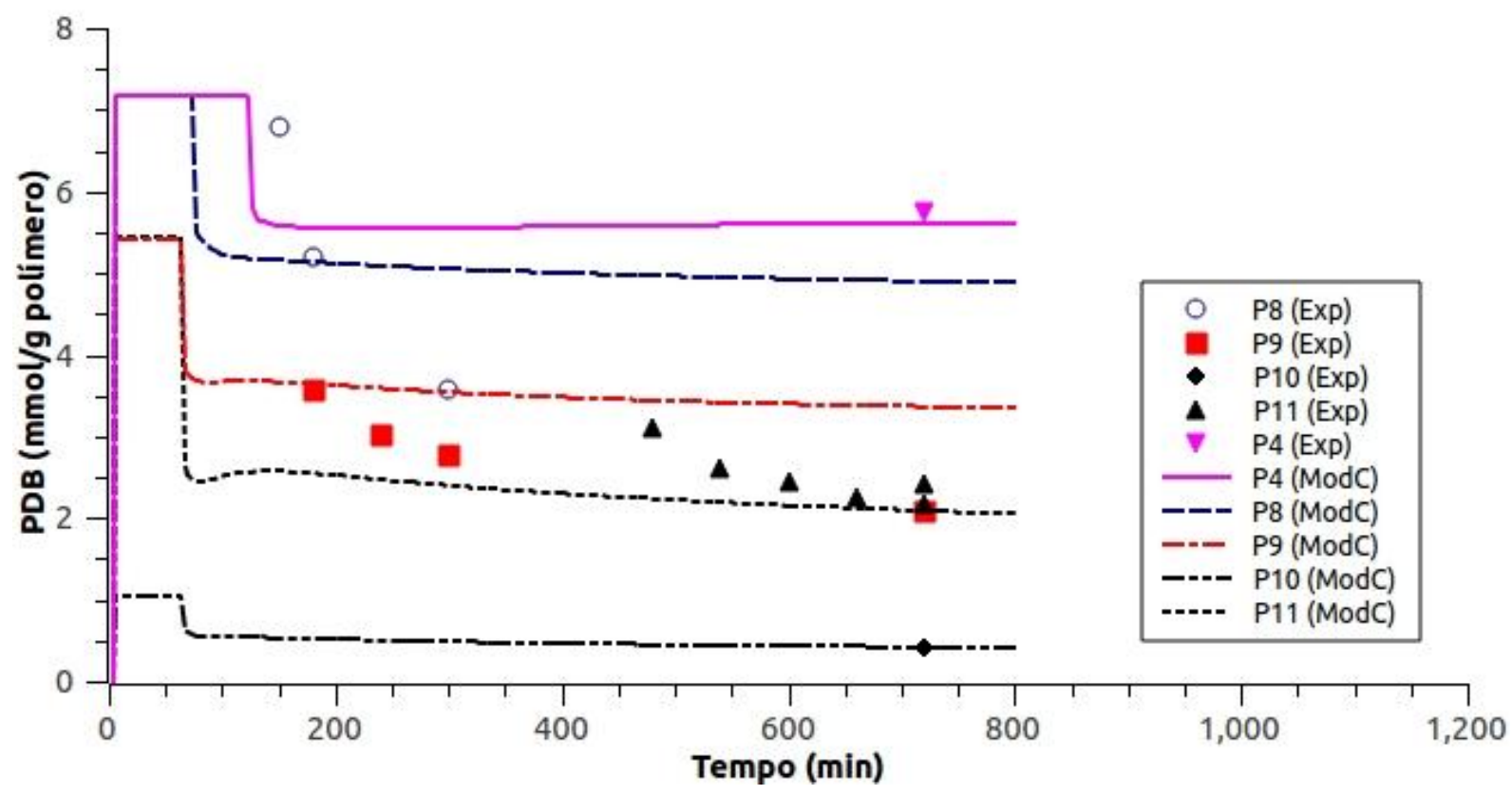

Figura 90 - Simulação da concentração de PDBs com o Modelo C para diferentes experimentos. $\mathrm{kcic}=450 \mathrm{~s}^{-1}$. 
Verifica-se que o Modelo A apresenta perfis de concentração de PDBs consideravelmente acima dos dados experimentais para a maioria dos casos. Uma vez que o consumo das duplas pendentes, neste modelo, se dá somente através da iniciação e da propagação das mesmas, a discrepância pode ser explicada pela ausência de reações de ciclização. Apesar de o Modelo $C$ apresentar uma nova hipótese em relação ao Modelo $\mathrm{B}$, os perfis de concentração de PDBs não apresentaram variação considerável relativamente ao que foi exposto no item 4.2.2. Mesmo obtendo um resultado comparativamente melhor com $\mathrm{kcic}=450 \mathrm{~s}^{-1}$, não se pode concluir que este é o valor real da constante cinética da reação de ciclização. Deve-se levar em conta que, o método dos caminhos possui hipóteses simplificadoras, as quais podem gerar desvios entre o valor aqui estimado e o valor real, como por exemplo, a hipótese de que somente cadeias primárias podem reagir por ciclização. De qualquer forma, tem-se uma estimativa inicial da constante cinética de ciclização para uma cadeia de estireno-divinilbenzeno contendo 3 unidades. $O$ valor numérico desta estimativa inicial se situa na ordem das centenas $\left(\mathrm{kcic}=450 \mathrm{~s}^{-1}\right)$, porém, conforme mostrado no capítulo 3 , a constante cinética de ciclização diminui com o aumento das cadeias. Desta forma, a constante média de ciclização seria consideravelmente menor, podendo chegar à ordem das dezenas ou unidades. Estas ordens de grandeza estão de acordo com os valores das constantes médias de ciclização publicadas por Hernández-Ortiz et al. (2012), que foram estimadas em: $5 \mathrm{~s}^{-1}$ para copolimerizações em massa a $393,15 \mathrm{~K}$ e $20 \mathrm{~s}^{-1}$ para copolimerizações em solução a 403,15K. As Figuras 91-94 mostram comparações entre resultados experimentais de conversão e as previsões com os modelos A e C.
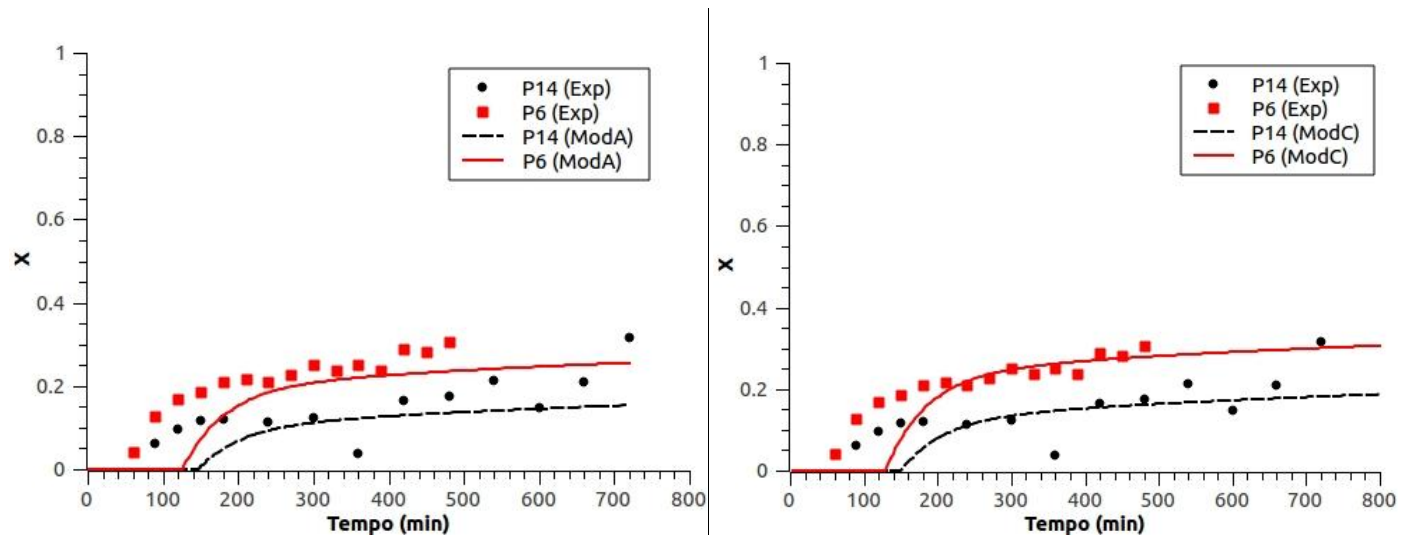

Figura 91 - Resultados de conversão. Comparação entre experimentos e simulações com os modelos A e C. Experimentos P6 e P14 (90º). 

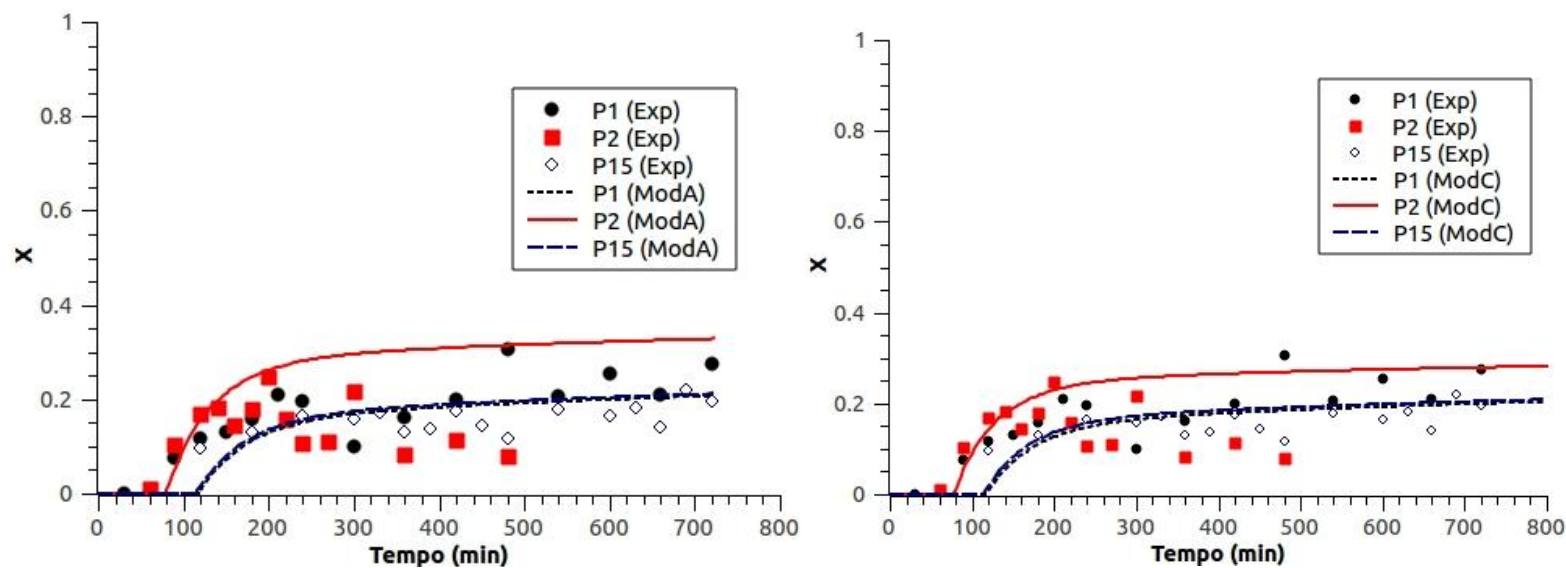

Figura 92 - Resultados de conversão. Comparação entre experimentos e simulações com os modelos A e C. Experimentos P1, P2 e P15 (90C).
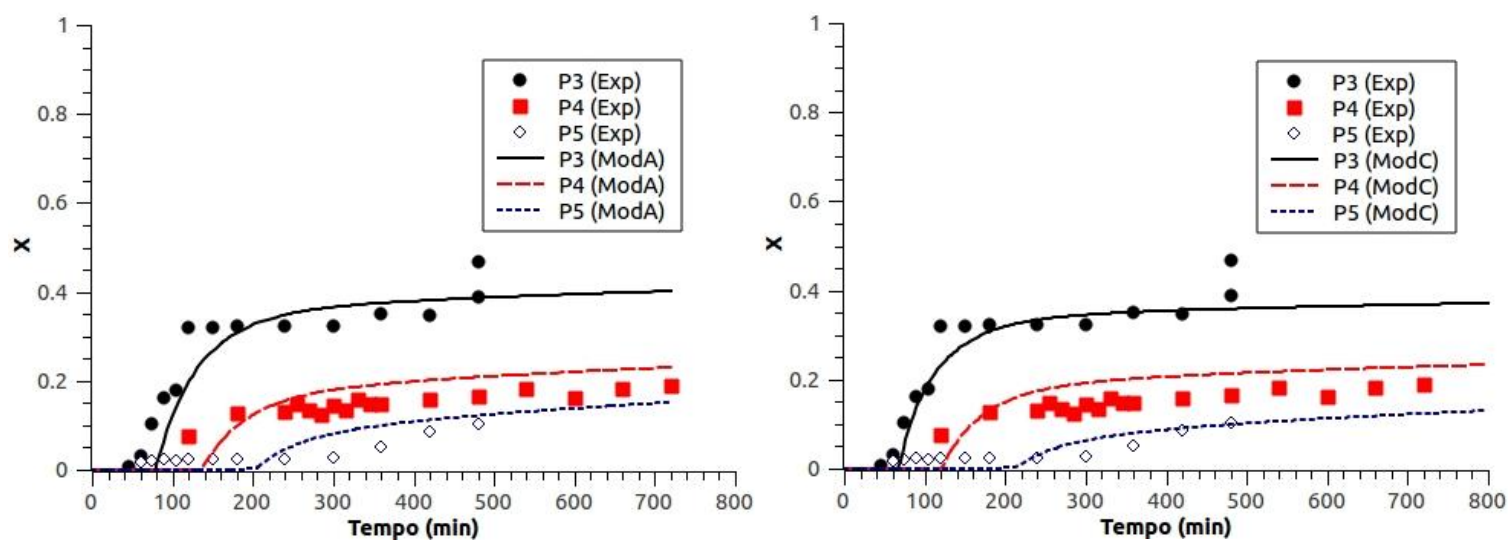

Figura 93 - Resultados de conversão. Comparação entre experimentos e simulações com os modelos A e C. Experimentos P3, P4 e P5 (90ㄷ).
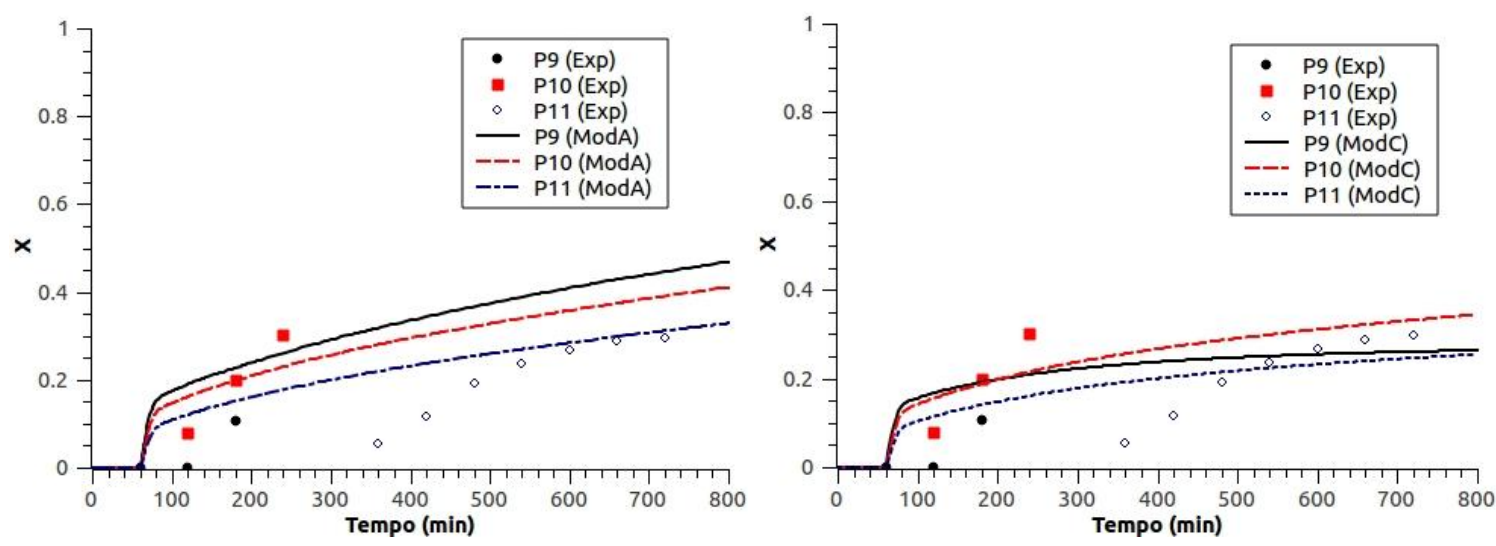

Figura 94 - Resultados de conversão. Comparação entre experimentos e simulações com os modelos A e C. Experimentos P9, P10 e P11 (130C).

As previsões de conversão não apresentaram diferenças consideráveis entre os modelos $\mathrm{A}$ e $\mathrm{C}$, conforme ilustrado nas figuras 91-94. A comparação entre as 
conversões obtidas com os modelos B e C não se mostrou relevante, uma vez que estes são idênticos, exceto pela hipótese da variação da reatividade das ligações cruzadas. Tal hipótese não afeta significativamente os resultados de conversão, de forma que os perfis desta variável são praticamente os mesmos para os modelos $B$ e C. A concordância experimentos/previsões para os modelos $A$ e $C$ se mostraram aceitáveis para os experimentos realizados a $90^{\circ} \mathrm{C}$, porém, observa-se certa discrepância entre as simulações e os dados dos experimentos realizados a $130^{\circ} \mathrm{C}$. Os dados de conversão do experimento P11 indicam um considerável atraso na formação de polímero relativamente aos outros experimentos. Para este experimento, a fração volumétrica inicial de monômeros foi de $20 \%$ relativamente à fase orgânica. $O$ longo atraso pode ser atribuído a esta diluição, porém, mesmo considerando-a nos modelos, não há um bom ajuste, principalmente no trecho correspondente ao período inicial da reação. Este atraso pode estar associado à temperatura de operação, visto que ele também ocorre em outros experimentos à $130^{\circ} \mathrm{C}$. As figuras $95-98$ ilustram este atraso para as variáveis massa molecular média mássica $(\mathrm{Mw})$ e fração de gel $(\mathrm{Wg})$.

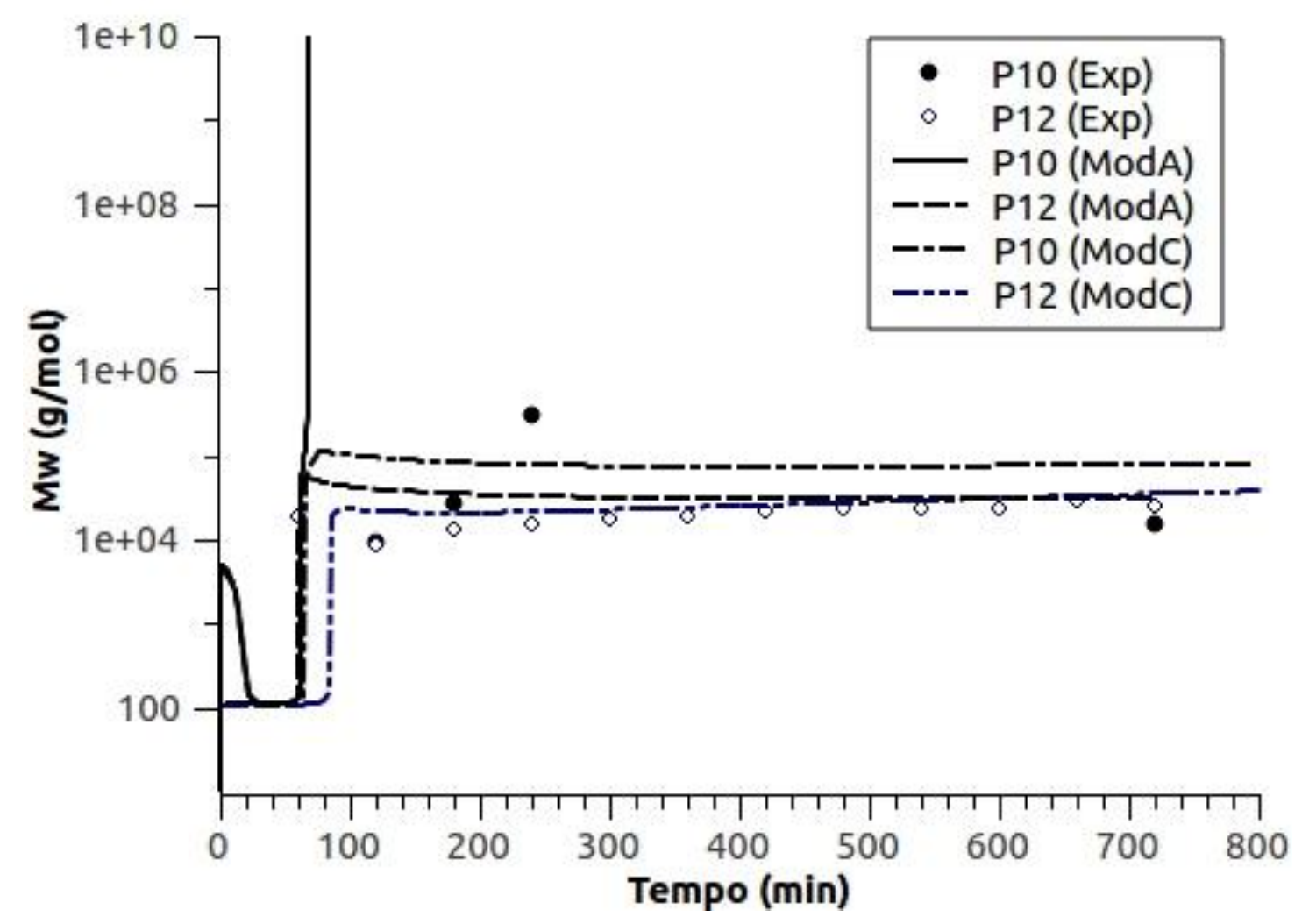

Figura 95 - Comparação entre os modelos A e C em previsões de Mw para experimentos a $130^{\circ} \mathrm{C}$. 


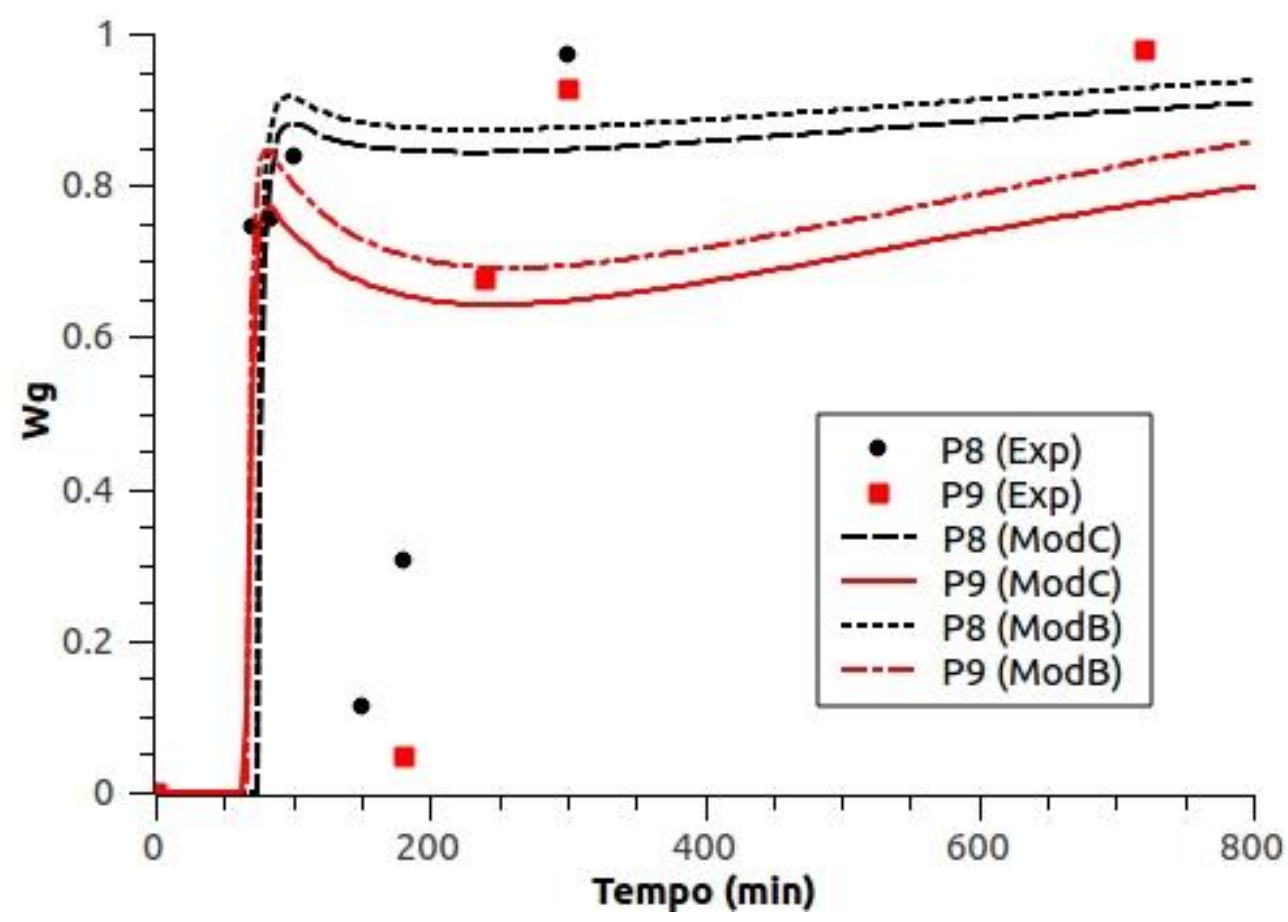

Figura 96 - Comparação entre os modelos $\mathrm{B}$ e C em previsões de $\mathrm{Wg}$ para experimentos a $130^{\circ} \mathrm{C}$.

É possível que haja correções a serem feitas na equação de Arrhenius para as reações de ativação e desativação de radicais de forma a reduzir as discrepâncias observadas. Outra possível causa deste atraso maior do que o esperado seria o mecanismo das reações de ativação e desativação de radicais primários. No presente trabalho foi considerada a mesma constante cinética para as reações de desativação de radicais poliméricos e primários. O mesmo foi feito para as reações de ativação. É possível que haja uma pequena diferença entre a taxa de reação envolvendo radical primário e a taxa de reação envolvendo radical polimérico. Também é possível que esta diferença se acentue em altas temperaturas (ex.: $130^{\circ} \mathrm{C}$ ). Estudos futuros sobre o mecanismo NMRP, explorando faixas de diluição de monômero e de temperaturas podem ser úteis na obtenção de um melhor entendimento deste processo.

Uma comparação de resultados de $\mathrm{Mw}$ com os 3 modelos é feita nas figuras 97 e 98. Os resultados de Mw com o experimento P8 não podem ser avaliados no período pós-gelificação devido à ausência de dados. Nas simulações com este caso, os 3 modelos apresentaram um ponto de gel adiantado em relação aos dados experimentais. 


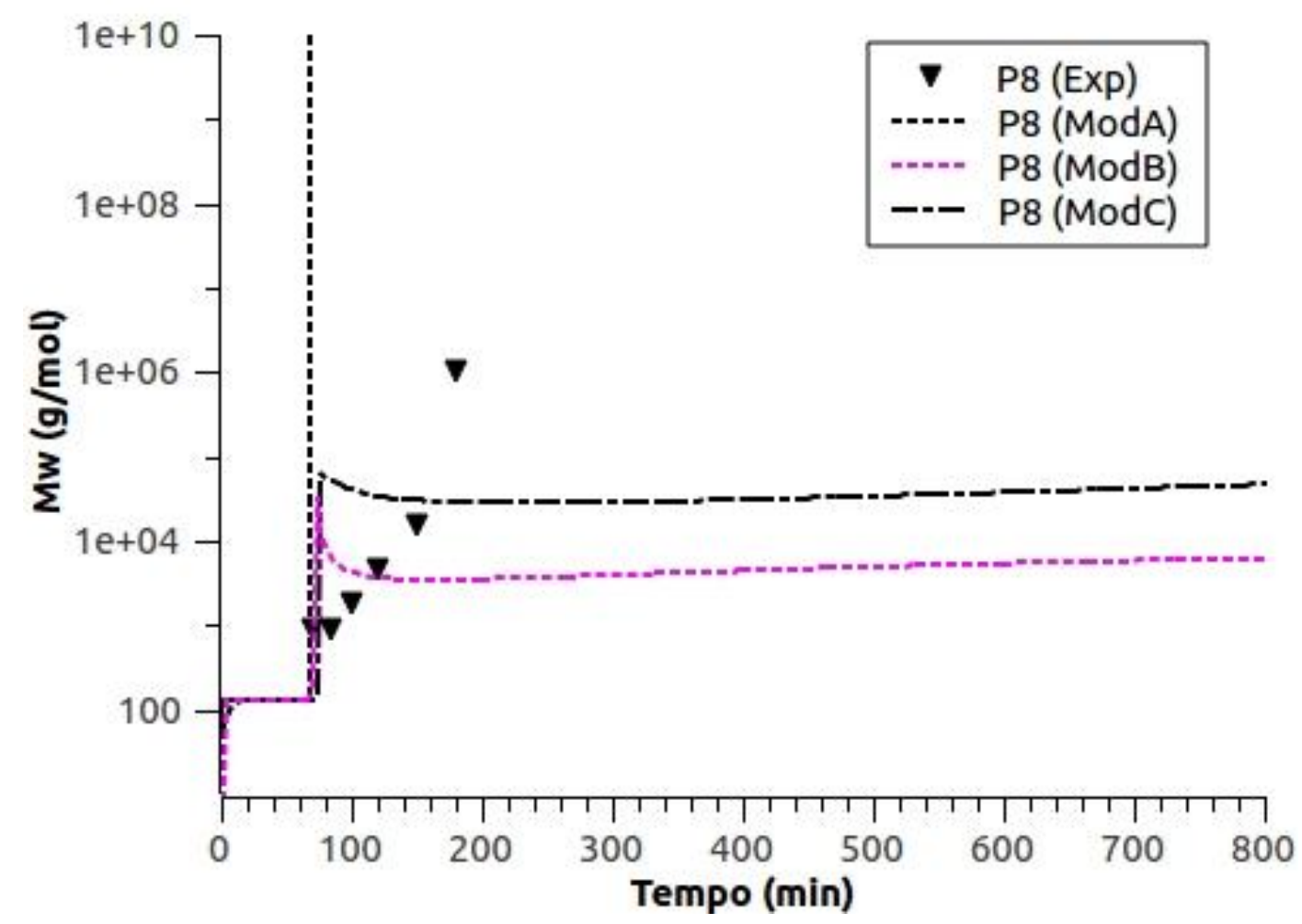

Figura 97 - Resultados de Mw para o experimento P8. Comparação entre os modelos A, B e C.

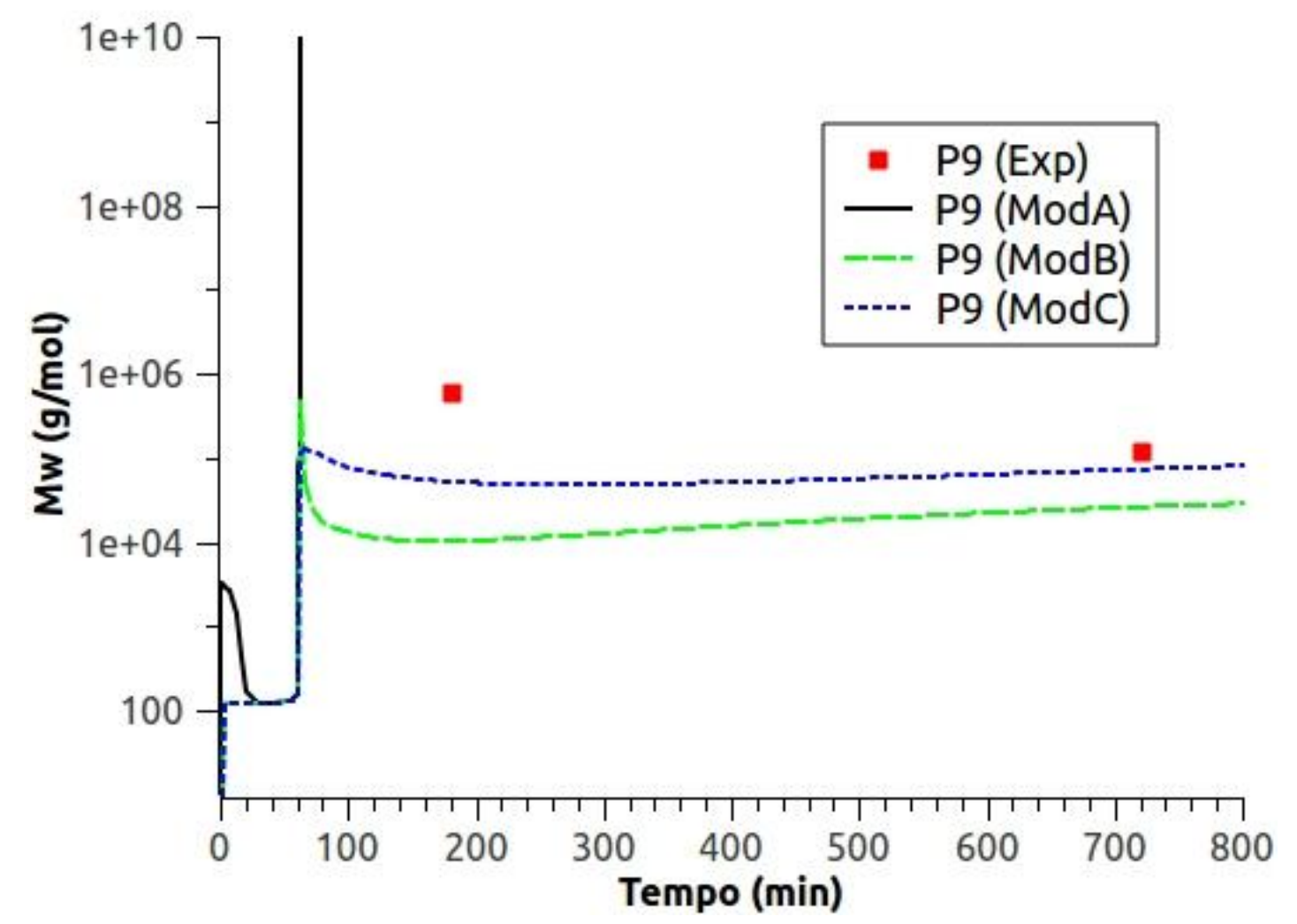

Figura 98 - Resultados de Mw para o experimento P9. Comparação entre os modelos A, B e C. 
Na Figura 98, observa-se a mesma discrepância entre os pontos de gel experimental e previstos pelos modelos. Porém, no período pós-gelificação, apesar da escassez de dados, observa-se um bom ajuste entre o Modelo $\mathrm{C}$ e os dados experimentais.

As copolimerizações realizadas a $90^{\circ} \mathrm{C}$ apresentaram melhores resultados quando comparadas às reações a $130^{\circ} \mathrm{C}$. Conforme mostrado nas Figuras 72 e 73, o problema referente ao ajuste simultâneo de $\mathrm{Mw}$ e Wg com um único valor de Cp não pôde ser solucionado com o Modelo B. A Figura 72 indica uma rápida incorporação de moléculas solúveis grandes ao gel, por parte do modelo, o que reduz a massa molecular média. Porém, os dados experimentais, indicam que a massa molecular média de moléculas solúveis, ainda se mantém relativamente alta após a gelificação. Isto sugere que a reação de ligação cruzada tem uma reatividade menor para moléculas grandes, conforme descrito no Modelo C (ver capítulo 3). As figuras 99101 apresentam os resultados de simulação com os modelos A e C para as variáveis $\mathrm{Mw}$ e $\mathrm{Wg}$ em experimentos a $90^{\circ} \mathrm{C}$.

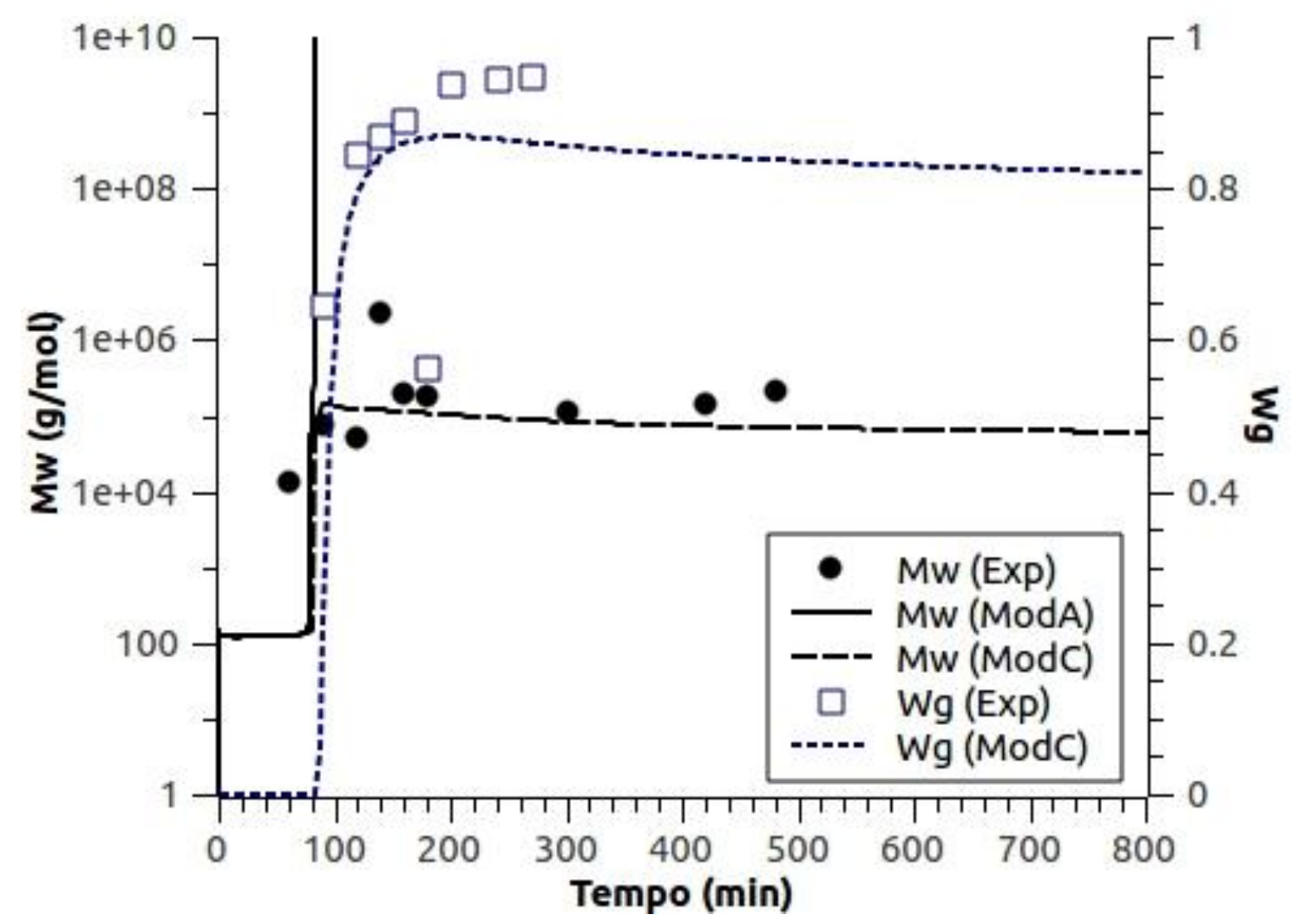

Figura 99 - Comparação entre dados experimentais e previsões de $\mathrm{Mw}$ e $\mathrm{Wg}$ com os modelos $\mathrm{A}$ e C para o experimento P2. 


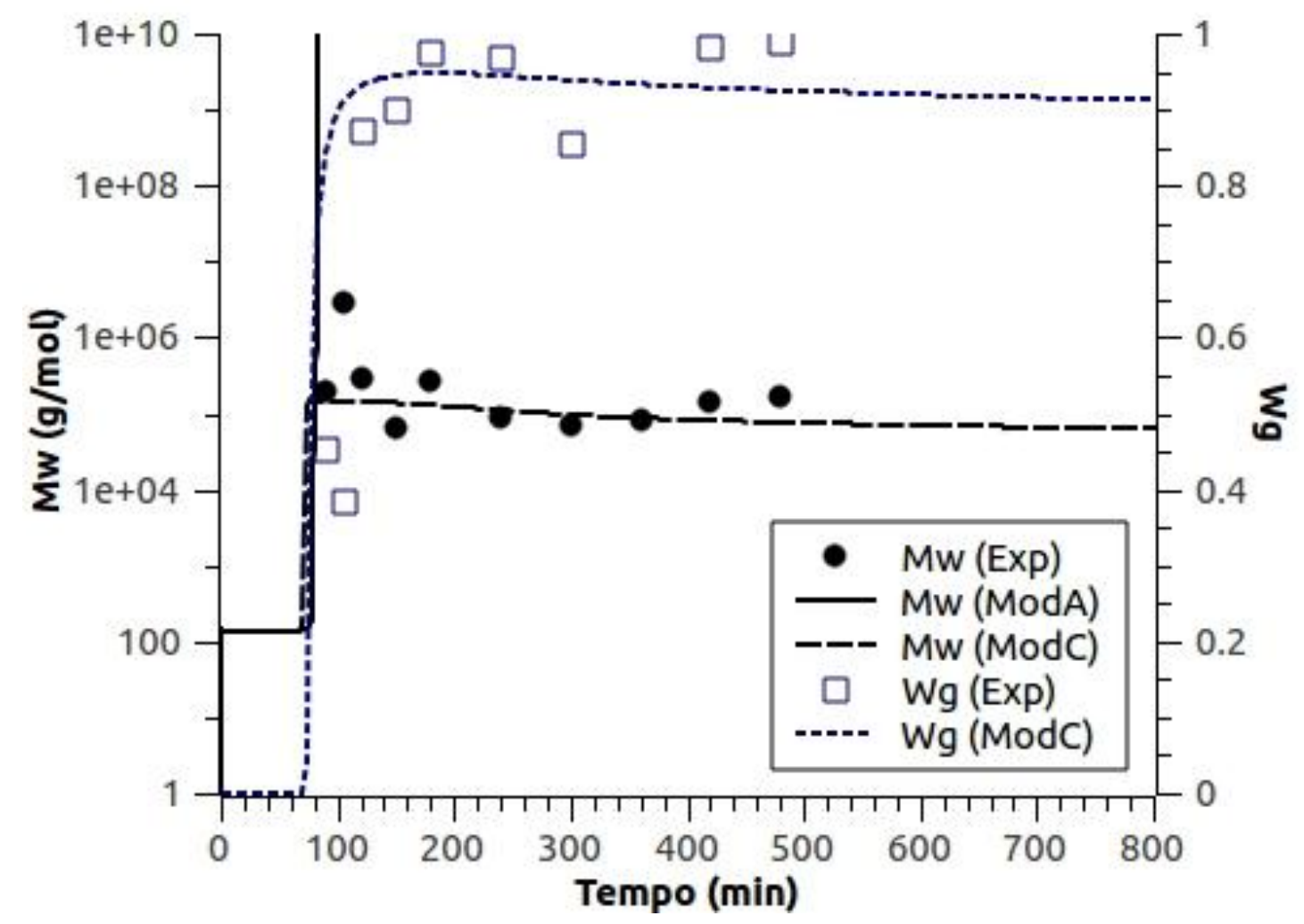

Figura 100 - Comparação entre dados experimentais e previsões de $\mathrm{Mw}$ e Wg com os modelos A e C para o experimento P3.

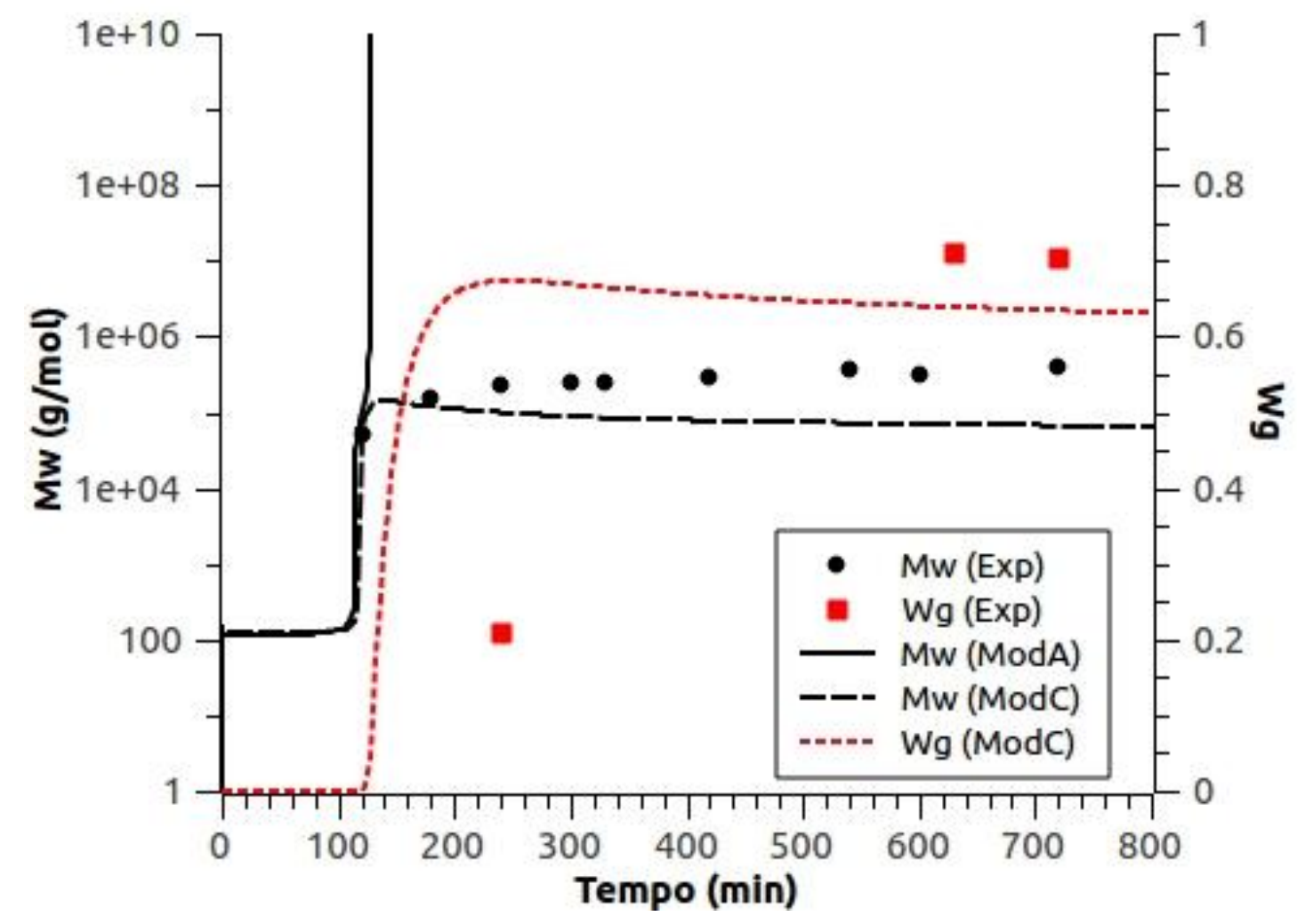

Figura 101 - Comparação entre dados experimentais e previsões de Mw e Wg com os modelos A e C para o experimento P15. 
Nas figuras 99-101, verifica-se clara melhoria no ajuste das variáveis Mw e Wg quando comparado com o ajuste da Figura 72. A limitação do Modelo C em termos do número de gerações (do fracionamento numérico) dificulta a visualização do ponto de gel através do perfil de Mw. No entanto, o perfil de fração de gel permite que o ponto de gel seja localizado com facilidade. Pode-se notar nas Figuras 99101, que sua localização coincide com o ponto de gel obtido pelo Modelo A (perfil de Mw). É importante observar que, no começo da reação (período de pré-gelificação), as moléculas de polímero ainda são relativamente pequenas e a concentração de moléculas de gerações maiores (ex.: 2, 3 e 4) ainda é baixa. Por esta razão, as constantes cinéticas das reações de ligação cruzada são praticamente as mesmas para os 3 modelos, resultando em previsões similares para o período de prégelificação.

Nota-se que o Modelo $\mathrm{C}$ se adéqua melhor às copolimerizações do tipo NMRP do que às copolimerizações do tipo FRP. Conforme discutido no capítulo 2 do presente trabalho, a estrutura das cadeias de polímero formadas por FRP apresenta grandes diferenças em relação à estrutura das cadeias formadas por NMRP. Estas últimas são mais homogêneas, pois são resultado de um consumo de PDBs menos desigual ao longo do processo. A desativação de radicais poliméricos promove o tempo de relaxamento das cadeias, afastando os centros radicalares das PDBs presentes na mesma molécula. Isto gera um crescimento de cadeia mais comedido e uma distribuição de unidades monoméricas mais homogênea em relação ao processo FRP. Supõe-se que este conjunto de fenômenos promova um aprisionamento sistemático de duplas ligações pendentes ao longo do crescimento da cadeia no processo NMRP. Por outro lado, o relaxamento de cadeias não ocorre no processo FRP, que pode gerar uma alta taxa de ciclização no início da reação. Além disso, a concentração de radicais ativos é maior em relação ao processo NMRP e isso gera maior taxa de reações de ligação cruzada. A Figura 102 mostra uma comparação das cadeias formadas pelos diferentes processos, conforme 0 raciocínio acima.

O alto consumo de PDBs no início do processo FRP resulta na formação de densos aglomerados de unidades monoméricas (microgéis). À medida que a reação caminha para o fim, os microgéis se conectam através de segmentos de cadeia. Entende-se que estas conexões geram regiões de baixa densidade na molécula de polímero, conforme mostrado na Figura 102. Estas regiões permitem melhor acesso 
de radicais poliméricos quando comparado com a acessibilidade em cadeias homogêneas (formadas por NMRP). Esta divergência de estruturas tem impacto direto na taxa de reação de ligações cruzadas. Como o Modelo C leva em conta o aprisionamento sistemático de PDBs devido ao crescimento da molécula, é compreensível que não sejam obtidos bons resultados quando este modelo é aplicado a processos FRP (ver Figura 87).

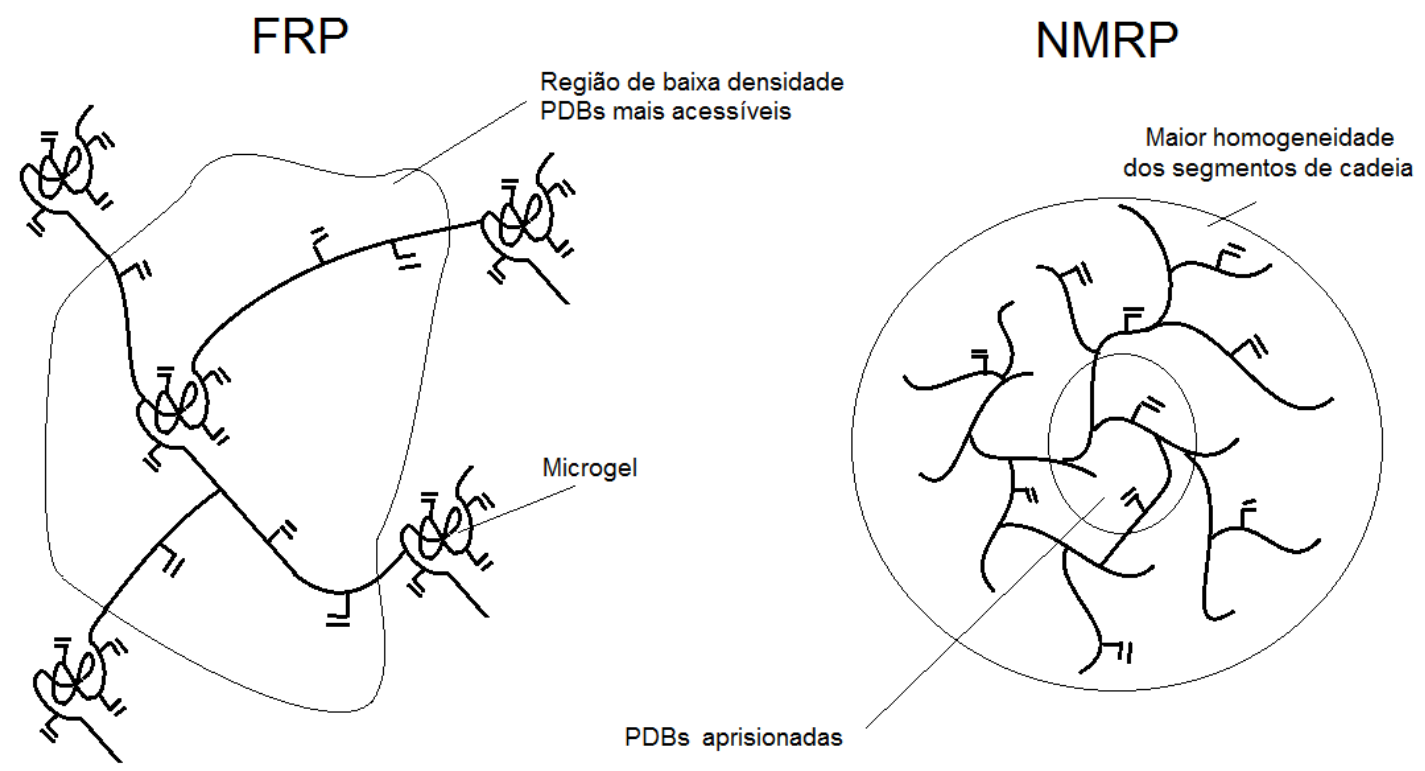

Figura 102 - Estrutura das moléculas de polímero formadas pelos diferentes processos de copolimerização, que explicaria as diferenças de aprisionamento de PDBs em função do tipo de processo.

\subsection{Considerações finais}

Estudos experimentais e de modelagem foram desenvolvidos para homo e copolimerizações convencionais e mediadas por nitróxido de estireno-divinilbenzeno em solução e suspensão aquosa. Com base nos resultados experimentais do presente trabalho, pode-se concluir que a conversão de monômero em processos FRP em solução, não é afetada significativamente pela concentração inicial de divinilbenzeno. A diluição da mistura monomérica utilizada (10-60\%) também não gerou diferenças consideráveis nos dados experimentais de conversão em copolimerizações convencionais. Conforme esperado, diferenças consideráveis 
entre os perfis de conversão de experimentos a $80^{\circ} \mathrm{C}$ e $85^{\circ} \mathrm{C}$ foram observadas. As variáveis: fração de gel e concentração de PDBs se mostraram sensíveis à diluição dos monômeros e à concentração inicial de DVB nos experimentos realizados em solução.

Nas polimerizações em suspensão, avaliou-se o impacto de parâmetros operacionais como a quantidade inicial de DVB, a diluição inicial dos monômeros, a temperatura de polimerização e o tipo da polimerização (FRP ou NMRP). A análise por SEC/RI/MALLS se mostrou útil no presente estudo. A evolução de variáveis das reações com o tempo pôde ser estudada e as estruturas moleculares dos polímeros formados por diferentes condições de polimerização, foram comparadas. As análises mostraram que, quando comparada com a FRP, a polimerização NMRP permite somente um controle limitado sobre o processo de reticulação. Neste aspecto, polimerizações não lineares do tipo NMRP procedem de forma semelhante ao processo FRP e, portanto, uma larga população de polímero é formada. A análise por microscopia eletrônica de varredura de diferentes produtos sintetizados não forneceu claras conclusões sobre o efeito das condições de operação sobre a morfologia dos materiais. Micro e nanoestruturas foram identificadas em produtos obtidos por FRP e NMRP lineares e não lineares. Estas estruturas parecem ser consequência do processo de síntese (ex:: operação em temperatura de reação acima da temperatura de transição vítrea) e do tratamento dos produtos (precipitação / secagem). A investigação de novas condições de operação (Ex.: reação em suspensão utilizando-se reatores de microcanais) é necessária a fim de elucidar o real efeito da micro e nanogelificação sobre a morfologia dos produtos. Segundo Costa e Dias (2010), previsões indicam que um processo ideal de reticulação conduz a populações de polímeros com diferentes números de pontos de reticulação e distribuições estreitas. Entretanto, os resultados de copolimerização NMRP aqui apresentados mostram grandes desvios em relação a este comportamento, em contraste com as recentes observações de Hirao et al. (2011), para polimerização aniônica viva de 1,4-divinilbenzeno. Condições de operação que combinem polimerização radicalar controlada com uma concentração de reticulante variável com o tempo (ex.: processo semi-contínuo) podem, eventualmente, conduzir a um maior controle na formação das redes poliméricas. Apesar das dificuldades de se trabalhar com a técnica NMRP em temperaturas relativamente baixas, foi possível 
obter polímero trabalhando-se a $90^{\circ} \mathrm{C}$, o que pode ser considerando um ponto relevante do presente trabalho.

Três abordagens foram escritas a fim de se aperfeiçoar a representação matemática do processo de copolimerização de estireno-divinilbenzeno. Pode-se concluir que as abordagens que levaram em conta o mecanismo cinético de ciclização retratado pelo método dos caminhos são capazes de melhor prever a faixa de concentrações de duplas ligações pendentes quando comparadas aos modelos que não levam em conta as reações de ciclização. O efeito da ciclização sobre a conversão de monômero se mostrou pouco pronunciado, afetando esta variável somente no que diz respeito à reatividade dos diferentes tipos de radical. Mw e Wg são afetados consideravelmente pelas reações de ciclização em copolimerizações FRP, porém apresentaram pouca sensibilidade a estas reações em copolimerizações NMRP. Com base em ajustes modelo/experimentos, pode-se fazer uma estimativa inicial de $450 \mathrm{~s}^{-1}$ (à 90ํㅡ) para a constante cinética de ciclização de um caminho de 3 unidades monoméricas, que conecta um radical de estireno à uma mPDB. Este valor e as demais considerações do método dos caminhos (ex.: energia de ativação e equação de Rolfes e Stepto) puderam ser corroborados através dos ajustes modelo/experimentos obtidos para a variável concentração de PDBs, tanto nas copolimerizações FRP quanto nas copolimerizações NMRP.

A inclusão do mecanismo de ciclização, por si só (no Modelo B), não é suficiente para produzir bons ajustes modelo/experimentos em termos de massa molecular média mássica $(\mathrm{Mw})$ e fração de gel $(\mathrm{Wg})$. No entanto, o Modelo $\mathrm{C}$ é capaz de fornecer boas previsões de Mw e Wg simultaneamente para os experimentos realizados a $90^{\circ} \mathrm{C}$. Este modelo apresenta uma limitação ao representar o pico a ser obtido no perfil de Mw para os casos em que ocorre gelificação. Esta deficiência pode ser suprida pelo modelo $A$, uma vez que, no período pré-gelificação, pode-se considerar a mesma constante cinética de ligações cruzadas para ambos os modelos. A concordância entre simulações e experimentos obtida com o Modelo C sugere que moléculas grandes solúveis de polímero, apesar de possuírem alta concentração de PDBs, possuem baixa reatividade de ligações cruzadas, relativamente a moléculas menores. Entende-se que a mobilidade e a interpenetração de cadeias são beneficiadas pelo aumento de temperatura. Isto compõe uma explicação para os melhores resultados de fração de gel obtidos com o 
Modelo $\mathrm{B}$ quando comparados com os resultados obtidos com o Modelo $\mathrm{C}$ para experimentos a $130^{\circ} \mathrm{C}$. Aumentando-se a interpenetração de cadeias (através do aumento de temperatura e consequente diminuição da viscosidade e da densidade), as PDBs, supostamente, se tornam mais acessíveis e a constante de taxa de ligações cruzadas aumenta. $\mathrm{O}$ uso de diferentes abordagens pode auxiliar no estudo da integração de métodos na modelagem de copolimerizações controladas de estireno-divinilbenzeno. O presente estudo mostrou uma análise na qual os modelos podem se complementar e fornecer subsídios para o desenvolvimento de um modelo unificado. 


\section{CONCLUSÕES}

Com base nos resultados obtidos no presente trabalho, pode-se concluir que:

- tanto a copolimerização de estireno-divinilbenzeno convencional quanto a mediada por nitróxido apresentam um grau de complexidade elevado em termos de modelagem matemática, principalmente quando se trata de alto teor de DVB (> 5\%);

- polimerizações não lineares do tipo NMRP, procedem de forma semelhante ao processo FRP e, portanto, uma larga população de polímero é formada;

- as abordagens que levaram em conta o mecanismo cinético de ciclização retratado pelo método dos caminhos são capazes de melhor prever a faixa de concentrações de duplas ligações pendentes quando comparadas aos modelos que não levam em conta as reações de ciclização;

- com base em ajustes modelo/experimentos, pode-se fazer uma estimativa inicial de $450 \mathrm{~s}^{-1}$ (a 90을 para a constante cinética de ciclização de um caminho de 3 unidades monoméricas, que conecta um radical de estireno à uma mPDB;

- o Modelo C é capaz de fornecer boas previsões de Mw e Wg simultaneamente para experimentos realizados a $90^{\circ} \mathrm{C}$;

- a concordância entre simulações e experimentos obtida com o Modelo C sugere que moléculas grandes solúveis de polímero, apesar de possuírem alta concentração de PDBs, possuem baixa reatividade de ligações cruzadas, relativamente a moléculas menores; 
- a mobilidade e a interpenetração de cadeias são beneficiadas pelo aumento de temperatura. Isto compõe uma explicação para melhores resultados obtidos com o Modelo B quando comparados com os resultados obtidos com o Modelo C para experimentos a $130^{\circ} \mathrm{C}$. 


\section{RECOMENDAÇÕES}

As seguintes recomendações são sugeridas para trabalhos futuros nesta linha de pesquisa:

- Incluir na modelagem, novas espécies referentes aos centros radicalares presentes em moléculas cíclicas a fim de se obter uma reatividade média de grupos radicalares mais próxima da real;

- Planejar experimentos destinados a avaliar a concentração de cadeias cíclicas e estudar a possibilidade de detectá-las por espectroscopia. Com a quantificação dos ciclos, o método dos caminhos pode ser validado com melhor precisão;

- Realizar novos experimentos ampliando-se a faixa de diluição da mistura monomérica inicial a fim de se corrigir equações cinéticas do sistema de polimerização;

- Estudar a taxa de reação de ligações cruzadas partindo-se de polímeros previamente produzidos e analisados quanto à quantidade de duplas ligações pendentes. Este estudo poderá auxiliar na correção das cinéticas das reações de ligação cruzada e ciclização;

- Explorar faixas de temperaturas visando-se validar as expressões cinéticas das reações de ativação e desativação. Correções na expressões de Arrhenius poderão ser feitas através deste estudo;

- Promover reações entre iniciador e radical nitróxido visando-se quantificar a taxa de desativação de radicais primários, a fim de se obter uma expressão cinética mais correta para esta reação;

- Verificar se há variação na constante cinética de ciclização envolvendo caminhos pequenos (por exemplo: entre 3 e 10 unidades monoméricas), 
através de estudos de simulação. Este estudo poderá fornecer melhores ajustes para os perfis de concentração de PDBs.

- Acrescentar a reação de iniciador com radical nitróxido a fim de melhor contemplar o conjunto de mecanismos reacionais e se obter maior flexibilidade para o modelo. 


\section{REFERÊNCIAS BIBLIOGRÁFICAS 1}

Almdal, K., Dyre, J., Hvidt, S., Kramer, O., Towards a phenomenological definition of the term 'gel', Polym. Gels and Networks, 1, 5-17, 1993.

Bamford, C. H., Comprehensive Polymer Science, Oxford, 1989.

Bannister, I., Billingham, N.C., Armes, S.P., Rannard, S.P., Findlay, P., Development of Branching in Living Radical Copolymerization of Vinyl and Divinyl Monomers, Macromolecules, 39, 7483-7492, 2006

Bayramoglu, G. Senkal, F. B. Celik, G. Arica, M. Y., Preparation and characterization of sulfonyl-hydrazine attached poly (styrene-divinylbenzene) beads for separation of albumin, Colloids and Surfaces A: Physicochem. Eng. Aspects 294, 56-63, 2007.

Belincanta-Ximenes, J., Mesa1 P. V. R., Lona, L. M. F., Vivaldo-Lima, E., McManus, N. T., Penlidis, A., Simulation of Styrene Polymerization by Monomolecular and Bimolecular Nitroxide-Mediated Radical Processes over a Range of Reaction Conditions, Macromolecular Theory and Simulations, 16, 2, 194-208, 2007.

Bradley, T. F., DRYING OILS AND RESINS Polymeric Functionality with Relation to the Addition Polymerization of Drying Oils, Ind. Eng. Chem, 30, 689, 1938.

Carol H. Collins, Gilberto L. Braga, Pierina S. Bonato, Fundamentos de Cromatografia, Ed. Unicamp, Campinas, 2006.

Cheyney, L. V. E., Kelley, E. J., Unsaturation of Synthetic Rubberlike Materials, Ind. Eng. Chem., 34, 1323, 1942.

Costa, M. R. P. F. N. Dias, R. C. S., A general kinetic analysis of non-linear irreversible copolymerizations, Chemical Engineering Science, 49, 4, 491, 1994.

Costa, M. R. P. F. N. Dias, R. C. S., Prediction of Sol Fraction and Average Molecular Weights after Gelation for Non-Linear Free Radical Polymerizations Using a Kinetic Approach, Macromol. Theory Simul., 12, 560-572, 2003. 
Costa, M. R. P. F. N. Dias, R. C. S., An improved general kinetic analysis of nonlinear irreversible polymerisations, Chemical Engineering and Science, 60, 423446, 2005.

Costa, M. R. P. F. N. Dias, R. C. S., GENLP USER MANUAL (version 1.1.2), Faculdade de Engenharia da Universidade do porto (FEUP), Portugal, 2011.

Crompton, T. R., Reid, V. W., Unsaturation in high impact polystyrene analytical studies, J. Polym. Sci. Part A, 1, 347, 1963.

Dias, R. C. S., Costa, M. R. P. F. N., Semibatch operation and primary cyclization effects in homogeneous free-radical crosslinking copolymerizations, Polymer 46, 6163-6173, 2005.

Dias, R. C. S., Costa, M. R. P. F. N., Calculation of CLD Using Population Balance Equations of Generating Functions: Linear and Non- Linear Ideal Controlled Radical Polymerization, Macromol. Theory Simul., 19, 323, 2010.

Dusek, K., Are cured thermoset resins inhomogeneous?, Angew. Makromol. Chem., 240, 1, 1996.

Dusek, K. Spevacek, J, Cyclization in vinyl-divinyl copolymerization, Polymer, 21, 750, 1980.

Errede L. A, Tiers G. V. D., Polymer Swelling. 19. Sorption of $\alpha$, $\boldsymbol{\omega}$-DialkoxySubstituted Linear Poly (methylenes) and Poly (oxyethylenes) by Poly (styreneco-divinylbenzene), J. Phys. Chem. B, 101, 7794-7807, 1997.

Flory, P. J, Molecular Size Distribution in Three Dimensional Polymers. I. Gelation1, J. Am. Chem. Soc, 63, 3083, 1941.

Flory, P. J, Viscosities of polyester solutions. Application of the melt viscosityMolecular weight relationship to solutions, J. Phys. Chem, 46, 132, 1942.

Flory, P. J, Molecular size distribution in three dimensional polymers. V. Postgelation relationships, J. Am. Chem. Soc, 69, 2893, 1947.

Flory, P. J. Principles of polymer chemistry, Cornell University Press, Ithaca, New York, 1953. 
Gao, C., Yan, Hyperbranched polymers: from synthesis to applications, Progress in Polymer Science, 29, 183-275, 2004

Georges, M, K, Veregin, R, P, N, Kazmaier, P, K, Hamer, G, K., Narrow molecular weight resins by a free-radical polymerization process, Macromolecules, 26, 2987, 1993.

Gonçalves, M.A.D., Dias, R.C.S. Costa, M. R. P. F. N., Time Programmed Feed of Semi-Batch Reactors with Non-Linear Radical Copolymerizations: An Experimental Study of the System Styrene-Divinylbenzene Using SEC/MALLS, Macromol. Symp, 259, 124, 2007.

Gonçalves, M. A. D. Síntese controlada por nitróxidos de copolímeros estirenodivinilbenzeno. Dissertação de mestrado. Instituto Politécnico de Bragança, Bragança, Portugal, 2008.

Gonçalves, M. A. D. Trigo, I. M. R. Dias, R. C. S. Costa, M. R. P. F. N., Kinetic Modeling of the Molecular Architecture of Cross-Linked Copolymers Synthesized by Controlled Radical Polymerization Techniques, Macromol. Symp., 291, 239, 2010.

Gonçalves, M. A. D., Pinto, V. D., Dias, R. C. S., Costa, M. R. P. F. N., Aguiar, L. G., Giudici, R., Gel Formation in Aqueous Suspension Nitroxide-Mediated Radical Co-Polymerization of Styrene/Divinylbenzene. Macromolecular Reaction Engineering. doi: 10.1002/mren.201200058.

Gretton-Watson, S.P., Alpay, E., Steinke, J.H.G., Higgins J.S., Multifunctional monomer derived hyperbranched poly(methyl methacrylate): Kinetic modelling and experimental validation, Chemical Engineering Science, 61, 1421-1433, 2006

Hecker, M., Experimentelle Untersuchungen und Monte-Carlo-Simulation netzwerkbildender Copolymerisationen., Tese de doutorado, Fortscheritte der Polymerisationstechnik II (H.U. Moritz ed.) Wissenschaft \& Technik Verlag Berlin, Alemanha, 2000.

Hernández-Ortiz, J. C. H. Modelación de la cinética de copolimerización controlada cón agentes tipo nitróxido (NMRP) de monômeros vinílicos/divinílicos, Dissertação de mestrado, UNAM, México, 2008. 
Hernández -Ortiz, J. C. H. Vivaldo-Lima, E. Lona, L. M .F. McManus N. T. Penlidis, A., Modeling of the Nitroxide-Mediated Radical Copolymerization of Styrene and Divinylbenzene, Macromol. React. Eng, 3, 288, 2009.

Hicks, C, R, Crowford, G, J, Lou, X, Tan, D, T, Snibson G. R. Sutton, G. Downie, N. Werner, L. Chirila T. V. Constable, I. J., Corneal replacement using a synthetic hydrogel cornea, AlphaCor ${ }^{\mathrm{TM}}$ : device, preliminary outcomes and complications, Eye, 17, 385-392, 2003.

Hirao, A., Tanaka, S., Goseki, R., Ishizone, T., Living Anionic Polymerization of 1, 4-Divinylbenzene, Macromolecules, 44, 4579, 2011.

Hoare, T. R. Kohane, D. S., Hydrogels in drug delivery: progress and challenges, Polymer 49, 1993-2007, 2008.

Ide, N. Fukuda, T. Nitroxide controlled free-radical copolymerization of vinyl and divinyl monomers. Evaluation of pendant-vinyl reactivity, Macromolecules, 30, 4268-4271, 1997.

Ide, N. Fukuda, T. Nitroxide-Controlled Free-Radical Copolymerization of Vinyl and Divinyl Monomers. 2. Gelation, Macromolecules, 32, 95, 1999.

Kavanagh, G.M., Ross-Murphy, S.B., Rheological characterisation of polymer gels, Prog. Polym. Sci., 23, 533-562, 1998.

Kemp, A. R., Peters, H., Viscosity of $\mathbf{n}$-Paraffin Solutions, Ind. Eng. Chem. Analytical Ed., 15, 453, 1943.

Kienle, R. H. van der Meulen, P. A. Petke, F. E., The Polyhydric AlcoholPolybasic Acid Reaction. III. Further Studies of the Glycerol-Phthalic Anhydride Reaction, Journal of the American Chemical Society., 61, 2258, 2268, 1939. Knothe, G., Structure indices in FA chemistry. How relevant is the iodine value?, J. Am. Oil Chemists Soc, 79, 847, 2002.

Lee, T. S., Kolthoff, I. M., Mairs, M. A., Determination of unsaturation of synthetic and natural rubbers by means of iodine monochloride, J. Polym. Sci., 3, 66, 1948. 
Lee, T. S., Kolthoff, I. M., Johnson, E., Determination of Unsaturation of Butyl Rubbers and Certain Branched Olefins. Iodine Monochloride Method, Anal. Chem., 22, 995, 1950.

Mehr, M. J. Z. Kabiri, K., Superabsorbent polymer materials: a review, Iranian Polymer Journal 17 (6), 451-477, 2008.

Montezuma, G. G. C., Contant, S., Lona, L. M. F., Emulsion Polymerization of Styrene Mediated by TEMPO at Low Temperature, Macromolecular reaction engineering, 6, 12, 516-522, 2012.

Mrkvicková, L, Kratochvil, P., Analysis of the products of copolymerization with chain branching in the pregelation stage, J. Polym. Sci. Polym. Phys. Ed, 19, 1675, 1981.

Murari, A. R., Contant, S., Lona, L. M. F., Vivaldo-Lima, E., McManus, N. T., Penlidis, A. Modeling Insights on the TEMPO Mediated Radical Polymerization of Styrene, Journal of Macromolecular Science Part A-Pure and Applied Chemistry, 48, 9, 681-687, 2011.

Otsu, T, Yoshida, M, Role of initiator-transfer agent-terminator (Iniferter) in radical polymerizations: polymer design by organic disulfides as iniferters, Makromol. Chem. Rapid Commun., 3, 127, 1982.

Quintero-Ortega, I. A. Vivaldo-Lima, E., Barcenas, G. L. Alvarado, J.F.J. LouvierHernandez, J. F. Sanchez, I. C., Modeling of the free-radical copolymerization kinetics with cross linking of vinyl/divinyl monomers in supercritical carbon dioxide, Ind. Chem. Res, 44, 2823, 2005.

Reis, K. R. Bonfante, G. Pegoraro, L. F. Conti, P. C. R. Oliveira, P. C. G. Kaizer O. $B$. In vitro wear resistance of three types of polymethyl methacrylate denture teeth, J Appl Oral Sci., 16(3):176-80, 2008.

Roa-Luna, M., Afsaneh, N., Díaz-Barber, M. P., Mcmanus, N., Vivaldo-Lima, E., Lona, L., Penlidis, A., Another Perspective on the Nitroxide Mediated Radical Polymerization (NMRP) of Styrene Using 2,2,6,6-Tetramethyl-1-piperidinyloxy (TEMPO) and Dibenzoyl Peroxide (BPO), Journal of Macromolecular Science, Part A: Pure and Applied Chemistry, 44, 3, 337-349(13), 2007. 
Roa-Luna, M., Nabifar, A., McManus, N. T., Vivaldo-Lima, E., Lona, L. M .F., Penlidis, A., Effect of the addition of inert or TEMPO-capped prepolymer on polymerization rate and molecular weight development in the nitroxidemediated radical polymerization of styrene, Journal of Applied Polymer Science, 109, 6, 3665-3678, 2008.

Rolfes, H., Stepto, R.F.T., Network formation and properties: Rate theory description of effects of ring formation on elastic shear modulus of RA2+ RB3 networks, Makromol. Chem, Macromol. Symp, 40, 61-79, 1990;

Saidel, M. S. Katz S., Dynamic analysis of branching in radical polymerization, J. Polym. Sci. PA2, 6, 1149, 1969.

Solomon, D, H, Rizzardo, E, Cacioli, P., Polymerization process and polymers produced thereby, US Patent 4, $581,429,1986$.

Stockmayer, W. H, Theory of molecular size distribution and gel formation in branched-chain polymers, J. Chem Phys. 11, 45, 1943.

Stockmayer, W. H, Theory of molecular size distribution and gel formation in branched polymers II. General cross linking, J. Chem. Phys, 12, 125, 1944.

Soper, B. Haward, R. N. White, E. F. T, Intramolecular cyclization of styrene-pdivinylbenzene copolymers, J. Polym. Sci. P.A-1, 10, 2545, 1972.

Tanaka, T. Suzuki, T, Saka, Y. Zetterlund, P. B. Okubo M., Mechanical properties of cross-linked polymer particles prepared by nitroxide-mediated radical polymerization in aqueous micro-suspension, Polymer 48, 3836-3843, 2007.

Teraoka, I. Polymer Solutions An introduction to physical properties, Nova York, Estados Unidos, 2002.

Teymour, F. Campbell, J. D., Analysis of the dynamics of gelation in polymerization reactors using the" numerical fractionation" technique, Macromolecules, 27, 2460, 1994.

Tobita, H. Hamielec, A. E, Modeling of network formation in free radical polymerization, Macromolecules, 22, 3098, 1989. 
Tobita, $\mathrm{H}$., Molecular weight distribution in free-radical crosslinking copolymerization, Macromolecules, 26, 5427, 1993.

Vervoort M. S, Comportement D'Hydrogels Gonfles De Solutions de Polimeres Sous Actions Mecanique, Tese de Doutorado, Ecole de Mines de Paris, Paris, França, 2006.

Vivaldo-Lima, E., Wood, P. E. Hamielec, A. E. Penlidis, A, Kinetic model-based experimental design of the polymerization conditions in suspension copolymerization of styrene/divinylbenzene, J. Polym. Sci. P.A: Polymer chemistry, 36, 2081, 1998.

Ward, J. H. Peppas, N. A., Kinetic gelation modeling of controlled radical polymerizations, Macromolecules, 33, 5137-5142, 2000.

Yamauchi, A., Osada, Y. and Kajiwara, K., Gels Handbook, Vol.1, Academic Press, San Diego, Estados Unidos, 4-11, 2001.

Yu, Q, Zhu, Y, Ding, Y, Zhu, S., Reaction Behavior and Network Development in RAFT Radical Polymerization of Dimethacrylates, Macromolecular chemistry and Physics, 209, 551, 2008.

Zetterlund, P. B. Alam, M. N. Minami, H. Okubo, M., Nitroxide-Mediated Controlled/Living Free Radical Copolymerization of Styrene and Divinylbenzene in Aqueous Miniemulsion, Macromol Rapid Commun., 26, 955960, 2005.

Zhu, S. Hamielec, A. E., Chain-length-dependent termination for free radical polymerization, Macromolecules, 22, 3093, 1989.

Referências da internet

http://www.lookchem.com/cas-78/78-67-1.html. Acessado em: 07/11/2010.

http://www.chemspider.com/Chemical-Structure.6919.html;

http://www.chemspider.com/Chemical-Structure.2006285.html?rid=71fc14dd-b867-

46b9-af8a-d7ed791d0f8d;

http://www.chemspider.com/Chemical-Structure.5730.html?rid=31f45478-b73c-47df-

96e0-2ded430b5d6c; 
http://www.chemspider.com/Chemical-Structure.4709.html?rid=d2ed4df4-2184-4d5dbde8-ea77d207e970;

http://www.chemspider.com/Chemical-Structure.22885.html?rid=59ce8962-88e042e9-aea3-f78d40cb1e31;

http://www.chemspider.com/Chemical-Structure.937.html?rid=4c1d7a8f-d2c3-41729fb4-9e1fda0a6539.

Acessados em 18/10/2012.

http://www.emsdiasum.com/microscopy/technical/msds/19800.pdf. Acessado em 18/10/2012.

http://www.chemicalbook.com/ChemicalProductProperty_EN_CB6309451.htm. Acessado em 18/10/2012.

http://sistemasinter.cetesb.sp.gov.br/produtos/ficha_completa1.asp?consulta=TETRA CLORETO\%20DE\%20CARBONO. Acessado em 18/10/2012.

http://en.wikipedia.org/wiki/Starch. Acessado em 18/10/2012. 


\section{APÊNDICE A - Estudo preliminar sobre a redução da reatividade da constante cinética de ligações cruzadas em função do tamanho da molécula de polímero}

Analisando-se de forma crescente as gerações do fracionamento numérico, o Modelo $\mathrm{C}$ indica que, a partir de determinada geração, há uma redução na constante cinética de ligações cruzadas. Esta redução se acentua à medida que o número da geração aumenta à partir deste ponto. Desta forma, a equação (145) se originou de estudos preliminares com a equação genérica a seguir.

$k_{p p, i}=\frac{V_{G}}{V_{i}} k_{p p}\left(1-W_{g}\right)+f_{r g} \frac{V_{1}}{V_{i}} k_{p p} W_{g}$

sendo que $V_{G}$ é o volume médio das moléculas da geração $G$, que é a última geração na qual $k_{p p}$ ainda é constante, ou seja, a partir da geração $G+1$, inicia-se a redução da reatividade. $f_{r g}$ é o fator de redução da reatividade referente à reação com o gel. A determinação de $V_{G}$ e $f_{r g}$ foi feita através de simulações preliminares conforme mostrado nas figuras 103 e 104.

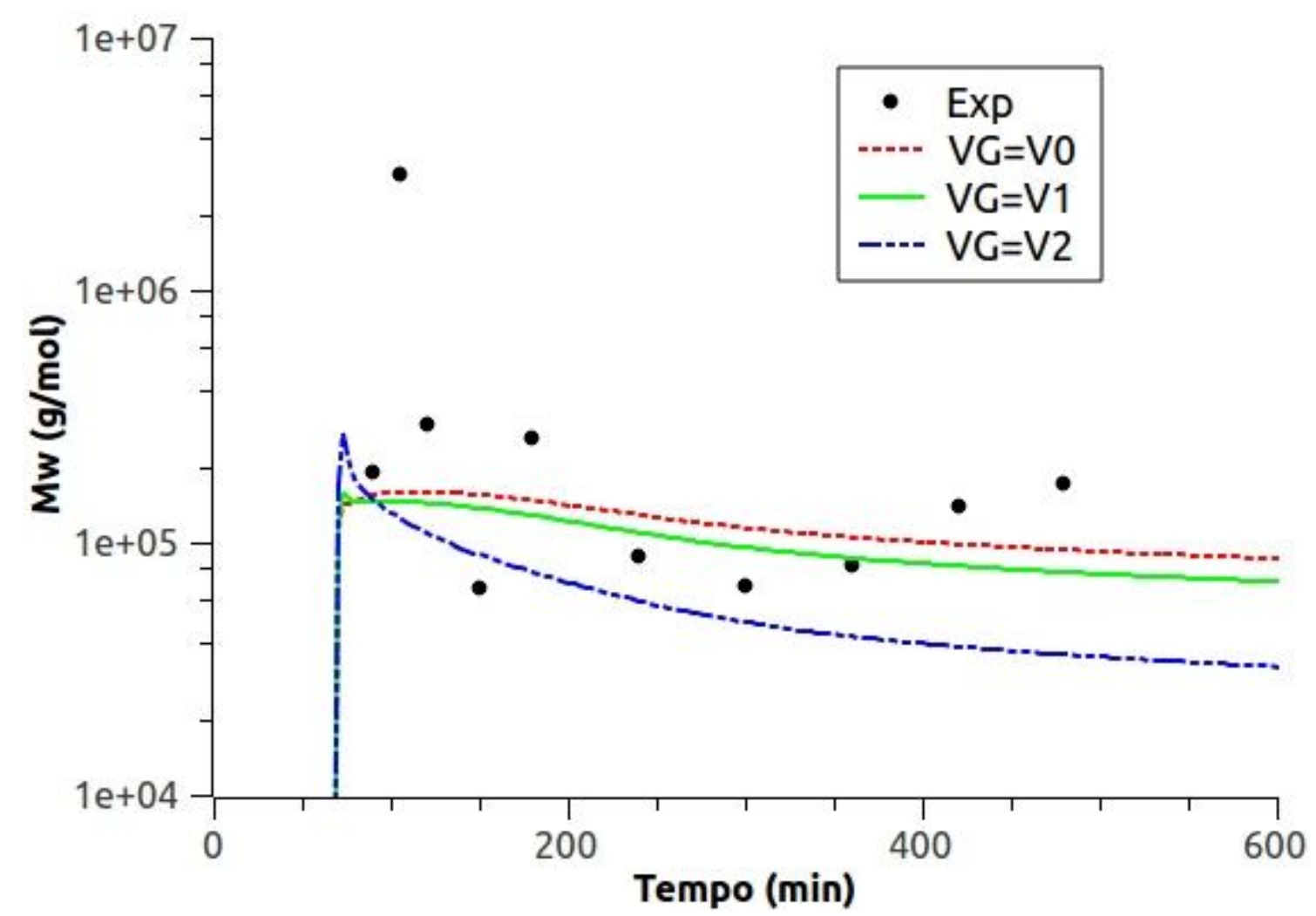

Figura 103 - Modelo C: Variação do parâmetro $V_{G}$. Simulações com o experimento $P 3$. 


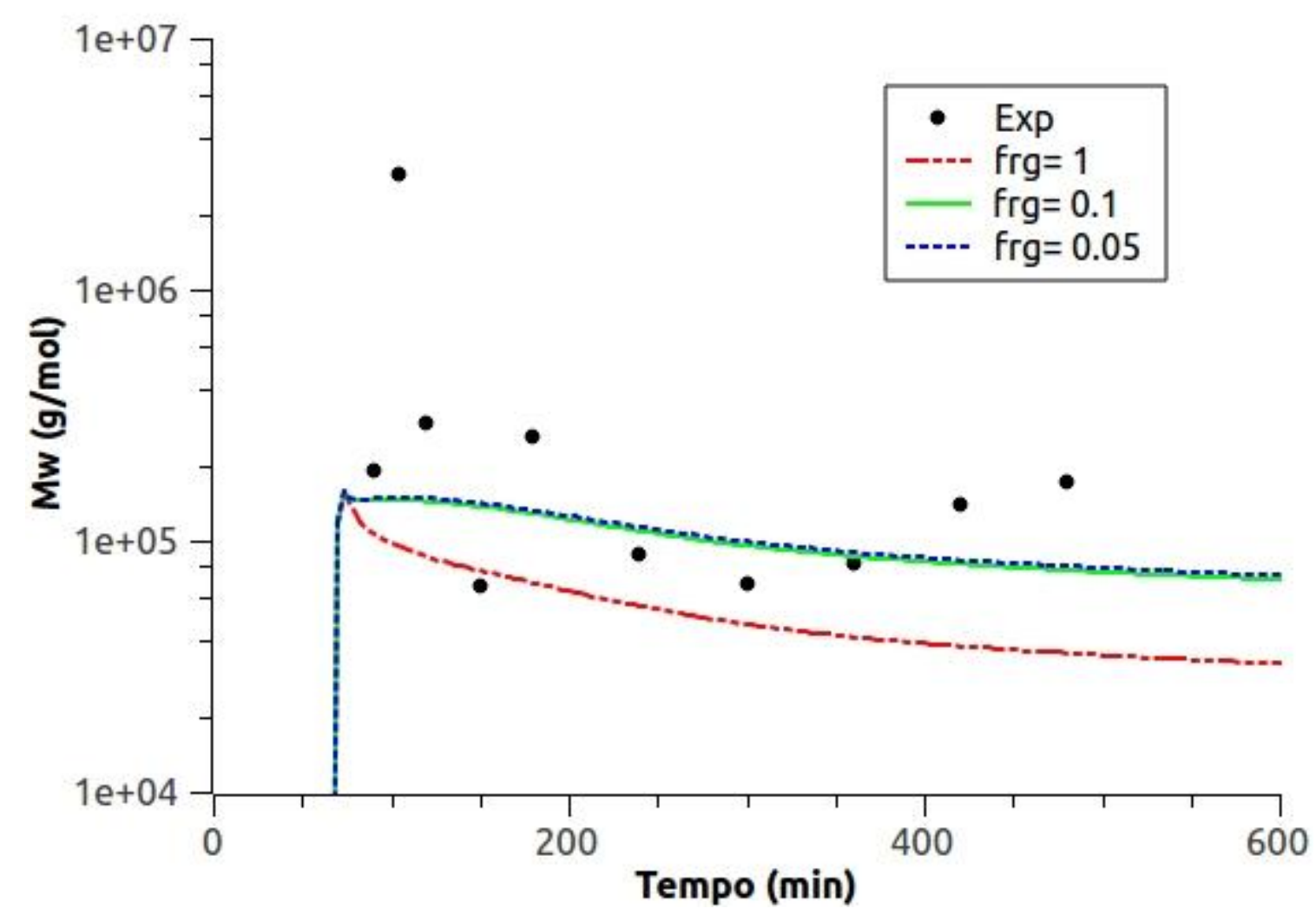

Figura 104 - Modelo C: Variação do parâmetro f $\mathrm{frg}_{\text {g }}$ Simulações com o experimento P3.

Observa-se na Figura 103 que obtém-se melhor ajuste quando $V_{G}=V_{1}$. Na Figura 104, verifica-se que a reatividade com moléculas de gel é, no mínimo, 10 vezes menor do que a reatividade com moléculas solúveis. Com base nestes resultados, considerou-se $V_{G}=V_{1}$ e $f_{r g}=1 / 10$ em todas as simulações realizadas com o Modelo C. 


\section{APÊNDICE B - Dados experimentais}

Tabela 13 - Resultados experimentais (continua)

\begin{tabular}{|c|c|c|c|c|c|c|}
\hline Experimento & $\begin{array}{l}\text { Tempo } \\
\text { (min) }\end{array}$ & $X$ & $\begin{array}{c}\mathrm{Mn} \\
(\mathrm{g} / \mathrm{mol})\end{array}$ & $\begin{array}{c}\mathrm{Mw} \\
(\mathrm{g} / \mathrm{mol})\end{array}$ & $\mathrm{Wg}$ & $\begin{array}{c}\text { PDBs } \\
(\mathrm{mmol} / \mathrm{g} \mathrm{pol} .)\end{array}$ \\
\hline \multirow[t]{13}{*}{ B1 } & 5 & 0,010 & & & & \\
\hline & 10 & 0,004 & & & & \\
\hline & 17 & 0,009 & & & & \\
\hline & 21 & 0,035 & & & & \\
\hline & 28 & 0,046 & & & 0,506 & \\
\hline & 45 & 0,286 & & & 0,528 & \\
\hline & 60 & 0,434 & & & 0,706 & \\
\hline & 75 & 0,493 & & & 0,677 & \\
\hline & 90 & 0,787 & & & 0,792 & \\
\hline & 120 & & & & 0,793 & \\
\hline & 180 & 0,746 & & & 0,818 & \\
\hline & 240 & 0,603 & & & 0,849 & \\
\hline & 300 & & & & 0,856 & \\
\hline
\end{tabular}

B2

$\begin{array}{ccc}5 & 0,023 & \\ 10 & 0,042 & \\ 15 & 0,064 & \\ 20 & 0,086 & \\ 25 & 0,126 & \\ 30 & 0,164 & 0,399 \\ 60 & 0,322 & 0,113 \\ 120 & 0,444 & 0,233 \\ 180 & 0,597 & 0,517 \\ 200 & 0,621 & 0,665 \\ 220 & 0,758 & 0,678 \\ 240 & 0,748 & 0,692 \\ 260 & 0,753 & 0,687 \\ 280 & 0,736 & \end{array}$


Tabela 13 - Resultados experimentais (continuação)

\begin{tabular}{|c|c|c|c|c|c|c|}
\hline Experimento & $\begin{array}{c}\text { Tempo } \\
\text { (min) }\end{array}$ & $X$ & $\begin{array}{c}\mathrm{Mn} \\
(\mathrm{g} / \mathrm{mol})\end{array}$ & $\begin{array}{c}\text { Mw } \\
(\mathrm{g} / \mathrm{mol})\end{array}$ & $\mathrm{Wg}$ & $\begin{array}{c}\text { PDBs } \\
(\mathrm{mmol} / \mathrm{g} \text { pol. })\end{array}$ \\
\hline \multirow[t]{2}{*}{ B2 } & 300 & 0,741 & & & 0,698 & \\
\hline & 360 & 0,782 & & & 0,797 & \\
\hline \multirow[t]{13}{*}{ B3 } & 5 & 0,010 & & & & \\
\hline & 10 & 0,004 & & & & \\
\hline & 17 & 0,008 & & & & \\
\hline & 21 & 0,035 & & & & \\
\hline & 28 & 0,046 & & & 0,506 & \\
\hline & 45 & 0,285 & & & 0,528 & \\
\hline & 60 & 0,434 & & & 0,706 & \\
\hline & 75 & 0,493 & & & 0,677 & 0,158 \\
\hline & 90 & 0,787 & & & 0,792 & 0,051 \\
\hline & 120 & & & & 0,793 & \\
\hline & 180 & 0,746 & & & 0,818 & 0,241 \\
\hline & 240 & 0,604 & & & 0,849 & \\
\hline & 300 & & & & 0,856 & 0,281 \\
\hline \multirow[t]{13}{*}{ B4 } & 10 & 0,039 & & & & \\
\hline & 20 & 0,076 & & & & \\
\hline & 30 & 0,122 & & & & \\
\hline & 40 & 0,171 & & & & \\
\hline & 60 & 0,236 & & & & \\
\hline & 75 & & & & 0,781 & 0,440 \\
\hline & 90 & 0,304 & & & & \\
\hline & 105 & & & & 0,793 & 0,373 \\
\hline & 120 & 0,354 & & & & \\
\hline & 140 & & & & 0,780 & 0,462 \\
\hline & 160 & & & & 0,791 & \\
\hline & 180 & 0,493 & & & & \\
\hline & 200 & & & & 0,741 & 0,401 \\
\hline
\end{tabular}


Tabela 13 - Resultados experimentais (continuação)

\begin{tabular}{|c|c|c|c|c|c|c|}
\hline Experimento & $\begin{array}{c}\text { Tempo } \\
\text { (min) }\end{array}$ & $X$ & $\begin{array}{c}\mathrm{Mn} \\
(\mathrm{g} / \mathrm{mol})\end{array}$ & $\begin{array}{c}\text { Mw } \\
(\mathrm{g} / \mathrm{mol})\end{array}$ & $\mathrm{Wg}$ & $\begin{array}{c}\text { PDBs } \\
\text { (mmol/g pol.) }\end{array}$ \\
\hline \multirow[t]{2}{*}{ B4 } & 220 & & & & 0,762 & \\
\hline & 240 & & & & 0,668 & \\
\hline \multirow[t]{8}{*}{ B5 } & 10 & 0,019 & & & & \\
\hline & 20 & 0,112 & & & & \\
\hline & 30 & 0,258 & & & & \\
\hline & 40 & 0,125 & & & & \\
\hline & 60 & 0,179 & & & & \\
\hline & 90 & 0,247 & & & & \\
\hline & 75 & & & & 0,898 & 0,912 \\
\hline & 120 & & & & 0,936 & 1,570 \\
\hline \multirow[t]{16}{*}{ B6 } & 10 & 0,048 & & & & \\
\hline & 20 & 0,078 & & & & \\
\hline & 30 & 0,130 & & & & \\
\hline & 40 & 0,155 & & & & \\
\hline & 50 & & & & 0,110 & \\
\hline & 60 & 0,252 & & & & \\
\hline & 70 & & & & 0,214 & \\
\hline & 80 & 0,286 & & & & \\
\hline & 90 & & & & 0,329 & \\
\hline & 100 & 0,342 & & & & \\
\hline & 110 & & & & 0,423 & \\
\hline & 120 & 0,395 & & & & \\
\hline & 180 & 0,550 & & & & \\
\hline & 240 & 0,636 & & & & \\
\hline & 300 & 0,717 & & & & \\
\hline & 360 & 1,013 & & & & \\
\hline
\end{tabular}


Tabela 13 - Resultados experimentais (continuação)

\begin{tabular}{|c|c|c|c|c|c|c|}
\hline Experimento & $\begin{array}{c}\text { Tempo } \\
(\min )\end{array}$ & $X$ & $\begin{array}{c}\mathrm{Mn} \\
(\mathrm{g} / \mathrm{mol})\end{array}$ & $\begin{array}{c}\mathrm{Mw} \\
(\mathrm{g} / \mathrm{mol})\end{array}$ & $\mathrm{Wg}$ & $\begin{array}{c}\text { PDBs } \\
(\mathrm{mmol} / \mathrm{g} \text { pol. })\end{array}$ \\
\hline \multirow[t]{14}{*}{$\mathrm{P} 1$} & 90 & 0,074 & $1,050 \mathrm{E}+04$ & $1,287 \mathrm{E}+04$ & & \\
\hline & 120 & 0,117 & $9,287 E+03$ & $1,369 \mathrm{E}+04$ & & \\
\hline & 150 & 0,130 & $1,524 \mathrm{E}+04$ & $2,232 \mathrm{E}+04$ & & \\
\hline & 180 & 0,159 & $1,633 E+04$ & $2,306 \mathrm{E}+04$ & & \\
\hline & 210 & 0,208 & $3,566 \mathrm{E}+04$ & $4,648 \mathrm{E}+04$ & & \\
\hline & 240 & 0,197 & $2,833 E+04$ & $3,494 \mathrm{E}+04$ & & \\
\hline & 300 & 0,099 & $2,437 \mathrm{E}+04$ & $3,214 \mathrm{E}+04$ & & \\
\hline & 360 & 0,161 & $2,457 \mathrm{E}+04$ & $3,055 \mathrm{E}+04$ & & \\
\hline & 420 & 0,200 & $1,020 \mathrm{E}+04$ & $1,984 \mathrm{E}+04$ & & \\
\hline & 480 & 0,306 & $6,097 \mathrm{E}+03$ & $1,646 \mathrm{E}+04$ & & \\
\hline & 540 & 0,208 & $1,032 E+04$ & $1,840 \mathrm{E}+04$ & & \\
\hline & 600 & 0,255 & $5,848 \mathrm{E}+03$ & $1,605 \mathrm{E}+04$ & & \\
\hline & 660 & 0,210 & $9,393 E+03$ & $1,893 \mathrm{E}+04$ & & \\
\hline & 720 & 0,275 & $6,638 \mathrm{E}+03$ & $1,754 \mathrm{E}+04$ & & 0,291 \\
\hline \multirow[t]{14}{*}{ P2 } & 60 & 0,010 & $1,288 \mathrm{E}+04$ & $1,379 \mathrm{E}+04$ & & \\
\hline & 90 & 0,102 & $3,025 E+04$ & $7,371 \mathrm{E}+04$ & 0,647 & \\
\hline & 120 & 0,167 & $9,802 E+04$ & $4,968 \mathrm{E}+04$ & 0,844 & \\
\hline & 140 & 0,182 & 4,417E+05 & $2,189 \mathrm{E}+06$ & 0,869 & \\
\hline & 160 & 0,144 & $7,159 \mathrm{E}+04$ & $2,011 E+05$ & 0,891 & \\
\hline & 180 & 0,180 & $3,991 \mathrm{E}+04$ & $1,851 \mathrm{E}+05$ & 0,562 & \\
\hline & 200 & 0,248 & & & 0,938 & \\
\hline & 220 & 0,159 & & & 1,135 & \\
\hline & 240 & 0,106 & & & 0,945 & \\
\hline & 270 & 0,110 & & & 0,949 & \\
\hline & 300 & 0,216 & $3,722 \mathrm{E}+04$ & $1,136 \mathrm{E}+05$ & 1,400 & \\
\hline & 360 & 0,083 & & & 1,435 & \\
\hline & 420 & 0,114 & $8,263 E+04$ & $1,446 \mathrm{E}+05$ & & \\
\hline & 480 & 0,081 & $1,488 E+05$ & $2,064 \mathrm{E}+05$ & & 2,842 \\
\hline
\end{tabular}


Tabela 13 - Resultados experimentais (continuação)

\begin{tabular}{|c|c|c|c|c|c|c|}
\hline Experimento & $\begin{array}{c}\text { Tempo } \\
\text { (min) }\end{array}$ & X & $\begin{array}{c}\mathrm{Mn} \\
(\mathrm{g} / \mathrm{mol})\end{array}$ & $\begin{array}{c}\text { Mw } \\
(\mathrm{g} / \mathrm{mol})\end{array}$ & Wg & $\begin{array}{c}\text { PDBs } \\
\text { (mmol/g pol.) }\end{array}$ \\
\hline \multirow[t]{13}{*}{ P3 } & 45 & 0,007 & & & & \\
\hline & 60 & 0,030 & & & & \\
\hline & 75 & 0,104 & & & 1,054 & \\
\hline & 90 & 0,162 & 5,307E+04 & 1,918E+05 & 0,454 & \\
\hline & 105 & 0,180 & $4,236 E+05$ & $2,886 E+06$ & 0,385 & \\
\hline & 120 & 0,321 & $7,598 \mathrm{E}+04$ & 2,934E+05 & 0,872 & \\
\hline & 150 & 0,320 & $3,127 \mathrm{E}+04$ & $6,549 E+04$ & 0,902 & \\
\hline & 180 & 0,322 & $2,050 \mathrm{E}+05$ & 2,617E+05 & 0,975 & \\
\hline & 240 & 0,322 & $3,857 E+04$ & $8,875 E+04$ & 0,969 & \\
\hline & 300 & 0,323 & $6,142 E+04$ & 6,797E+04 & 0,856 & \\
\hline & 360 & 0,351 & $2,909 E+04$ & 8,085E+04 & 1,005 & \\
\hline & 420 & 0,348 & 1,117E+05 & $1,390 E+05$ & 0,983 & \\
\hline & 480 & 0,387 & 1,473E+05 & 1,703E+05 & 0,989 & 3,904 \\
\hline \multirow[t]{16}{*}{ P4 } & 120 & 0,077 & 1,589E+04 & $3,022 E+04$ & & \\
\hline & 180 & 0,126 & $2,154 \mathrm{E}+04$ & $5,467 \mathrm{E}+04$ & & \\
\hline & 240 & 0,132 & 1,637E+04 & $4,950 E+04$ & & \\
\hline & 255 & 0,147 & & & & \\
\hline & 270 & 0,133 & & & & \\
\hline & 285 & 0,123 & & & & \\
\hline & 300 & 0,145 & $2,620 \mathrm{E}+04$ & $5,769 E+04$ & & \\
\hline & 315 & 0,134 & & & & \\
\hline & 330 & 0,157 & & & & \\
\hline & 345 & 0,149 & $2,540 E+04$ & $5,991 E+04$ & & \\
\hline & 360 & 0,149 & 1,219E+04 & $5,472 E+04$ & & \\
\hline & 420 & 0,159 & & & & \\
\hline & 480 & 0,165 & $2,852 E+04$ & $7,729 \mathrm{E}+04$ & & \\
\hline & 540 & 0,182 & $7,796 \mathrm{E}+03$ & $5,856 E+04$ & & \\
\hline & 600 & 0,163 & $1,148 \mathrm{E}+04$ & $6,745 E+04$ & & \\
\hline & 660 & 0,181 & & & & \\
\hline
\end{tabular}


Tabela 13 - Resultados experimentais (continuação)

\begin{tabular}{|c|c|c|c|c|c|c|}
\hline Experimento & $\begin{array}{l}\text { Tempo } \\
\text { (min) }\end{array}$ & $X$ & $\begin{array}{c}\mathrm{Mn} \\
(\mathrm{g} / \mathrm{mol})\end{array}$ & $\begin{array}{c}\text { Mw } \\
(\mathrm{g} / \mathrm{mol})\end{array}$ & $\mathrm{Wg}$ & $\begin{array}{c}\text { PDBs } \\
\text { (mmol/g pol.) }\end{array}$ \\
\hline $\mathrm{P} 4$ & 720 & 0,190 & $2,279 E+04$ & $8,410 \mathrm{E}+04$ & & 5,745300 \\
\hline \multirow[t]{12}{*}{ P5 } & 60 & 0,018 & & & & \\
\hline & 75 & 0,021 & & & & \\
\hline & 90 & 0,022 & & & & \\
\hline & 105 & 0,022 & & & & \\
\hline & 120 & 0,024 & & & & \\
\hline & 150 & 0,022 & $5,549 E+03$ & $5,704 \mathrm{E}+03$ & & \\
\hline & 180 & 0,024 & & & & \\
\hline & 240 & 0,024 & & & & \\
\hline & 300 & 0,028 & & & & \\
\hline & 360 & 0,053 & $3,079 E+03$ & 4,075E+03 & & \\
\hline & 420 & 0,087 & & & & \\
\hline & 480 & 0,104 & 6,390E+03 & $1,015 \mathrm{E}+04$ & & 4,302 \\
\hline \multirow[t]{14}{*}{ P6 } & 60 & 0,042 & 4,594E+03 & $6,665 E+03$ & & \\
\hline & 90 & 0,129 & $5,363 E+03$ & 1,228E+04 & & \\
\hline & 120 & 0,167 & & & & \\
\hline & 150 & 0,186 & $6,074 \mathrm{E}+03$ & $1,000 \mathrm{E}+04$ & & \\
\hline & 180 & 0,211 & & & & \\
\hline & 210 & 0,217 & $6,961 \mathrm{E}+03$ & 1,295E+04 & & \\
\hline & 240 & 0,208 & & & & \\
\hline & 270 & 0,227 & 7,638E+03 & 1,246E+04 & & \\
\hline & 300 & 0,252 & & & & \\
\hline & 330 & 0,237 & $7,370 E+03$ & 1,269E+04 & & \\
\hline & 360 & 0,251 & & & & \\
\hline & 390 & 0,236 & $5,413 E+03$ & $1,144 \mathrm{E}+04$ & & \\
\hline & 420 & 0,290 & & & & \\
\hline & 450 & 0,281 & $7,426 \mathrm{E}+03$ & $9,392 E+03$ & & \\
\hline
\end{tabular}


Tabela 13 - Resultados experimentais (continuação)

\begin{tabular}{|c|c|c|c|c|c|c|}
\hline Experimento & $\begin{array}{c}\text { Tempo } \\
\text { (min) }\end{array}$ & $X$ & $\begin{array}{c}\mathrm{Mn} \\
(\mathrm{g} / \mathrm{mol})\end{array}$ & $\begin{array}{c}\mathrm{Mw} \\
(\mathrm{g} / \mathrm{mol})\end{array}$ & $\mathrm{Wg}$ & $\begin{array}{c}\text { PDBs } \\
\text { (mmol/g } \\
\text { pol.) }\end{array}$ \\
\hline P6 & 480 & 0,306 & $2,059 E+04$ & $2,522 E+04$ & & \\
\hline \multirow[t]{15}{*}{ P7 } & 10 & 0,084 & $7,390 \mathrm{E}+04$ & $8,858 \mathrm{E}+04$ & & \\
\hline & 20 & 0,102 & $7,006 \mathrm{E}+04$ & $1,968 \mathrm{E}+05$ & & \\
\hline & 40 & 0,199 & $4,192 \mathrm{E}+05$ & $1,130 \mathrm{E}+06$ & 0,000 & \\
\hline & 60 & 0,297 & $2,123 E+05$ & $3,625 E+05$ & 0,331 & \\
\hline & 90 & 0,475 & $2,669 \mathrm{E}+05$ & $7,332 \mathrm{E}+05$ & 0,642 & \\
\hline & 110 & 0,805 & 1,647E+05 & $3,076 \mathrm{E}+05$ & 0,680 & \\
\hline & 120 & 0,722 & 1,087E+05 & $1,308 \mathrm{E}+05$ & 0,796 & \\
\hline & 125 & & $9,119 \mathrm{E}+04$ & $3,067 \mathrm{E}+05$ & 0,791 & \\
\hline & 130 & & $8,923 \mathrm{E}+04$ & $2,932 E+05$ & 0,780 & \\
\hline & 135 & & $6,869 \mathrm{E}+04$ & 2,837E+05 & 0,787 & \\
\hline & 140 & & $6,724 \mathrm{E}+04$ & $2,970 \mathrm{E}+05$ & 0,817 & \\
\hline & 160 & & $8,492 \mathrm{E}+04$ & $2,617 \mathrm{E}+05$ & 0,667 & \\
\hline & 180 & & $4,273 \mathrm{E}+04$ & $1,689 \mathrm{E}+05$ & 1,000 & \\
\hline & 270 & & $6,043 E+03$ & $2,629 \mathrm{E}+04$ & 0,910 & \\
\hline & 360 & & & & 0,877 & 0,204 \\
\hline \multirow[t]{7}{*}{ P8 } & 70 & 0,056 & & $8,645 E+02$ & 0,7473 & \\
\hline & 83 & 0,062 & & $8,867 \mathrm{E}+02$ & 0,7543 & \\
\hline & 100 & 0,054 & & $1,821 \mathrm{E}+03$ & 0,8376 & \\
\hline & 120 & 0,150 & & $4,505 E+03$ & & \\
\hline & 150 & 0,284 & & $1,499 \mathrm{E}+04$ & 0,1140 & 6,794 \\
\hline & 180 & 0,304 & & $1,033 E+06$ & 0,3054 & 5,202 \\
\hline & 300 & & & & 0,9733 & 3,584 \\
\hline
\end{tabular}

P9 
Tabela 13 - Resultados experimentais (continuação)

\begin{tabular}{|c|c|c|c|c|c|c|}
\hline Experimento & $\begin{array}{c}\text { Tempo } \\
\text { (min) }\end{array}$ & $x$ & $\begin{array}{c}\mathrm{Mn} \\
(\mathrm{g} / \mathrm{mol})\end{array}$ & $\begin{array}{c}\mathrm{Mw} \\
(\mathrm{g} / \mathrm{mol})\end{array}$ & $\mathrm{Wg}$ & $\begin{array}{c}\text { PDBs } \\
\text { (mmol/g pol.) }\end{array}$ \\
\hline \multirow[t]{3}{*}{ P9 } & 240 & & & & 0,677 & 3,034 \\
\hline & 300 & & & & 0,928 & 2,767 \\
\hline & 720 & & $7,042 \mathrm{E}+04$ & $1,181 \mathrm{E}+05$ & 0,978 & 2,093 \\
\hline \multirow[t]{4}{*}{ P10 } & 120 & 0,078 & $7,923 E+03$ & $9,642 \mathrm{E}+03$ & & \\
\hline & 180 & 0,200 & $1,677 \mathrm{E}+04$ & $2,721 E+04$ & & \\
\hline & 240 & 0,303 & $4,800 E+04$ & $3,162 \mathrm{E}+05$ & & \\
\hline & 720 & & $1,065 E+04$ & $1,478 \mathrm{E}+04$ & 0,976 & 0,425 \\
\hline \multirow[t]{7}{*}{ P11 } & 360 & 0,056 & $1,833 E+04$ & $1,894 \mathrm{E}+04$ & & \\
\hline & 420 & 0,116 & $1,744 \mathrm{E}+04$ & $2,220 \mathrm{E}+04$ & & \\
\hline & 480 & 0,191 & $2,689 E+04$ & $4,772 \mathrm{E}+04$ & & 3,102 \\
\hline & 540 & 0,236 & $5,104 \mathrm{E}+04$ & $1,038 \mathrm{E}+05$ & & 2,623 \\
\hline & 600 & 0,266 & $6,091 \mathrm{E}+04$ & $1,505 \mathrm{E}+05$ & & 2,434 \\
\hline & 660 & 0,289 & $9,849 \mathrm{E}+04$ & $2,721 \mathrm{E}+05$ & & 2,252 \\
\hline & 720 & 0,296 & $1,350 \mathrm{E}+05$ & $3,850 \mathrm{E}+05$ & 0,023 & 2,179 \\
\hline \multirow[t]{11}{*}{ P12 } & 60 & 0,015 & $1,804 \mathrm{E}+04$ & $1,893 E+04$ & & \\
\hline & 120 & 0,133 & $7,511 \mathrm{E}+03$ & $8,791 \mathrm{E}+03$ & & \\
\hline & 180 & 0,228 & $1,214 \mathrm{E}+04$ & $1,337 \mathrm{E}+04$ & & \\
\hline & 240 & 0,333 & $1,405 E+04$ & $1,545 \mathrm{E}+04$ & & \\
\hline & 300 & 0,392 & $1,551 \mathrm{E}+04$ & $1,713 \mathrm{E}+04$ & & \\
\hline & 360 & 0,446 & $1,771 \mathrm{E}+04$ & $1,929 E+04$ & & \\
\hline & 420 & 0,473 & $2,007 E+04$ & $2,146 \mathrm{E}+04$ & & \\
\hline & 480 & 0,537 & $2,174 \mathrm{E}+04$ & $2,315 \mathrm{E}+04$ & & \\
\hline & 540 & 0,540 & $2,234 \mathrm{E}+04$ & $2,392 \mathrm{E}+04$ & & \\
\hline & 600 & 0,567 & $2,217 \mathrm{E}+04$ & $2,400 \mathrm{E}+04$ & & \\
\hline & 660 & 0,602 & $2,568 E+04$ & $2,860 E+04$ & & \\
\hline
\end{tabular}


Tabela 13 - Resultados experimentais (continuação)

\begin{tabular}{|c|c|c|c|c|c|c|}
\hline Experimento & $\begin{array}{c}\text { Tempo } \\
\text { (min) }\end{array}$ & $x$ & $\begin{array}{c}\mathrm{Mn} \\
(\mathrm{g} / \mathrm{mol})\end{array}$ & $\begin{array}{c}\mathrm{Mw} \\
(\mathrm{g} / \mathrm{mol})\end{array}$ & Wg & $\begin{array}{c}\text { PDBs } \\
(\mathrm{mmol} / \mathrm{g} \mathrm{pol} .)\end{array}$ \\
\hline \multirow[t]{4}{*}{$\mathrm{P} 13$} & 10 & 0,028 & $1,507 \mathrm{E}+05$ & $1,698 \mathrm{E}+05$ & & \\
\hline & 20 & 0,078 & $7,121 \mathrm{E}+04$ & $8,634 \mathrm{E}+04$ & & \\
\hline & 40 & 0,013 & $7,191 \mathrm{E}+05$ & 8,727E+05 & & \\
\hline & 220 & 0,557 & $6,703 \mathrm{E}+05$ & $1,190 \mathrm{E}+06$ & & \\
\hline \multirow[t]{13}{*}{ P14 } & 90 & 0,062 & & & & \\
\hline & 120 & 0,097 & & & & \\
\hline & 150 & 0,117 & $8,290 \mathrm{E}+03$ & $1,174 \mathrm{E}+04$ & & \\
\hline & 180 & 0,120 & $5,971 \mathrm{E}+03$ & $1,129 \mathrm{E}+04$ & & \\
\hline & 240 & 0,115 & $5,011 \mathrm{E}+03$ & $8,689 E+03$ & & \\
\hline & 300 & 0,125 & $4,965 \mathrm{E}+03$ & $6,977 \mathrm{E}+03$ & & \\
\hline & 360 & 0,039 & & & & \\
\hline & 420 & 0,164 & & $1,030 \mathrm{E}+04$ & & \\
\hline & 480 & 0,176 & $1,142 \mathrm{E}+04$ & $1,429 E+04$ & & \\
\hline & 540 & 0,214 & $6,090 \mathrm{E}+03$ & $9,710 \mathrm{E}+03$ & & \\
\hline & 600 & 0,149 & $4,743 \mathrm{E}+03$ & $8,088 \mathrm{E}+03$ & & \\
\hline & 660 & 0,210 & $3,722 \mathrm{E}+03$ & $9,024 \mathrm{E}+03$ & & \\
\hline & 720 & 0,317 & & & & \\
\hline \multirow[t]{11}{*}{ P15 } & 120 & 0,097 & $1,015 \mathrm{E}+04$ & $5,262 \mathrm{E}+04$ & & \\
\hline & 180 & 0,131 & $2,796 \mathrm{E}+04$ & $1,579 \mathrm{E}+05$ & & \\
\hline & 240 & 0,166 & $3,612 \mathrm{E}+04$ & $2,257 \mathrm{E}+05$ & 0,211 & \\
\hline & 300 & 0,157 & $3,308 \mathrm{E}+04$ & $2,404 E+05$ & & \\
\hline & 330 & 0,172 & $3,809 \mathrm{E}+04$ & $2,483 E+05$ & & \\
\hline & 360 & 0,129 & & & & \\
\hline & 390 & 0,138 & & & & \\
\hline & 420 & 0,175 & $3,973 \mathrm{E}+04$ & $2,844 \mathrm{E}+05$ & & \\
\hline & 450 & 0,146 & & & & \\
\hline & 480 & 0,117 & & & & \\
\hline & 540 & 0,179 & $5,630 \mathrm{E}+04$ & $3,672 \mathrm{E}+05$ & & \\
\hline
\end{tabular}


Tabela 13 - Resultados experimentais (conclusão)

\begin{tabular}{ccccccc}
\hline Experimento & $\begin{array}{c}\text { Tempo } \\
(\mathrm{min})\end{array}$ & $\mathrm{X}$ & $\begin{array}{c}\text { Mn } \\
(\mathrm{g} / \mathrm{mol})\end{array}$ & $\begin{array}{c}\text { Mw } \\
(\mathrm{g} / \mathrm{mol})\end{array}$ & Wg & $\begin{array}{c}\text { PDBs } \\
\text { (mmol/g pol. })\end{array}$ \\
\hline P15 & 600 & 0,165 & $4,268 \mathrm{E}+04$ & $3,109 \mathrm{E}+05$ & & \\
& 630 & 0,182 & & & 0,710 & \\
& 660 & 0,140 & & & & \\
& 690 & 0,219 & & & & \\
& 720 & 0,195 & $5,298 \mathrm{E}+04$ & $3,856 \mathrm{E}+05$ & 0,704 & 2,508 \\
\hline
\end{tabular}

'E' representa a potência de $10\left(e x .: \mathrm{E}+3=10^{3}\right)$.

Os experimentos conduzidos a $130^{\circ} \mathrm{C}$ possuem um período inicial de aquecimento, ou seja, as reações tiveram início à temperatura ambiente e atingiram $130^{\circ} \mathrm{C}$ após um determinado tempo. A Tabela 14 e a Figura 105 mostram o perfil médio de temperaturas obtido nestes experimentos, o qual foi também considerado ao modelo.

Tabela 14 - Perfil de temperaturas para as reações à $130^{\circ} \mathrm{C}$

\begin{tabular}{cc}
\hline Tempo de reação $(\min )$ & Temperatura $\left({ }^{\circ} \mathrm{C}\right)$ \\
\hline 0 & 20,0 \\
15 & 55,0 \\
30 & 85,0 \\
60 & 102,5 \\
90 & 117,5 \\
120 & 124,0 \\
180 & 127,5 \\
240 & 129,0 \\
800 & 130,2 \\
\hline
\end{tabular}

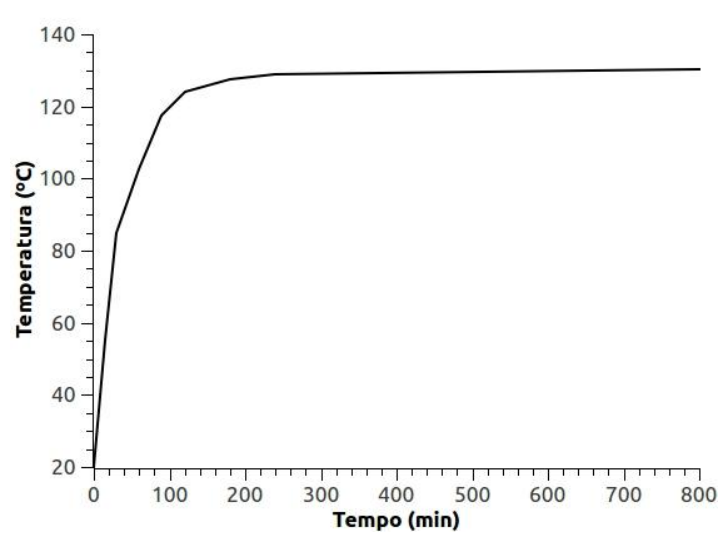

Figura 105 - Perfil de temperaturas para as reações à $130^{\circ} \mathrm{C}$. 
ANEXOS 
Full Paper: Mass balance equations in terms of the moment generating function of the distribution of mole concentrations of polymer species for free radical copolymerizations of mono/divinyl monomers could be numerically solved after gel point using open source code ACDC, needed for extremely stiff two-point boundary value problems. For the first time, it became possible to compare the error of earlier wellknown approximated estimation methods for the weight fraction of sol and average molecular weights to this accurate mathematical solution. It turns out that predictions by the pseudo-kinetic method are reasonable only when equal reactivity of double bonds prevails, causing early gelation in the batch reactor. Otherwise the discrepancies between the exact and approximate solutions are quite important.

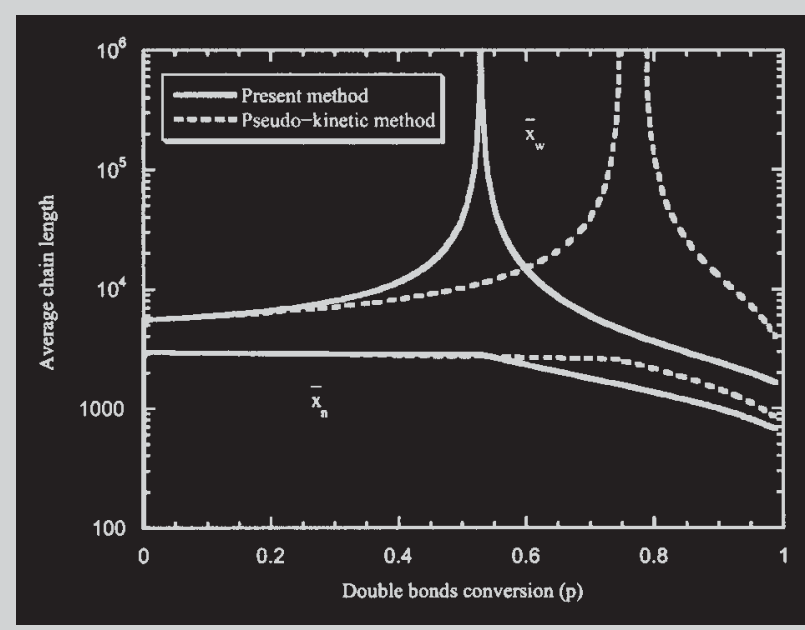

Comparison between predicted number-average and weightaverage degrees of polymerization of sol in batch non-linear free radical polymerizations of model system III.

\title{
Prediction of Sol Fraction and Average Molecular Weights after Gelation for Non-Linear Free Radical Polymerizations Using a Kinetic Approach
}

\author{
Mário Rui P. F. N. Costa, ${ }^{* 1}$ Rolando C. S. Dias ${ }^{2}$ \\ ${ }^{1}$ LSRE, Faculty of Engineering University of Porto, Rua Roberto Frias s/n, 4200-465 Porto Codex, Portugal \\ Fax: 351225081666; E-mail: mrcosta@fe.up.pt \\ ${ }^{2}$ LSRE, Instituto Politécnico de Bragança, Quinta de S. Apolónia, 5300 Bragança, Portugal
}

Received: March 11, 2003; Revised: May 23, 2003; Accepted: June 25, 2003; DOI: 10.1002/mats.200350011

Keywords: average molecular weights; divinyl monomers; free radical polymerization; gels; kinetics (polym.)

\section{Introduction}

Many key features of kinetic modeling of non-linear free radical polymerizations through the use of the moment generating functions of chain length distributions (CLD) of polymer species have been acknowledged by Kuchanov and Pis'men, ${ }^{[1]}$ namely the need of avoiding the quasi-steady state hypothesis for radical concentrations and the consideration of multiple radical centers near the gelation and beyond.

Lack of suitable numerical methods has precluded the use of this approach for modeling purposes after gelation. The well-known method of moments, which some commercial packages implement, results from similar sets of equations before gel point, but only a limited description of the chemical system is then available.

This kinetic approach for modeling irreversible nonlinear polymerizations has lately been developed by the present authors (Costa and Dias ${ }^{[2]}$ ) with some success as far as non-linear polycondensations and non-radical polyadditions (Costa and Dias ${ }^{[3]}$ ) are concerned. At the same time, some results concerning free radical polymerizations before gelation have been obtained, and some severe numerical difficulties were identified.

It is the purpose of this paper to present a successful way of dealing with those problems and to discuss the value and possible usefulness of this general approach. 


\section{Chemical Modeling}

Polymer molecules are described by the count of their chemical groups regardless of their sequence. Only a very simple kinetic scheme will be considered, in order to present the essential numerical modeling difficulties with a minimum set of equations.

The chemical groups are named $A_{j}$, with $j$ being an integer variable, and in these case studies group $A_{1}$ is a radical site coming from the monovinyl monomer $M_{1}, A_{2}$ is a radical site coming from the divinyl monomer $M_{2}$, and $A_{3}$ is a pending vinyl group. The count of repeating units coming from either monomer, $A_{4}$ and $A_{5}$, is necessary in order to compute molecular weight. Notice that groups $A_{4}$ and $A_{5}$ are only formed, not consumed, by chemical reaction. Remaining active species are the monofunctional initiator $I$ and the primary radicals $R_{0}$ it forms when it decomposes by a first order reaction with rate constant $k_{\mathrm{d}}$ and an efficiency factor $f$ :

$$
I \stackrel{k_{\mathrm{d}}}{\longrightarrow} 2 f R_{0}
$$

Primary radicals initiate kinetic chains by reaction with monomers and pending double bonds:

$$
\begin{aligned}
& R_{0}+M_{1} \stackrel{k_{\mathrm{I}_{1}}}{\longrightarrow} A_{1}+A_{4} \\
& R_{0}+M_{2} \stackrel{k_{\mathrm{I}_{2}}}{\longrightarrow} A_{2}+A_{3}+A_{5} \\
& R_{0}+A_{3} \stackrel{k_{\mathrm{I}_{3}}}{\longrightarrow} A_{2}
\end{aligned}
$$

Considering only the effect of the terminal unit of the radicals in the reactivity, there are six different propagation reactions:

$$
\begin{aligned}
& A_{1}+M_{1} \stackrel{k_{\mathrm{p}_{11}}}{\longrightarrow} A_{1}+A_{4} \\
& A_{1}+M_{2} \stackrel{k_{\mathrm{p}_{12}}}{\longrightarrow} A_{2}+A_{3}+A_{5} \\
& A_{1}+A_{3} \stackrel{k_{\mathrm{p}_{13}}}{\longrightarrow} A_{2} \\
& A_{2}+M_{1} \stackrel{k_{\mathrm{p}_{21}}}{\longrightarrow} A_{1}+A_{4} \\
& A_{2}+M_{2} \stackrel{k_{\mathrm{p}_{22}}}{\longrightarrow} A_{2}+A_{3}+A_{5} \\
& A_{2}+A_{3} \stackrel{k_{\mathrm{p}_{23}}}{\longrightarrow} A_{2}
\end{aligned}
$$

Accordingly, there are six different termination reactions, half by combination and half by dismutation:
$A_{1}+A_{1} \stackrel{k_{\mathrm{tc}} 11}{\longrightarrow}$ Head - Head unit

$A_{1}+A_{1} \stackrel{k_{\mathrm{td}_{11}}}{\longrightarrow}$ Saturated endgroup + Unsaturated endgroup

$A_{1}+A_{2} \stackrel{k_{\mathrm{tc}_{12}}}{\longrightarrow}$ Head - Head unit

$A_{1}+A_{2} \stackrel{k_{\mathrm{td}_{12}}}{\longrightarrow}$ Saturated endgroup + Unsaturated endgroup

$A_{2}+A_{2} \stackrel{k_{\mathrm{tc}_{22}}}{\longrightarrow}$ Head - Head unit

$A_{2}+A_{2} \stackrel{k_{\mathrm{td}_{22}}}{\longrightarrow}$ Saturated endgroup + Unsaturated endgroup

No less than three different conventions for relating rates of group formation with the values of rate constants of termination can be found in the literature. In the convention we follow, the rate of consumption of $A_{1}$ radical groups terminating by combination with themselves is $2 k_{\mathrm{tc}_{11}} A_{1}^{2}$ and rate of formation of head-to-head units is $k_{\mathrm{tc}_{11}} A_{1}^{2}$. In the same way, rate of consumption of $A_{1}$ radical groups by dismutation is $2 k_{\mathrm{td}_{11}} A_{1}^{2}$.

The set of polymer species with $a_{1}$ groups $A_{1}$ (radical sites from monomer $M_{1}$ ), $a_{2}$ radicals $A_{2}$ and $a_{3}$ pending double bonds $A_{3}, a_{4}$ units of monomer " 1 " and $a_{5}$ units of monomer " 2 " ( $a_{4}$ and $a_{5}$ are the degrees of polymerization) is supposed to have an overall mole concentration $P\left(a_{1}, a_{2}\right.$, $\left.a_{3}, a_{4}, a_{5}\right)$. We will often use its moment generating function $G\left(s_{1}, s_{2}, s_{3}, s_{4}, s_{5}\right)$ below defined:

$$
\begin{aligned}
& G\left(s_{1}, s_{2}, s_{3}, s_{4}, s_{5}\right)=\sum_{a_{1}=0}^{\infty} \sum_{a_{2}=0}^{\infty} \sum_{a_{3}=0}^{\infty} \sum_{a_{4}=0}^{\infty} \sum_{a_{5}=0}^{\infty} s_{1}^{a_{1}} s_{2}^{a_{2}} s_{3}^{a_{3}} s_{4}^{a_{4}} s_{5}^{a_{5}} \\
& \quad \times P\left(a_{1}, a_{2}, a_{3}, a_{4}, a_{5}\right)
\end{aligned}
$$

Laplace parameters $s_{j}$, with $j=1-5$, are complex numbers. As $G(1,1,1,1,1)$ is some finite value equal to the overall mole concentration of polymer, the comparison test guarantees convergence of the series in Equation (17) in the five-dimensional sphere in complex space $|\mathbf{s}| \leq 1$, moment generating function $G$ being thus an analytical function of those parameters for $|\mathbf{s}|<1$.

Partial moments with respect to the counts of groups are obtained through differentiation of Equation (17) with respect to the $\log s_{j}$ followed by setting all values of Laplace parameters equal to 1 . The notation $G_{i j \ldots k}=$ $\frac{\partial \partial \ldots \partial G}{\partial \log s_{i} \partial \log s_{j} \ldots \partial \log s_{k}}$ will often be used for those derivatives (notice that the indices $i, j, \ldots k$ may be repeated any number 
of times), leading to:

$\sum_{a_{1}=0}^{\infty} \sum_{a_{2}=0}^{\infty} \cdots \sum_{a_{5}=0}^{\infty} a_{i} a_{j} \cdots a_{k} P\left(a_{1}, \ldots, a_{5}\right)=G_{i j \ldots k}(1,1,1,1,1)$

It might also be possible to use fast Fourier transform to numerically invert $G^{[2]}$ One could obtain the full multidimensional or any sub-set of marginal distributions given a sufficiently large number (a few thousands or tens of thousands per variable) of equally spaced values of $G$ in a sphere in complex five-dimensional space centered in the origin of radius slightly below 1 . Too high computing time needed to obtain those required values of $G$ with current implementation of numerical methods, as will be discussed with more detail towards the end of this paper, precluded the use of this approach in the current work.

Using techniques we have presented before, ${ }^{[2]}$ for a batch reactor with negligible volume change and no chain-length dependence of rate constants, the moment generating function of mass balance of polymer species verifies the partial differential equation shown below: $\frac{\mathrm{d} M_{2}}{\mathrm{~d} t}=-k_{\mathrm{I}_{2}} R_{0} M_{2}-k_{\mathrm{p}_{12}} A_{1} M_{2}-k_{\mathrm{p}_{22}} A_{2} M_{2}$

$\frac{\mathrm{d} R_{0}}{\mathrm{~d} t}=2 f k_{\mathrm{d}} I-\left(k_{\mathrm{I}_{1}} M_{1}+k_{\mathrm{I}_{2}} M_{2}+k_{\mathrm{I}_{3}} A_{3}\right) R_{0}$

$\frac{\mathrm{d} I}{\mathrm{~d} t}=-k_{\mathrm{d}} I$

with initial conditions (assuming there are only monomers and initiator at the beginning):

$$
\begin{aligned}
& G_{\mid t=0}=0 \\
& A_{j_{\mid t=0}}=0 \quad j=1 \ldots 3 \\
& M_{\left.\right|_{t=0}}=M_{1_{0}} \\
& M_{2_{\mid t=0}}=M_{2_{0}} \\
& R_{\left.0\right|_{t=0}}=0
\end{aligned}
$$

$$
\begin{aligned}
\frac{\partial G}{\partial t}= & k_{\mathrm{p}_{13}}\left(\frac{s_{2}}{s_{1} s_{3}} \frac{\partial G}{\partial \log s_{1}} \frac{\partial G}{\partial \log s_{3}}-\frac{\partial G}{\partial \log s_{1}} A_{3}-\frac{\partial G}{\partial \log s_{3}} A_{1}\right)+k_{\mathrm{p}_{23}}\left(\frac{1}{s_{3}} \frac{\partial G}{\partial \log s_{2}} \frac{\partial G}{\partial \log s_{3}}-\frac{\partial G}{\partial \log s_{2}} A_{3}-\frac{\partial G}{\partial \log s_{3}} A_{2}\right) \\
& +k_{\mathrm{tc}_{11}}\left[\frac{1}{s_{1}^{2}}\left(\frac{\partial G}{\partial \log s_{1}}\right)^{2}-2 \frac{\partial G}{\partial \log s_{1}} A_{1}\right]+k_{\mathrm{tc} 22}\left[\frac{1}{s_{2}^{2}}\left(\frac{\partial G}{\partial \log s_{2}}\right)^{2}-2 \frac{\partial G}{\partial \log s_{2}} A_{2}\right] \\
& +k_{\mathrm{tc}_{12}}\left(\frac{1}{s_{1} s_{2}} \frac{\partial G}{\partial \log s_{1}} \frac{\partial G}{\partial \log s_{2}}-\frac{\partial G}{\partial \log s_{1}} A_{2}-\frac{\partial G}{\partial \log s_{2}} A_{1}\right)+k_{\mathrm{p}_{11}} \frac{\partial G}{\partial \log s_{1}} M_{1}\left(s_{4}-1\right)+k_{\mathrm{p}_{12}} \frac{\partial G}{\partial \log s_{1}} M_{2}\left(\frac{s_{2} s_{3} s_{5}}{s_{1}}-1\right) \\
& +k_{\mathrm{p}_{21}} \frac{\partial G}{\partial \log s_{2}} M_{1}\left(\frac{s_{1} s_{4}}{s_{2}}-1\right)+k_{\mathrm{p}_{22}} \frac{\partial G}{\partial \log s_{2}} M_{2}\left(s_{3} s_{5}-1\right)+2 k_{\mathrm{td}_{11}} \frac{\partial G}{\partial \log s_{1}} A_{1}\left(\frac{1}{s_{1}}-1\right) \\
& +k_{\mathrm{td}_{12}}\left[\frac{\partial G}{\partial \log s_{1}} A_{2}\left(\frac{1}{s_{1}}-1\right)+\frac{\partial G}{\partial \log s_{2}} A_{1}\left(\frac{1}{s_{2}}-1\right)\right]+2 k_{\mathrm{td} 22} \frac{\partial G}{\partial \log s_{2}} A_{2}\left(\frac{1}{s_{2}}-1\right) \\
& +k_{\mathrm{I}_{3}} \frac{\partial G}{\partial \log s_{3}} R_{0}\left(\frac{s_{2}}{s_{3}}-1\right)+k_{\mathrm{I}_{1}} M_{1} R_{0} s_{1} s_{4}+k_{\mathrm{I}_{2}} M_{2} R_{0} s_{2} s_{3} s_{5}
\end{aligned}
$$

$$
\begin{aligned}
\frac{\mathrm{d} A_{1}}{\mathrm{~d} t}= & k_{\mathrm{I}_{1}} R_{0} M_{1}-k_{\mathrm{p}_{12}} A_{1} M_{2}+k_{\mathrm{p}_{21}} A_{2} M_{1}-k_{\mathrm{p}_{13}} A_{1} A_{3} \\
& -2 k_{\mathrm{tc}_{11}} A_{1}^{2}-k_{\mathrm{tc}_{12}} A_{1} A_{2}-2 \mathrm{k}_{\mathrm{td}_{11}} A_{1}^{2}-k_{\mathrm{td}_{12}} A_{1} A_{2} \\
\frac{\mathrm{d} A_{2}}{\mathrm{~d} t}= & k_{\mathrm{I}_{2}} R_{0} M_{2}+k_{\mathrm{I}_{3}} R_{0} A_{3}+k_{\mathrm{p}_{12}} A_{1} M_{2}-k_{\mathrm{p}_{21}} A_{2} M_{1}+k_{\mathrm{p}_{13}} A_{1} A_{3} \\
& -2 k_{\mathrm{tc}_{22}} A_{2}^{2}-k_{\mathrm{tc}_{12}} A_{1} A_{2}-2 \mathrm{k}_{\mathrm{td}_{22}} A_{2}^{2}-k_{\mathrm{td}_{12}} A_{1} A_{2}
\end{aligned}
$$

$$
\begin{aligned}
\frac{\mathrm{d} A_{3}}{\mathrm{~d} t}= & k_{\mathrm{I}_{2}} R_{0} M_{2}-k_{\mathrm{I}_{3}} R_{0} A_{3}+k_{\mathrm{p}_{12}} A_{1} M_{2}+k_{\mathrm{p}_{22}} A_{2} M_{2} \\
& -k_{\mathrm{p}_{13}} A_{1} A_{3}-k_{\mathrm{p}_{23}} A_{2} A_{3} \\
\frac{\mathrm{d} M_{1}}{\mathrm{~d} t} & =-k_{\mathrm{I}_{1}} R_{0} M_{1}-k_{\mathrm{p}_{11}} A_{1} M_{1}-k_{\mathrm{p}_{21}} A_{2} M_{1}
\end{aligned}
$$

$$
I_{\mid t=0}=I_{0}
$$

The solution of Equation (19) together with ordinary differential Equation (20)-(26) and their initial conditions, Equation (27)-(32), is obtained by the method of characteristics (Courant and Hilbert ${ }^{[4]}$ ) as explained in more detail elsewhere. ${ }^{[2]}$ The characteristics are the solution of the system below:

$$
\begin{aligned}
\frac{d G_{1}}{d t}= & k_{\mathrm{I}_{1}} R_{0} M_{1} s_{1}-k_{\mathrm{p}_{12}} \frac{s_{2} s_{3}}{s_{1}} G_{1} M_{2}+k_{\mathrm{p}_{21}} \frac{s_{1}}{s_{2}} G_{2} M_{1} \\
& -k_{\mathrm{p}_{13}} \frac{s_{2}}{s_{1} s_{3}} G_{1} G_{3}-2 k_{\mathrm{tc}_{11}} \frac{G_{1}^{2}}{s_{1}^{2}}-k_{\mathrm{tc}_{12}} \frac{G_{1} G_{2}}{s_{1} s_{2}} \\
& -2 k_{\mathrm{td}_{11}} A_{1} \frac{G_{1}}{s_{1}}-k_{\mathrm{td}_{12}} A_{2} \frac{G_{1}}{s_{1}}
\end{aligned}
$$




$$
\begin{aligned}
\frac{\mathrm{d} G_{2}}{\mathrm{~d} t}= & k_{\mathrm{I}_{2}} R_{0} M_{2} s_{2} s_{3}+k_{\mathrm{I}_{3}} \frac{s_{2}}{s_{3}} R_{0} G_{3}+k_{\mathrm{p}_{12}} \frac{s_{2} s_{3}}{s_{1}} G_{1} M_{2} \\
& -k_{\mathrm{p}_{21} 1} \frac{s_{1}}{s_{2}} G_{2} M_{1}+k_{\mathrm{p}_{13}} \frac{s_{2}}{s_{1} s_{3}} G_{1} G_{3}-2 k_{\mathrm{tc}_{22}} \frac{G_{2}^{2}}{s_{2}^{2}} \\
& -k_{\mathrm{tc}_{12}} \frac{G_{1} G_{2}}{s_{1} s_{2}}-2 k_{\mathrm{td}_{22}} A_{2} \frac{G_{2}}{s_{2}}-k_{\mathrm{td}_{12}} A_{1} \frac{G_{2}}{s_{2}}
\end{aligned}
$$

$$
\begin{aligned}
\frac{\mathrm{d} G_{3}}{\mathrm{~d} t}= & k_{\mathrm{I}_{2}} R_{0} M_{2} s_{2} s_{3}-k_{\mathrm{I}_{3}} \frac{s_{2}}{s_{3}} R_{0} G_{3}+k_{\mathrm{p}_{12}} \frac{s_{2} s_{3}}{s_{1}} G_{1} M_{2} \\
& +k_{\mathrm{p}_{22}} s_{3} G_{2} M_{2}-k_{\mathrm{p}_{13}} \frac{s_{2}}{s_{1} s_{3}} G_{1} G_{3}-k_{\mathrm{p}_{23}} \frac{G_{2} G_{3}}{s_{3}}
\end{aligned}
$$

$$
\begin{aligned}
\frac{\mathrm{d} s_{1}}{\mathrm{~d} t}= & k_{\mathrm{p}_{13}}\left(s_{1} A_{3}-\frac{s_{2}}{s_{3}} G_{3}\right)+k_{\mathrm{p}_{12}} M_{2}\left(s_{1}-s_{2} s_{3}\right) \\
& +2 k_{\mathrm{tc}_{11}}\left(s_{1} A_{1}-\frac{G_{1}}{s_{1}}\right)+k_{\mathrm{tc}_{12}}\left(s_{1} A_{2}-\frac{G_{2}}{s_{2}}\right) \\
& +2 k_{\mathrm{td}_{11}} A_{1}\left(s_{1}-1\right)+k_{\mathrm{td}_{12}} A_{2}\left(s_{1}-1\right)
\end{aligned}
$$

$$
\begin{aligned}
\frac{\mathrm{d} s_{2}}{\mathrm{~d} t}= & k_{\mathrm{p}_{23}}\left(s_{2} A_{3}-\frac{s_{2}}{s_{3}} G_{3}\right)+k_{\mathrm{p}_{21}} M_{1}\left(s_{2}-s_{1}\right) \\
& +k_{\mathrm{p}_{22}} M_{2}\left(s_{2}-s_{2} s_{3}\right)+2 k_{\mathrm{tc}_{22}}\left(s_{2} A_{2}-\frac{G_{2}}{s_{2}}\right) \\
& +k_{\mathrm{tc}_{12}}\left(s_{2} A_{1}-\frac{G_{1}}{s_{1}}\right)+2 k_{\mathrm{td}_{22}} A_{2}\left(s_{2}-1\right) \\
& +k_{\mathrm{td}_{12}} A_{1}\left(s_{2}-1\right)
\end{aligned}
$$

$$
\begin{aligned}
\frac{\mathrm{d} s_{3}}{\mathrm{~d} t}= & k_{\mathrm{I}_{3}} R_{0}\left(s_{3}-s_{2}\right)+k_{\mathrm{p}_{13}}\left(s_{3} A_{1}-\frac{s_{2}}{s_{1}} G_{1}\right) \\
& +k_{\mathrm{p}_{23}}\left(s_{3} A_{2}-G_{2}\right)
\end{aligned}
$$

$$
\begin{aligned}
\frac{\mathrm{d} G}{\mathrm{~d} t}= & k_{\mathrm{I}_{1}} R_{0} M_{1} s_{1}+k_{\mathrm{I}_{2}} R_{0} M_{2} s_{2} s_{3}-k_{\mathrm{p}_{13}} \frac{s_{2}}{s_{1} s_{3}} G_{1} G_{3} \\
& -k_{\mathrm{P}_{23}} \frac{G_{2} G_{3}}{s_{3}}-k_{\mathrm{tc}_{11}} \frac{G_{1}^{2}}{s_{1}^{2}}-k_{\mathrm{tc}_{12}} \frac{G_{1} G_{2}}{s_{1} s_{2}}-k_{\mathrm{tc}_{22} 2} \frac{G_{2}^{2}}{s_{2}^{2}}
\end{aligned}
$$

With further initial conditions:

$$
\begin{gathered}
G_{\left.j\right|_{t=0}}=0 \quad j=1 \ldots 3 \\
s_{\left.j\right|_{t=0}}=s_{j_{0}} \quad j=1 \ldots 3
\end{gathered}
$$

Since the goal is computing the value of $G$ and, very often, some of its derivatives with respect to the Laplace parameters at some prescribed time $t_{f}$ and vector of the $s_{j}$, $\mathbf{s}_{\mathbf{f}}=\left[s_{j f}\right]$, one has to solve a two point boundary value problem with the conditions at the right point $t=t_{f}$ :

$$
\left.s_{j}\right|_{t=t_{f}}=s_{j_{f}} \quad j=1 \ldots 3
$$

If the method for computing CLD by fast Fourier transform as described in ref. ${ }^{[2]}$ is to be used, the vector $\mathbf{S}_{\mathbf{f}}$ shall lie over a spherical surface in complex space centered in the origin and with radius $1\left(\left|\mathbf{s}_{\mathbf{f}}\right|=1\right)$ or slightly less than 1. But more often, the goal is only to compute the moments of CLD and therefore all $s_{j_{f}}=1$.

Before gelation, the physically meaningful solution when all $s_{j_{f}}=1$ (or $\left.\mathbf{s}_{\mathbf{f}}=\mathbf{1}\right)$ is $s_{j_{0}}=1$ for all $j\left(\right.$ or $\mathbf{s}_{\mathbf{0}}=\mathbf{1}$ ); all $s_{j}$ are constant along the characteristic lines. This is what we call thereafter the trivial solution branch.

Gel point is a bifurcation point where a second solution branch with at least some $s_{j_{0}}<1$ intersects the trivial solution for $t=t_{g}$, the gelation time.

For $t_{f}>t_{g}$ the physically meaningful solution is the nontrivial solution branch.

After gelation, this minimum problem can not be avoided and its solution is not easy at all. We will discuss next a practical way of solving it, which has worked for this relatively simple chemical system.

\section{Numerical Solution of the Minimum System for Characteristics}

Laplace parameters associated to non-reactive groups, such as $s_{4}$ and $s_{5}$ in this example, are constant along the characteristics. In this study, chain length distributions will not be computed, only their moments, and so they will be set to 1 for the rest of this presentation.

This particular class of boundary value problems is of the "time-like" variety in Deuflhard's classification. ${ }^{[5]} \mathrm{A}$ shooting method using integration for increasing time values is the natural way of finding a numerical solution, as we have used previously. ${ }^{[2,3]}$

Because of the high relative values of termination rate constants relatively to propagation, it can be guessed that the system becomes extremely "stiff", ${ }^{[6]}$ and this can be verified in a number of ways.

A widely used measure of numerical stiffness ${ }^{[7]}$ is found by multiplying the end value of time $t_{f}$ by the lowest real part of the eigenvalues of the Jacobian of the system right hand sides. After obtaining an accurate numerical solution of Equation (20)-(26) and (33)-(39), as will be described later on, this criterion can be evaluated. It increases rapidly in modulus with time (being already $-10^{6}$ at double bonds conversion of 0.01 ), and it reaches values of about $-2 \times 10^{7}$ for the numerical case studies next presented.

Well known code for "stiff" systems of ordinary differential equations RADAU5 ${ }^{[8]}$ can successfully solve the system consisting only of the end-group mass balances, Equation (20)-(26). However, on trying to use that method to numerically solve the full system with additional Equation (33)-(38), it turns out that numerical values "blow out" even with the exact solution (trivial solution branch) for the initial values of $s_{j_{0}}$ (Figure 1)!

Therefore, parallel multiple shooting ${ }^{[9]}$ is needed to overcome this difficulty. 


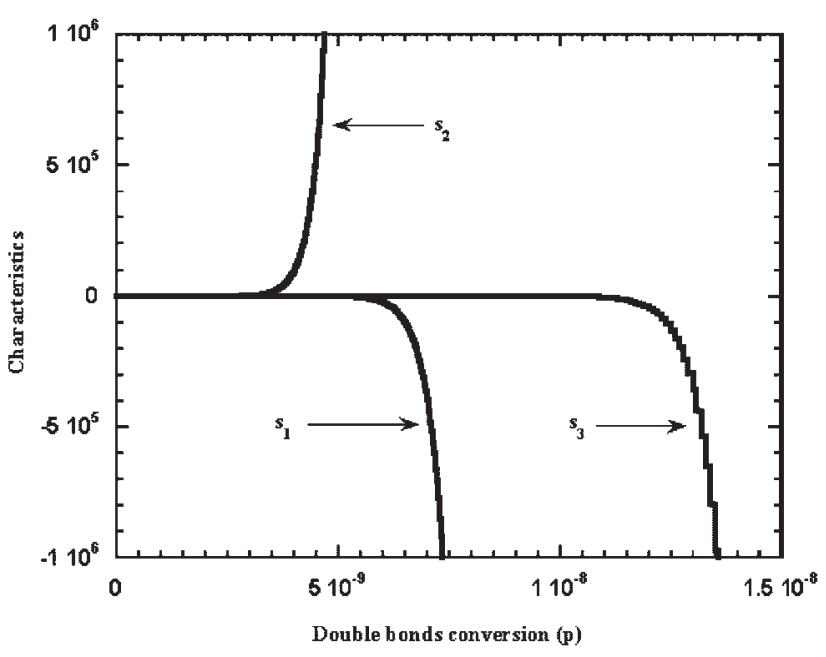

Figure 1. Example of integration of characteristics showing the "blow up" of numerical solution.

The extreme numerical sensitivity of these problems made all currently available codes fail, except the integrator in Cash et al.'s automatic continuation code ACDC, ${ }^{[10-12]}$ available at http://www.netlib.org/ode/acdc.f. Although its continuation procedure (in its present form) usually leads to the trivial solution branch instead of the physically meaningful branch, its implicit Runge-Kutta integrator based on a Lobatto quadrature does succeed in finding the required solutions.

Three sets of numerical values for parameters used in simulations are presented in Table 1. A few common values for the three systems are representative ${ }^{[13]}$ of real freeradical polymerizations. Some ratios of constants, including the well-known copolymerization ratios $r_{1}$ and $r_{2}$ for the classical terminal unit effect, were chosen in order to explore numerical sensitivities.

Table 1. Values of rate parameters used in simulations.

\begin{tabular}{|c|c|c|c|}
\hline Parameter & $\begin{array}{l}\text { System } \\
\text { I }\end{array}$ & $\begin{array}{l}\text { System } \\
\text { II }\end{array}$ & $\begin{array}{c}\text { System } \\
\text { III }\end{array}$ \\
\hline$C_{\mathrm{I}_{1}}=k_{\mathrm{I}_{1}} / k_{\mathrm{p}_{11}}$ & 1 & 1 & 1 \\
\hline$C_{\mathrm{I}_{2}}=k_{\mathrm{I}_{2}} / k_{\mathrm{p}_{11}}$ & 2 & 5 & 20 \\
\hline$C_{\mathrm{I}_{3}}=k_{\mathrm{I}_{3}} / k_{\mathrm{p}_{11}}$ & 1 & 0.5 & 10 \\
\hline$r_{1}=k_{\mathrm{p}_{11}} / k_{\mathrm{p}_{12}}$ & 0.5 & 0.2 & 2 \\
\hline$r_{2}=k_{\mathrm{p}_{22}} / k_{\mathrm{p}_{21}}$ & 2 & 0.5 & 500 \\
\hline$C_{\mathrm{p}_{1}}=k_{\mathrm{p}_{21}} / k_{\mathrm{p}_{11}}$ & 1 & 1 & 0.2 \\
\hline$C_{\mathrm{p}_{2}}=k_{\mathrm{p}_{13}} / k_{\mathrm{p}_{11}}$ & 1 & 0.15 & 0.1 \\
\hline$C_{\mathrm{p}_{3}}^{\mathrm{P}_{2}}=k_{\mathrm{p}_{23}}^{\mathrm{P}_{13}} / k_{\mathrm{p}_{21}}$ & 1 & 0.05 & 250 \\
\hline & 0.5 & 0.5 & 0.5 \\
\hline$k_{\mathrm{d}} / \mathrm{s}^{-1}$ & $10^{-6}$ & $10^{-6}$ & $10^{-6}$ \\
\hline$k_{\mathrm{p}_{1}} /\left(\mathrm{dm}^{3} \cdot \mathrm{mol}^{-1} \cdot \mathrm{s}^{-1}\right)$ & 100 & 100 & 100 \\
\hline$k_{\mathrm{t}_{11}}=k_{\mathrm{tc}_{11}}+k_{\mathrm{td}_{11}} /\left(\mathrm{dm}^{3} \cdot \mathrm{mol}^{-1} \cdot \mathrm{s}^{-1}\right)$ & $10^{6}$ & $10^{6}$ & $10^{6}$ \\
\hline$k_{\mathrm{t}_{12}}=k_{\mathrm{tc}_{12}}+k_{\mathrm{td}_{12}} /\left(\mathrm{dm}^{3} \cdot \mathrm{mol}^{-1} \cdot \mathrm{s}^{-1}\right)$ & $10^{6}$ & $10^{6}$ & $10^{6}$ \\
\hline$k_{\mathrm{t}_{22}}=k_{\mathrm{tc}_{22}}+k_{\mathrm{td}_{22}} /\left(\mathrm{dm}^{3} \cdot \mathrm{mol}^{-1} \cdot \mathrm{s}^{-1}\right)$ & $10^{6}$ & $10^{6}$ & $10^{6}$ \\
\hline$\delta_{\mathrm{c}_{11}}=k_{\mathrm{tc}_{11}} / k_{\mathrm{t}_{11}}$ & 0.5 & 0.5 & 0.5 \\
\hline $\mathrm{c}_{12} / k_{\mathrm{t}_{12}}$ & 0.5 & 0.5 & 0.5 \\
\hline$\delta_{\mathrm{c}_{22}}=k_{\mathrm{tc}_{22}} / k_{\mathrm{t}_{22}}$ & 0.5 & 0.5 & 0.5 \\
\hline
\end{tabular}

System I is the "ideal" base system $\left(r_{1} r_{2}=1\right)$, whereas in system II cross-polymerization is favored $\left(r_{1} r_{2}=0.1\right)$ and nearly forbidden in system III $\left(r_{1} r_{2}=1000\right)$.

In all simulations, the initial composition is the same:

i) initiator concentration is $1 / 1000$ of the double bonds;

ii) divinyl monomer mole fraction is 0.001 with respect to the total monomer content.

Especially important is the effect of the relative reactivity of pendent double bond (determined by $C_{\mathrm{p}_{2}}$ and $C_{\mathrm{p}_{3}}$ parameters). These parameters were varied in order to obtain a lower or higher value of conversion of double bonds at the gel point.

The initial total monomer concentration was fixed to $1 \mathrm{~mol} \cdot \mathrm{dm}^{-3}$.

Code ACDC requires subroutines for defining right hand sides of the system of 13 differential equations, Equation (20)-(26) and (33)-(38), boundary conditions at the two end-points $t=0$ and $t=t_{f}$, Equation (28)-(32), (40), and (42), as well as their Jacobians. Jacobian of right-hand sides of those differential equations has 90 non-zero components.

The first step of the simulations is the prediction of gelation time, since it makes no sense to find again the known trivial solution branch. Both natural ways of carrying out this calculation were used:

1) Integration of the equations for the 2 nd order moments (along the trivial solution branch) until divergence to infinity;

2) Evaluation of the determinant of the Jacobian of the $s_{j}$ relatively to the $s_{j_{0}}$ as a function of time $t$ until it becomes zero, for $t=t_{g}$.

After finding gelation time, a vector of final times will be chosen for the presentation of results, although for easier comparison of chemical systems, overall double bonds conversion will be used instead of the corresponding reaction time.

ACDC computes iteratively the characteristics in a mesh of intermediate time values between $t=0$ and $t=t_{f}$. It adapts the mesh along this process, but a good initial definition of number and placement of the grid is important, and a good approximation of the true solution can be of a great help.

For the first value of final time $t_{f}$, there is no information concerning the values of the $s_{j_{0}}$, except that they should be slightly a bit less than 1 if $t_{f}$ is not far from $t_{g}$, although this does not help much. Fortunately, ACDC finds the wanted solution without many retrials, if one respects the following rules:

The integration interval from $t=0$ to $t=t_{f}$ must be divided into a fairly large number of grid points, with 3 sections, because there are two boundary layers for the solution in each side of the interval, as shown in Figure 2; good choices were 1000, 20000 and 1000, with break points $t=t_{s}$ and $t_{f}-t_{s}$, with $t_{s}=100 \mathrm{~s}$ for these numerical examples. $t_{s}$ is of the order of the time needed to reach a slowly changing radical concentration. 


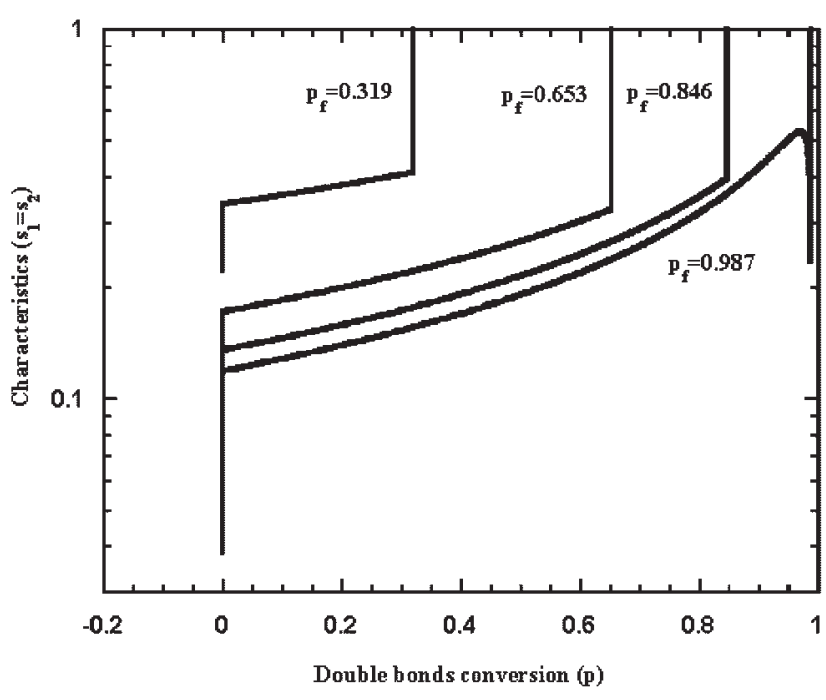

Figure 2. Values of $s_{1}=s_{2}$ along the characteristics for system I and different values of final time (expressed as conversion of double bonds).

In these grid points, as the exact values of the concentrations of active groups can be independently computed, they must be fed to the routine as starting points in order to accelerate convergence.

Initial estimations for $G_{1}, G_{2}$, and $G_{3}$ on the grid points were chosen as some fraction (0.001 gave good results) of the corresponding concentrations $A_{1}, A_{2}$, and $A_{3}$.

Initial estimations for $s_{1}, s_{2}$, and $s_{3}$ on the grid points should follow a pattern similar to the solution in Figure 2: in the left boundary layer, a small value like $10^{-5}$, in the middle region 0.001 or so, and 1 in the right boundary layer.

It took a fairly large number of failed attempts of convergence until these basic rules were found and could thus provide decisive help in finding the solutions with a good reliability now.

In Figure 3, a typical profile of characteristics associated to the different active groups for system III can be observed. Only, for this system, values of $s_{1}$ and $s_{2}$ are very different.

Contrarily to common sense, there is no visible advantage of using a previously found numerical solution as a starting point of the one for the next final value of time. Figure 4 shows why: the changes of profiles are so sudden that one should use extremely close values of successive final times in order for that strategy to succeed. Each prediction of a certain value of final time is thus a nearly independent problem.

The computations were carried out using a PIV $1.5 \mathrm{GHz}$ computer with $512 \mathrm{Mb}$ memory, running Red Hat Linux 7.1 (kernel version 2.4.7-10). Fortran sources were compiled using GNU compiler g77 based on gcc 2.96. In the worst cases, CPU time spent for integrating the characteristics in order to attain each prescribed final time was $270 \mathrm{~s}$ after gelation. Predicting average molecular weights vs. time

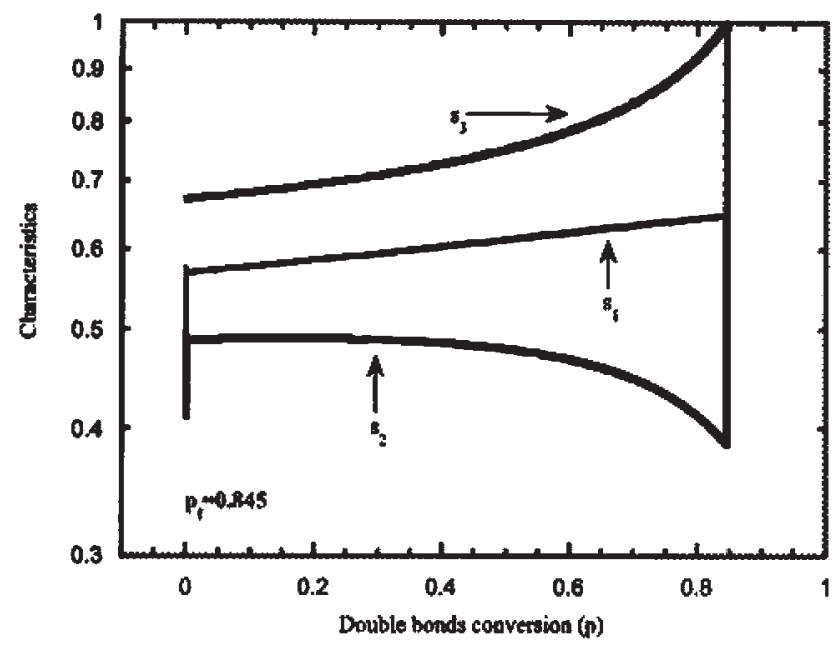

Figure 3. Profiles of $s_{1}, s_{2}$, and $s_{3}$ along the characteristics for system III at conversion of double bonds 0.845 .

before gelation is a much easier problem, only $17 \mathrm{~s}$ are needed for performing the whole computation.

Memory use reached $60 \%$ of the available; this is a likely bottleneck with more complex problems.

\section{Prediction of Sol Fraction and Average Molecular Weights}

Computing higher derivatives of Equation (19) with respect to $\log s_{j}$ yields a system of first-order partial differential equations sharing the same characteristics. In order to predict weight fraction of sol, the moments with respect to the numbers of units $A_{4}$ and $A_{5}$ must be known. They result

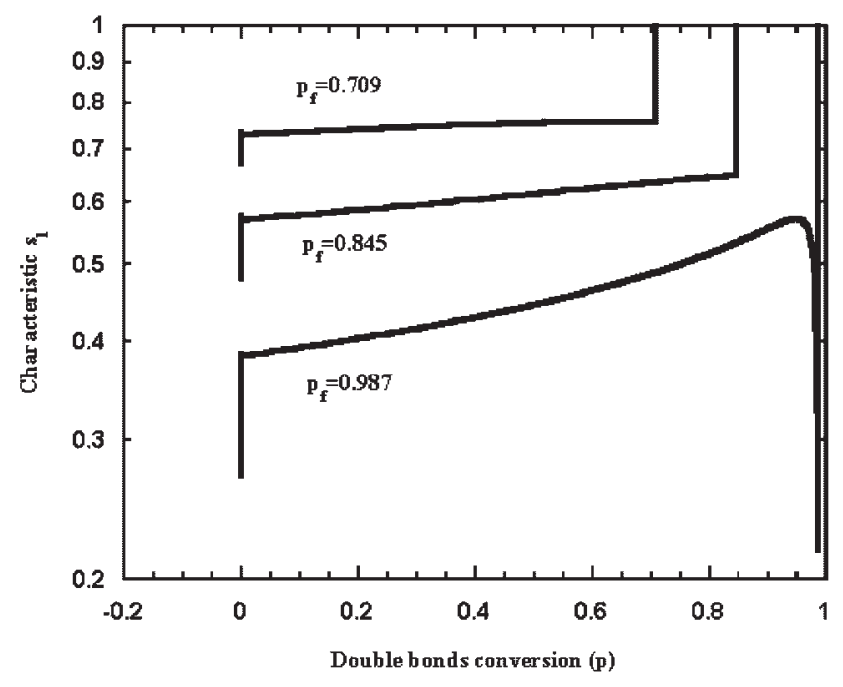

Figure 4. Profiles of $s_{1}$ along the characteristics for system III and different values of final conversion of double bonds. 
from integrating the two differential equations below along the characteristics:

$\frac{\mathrm{d} G_{4}}{\mathrm{~d} t}=k_{\mathrm{I}_{1}} R_{0} M_{1} s_{1}+k_{\mathrm{p}_{11}} G_{1} M_{1}+k_{\mathrm{p}_{21}} \frac{s_{1}}{s_{2}} G_{2} M_{1}$

$\frac{\mathrm{d} G_{5}}{\mathrm{~d} t}=k_{\mathrm{I}_{2}} s_{2} s_{3} R_{0} M_{2}+k_{\mathrm{p}_{12}} \frac{s_{2} s_{3}}{s_{1}} G_{1} M_{2}+k_{\mathrm{p}_{22}} s_{3} G_{2} M_{2}$

$G_{j \mid t=0}=0 \quad j=4,5$

Weight fraction of sol $w_{\mathrm{s}}$ is thus:

$w_{\mathrm{s}}=\frac{M_{M_{1}} G_{4}(\mathbf{1})+M_{M_{2}} G_{5}(\mathbf{1})}{M_{M_{1}}\left(M_{1_{0}}-M_{1}\right)+M_{M_{2}}\left(M_{2_{0}}-M_{2}\right)}$

Equation (43) and (44) must be integrated after successful convergence of the boundary value problem, which determines the characteristics. The solution vector of $s_{1}, s_{2}$, and $s_{3}$ on the grid points of the final mesh was stored in order to allow its interpolation at any value of time along the characteristics. The RADAU5 integrator could compute $G_{4}$ and $G_{5}$ as a succession of initial value problems (and afterwards higher-order derivatives, see below), preventing numerical "blow-up".

Results for systems I, II, and III are presented in Figure 5.

Number-average and weight-average molecular weights of sol are obtained through:

$\bar{M}_{\mathrm{n}}=\frac{M_{M_{1}} G_{4}(\mathbf{1})+M_{M_{2}} G_{5}(\mathbf{1})}{G(\mathbf{1})}$

$\bar{M}_{\mathrm{w}}=\frac{M_{M_{1}}^{2} G_{44}(\mathbf{1})+2 M_{M_{1}} M_{M_{2}} G_{45}(\mathbf{1})+M_{M_{2}}^{2} G_{55}(\mathbf{1})}{M_{M_{1}} G_{4}(\mathbf{1})+M_{M_{2}} G_{5}(\mathbf{1})}$

Molecular masses of monomers were chosen as $M_{M_{1}}=$ 104 and $M_{M_{2}}=130$ (same as styrene and divinylbenzene).

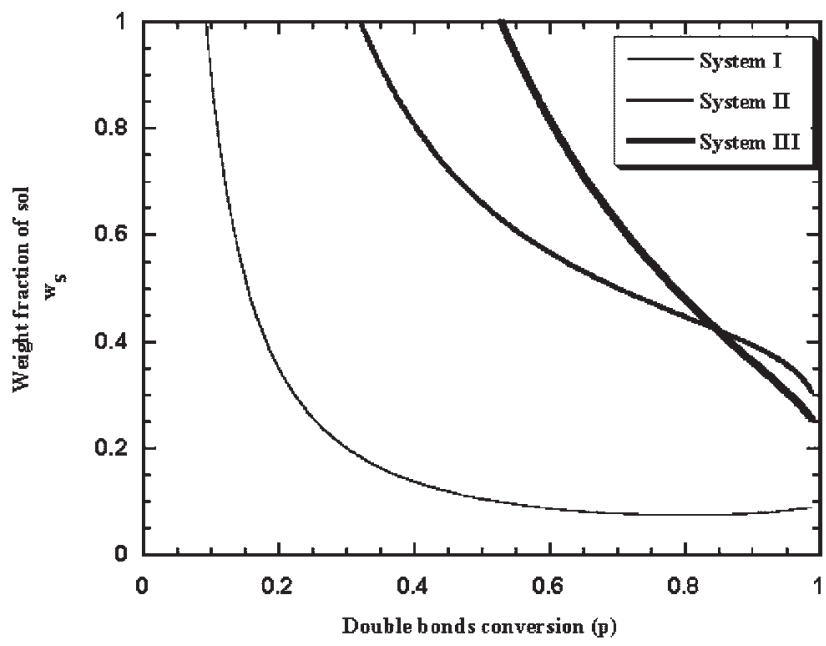

Figure 5. Fraction of sol vs. conversion of double bonds in batch polymerization of model systems I-III.
Average overall degrees of polymerization $\bar{x}_{\mathrm{n}}$ and $\bar{x}_{\mathrm{w}}$ can be obtained through Equation (47) and (48) setting molecular weights of monomers equal to 1 instead of their true values.

The system of ordinary differential equations to be integrated along characteristics in order to compute the second derivatives of $G$ (leading to the second-order moments of chain length distribution) is presented in Table 2.

Notice there is no need to use "closure assumptions" as in most proposed approximate methods. This is a consequence of not using the pseudo steady state hypothesis for radical concentrations.

Before gelation, the trivial branch $\mathbf{s}=\mathbf{1}$ is the correct solution of the two-point boundary value problem for characteristics, so it is only necessary to set the Laplace parameters $s_{j}$ equal to a constant value of 1 .

Numerical results for systems I-III are presented in Figure 6 and 7.

\section{Comparison with Predictions Using Tobita-Hamielec's Pseudo-Kinetic Rate Method}

A few approximate methods of prediction of average molecular weights and sol fraction in non-linear free radical polymerization have been proposed over the past few years. ${ }^{[14-17]}$ It is important to check those predictions with our new numerical method.

We have thus computed number-average and weightaverage molecular degrees of polymerization for systems I-III both before and after gelation using Tobita-Hamielec's pseudo-kinetic rate method ${ }^{[14,15]}$ (by far the fastest and easiest to implement) and the corresponding results are presented in Figure 8 and 9.

Agreement is fairly good for the "ideal" system I, except for high conversion.

However, for systems II and III, predicted gel points are rather different, and the curves for molecular weights and sol fraction diverge considerably from the more exact mathematical predictions developed in this paper. Moreover, we have found a slight inconsistency between pseudokinetic method predictions before and after gel point, which is especially conspicuous with system II, as can be observed in Figure 8 and 9b.

\section{Discussion}

The numerical technique presented here could yield a mathematical solution to modeling of simple non-linear free radical polymerizations with no need to use many simplifications with non-universal applicability, such as neglecting multifunctional radicals and using the pseudosteady state hypothesis. A less evident approximation is neglecting the fact that fragments of the same molecule come from gluing other molecules formed at possibly very 
Table 2. Equations of change of second order derivatives of $G$ along characteristics.

$$
\begin{aligned}
\frac{\mathrm{d} G_{11}}{\mathrm{~d} t}= & k_{\mathrm{I}_{1}} s_{1} R_{0} M_{1}+k_{\mathrm{p}_{12}} \frac{s_{2} s_{3}}{s_{1}} M_{2}\left(G_{1}-2 G_{11}\right)+k_{\mathrm{p}_{21}} \frac{s_{1}}{s_{2}} M_{1}\left(G_{2}+2 G_{12}\right) \\
& +k_{\mathrm{p}_{13}} \frac{s_{2}}{s_{1} s_{3}}\left(G_{1} G_{3}-2 G_{11} G_{3}-2 G_{13} G_{1}+2 G_{11} G_{13}\right)+2 \frac{k_{\mathrm{p}_{23}}}{s_{3}} G_{12} G_{13} \\
& +\frac{k_{\mathrm{tc}_{11}}}{s_{1}^{2}}\left(4 G_{1}^{2}-8 G_{11} G_{1}+2 G_{11}^{2}\right)+\frac{k_{\mathrm{tc}_{12}}}{s_{1} s_{2}}\left(G_{1} G_{2}-2 G_{11} G_{2}-2 G_{12} G_{1}+2 G_{11} G_{12}\right) \\
& +\frac{2 k_{\mathrm{tc}_{22}}}{s_{2}^{2}} G_{12}^{2}+2 \frac{k_{\mathrm{td}_{11}}}{s_{1}} A_{1}\left(G_{1}-2 G_{11}\right)+\frac{k_{\mathrm{td}_{12}}}{s_{1}} A_{2}\left(G_{1}-2 G_{11}\right)
\end{aligned}
$$

$$
\begin{aligned}
\frac{\mathrm{d} G_{12}}{\mathrm{~d} t}= & k_{\mathrm{I}_{3}} \frac{s_{2}}{s_{3}} R_{0} G_{13}+k_{\mathrm{p}_{12}} \frac{s_{2} s_{3}}{s_{1}} M_{2}\left(G_{11}-G_{21}-G_{1}\right)+k_{\mathrm{p}_{21}} \frac{s_{1}}{s_{2}} M_{1}\left(G_{22}-G_{12}-G_{2}\right) \\
& +k_{\mathrm{p}_{13}} \frac{s_{2}}{s_{1} s_{3}}\left(-G_{1} G_{3}-G_{21} G_{3}-G_{23} G_{1}+G_{11} G_{3}+G_{13} G_{1}+G_{11} G_{23}+G_{13} G_{21}\right) \\
& +\frac{k_{\mathrm{p}_{23}}}{s_{3}}\left(G_{12} G_{23}+G_{13} G_{22}\right)+\frac{k_{\mathrm{tc}} 11}{s_{1}^{2}}\left(2 G_{11} G_{21}-4 G_{21} G_{1}\right) \\
& +\frac{k_{\mathrm{tc}_{12}}}{s_{1} s_{2}}\left(G_{1} G_{2}-G_{21} G_{2}-G_{22} G_{1}-G_{11} G_{2}-G_{12} G_{1}+G_{11} G_{22}+G_{12} G_{21}\right) \\
& +\frac{k_{\mathrm{tc}_{22}}}{s_{2}^{2}}\left(2 G_{12} G_{22}-4 G_{12} G_{2}\right)-2 \frac{k_{\mathrm{td}_{11}}}{s_{1}} A_{1} G_{21}-k_{\mathrm{td}_{12}}\left(\frac{A_{2} G_{21}}{s_{1}}+\frac{A_{1} G_{12}}{s_{2}}\right)-2 \frac{k_{\mathrm{td}_{22}}}{s_{2}} A_{2} G_{12}
\end{aligned}
$$

$$
\begin{aligned}
\frac{\mathrm{d} G_{13}}{\mathrm{~d} t}= & -k_{\mathrm{I}_{3}} \frac{s_{2}}{s_{3}} R_{0} G_{13}+k_{\mathrm{p}_{12}} \frac{s_{2} s_{3}}{s_{1}} M_{2}\left(G_{11}-G_{31}-G_{1}\right)+k_{\mathrm{p}_{21}} \frac{s_{1}}{s_{2}} M_{1} G_{32}+k_{\mathrm{p}_{22}} s_{3} M_{2} G_{12} \\
& +k_{\mathrm{p}_{13}} \frac{s_{2}}{s_{1} s_{3}}\left(G_{1} G_{3}-G_{31} G_{3}-G_{33} G_{1}-G_{11} G_{3}-G_{13} G_{1}+G_{11} G_{33}+G_{13} G_{31}\right) \\
& +\frac{k_{\mathrm{p}_{23}}}{s_{3}}\left(-G_{12} G_{3}-G_{13} G_{2}+G_{12} G_{33}+G_{13} G_{32}\right) \\
& +\frac{k_{\mathrm{tc}_{11}}}{s_{1}^{2}}\left(2 G_{11} G_{31}-4 G_{31} G_{1}\right)+\frac{k_{\mathrm{tc}_{12}}}{s_{1} s_{2}}\left(-G_{31} G_{2}-G_{32} G_{1}+G_{11} G_{32}+G_{12} G_{31}\right) \\
& +2 \frac{k_{\mathrm{tc}_{22}}}{s_{2}^{2}} G_{12} G_{32}-2 \frac{k_{\mathrm{td}_{11}}}{s_{1}} A_{1} G_{31}-\frac{k_{\mathrm{td}_{12}}}{s_{1}} A_{2} G_{31}
\end{aligned}
$$

$$
\begin{aligned}
\frac{\mathrm{d} G_{14}}{\mathrm{~d} t}= & k_{\mathrm{I}_{1}} s_{1} R_{0} M_{1}+k_{\mathrm{p}_{11}} M_{1} G_{11}-k_{\mathrm{p}_{12}} \frac{s_{2} s_{3}}{s_{1}} M_{2} G_{41}+k_{\mathrm{p}_{21}} \frac{s_{1}}{s_{2}} M_{1}\left(G_{42}+G_{2}+G_{12}\right) \\
& +k_{\mathrm{p}_{13}} \frac{s_{2}}{s_{1} s_{3}}\left(G_{11} G_{43}+G_{13} G_{41}-G_{41} G_{3}-G_{43} G_{1}\right)+\frac{k_{\mathrm{p}_{23}}}{s_{3}}\left(G_{12} G_{43}+G_{13} G_{42}\right) \\
& +\frac{k_{\mathrm{tc}_{11}}}{s_{1}^{2}}\left(2 G_{11} G_{41}-4 G_{14} G_{1}\right)+\frac{k_{\mathrm{tc}_{12}}}{s_{1} s_{2}}\left(-G_{41} G_{2}-G_{42} G_{1}+G_{11} G_{42}+G_{12} G_{41}\right) \\
& +2 \frac{k_{\mathrm{tc}_{22}}}{s_{2}^{2}} G_{12} G_{42}-2 \frac{k_{\mathrm{td}_{11}}}{s_{1}} A_{1} G_{41}-\frac{k_{\mathrm{td}_{12}}}{s_{1}} A_{2} G_{41}
\end{aligned}
$$

$$
\begin{aligned}
\frac{\mathrm{d} G_{15}}{\mathrm{~d} t}= & k_{\mathrm{p}_{12}} \frac{s_{2} s_{3}}{s_{1}} M_{2}\left(G_{11}-G_{51}-G_{1}\right)+k_{\mathrm{p}_{21}} \frac{s_{1}}{s_{2}} M_{1} G_{52}+k_{\mathrm{p}_{22}} s_{3} M_{2} G_{12} \\
& +k_{\mathrm{p}_{13}} \frac{s_{2}}{s_{1} s_{3}}\left(G_{11} G_{53}+G_{13} G_{51}-G_{51} G_{3}-G_{53} G_{1}\right)+\frac{k_{\mathrm{p}_{23}}}{s_{3}}\left(G_{12} G_{53}+G_{13} G_{52}\right) \\
& +\frac{k_{\mathrm{tc}_{11}}}{s_{1}^{2}}\left(2 G_{11} G_{51}-4 G_{51} G_{1}\right)+\frac{k_{\mathrm{tc}_{12}}}{s_{1} s_{2}}\left(-G_{51} G_{2}-G_{52} G_{1}+G_{11} G_{52}+G_{12} G_{51}\right) \\
& +2 \frac{k_{\mathrm{tc}_{22}}}{s_{2}^{2}} G_{12} G_{52}-2 \frac{k_{\mathrm{td}_{11}}}{s_{1}} A_{1} G_{51}-\frac{k_{\mathrm{td}_{12}}}{s_{1}} A_{2} G_{51}
\end{aligned}
$$


Table 2. (Continued)

$$
\begin{aligned}
\frac{\mathrm{d} G_{22}}{\mathrm{~d} t}= & k_{\mathrm{I}_{2}} s_{2} s_{3} R_{0} M_{2}+k_{\mathrm{I}_{3}} \frac{s_{2}}{s_{3}} R_{0}\left(2 G_{23}+G_{3}\right)+k_{\mathrm{p}_{12}} \frac{s_{2} s_{3}}{s_{1}} M_{2}\left(2 G_{21}+G_{1}\right) \\
& +k_{\mathrm{p}_{21}} \frac{s_{1}}{s_{2}} M_{1}\left(G_{2}-2 G_{22}\right)+k_{\mathrm{p}_{13}} \frac{s_{2}}{s_{1} s_{3}}\left(G_{1} G_{3}+2 G_{21} G_{3}+2 G_{23} G_{1}+2 G_{21} G_{23}\right)+2 \frac{k_{\mathrm{p}_{23}}}{s_{3}} G_{22} G_{23} \\
& +\frac{2 k_{\mathrm{tc}_{11}}}{s_{1}^{2}} G_{21}^{2}+\frac{k_{\mathrm{tc}_{12}}}{s_{1} s_{2}}\left(G_{1} G_{2}-2 G_{21} G_{2}-2 G_{22} G_{1}+2 G_{21} G_{22}\right) \\
& +\frac{k_{\mathrm{tc}_{22}}}{s_{2}^{2}}\left(4 G_{2}^{2}-8 G_{22} G_{2}+2 G_{22}^{2}\right)+2 \frac{k_{\mathrm{td}_{12}}}{s_{2}} A_{1}\left(G_{2}-2 G_{22}\right)+\frac{2 k_{\mathrm{td}_{22}}}{s_{2}} A_{2}\left(G_{2}-2 G_{22}\right) \\
\frac{\mathrm{d} G_{23}}{\mathrm{~d} t}= & k_{\mathrm{I}_{2}} s_{2} s_{3} R_{0} M_{2}+k_{\mathrm{I}_{3}} \frac{s_{2}}{s_{3}} R_{0}\left(G_{33}-G_{23}-G_{3}\right)+k_{\mathrm{p}_{12}} \frac{s_{2} s_{3}}{s_{1}} M_{2}\left(G_{31}+G_{21}+G_{1}\right)-k_{\mathrm{p}_{21}} \frac{s_{1}}{s_{2}} M_{1} G_{32} \\
& +k_{\mathrm{p}_{22}} s_{3} M_{2} G_{22}+k_{\mathrm{p}_{13}} \frac{s_{2}}{s_{1} s_{3}}\left(-G_{1} G_{3}+G_{31} G_{3}+G_{33} G_{1}-G_{21} G_{3}-G_{23} G_{1}+G_{21} G_{33}+G_{23} G_{31}\right) \\
& +\frac{k_{\mathrm{p}_{23}}}{s_{3}}\left(-G_{22} G_{3}-G_{23} G_{2}+G_{22} G_{33}+G_{23} G_{32}\right)+\frac{2 k_{\mathrm{tc}_{11}}}{s_{1}^{2}} G_{21} G_{31}+\frac{k_{\mathrm{tc}_{22}}}{s_{2}^{2}} G_{32}\left(2 G_{22}-4 G_{2}\right) \\
& +\frac{k_{\mathrm{tc}_{12}}}{s_{1} s_{2}}\left(-G_{31} G_{2}-G_{32} G_{1}+G_{21} G_{32}+G_{22} G_{31}\right)-\frac{k_{\mathrm{td}_{12}}}{s_{2}} A_{1} G_{32}-\frac{2 k_{\mathrm{td}_{22}}}{s_{2}} A_{2} G_{32}
\end{aligned}
$$

$$
\begin{aligned}
\frac{\mathrm{d} G_{24}}{\mathrm{~d} t}= & k_{\mathrm{I}_{3}} \frac{s_{2}}{s_{3}} R_{0} G_{43}+k_{\mathrm{p}_{11}} M_{1} G_{21}+k_{\mathrm{p}_{12}} \frac{s_{2} s_{3}}{s_{1}} M_{2} G_{41}+k_{\mathrm{p}_{21}} \frac{s_{1}}{s_{2}} M_{1}\left(G_{22}-G_{42}-G_{2}\right) \\
& +k_{\mathrm{p}_{13}} \frac{s_{2}}{s_{1} s_{3}}\left(G_{41} G_{3}+G_{43} G_{1}+G_{21} G_{43}+G_{23} G_{41}\right)+\frac{k_{\mathrm{p}_{23}}}{s_{3}}\left(G_{22} G_{43}+G_{23} G_{42}\right) \\
& +\frac{2 k_{\mathrm{tc}_{11}}}{s_{1}^{2}} G_{21} G_{41}+\frac{k_{\mathrm{tc}_{12}}}{s_{1} s_{2}}\left(-G_{41} G_{2}-G_{42} G_{1}+G_{21} G_{42}+G_{22} G_{41}\right)+\frac{k_{\mathrm{tc}_{22}}}{s_{2}^{2}} G_{42}\left(2 G_{22}-4 G_{2}\right) \\
& -\frac{k_{\mathrm{td}_{12}}}{s_{2}} A_{1} G_{42}-\frac{2 k_{\mathrm{td}_{22}}}{s_{2}} A_{2} G_{42}
\end{aligned}
$$

$$
\begin{aligned}
\frac{\mathrm{d} G_{25}}{\mathrm{~d} t}= & k_{\mathrm{I}_{2}} s_{2} s_{3} R_{0} M_{2}+k_{\mathrm{I}_{3}} \frac{s_{2}}{s_{3}} R_{0} G_{53}+k_{\mathrm{p}_{12}} \frac{s_{2} s_{3}}{s_{1}} M_{2}\left(G_{51}+G_{21}+G_{1}\right)-k_{\mathrm{p}_{21}} \frac{s_{1}}{s_{2}} M_{1} G_{52} \\
& +k_{\mathrm{p}_{22}} s_{3} M_{2} G_{22}+k_{\mathrm{p}_{13}} \frac{s_{2}}{s_{1} s_{3}}\left(G_{51} G_{3}+G_{53} G_{1}+G_{21} G_{53}+G_{23} G_{51}\right)+\frac{k_{\mathrm{p}_{23}}}{s_{3}}\left(G_{22} G_{53}+G_{23} G_{52}\right) \\
& +\frac{2 k_{\mathrm{tc}_{11}}}{s_{1}^{2}} G_{21} G_{51}+\frac{k_{\mathrm{tc}_{12}}}{s_{1} s_{2}}\left(-G_{51} G_{2}-G_{52} G_{1}+G_{21} G_{52}+G_{22} G_{51}\right)+\frac{k_{\mathrm{tc}_{22}}}{s_{2}^{2}} G_{52}\left(2 G_{22}-4 G_{2}\right) \\
& -\frac{k_{\mathrm{td}_{12}}}{s_{2}} A_{1} G_{52}-\frac{2 k_{\mathrm{td}_{22}}}{s_{2}} A_{2} G_{52}
\end{aligned}
$$

$$
\begin{aligned}
\frac{\mathrm{d} G_{33}}{\mathrm{~d} t}= & k_{\mathrm{I}_{2}} s_{2} s_{3} R_{0} M_{2}+k_{\mathrm{I}_{3}} \frac{s_{2}}{s_{3}} R_{0}\left(G_{3}-2 G_{33}\right)+k_{\mathrm{p}_{12}} \frac{s_{2} s_{3}}{s_{1}} M_{2}\left(2 G_{31}+G_{1}\right) \\
& +k_{\mathrm{p}_{22}} s_{3} M_{2}\left(2 G_{32}+G_{2}\right)+k_{\mathrm{p}_{13}} \frac{s_{2}}{s_{1} s_{3}}\left(G_{1} G_{3}-2 G_{31} G_{3}-2 G_{33} G_{1}+2 G_{31} G_{33}\right) \\
& +\frac{k_{\mathrm{p}_{23}}}{s_{3}}\left(G_{2} G_{3}-2 G_{32} G_{3}-2 G_{33} G_{2}+2 G_{32} G_{33}\right)+\frac{2 k_{\mathrm{tc}_{11}}}{s_{1}^{2}} G_{31}^{2}+\frac{2 k_{\mathrm{tc}_{12}}}{s_{1} s_{2}} G_{31} G_{32}+\frac{2 k_{\mathrm{tc}_{22}}}{s_{2}^{2}} G_{32}^{2}
\end{aligned}
$$

$$
\begin{aligned}
\frac{\mathrm{d} G_{34}}{\mathrm{~d} t}= & -k_{\mathrm{I}_{3}} \frac{s_{2}}{s_{3}} R_{0} G_{43}+k_{\mathrm{p}_{11}} M_{1} G_{31}+k_{\mathrm{p}_{12}} \frac{s_{2} s_{3}}{s_{1}} M_{2} G_{41}+k_{\mathrm{p}_{21}} \frac{s_{1}}{s_{2}} M_{1} G_{32} \\
& +k_{\mathrm{p}_{22}} s_{3} M_{2} G_{42}+k_{\mathrm{p}_{13}} \frac{s_{2}}{s_{1} s_{3}}\left(G_{31} G_{43}+G_{33} G_{41}-G_{41} G_{3}-G_{43} G_{1}\right) \\
& +\frac{k_{\mathrm{p}_{23}}}{s_{3}}\left(G_{32} G_{43}+G_{33} G_{42}-G_{42} G_{3}-G_{43} G_{2}\right)+\frac{2 k_{\mathrm{tc}_{11}}}{s_{1}^{2}} G_{31} G_{41}+\frac{k_{\mathrm{tc}_{12}}}{s_{1} s_{2}}\left(G_{31} G_{42}+G_{32} G_{41}\right)+\frac{2 k_{\mathrm{tc}_{22}}}{s_{2}^{2}} G_{32} G_{42}
\end{aligned}
$$


Table 2. (Continued)

$$
\begin{aligned}
& \frac{\mathrm{d} G_{35}}{\mathrm{~d} t}=k_{\mathrm{I}_{2}} s_{2} s_{3} R_{0} M_{2}-k_{\mathrm{I}_{3}} \frac{s_{2}}{s_{3}} R_{0} G_{53}+k_{\mathrm{p}_{12}} \frac{s_{2} s_{3}}{s_{1}} M_{2}\left(G_{51}+G_{31}+G_{1}\right) \\
& +k_{\mathrm{p}_{22}} s_{3} M_{2}\left(G_{52}+G_{32}+G_{2}\right)+k_{\mathrm{p}_{13}} \frac{s_{2}}{s_{1} s_{3}}\left(G_{31} G_{53}+G_{33} G_{51}-G_{51} G_{3}-G_{53} G_{1}\right) \\
& +\frac{k_{\mathrm{p}_{23}}}{s_{3}}\left(G_{32} G_{53}+G_{33} G_{52}-G_{52} G_{3}-G_{53} G_{2}\right)+\frac{2 k_{\mathrm{tc}_{11}}}{s_{1}^{2}} G_{31} G_{51} \\
& +\frac{k_{\mathrm{tc}_{12}}}{s_{1} s_{2}}\left(G_{31} G_{52}+G_{32} G_{51}\right)+\frac{2 k_{\mathrm{tc}_{22}}}{s_{2}^{2}} G_{32} G_{52} \\
& \frac{\mathrm{d} G_{44}}{\mathrm{~d} t}=k_{\mathrm{I}_{1}} s_{1} R_{0} M_{1}+k_{\mathrm{p}_{11}} M_{1}\left(2 G_{41}+G_{1}\right)+k_{\mathrm{p}_{21}} \frac{s_{1}}{s_{2}} M_{1}\left(2 G_{42}+G_{2}\right) \\
& +2 k_{\mathrm{p}_{13}} \frac{s_{2}}{s_{1} s_{3}} G_{41} G_{43}+\frac{2 k_{\mathrm{p}_{23}}}{s_{3}} G_{42} G_{43}+\frac{2 k_{\mathrm{tc}_{11}}}{s_{1}^{2}} G_{41}^{2}+\frac{2 k_{\mathrm{tc}_{12}}}{s_{1} s_{2}} G_{41} G_{42}+\frac{2 k_{\mathrm{tc}_{22}}}{s_{2}^{2}} G_{42}^{2} \\
& \frac{\mathrm{d} G_{45}}{\mathrm{~d} t}=k_{\mathrm{p}_{11}} M_{1} G_{51}+k_{\mathrm{p}_{12}} \frac{s_{2} s_{3}}{s_{1}} M_{2} G_{41}+k_{\mathrm{p}_{21}} \frac{s_{1}}{s_{2}} M_{1} G_{52}+k_{\mathrm{p}_{22}} s_{3} M_{2} G_{42} \\
& +k_{\mathrm{p}_{13}} \frac{s_{2}}{s_{1} s_{3}}\left(G_{41} G_{53}+G_{43} G_{51}\right)+\frac{k_{\mathrm{p}_{23}}}{s_{3}}\left(G_{42} G_{53}+G_{43} G_{52}\right) \\
& +\frac{2 k_{\mathrm{tc}_{11}}}{s_{1}^{2}} G_{41} G_{51}+\frac{k_{\mathrm{tc}_{12}}}{s_{1} s_{2}}\left(G_{41} G_{52}+G_{42} G_{51}\right)+\frac{2 k_{\mathrm{tc}_{22}}}{s_{2}^{2}} G_{42} G_{52} \\
& \frac{\mathrm{d} G_{55}}{\mathrm{~d} t}=k_{\mathrm{I}_{2}} s_{2} s_{3} R_{0} M_{2}+k_{\mathrm{p}_{12}} \frac{s_{2} s_{3}}{s_{1}} M_{2}\left(2 G_{51}+G_{1}\right)+k_{\mathrm{p}_{22}} s_{3} M_{2}\left(2 G_{52}+G_{2}\right) \\
& +2 k_{\mathrm{p}_{13}} \frac{s_{2}}{s_{1} s_{3}} G_{51} G_{53}+\frac{2 k_{\mathrm{p}_{23}}}{s_{3}} G_{52} G_{53}+\frac{2 k_{\mathrm{tc}_{11}}}{s_{1}^{2}} G_{51}^{2}+\frac{2 k_{\mathrm{tc}_{12}}}{s_{1} s_{2}} G_{51} G_{52}+\frac{2 k_{\mathrm{tc}_{22}}}{s_{2}^{2}} G_{52}^{2}
\end{aligned}
$$

different times. There is no uniformity of link probabilities inside the same molecule (as would happen in equilibrium reversible polymerization) and description by a simple Markovian process, which could be treated by the theory of branching processes, is not exact. This is one of the main

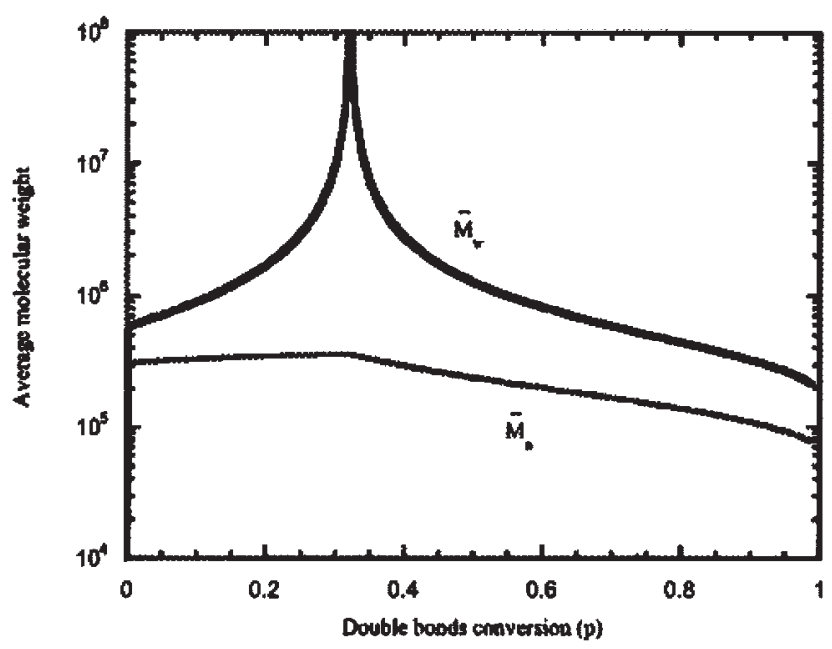

Figure 6. Number-average and weight-average molecular weights of sol in batch non-linear free radical polymerizations of model system II. alerts already formulated in ref. ${ }^{[1]}$ (only when gelation conversion is low should a good agreement with usual approximations be expected). It is no wonder that the pseudo-kinetic rate method fails to give an acceptable quantitative approximation of the behavior of molecular weight

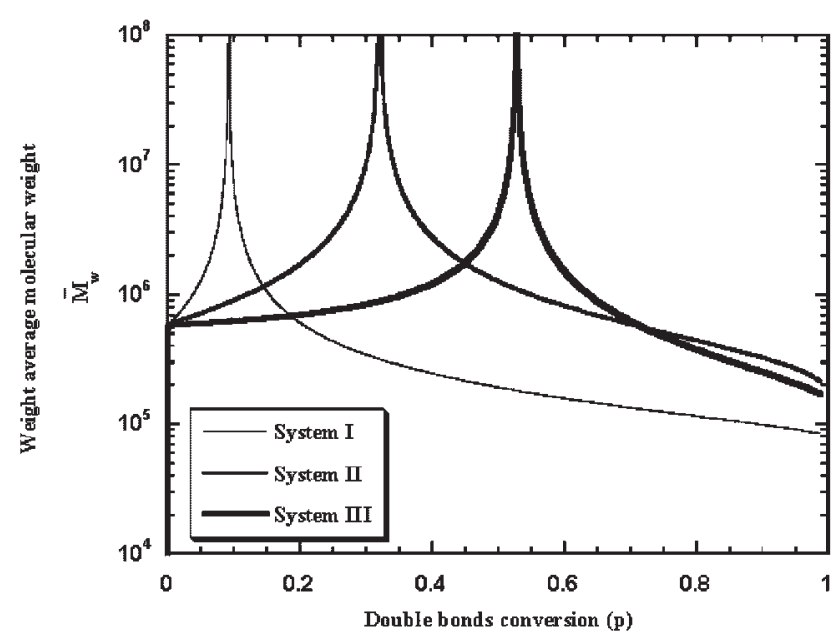

Figure 7. Weight-average molecular weights of sol in batch nonlinear free radical polymerizations of model systems I-III. 


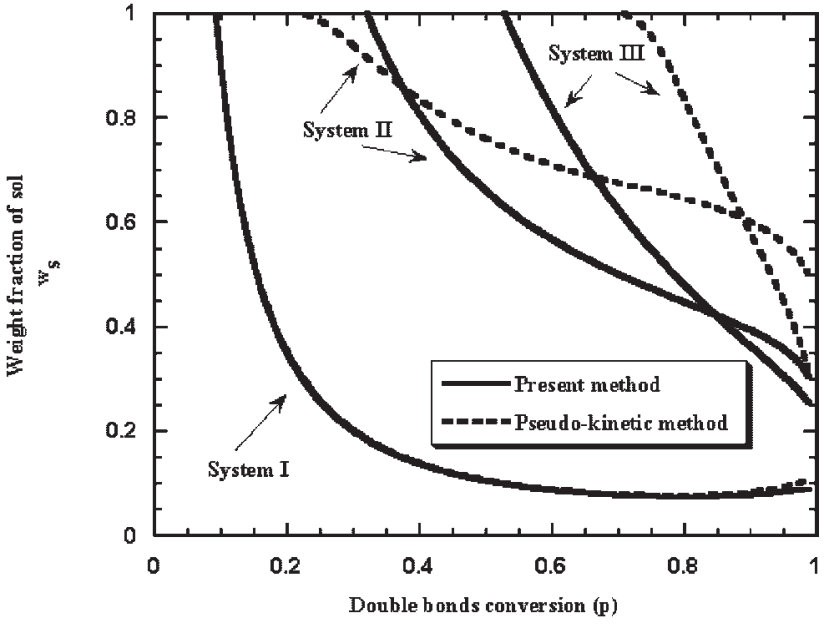

Figure 8. Comparison between predicted sol fraction in batch non-linear free radical polymerizations of model systems I-III according to Tobita-Hamielec's pseudo-kinetic method and our present approach.

or sol fraction changes along time in some circumstances, when reactivity ratios are very different from 1 .

Other researchers have described these and other polymerization systems staying in the domain of real chain lengths and aiming at obtaining if not the full multidimensional CLD, at least some of its marginal distributions, the prediction of average molecular weights becoming a "byproduct" of those computations.

Although, in theory, any distribution can be reconstructed from the knowledge of the infinite set of its moments, and this work has provided a way of computing them with comparatively little difficulty (before gelation), we do not recommend this procedure. Such Gram-Charlier series often converge slowly, and there is no way to guarantee the accuracy of the computations. A similar problem, the prediction of the shape of chromatographic peaks in linear chromatography, presents striking similarities. Villermaux ${ }^{[18]}$ proved a long time ago that numerical inversion of its Laplace transform is a fast and reliable way of solving the problem, in contrast to the series approximation. More recently, Tobita and Ito ${ }^{[19]}$ have also cast serious doubts concerning the usefulness of those series to represent the CLD of polymers.

There is no need ${ }^{[20]}$ to assume that chain length is a continuous variable, as suitable base functions of orthogonal polynomials of discrete variables can be found. But this approach faces serious problems when dealing with multidimensional distributions such as the ones discussed in these case studies: there are five kinds of groups which have to be counted for each set of isomeric polymer molecules, disregarding the way the units are connected. Indeed, commercial code PREDICI, using this principle, can only compute one-dimensional distributions. Nevertheless, with some adaptations ${ }^{[21]}$ (remembering Teymour's "numerical
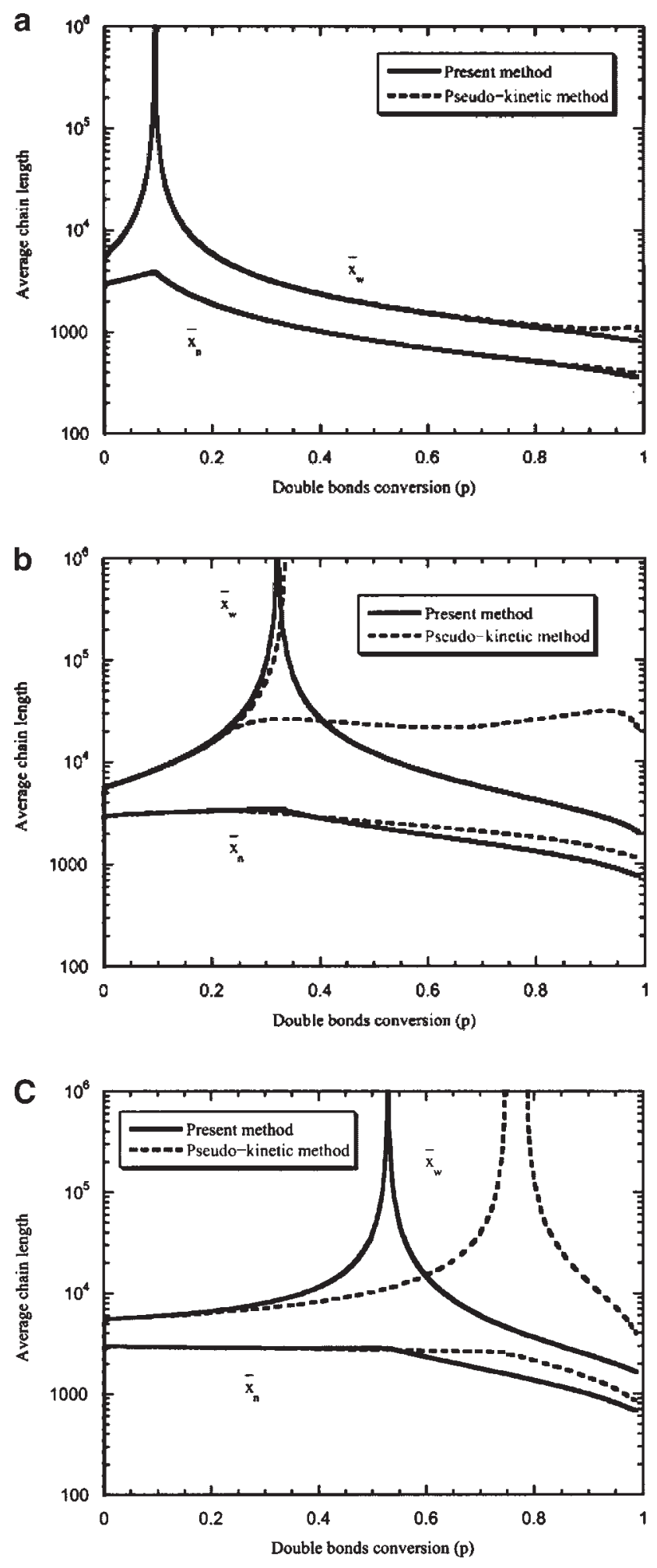

Figure 9. Comparison between predicted number-average and weight-average degrees of polymerization of sol in batch nonlinear free radical polymerizations of model systems I-III according to Tobita-Hamielec pseudo-kinetic method and present approach. (a) System I, (b) System II, (c) System III. 
fractionating" approach ${ }^{[16,22]}$ ) it could be used for modeling ethylene free radical polymerization.

Free radical polymerizations with very low concentrations of polyradicals (species with $a_{1}+a_{2}>1$ in our notation) might be amenable to a fairly accurate description with the help of the "numerical fractionating" concept. We doubt this could be valid for the kind of chemical systems discussed in this current work, but it remains an open question whether our suspicion is real.

Another possible solution for predicting CLD is the use of Monte Carlo simulation, widely used in the last decade by Tobita and Zhu. ${ }^{[23,24]}$ This approach presents some additional important advantages, such as the possibility of prediction of the distribution of molecular sizes (very difficult otherwise) or the analysis of reversible polymerization. Its main drawback lies in the computational resources needed for a reasonable accuracy. They are moderate for simple problems such as non-linear polycondensation modeling, but dealing with free-radical polymerization has been done using some approximations introduced in order to save computer time. The main difficulty lies in the very small time scales of the molecular weight growth by propagation, as compared to the time span needed to convert an appreciable amount of monomer. So, the objection raised before also applies: it is nearly as inaccurate as the theory of branching processes (no wonder that both give similar results), and a new Monte Carlo method taking care of that problem (unfortunately extremely slow) is yet to be attempted.

A comprehensive comparison with the proposed computational method would certainly be worthwhile, but it depends on the ability to drastically reduce its computing time requirements.

Nevertheless, prediction of CLD by Monte Carlo method or finite elements with the sole purpose of computing average molecular weights seems a waste of computer resources. It is unlikely that this can be done as efficiently for the same accuracy as with the present method.

Realistic models for non-linear free radical polymerization, introducing, for instance, intramolecular transfers and terminations giving rise to short sized rings, have to take into account a huge number of chemical groups. Thus, the number of variables of the system of characteristics will grow a lot and it may become quite demanding in computational resources (memory and computing speed). It can not be stated for the moment whether these problems will become easily tractable or not by the present approach, but we consider it to be worth the effort of pursuing this research in view of the first encouraging results just presented.

\section{Conclusions}

It has been possible for the first time to find a numerical solution for the equations describing the evolution of generating function of chain length distribution for nonlinear free-radical polymerization, assuming no chain length dependence of termination constant and no intramolecular reaction in finite molecules. Pseudo-steady hypothesis and other widespread simplifications are not required.

Sol fraction and number- and weight-average molecular weights were computed for monovinyl/divinyl polymerizations with different reactivity ratios.

A computer with a single Intel PIV $1.5 \mathrm{GHz}$ with $512 \mathrm{Mb}$ using public domain software was enough for solving these rather simple problems, but memory use was $60 \%$ of the available, and a more powerful machine seems needed for most systems of practical interest.

A comparison with Tobita-Hamielec's pseudo-kinetic method showed minor differences for the ideal equal reactivity system, but discrepancies are important when reactivity ratios become very different from 1 .

Acknowledgement: We acknowledge financial support by Fundação da Ciência e Tecnologia through programs Praxis (proposal 3/3.1/CEG/2525/95) and POCTI.

[1] S. I. Kuchanov, L. M. Pis'men, Vysokomol. Soyed. 1971, A13, 2035.

[2] M. R. P. F. N. Costa, R. C. S. Dias, Chem. Eng. Sci. 1994, 49, 491.

[3] M. R. P. F. N. Costa, R. C. S. Dias, "New Developments in Kinetical Modeling of Complex Non-linear Polymerizations", in: 5th International Workshop on Polymer Reaction Engineering, K. H. Reichert, H.-U. Moritz, Eds., VCH, Weinheim 1995, pp. 523-530.

[4] R. Courant, D. Hilbert, "Methods of Mathematical Physics, Vol. II-Partial Differential Equations", 1st edition, WileyInterscience, New York 1962, pp. 97-105.

[5] P. Deuflhard, F. Bornemann, "Scientific Computing with Ordinary Differential Equations", 1st edition, Springer, New York 2002, p. 390.

[6] E. Hairer, G. Wanner, "Solving Ordinary Differential Equations II', 2nd revised edition, Springer, New York 2002, p. 1.

[7] U. Ascher, L. R. Petzold, "Computer Methods for Ordinary Differential and Differential-Algebraic Equations", 1st edition, SIAM 1998, pp. 50-51.

[8] E. Hairer, G. Wanner, "Solving Ordinary Differential Equations II', 2nd revised edition, Springer, New York 2002, pp. 566-574.

[9] H. B. Keller, "Numerical Methods for Two-Point BoundaryValue Problems", 2nd edition, Dover, Mineola, New York 1992, pp. 61.

[10] J. R. Cash, G. Moore, R. W. Wright, J. Comp. Phys. 1995, 122, 266.

[11] Z. Bashir-Ali, J. R. Cash, H. H. M. Silva, Comput. Math. Appl. 1998, 36, 59. 
[12] J. R. Cash, G. Moore, R. W. Wright, ACM Trans. Math. Soft. 2001, 27, 245.

[13] G. Moad, D. H. Solomon, "The Chemistry of Free Radical Polymerization", 1st edition, Elsevier, New York 1995, pp. 191 and 209.

[14] H. Tobita, A. E. Hamielec, Macromolecules 1989, 23, 3098.

[15] H. Tobita, A. E. Hamielec, "Crosslinking Kinetics in FreeRadical Copolymerization", in: 3rd International Workshop on Polymer Reaction Engineering, K. H. Reichert, W. Geiseler, Eds., VCH, Weinheim 1989, pp. 43-83.
[16] F. Teymour, J. D. Campbell, Macromolecules 1994, 27, 2460.

[17] H. Tobita, Macromol. Theory Simul. 1998, 7, 675.

[18] J. Villermaux, J. Chromatogr. 1973, 83, 205.

[19] H. Tobita, K. Ito, Polym. React. Eng. 1993, 1, 407.

[20] U. Budde, M. Wulkow, Chem. Eng. Sci. 1991, 46, 497.

[21] P. D. Iedema, M. Wulkow, H. C. J. Hoefsloot, Macromolecules 2000, 33, 7173.

[22] P. Pladis, C. Kiparissides, Chem. Eng. Sci. 1998, 53, 3315.

[23] H. Tobita, J. Polym. Sci., Part B: Polym. Phys. 1993, 31, 1363.

[24] H. Tobita, S. Zhu, J. Polym. Sci., Part B: Polym. Phys. 1996, 34, 2099. 


\title{
Chemical Engineering Science
}

ELSEVIER

Chemical Engineering Science 60 (2005) 423-446

www.elsevier.com/locate/ces

\section{An improved general kinetic analysis of non-linear irreversible polymerisations}

\author{
Mário Rui P.F.N. Costa ${ }^{\mathrm{a}, *}$, Rolando C.S. Dias ${ }^{\mathrm{b}}$ \\ ${ }^{a}$ LSRE - Fac. Eng. Univ. Porto, Departamento de Eng. Química, R. Roberto Frias, 4200-465 Porto Codex, Portugal \\ ${ }^{\mathrm{b}}$ LSRE - Instituto Politécnico de Bragança, Quinta de S. Apolónia, 5300 Bragança, Portugal
}

Received 23 June 2003; received in revised form 30 June 2004; accepted 27 July 2004

Available online 7 October 2004

\begin{abstract}
A method to predict average molecular weights before and after gelation for general irreversible non-linear polymerisations forming tree-like molecules is described. Recently developed numerical methods for solving two point boundary value problems are essential for the success of these calculations after gelation and open the way to eventually be able to efficiently predicting chain length distributions. Anionic and free-radical polymerisation of vinyl monomers in the presence of divinyl monomers or with transfer to polymer are taken as case studies. Comparison to experimental data and with simulation results obtained through "numerical fractionation" confirms the usefulness of current approach.
\end{abstract}

(C) 2004 Elsevier Ltd. All rights reserved.

Keywords: Polymerisation; Kinetics; Modelling; Gels; Free radical; Anionic

\section{Introduction}

Since more than one decade a few modelling schemes of general polymerisation reactions and reactors have been proposed. Following Villermaux and Blavier (1984), their development has been pursued by, among others, Ray and collaborators (Ray, 1991; Saldivar and Ray, 1995) and Kiparissides and collaborators (Achilias and Kiparissides, 1992; Konstadinides et al., 1992). Fairly general kinds of polymerisations (radical copolymerisations, linear polycondensations and polyadditions ...) have been treated using kinetic approaches, with the aim of giving to engineers and scientists a faster and less error-prone way of dealing with the complex systems which occur in practice. Commercial software packages have been using these principles since more than one decade.

The kinetic approach for modelling irreversible non-linear polymerisations which has been independently developed

\footnotetext{
${ }^{*}$ Corresponding author. Fax: +351-225-081-666.

E-mail addresses: mrcosta@fe.up.pt (M.R.P.F.N. Costa), rdias@ipb.pt (R.C.S. Dias).
}

by the present authors (Costa and Dias, 1994) shares similar objectives with the above cited lines of thought and is also based in the numerical solution of species conservation equations, but it tries in addition to:

- deal with more general classes of irreversible polymerisations;

- eliminate unwanted assumptions such as the pseudosteady state hypothesis, neglect of multi-radicals or multiple growth centres in general and small ring formation;

- take into account the presence of gel;

- provide ways of efficiently computing molecular weight distributions, molecular average radius of gyration and gel properties.

Its two more distinctive peculiarities reside in the simultaneous use of a description based on sets of stoichiometric coefficients and numerical computation of moment generating functions. It is the combination of the two which makes the originality and strength of this approach: isolated uses of either technique were previously known and are more widespread. 
There is a problem with the easiness of use of the previously defined stoichiometric relations with polyadditions. Therefore, a thorough revision of its basic notation has been carried out in order to improve its numerical performance and applicability to other polymerisation schemes, a task which has been started in a previous work (Costa and Dias, 1995). Prediction of gel properties related to elastic properties and the prediction of $z$-average molecular radius of gyration of polymer molecules (Costa and Dias, 1998) will not here be described in order to keep this presentation within a manageable size.

The whole approach would be close to useless should the equations for the moment generating functions become intractable. Numerical solution of non-linear free radical polymerisation models do present severe problems, which only recently (Costa and Dias, 2003) could be overcome. A general procedure for solving the resulting equations should therefore be considered an essential component of this method in order to make possible its widespread use.

Numerical inversion of moment generating functions of discrete probability distributions or $z$-transforms has also been known (Mills, 1986; Costa and Villermaux, 1988) to be useful for obtaining chain length distributions (CLD) with polycondensations and some non-radical polyadditions (Costa and Dias, 1995). An analysis of its truncation and round-off errors (Abate and Whitt, 1992) shows this is a reliable method. Still, when average chain length increases, it becomes too slow, as it requires as many values of the transform or generating function as the upper value of chain length where distribution is to be evaluated. A better algorithm is needed to deal with that situation. It has been suggested (Abate and Whitt, 1992) that determination of the asymptotic behaviour of the distribution should be tried. This would require finding the singularities of the generating function closer to the origin, or Hayman's method (Hayman, 1956) in case they do not exist. A practical way to do it with numerically estimated generating functions is yet to be found.

In recent years, some researchers have developed the use of Laplace transforms, the continuous counterpart of discrete moment generating functions or $z$-transforms, aiming at computing CLD. After Miller et al. (1996) have shown the potential of this method, Sarmoria and collaborators have been using it in process modelling of polyolefines viscosity breaking by peroxides (Asteasuain et al., 2002a) and both linear (Asteasuain et al., 2004) and branched (Brandolin et al., 2002) simple free radical polymerisations.

There is some convergence of the above described approach with the methods described in this paper, but considerable differences in the mathematical treatments are also conspicuous: a continuous variable approximation is introduced, and partial differential equations are solved using discretisation in dummy Laplace variables, avoiding the method of characteristics. No way to compute CLD in the presence of gel is presented either.
A thorough comparison of the performances of these approaches is certainly worth doing, but is outside the scope of this paper.

Whatever the detailed mathematical approach is used, manipulation of mass balance equations of polymer species is a tedious and error-prone task. The same way as it is possible now to solve fairly complex mathematical problems using commercial packages or open-source programs like Octave, it would be interesting to develop some sort of interpreter of polymerisation schemes. It is hoped that the methods here described can pave the way to such a development.

\section{Statistical description of polymer molecular structure}

\subsection{Nomenclature of groups}

Chemical groups in polymer molecules, as well as monomers, initiators, transfer agents, by-products of polymerisation (such as water liberated in polyesterification reactions), and all other non-polymer molecules, are given the common name $A_{n}$, with $n=1, N_{A}$. Their mole concentration will also be called $A_{n}$. A subset of these comprises the $N_{Y}$ monomers $Y_{1} \ldots Y_{N_{Y}}$.

For each of the monomers there is a corresponding repeating unit (RU) $X_{1} \ldots X_{N_{Y}}$.

Each RU is supposed to contain some root group (RG), to which all other groups in polymer belonging to same RU are directly attached. Root groups are not changed by chemical reaction.

So, degree of polymerisation is the count of RG per molecule.

Besides RG, other examples of polymer groups include the repeating units and any side or main chain groups formed by chemical reaction. A total of $N_{P}$ groups comprises the chemical moieties belonging to polymer molecules.

A sub-set of those $N_{P}$ groups, the active $N_{A_{P}}$ polymer groups, are consumed by chemical reaction.

This notation provides the means of adding new groups and reactions to a polymerisation scheme without disrupting the results previously obtained with a scheme with less groups and reactions.

Our first examples (case studies I and II) are based upon the $n$-butyllithium (or any monofunctional lithium alkyl or aryl) initiated anionic copolymerisation of styrene $\left(Y_{1}\right)$ and $m$ - or $p$-divinylbenzene $\left(Y_{2}\right)$ with ethylbenzene $(S)$ as the solvent.

After a few fundamental studies on its chemical kinetics (Worsfold, 1970; Eschwey and Burchard, 1975) have been carried out, this system was later found to be useful as a model for RIM encapsulation of electronic parts (Your et al., 1989; Christiansen et al., 1990; Karles et al., 1991).

The initiator and the $n$-butyl fragment are groups $A_{1}$ and $A_{2}$ (see Table 3). Styrene monomer $\left(Y_{1}\right.$ or $\left.A_{3}\right)$ is associated to a root group $X_{1}$ (or $A_{4}$ ), which can be identified as the pending phenyl group. 
The 1,1,2-ethanetriyl carbanion with its lithium countercation is an active group belonging to polymer $\left(A_{5}\right)$, while the ethylene group formed after propagation is an example of an inactive group in $\operatorname{polymer}\left(A_{6}\right)$.

Copolymerisation with $m$ - or $p$-divinylbenzene $\left(Y_{2}\right)$ introduces the divinyl monomer as a new chemical group not belonging to polymer $\left(A_{7}\right)$. It is associated to a new root group $\left(A_{8}\right)$, a phenylene group.

For $p$-divinylbenzene, kinetic measurements (Worsfold, 1970; Karles et al., 1991) show that the pending vinyl group is about 10 times less reactive than the initial one, and about as reactive as the vinyl groups in styrene and $m$ divinylbenzene. On the contrary, anion reactivities look more or less similar.

So, in case study I, the divinyl monomer will be the meta isomer, so that its lithium anion can be lumped with the lithium anion of styrene into a single anion group $A_{5}$. The same assumptions were used in Flory's classical analysis of non-linear polyadditions (Flory, 1953).

Another active polymer group is the pendant vinyl group A9.

This "ideal" living anionic homopolymerisation styrene/mdivinylbenzene would therefore be described by a set of $N_{A}=9$ groups, from which $N_{P}=6$ belong to polymer ("groups" 1,3 and 7 are chemical compounds, the initiator and monomers styrene and $m$-divinylbenzene). Two active polymer group exist $\left(A_{5}\right.$ and $\left.A_{9}\right)$ and so $N_{A_{P}}=2$.

In case study II, lithium 1,1,2-ethanetriyl anion is a new active group in polymer $A_{10}$. A few secondary reactions (transfer to solvent, termination and transfer through hydride elimination) are also taken into account. The overall number of groups increases now to $N_{A}=18, N_{P}=$ 12 of them belonging to polymer, of which $N_{A_{P}}=5$ are active.

In case study III, free radical copolymerisation of a monovinyl monomer with a divinyl monomer is considered. Styrene copolymerisations with $m$ - and $p$-divinylbenzene, as well as ethylene dimethacrylate and diisopropenylbenzene have been extensively investigated before and after gelation (Hild and Okasha, 1985a,b; Hild et al., 1985) and will be here briefly discussed.

Case study IV is the free radical polymerisation of a single vinyl monomer with transfer to polymer in a batch reactor. This is a classical problem in non-linear free radical polymerisations (Bamford and Tompa, 1954) which has been analysed in the past by the method of the moments (Tobita and Hamielec, 1988) and "numerical fractionation" (Teymour and Campbell, 1994).

\subsection{Molecular chain length and mass distributions}

The vector with $N_{A}$ components containing the counts of groups $A_{1} \ldots A_{N_{A}}$ in a given polymer molecule $P_{m}$, with $m$ being some arbitrary index, will be named $\mathbf{a}_{m}$.
The $N_{A}-N_{P}$ components $a_{j}$ such that $\delta_{P_{j}}=0$ will always be nil and their storage should be avoided in a computational implementation.

The ensemble of molecular trees with same vectors of numbers of groups will be named $P\left(a_{m}\right)$, with mole concentration written as $P\left(\mathbf{a}_{m}\right)$. Letting the counting variable $m$ sweep all natural numbers, an overall mole concentration $P(\mathbf{a})$, is obtained.

$P(\mathbf{a}) / P$ is also the probability function of the number chain length distribution (NCLD) of polymer molecules. We will rather use the mole concentration distribution without normalising by $P$.

Most of the times its vectorial moment generating function $G(\mathbf{s})$ instead of its real counterpart will be used:

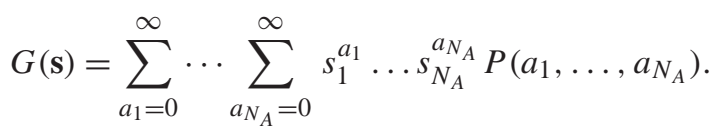

As the $N_{A}-N_{P}$ components $s_{j}$ such that $\delta_{P_{j}}=0$ are useless, they will be considered equal to 1 . The molecular mass $M_{m}$ of a generic molecule $P\left(\mathbf{a}_{m}\right)$ is obtained from the molecular masses of the groups it contains:

$M_{m}=\sum_{j=1}^{N_{A}} a_{j_{m}} M_{A_{j m}}$.

Number molecular mass distribution (NMMD) of polymer molecules is related to the NCLD by introducing its moment generating function, as shown in Table 1. Some widely used average molecular masses are defined as the ratios of integer moments relative to molecular mass, obtained by differentiation of $G$, and are thus related to the moments relative to the numbers of groups.

A convenient notation for those moments adapts the index convention for partial derivatives, leading to expressions like those below, using the abbreviation $\mathbf{1}_{N}$ for a vector of $N$ components all equal to 1 :

$$
\begin{aligned}
\lambda_{n \ldots p} & =\sum_{a_{1}=0}^{\infty} \ldots \sum_{a_{N_{A}}=0}^{\infty} a_{n} \ldots a_{p} P(\mathbf{a}) \\
& =\frac{\partial \ldots \partial G}{\partial \log s_{n} \ldots \partial \log s_{p}}\left(\mathbf{1}_{N_{A}}\right) \\
& =G_{n \ldots p}\left(\mathbf{1}_{N_{A}}\right)
\end{aligned}
$$

Oth order moment is simply $\lambda_{0}$. Moments with any index $j$ such that $\delta_{P_{j}}=0$ are obviously nil.

Well-known definitions of number, weight and $z$-average molecular masses make use of lower integer moments of NMMD, and can thus be computed as further shown in Table 1 .

\subsection{Kinetic description of polymer formation}

A classification of chemical reactions will be next introduced according to their effects on the number and kind of 
Table 1

Summary of notation describing molecular mass distributions

\begin{tabular}{|c|c|}
\hline Variable & Mathematical definition \\
\hline Moment generating function of number molecular mass distribution (NMMD) & $G\left(s_{M}\right)=\sum_{m=1}^{\infty} s_{M}^{M_{m}} P\left(M_{m}\right)=G\left(s_{M}^{M_{A_{1}}}, \ldots, s_{M}^{M_{A_{N}}}\right)$ \\
\hline First-order moment of NMMD & $\lambda_{M}=\sum_{n=1}^{N_{A}} M_{A_{n}} \lambda_{n}$ \\
\hline Second-order moment of NMMD & $\lambda_{M M}=\sum_{m=1}^{N_{A}} \sum_{n=1}^{N_{A}} M_{A_{m}} M_{A_{n}} \lambda_{m n}$ \\
\hline Third-order moment of NMMD & $\lambda_{M M M}=\sum_{l=1}^{N_{A}} \sum_{m=1}^{N_{A}} \sum_{n=1}^{N_{A}} M_{A_{l}} M_{A_{m}} M_{A_{n}} \lambda_{l m n}$ \\
\hline Number-average molecular mass & $\bar{M}_{n}=\frac{\lambda_{M}}{\lambda_{0}}$ \\
\hline Weight-average molecular mass & $\bar{M}_{w}=\frac{\lambda_{M M}}{\lambda_{M}}$ \\
\hline$z$-average molecular mass & $\bar{M}_{z}=\frac{\lambda_{M M M}}{\lambda_{M M}}$ \\
\hline
\end{tabular}

Table 2

Summary of notation describing polymerisation reactions

\begin{tabular}{|c|c|c|c|}
\hline Reaction description & Number & Rate constant & Net change of number of polymer molecules \\
\hline $\begin{array}{l}\text { Polymer/polymer propagations, } \\
\text { condensations or terminations }\end{array}$ & $N_{R_{P}}$ & $\begin{array}{l}k_{n} \\
n=1, N_{R_{P}}\end{array}$ & -1 \\
\hline Polymer/monomer propagations & $N_{R}-N_{R_{P}}$ & $\begin{array}{l}k_{n} \\
n=N_{R_{P}}+1, N_{R}\end{array}$ & 0 \\
\hline Unimolecular reactions of polymer & $N_{R_{P}}^{*}$ & $\begin{array}{l}k_{n}^{*} \\
n=1, N_{R_{P}}^{*}\end{array}$ & 0 \\
\hline Unimolecular reactions & $N_{R}^{*}-N_{R_{P}}^{*}$ & $\begin{array}{l}k_{n}^{*} \\
n=N_{R_{P}}^{*}+1, N_{R}^{*}\end{array}$ & 0 \\
\hline $\begin{array}{l}\text { Polymer/polymer reactions, no new } \\
\text { connections between RU }\end{array}$ & $N_{R_{P}}^{* *}$ & $\begin{array}{l}k_{n}^{* *} \\
n=1, N_{R_{P}}^{* *}\end{array}$ & 0 \\
\hline $\begin{array}{l}\text { Polymer/non-polymer reactions, no } \\
\text { new connections between RU }\end{array}$ & $N_{R_{S}}^{* *}$ & $\begin{array}{l}k_{n}^{* *} \\
n=N_{R_{P}}^{* *}+1, N_{R_{P}}^{* *}+N_{R_{S}}^{* *}\end{array}$ & 0 \\
\hline $\begin{array}{l}\text { Non-polymer/non-polymer reactions, } \\
\text { without creation of new polymer } \\
\text { molecules }\end{array}$ & $N_{S}$ & $\begin{array}{l}k_{n}^{* *} \\
n=N_{R_{P}}^{* *}+N_{R_{S}}^{* *}+1, N_{R}^{* *}\end{array}$ & 0 \\
\hline Bimolecular initiations & $N_{I}$ & $\begin{array}{l}k_{I_{n}} \\
n=1, N_{I}\end{array}$ & 1 \\
\hline Transfers to monomers & $N_{M}$ & $\begin{array}{l}k_{M_{n}} \\
n=1, N_{M}\end{array}$ & 1 \\
\hline
\end{tabular}

polymer molecules. Table 2 summarises the notations here used. Some reactions (propagation, termination or end group linking) create connections between repeating units and thus lead to an increase of molecular mass. A total of $N_{R}$ such reactions are supposed to create connection between RU.

First $N_{R_{P}}$ reactions of this class are supposed to involve only groups present in polymer molecules. So, they cause the net disappearance of a polymer molecule.
The other $N_{R}-N_{R_{P}}$ reactions occur between a group belonging to a polymer molecule and a non-polymeric molecule. Therefore, the overall number of polymer molecules is conserved. Tables 3 and 4 summarize the descriptions of groups in cases I and II respectively.

In case study I, $N_{R_{P}}=1$ (propagation over pending double bonds in polymer), while another 2 involve a monomer and a polymer anion (Table 5); in case study II, as reactivities of 
Table 3

Description of groups in a simplified model of anionic copolymerisation of styrene with $m$-divinylbenzene (case study I)

\begin{tabular}{|c|c|c|c|c|c|c|}
\hline Group description & $n$ & $\delta_{P_{j}}$ & $\delta_{A_{j}}$ & Alias & Chemical formula & $M_{A_{n}}$ \\
\hline$n$-butyllithium & 1 & 0 & 0 & $I$ & $\mathrm{LiC}_{4} \mathrm{H}_{9}$ & 64 \\
\hline Initiator fragment & 2 & 1 & 0 & & $-\mathrm{C}_{4} \mathrm{H}_{9}$ & 57 \\
\hline Styrene & 3 & 0 & 0 & $Y_{1}$ & $\mathrm{CH}_{2}=\mathrm{CHC}_{6} \mathrm{H}_{5}$ & 104 \\
\hline Phenyl in RG styryl & 4 & 1 & 0 & $X_{1}$ & $-\mathrm{C}_{6} \mathrm{H}_{5}$ & 77 \\
\hline Lithium carbanion & 5 & 1 & 1 & & $-\mathrm{CH}_{2} \mathrm{CH}^{-}(\ldots) \mathrm{Li}^{+}$ & 34 \\
\hline 1,1,2-ethanetriyl & 6 & 1 & 0 & & $-\mathrm{CH}_{2} \mathrm{CH}<$ & 27 \\
\hline$m$-divinylbenzene (DVB) & 7 & 0 & 0 & $Y_{2}$ & $\left(\mathrm{CH}_{2}=\mathrm{CH}\right)_{2} \mathrm{C}_{6} \mathrm{H}_{4}$ & 130 \\
\hline Phenylene in RG from DVB & 8 & 1 & 0 & $X_{2}$ & $-\mathrm{C}_{6} \mathrm{H}_{4}-$ & 76 \\
\hline Pendant vinyl group in polymer & 9 & 1 & 1 & & $-\mathrm{CH}=\mathrm{CH}_{2}$ & 27 \\
\hline
\end{tabular}

Table 4

Description of groups in anionic copolymerisation of styrene with a divinylbenzene (case study II)

\begin{tabular}{|c|c|c|c|c|c|c|}
\hline Group description & $n$ & $\delta_{P_{j}}$ & $\delta_{A_{j}}$ & Alias & Chemical formula & $M_{A_{n}}$ \\
\hline$n$-butyllithium & 1 & 0 & 0 & \multirow[t]{2}{*}{$I$} & $\mathrm{LiC}_{4} \mathrm{H}_{9}$ & 64 \\
\hline Initiator fragment & 2 & 1 & 0 & & $-\mathrm{C}_{4} \mathrm{H}_{9}$ & 57 \\
\hline Styrene & 3 & 0 & 0 & $Y_{1}$ & $\mathrm{CH}_{2}=\mathrm{CHC}_{6} \mathrm{H}_{5}$ & 104 \\
\hline Phenyl in RG styryl & 4 & 1 & 0 & \multirow[t]{3}{*}{$X_{1}$} & $-\mathrm{C}_{6} \mathrm{H}_{5}$ & 77 \\
\hline Lithium carbanion from styrene & 5 & 1 & 1 & & $-\mathrm{CH}_{2} \mathrm{CH}^{-}(\ldots) \mathrm{Li}^{+}$ & 34 \\
\hline 1,1,2-ethanetriyl & 6 & 1 & 0 & & $-\mathrm{CH}_{2} \mathrm{CH}<$ & 27 \\
\hline$p$-divinylbenzene (DVB) & 7 & 0 & 0 & $Y_{2}$ & $\left(\mathrm{CH}_{2}=\mathrm{CH}\right)_{2} \mathrm{C}_{6} \mathrm{H}_{4}$ & 130 \\
\hline Phenylene in RG from DVB & 8 & 1 & 0 & \multirow[t]{4}{*}{$X_{2}$} & $-\mathrm{C}_{6} \mathrm{H}_{4}-$ & 76 \\
\hline Pendant vinyl group in polymer & 9 & 1 & 1 & & $-\mathrm{CH}=\mathrm{CH}_{2}$ & 27 \\
\hline Lithium carbanion from DVB & 10 & 1 & 1 & & $-\mathrm{CH}_{2} \mathrm{CH}^{-}(\ldots-) \mathrm{Li}^{+}$ & 34 \\
\hline Terminal ethylene & 11 & 1 & 0 & & $-\mathrm{CH}_{2} \mathrm{CH}_{2}(\ldots)$ & 28 \\
\hline $\begin{array}{l}\text { Vinylene anion (one hydrogen is considered to } \\
\text { belong to the contiguous repeating unit) }\end{array}$ & 12 & 1 & 0 & & $-\mathrm{CH}^{-} \mathrm{Li}^{+}=\mathrm{CH}(\ldots)$ & 32 \\
\hline Terminal vinylene from styrene & 13 & 1 & 1 & & $-\mathrm{CH}=\mathrm{CH}-(\ldots)$ & 26 \\
\hline Terminal vinylene from DVB & 14 & 1 & 1 & & $-\mathrm{CH}=\mathrm{CH}-(\ldots-)$ & 26 \\
\hline Lithium hydride & 15 & 0 & 0 & & $\mathrm{LiH}$ & 8 \\
\hline Ethylbenzene (EB) & 16 & 0 & 1 & \multirow[t]{3}{*}{$S$} & $\mathrm{CH}_{3} \mathrm{CH}_{2} \mathrm{C}_{6} \mathrm{H}_{5}$ & 106 \\
\hline Lithium carbanion from EB & 17 & 0 & 1 & & $\mathrm{CH}^{-}\left(\mathrm{CH}_{3}\right) \mathrm{C}_{6} \mathrm{H}_{5} \mathrm{Li}^{+}$ & 112 \\
\hline Phenylmethylmethine end group & 18 & 1 & 0 & & $-\mathrm{CH}\left(\mathrm{CH}_{3}\right) \mathrm{C}_{6} \mathrm{H}_{5}$ & 105 \\
\hline
\end{tabular}

Table 5

Reaction stoichiometry for a simplified model of anionic copolymerisation of styrene and a divinylbenzene (case study I)

\begin{tabular}{|c|c|c|}
\hline Reaction name & Chemical equation & Stoichiometric functions \\
\hline Styrene initiation & $I+Y_{1} \stackrel{k_{I_{1}}}{\longrightarrow} A_{2}+X_{1}+A_{5}$ & $\Psi_{I_{1}}=s_{2} s_{4} s_{5}$ \\
\hline DVB initiation & $I+Y_{2} \stackrel{k_{I}}{\longrightarrow} A_{2}+X_{2}+A_{5}+A_{9}$ & $\Psi_{I_{2}}=s_{2} s_{5} s_{8} s_{9}$ \\
\hline Pendant vinyl initiation & $I+A_{9} \stackrel{k_{1}^{* *}=k_{I_{3}}}{\longrightarrow} A_{2}+A_{5}$ & $\begin{array}{l}\Psi_{1}^{* *-}=1 \\
\Psi_{1}^{* *+}=\frac{s_{2} s_{5}}{s_{9}}\end{array}$ \\
\hline Propagation on pendant vinyl group & $A_{5}+A_{9} \stackrel{k_{1}=k_{p}}{\longrightarrow} A_{6}+A_{5}$ & $\begin{array}{l}\Psi_{1}^{-}=\frac{s_{6}}{s_{5}} \\
\Psi_{1}^{+}=\frac{s_{5}}{s_{9}}\end{array}$ \\
\hline Propagation on styrene & $Y_{1}+A_{5} \stackrel{k_{2}=k_{p}}{\longrightarrow} A_{5}+X_{1}+A_{6}$ & $\begin{array}{l}\Psi_{2}^{-}=s_{4} s_{5} \\
\Psi_{2}^{+}=\frac{s_{6}}{s_{5}}\end{array}$ \\
\hline Propagationon DVB & $A_{5}+Y_{2} \stackrel{k_{3}=k_{p}}{\longrightarrow} X_{2}+A_{5}+A_{9}+A_{6}$ & $\begin{array}{l}\Psi_{3}^{-}=\frac{s_{6}}{s_{5}} \\
\Psi_{3}^{+}=s_{5} s_{8} s_{9}\end{array}$ \\
\hline
\end{tabular}

carbanions and double bonds are distinguished according to the nature of the repeating unit or monomer to which they are attached, 6 different propagation reactions are defined (Table 6).

The $n$th such reaction involves the groups $A_{g_{n}^{-}}$and $A_{g_{n}^{+}}$. It will be assumed that $g_{n}^{-} \leqslant g_{n}^{+}$.
In order to avoid the multiple levels of indexing as above and make the resulting expressions more readable, a notation inspired in the way computer assembly languages describe indirect addressing will be used, as vectors $\mathbf{g}^{+}$and $\mathbf{g}^{-}$are just collections of indices. Thus, the two groups directly involved in the $n$th reaction 
Table 6

Reaction stoichiometry of anionic copolymerisation of styrene and a divinylbenzene (case study II)

\begin{tabular}{|c|c|c|}
\hline Reaction name & Chemical equation & Stoichiometric functions \\
\hline Styrene initiation & $I+Y_{1} \underset{k_{I}}{\stackrel{k_{I}}{\longrightarrow}} A_{2}+X_{1}+A_{5}$ & $\Psi_{I_{1}}=s_{2} s_{4} s_{5}$ \\
\hline DVB initiation & $I+Y_{2} \stackrel{{ }^{K} I_{2}}{\longrightarrow} A_{2}+X_{2}+A_{9}+A_{10}$ & $\Psi_{I_{2}}=s_{2} s_{8} s_{9} s_{10}$ \\
\hline Pendant vinyl initiation & $I+A_{9} \stackrel{k_{1}^{* *}=k_{I}}{\longrightarrow} A_{2}+A_{10}$ & $\begin{array}{l}\Psi_{1}^{* *-}=1 \\
\Psi_{1}^{* *+}=\frac{s_{2} s_{10}}{s_{9}}\end{array}$ \\
\hline Propagation of styryl anion on pendant vinyl group & $A_{5}+A_{9} \stackrel{k_{1}=k_{p}}{\longrightarrow} A_{6}+A_{10}$ & $\begin{array}{l}\Psi_{1}^{-}=\frac{s_{6}}{s_{5}} \\
\Psi_{1}^{+}=\frac{s_{10}}{s_{9}}\end{array}$ \\
\hline Propagation of DVB anion on pendant vinyl group & $A_{9}+A_{10} \stackrel{k_{2}=k_{p_{23}}}{\longrightarrow} A_{6}+A_{10}$ & $\begin{array}{l}\Psi_{2}^{-}=\frac{s_{10}}{s_{9}} \\
\Psi_{2}^{+}=\frac{s_{6}}{s_{10}}\end{array}$ \\
\hline Propagation of styryl anion on styrene & $Y_{1}+A_{5} \stackrel{k_{3}=k_{p_{11}}}{\longrightarrow} A_{5}+X_{1}+A_{6}$ & $\begin{array}{l}\Psi_{3}^{-}=s_{4} s_{5} \\
\Psi_{3}^{+}=\frac{s_{6}}{s_{5}}\end{array}$ \\
\hline Propagation of DVB anion on styrene & $Y_{1}+A_{10} \stackrel{k_{4}=k_{p_{21}}}{\longrightarrow} A_{5}+X_{1}+A_{6}$ & $\begin{array}{l}\Psi_{4}^{-}=s_{4} s_{5} \\
\Psi_{4}^{+}=\frac{s_{6}}{s_{5}}\end{array}$ \\
\hline Propagation of styryl anion on DVB & $A_{5}+Y_{2} \stackrel{k_{5}=k_{p_{12}}}{\longrightarrow} X_{2}+A_{9}+A_{10}+A_{6}$ & $\begin{array}{l}\Psi_{5}^{-}=\frac{s_{6}}{s_{5}} \\
\Psi_{5}^{+}=s_{8} s_{9} s_{10}\end{array}$ \\
\hline Propagation of DVB anion on DVB & $Y_{2}+A_{10} \stackrel{k_{6}=k_{p_{22}}}{\longrightarrow} X_{2}+A_{9}+A_{10}+A_{6}$ & $\begin{array}{l}\Psi_{6}^{-}=s_{8} s_{9} s_{10} \\
\Psi_{6}^{+}=\frac{s_{6}}{s_{10}}\end{array}$ \\
\hline
\end{tabular}

coalescing polymer molecules will rather be designated as $A_{[n-]}$ and $A_{[n+]}$.

The other groups in the same repeating unit may also be transformed by that reaction (first shell substitution effect). By introducing stoichiometric coefficients, equal to the numbers of moles in products minus the number of moles in reagents for each group (or species), taking the formation of 1 mole of bonds as reference, the $N_{R}$ bimolecular reactions between groups $A_{[n-]}$ and $A_{[n+]}$ are written as:

$\sum_{j=1}^{N_{A}}\left(v_{n j}^{-}+v_{n j}^{+}\right) A_{j}=0, \quad n=1, N_{R}$.

Two sets of stoichiometric coefficients have been distinguished: those which concern the groups connected to the $\mathrm{RU}$ at the RG attached to group, and those related to the other RG. They may be equal in the less frequent cases where an end-group reacts with itself, such as in the condensation of silanols.

The rate of the $n$th reaction of this kind will be written as:

$R_{n}=k_{n} A_{[n-]} A_{[n+]}$.

According to Flory's Principle of Equal Reactivity, $k_{n}$ does not depend on the nature of the molecule to which the groups are attached, but the above defined pseudo second-order rate constant $k_{n}$ is often not a true constant and is a function of the composition of the reaction media.

This remark is particularly pertinent in anionic polymerisation of hydrocarbons (Table 5). The observed fractional orders with respect to initiator, both in propagation and initiation, have been described through a simple association model for anionic species (Lewis and Brown, 1970; Bywater and Worsfold, 1967; Bywater, 1998). Only a fraction of the anions is available at every moment for participating in initiation or propagation. That fraction should be the same for every chemically similar anionic group, irrespective of molecular chain length (Worsfold and Bywater, 1960; Arest-Yakubovich, 1997). Apparent kinetic constants should follow a power law with respect to overall anion concentration, with a negative exponent slightly less than 1, explaining thus the observed apparent orders with respect to initiator which are much less than 1 .

In general, $N_{I}$ bimolecular initiation reactions involving a pair of groups $A_{[I n-]}$ and $A_{[I n+]}$ not present in polymer, with rate constants $k_{I_{n}}$, create a new polymer molecule with a vector of groups $v_{I_{n}}$ :

$A_{[I n-]}+A_{[I n+]} \stackrel{k_{I_{n}}}{\longrightarrow} \mathrm{P}\left(v_{I_{n}}\right)$.

There are in case study II six initiation reactions (see Table 6), four of them creating new polymer molecules from non-polymeric ones; the other two are the initiations of the pendent double bonds, either by initiator or by an anion formed by transfer to solvent.

Other reactions between groups, both bimolecular (for example, termination by dismutation in free-radical polymerisation), sometimes unimolecular (such as the termination by hydride expulsion in anionic polymerisation), do not create connections between repeating units, and do not change the number of polymer molecules.

It is assumed there are $N_{R}^{*}$ such unimolecular reactions, $N_{R_{P}}^{*}$ of which involving groups in polymer molecules and the others only non-polymer molecules (for instance, initiator decomposition), with rate constants $k_{n}^{*}$ :

$\sum_{j=1}^{N_{A}} v_{n j}^{*} A_{j}=0, \quad n=1, N_{R}^{*}$. 
Table 7

Reaction stoichiometry of anionic copolymerisation of styrene and a divinylbenzene (case study II) (cont.)

\begin{tabular}{|c|c|c|}
\hline Reaction name & Chemical equation & Stoichiometric functions \\
\hline Hydride elimination of $\mathrm{A}_{5}$ & $A_{5} \stackrel{k_{1}^{*}=k_{e_{1}}}{\longrightarrow} A_{13}+A_{15}$ & $\Psi_{1}^{*}=\frac{s_{13}}{s_{5}}$ \\
\hline Hydride elimination of $A_{10}$ & $A_{10} \stackrel{k_{2}^{*}=k_{e_{2}}}{\longrightarrow} A_{14}+A_{15}$ & $\Psi_{2}^{*}=\frac{s_{14}}{s_{10}}{ }_{\Psi_{11}}$ \\
\hline Transfer of styryl anion to vinylene group from styrene & $A_{5}+A_{13} \stackrel{k_{2}^{* *}=k_{t}}{\longrightarrow} A_{11}+A_{12}$ & $\begin{array}{l}\Psi_{2}^{* *-}=\frac{s_{11}}{s_{5}} \\
\Psi_{2}^{* *+}=\frac{s_{12}}{s_{13}}\end{array}$ \\
\hline Transfer of styryl anion to vinylene group from DVB & $A_{5}+A_{14} \stackrel{k_{3}^{* *}=k_{t}}{\longrightarrow} A_{11}+A_{12}$ & $\begin{array}{l}\Psi_{3}^{* *-}=\frac{s_{11}}{s_{5}} \\
\Psi_{3}^{* *+}=\frac{s_{12}}{s_{14}}\end{array}$ \\
\hline Transfer of DVB anion to vinylene group from styrene & $A_{10}+A_{13} \stackrel{k_{4}^{* *}=k_{t 21}}{\longrightarrow} A_{11}+A_{12}$ & $\begin{aligned} \Psi_{4}^{* *-} & =\frac{s_{11}}{s_{10}} \\
\Psi_{4}^{* *+} & =\frac{s_{12}}{s_{14}}\end{aligned}$ \\
\hline Transfer of DVB anion to vinylene group from DVB & 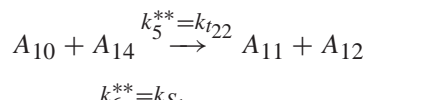 & $\begin{array}{l}\Psi_{5}^{* *-}=\frac{s_{11}}{s_{5}} \\
\Psi_{5}^{* *+}=\frac{s_{12}}{s_{13}}\end{array}$ \\
\hline Transfer of styrene anion to solvent & $A_{5}+S \stackrel{k_{6}}{\longrightarrow=k^{*}} S_{1} A_{11}+A_{17}$ & $\Psi_{6}^{* *-}=\frac{s_{11}}{s_{5}}$ \\
\hline Transfer of DVB anion to solvent & $A_{10}+S \stackrel{k_{7}^{* *}=k_{S_{2}}}{\longrightarrow} A_{11}+A_{17}$ & $\Psi_{7}^{* *-}=\frac{s_{11}}{s_{10}}$ \\
\hline Initiation of styrene by solvent anion & $Y_{1}+A_{17} \underset{k_{I_{5}}}{\stackrel{\kappa_{I_{4}}}{\longrightarrow}} A_{18}+X_{1}+A_{5}$ & $\Psi_{I_{4}}=s_{18} s_{4} s_{5}$ \\
\hline $\begin{array}{l}\text { Initiation of DVB by solvent anion } \\
\text { Initiation of pendant vinyl by solvent anion }\end{array}$ & $\begin{array}{l}Y_{2}+A_{17} \stackrel{I_{5}}{\longrightarrow} A_{18}+X_{2}+A_{9}+A_{10} \\
A_{9}+A_{17} \stackrel{k_{8}^{* *}=k_{I}}{\longrightarrow}{ }^{\prime} A_{18}+A_{10}\end{array}$ & $\begin{array}{l}\Psi_{I_{4}}=s_{18} s_{8} s_{9} s_{10} \\
\Psi_{8}^{* *}=\frac{s_{10} s_{18}}{s_{9}} \\
\Psi_{8}^{* *+}=1\end{array}$ \\
\hline
\end{tabular}

Hydride elimination in anionic polymerisations (Kern et al., 1972; Spach et al., 1962) is an example of these reactions. It transforms the carbanions into terminal vinylene groups. Two different elimination reactions can be distinguished in case study II according to the nature of the carbanion, as shown in Table 7.

Intramolecular reactions can be described using this formalism. The pair of groups in same molecule which react intramolecularly have to be defined as a new active group.

$N_{R}^{* *}$ bimolecular reactions between groups in polymer molecules, with rate constants $k_{n}^{* *}$ do not create new connections between repeating units. Transfer reactions are an example. Their description in terms of stoichiometric coefficients follows from the definitions below:

$\sum_{j=1}^{N_{A}}\left(v_{n j}^{* *-}+v_{n j}^{* *+}\right) A_{j}=0, \quad n=1, N_{R}^{* *}$.

The degradative transfer reaction between styryl carbanions and the terminal vinylene groups is also an example of such reactions. It is convenient to distinguish two kinds of reactions among this latter class:

- The first $N_{R_{P}}^{* *}$ involve two polymer molecules, examples being transfer to polymer, termination by dismutation and the transfers from anions to vinylene end groups in anionic polymerisation (case study II);

- The next $N_{R_{S}}^{* *}$ involve one polymer molecule and a small molecule, a typical example being transfer to solvent;

- The remaining $N_{S}$ reactions concern only small molecules.

For $N_{M}$ reactions between a group in a polymer molecule and a monomer (transfer to monomer), with rate constants
$k_{M_{n}}$, a new polymer molecule is created from that monomer:

$\sum_{j=1}^{N_{A}}\left(v_{M_{n j}}^{-}+v_{M_{n j}}^{+}\right) A_{j} \stackrel{k_{M_{n}}}{\longrightarrow} \mathrm{P}\left(v_{M_{n}}^{+}\right), \quad n=1, N_{M}$.

Notice that the new polymer molecule with degree of polymerisation one does not keep unchanged the previously extant double bonds in monomer-their reactivity is most often much lower than double bonds of monomer. An important exception is vinyl acetate.

In any case, this model keeps track of such reactivity changes.

The overall rate of formation or disappearance of groups by chemical reaction is the sum of the contributions of the above-mentioned processes:

$$
\begin{aligned}
R_{A_{n}}= & \sum_{m=1}^{N_{R}} k_{m}\left(v_{m n}^{-}+v_{m n}^{+}\right) A_{[m-]} A_{[m+]} \\
& +\sum_{m=1}^{N_{R}^{*}} k_{m}^{*} v_{m n}^{*} A_{[m *]} \\
& +\sum_{m=1}^{N_{R}^{* *}} k_{m}^{* *}\left(v_{m n}^{* *-}+v_{m n}^{* *+}\right) A_{[m * *-]} A_{[m * *+]} \\
& +\sum_{m=1}^{N_{I}} k_{I_{m}} v_{I_{m n}} A_{[I m-]} A_{[I m+]} \\
& +\sum_{m=1}^{N_{M}} k_{M_{m}}\left(v_{M_{m n}}^{-}+v_{M_{m n}}^{+}\right) A_{[M m-]} A_{[M m+]} .
\end{aligned}
$$

Whenever the excess volume of mixing of the various species can be neglected, the density of the mixture in the reac- 
tor is easily computed from the knowledge of the volume difference between products and reagents for each chemical reaction. Defining $\Delta V_{m}, \Delta V_{m}^{*}$ and $\Delta V_{m}^{* *}$, and so on, as the mole volume changes due to each kind of reaction in the system (because of density changes and evaporation or precipitation of by-products), the rate of relative change of volume caused by chemical reactions, $R_{v}$, results from the expression below:

$$
\begin{aligned}
R_{v}= & \sum_{m=1}^{N_{R}} k_{m} A_{[m-]} A_{[m+]} \Delta V_{m}+\sum_{m=1}^{N_{R}^{*}} k_{m}^{*} A_{[m *]} \Delta V_{m}^{*} \\
& +\sum_{m=1}^{N_{R}^{* *}} k_{m}^{* *} A_{[m * *-]} A_{[m * *+]} \Delta V_{m}^{* *} \\
& +\sum_{m=1}^{N_{I}} k_{I_{m}} A_{[I m-]} A_{[I m+]} \Delta V_{I_{m}} \\
& +\sum_{m=1}^{N_{M}} k_{M_{m}} A_{[M m-]} A_{[M m+]} \Delta V_{M_{m}} .
\end{aligned}
$$

It is also possible to write a rate equation for the overall number of polymer molecules:

$$
\begin{aligned}
R_{\lambda_{0}}= & -\sum_{m=1}^{N_{R_{P}}} k_{m} A_{[m-]} A_{[m+]}+\sum_{m=1}^{N_{I}} k_{I_{m}} A_{[I m-]} A_{[I m+]} \\
& +\sum_{m=1}^{N_{M}} k_{M_{m}} A_{[M m-]} A_{[M m+]} .
\end{aligned}
$$

The following auxiliary functions, extensively used from now on, will be named stoichiometric functions:

$$
\begin{aligned}
& \Psi_{L}^{U}(\mathbf{s})=\prod_{\substack{j=1 \\
\delta_{P_{j}}=1}}^{N_{A}}\left(s_{j}\right)^{v_{L_{j}}^{U}}, \\
& U=+;-; * ; * *+; * *-, \\
& L=n ; I_{n} ; M_{n} .
\end{aligned}
$$

Methods documented in Costa and Dias (1994) make now possible to write the generating function of the rate equations of formation of polymer species by chemical reaction:

$$
\begin{aligned}
G_{R_{P}}= & \sum_{m=1}^{N_{R_{P}}} k_{m}\left(\Psi_{m}^{-} \Psi_{m}^{+} \frac{\partial G}{\partial \log s_{[m-]}} \frac{\partial G}{\partial \log s_{[m+]}}\right. \\
& \left.-\frac{\partial G}{\partial \log s_{[m-]}} A_{[m+]}-\frac{\partial G}{\partial \log s_{[m+]}} A_{[m-]}\right) \\
& +\sum_{m=N_{R_{P}}+1}^{N_{R}} k_{m} \frac{\partial G}{\partial \log s_{[m-]}} A_{[m+]}\left(\Psi_{m}^{-} \Psi_{m}^{+}-1\right) \\
& +\sum_{m=1}^{N_{R_{P}}^{*}} k_{m}^{*} \frac{\partial G}{\partial \log s_{[m *]}}\left(\Psi_{m}^{*}-1\right)
\end{aligned}
$$

$$
\begin{aligned}
& +\sum_{m=1}^{N_{R_{P}}^{* *}} k_{m}^{* *}\left[\frac{\partial G}{\partial \log s_{[m * *-]}} A_{[m * *+]}\left(\Psi_{m}^{* *-}-1\right)\right. \\
& \left.+\frac{\partial G}{\partial \log s_{[m * *+]}} A_{[m * *-]}\left(\Psi_{m}^{* *+}-1\right)\right] \\
& +\sum_{m=N_{R_{P}}^{*}+1}^{N_{R}^{* *}-N_{S}} k_{m}^{* *} \frac{\partial G}{\partial \log s_{[m * *-]}} A_{[m * *+]}\left(\Psi_{m}^{* *-}-1\right) \\
& +\sum_{m=1}^{N_{I}} k_{I_{m}} A_{[I m-]} A_{[I m+]} \Psi_{I_{m}}+\sum_{m=1}^{N_{M}} k_{M_{m}} A_{[M m+]} \\
& \times\left[A_{[M m-]} \Psi_{M_{m}}^{+}+\frac{\partial G}{\partial \log s_{[M m-]}}\left(\Psi_{M_{m}}^{-}-1\right)\right] .
\end{aligned}
$$

\section{Prediction of average molecular weights and chain length distributions in ideal reactors: general aspects}

\subsection{Mass balance equations}

Integration of mass balance equations for a non-steady state perfectly mixed continuous stirred tank reactor will be done in the same way as described in Costa and Dias (1994). For a reaction volume $V$ and inlet and outlet flow-rates $Q_{F}$ and $Q$, the following overall mass balance holds:

$\frac{\mathrm{d} V}{\mathrm{~d} t}=R_{v} V+Q_{F}(t)-Q(t)$.

Introducing a space-time $\tau$ based on the inlet flow-rate, $\tau=$ $V / Q_{F}$, the mass balance of an active group $A_{j}$ becomes:

$\frac{\mathrm{d} A_{j}}{\mathrm{~d} t}=R_{A_{j}}+\frac{A_{j_{F}}-A_{j}}{\tau}-R_{v} A_{j}$,

$A_{j \mid t=0}=A_{j_{0}}$.

Space-time $\tau$ may be an unknown function of time and reaction volume. It can be computed with help of Eq. (15) and suitable additional conditions.

Moment generating functions of the distributions above defined also verify similar mass balance equations, which are first-order partial differential equations. The moment generating function of the NCLD of polymer $G(\mathbf{s})$ is obtained by solving Eq. (18) with the initial condition Eq. (19), simultaneously with the above mass balances of groups Eq. (16) and initial conditions given by Eq. (17):

$$
\begin{aligned}
& \frac{\partial G}{\partial t}=G_{R_{P}}+\frac{G_{F}(t)-G}{\tau}-R_{v} G, \\
& G_{\mid t=0}=G_{0}\left[\mathbf{s}_{0}(t, \mathbf{s})\right] .
\end{aligned}
$$

The solution of similar equations by the method of characteristics (Courant and Hilbert, 1962) has already been presented in detail elsewhere (Costa and Dias, 1994, 2003), 
and so only the final results are shown. The system of characteristic equations for computing the moment generating function of polymer NCLD can be found in Appendix A.

In order to compute $G(\mathbf{s})$ for complex values along a circle or a spherical surface (according to the number of dimensions of the problem) of radius close to 1 centred in the origin (Abate and Whitt, 1992; Mills, 1986; Costa and Villermaux, 1988), as well as its derivatives at $\mathbf{s}=1_{N_{A}}$ (for the evaluation of the moments), it is necessary to compute the starting vector of the characteristics $\mathbf{s}_{0}$ for each value of $\mathbf{s}$. There are two situations which require very different levels of computing effort:

- For the evaluation of average degrees of polymerisation and average molecular masses before gelation, since $\mathbf{s}_{0}=$ $1_{N_{A}}$ it is only necessary to set $\mathbf{s}=1_{N_{A}}$ in Eqs. (A.1)-(A.3) or additional differential equations for time derivatives along characteristics of higher derivatives of $G$, and a set of ordinary differential equations with respect to time is obtained, leading to an initial value problem, which is more or less easily solved. As before stated, it is recommended to always carry out a prediction of gel time by integration of the above-mentioned initial value problem.

- If there is gel, or if $\mathbf{s} \neq 1_{N_{A}}$ (for computing the NCLD), vector $\mathbf{s}_{0}$ must be found, leading to a boundary value problems of the "time-like" variety (Deuflhard and Bornemann, 2002) for obtaining a numerical solution of the boundary value problem for computing characteristics. A shooting method using integration for increasing time values is the natural way of finding a numerical solution. A few representative examples of polycondensations and non-radical polymerisations have been solved with this approach (Costa and Dias, 1994, 1995).

Numerical sensitivity already occurs with some polyadditions: it is enough to take into account the effect of the last repeating unit in the propagation or initiation rate constants in order to be struck by that problem. Parallel multiple shooting (Keller, 1972) must be used to overcome this difficulty. Free radical polymerisations present a more difficult challenge. Owing to the high relative values of termination rate constants relatively to propagation, the system becomes very "stiff" and extreme numerical sensitivity occurs.

Only recently (Costa and Dias, 2003) could a solution be found, thanks to the use of the integrator in automatic continuation code ACDC (Cash et al., 1995, 2001; Bashir-Ali et al., 1998).

In fact, its continuation procedure was not successful, as it usually leads to the trivial solution branch after gelation instead of the physical meaningful solution branch, but its implicit Runge-Kutta integrator based on a Lobatto quadrature does succeed in finding the required solutions.

Some numerical case studies will next be discussed in order to provide an overview of its expected performance in terms of accuracy, CPU time and memory requirements when dealing with complex polymerisations.

\section{Numerical treatment of non-radical polymerisation models}

It is enlightening to find the analytical solution of Flory's simplified kinetic scheme (case study I) which presents a behaviour typical of the more general chemical system; this is nearly the only way of independently checking the calculations of average molecular weights or CLD with a solution computed through a different method. Using the stoichiometric functions in Table 5, the mass balance in Laplace domain leading to the generating function of polymer NCLD in a batch reactor, neglecting density changes, may be written as follows:

$$
\begin{aligned}
\frac{\partial G}{\partial t}= & k_{I} I\left[s_{2} s_{4} s_{5} Y_{1}+2 s_{2} s_{5} s_{8} s_{9} Y_{2}\right. \\
& \left.+\frac{\partial G}{\partial \log s_{9}}\left(\frac{s_{2} s_{5}}{s_{9}}-1\right)\right] \\
& +k_{p}\left\{\frac { \partial G } { \partial \operatorname { l o g } s _ { 5 } } \left[Y_{1}\left(s_{4} s_{6}-1\right)+2 Y_{2}\left(s_{6} s_{8} s_{9}-1\right)\right.\right. \\
& \left.\left.+\frac{s_{6}}{s_{9}} \frac{\partial G}{\partial \log s_{9}}-A_{9}\right]-A_{5} \frac{\partial G}{\partial \log s_{9}}\right\} .
\end{aligned}
$$

In fact, it is possible to generalise this scheme to an arbitrary number $N_{Y}$ of monomers $Y_{j}$ with functionalities (numbers of double bonds) $j=1, N_{Y}$, provided the reactivity of all double bonds and anions is the same. This slightly more complicated scheme is discussed in Appendix B. It is convenient to introduce an overall concentration of double bonds $B$ :

$B=A_{9}+\sum_{j=1}^{N_{Y}} j Y_{j}$.

Mass balance equations of initiator, anions $A_{5}$, monomers, double bonds (adding monomer balances) and pendant double bonds $A_{9}$ can be written as:

$$
\begin{aligned}
& \frac{\mathrm{d} I}{\mathrm{~d} t}=-\frac{\mathrm{d} A_{5}}{\mathrm{~d} t}=-k_{I} I B, \\
& \frac{\mathrm{d} Y_{j}}{\mathrm{~d} t}=-j Y_{j}\left(k_{I} I+k_{p} A_{5}\right) \quad j=1, N_{Y}, \\
& \frac{\mathrm{d} B}{\mathrm{~d} t}=-B\left(k_{I} I+k_{p} A_{5}\right), \\
& \frac{\mathrm{d} A_{9}}{\mathrm{~d} t}=k_{I} I\left[-A_{9}+\sum_{j=1}^{N_{Y}} j(j-1) Y_{j}\right]-k_{p} A_{5} A_{9} .
\end{aligned}
$$

Introducing the conversions of double bonds $p$ and of initiator $p_{I}$, they verify:

$$
\begin{aligned}
& \frac{\mathrm{d} p}{\mathrm{~d} t}=I_{0}(1-p)\left[k_{I}\left(1-p_{I}\right)+k_{p} p_{I}\right], \\
& \frac{\mathrm{d} p_{I}}{\mathrm{~d} t}=k_{I} B_{0}(1-p)\left(1-p_{I}\right) .
\end{aligned}
$$


Initial weight distribution of functionalities $f_{w_{j}}$ is defined through the initial fractions of active groups belonging to each monomer $Y_{j}$ :

$f_{w_{j}}=\frac{j Y_{j_{0}}}{\sum_{j=1}^{N_{Y}} j Y_{j_{0}}}=\frac{j Y_{j_{0}}}{B_{0}}$.

The initial concentration of initiator will be given in terms of the average chain length $r$, equal to the final number average degree of polymerisation which would be achieved for $\overline{f_{w}}=1$ :

$r=\frac{B_{0}}{I_{0}}$

Anions are associated (Lewis and Brown, 1970) in the hydrocarbon solvents used in anionic polymerisations of vinyl monomers. Rate of monomer consumption is usually not first order with respect to the overall anion concentration $A_{5}$. Although some controversy is not absent (Arest-Yakubovich, 1997; Bywater, 1998) a simple model considering association of anions $I$ and $A_{5}$ leads to a power-law dependency of apparent initiation and propagation rate constants on overall anion concentrations as shown in Eqs. (30) and (31) below, explaining observed experimental orders $\frac{1}{m_{I}}$ and $\frac{1}{m_{P}}$ (although no direct correspondence exists in many cases between degree of aggregation and these parameters, as shown by Young et al. (1984))

$k_{I}=k_{I_{0}} I^{-1+1 / m_{I}}$,

$k_{p}=k_{p_{0}} I^{-1+1 / m_{p}}$.

An example is $n$-butyllithium initiated bulk polymerisation of styrene in benzene, for which $m_{I}=6$ (Worsfold and Bywater, 1960), and $m_{P}=2$.

Karles et al. (1991) have found that $m_{P}=1.2 \pm 0.8$ for bulk polymerisation of DVB, different from styrene, which is a source of some complications in kinetic modelling. Notice that no mixed association of anions coming from initiator and from polymer would be allowed using this simplified model (which does not allow either for dependence of $m_{P}$ on the nature of terminal unit). According to Eqs. (30), (31) and (27), the two conversions would be related through a binomial integral:

$p=\frac{k_{I_{0}}}{k_{p_{0}}} I_{0}^{\frac{1}{m_{I}}-\frac{1}{m_{p}}} \int_{0}^{p_{I}} u^{1-\frac{1}{m_{p}}}(1-u)^{\frac{1}{m_{I}}-1} \mathrm{~d} u$.

Owing to the binomial integral in Eq. (32) above, a full analytical solution is possible only for instantaneous initiation or for a constant ratio of initiation and propagation apparent constants $C_{I}=\frac{k_{I}}{k_{p}}$. If this condition holds, conversions of initiator $p_{I}$ and of active groups in monomers $p$ are related through:

$\log \left(1-p_{I}\right)=\left(C_{I}-1\right) p_{I}-r C_{I} p$.
The critical conversion for gelation $p_{g}$, related to $p_{I_{g}}$ through Eq. (33) above, results from the calculations in Appendix B:

$$
\begin{aligned}
\frac{1}{\overline{f_{w}}-1}= & r p_{g}^{2}-\left(1-1 / C_{I}\right)\left\{2\left(1-1 / C_{I}\right) p_{g}\right. \\
& \left.+\left[\left(1-1 / C_{I}\right) p_{I_{g}}-2\right] p_{I_{g}} / r\right\} .
\end{aligned}
$$

For a given initial weight average monomer functionality, gelation occurs only if the initial mole ratio $r$ is above a critical value $r_{c}$ obtained by setting $p_{g}=p_{I_{g}}=1$ in Eq. (34) above.

As previously stated, inclusion of hydride expulsion and transfer to solvent, which are important reactions unless temperature is much lower than ambient (Priddy et al., 1992), makes impossible to find an analytical solution for the prediction of average molecular weights.

The set of kinetic parameters and initial concentrations used in case studies I and II is presented in Table 8. Values for relative reactivities of double bonds were taken from Worsfold (1970) and rate constants for secondary reactions were taken from Priddy et al. (1992). Some values had to be assumed owing to lack of experimental data.

We have considered three variants of the kinetic scheme:

- System I: as described in Table 8;

- System II: equal reactivities of double bonds and anions, as would approximately hold for styrene $+m$ divinylbenzene;

- System III: as system II without transfer to solvent and termination, corresponding to case study I.

The analytical solution (case study I, system III) was precious in order to test the numerical solution method. A very serious problem, as shown in Fig. 1, is the numerical sensitivity of system of characteristics Eqs. (A.1)-(A.6), forcing the use of parallel multiple shooting (Keller, 1972), as we have already done in an earlier research (Costa and Dias, 1995) with a "home-made" code.

Notice in Fig. 2 the very different shapes of characteristic curves associated to the different variables; characteristics associated to the numbers of anions are smooth (Fig. 3), while those associated to the numbers of double bonds have a steep growth towards the end of the integration interval (Fig. 4).

Code ACDC (Cash et al., 2001) can deal with the "stiff" systems (Hairer and Wanner, 2002) found in free-radical polymerisation (discussed in next section) and this is a relatively easy problem for that method. Prediction of weight-average molecular weight takes about $30 \mathrm{~s}$ CPU before gelation, and each prediction of sol fraction and $\bar{M}_{w}$ after gelation takes about $59 \mathrm{~s}$. Computations were performed with a PIV $1.5 \mathrm{GHz}$ running Linux (computing times are about the same with a dual G4 Power PC running Apple MacOSX, also with a program compiled with GNU C compiler gcc-2.95 and associated Fortran compiler). 
Table 8

Kinetic parameters for simulations of anionic copolymerisation of styrene $+p$-divinylbenzene (case study II)

\begin{tabular}{|c|c|c|}
\hline Parameter & Relative value & Absolute value \\
\hline$M_{1_{0}}$ & & $3.996 \mathrm{~mol} \mathrm{dm}^{-3}$ \\
\hline$M_{20}$ & & $0.004 \mathrm{~mol} \mathrm{dm}^{-3}$ \\
\hline$I_{0}$ & & $0.004 \mathrm{~mol} \mathrm{dm}^{-3}$ \\
\hline$S_{0}$ & & $4 \mathrm{~mol} \mathrm{dm}^{-3}$ \\
\hline$k_{I}$ & & $0.7 \mathrm{dm}^{3} \mathrm{~mol}^{-1} \mathrm{~s}^{-1}$ \\
\hline$k_{p}$ & & $220 \mathrm{dm}^{3} \mathrm{~mol}^{-1} \mathrm{~s}^{-1}$ \\
\hline$k_{S}$ & & $1.4 \times 10^{-4} \mathrm{dm}^{3} \mathrm{~mol}^{-1} \mathrm{~s}^{-1}$ \\
\hline$k_{e}$ & & $2 \times 10^{-4} s^{-1}$ \\
\hline$k_{p_{11}}$ & $k_{p_{11}}=k_{p}$ & \\
\hline$k_{p_{22}}$ & $C_{p}=k_{p_{22}} / k_{p_{11}}=9.7$ & \\
\hline$k_{p_{12}}$ & $r_{1}=k_{p_{11}} / k_{p_{12}}=0.094$ & \\
\hline$k_{p_{21}}$ & $r_{2}=k_{p_{22}} / k_{p_{21}}=10$ & \\
\hline$k_{p_{13}}$ & $C_{p_{1}}=k_{p_{13}} / k_{p_{11}}=0.8$ & \\
\hline$k_{p_{23}}$ & $C_{p_{2}}=k_{p_{23}} / k_{p_{22}}=0.07$ & \\
\hline$k_{I_{1}}$ & $C_{I_{1}}=k_{I_{1}} / k_{p_{11}}=k_{I} / k_{p}=0.0032$ & \\
\hline$k_{I_{2}}$ & $C_{I_{2}}=k_{I_{2}} / k_{p_{12}}=C_{I_{1}}=0.0032$ & \\
\hline$k_{I_{3}}$ & $C_{I_{3}}=k_{I_{3}} / k_{p_{13}}=C_{I_{1}}=0.0032$ & \\
\hline$k_{I_{4}}$ & $C_{I_{4}}=k_{I_{4}} / k_{p_{11}}=C_{I_{1}}=0.0032$ & \\
\hline$k_{I_{5}}$ & $C_{I_{5}}=k_{I_{5}} / k_{p_{12}}=C_{I_{1}}=0.0032$ & \\
\hline$k_{I_{6}}$ & $C_{I_{6}}=k_{I_{6}} / k_{p_{13}}=C_{I_{1}}=0.0032$ & \\
\hline$k_{e_{1}}$ & $k_{e_{1}}=k_{e}$ & \\
\hline$k_{e_{2}}$ & $k_{e_{2}}=k_{e}$ & \\
\hline$k_{t_{11}}$ & $k_{t_{11}}=k_{p_{11}}$ & \\
\hline$k_{t_{12}}$ & $k_{t_{12}}=k_{p_{12}} / 2$ & \\
\hline$k_{t_{21}}$ & $k_{t_{21}}=k_{p_{12}}$ & \\
\hline$k_{t_{22}}$ & $k_{t_{22}}=k_{p_{22}} / 2$ & \\
\hline$k_{S_{1}}$ & $k_{S_{1}}=k_{S}$ & \\
\hline$k_{S_{2}}$ & $k_{S_{2}}=k_{S}$ & \\
\hline
\end{tabular}

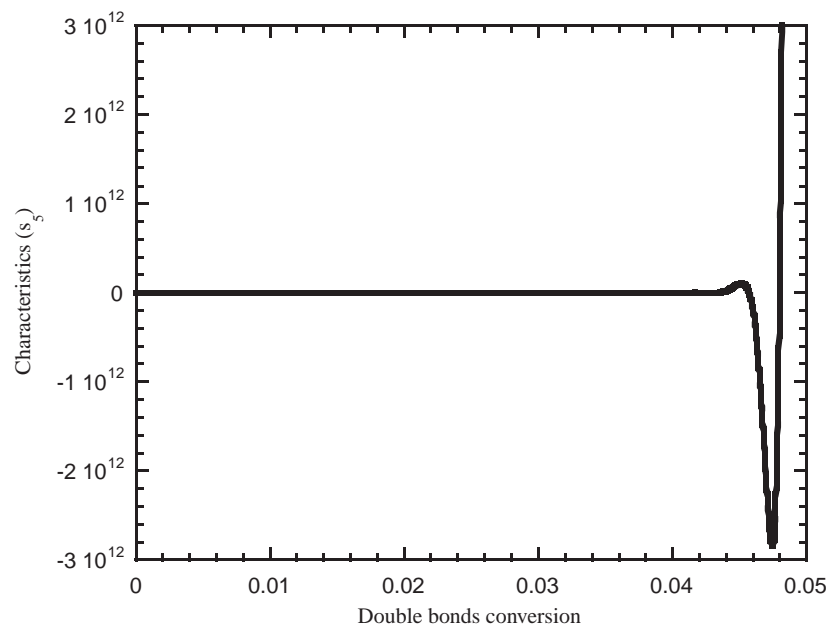

Fig. 1. Numerical "blow-up" of solution of system of differential equations for computing characteristics.

Numerical accuracy can be checked for system III comparing predicted values of $G$ obtained with the analytical solution described in Appendix B. In fact, this solution involves the numerical resolution of the algebraic equation Eq. (B.12) or Eq. (B.13), which is rather tricky for high dou-

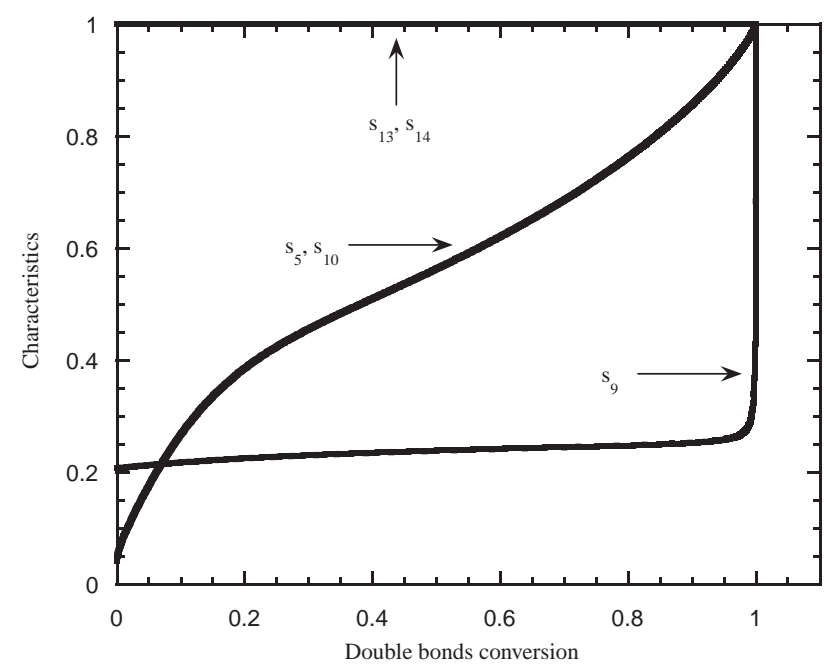

Fig. 2. Characteristics for case study II, system I, at $p=1$.

ble bond conversions and so it can have a non-negligible numerical error too.

Nevertheless, in the worst case (conversion $p=0.999$ ), there is agreement of $G(\mathbf{1})$ by the two methods within 9 decimal places, and except for that extreme case we have 


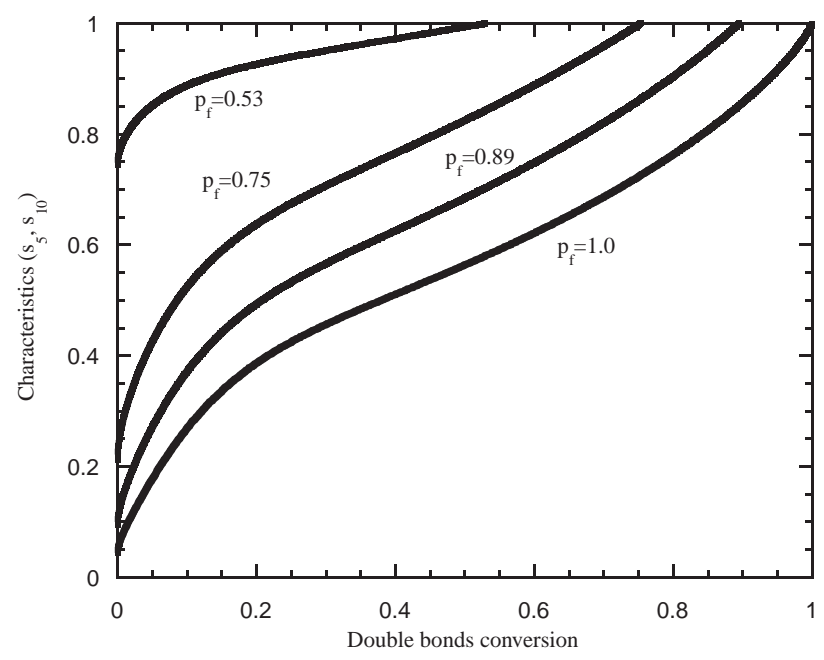

Fig. 3. Characteristics for case study II, system I, for different values of double bonds conversion $p$.

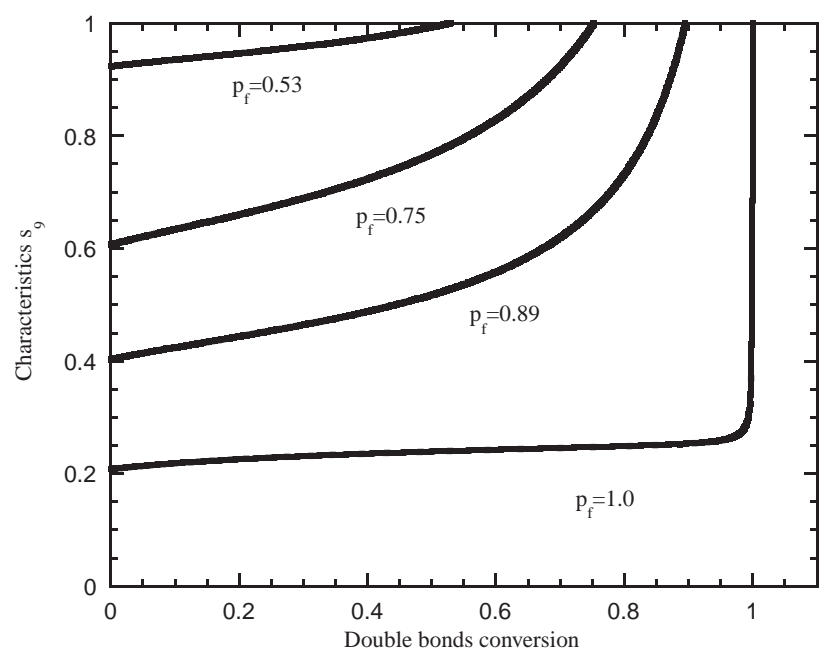

Fig. 4. Characteristics for case study II, system I, for different values of double bonds conversion $p$.

obtained 11 decimal places agreement, so this should be regarded as satisfactory.

In Fig. 5 is shown an example of number and weight average molecular weights prediction, while in Figs. 6 and 7 are compared the changes brought up by the different values of rate parameters.

Unfortunately, no experimental data for molecular weight have been published for these systems.

\section{Modelling of free radical copolymerisation of monovinyl and divinyl monomers and its application to styrene + divinylbenzene systems (case study III)}

In order to present a comparison of predictions of the present method with experimental data, the classical prob-

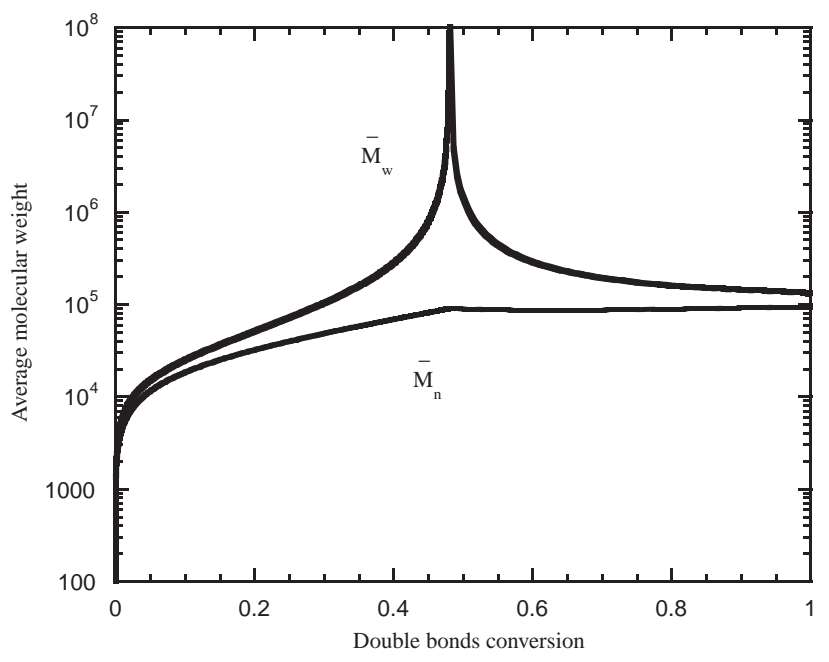

Fig. 5. $\bar{M}_{n}$ and $\bar{M}_{w}$ for case study II.

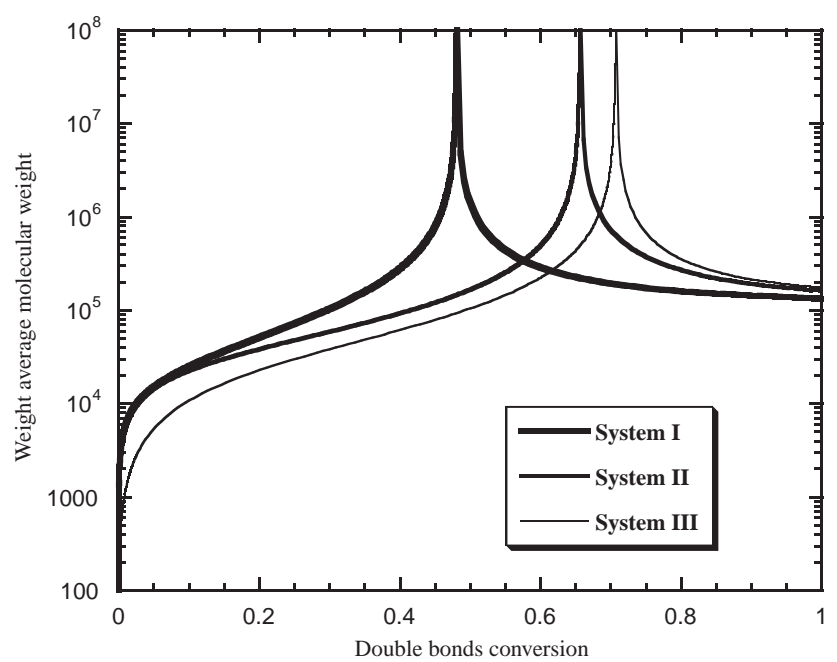

Fig. 6. $\bar{M}_{w}$ for case study II with different kinetics.

lem of the free radical crosslinking copolymerisation will be used as an example. For this kind of systems, some experimental studies can be found in the literature namely for the copolymerisation of mono/divinyl monomers. It was important for our goals to have available experimental data in the pre- and post-gel regimes, and the extensive investigation on kinetics of free radical copolymerisation, in benzene and $60^{\circ} \mathrm{C}$, of styrene with $m$ - and $p$-divinylbenzene, ethylene dimethacrylate and diisopropenylbenzene (Hild and Okasha, 1985a,b; Hild et al., 1985) could fulfil these requirements. This chemical system should only present a low extent of cyclisations, which are an important factor in most nonlinear free-radical polymerisations (see Elliott and Bowman (2002) as an example of a sustained modelling effort of these systems).

Variable, but always small, mole ratios of divinyl monomer to styrene have been used in these experiments. 


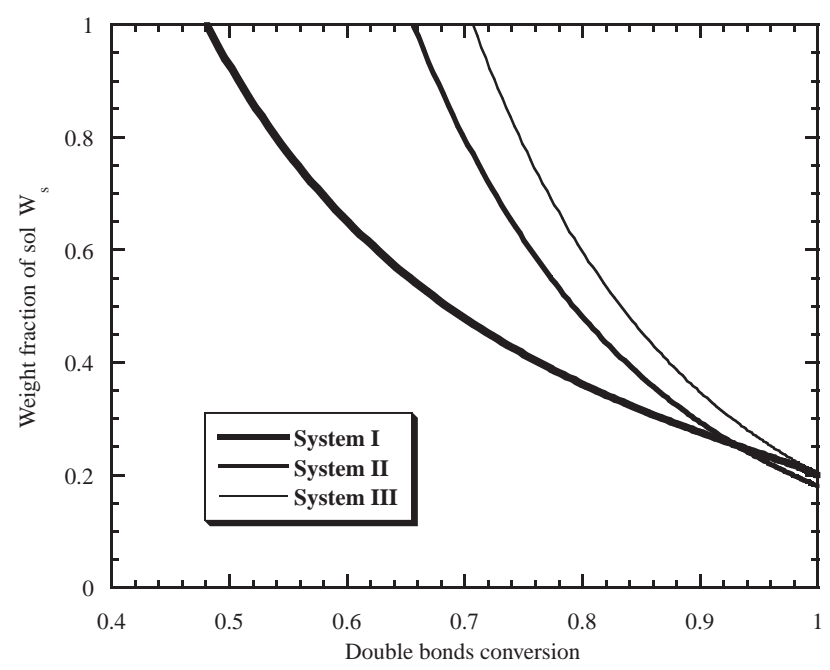

Fig. 7. Weight fraction of sol for case study II with different kinetics.

Table 9

Description of groups considered in the free radical crosslinking copolymerisation of styrene with $m$-divinylbenzene

\begin{tabular}{llll}
\hline Group description & $j$ & $\delta_{P_{j}}$ & $\delta_{A_{j}}$ \\
\hline Free radical from styrene & 1 & 1 & 1 \\
Free radical from $m$-divinylbenzene & 2 & 1 & 1 \\
Pendant double bond from $m$-divinylbenzene & 3 & 1 & 1 \\
Monomeric styrene & 4 & 0 & 1 \\
Monomeric $m$-divinylbenzene & 5 & 0 & 1 \\
Primary radical & 6 & 0 & 1 \\
Initiator (AIBN) & 7 & 0 & 1 \\
& & & \\
Polymerised styrene unit & 8 & 1 & 0 \\
Polymerised $m$-divinylbenzene unit & 9 & 1 & 0 \\
\hline
\end{tabular}

System styrene/m-divinylbenzene was investigated before gelation with initial concentrations $M_{1_{0}}=4 \mathrm{~mol} \mathrm{dm}^{-3}$ for styrene, $M_{2_{0}}=0.08 \mathrm{~mol} \mathrm{dm}^{-3}$ for $m$-divinylbenzene and $I_{0}=0.08 \mathrm{~mol} \mathrm{dm}^{-3}$ for AIBN. This corresponds to an initial mole ratio of divinyl monomer with respect to monovinyl monomer of $\alpha=\frac{M_{2_{0}}}{M_{1}}=0.02$ (2\%). The same system was studied after gelation for an initial composition of $M_{1_{0}}=4 \mathrm{~mol} \mathrm{dm}^{-3}, M_{2_{0}}=0.2 \mathrm{~mol} \mathrm{dm}^{-3}$ and $I_{0}=0.08 \mathrm{~mol} \mathrm{dm}^{-3}$ which corresponds to $\alpha=5 \%$. Average molecular weights have been measured by size exclusion chromatography (SEC) and in some cases by light scattering (LS) and are available in these works in a tabular form.

A description of groups and kinetic scheme for the simulation of this system is presented in Tables 9 and 10. Free radicals from styrene, free radicals from $m$-divinylbenzene and pendant double bonds from $m$-divinylbenzene are the active species present in the polymer. Monomers, primary radicals and initiator are active but are not present in the polymer. Polymerised monomer units are present in the polymer but are inactive. The kinetic scheme comprises the usual steps in this kind of systems: initiator decomposition, initiation of monomers and pendant double bonds with primary radicals, propagation of monomers and pendant double bonds with the different kinds of radicals and termination between the different polymeric radicals, which in this systems is known to occur predominantly by combination.

Kinetic parameters assumed in this case study are presented in Table 11. A set of parameters were fixed as reference values (Hild and Okasha, 1985a): $k_{p 11}$ is the rate constant of homopropagation of styrene and $k_{t c}$ is the correspondent value termination rate constant, $f=0.6$ was kept fixed and $k_{d}$ a known value for the dissociation of AIBN.

Recent experimental studies (Zetterlund et al., 2002) have found that apparent termination rate constant and initiator efficiency are neither independent from conversion nor from divinylbenzene content. We have nevertheless kept using earlier found values because they fit these observed conversion vs. time values.

Reactivity ratio of styrene $r_{1}$ was experimentally determined in that work, where it is also reported the impossibility of a precise determination of the reactivity ratio for $m$-divinylbenzene due to the small amount of this monomer in the initial reaction mixture. In these conditions, an ideal copolymerisation has been assumed: $r_{1} r_{2}=1$. Only with a strong deviation from ideality a noticeable influence of this parameter in the gelation of the system (Costa and Dias, 2003) is expected. Conversely, reactivity of pendant double bonds has a strong influence in the behaviour of this kind of systems. Its relative value to the propagation of styrene $\left(C_{p_{13}}\right)$ is used as a reference value. The remaining kinetic parameters needed for the simulations can be obtained from this basic set as reported in Table 11. Here the present simulation method was used to obtain an estimation of $C_{p_{13}}$ : the observed gelation time for the experimental system with $\alpha=2 \%, t_{g}=7.5 \mathrm{~h}$ could be reproduced and $C_{p_{13}}=0.138$ was estimated with a relative error of $0.06 \%$ in the gelation time.

For these reaction conditions, in Fig. 8 are compared the predictions of the present method with experimental values for weight and number average molecular weights (Hild and Okasha, 1985a) in the polymers produced with $\alpha=2 \%$. Some discrepancies were observed between the experimentally measured weight average molecular weight by SEC and LS, namely in the neighbourhood of gelation. Nevertheless, the agreement between predictions and experimental values is fairly good.

With the same set of kinetic parameters, the system with $\alpha=5 \%$ was also simulated and a comparison with the correspondent experimental values obtained by Hild et al. (1985) can be found in Fig. 9; in this case (post-gel results) only experimental observations by SEC are available. At first sight, agreement is not bad either, but, unfortunately, inconsistent results are found: predicted gelation time is $t_{g}=2.1 \mathrm{~h}$ while the experimental value is $t_{g}=3.5 \mathrm{~h}$. In order to reproduce the reported gelation time, a new value of $C_{p_{13}}=0.091$ was 
Table 10

Reaction scheme in the free radical crosslinking copolymerisation of styrene with $m$-divinylbenzene

\begin{tabular}{|c|c|}
\hline Reaction name & Chemical equation \\
\hline Initiator decomposition & $A_{7} \stackrel{k_{1}^{*}=k_{d}}{\longrightarrow} \underset{k_{L}=k_{i}}{2 f A_{6}}$ \\
\hline Styrene initiation & $A_{4}+A_{6} \underset{k_{l}=k_{i 2}}{\stackrel{I_{1}}{\longrightarrow}=\kappa_{i 1}} A_{1}+A_{8}$ \\
\hline$m$-divinylbenzene initiation & $A_{5}+A_{6} \underset{k_{1}=k}{\longrightarrow} A_{2}+A_{3}+A_{9}$ \\
\hline Pendant double bond propagation with radical from styrene & $A_{1}+A_{3} \stackrel{\kappa_{1}=\kappa_{p 13}}{\longrightarrow} A_{2}$ \\
\hline Pendant double bond propagation with radical from $m$-divinylbenzene & $A_{2}+A_{3} \stackrel{k_{2}=k_{p 23}}{\longrightarrow} A_{2}$ \\
\hline Termination by combination of radicals from styrene & $A_{1}+A_{1} \stackrel{k_{3}=k_{t c 11}}{\longrightarrow}$ products \\
\hline Cross termination by combination & $A_{1}+A_{2} \stackrel{k_{4}=k_{t c 12}}{\longrightarrow}$ products \\
\hline Termination by combination of radicals from $m$-divinylbenzene & $A_{2}+A_{2} \stackrel{k_{5}=k_{t c 22}}{\longrightarrow}$ products \\
\hline Propagation of styrene with radical from styrene & $A_{1}+A_{4} \stackrel{k_{6}=k_{p} 11}{\longrightarrow} A_{1}+A_{8}$ \\
\hline Propagation of styrene with radical from $m$-divinylbenzene & 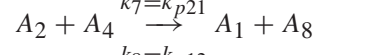 \\
\hline Propagation of $m$-divinylbenzene with radical from styrene & $A_{1}+A_{5} \stackrel{k_{8}=k_{p} 12}{\longrightarrow} A_{2}+A_{3}+A_{9}$ \\
\hline Propagation of $m$-divinylbenzene with radical from $m$-divinylbenzene & $A_{2}+A_{5} \stackrel{\kappa_{9}=\kappa_{p 22}}{\longrightarrow} A_{2}+A_{3}+A_{9}$ \\
\hline Initiation of pendant double bonds from $m$-divinylbenzene & $A_{3}+A_{6} \stackrel{k_{1}^{N+1}=k_{i 3}}{\longrightarrow} A_{2}$ \\
\hline
\end{tabular}

Table 11

Kinetic parameters in free radical crosslinking copolymerisation of styrene with $m$-divinylbenzene

\begin{tabular}{|c|c|c|}
\hline Kinetic constant & Relative value & Absolute value \\
\hline$k_{p 11}$ & & $145 \mathrm{dm}^{3} \mathrm{~mol}^{-1} \mathrm{~s}^{-1}$ \\
\hline$k_{t c}$ & & $2.9 \times 10^{7} \mathrm{dm}^{3} \mathrm{~mol}^{-1} \mathrm{~s}^{-1}$ \\
\hline$k_{d}$ & & $8.5 \times 10^{-6} \mathrm{~s}^{-1}$ \\
\hline$f$ & & 0.6 \\
\hline$r_{1}$ & $r_{1}=\frac{k_{p 11}}{k_{p 12}}$ & 0.44 \\
\hline$k_{p 13}$ & $C_{p_{13}}=\frac{k_{p 13}}{k_{p 11}}=0.138$ & $20.01 \mathrm{dm}^{3} \mathrm{~mol}^{-1} \mathrm{~s}^{-1}$ \\
\hline$k_{i 1}$ & $C_{i 1}=\frac{k_{i 1}}{k_{p 11}}=1$ & $145 \mathrm{dm}^{3} \mathrm{~mol}^{-1} \mathrm{~s}^{-1}$ \\
\hline$k_{i 2}$ & $C_{i 2}=\frac{k_{i 2}}{k_{p 11}}=\frac{1}{r_{1}}$ & $329.5 \mathrm{dm}^{3} \mathrm{~mol}^{-1} \mathrm{~s}^{-1}$ \\
\hline$k_{i 3}$ & $C_{i 3}=\frac{k_{i 3}}{k_{p 11}}=C_{p_{13}}$ & $20.01 \mathrm{dm}^{3} \mathrm{~mol}^{-1} \mathrm{~s}^{-1}$ \\
\hline$k_{p 12}$ & $r_{1}=\frac{k_{p 11}}{k_{p 12}}$ & $329.5 \mathrm{dm}^{3} \mathrm{~mol}^{-1} \mathrm{~s}^{-1}$ \\
\hline$k_{p 21}$ & $C_{p_{21}}=\frac{k_{p 21}}{k_{p 11}}=1$ & $145 \mathrm{dm}^{3} \mathrm{~mol}^{-1} \mathrm{~s}^{-1}$ \\
\hline$k_{p 22}$ & $r_{2}=\frac{k_{p 22}}{k_{p 21}}=\frac{1}{r_{1}}$ & $329.5 \mathrm{dm}^{3} \mathrm{~mol}^{-1} \mathrm{~s}^{-1}$ \\
\hline$k_{p 23}$ & $C_{p_{23}}=\frac{k_{p 23}}{k_{p 11}}=C_{p_{13}}$ & $20.01 \mathrm{dm}^{3} \mathrm{~mol}^{-1} \mathrm{~s}^{-1}$ \\
\hline$k_{t c 11}$ & & $2.9 \times 10^{7} \mathrm{dm}^{3} \mathrm{~mol}^{-1} \mathrm{~s}^{-1}$ \\
\hline$k_{t c 12}$ & & $2.9 \times 10^{7} \mathrm{dm}^{3} \mathrm{~mol}^{-1} \mathrm{~s}^{-1}$ \\
\hline$k_{t c 22}$ & & $2.9 \times 10^{7} \mathrm{dm}^{3} \mathrm{~mol}^{-1} \mathrm{~s}^{-1}$ \\
\hline
\end{tabular}

calculated and the correspondent simulations have also been compared with experimental results in Fig. 9. Agreement is not so good as the observed with the previous set of kinetic parameters.

A similar apparent reactivity decrease of pendant double bonds with increasing amounts of divinyl monomer has been reported with this same chemical system (Zetterlund et al., 2002) as well as many others, namely by Tobita and Hamielec (1989) in their analysis of the copolymerisation of methyl methacrylate with ethylene glycol dimethacrylate. The effect of cyclisation has been pointed as a contributing factor for this kind of inconsistencies observed in these chemical systems, but this is unlikely for this system. 


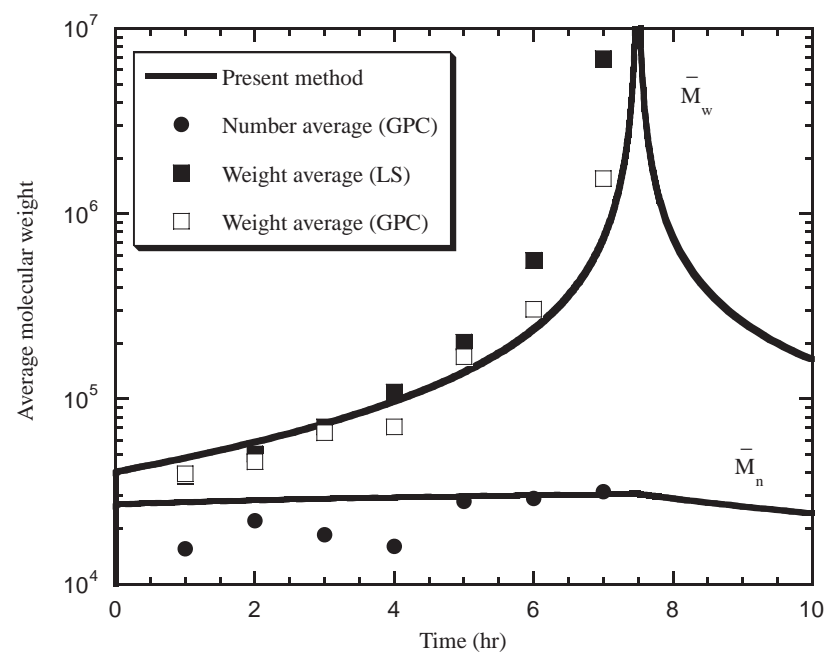

Fig. 8. Comparison between the predictions of the present method and experimental data (Hild and Okasha, 1985a) for the free radical crosslinking copolymerisation of styrene and $m$-divinylbenzene with an initial mole ratio $\alpha=2 \%$.

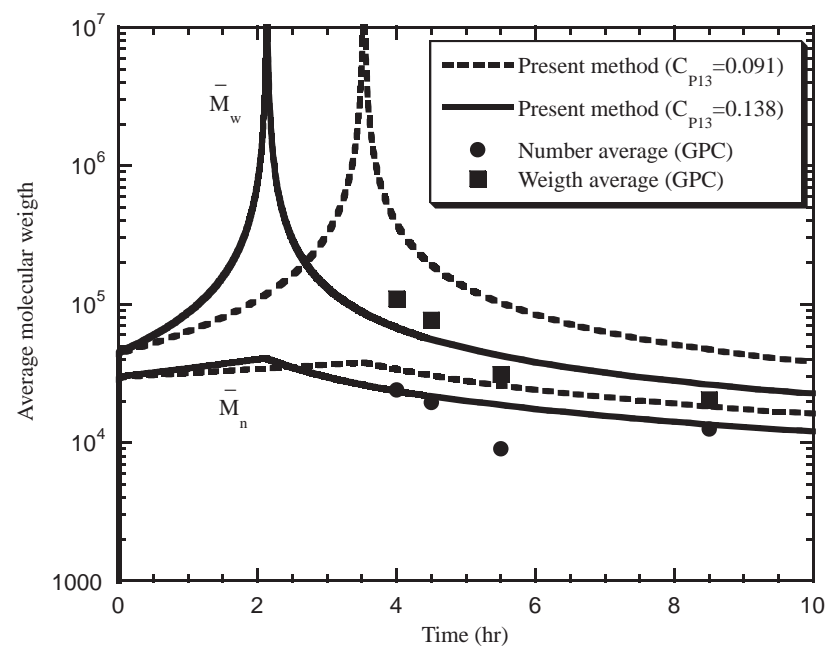

Fig. 9. Comparison between the predictions of the present method and experimental data (Hild et al., 1985) for the free radical crosslinking copolymerisation of styrene and $m$-divinylbenzene with an initial mole ratio $\alpha=5 \%$.

In our opinion, the problem should rather involve the modelling of the termination reaction and the assumed constant initiator efficiency. Further investigation is needed in this subject, namely to clarify the adequacy of the kinetic schemes involved in these kind of polymerisations and to obtain more reliable experimental results, particularly in the post-gel region.

Owing to its improved mathematical exactness, the ability to deal with gel and the possibility to consider complex kinetic schemes, the method presented in this work could be a valuable tool for this purpose.

\section{Modelling of free radical polymerisation with transfer to polymer (case study IV)—a comparison with other approaches}

As free-radical polymerisations are kinetically controlled, the condition for random branch points in a statistical gelation process often cannot be used. This fact invalidates the mathematical treatment of this systems by the theory of branching processes.

Modelling non-linear free radical polymerisations has been for a long time a controversial subject. Based on pioneering work by Bamford and Tompa (1954), several models have been applied to the treatment of non-linear free radical polymerisations. These models have been derived by writing population balances in the reactor and a set of ordinary differential equations results for the moments of the CLD (method of the moments). Nevertheless, in order to obtain a tractable model, some mathematical approximations have been introduced, such as (among others) pseudo-steady state for radical concentrations and negligible presence of multiple radical centres. Additionally, it is necessary to consider closure conditions to make possible the resolution of the equations for the moments. Extension of the method of the moments to the post gel region remains difficult (Tobita and Hamielec, 1989). Therefore the method of moments or related methods that use this kind of population balances are mostly used to the analysis of pregel conditions and a set of approximation conditions has to be used (Miller et al., 1996; Asteasuain et al., 2002a,b).

Important discrepancies can be observed when predictions by the method of moments are compared with more accurate methods (Costa and Dias, 2003).

Monte Carlo simulation has the advantage of providing a detailed view of molecular structure and is a possible alternative method for dealing with these problems. Its successful use with polycondensations has been known since long ago (Mikeš and Dušek, 1982). However, widely different time scales in free radical polymerisation make its straightforward application very time consuming, and so some simplifications had to be introduced (Tobita, 1994b,c).

Recent simulations of non-linear free radical polymerisations using Galerkin finite-elements method (Iedema and Hoefsloot, 2002) have once again neglected the presence of multiple radical centres together with some simplifications in the kinetic schemes. In addition, the properties of the gel cannot be obtained by this method.

"Numerical fractionation" (Teymour and Campbell, 1994) overcomes many difficulties associated with the use of the method of moments when gel is present and can be used for reconstructing an approximate CLD. Nevertheless, this technique is based on population balances making use of many approximations also present in the method of moments.

For comparison purposes of theoretical predictions, the free radical polymerisation of a single monomer with transfer to polymer in a batch reactor has been chosen. This is a 
Table 12

Description of groups in a free radical polymerisation with transfer to polymer

\begin{tabular}{|c|c|c|c|c|}
\hline Group description & $j$ & $\delta_{P_{j}}$ & $\delta_{A_{j}}$ & Chemical formula (example) \\
\hline Free radical & 1 & 1 & 1 & $-\mathrm{HYC}^{\bullet}$ \\
\hline Transfer to polymer center & 2 & 1 & 1 & $-\mathrm{CH}_{2}-\mathrm{C} \underline{\mathrm{HY}}-\mathrm{CH}_{2}-$ \\
\hline Monomer & 3 & 0 & 1 & $\mathrm{CH}_{2}=\overline{\mathrm{CH}} \mathrm{Y}$ \\
\hline Primary radical & 4 & 0 & 1 & $\left(\mathrm{CH}_{3}\right)_{2} \mathrm{CNC}^{\bullet}$ \\
\hline Initiator & 5 & 0 & 1 & $\left(\mathrm{CH}_{3}\right)_{2} \mathrm{CNCN}=\mathrm{NCCN}\left(\mathrm{CH}_{3}\right)_{2}$ \\
\hline Polymerised monomer unit & 6 & 1 & 0 & $-\mathrm{CH}_{2}-\mathrm{CHY}-$ \\
\hline
\end{tabular}

Table 13

Reaction scheme in a free radical polymerisation with transfer to polymer

\begin{tabular}{ll}
\hline Reaction name & Chemical equation \\
\hline Initiator decomposition & $A_{5} \stackrel{k_{1}^{*}=k_{d}}{\longrightarrow} 2 f A_{4}$ \\
Monomer initiation & $A_{3}+A_{4} \stackrel{k_{I_{1}}=k_{i}}{\longrightarrow} A_{1}+A_{6}$ \\
Termination by combination & $A_{1}+A_{1} \stackrel{k_{1}=k_{t c}}{\longrightarrow}$ products \\
Propagation of monomer & $A_{1}+A_{3} \stackrel{k_{2}=k_{p}}{\longrightarrow} A_{2}+A_{1}+A_{6}$ \\
Transfer to polymer & $A_{1}+A_{2} \stackrel{k_{1}^{* *}=k_{f p}}{\longrightarrow} A_{1}$ \\
Termination by disproportionation & $A_{1}+A_{1} \stackrel{k_{2}^{* *}=k_{t d}}{\longrightarrow}$ products
\end{tabular}

classical problem which has been analysed in the past by the method of the moments (Tobita and Hamielec, 1988) and "numerical fractionation" (Teymour and Campbell, 1994). The description of groups and kinetic scheme considered is presented in Tables 12 and 13. Kinetic parameters for this case study are presented in Table 14. The propagation rate constant for the monomer is a recently measured value by PLP for vinyl acetate (Hutchinson et al., 1994). Initiator decomposition rate constant and efficiency were taken as usual values for AIBN.

Initial monomer and initiator concentration has been kept fixed at, respectively, $M_{0}=3 \mathrm{moldm}^{-3}$ and $I_{0}=$ $4.29 \times 10^{-3} \mathrm{~mol} \mathrm{dm}^{-3}$. Remaining parameters in Table 14 were chosen in order to specify simulation conditions close to the used in other analysis of this polymerisation system (Teymour and Campbell, 1994; Tobita and Hamielec, 1988).

For these reaction conditions, predictions of "numerical fractionation" technique have been obtained according to the principles presented in literature (Teymour and Campbell, 1994). Saidel-Katz approximation for the third moment was used as closure condition and $n=10$ generations were considered in the calculations.

In Fig. 10 are presented the predictions by the two methods for the number- and weight-average chain lengths as a function of monomer conversion. Number-average chain length shows only small differences in the post gel region. Nevertheless, for the weight average chain length the predictions present important differences in the vicinity of the gel point and beyond. To test the consistency of the methods the linear case $\left(C_{P}=0\right)$ has also been simulated, and, as expected, no significant differences have been observed (Fig. 11).

This fact, in our opinion, is explained by the effect of the approximation conditions used in "numerical fractionation", namely the neglect of the existence of poly-radicals, which are known to exist in fairly large amounts close to gelation (Tobita and Zhu, 1996).

\section{Conclusions}

This work could offer some significant steps towards building a kind of interpreter of irreversible polymerisation schemes. Fairly general and complex chemical systems can be analysed without the need for approximations like pseudo-steady state hypothesis. Any number of radical or ion sites can exist in a single molecule, and this helps to eliminate approximations or even inconsistencies that arise from treating non-linear polymerisations as a perturbation of linear polymerisation schemes (Costa and Dias, 2003).

Intrinsic mathematical limitations of commercial software dealing with polymerisation reactions and reactors could therefore be overcome.

Practical implementation of this approach shows that computational resources needed for prediction of average molecular weights before gelation are quite modest for current personal computers.

Prediction of sol fraction and average molecular weights after gelation is a much more difficult problem, especially for free radical polymerisation, and some tens of hours of CPU time and 512 or more of RAM with a personal computer are the bare minimum.

Predictions of average molecular weights and gelation time for styrene $+m$-divinylbenzene assuming no intramolecular reaction could not fit experimental data using a single value of relative reactivity of pending double bonds for different initial mole ratios of divinyl monomer. Even if this chemical system should not be too sensitive to intramolecular reaction, this factor is possibly at the origin of these discrepancies. It is expected that the computational approach described in this paper can help in further investigations of these polymerisations, as it can be readily extended to encompass other chemical reactions, such as intramolecular propagation, transfer and termination. 
Table 14

Kinetic parameters in free radical polymerisation with transfer to polymer

\begin{tabular}{|c|c|c|}
\hline Kinetic constant & Relative value & Absolute value \\
\hline$k_{p}$ & & $1.17 \times 10^{4} \mathrm{dm}^{3} \mathrm{~mol}^{-1} \mathrm{~s}^{-1}$ \\
\hline$k_{d}$ & & $9 \times 10^{-6} \mathrm{~s}^{-1}$ \\
\hline$f$ & & 0.5 \\
\hline$k_{i}$ & $C_{i}=\frac{k_{i}}{k_{p}}=1.0$ & $1.17 \times 10^{4} \mathrm{dm}^{3} \mathrm{~mol}^{-1} \mathrm{~s}^{-1}$ \\
\hline$k_{f p}$ & $C_{P}=\frac{k_{f p}}{k_{p}}=10^{-3}$ & $11.7 \mathrm{dm}^{3} \mathrm{~mol}^{-1} \mathrm{~s}^{-1}$ \\
\hline$k_{t d}$ & & $17.55 \times 10^{7} \mathrm{dm}^{3} \mathrm{~mol}^{-1} \mathrm{~s}^{-1}$ \\
\hline$k_{t c}$ & $C_{t c}=\frac{k_{t c}}{k_{t d}}=0.1$ & $1.755 \times 10^{7} \mathrm{dm}^{3} \mathrm{~mol}^{-1} \mathrm{~s}^{-1}$ \\
\hline
\end{tabular}

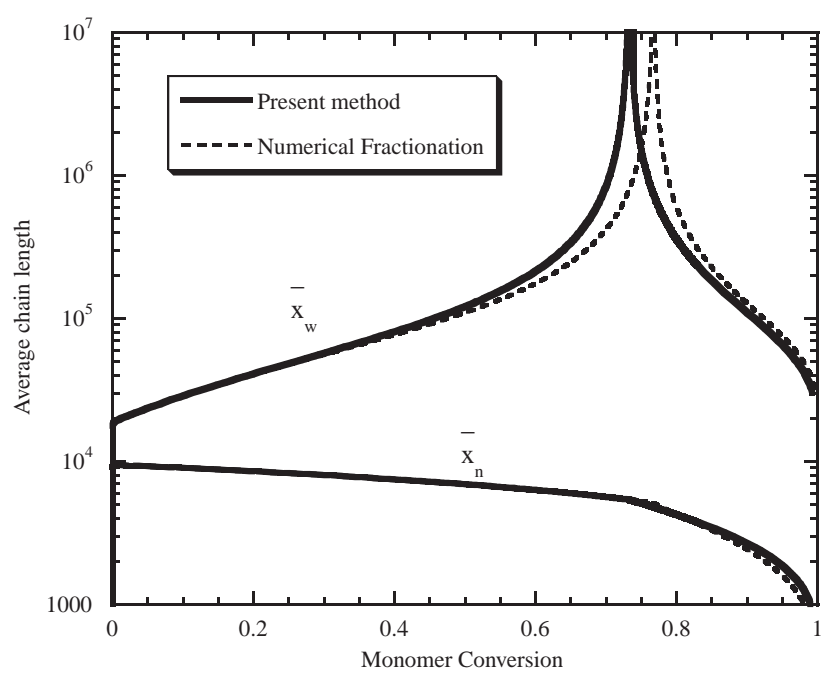

Fig. 10. Comparison between the predictions of the present method and "Numerical Fractionation" technique for a non-linear free radical polymerisation with transfer to polymer in a batch reactor.

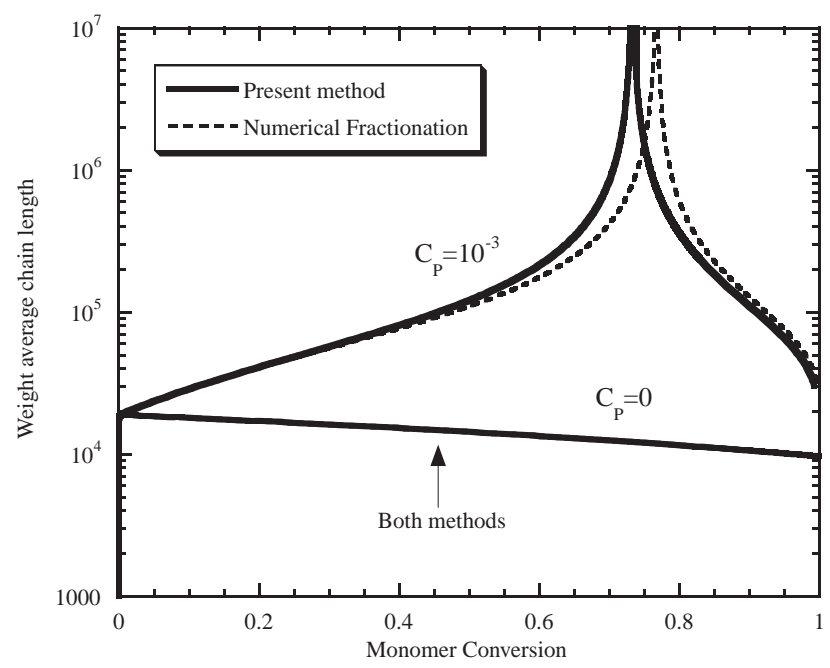

Fig. 11. Effect of transfer to polymer in the predictions of the present method and "Numerical Fractionation" technique for free radical polymerisation with transfer to polymer in a batch reactor.

Although in principle this method should also be able to compute chain length distributions, a lot of improvement in the numerical methods for solving the stiff two point bound-

ary value problems and in the inversion method itself (for decreasing the number of required values of moment generating function) is needed. Evaluation of CLD for chain lengths above a few hundreds is for the moment rather expensive in computer time.

\section{Notation}

a

$A_{j}$

$B$

$C_{I}=\frac{k_{I}}{k_{p}}$

$f_{w_{j}}$

$g_{j}^{-}$and $g_{j}^{+}$

$g_{j}^{*}$

$g_{M_{j}}^{-}$and $g_{M_{j}}^{+}$

$g_{j}^{* *-} \quad$ and
$g_{j}^{* *+}$

$g_{I_{j}}^{-}$and $g_{I_{j}}^{+}$

$G(\mathbf{s})$

$G\left(s_{M}\right)$ vector containing the counts of groups of a polymer molecule, in which $a_{j}$ is the number of groups $A_{j}$ belonging to polymer molecules

mole concentration of groups $A_{j}$ overall concentration of double bonds in case study I

ratio of the two average rate constants of initiation and propagation in case study I initial weight distribution of functionalities in case study I, defined as the initial fraction of active groups belonging to monomer $Y_{j}$

indices of groups (with $g_{j}^{-} \leqslant g_{j}^{+}$) causing the $j$ th bimolecular reaction creating links connecting RU; usually written as $[j-]$ and $[j+]$

index of group causing the $j$ th unimolecular reaction; usually written as $[j *]$ indices of a group belonging to a polymer and a group, corresponding to a monomer, which are involved in the $j$ th transfer to monomer reaction; usually written as $[M j-]$ and $[M j+]$ groups (with $g_{j}^{* *-} \leqslant g_{j}^{* *+}$ ) reacting in the $j$ th bimolecular reaction not creating links between RU; usually written as $[j * *-]$ and $[j * *+]$

indices of groups (with $g_{I_{j}}^{-} \leqslant g_{I_{j}}^{+}$) involved in the $j$ th bimolecular initiation reaction; usually written as $[I j-]$ and $[I j+]$

moment generating function of polymer NCLD

moment generating function of the NMMD of polymer species 


\begin{tabular}{|c|c|c|}
\hline$G_{j k \ldots .}$ & $\begin{array}{l}\text { partial derivative of } G(\mathbf{s}) \text { with respect to } \\
s_{i}, s_{k}, \ldots\end{array}$ & $N_{R_{S}}^{* *}$ \\
\hline$k_{j}$ & $\begin{array}{l}\text { apparent second-order rate constant of } j \text { th } \\
\text { reaction between groups forming a link }\end{array}$ & \\
\hline$k_{j}^{*}$ & $\begin{array}{l}\text { between the repeating units carrying them } \\
\text { apparent first-order rate constant of } j \text { th } \\
\text { unimolecular reaction }\end{array}$ & $N_{S}$ \\
\hline$k_{j}^{* *}$ & $\begin{array}{l}\text { apparent second-order rate constant of } j \text { th } \\
\text { bimolecular reaction not creating links }\end{array}$ & $N_{Y}$ \\
\hline & $\begin{array}{l}\text { between repeating units and thus keep- } \\
\text { ing unchanged the number of polymer } \\
\text { molecules }\end{array}$ & $p$ \\
\hline$k_{I_{n}}$ & $\begin{array}{l}\text { apparent second-order rate of } n \text {th bi- } \\
\text { molecular initiation reaction (which cre- } \\
\text { ates one polymer molecule with a sin- }\end{array}$ & $P(\mathbf{a})$ \\
\hline & gle repeating unit from the reaction of a & $Q$ \\
\hline & monomer and an initiator) & $r$ \\
\hline$k_{M_{n}}$ & $\begin{array}{l}\text { apparent second-order rate of the } n \text {th } \\
\text { transfer to monomer reaction }\end{array}$ & \\
\hline$m_{I}$ & $\begin{array}{l}\text { association number of initiator when be- } \\
\text { longing to inactive complexes }\end{array}$ & \\
\hline$m_{P}$ & association number of terminal anions & $R$ \\
\hline & when belonging to inactive complexes & $R_{j}$ \\
\hline$\underline{M_{j}}$ & relative molecular mass of $j$ th species & \\
\hline $\bar{M}_{n}$ & number-average relative molecular mass & $R_{v}$ \\
\hline $\bar{M}_{w}$ & weight-average relative molecular mass & \\
\hline $\bar{M}_{z}$ & $z$-average relative molecular mass & $\mathbf{s}$ \\
\hline$N_{A}$ & $\begin{array}{l}\text { number of different kinds of chemi- } \\
\text { cal groups (including special individual } \\
\text { molecules, like monomers and initiators) }\end{array}$ & \\
\hline & in the chemical system & $s_{X_{j}}$ \\
\hline$N_{A_{P}}$ & $\begin{array}{l}\text { number of different kinds of groups } \\
\text { present in polymer molecules which may }\end{array}$ & \\
\hline & be consumed by chemical reactions & $t$ \\
\hline$N_{I}$ & number of initiation reactions (reactions & $T$ \\
\hline & between non-polymer molecules forming & $V$ \\
\hline & a polymer molecule) & $w$ \\
\hline$N_{M}$ & number of transfer to monomerreactions & $w_{s}$ \\
\hline$N_{P}$ & $\begin{array}{l}\text { number of different kinds of groups } \\
\text { present in polymer molecules }\end{array}$ & $\begin{array}{l}X_{j} \\
Y_{j}\end{array}$ \\
\hline$N_{R}$ & $\begin{array}{l}\text { number of reactions creating links be- } \\
\text { tween repeating units }\end{array}$ & $\begin{array}{l}\mathbf{0}_{\mathbf{N}} \\
\mathbf{0}_{\mathbf{M N}} \ldots\end{array}$ \\
\hline$N_{R}^{*}$ & number of unimolecular reactions & $\mathbf{1}_{\mathbf{N}}$ \\
\hline
\end{tabular}

$N_{R}^{*} \quad$ number of unimolecular reactions involving groups in polymer molecules

$N_{R}^{* *} \quad$ number of bimolecular reactions which do not create connections between repeating units

$N_{R_{P}}^{* *} \quad$ number of bimolecular reactions involving groups in polymer molecules and which do not create connections between repeating units

$N_{R_{P}} \quad$ number of reactions creating links between RU which involve only groups present in polymer molecules number of bimolecular reactions involving one group in a polymer molecule and a small molecule, without net creation or destruction of polymer molecules number of bimolecular reactions involving non-polymer molecules without creation of polymer molecules number of different kinds of repeating units overall conversion of double bonds in case study I conversion of initiator in case study I mole concentration of the set of polymer molecules $P(\mathbf{a})$, containing a groups of the various possible kinds volume flow rate initial ratio of mole concentrations of double bonds and of initiator (same as the final number average degree of polymerisation for a single monofunctional monomer) in case study I

ideal gas constant

rate of formation by chemical reaction of $j$ th species

relative rate of change of volume caused by chemical reaction

vector of Laplace parameters of the moment generating function associated with distributions of the vector a of counts of groups of a polymer species

Laplace parameter of the moment generating function associated with the count of $j$ th $\mathrm{RU}$ of a polymer species time absolute temperature reaction volume weight fraction weight fraction of sol mole concentration of $j$ th repeating unit mole concentration of $j$ th monomer null vector of size $N$ null matrix of size $M \times N \times \cdots$ vector with all its $N$ components equal to one

\section{Greek letters}

$\alpha$

$\gamma_{9}$

$\delta_{A_{j}}$ initial mole ratio of divinyl to monovinyl monomer

auxiliary variable in case study I related to $G_{9}$ as defined by Eq. (B.11) variable which takes the value one when $A_{j}$ is an active group or species which causes chemical reaction and zero when it is only a product of chemical reactions 
$\delta_{P_{j}} \quad$ variable which takes the value one when $A_{j}$ is a group in polymer species and zero when it is an isolated chemical species

$\delta_{j}^{i}$

$\Delta V_{j}$

$\lambda_{0}$

$\lambda_{j k l \ldots}$

$\lambda_{M M}$

$v_{n k}^{-}$and $v_{n k}^{+}$

$v_{n k}^{*}$

$v_{n k}^{* *-}$
$v_{n k}^{* *+}$$\quad$ and

$v_{I_{n k}}$

$v_{M_{n k}}^{-}$

$v_{M_{n k}}^{+}$

$\tau$

$\Psi_{L}^{U}$

\section{Subscripts}

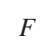

$F$

$g$
$n$

s

$M A X$

$w$

0

Superscript

tively, in the repeating unit carrying the group with lower index and in the one with greater index

number of $A_{k}$ groups of the polymer molecule produced by the $n$th bimolecular initiation reaction (if $k \leqslant N_{A_{P}}$ ), -1 for the two groups starting this reaction change of number of $A_{k}$ groups for the polymer molecule involved in the $n$th transfer to monomer reaction

number of $A_{k}$ groups for the new polymer molecule produced by the $n$th transfer to monomer reaction

space time (ratio of reactor volume and inlet volume flowrate)

stoichiometric functions defined by Eq. (13)

in gel

number

in sol

upper limit

weight

initial
Abbreviations

$\begin{array}{ll}\text { CLD } & \text { chain length distribution } \\ \text { CSTR } & \text { continuous stirred tank reactor } \\ \text { DVB } & \text { divinylbenzene } \\ \text { EB } & \text { ethylbenzene } \\ \text { LS } & \text { light scattering } \\ \text { NCLD } & \text { number chain length distribution } \\ \text { NMMD } & \text { number molecular mass distribution } \\ \text { RG } & \text { root group (invariant moiety in a RU) } \\ \text { RU } & \text { repeating units } \\ \text { SEC } & \text { size exclusion chromatography }\end{array}$

\section{Acknowledgements}

This research was a part of project PRAXIS XXI and POCTI 3/3.1/CEG/2525/95. Its financial support by FCT, PRODEP, and European Community through FEDER is gratefully acknowledged.

\section{Appendix A}

\section{A.1. Prediction of NCLD and its moments in ideal reactors using the method of characteristics in a CSTR}

The moment generating function of polymer NCLD is obtained by solving the system of ordinary differential equations consisting of Eqs. (A.1)-(A.6) below ( $\delta_{j}^{i}$ is Krönecker's symbol):

$$
\begin{aligned}
\frac{\mathrm{d} G}{\mathrm{~d} t}= & -\sum_{m=1}^{N_{R_{P}}} k_{m} \Psi_{m}^{+} \Psi_{m}^{-} G_{[m-]} G_{[m+]} \\
& +\sum_{m=1}^{N_{I}} k_{I_{m}} A_{[I m-]} A_{[I m+]} \Psi_{I_{m}} \\
& +\sum_{m=1}^{N_{M}} k_{M_{m}} A_{[M m-]} A_{[M m+]} \Psi_{M_{m}}^{+} \\
& +\frac{G_{F}(t)-G(t)}{\tau}-R_{v} G,
\end{aligned}
$$

$$
\begin{aligned}
\frac{\mathrm{d} G_{j}}{\mathrm{~d} t}= & \sum_{m=1}^{N_{R_{P}}} k_{m}\left(v_{m j}^{-}+v_{m j}^{+}\right) \Psi_{m}^{-} \Psi_{m}^{+} G_{[m-]} G_{[m+]} \\
& +\sum_{m=N_{R_{P}}+1}^{N_{R}} k_{m}\left(v_{m j}^{-}+v_{m j}^{+}\right) \Psi_{m}^{-} \Psi_{m}^{+} A_{[m+]} G_{[m-]}
\end{aligned}
$$

$$
+\sum_{m=1}^{N_{R_{P}}^{*}} k_{m}^{*} v_{m j}^{*} \Psi_{m}^{*} G_{[m *]}
$$




$$
\begin{aligned}
& \sum_{m=1}^{N_{R_{P}}^{* *}} k_{m}^{* *}\left(v_{m j}^{* *-} \Psi_{m}^{* *-} A_{[m * *+]} G_{[m * *-]}\right. \\
+ & \left.v_{m j}^{* *+} \Psi_{m}^{* *+} A_{[m * *-]} G_{[m * *+]}\right) \\
+ & \sum_{m=N_{R_{P}}^{*}+1}^{N_{R}^{* *}-N_{S}} k_{m}^{* *} v_{m j}^{* *-} \Psi_{m}^{* *-} A_{[m * *+]} G_{[m * *-]} \\
+ & \sum_{m=1}^{N_{I}} k_{I_{m}} v_{I_{m j}} \Psi_{I_{m}} A_{[I m-]} A_{[I m+]} \\
+ & \sum_{m=1}^{N_{m}} k_{M_{m}} A_{[M m+]}\left(v_{M_{m j}}^{+} \Psi_{M_{m}}^{+} A_{[M m-]}\right. \\
+ & \left.v_{M_{m j}}^{-} \Psi_{M_{m}}^{-} G_{[M m-]}\right) \\
+ & \frac{G_{j_{F}}(t)-G_{j}}{\tau}-R_{v} G_{j},
\end{aligned}
$$

$$
\begin{aligned}
& \frac{\mathrm{d} \log s_{j}}{\mathrm{~d} t}=\sum_{m=1}^{N_{R_{P}}} k_{m}\left[\delta_{[m-]}^{j}\left(A_{[m+]}-\Psi_{m}^{-} \Psi_{m}^{+} G_{[m+]}\right)\right. \\
& \left.+\delta_{[m+]}^{j}\left(A_{[m-]}-\Psi_{m}^{-} \Psi_{m}^{+} G_{[m-]}\right)\right] \\
& +\sum_{m=N_{R_{P}}+1}^{N_{R}} k_{m} \delta_{[m-]}^{j} A_{[m+]}\left(1-\Psi_{m}^{-} \Psi_{m}^{+}\right) \\
& +\sum_{m=1}^{N_{R_{P}}^{*}} k_{m}^{*} \delta_{[m *]}^{j}\left(1-\Psi_{m}^{*}\right) \\
& +\sum_{m=1}^{N_{R_{P}}^{* *}} k_{m}^{* *}\left[\delta_{[m * *-]}^{j} A_{[m * *+]}\left(1-\Psi_{m}^{* *-}\right)\right. \\
& \left.+\delta_{[m * *+]}^{j} A_{[m * *-]}\left(1-\Psi_{m}^{* *+}\right)\right] \\
& N_{R}^{* *}-N_{S} \\
& +\sum_{m=N_{R_{P}}^{*}+1}^{N_{R}^{* *}-N_{S}} k_{m}^{* *} \delta_{[m * *-]}^{j} A_{[m * *+]}\left(1-\Psi_{m}^{* *-}\right) \\
& +\sum_{m=1}^{N_{m}} k_{M_{m}} \delta_{[M m-]}^{j} A_{[M m+]}\left(1-\Psi_{M_{m}}^{-}\right),
\end{aligned}
$$

$G_{\mid t=0}=G_{0}\left(\mathbf{s}_{0}\right)$,

$G_{j_{\mid t=0}}=\frac{\partial G_{0}}{\partial \log s_{j}}\left(\mathbf{s}_{0}\right)$,

$s_{j_{\mid t=0}}=s_{j_{0}}$.

Vector $\mathbf{s}_{0}$ defining the starting point of the characteristic at time $t=0$ must be computed in order that the characteristic curve passes through the prescribed values of $\mathbf{s}$ at time $t$. In fact, only the $N_{A_{P}}$ components related to the active polymer groups are unknown, since the other are constant values. Therefore, a two-point boundary value problem for the above system of ordinary differential equations must be solved.

In the prediction of average molecular weights, only the solution at $\mathbf{s}=1_{N_{A}}$ is wanted and the problem becomes much simpler if there is no gelation, because the solution is then $\mathbf{s}_{0}=1_{N_{A}}$ and there is no need to solve the above mentioned two point boundary value problem. After computing vector $\mathbf{s}_{0}$ (in case there is gel) or, alternatively, setting it equal to $\mathbf{1}_{N_{A}}$, it becomes possible to obtain $G$ and any of its derivatives at $\mathbf{s}=1_{N_{A}}$, yielding thus the moments of the NCLD of polymer and finally the moments of the NMMD of polymer, leading to weight fraction of sol and average molecular weights.

Differentiation of Eq. (18) leads to additional ordinary differential equations analogous to Eq. (A.2) above, which are used to compute higher positive integer order derivatives of $G$, such as:

$$
\begin{aligned}
& \frac{\mathrm{d} G_{j k}}{\mathrm{~d} t} \\
& =\sum_{m=1}^{N_{R_{P}}} k_{m} \Psi_{m}^{-} \Psi_{m}^{+}\left[\left(v_{m j}^{-}+v_{m j}^{+}\right)\left(v_{m k}^{-}+v_{m k}^{+}\right) G_{[m-]} G_{[m+]}\right. \\
& +\left(v_{m j}^{-}+v_{m j}^{+}\right)\left(G_{[m-] k} G_{[m+]}+G_{[m+] k} G_{[m+]}\right) \\
& +\left(v_{m k}^{-}+v_{m k}^{+}\right)\left(G_{[m-] j} G_{[m+]}+G_{[m+] j} G_{[m-]}\right) \\
& \left.+G_{[m-] j} G_{[m+] k}+G_{[m+] j} G_{[m-] k}\right] \\
& +\sum_{m=N_{R_{P}}+1}^{N_{R}} k_{m} \Psi_{m}^{-} \Psi_{m}^{+} A_{[m+]}\left[\left(v_{m j}^{-}+v_{m j}^{+}\right)\left(v_{m k}^{-}+v_{m k}^{+}\right)\right. \\
& \times G_{[m-]}+\left(v_{m j}^{-}+v_{m j}^{+}\right) G_{[m-] k}+\left(v_{m k}^{-}+v_{m k}^{+}\right) G_{[m-] j]} \\
& +\sum_{m=1}^{N_{R_{P}}^{*}} k_{m}^{*} \Psi_{m}^{*}\left(v_{m k}^{*} G_{[m *] j}\right. \\
& \left.+v_{m j}^{*} G_{[m *] k}+v_{m j}^{*} v_{m k}^{*} G_{[m *]}\right) \\
& +\sum_{m=1}^{N_{R_{P}}^{* *}} k_{m}^{* *}\left[A _ { [ m * * + ] } \Psi _ { m } ^ { * * - } \left(v_{m k}^{* *-} G_{[m * *-] j}\right.\right. \\
& \left.+v_{m j}^{* *-} G_{[m * *-] k}+v_{m j}^{* *-} v_{m k}^{* *-} G_{[m * *+]}\right) \\
& +A_{[m * *-]} \Psi_{m}^{* *+}\left(v_{m k}^{* *+} G_{[m * *+] j}\right. \\
& \left.\left.+v_{m j}^{* *+} G_{[m * *+] k}+v_{m j}^{* *+} v_{m k}^{* *+} G_{[m * *+]}\right)\right] \\
& +\sum_{m=N_{R_{P}}^{*}+1}^{N_{R}^{* *}-N_{S}} k_{m}^{* *} A_{[m * *+]} \Psi_{m}^{* *-}\left(v_{m k}^{* *-} G_{[m * *-] j}\right.
\end{aligned}
$$




$$
\begin{aligned}
& \left.+v_{m j}^{* *-} G_{[m * *-] k}+v_{m j}^{* *-} v_{m k}^{* *-} G_{[m * *-]}\right) \\
& +\sum_{m=1}^{N_{m}} k_{M_{m}} A_{[M m+]}\left[A_{[M m-]} v_{M_{m j}}^{+} v_{M_{m k}}^{+} \Psi_{M_{m}}^{+}\right. \\
& +\Psi_{M_{m}}^{-}\left(v_{M_{m j}}^{-} G_{[M m-] k}+v_{M_{m k}}^{-} G_{[M m-] j}+v_{M_{m j}}^{-} v_{M_{m k}}^{-}\right. \\
& \left.\left.\times G_{[M m-]}\right)\right]+\sum_{m=1}^{N_{I}} k_{I_{m}} A_{[I m-]} A_{[I m+]} v_{I_{m j}} v_{I_{m k}} \Psi_{I_{m}} \\
& +\frac{G_{j k_{F}}(t)-G_{j k}}{\tau}-R_{v} G_{j k} .
\end{aligned}
$$

Numerical solution of those systems of ordinary differential equations requires the jacobian of their right-hand sides, which can be analytically obtained. It is not presented here by conciseness, but is available free of charge from the authors.

No gel exists if there is no second solution for $\mathbf{s}_{0}$ when $\mathbf{s}=1_{N_{A}}$ with real positive values lower than 1 for any of its components; if it does exist, that solution should be chosen instead of $\mathbf{s}_{0}=1_{N_{A}}$.

In practice, it is better to compute gel time $t_{g}$ as the time for which weight average degree of polymerisation becomes infinite and check afterwards whether the reaction time is higher than $t_{g}$.

\section{Appendix B}

\section{B.1. Analytical treatment of a simple non-linear living polymerisation in a batch reactor}

A more elegant way of writing Eq. (20), also leading to a slight generalisation of this kinetic scheme, results when the set of Laplace parameters of RG $s_{X_{j}}\left(j=1, N_{Y}\right)$ is introduced. In this case, $s_{X_{1}}=s_{4}$ and $s_{X_{2}}=s_{8}$. If there are still other monomers, provided their functional groups have the same reactivities, in the above scheme, assuming that monomer $Y_{j}$ has functionality $j$, Eq. (20) may be rewritten as:

$$
\begin{aligned}
\frac{\partial G}{\partial t}= & k_{I} I\left[s_{2} s_{5} \sum_{j=1}^{N_{Y}} j s_{X_{j}} s_{9}^{j-1} Y_{j}+\frac{\partial G}{\partial \log s_{9}}\left(\frac{s_{2} s_{5}}{s_{9}}-1\right)\right] \\
& +k_{p}\left\{\frac { \partial G } { \partial \operatorname { l o g } s _ { 5 } } \left[\sum_{j=1}^{N_{Y}} j Y_{j}\left(s_{6} s_{X_{j}} s_{9}^{j-1}-1\right)\right.\right. \\
& \left.\left.+\frac{s_{6}}{s_{9}} \frac{\partial G}{\partial \log s_{9}}-A_{9}\right]-A_{5} \frac{\partial G}{\partial \log s_{9}}\right\}
\end{aligned}
$$

The equations of the characteristics derived from Eq. (B.1) are:

$$
\begin{aligned}
& \frac{\mathrm{d} G}{\mathrm{~d} t}= k_{I} I s_{2} s_{5} \sum_{j=1}^{N_{Y}} j s_{X_{j}} s_{9}^{j-1} Y_{j}+k_{p} \frac{s_{6}}{s_{9}} G_{5} G_{9}, \\
& \frac{\mathrm{d} G_{5}}{\mathrm{~d} t}= k_{I} I s_{2} s_{5}\left(\sum_{j=1}^{N_{Y}} j s_{X_{j}} s_{9}^{j-1} Y_{j}+\frac{G_{9}}{s_{9}}\right) \\
&= k_{I} I s_{2} s_{5} B \gamma_{9}, \\
& \frac{\mathrm{d} G_{9}}{\mathrm{~d} t}=\left(k_{I} I s_{2} s_{5}+k_{p} s_{6} G_{5}\right) \\
& \times {\left[\sum_{j=1}^{N_{Y}} j(j-1) s_{X_{j}} s_{9}^{j-1} Y_{j}-\frac{G_{9}}{s_{9}}\right], } \\
& \frac{\mathrm{d} \log s_{5}}{\mathrm{~d} t}=k_{p} B\left(1-s_{6} \gamma_{9}\right), \\
& \frac{\mathrm{d} \mathrm{log} s_{9}}{\mathrm{~d} t}=k_{I} I\left(1-\frac{s_{2} s_{5}}{s_{9}}\right)+k_{p}\left(A_{5}-\frac{s_{6} G_{5}}{s_{9}}\right) .
\end{aligned}
$$

Assuming that reaction starts from monomers only, but allowing for a partial conversion of double bonds resulting from instantaneous initiation, the initial conditions are:

$$
\begin{aligned}
s_{j \mid t=0}= & s_{j_{0}} \quad j=5,9, \\
G_{\mid t=0}= & B_{0} \sum_{j=1}^{N_{Y}} \frac{f_{w_{j}}}{j} s_{X_{j}}\left\{\left[s_{2} s_{5_{0}} p_{0}+s_{9_{0}}\left(1-p_{0}\right)\right]^{j}\right. \\
& \left.-\left[s_{9_{0}}\left(1-p_{0}\right)\right]^{j}\right\}, \\
G_{9 \mid t=0}= & B_{0} s_{9_{0}}\left(1-p_{0}\right) \sum_{j=1}^{N_{Y}} f_{w_{j}} s_{X_{j}}\left\{\left[s_{2} s_{5_{0}} p_{0}\right.\right. \\
& \left.\left.+s_{9_{0}}\left(1-p_{0}\right)\right]^{j-1}-\left[s_{9_{0}}\left(1-p_{0}\right)\right]^{j-1}\right\}, \\
G_{5 \mid t=0}= & I_{0} s_{2} s_{5_{0}} \sum_{j=1}^{N_{Y}} f_{w_{j}} s_{X_{j}}\left[s_{2} s_{5_{0}} p_{0}\right. \\
& \left.+s_{9_{0}}\left(1-p_{0}\right)\right]^{j-1}=I_{0} s_{2} s_{5_{0}} \gamma_{0} .
\end{aligned}
$$

Owing to the binomial integral in Eq. (33), a full analytical solution is possible only for constant $C_{I}$, including the case of instantaneous initiation. The crux for obtaining the analytical solution is the invariance along each characteristic of the auxiliary variable $\gamma_{9}$ :

$\gamma_{9}=\frac{G_{9}}{B s_{9}}+\sum_{j=1}^{N_{Y}} s_{X_{j}} s_{9}^{j-1} \frac{j Y_{j}}{B}$.

According to these solutions, the first step to compute $G(\mathbf{s})$ consists in solving a single algebraic equation in terms of the auxiliary variable $\gamma_{9}$, Eqs. (B.12), or (B.13) for instantaneous 
initiation:

$$
\begin{aligned}
\gamma_{9}= & \sum_{j=1}^{N_{Y}} f_{w_{j}} s_{X_{j}}\left\{s_{9}(1-p)+\frac{s_{2} s_{5}}{r}\right. \\
& \times\left\{\frac{C_{I}\left(C_{I}-1\right)\left[1-\left(1-p_{I}\right)^{\frac{s_{6} \gamma_{9}+C_{I}-1}{C_{I}}}\right]}{\left(s_{6} \gamma_{9}+C_{I}-1\right)^{2}}\right. \\
& \left.\left.-\frac{s_{6} \gamma_{9} \log \left(1-p_{I}\right)}{s_{6} \gamma_{9}+C_{I}-1}\right\}\left(1-p_{I}\right)^{\frac{1-s_{6} \gamma_{9}}{C_{I}}}\right\}^{j-1},
\end{aligned}
$$

$$
\begin{aligned}
\gamma_{9}= & \sum_{j=1}^{N_{Y}} f_{w_{j}} s_{X_{j}}\left\{s_{9}(1-p)+s_{2} s_{5}\left[\frac{1}{r}+s_{6} \gamma_{9}\left(p-\frac{1}{r}\right)\right]\right. \\
& \left.\times \exp \left[\left(1-s_{6} \gamma_{9}\right)(1-r p)\right]\right\}^{j-1} \quad C_{I} \rightarrow \infty, \quad \text { B. } 13
\end{aligned}
$$

$s_{5_{0}}=s_{5}\left(1-p_{I}\right)^{\frac{1-s_{6} \gamma_{9}}{C_{I}}}$,

$$
G_{5}=\frac{I_{0} C_{I} \gamma_{9} s_{2} s_{5_{0}}\left[1-\left(1-p_{I}\right)^{\frac{s_{6} \gamma_{9}+C_{I}-1}{C_{I}}}\right]}{s_{6} \gamma_{9}+C_{I}-1},
$$

$$
\begin{aligned}
s_{9}(1-p)= & s_{9_{0}}+\frac{s_{2} s_{5_{0}}}{r}\left\{\frac{s_{6} \gamma_{9} \log \left(1-p_{I}\right)}{C_{I}-1+s_{6} \gamma_{9}}\right. \\
& +\frac{C_{I}\left(C_{I}-1\right)}{\left(s_{6} \gamma_{9}+C_{I}-1\right)^{2}} \\
& \left.\times\left[1-\left(1-p_{I}\right)^{\frac{C_{I}-1+s_{6} \gamma_{9}}{C_{I}}}\right]\right\},
\end{aligned}
$$

$$
\frac{G_{9}}{B_{0}}=\gamma_{9} s_{9}(1-p)-\sum_{j=1}^{N_{Y}} f_{w_{j}} s_{X_{j}}\left[s_{9}(1-p)\right]^{j},
$$

$$
\begin{aligned}
\frac{G}{B_{0}}= & \frac{C_{I} s_{2} s_{6} s_{5_{0}} \gamma_{9}^{2}}{s_{6} \gamma_{9}+C_{I}-1} \\
& \times\left[\frac{1-\left(1-p_{I}\right)^{\frac{C_{I}-1+s_{6} \gamma_{9}}{C_{I}}}}{r\left(s_{6} \gamma_{9}+C_{I}-1\right)}-p+\frac{\left(C_{I}-1\right) p_{I}}{C_{I} r}\right] \\
& +\sum_{j=1}^{N_{Y}} \frac{f_{w_{j}}}{j} s_{X_{j}}\left\{s_{9_{0}}^{j}-\left[s_{9}(1-p)\right]^{j}\right\} .
\end{aligned}
$$

For instantaneous initiation, the simplified relationships below hold:

$$
\begin{aligned}
s_{5_{0}} & =s_{5} \exp \left[\left(1-s_{6} \gamma_{9}\right)(1-r p)\right], \\
G_{5} & =\frac{B_{0}}{r} s_{2} s_{5_{0}} \gamma_{9}, \\
s_{9_{0}} & =\frac{s_{9}(1-p)}{1-1 / r}+\frac{s_{2} s_{6} s_{5_{0}} \gamma_{9}(r p-1)}{r-1}, \\
\frac{G_{9}}{B_{0}} & =\gamma_{9} s_{9}(1-p)-\sum_{j=1}^{N_{Y}} f_{w_{j}} s_{X_{j}}\left[s_{9}(1-p)\right]^{j},
\end{aligned}
$$

$$
\begin{aligned}
\frac{G}{B_{0}}= & \gamma_{9}\left[s_{9}(1-p)-s_{9_{0}}(1-1 / r)\right]+\sum_{j=1}^{N_{Y}} \frac{f_{w_{j}}}{j} s_{X_{j}} \\
& \times\left\{\left[s_{9_{0}}(1-1 / r)\right]^{j}-\left[s_{9}(1-p)\right]^{j}\right\} .
\end{aligned}
$$

Eqs. (B.12) or (B.13) have multiple solution branches. The physically meaningful branch has to be chosen from the behaviour at $\mathbf{s}=1_{N_{A}}$.

From its definition Eq. (B.11), taking into account the meaning of $G_{9}$ as well as Eqs. (B.17) or (B.18), $\gamma_{9}$ is a real positive value less than or equal to 1 . If all polymer molecules are finite, $\gamma_{9}=1$; this solution always exists. If a second solution for $\gamma_{9}$ between 0 and 1 can be found, it takes precedence over that trivial solution $\gamma_{9}=1$, and this means that an infinite network is present.

Stating that a double root 1 exists for Eqs. (B.12) or (B.13), Eq. (34) for critical gel conversions is obtained. Differentiation of equations above on $\mathbf{s}=1_{N_{A}}$ would allow analytical expressions for the various moments of the NCLD to be obtained.

It is possible to obtain a full analytical solution (Tobita, 1994a) for a somewhat simpler description (only mono- and difunctional monomers were considered in that work). It is useful for testing numerical inversion methods.

\section{References}

Abate, J., Whitt, W., 1992. Numerical inversion of probability generating functions. Operations Research Letters 12, 245-251.

Achilias, D.S., Kiparissides, C., 1992. Toward the development of a general framework for modelling molecular weight and compositional changes in free-radical copolymerisation reactions. Journal of Macromolecular Science, Reviews in Macromolecular Chemistry Phys. C 32, 183-234.

Arest-Yakubovich, A.A., 1997. On the kinetics of lithium-initiated anionic polymerization in nonpolar solvents. Journal of Polymer Science Part A: Polymer Chemistry Edition 35, 3613-3615.

Asteasuain, M., Sarmoria, C., Brandolin, A., 2002a. Peroxide modification of polyethylene. Prediction of molecular weight distributions by probability generating functions. Polymer 43, 2363-2373.

Asteasuain, M., Sarmoria, C., Brandolin, A., 2002b. Recovery of molecular weight distributions from transformed domains. Part I. Application of pgf to mass balances describing reactions involving radicals. Polymer 43, 2513-2527.

Asteasuain, M., Sarmoria, C., Brandolin, A., 2004. Molecular weight distributions in styrene polymerisation with asymmetric difunctional initiators. Polymer 45, 321-335.

Bamford, C.H., Tompa, H., 1954. The calculation of molecular weight distributions from kinetic schemes. Transactions of the Faraday Society 50, 1097-1115.

Bashir-Ali, Z., Cash, J.R., Silva, H.H.M., 1998. Lobatto deferred correction for stiff two-point boundary value problems. Comput. Math. Appl. 36, 59-69.

Brandolin, A., Sarmoria, C., Lòpez-Rodríguez, A., Whiteley, K.S., del Amo Fernández, B., 2002. Prediction of molecular weight distributions by probability generating functions. Application to industrial autoclave reactors for high pressure polymerisation of ethylene and ethylenevinyl acetate. Polymer Engineering and Science 41, 1413-1426.

Bywater, S.D., 1998. Active centre aggregation in lithium-based anionic polymerization. Are very large aggregates present? Macromolecules 31, 6010-6013. 
Bywater, S.D., Worsfold, J., 1967. Alkyl lithium anionic polymerisation initiators in hydrocarbon solvents. Journal of Organometallic Chemistry $10,1-6$.

Cash, J.R., Moore, G., Wright, R.W., 1995. An automatic continuation strategy for the solution of singularly perturbed linear two point boundary value problems. Journal of Computational Physics 122, 266-279.

Cash, J.R., Moore, G., Wright, R.W., 2001. An automatic continuation strategy for the solution of singularly perturbed nonlinear boundary value problems. ACM Transactions on Mathematical Software 27, 245-266.

Christiansen, W.H., Ekerdt, J.G., Trachtenberg, I., Barlow, J.W., 1990. Development of a reaction injection molding encapsulant system. 2. Chemorheology of the anionic bulk polymerization of styrene. Industrial and Engineering Chemistry Research 30, 646-653.

Costa, M.R.P.F.N., Dias, R.C.S., 1994. A general kinetic analysis of nonlinear irreversible copolymerisations. Chemical Engineering Science 49, 491-516.

Costa, M.R.P.F.N., Dias, R.C.S., 1995. New developments in the kinetic modelling of complex non-linear polymerizations. In: Reichert, K.H., Moritz, H.-U. (Eds.), Fifth International Workshop on Polymer Reaction Engineering, DECHEMA Monographs, vol. 131. Wiley-VCH, Weinheim, pp. 523-530.

Costa, M.R.P.F.N., Dias, R.C.S., 1998. Prediction of average radius of gyration of branched polymers by a general kinetic approach. In: Reichert, K.H., Moritz, H.-U. (Eds.), Sixth International Workshop on Polymer Reaction Engineering, DECHEMA Monographs, vol. 134. Wiley-VCH, Weinheim, pp. 197-205.

Costa, M.R.P.F.N., Dias, R.C.S., 2003. Prediction of sol fraction and average molecular weights after gelation for non-linear free radical polymerizations using a kinetic approach. Macromolecular Theory and Simulations $12,560-572$.

Costa, M.R.P.F.N., Villermaux, J., 1988. Mathematical and experimental foundations of linear polycondensation modeling. 1. Modeling and simulation of linear, irreversible polycondensation. Industrial and Engineering Chemistry Research 27, 421-429.

Courant, R., Hilbert, D., 1962. Methods of Mathematical Physics, Vol. II-Partial Differential Equations. Wiley-Interscience, New York, pp. 97-105.

Deuflhard, P., Bornemann, F., 2002. Scientific Computing with Ordinary Differential Equations. Springer, Berlin, pp. 390.

Elliott, J.B., Bowman, C.N., 2002. Effect of primary cyclization on free radical polymerization kinetics: modeling approach. Macromolecules 35, 7125-7131.

Eschwey, H., Burchard, W., 1975. Conditions of gelation in the anionic divinylbenzene-styrene copolymerisation. Journal of Polymer Science, Polymer Symposia Series 53, 1-9.

Flory, P.J., 1953. Principles of Polymer Chemistry, Cornell University Press, Ithaka, NY. (Chapter 9).

Hairer, E., Wanner, G., 2002. Solving Ordinary Differential Equations II, second revised ed. Springer, Berlin, pp. 566-574.

Hayman, W., 1956. A generalisation of Stirling's formula. Journal für die Reine and Angewandte Mathematik 196, 67-195.

Hild, G., Okasha, R., 1985a. Kinetic investigation of the free-radical crosslinking copolymerization in the pre-gel state. 1 . Styrene $/ m$ - and p-divinylbenzene systems. Makromolekulare Chemie 186, 93-110.

Hild, G., Okasha, R., 1985b. Free radical crosslinking copolymerization in the pre-gel state, 2. Styrene/ethylene dimethacrylate and styrenediisopropenylbenzene systems. Makromolekulare Chemie 186, 389-406.

Hild, G., Okasha, R., Rempp, P., 1985. Free radical crosslinking copolymerization in the post-gel state, 3. Swelling and mechanical properties of polystyrene networks. Makromolekulare Chemie 186, 407-422.

Hutchinson, K.A., Richards, J.R., Aronson, M.T., 1994. Determination of propagation rate coefficients by pulsed-laser polymerization for systems with rapid chain growth: vinyl acetate. Macromolecules 27, 4530-4537.

Iedema, P.D., Hoefsloot, H.C., 2002. Molecular-weight-distribution modelling of radical polymerization in batch and continuous reactors with transfer to polymer leading to gel formation. Macromolecular Theory and Simulations 11, 410-428.

Karles, G.D., Christiansen, W.H., Ekerdt, J.G., Trachtenberg, I., Barlow, J.W., 1991. Development of a reaction injection molding encapsulant system. 3. Gel times for the anionic bulk polymerization of styrene with divinylbenzene. Industrial and Engineering Chemistry Research 30, 646-653.

Keller, H.B., 1972. Numerical Methods for Two-Point Boundary-Value Problems, second ed. Dover, New York, pp. 61.

Kern, W.J., Anderson, J.N., Adams, H.E., Bouton, T.C., Bethea, T.W., 1972. Thermal stability of living polymer-lithium systems. Journal of Polymer Science Part A: Polymer Chemistry Edition 16, 3123-3131.

Konstadinides, K., Achilias, D.S., Kiparissides, C., 1992. Development of a unified mathematical framework for modeling molecular and structural changes in free-radical homopolymerisation reactions. Polymer 33, 5019-5031.

Lewis, H.L., Brown, T.L., 1970. Association of alkyllithium compounds in hydrocarbon media. Alkyllithium-base interactions. Journal of the American Chemical Society 92, 4664-4670.

Mikeš, J., Dušek, K., 1982. Simulation of polymer network formation by the Monte Carlo method. Macromolecules 15, 93-99.

Miller, N.C., Toffolo, R.W., McAuley, K.B., McLellan, P.J., 1996. Determining polymer chain length distributions using numerical inversion of Laplace transforms. Polymer Reaction Engineering 4, 279-301.

Mills, P.L., 1986. Determination of polymer chain length distributions by numerical inversion of $z$-transforms. Computers \& Chemical Engineering 10, 399-420.

Priddy, D.B., Pirc, M., Meister, B.J., 1992. Development of continuous anionic styrene polymerization technology. Polymer Reaction Engineering 1, 343-356.

Ray, W.H., 1991. Modeling of addition polymerisation processes-free radical, ionic, group transfer and Ziegler-Natta kinetics. Canadian Journal of Chemical Engineering 69, 626-629.

Saldivar, E., Ray, W.H., 1995. Detailed modeling of emulsion copolymerisation processes. In: Reichert, K.H., Moritz, H.-U. (Eds.), Fifth International Workshop on Polymer Reaction Engineering, DECHEMA Monographs, vol. 131. VCH, Weinheim, pp. 105-112.

Spach, G., Levy, M., Szwarc, M., 1962. Spontaneous slow transformations in the "living" polystyrene system. Journal of the Chemical Society, $355-361$.

Teymour, F., Campbell, J.D., 1994. Analysis of the dynamics of gelation in polymerization reactors using the "numerical fractionation" technique. Macromolecules 27, 2460-2469.

Tobita, H., 1994a. Dimensions of cross-linked polymers formed in living vinyl/divinyl copolymerization. Macromolecules 27, 5413-5420.

Tobita, H., 1994b. A simulation model for long-chain branching in vinyl acetate polymerization: 1. Batch polymerization. Journal of Polymer Science Part B: Polymer Physics Edition 32(B), 901-910.

Tobita, H., 1994c. A simulation model for long-chain branching in vinyl acetate polymerization: 2 . Continuous polymerization in a stirred tank reactor. Journal of Polymer Science Part B: Polymer Physics Edition 32(B), 911-919.

Tobita, H., Hamielec, A.E., 1988. A kinetic model for network formation in free radical polymerization. Makromolekulare Chemie, Macromolecular Symposia 20/21, 501-543.

Tobita, H., Hamielec, A.E., 1989. Crosslinking kinetics in free radical copolymerization. In: Reichert, K.H., Geiseler, W. (Eds.), Proceedings of the Third International Workshop on Polymer Reaction Engineering. VCH, Weinheim, pp. 43-83.

Tobita, H., Zhu, S., 1996. Polyradical distribution in free radical crosslinking of polymer chains. Journal of Polymer Science Part B: Polymer Physics Edition 34(B), 2099-2104. 
Villermaux, J., Blavier, L., 1984. Free radical polymerisation engineering-I: A new method for modeling free radical homogeneous polymerisation reactions. Chemical Engineering Science 39, 87-99.

Worsfold, D.J., 1970. Anionic polymerization of styrene with paradivinylbenzene. Macromolecules 3, 514-517.

Worsfold, D.J., Bywater, S., 1960. Anionic polymerization of styrene. Canadian Journal of Chemistry 38, 1891-1900.

Young, R.N., Quirk, R.P., Fetters, L.J., 1984. Anionic polymerizations of non-polar monomers involving lithium. Advances in Polymer Science $56,1-90$.
Your, J.-J.A., Karles, G.D., Ekerdt, J.G., Trachtenberg, I., Barlow, J.W., 1989. Development of a reaction injection molding encapsulant system. 1. Kinetic studies of a butyllithium catalyzed styrene polymerization. Industrial and Engineering Chemistry Research 28, 1456-1463.

Zetterlund, P.B., Yamazoe, H., Yamada, B., 2002. Propagation and termination kinetics in high conversion free radical co-polymerization of styrene/divinylbenzene investigated by electron-spin resonance and Fourier transform near-infrared spectroscopy. Polymer 43, 7027-7035. 